\title{
Excess Weapons Plutonium Immobilization in Russia
}

\author{
A Review of LLNL Contract Work
}

\author{
L. J. Jardine, LLNL
}

G. B. Borisov, VNIINM

April 15, 2000

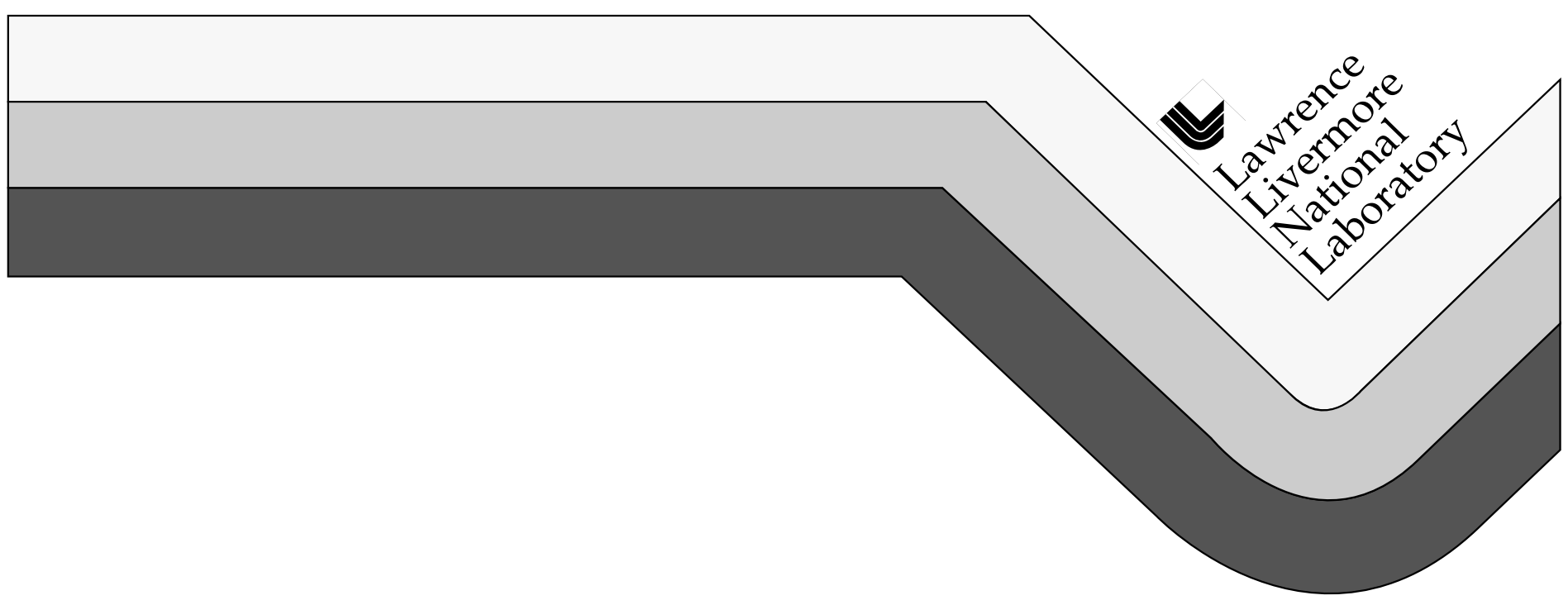




\section{DISCLAIMER}

This document was prepared as an account of work sponsored by an agency of the United States Government. Neither the United States Government nor the University of California nor any of their employees, makes any warranty, express or implied, or assumes any legal liability or responsibility for the accuracy, completeness, or usefulness of any information, apparatus, product, or process disclosed, or represents that its use would not infringe privately owned rights. Reference herein to any specific commercial product, process, or service by trade name, trademark, manufacturer, or otherwise, does not necessarily constitute or imply its endorsement, recommendation, or favoring by the United States Government or the University of California. The views and opinions of authors expressed herein do not necessarily state or reflect those of the United States Government or the University of California, and shall not be used for advertising or product endorsement purposes.

Work performed under the auspices of the U.S. Department of Energy by Lawrence Livermore National Laboratory under Contract W-7405-ENG-48. 


\title{
Excess Weapons Plutonium Immobilization in Russia: A Review of LLNL Contract Work
}

\author{
L. J. Jardine, LLNL \\ G. B. Borisov, VNIINM
}

U.S. and Russia Co-chairs for Joint Plutonium Immobilization Working Group for Plutonium Disposition

Proceedings of the Meeting for Coordination and Review of Work Held in St. Petersburg, Russia

November 1-4, 1999

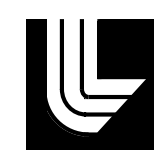

Lawrence Livermore National Laboratory 



\section{Contents}

\section{Opening Session}

Welcome, Introductions, Objectives, L. Jardine, LLNL 1

Approaches and Status of Pu-containing Materials Immobilization

in the US and Russia, G. Borisov, VNIINM

Overview of the Russian Plutonium Immobilization Contracts, L. Jardine, LLNL.

\section{Russian Engineering and Industrial Site Plutonium Immobilization Contract Activities}

Technical and Economic Engineering Feasibility Study of Weapons Plutonium Sludge Immobilization at the K-26 Site

Engineering Feasibility Study of Immobilization of Pu-containing Wastes

Accumulated by MCC in K-26 [B347376] [B333685], K. Kudinov, MCC K-26.

Immobilization of Especially Hazardous Pu-containing Wastes Accumulated Due to

Previous Activities at Nuclear Facilities [B347376], A. Shvedov, VNIPIET

Engineering Tests and Demonstrations at the K-26 Site

Microwave Facility for Plutonium Immobilization in the "Hot" Cell

at MCC [B347676], K. Kudinov, A. Tretyakov, MCC K-26.

Initial Data for the Engineering Feasibility Study on Pu-Bearing Radioactive Waste

Immobilization at MCC [B347376], A. Aloy, KRI

Study of the Process of Pu-containing Wastes Vitrification Using a

Microwave Installation of $15 \mathrm{~kW}$ [B500995], M. Molokhov, NIKIMT

Weapons Plutonium Sludge Immobilization at the Mayak Site

Engineering Feasibility Study for Immobilization of Existing Sludges and

Suspensions Containing Weapons-Grade Plutonium

at PA Mayak [B506201], Y.V. Glagolenko, Mayak

VNIINM's Approach to Immobilize Pu-containing Wastes

at PA Mayak [B506206], T. Smelova, VNIINM.

The KRI Approach for Developing Immobilization Technology for Plutonium

Sludges at PA Mayak [B506209], A. Aloy, KRI.

Engineering Feasibility Study for Immobilization of Weapons-Grade Plutonium-Containing

Materials and Wastes from Future MOX and Conversion Facilities

in Russia [Draft SOW], Y. V. Glagolenko, Mayak 
Preliminary Feasibility Study: Plutonium-containing Pyrochemical Residues

and Waste Treatment and Immobilization at RIAR [B506204], A. Bychkov, RIAR

\section{Research and Development Plutonium Immobilization Contract Activities}

\section{Plutonium Glasses for Immobilization}

Cold Crucible Induction Melter Study of Glasses and Ceramic Compositions

for Immobilization of Pu-containing Materials [UTA-330 Mod1], Y. Matyunin, VNIINM

Development of Glass Compositions for Immobilization of

Pu-containing Wastes at PA Mayak [B501119], Y. Matyunin, VNIINM

Synthesis of Borosilicate and Phosphate Glasses Containing ${ }^{239} \mathrm{Pu}$

and Study of Their Properties [B338247], A. Aloy, KRI

Characterization of Borosilicate Compositions Developed for the Immobilization

of Plutonium-containing Sludges at MCC [B501118], A. Aloy, KRI..

\section{Plutonium Ceramics for Immobilization}

Summary of Pu Ceramics Developed for Pu Immobilization

[B338247, B501118], B. Burakov, KRI 167

Study of Properties of Ceramics Based on Zircon and Zirconia [B338243], G. Borisov, VNIINM 181

Study of Properties of the US-specified Ceramics Made Using the Expertise of MOX

Fuel Production [B503009], G. Borisov, VNIINM 187

\section{Geologic Disposal of Immobilized Plutonium}

Summary of Plutonium Sorption on Rocks and Materials of Destruction of Engineered

Barriers at Normal Pressure and Elevated Temperature [UTA-331], T. Gupalo, VNIPIPT.

Summary of Plutonium Sorption-Desorption on Rock Samples at Elevated

Pressure and Temperature [B338273], T. Gupalo, VNIPIPT

Comparison of K-26 Glass Properties and Plutonium Sorption on Hard Rock

Cores at Elevated Temperature and Pressure [B501120], V. Beygul, VNIPIPT

Laboratory Studies on the Behavior of Plutonium in the Solidified Radioactive Waste Repositories Located in the Low Fractured Rock Masses [B338273, B501120], E. Zakharova, RAS

\section{Accelerated Radiation Damage Studies of the US Pu Ceramic Formulation}

Production and Study of U.S. Ceramics for Plutonium

Immobilization [B501111], Y. Volkov, RIAR

Some Aspects of Study of Radiation Damages in Ceramics Intended for

Pu-containing Materials Immobilization [B506205], D. Alexseyev, VNIINM

KRI Studies of the US Pu Ceramics [B506203], B. Burakov, KRI 
Nonproliferation Studies of Pu Recovery from Pu Glass and Pu Ceramic Immobilization Forms

Recovery of Plutonium from Vitreous and Ceramic Materials

Used for Waste Immobilization [B344864], L. Lazarev, KRI

Study of Recovery of Plutonium from Ceramic and Glass-type

Materials [B344863], V. llyashenko, VNIINM

\section{Other LLNL-Russian Contracts and Topics}

Manufacture and Delivery of Salt Washing Apparatus for PuO $\mathrm{O}_{2}$ [B506207], A. Bychkov, RIAR ................ 271

Russian-US Pu Experts Workshop Support [B338290], M. Moshkov, KRI .............................................. 273

Matrices for Radioactive Waste Immobilization: Status and Prospects, S. Yudintsev, IGEM .................... 275

Study of Sorption-selective Properties of Special Asbestos, A. Tsvetokhin, VNIITF ................................ 283

\section{Closing Session}

Future Direction for Russian Plutonium Immobilization, G. Borisov, VNIINM, L. Jardine, LLNL 285

\section{Meeting Summary}

Meeting Overview Report-Accomplishments and Conclusions, L. Jardine, LLNL

\section{Appendices}

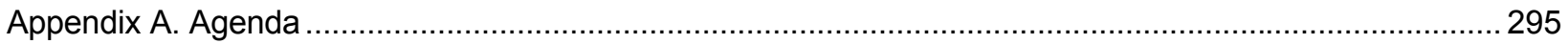

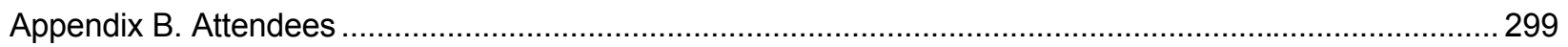

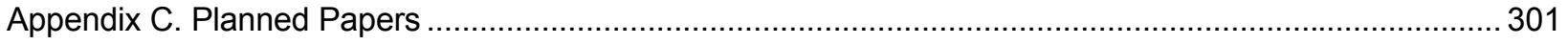

Appendix D. Participant Contributions to the Meeting, A. Orlova, UNG ……......................................... 303 


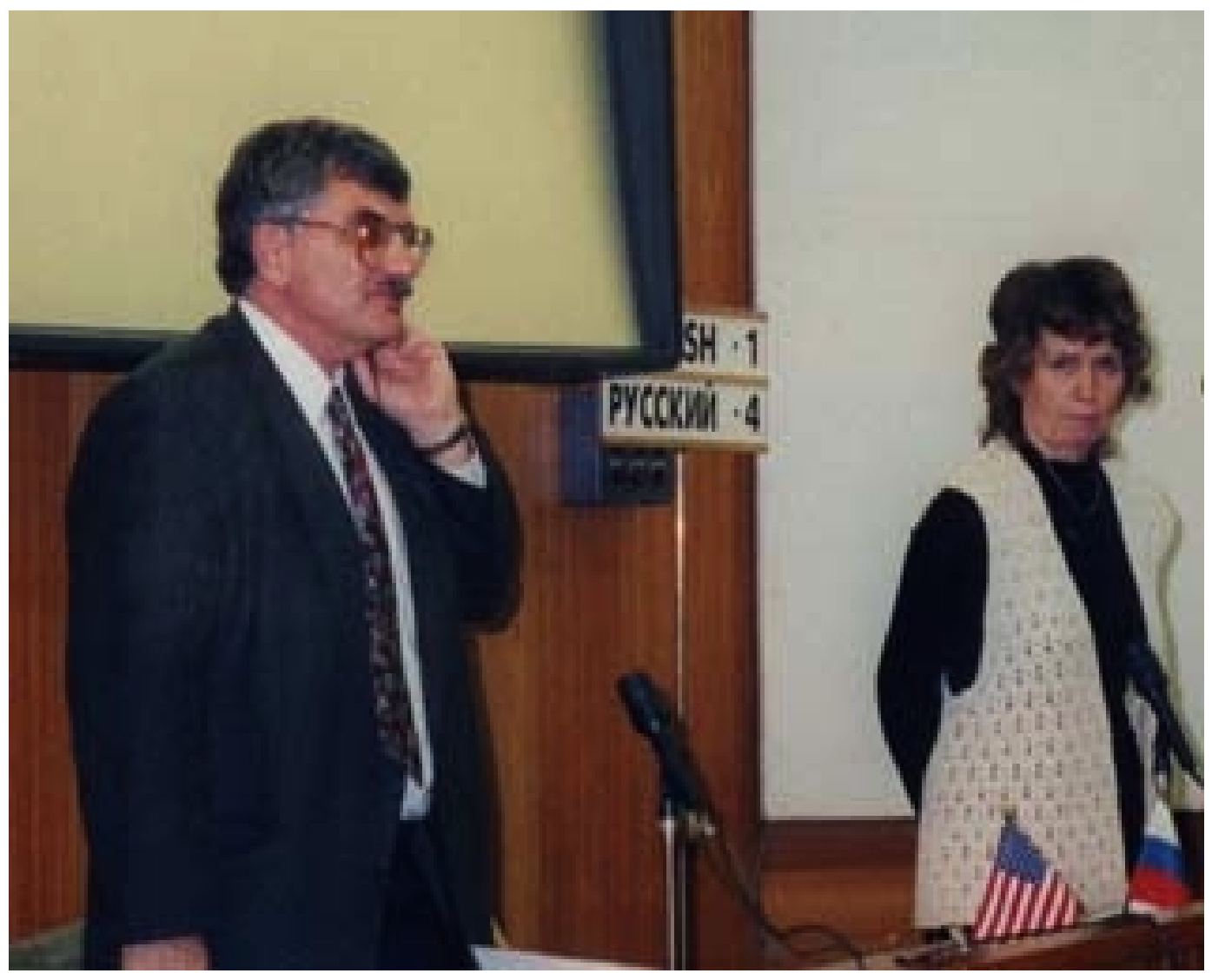

Leslie Jardine, LLNL (left), Lyudmila Manakova, K-26 (right), answering questions about the K-26 engineering feasibility study.

\section{Opening Session}





\section{Welcome, Introductions, and Objectives}

\section{Jardine, LLNL}

\section{Objectives}

Historical Context. The US-Russian activities on the disposition of excess plutonium from weapons that form the subject of this Contract Review meeting were initiated after a September, 1993, speech by President Clinton at the United Nations. After the Clinton-Yeltsen Summit, which followed in Moscow in January, 1994, joint expert working groups were created to conduct specific activities. The US-Russian experts held their first meeting on this topic in January, 1995, at the Los Alamos National Laboratory. Specific technical activities for six working groups were subsequently defined and carried out; the results were reported at the October, 1996, G8 meeting in Paris. ${ }^{1}$ The six working groups-water reactors, fast reactors, immobilization, geologic disposal, storage, and stabilization-continued their activities after the G8 meeting with US Department of Energy (DOE) and Ministry of Atomic Energy of the Russian Federation (Minatom) funding.

In April, 1997, the present Immobilization Working Group structure was formed from the integration of the immobilization, stabilization, and geologic disposal working groups into a single group. The technical efforts were refocused onto the specific needs of the Russian plutonium production industrial sites of Mayak, Krasnoyarsk-26, and Tomsk. A strategy and approach for the working immobilization group was developed and published (UCRL-JC-129790, 4/98, LLNL; UCRL-JC-132920, 2/99, LLNL); they are now being implemented.

These activities have contributed to the US-Russia process of irreversible nuclear arms reductions as well as both nations' non-proliferation objectives. Plutonium immobilization provides technical options as alternatives to burning MOX fuel in nuclear reactors as the sole means of dispositioning excess weapons plutonium.

Status-November 1999. Two years have passed since the May, 1997, Russian Immobilization Projects meeting at Lawrence Livermore National Laboratory (LLNL) began the definition and implementation of the integrated Russian Pu Immobilization Program. To date, twenty-three contracts involving plutonium immobilization have been issued to numerous Russian organizations, and well over one hundred deliverables and technical reports have been generated by Russian Institutes, such as VNIINM, VNIPIPT, KRI, RIAR, VNIPIET, and NIKIMT, and the Krasnoyarsk-26 and Mayak Industrial Sites.

For the first time, this November 1-4 1999, Contract Review meeting in St. Petersburg brought Russian plutonium experts together from 15 different organizations within Russia to discuss and integrate their plutonium technical work. St. Petersburg was selected as the time and the place to discuss and summarize the technical results in order to determine future areas of cooperation on the plutoniumimmobilization problem.

\footnotetext{
1 Joint Russian-U.S. Plutonium Disposition Options Study, Joint U.S.-Russian Plutonium Disposition Steering Committee, (National Academy of Sciences; Amarillo National Resource Center for Plutonium), September 1996. Report prepared in response to the Jan. 4, 1994, joint Yeltsin-Clinton statement on "Non-Proliferation of Weapons of Mass Destruction and the Means of Their Delivery."
} 
Forty-four experts from 15 Russian organizations took part in this meeting, which was held at the State Education Center (SEC) in St. Petersburg and organized by LLNL and the US DOE in conjunction with the V. G. Khlopin Radium Institute. The participants represented the following Russian scientific research institute centers, planning and design institutes, universities and various industrial enterprises: A. A. Bochvar All-Russia Scientific Research Institute of Inorganic Materials (VNIINM), a state science center (SSC); the V.G. Khlopin Radium Institute (KRI), a scientific production association (SPA); the Scientific Research Institute of Atomic Reactors (RIAR), a SSC; VNIPIPT All-Russian Research and Design Institute of Production Engineering (VNIPIPT); the All-Russia Scientific Research Institute of Theoretical Physics, Sneshinsk, (VNIITF); the Institute of Physical Chemistry of the Russian Academy of Sciences (RAS); the Institute of Ore-Deposit Geology, Petrography, Mineralogy, and Geochemistry of the RAS (IGEM); the Nizhnii Novogorod N.I. Lobachevskii State University; All-Russian Design and Research Institute of Complex Power Technology (VNIPIET); the Scientific Research and Design Institute of Installation Technology (NIKIMT); the State Union Design Institute (GSPI); and the industrial sites of the Mayak Production Association, the Mining and Chemical Combine at Krasonayarsk-26 (K-26), and the Tomsk Siberian Chemical Combine. Most of those participating in the meeting were contractors under LLNL contracts. Representatives of the US DOE and the RF Minatom also took part in the meeting. This wide participation is expected to provide a sound foundation for defining the future technical activities both for the Russian participants and those from the US.

Immobilization Objectives. The joint goal of the Russian work is to establish a full-scale plutonium immobilization facility at a Russian industrial site by 2005 . To achieve this requires that the necessary engineering and technical basis be developed in these Russian projects and the needed Russian approvals be obtained to conduct industrial-scale immobilization of plutonium-containing materials at a Russian industrial site by the 2005 date. This meeting and future work will provide the basis for joint decisions. Supporting R\&D projects are being carried out at Russian Institutes that directly support the technical needs of Russian industrial sites to immobilize plutonium-containing materials. Special R\&D on plutonium materials is also being carried out to support excess weapons disposition in Russia and the US, including nonproliferation studies of plutonium recovery from immobilization forms and accelerated radiation damage studies of the US-specified plutonium ceramic for immobilizing plutonium. This intriguing and extraordinary cooperation on certain aspects of the weapons plutonium problem is now progressing well and much work with plutonium has been completed in the past two years.

Meeting Objectives. Because much excellent and unique scientific and engineering technical work has now been completed in Russia in many aspects of plutonium immobilization, this meeting in St.

Petersburg was both timely and necessary to summarize, review, and discuss these efforts among those who performed the actual work. The results of this meeting will help the US and Russia jointly define the future direction of the Russian plutonium immobilization program, and make it an even stronger and more integrated Russian program.

The two objectives for the meeting were to:

1. Bring together the Russian organizations, experts, and managers performing the work into one place for four days to review and discuss their work with each other.

2 Publish a meeting summary and a proceedings to compile reports of all the excellent Russian plutonium immobilization contract work. This proceedings document presents the wide extent of Russian immobilization activities, provides a reference for their work, and makes it available to others. 


\section{Approaches and Status of Pu-containing Materials Immobilization in the US and Russia}

\section{G. Borisov, VNIINM}

At present, under the auspices of the July 24, 1998, agreement between the governments of the United States of America and the Russian Federation, scientific and technical cooperation is proceeding in the management of plutonium that has been withdrawn from nuclear military programs and other programs. A complex of work is underway in Russia to immobilize Pu-containing materials and waste with the aim of its eventual storage and disposal in geologic formations. This effort comprises R\&D work in scientific research institutes (VNIINM, Radium Institute, VNIPIPT, etc.) that is focused on development and selection of glass and mineral type or ceramic compositions, study of their physico-chemical properties; definition of approaches, and development of immobilization technologies at different industrial sites of Minatom, including PA Mayak, MCC, SCC, and RIAR. The final goal of the work is to first start up pilot demonstration installations (by the end of 2004), and then proceed to industrial facilities. Over the course of the project, work will be conducted to define the basic requirements for temporary storage, and then to construct a geologic repository for the immobilized Pu-containing forms.

In the approaches of the US and Russia to immobilize Pu-containing materials, there are definite discrepancies. The US has substantial inventories of impure Pu-containing materials, residues, and wastes of many types and forms that are still are in storage, and are being actively studied to establish a final disposition procedure. In Russia, there are no substantial quantities of weapons-grade Pu because, at present, Russia keeps to the practice of deep recovery of Pu from the waste up to $200 \mathrm{mg} / \mathrm{kg}$ of solid waste or 50-100 $\mu \mathrm{g} / \mathrm{l}$ of liquid waste. However, the possibility of using an immobilization approach without recovery, like that of the US, is being evaluated relevant to the Pu-containing waste from radiochemical production and materials. These are materials that can, in the future, be generated as a result of conversion and MOX-fuel fabrication processes. This bears a resemblance to the purposes and requirements of fissile materials nonproliferation due to its exclusion of possible recovery and respective accumulation of stockpiles of weapons-grade Pu. By the way, this will allow us to assess the abovementioned processes from the viewpoint of economic efficiency, i.e., to avoid expensive operations to deeply recover the plutonium from wastes. Deep recovery also results in the generation of considerable amounts of secondary waste and affects the radiation exposures to personnel and the environment. In Table 1, there are comparative descriptions of the Pu-containing materials subject to immobilization in the US and Russia.

The US developed a "can-in-canister" concept, according to which the Pu-containing materials are to be immobilized into a ceramic composition based on pyrochlore and then filled out by a high-radioactive glass with the aim of preventing its possible proliferation or reuse. In Russia, different options are under consideration-the immobilization into glass- and mineral-type or ceramic matrices using existing technologies and processes such as microwave heating, cold crucible inductive melting, and vitrification in a ceramic melter EP-500. However, as a result of persuing these different avenues, we expect to develop a multiple approach to the problem of immobilization that would permit us to treat all $\mathrm{Pu}$ containing wastes and materials from versatile productions and processes using facilities under development. 
Table 1. Comparison of Pu-containing materials subject to immobilization.

\begin{tabular}{|l|l|}
\hline \hline \multicolumn{1}{|c|}{ US } & \multicolumn{1}{c|}{ Russia } \\
\hline $\begin{array}{l}\text { Pu-containing materials from } \\
\text { the Chemical Metallurgical } \\
\text { Production, CMP (8-10 Mt) }\end{array}$ & $\begin{array}{l}\text { There are no substantial quantities of the waste from CMP since it is } \\
\text { being reprocessed up to the residual content Pu } 200 \mathrm{mg} / \mathrm{kg} \text { of solid } \\
\text { waste. }\end{array}$ \\
\hline $\begin{array}{l}\text { Pu in non-irradiated fuel } \\
\text { compositions (7-9 Mt) }\end{array}$ & $\begin{array}{l}\text { High-level waste (sludges and slurry), containing weapons-grade Pu } \\
\text { and being stored in tanks at MCC and PA "Mayak" (0.6 Mt and } \\
0.7-1.5 \mathrm{Mt} \text {, respectively). According to the current scheme of } \\
\text { reprocessing Pu is recovered up to 50-100 } \mu \mathrm{g} / \text { / of liquid waste. }\end{array}$ \\
\hline & $\begin{array}{l}\text { Pu-containing radioactive waste and sources of nuclear centers, for } \\
\text { example, VNIIT (Snezhinsk). }\end{array}$ \\
\hline & Pu-containing fuel compositions not to be subject to regeneration. \\
\hline & $\begin{array}{l}\text { Pu-containing waste from future processes of conversion and MOX } \\
\text { fuel production at industrial sites (PA "Mayak", MCC and RIAR). }\end{array}$ \\
\hline
\end{tabular}

Below, we list the basic activities that are under way or scheduled in order to design and construct a unified immobilization facility in Russia:

- R\&D work to select glass- or mineral-type and ceramic compositions and to study its basic physicochemical properties. Assessment of the feasibility of the immobilization of Pu-containing materials at industrial sites and nuclear centers of Minatom. Study of the behavior of Pu under the conditions of storage and disposal (1997-2001);

- Engineering Feasibility Study to immobilize Pu-containing sludge at MCC using microwave facilities with R\&D activities (1998-2000);

- Engineering Feasibility Study to immobilize Pu-containing sludge of the Radiochemical Plant of PA "Mayak" with R\&D activities (1999-2001);

- Engineering Feasibility Study to immobilize the Pu-containing waste from MOX-fuel fabrication using data on "Paket" and "Granat" facilities with R\&D activities (2000);

- Engineering Feasibility Study to immobilize the Pu-containing waste from a pyroelectrochemical technology at RIAR (2000);

- Declaration of Intent and Justification of Investments for the immobilization processes at MCC and PA Mayak (1999-2002);

- Development and construction of pilot-industrial facilities to immobilize waste from conversion and MOX-fuel production at MCC, PA Mayak, and RIAR (2002-2007).

Therefore, one can infer that, in Russia, wide-scale work is being carried out to immobilize the Pucontaining waste, embracing a vast spectrum of scientific-research institutes and organizations as well as industrial sites of Minatom. By the way, there is also an assessment of other sources of the Pu-containing materials to be subject to immobilization. For example, presently the possibility of the immobilization of Pu-Be sources, and diverse fuel compositions from research reactors are being evaluated. In addition, issues of eventual storage, transportation, and disposal of the immobilized forms are being worked out. 


\section{Overview of the Russian Plutonium Immobilization Contracts}

\section{Jardine, $L L N L$}

To gain the required safety and environmental approvals for licensing, as well as both public and political acceptance for any future excess weapons plutonium conversion and MOX fuel fabrication site activities in Russia, immobilization technology for solidifying their Pu-containing wastes for storage and geologic disposal must be available, demonstrated, and at the forefront of Russian plutonium technologies. The Mayak site, for example, requires that any new activity with radioactive materials must offer benefits that also reduce previous environmental site impacts from past defense and minimize any new impacts. There is a serious gap in Russian technology for immobilization of plutonium-containing materials caused by the Russian policy and practice of recovering plutonium to levels below $200 \mathrm{ppm}$ in discarded solid waste streams. The ongoing DOE-MD Russian plutonium immobilization activities are rapidly filling this technology gap and are developing a large number of Russian experts in immobilization technology at their scientific institutes, industrial sites, and design organizations.

For example, immobilization activities have changed the views and recommended approaches of K-26 management and technical staff over the past 18 months. The recently completed technical and economic feasibility study and the hot-cell plutonium immobilization tests at K-26 have convinced the K26 site staff that the new immobilization technology can be safely developed and implemented at their site and that there is a viable alternative technology to plutonium recovery. The K-26 site staff believes an immobilization approach can be better accepted by the public, local, and regional authorities because the liquid waste borehole injections will be reduced once immobilization is implemented. The fact that no additional $\mathrm{PuO}_{2}$ will be recovered by reprocessing from wastes for storage contributes to the US nonproliferation and other policy goals. The K-26 site management is currently advocating an immobilization, rather than plutonium recovery approach at Minatom based on factors such as economics, secondary wastes, environmental impacts, and radiation exposures.

Besides the K-26 industrial site shift in views toward immobilization, the Mayak site senior management has recognized and agreed to develop and study the potential implementation of immobilization technologies at Mayak for both past weapons Pu-containing materials and future materials. New plutonium immobilization technology alternatives to the current Mayak plutonium recovery methods, which they have mastered at the Chemical Metallurgical Plant (CMP) and still practice, need to be adopted if the new conversion and/or MOX plants are to be sited at Mayak. The change is needed both because of environmental impact and economic factors. The immobilization alternatives can be applied now to past weapons Pu-containing sludges ( 0.7 to $1.5 \mathrm{Mt}$ of weapons plutonium) in storage tanks and, perhaps, in the future to plutonium wastes and residues from the CMP used for defense activities.

The two current Russian immobilization activities, one at Mayak and one at K-26, are assessing the immobilization of up to $2.1 \mathrm{Mt}$ of excess weapons grade plutonium (0.6 Mt at K-26, and 0.7 to $1.5 \mathrm{Mt}$ at Mayak). The new Russian plutonium conversion and MOX plants have not yet defined the additional quantities of weapons plutonium that can be immobilized during the disposition of the $34 \mathrm{Mt}$ of Russian plutonium in reactors, but an additional 0.5 to $1.0 \mathrm{Mt}$ seems likely to be involved. It may be possible to employ new immobilization facilities that simultaneously immobilize future conversion and future MOX fabrication Pu-containing wastes, and also the past weapons plutonium sludges currently in storage at RF sites. This approach has benefits to both the U.S. and Russia. Currently, Russian sites are assessing 


\section{Overview of the Russian Plutonium Immobilization Contracts}

other sources of weapons plutonium that could be offered for immobilization rather than plutonium recovery. For example, there is a proposal to inventory and catalog the RF research and test reactor fuels and targets containing weapons grade plutonium and HEU. Tens of kilograms of plutonium and hundreds of kilograms of HEU are known to exist at many dispersed RF sites in poorly supervised areas; it is proposed that these fissile materials be assessed for immobilization rather than for plutonium recovery. Immobilization for geologic disposal rather than reprocessing is looking attractive due to the low quantities of fissile materials involved and the complexity and costs of preparing the various, one-of-a-kind materials for acceptance at the reprocessing plants in Russia. This is an excellent example of how immobilization activities continue to elicit re-evaluation of the RF policy position, i.e., that "all" plutonium is an asset worth recovering and immobilization of plutonium for disposal does not make sense.

A further example of new sources of plutonium being offered for immobilization assessment comes from the C-70 site. VNIITF have proposed that an inventory and catalog of plutonium sources be done for their site, and that an engineering feasibility study of how to immobilize the sources be performed. The C-70 site has said that storage conditions for Pu-containing materials are poor and that the facilities are full. An earlier disposition study was started by VNIPIET, but not completed due to lack of funds. The sources are known to include significant, but currently unknown, amounts of $\mathrm{Pu}^{239}-\mathrm{Be}$ sources and other $\mathrm{Pu}$ containing materials.

The Tomsk site has also recently expressed an interest in an engineering feasibility study of immobilizing plutonium in sludges accumulated from their past Chemical Metallurgical Plant defense activities. It is estimated that up to $1.0 \mathrm{Mt}$ of weapons plutonium could be immobilized rather than recovered for storage if immobilization activities were supported.

In summary, Russian experts and industrial sites are assessing and changing their opinions of current Russian plutonium recovery practices, based on new technical studies of immobilization of Pu-containing materials. They are asking for some US assistance together with their own resources to continue to study alternatives. Today, up to $2 \mathrm{Mt}$ of excess RF weapons-grade plutonium have been offered for study of the feasibility of immobilization rather than recovery at MCC and Mayak. This is progress and a worthy technical mission. 


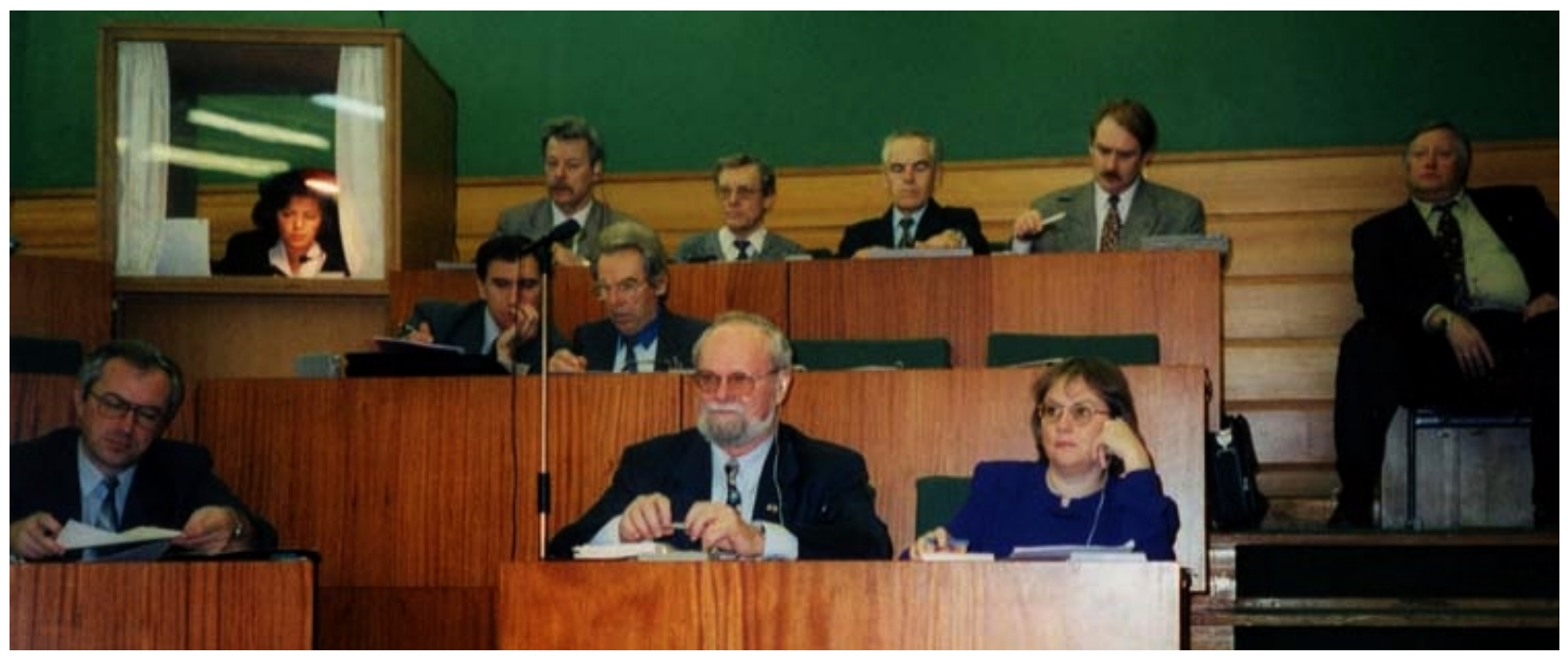

[Left to right, front row] A. Lukinykh, RIAR; John Baker, Shel Cullison, DOE; [middle row] A. Tretyakov, K26; M. Molokhov, NIKIMT; [back row] Elena Malofeeva, translator; V. Sorokin, VNIPIET; (unidentified); L. Babikov, A. Bychkov, RIAR; A. Shvedov, VNIPIET.

\section{Russian Engineering and Industrial Site Plutonium Immobilization Contract Activities}





\title{
Engineering Feasibility Study of Immobilization of Pu-containing Wastes Accumulated by MCC in K-26 [B347376, B333685]
}

\author{
K.G. Kudinov; A.A. Tretyakov; L.F. Manakova; Yu.P. Sorokin, MCC
}

The immobilization of plutonium-containing wastes within the frame of the contract with the Lawrence Livermore National Laboratory was performed based on Russian-US inter-governmental agreements and according to the agreements achieved between the Russian Ministry of Atomic Industry (Minatom) and the US Department of Energy.

The contract within the framework of which the Mining and Chemical Combine (MCC) performed their activities is the incorporated part of the General Agreement \#333685 concluded between Russian and American parties. These activities, which started in May 1998 and continued for the next 12 months, were aimed at the solution of the radioactive pulp processing problem.

A radioactive sludge (or pulp) is the main waste obtained as a result of radioactive production. In terms of activity, the wastes are divided into medium-active wastes (MAW) and high-active wastes (HAW). For temporary storage of these wastes, our enterprise uses vessels with volumes of 8500,3200 , or $300 \mathrm{~m}^{3}$.

Medium-active wastes are stored in vessels with volumes of 3200 or $8500 \mathrm{~m}^{3}$. First, MAW are placed into $3200-\mathrm{m}^{3}$ vessels. These are tanks made of reinforced concrete, $12 \mathrm{~m}$ in diameter, $30 \mathrm{~m}$ high with inner surfaces faced with stainless steel. They are located in rocky soil. The content of these tanks, the solid phase pulp, has been controlled since 1969. The analysis of the results shows significant differences in the content of the wastes depending on the sampling time and location. The content of the tanks has been the most thoroughly investigated, as well as the solid phase of other properties of pulps stored in the AG-8301/3 tank, because we are able to extract and analyze it with the help of specially designed equipment. Before being disposed of in deep wells, the liquid MAW produced by the Radiochemical Plant are held for an additional time in the $8500-\mathrm{m}^{3}$ tanks. These tanks are made of monolithic reinforced concrete, $7.2 \mathrm{~m}$ high and $35 \mathrm{~m}$ in diameter. The inner surfaces of some of these tanks are faced with stainless steel, and others are faced with carbon steel covered with epoxy.

High-active wastes are stored in tanks made of stainless steel with a volume of $300 \mathrm{~m}^{3}$, diameter of $9 \mathrm{~m}$, and height of $5 \mathrm{~m}$. These wastes are stored for a certain time in order to clarify the solutions and to decrease the level of radioactivity.

The total volume of pulps in the tanks is $7260 \mathrm{~m}^{3}$. The total calculated amount of plutonium is $593.3 \mathrm{~kg}$. These plutonium-bearing wastes are to be processed.

\section{Comparison of Methods}

Within the frame of the contract, the MCC specialists cooperated with the specialists of three institutes, namely, BNIPIET, KRI, Bochvar; and VNIINM. These specialists had to solve the following problem; they had to make a technical and economic comparison between these two methods:

- MCC method to process plutonium-bearing sludges with extraction of plutonium; 
- The method proposed by two companies in which the sludges are solidified (a) with non-extracted plutonium as a part of matrices of boric-silicate glass (method of KRI) or (b) phosphate glass (method of VNIINM) using the microwave heating facility.

This comparison was performed based on input data of compared methods and results obtained on the experimental mw-heating facility located in the "hot" cell of the MCC Central Lab. The aim was satisfied on a step-by-step basis according to the following scheme:

3. Task 1. Data preparation and collection for Engineering Feasibility Study (EFS) (three stages).

01 - Technical specification;

02 - Data collection status;

03 - Final report.

1. Task 2. EFS (three stages).

04 - Progress status 1;

05 - Progress status 2;

06 - Final report.

1. Task 3. Preparation activities and tests performed on model and production slime (four stages).

$$
\begin{aligned}
& 07 \text { - Working plan; } \\
& 08 \text { - Progress status 1; } \\
& 09 \text { - Progress status 2; } \\
& 10 \text { - Final report. }
\end{aligned}
$$

1. Task 4. Plan of forthcoming activities.

The aim of Task 1 was to collect, summarize, and analyze the data required for the EFS of the considered methods of radioactive waste processing. Note that only the results of earlier performed activities were used to prepare the input data.

The aim of Task 2 was to perform the EFS. BNIPIET, using the input data prepared by MCC, VNIINM, and $\mathrm{KRI}$, estimated the methods of immobilization of Pu-bearing wastes.

The engineering feasibility study considered three variants of waste processing:

- I variant - Pulp processing with plutonium extraction and cleaning, and cementing of non-dissolved sediments (pulp processing scheme employed at MCC).

- II variant - Microwave hardening of pulps with plutonium non-extracted resulting in boric-silicate glass (method developed by KRI)

- III variant - Microwave hardening of pulps with plutonium non-extracted resulting in phosphate glass (method developed by Bochvar VNIINM).

The scheme of pulp processing variant accepted for the EFS is given in Fig. 1 below.

The first stage of the pulp processing is to remove this pulp from the storage vessels. 


\section{Russian Engineering and Industrial Site Plutonium Immobilization Contract Activities}

The principal scheme of the pulp removal from tanks under all three waste processing methods is the same ,and includes the pulp washing-out and lifting with the help of intentionally designed pulp-lifting devices. They include hydro monitors, hydro elevators, and pumps of special design. This equipment is installed through work adits (or openings), which are integrated in the concrete overhead tank cover.

The pulp preparation scheme varies depending on the method of the next stage of pulp processing.

According to the first variant, the radioactive pulp with the help of condensate is washed from the salts and dissolved. The solution is processed to extract plutonium.

The second variant includes the following phases: (1) two-stage washing of pulp using condensate to decrease the content of sodium nitrate; and (2) pulp condensation up to $120 \mathrm{~g} / \mathrm{l}$ of solid phase content.

According to the third variant, the radioactive pulp is only condensated up to $120 \mathrm{~g} / \mathrm{l}$ of solid phase content.

Pulp hardening methods vary and are as follows:

- According to the base method, non-dissolved pulp sediment without plutonium is delivered into the cementing facility to be solidified. In this facility, the pulp and cementing solution are placed in the casks with volume of $0.2 \mathrm{~m}^{3}$. Casks are tightly closed with lids and rotated;

- The comparative methods include the direct immobilization of plutonium-containing pulps into either phosphate matrix or boric-silicate matrix. The final process of vitrification is performed in a cruciblecapsule, which is placed into a tube-can.

The solidified wastes are stored in the available MCC workings.

The engineering feasibility study considered the possibility of locating a storage facility in section $86 a$.

Besides a description and estimation of three technological schemes, the methods of use of available and newly purchased equipment are also compared in the EFS. Analytical requirements and technological process monitoring are determined. Also, power consumption and labor hours are estimated.

The aim of Task 3 was to test the laboratory facility and the method of plutonium-containing waste vitrification.

The laboratory microwave heating facility located inside the "hot" cell of the MCC Central Lab allowed us to perform several experiments to produce glass samples using both the model and the actual (production) wastes. 


\section{PULP}

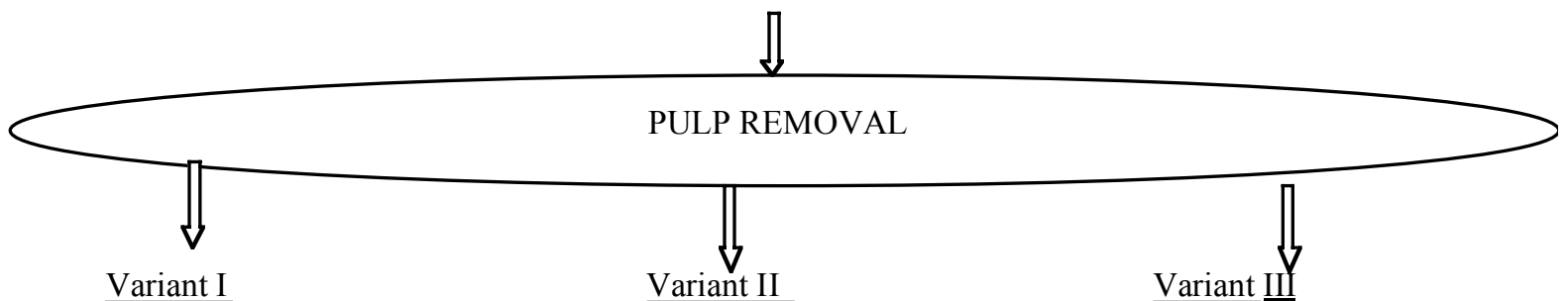

Variant I

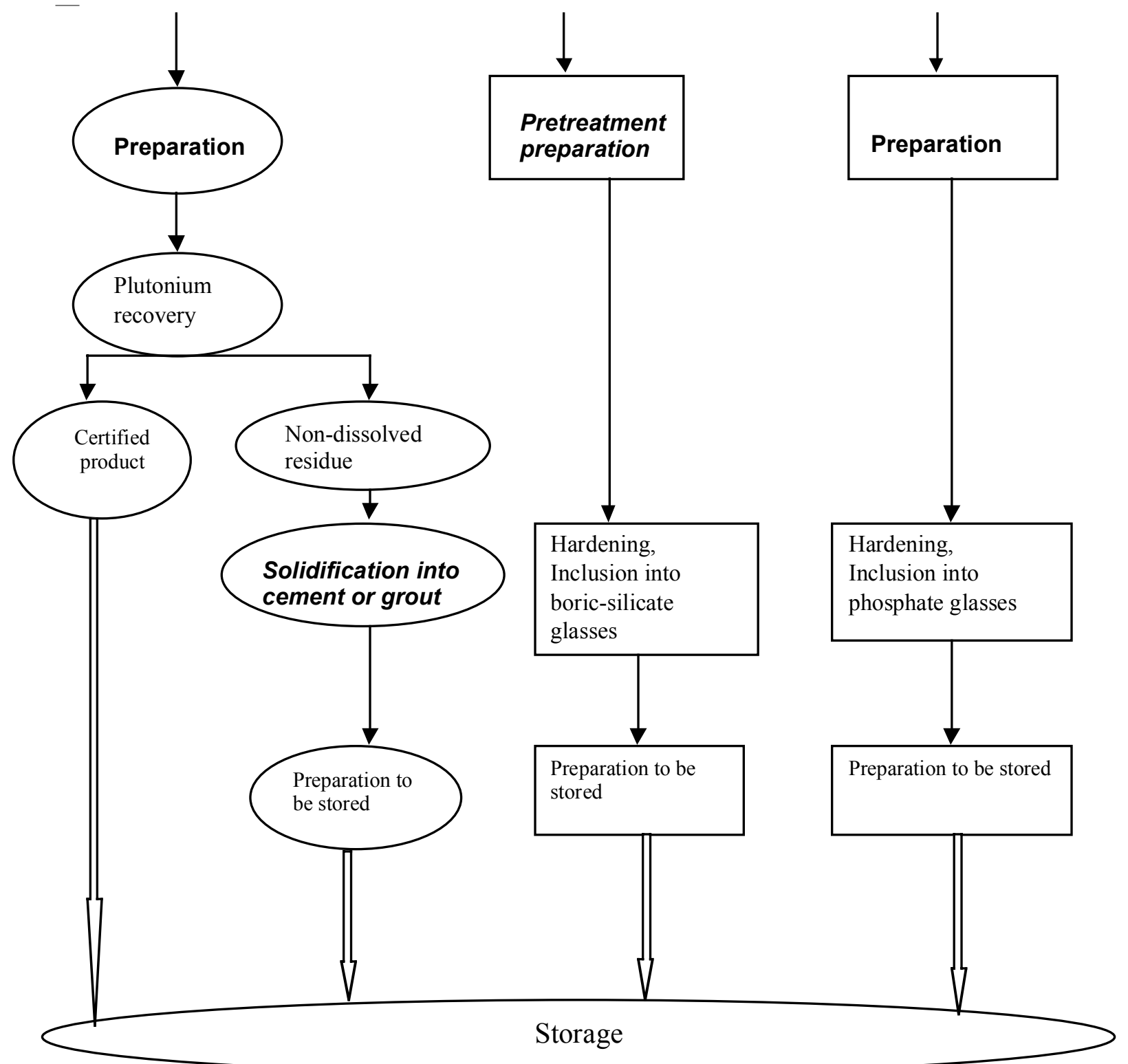

Fig. 1. Scheme of pulp processing variants accepted in EFS. 


\section{Russian Engineering and Industrial Site Plutonium Immobilization Contract Activities}

Task 4 was the final phase.

At this phase, the plan of forthcoming activities should be drawn up, including the possibility to continue the solution of such a complicated problem as the immobilization of radioactive pulps.

To discuss this problem, the following plan was proposed comprising seven steps:

- Declaration of intentions;

- Investment justification;

- Research and development activities

- Development of design documentation;

- Creation of a pilot facility and storage facility to store the solidified wastes;

- Construction and assembly activities;

- Commissioning of the facility.

The activities are planned to be completed in 4.5 years or 54 months. The rough cost of all activities is US\$18.0 M.

\section{Results}

Task 1 - Input data. Three reports were issued.

About 30 reporting materials including information required for the EFS were collected, summarized, and analyzed.

The following should be mentioned:

As for the base variant - for all technological processes, the equipment available at MCC was used to the maximum extent. This allowed us to find cost-attractive technological solutions.

The principal solution was to locate the hardening facilities (cementing and vitrification) and temporary storage facilities to store the solidified wastes in the available free workings.

As for each of variants under comparison - the primary solutions were made during the execution of the EFS.

Data was collected within 6 months beginning on the date the contract was signed.

Task 2 - EFS. Three reports were submitted to the Contractor.

The submitted materials described processes and material balance schemes; included the list and layout of primary equipment; described the main principles of radioactive and nuclear security measures; and described the production effect on the environment. The preliminary solutions concerning the burial of the solidified wastes were developed.

The final report includes the justification of technical possibilities and economic feasibility of the above variants of MCC-accumulated plutonium-bearing pulps immobilization.

The final report demonstrated the principal possibility of locating the pulp vitrification division on the free areas belonging to the operating radiochemical plant. 
The economic calculations showed that the process of direct inclusion of pulp into a glass matrix is 22$25 \%$ cheaper than the variant of the pulp processing method employed at MCC.

All the above activities were completed within 12 months.

Task 3. Experiments performed in the "hot" cell of MCC. These activities were performed within the Contract period.

During this time, the experimental facility to harden the radioactive wastes using MICROWAVE-energy was mounted inside the "hot" chamber of MCC. The tests were performed showing the serviceability of the facility. The principal possibility of producing boric-silicate glass and phosphate glass using two considered methods was demonstrated.

Four reporting documents were issued, including the working plan to co-ordinate the activities of all three parties participating the experiments: MCC, VNIINM, and KRI.

\section{Task 4. Plan of forthcoming activities}

The plan was prepared 10 months after the Contract had been signed; it provided for the solution of such long-term problems as the creation of the pilot facility and the solidified waste storage facility in MCC workings within 54 months.

The Plan was accepted and approved by Contractor.

For the purposes of more detailed discussion of some activities, the Russian party proposed a variant of the plan covering all the activities to be fulfilled within the period up to 18 months.

- This plan provided for the execution of the first three phases of the primary plan, namely, the declaration of intent, investment justification, and research and development activities-continuation of investigations.

- The stages of the new proposals had subsections with more details, including the duration and labor hours required for these activities.

The American party accepted and approved the new proposals and partially reflected them in the new Contract.

- The duration of the new Contract is limited to 6 months.

- During this period the declaration of intentions shall be prepared and approved by the local and regional administrations and by Minatom.

- The additional investigations of actual media shall be performed with the modification of several units of the laboratory microwave-facility.

- To develop the new direction means to obtain the results of investigations of the behavior of matrix materials stored in the rocky workings.

We are quite confident that the close cooperation of MCC, VNIPIET, VNIINM, KRI, and VNIPIPT will allow us to successfully solve the aforementioned scientific and technical problems.

The problem of processing the accumulated radioactive wastes is a problem not only of the Mining and Chemical Combine or Russian enterprises, but also of similar enterprises in other countries. And we are pleased that we are solving and trying to solve it together and with the support of American specialists, namely, with the experts from the Lawrence Livermore National Laboratory. 
Ed. Note: Viewgraphs

\section{IMMOBILIZATION OF PLUTONIUM-CONTAINING WASTES}

\section{SCHEME OF CONTRACT \#347676 ACTIVITIES}

Task 1. Data preparation and collection for EFS (three stages)

$$
\begin{aligned}
& 01 \text { - Technical specification; } \\
& 02 \text { - Data collection status; } \\
& 03 \text { - Final report. }
\end{aligned}
$$

Task 2. Engineering feasibility study (EFS) (three stages)

$$
\begin{aligned}
& 04 \text { - Progress status 1; } \\
& 05 \text { - Progress status 2; } \\
& 06 \text { - Final report. }
\end{aligned}
$$

Task 3. Preparation activities and tests performed on model and production slime (four stages)

$$
\begin{aligned}
& 07 \text { - Working plan; } \\
& 08 \text { - Progress status 1; } \\
& 09 \text { - Progress status 2; } \\
& 010 \text { - Final report. }
\end{aligned}
$$

Task 4. Plan of forthcoming activities (stage 011). 


\section{IMMOBILIZATION OF PLUTONIUM-CONTAINING WASTES}

\section{FUTURE WORKS PLANS}

\section{STAGE 4}

1. Activity stages

2. Declaration of intentions

3. Investment justification

4. Research \& development activities

5. Development of design documentation for pilot vitrification facility and solidified waste storage facility

6. Creation of pilot facility and solidified waste storage facility

7. Construction $\&$ assembly activities

8. Commission of facility and storage facility

Contract duration

Rough costs of the activities

Including :

Costs of $1,2,4$ stages

Costs of 3 stages

Costs of $5,6,7$ stages
Stage durations (in months)

4

15

30

21

12

21

21

54 months or 4.5 years

US $\$ 18.0 \mathrm{M}$

US\$ $3.0 \mathrm{M}$, US\$ $3.0 \mathrm{M}$, US\$ $12.0 \mathrm{M}$ 


\section{IMMOBILIZATION OF PLUTONIUM-CONTAINING WASTES}

\section{CONTRACT \#347676 RESULTS}

\section{Task 1 - Input data:}

- Three reports were issued.

- 30 reporting materials were collected,

- summarized and analyzed

- Activities were completed within 6 months

\section{Task 2 - EFS:}

- Three reports were issued.

- Technical possibility and economic feasibility of three variants of waste processing were investigated.

Principal possibility to locate the pulp vitrification division on free areas belonged to the operating radiochemical plant was demonstrated.

- Advantages of direct inclusion of pulp into glass matrix over processing method accepted at MCC was shown

- Duration of activities was 12 months.

\section{Task 3. Experimental investigations.}

- Four reports were issued.

- Inside the "hot" chamber, the experimental microwave heating facility was mounted and tested. The operatability of this facility was proved.

Principal possibility was shown to produce boric-silicate and phosphate glasses according to two considered methods.

- Activities were performed within 12 months.

\section{Task 4. Plan of forthcoming activities}

- 10 months after the Contract had been signed, the plan was composed providing for the solution of the problems within 54 months and creation of the pilot facility and the solidified waste storage facility in MCC workings 
Technical/Economic Engineering Feasibility Study of Weapons Pu Sludge Immobilization at K-26 


\title{
Immobilization of Especially Hazardous Pu-containing Wastes Accumulated Due to Previous Activities at Nuclear Facilities [B347376]
}

\author{
A.A. Shevdov, V.T. Sorokin, A.V. Dyomin, V.V. Ilyn, and T.A. Feofanova, VNIPIET
}

\begin{abstract}
In the process of spent nuclear fuel (SNF) treatment, liquid (LWR) and solid (SRW) wastes are formed that contain long-lived $\alpha$-emitting radionuclides. These constitute the highest radiation hazard, considering their specific contributions in the total amount of $\alpha$-radionuclides from transuranium series radionuclides such as Pu-239, Pu-240, Am-242, and Cm-244.

In accordance with NRB-96, these radionuclides refer to the highest group of radiation hazard (group A) and reach the values of permissible specific activity in water for the public $\left(\mathrm{PSA}_{\text {pub }}\right)$ basically at the level of $\approx 2 \times 10^{-10} \mathrm{Ci} / \mathrm{l}$.

Technical and economic feasibility studies made for Krasnoyarsk Chemical and Mining Combine (MCC) analyzed the promising methods for vitrification of plutonium-containing pulps accumulated during plant operation in two-stage solidification plants. These are characterized as "once-through evaporator-superhigh frequency plants" (OTE-SAF) where a matrix such as borosilicate or phosphate glass is the final product. The summary of the completed feasibility study for MCC is provided below.

Feasibility studies for the Cheliabinsk plant PO Mayak are also in progress to explore promising techniques for solidification of HLW from SNF treatment in a two-stage solidification plant, characterized as "spray dryer-induction melter with a cold crucible" (SD-IMCC). In these studies, a ceramic material of "synroc" type is the final product. This work is in progress and will build upon the completed study done for MCC.
\end{abstract}

\section{Summary of MCC Technical and Economic Feasibility Study}

This engineering feasibility study compared the possible technical options and economic viability of immobilizing plutonium-bearing sludges containing $0.6 \mathrm{Mt}$ of weapons-grade plutonium accumulated at MCC at Krasnoyarsk. Three options were defined in engineering detail sufficient to perform the comparative study. In Option \# 1, the baseline, the sludges are processed by extraction and purification of plutonium for storage using existing technologies, and the non-soluble residues generated in these processes undergo subsequent cementation. Option \# 2 is the direct immobilization of plutonium-bearing sludge into a solid matrix (without any Pu extraction) using a microwave solidification process in a metal crucible to produce a boron-silicate glass. Option \# 3 is the direct immobilization of sludge into a solid matrix (again without any Pu extraction) using a microwave solidification process in a crucible to produce a phosphate glass. In all three options, the end solid waste products will be placed in storage for eventual geologic disposal.

Immobilization of residual plutonium into glass-like matrices provides both safer storage over the lifetime of the radionuclides and greater security against unauthorized access to stored materials, supporting our efforts toward nonproliferation of fissile materials. These studies are being continued into the next pre- 
design "Declaration of Intent" stage. Although the boron-silicate glass appears now to be marginally preferable compared to the phosphate glass option, a number of technical issues remain to be assessed by further study.

\section{Description of Work}

We developed the principal technological flow diagrams and process and storage equipment layouts using existing facilities at K-26 to the maximum extent possible to minimize costs and implementation schedules. We designed approaches to packaging, handling, storage, and geologic disposal of solidified sludges, and developed baseline approaches for technological handling of the solidified sludge. In addition, we listed primary technological and handling equipment; developed baseline approaches to auxiliary and service systems; and formulated principles for radiation, nuclear, and general safety. Preliminary quantitative analyses of personnel radiation exposures during routine operations and in postulated emergencies were made. We considered preliminary approaches to geologic disposal of the solid wastes, including thermal and physical calculations. To substantiate the solidified waste storage mode, we calculated the dependencies of the waste heat releases. Technical and economical data were obtained relative to options of handling the sludge, and costs broken down into separate life-cycle phases of investment and operating costs, including processing, storage and geologic disposal.

The options were compared and assessed based on our criteria for

1. Process performance (e.g., temperature, volume, release of radionuclides);

2. Primary technological equipment and approaches to reconstructing the area;

3. Characteristics of solidified waste;

4. Safety of the solidified waste storage and disposal; and

5. Economic data.

Table 1 contains a summary of the three options, which are discussed in more detail below.

\section{Process Performance Characteristics}

The baseline plutonium recovery process, Option \#1, has an advantage over Options \#2 and \#3 in terms of development of the solidification process because it is carried out at lower temperatures and with a minimum of radionuclides generated in off-gasses during sludge solidification.

Option \#3 has an advantage over Options \# 1 and \# 2 in terms of minimizing the secondary liquid technological wastes arising from the immobilization process, which are then subject to underground deep borehole disposal as liquids.

\section{Primary Technological Equipment and Area Reconstruction}

The baseline option [\#1] has an advantage over both of the vitrification options because design documentation already exists for non-standardized cementation equipment. All three options are at the same level of design documentation development for non-standardized handling and technological equipment, as well as for the equipment for temporary storage of solidified products prior to geologic disposal. All three options are developed to the same extent in regard to modifications to existing areas at K-26 for installation of the appropriate equipment and for transportation of the solidified product to the temporary storage facility. Option \#1 does have an advantage over Options \#2 and \#3 in that fewer underground tanks must be modified to establish the temporary storage facility for the solidified products. 


\section{Russian Engineering and Industrial Site Plutonium Immobilization Contract Activities}

\section{Solidified Sludge Characteristics}

Option \#2, immobilization in boron-silicate glass, has the following advantages over Options \#1and \#3 for solidifying plutonium-bearing sludges at MCC:

- Lower leaching factors for alkali earth and transuranic elements inherent in a boron-silicate glass matrix;

- Higher percentages of inclusion of plutonium and other radionuclides, which preserve the stability to ionizing and thermal impacts when stored and subsequently disposed of;

- $\quad$ Crystalline structure;

- Lower specific volumetric outputs of the solidified products, again due to higher percentages of inclusion of plutonium and other radionuclides; and

- Higher matrix densities.

\section{Safety of Storage and Geologic Disposal}

Safe storage and geologic disposal of solidified sludge requires that the cooling air temperature be maintained below $45^{\circ} \mathrm{C}$ for the entire time of storage. Our estimates show that to meet this requirement for boron-silicate glass, the cooling air must be supplied at a temperature of $25^{\circ} \mathrm{C}$ at a rate of $0.1 \mathrm{~m} / \mathrm{s}$. For phosphate glass and cement compound, it is sufficient to again supply the cooling air at $25^{\circ} \mathrm{C}$ but at a rate of $0.02 \mathrm{~m} / \mathrm{s}$. Thermal and physical calculations show that the radioactive waste heat released in the geologic disposal site has no practical effect on the temperature of the surrounding rock massif. An increase in temperature in the center of the disposal area containing radioactive waste will not exceed $9^{\circ} \mathrm{C}$. The increase in temperature of the rocks inside the disposal site at a distance of $25 \mathrm{~m}$ from the disposal borehole will not exceed $2^{\circ} \mathrm{C}$. Such increases in temperature inside the disposal site will not affect the rock temperature outside the disposal facility. Estimates of ecological safety of the storage facility and geologic disposal site show that storage of the solidified waste for the entire lifetime of the storage facility will generate radioactive dose rates to the exposed population below allowable rates, and the design of the deep geologic disposal site allows the safe isolation of the radioactive waste for the entire period of actual danger from the radionuclides. The distance over which a concentration of ${ }^{90} \mathrm{Sr}$ transports does not exceed $160 \mathrm{~m}$, and that for ${ }^{239} \mathrm{Pu}$ does not exceed $110 \mathrm{~m}$ for any option.

\section{Economic Data}

Total investment and operating costs to implement the different technical approaches to immobilizing the plutonium-bearing sludge with the production of boron-silicate and phosphate glasses and to establish a long-term storage facility for the solidified waste are essentially the same at 84.9 and 87.4 million US\$, respectively (options \#2 and \#3). These costs are $22-25 \%$ less than the total investment and operating costs for implementation of Option \#1 for the existing plutonium-bearing sludges. For the solidified sludges, Option \#2 is 337.7 million US\$, which is $15 \%$ less than the total investment, operating and disposal costs for Option \#1 and 30\% less than those for Option \#3.

Assuming the geologic disposal of conditioned waste into deep boreholes of $\sim 1 \mathrm{~km}$, preliminary comparisons of overall economic data show that sludge immobilization in boron-silicate glass (Option \#2) may be marginally preferable to immobilization in phosphate glass (Option \#3) but both immobilization options are more economic than the baseline Option \#1. 


\section{Discussion of Results}

Immobilization of the plutonium-bearing sludges into glass-like matrixes instead of cementation matrixes increases the waste storage safety by fixing plutonium reliably in a strong and stable material. It also provides increased physical protection and nuclear safety of solidified waste during long-term storage and makes possible the final disposal of solidified waste into geological formations. Preliminary estimates show that keeping solidified plutonium-bearing materials in deep geologic disposal sites is safe. This type of disposal also excludes non-authorized access to these plutonium containing wastes, and resolves some issues associated with nonproliferation of fissile materials.

We recommend that the pre-design activities be continued into the next phase of development, the "Declaration of Intent" and the "Investment Justification." In these phases, we would further develop the processes to immobilize plutonium-bearing sludges (without any Pu extraction) into a solid matrix using microwave solidification to form boron-silicate glass (Option \#2) and phosphate glass (Option \#3).

The following technical issues also need to be assessed in these phases:

- Optimization of the size of the crucible;

- Optimization of the procedure to place solidified sludge in the storage facility;

- Specification of technological performance of the sludge solidification in terms of nuclear safety, including that for real sludge and simulations using pilot facilities placed in hot cells at MCC;

- Development of technology and equipment operating modes, including testing of serviceability of remotely controlled devices to replace the equipment and handle packages with solidified sludge on a pilot facility;

- Development of design documentation for non-standardized technological and transportation equipment;

- Study of solidified sludge storage and disposal safety by applying mathematical models to obtain risk estimates;

- Determination of an optimal amount of plutonium in solidified waste subject to disposal;

- Study of physical and chemical properties of the glasses and their components when subjected to long-term radiation exposure;

- Impact of temperature and underground water; and

- Development of regulatory documents addressing issues associated with storage and disposal of plutonium-bearing materials. 
Table 1. Comparison of two options for vitrification of Pu-bearing sludges with current, baseline techniques for Pu extraction and cementation of non-soluble residues.

\begin{tabular}{|c|c|c|c|c|}
\hline \# & Criterion & $\begin{array}{l}\text { Baseline } \\
\text { (Option \#1) }\end{array}$ & $\begin{array}{l}\text { Boron-silicate glass } \\
\text { (Option \#2) }\end{array}$ & $\begin{array}{l}\text { Phosphate glass } \\
\text { (Option \#3) }\end{array}$ \\
\hline 1. & Characteristics of the Process & & & \\
\hline 1.1 & Sludge solidification temperature, $\left({ }^{\circ} \mathrm{C}\right)$ & 20 & 1250 & 950 \\
\hline 1.2 & $\begin{array}{l}\text { Amount of secondary technological liquid waste subject to underground } \\
\text { disposal, }\left(\mathrm{m}^{3} / \mathrm{yr}\right)\end{array}$ & 2140 & 1210 & 815 \\
\hline 1.3 & Escape of radionuclides into the gas purification system (Ci/yr) & $1.5 \cdot 10^{2}$ & $7.7 \cdot 10^{4}$ & $7.7 \cdot 10^{4}$ \\
\hline 2. & \multicolumn{4}{|c|}{ Primary Technological Equipment and Reconstruction Approaches } \\
\hline \multirow[t]{3}{*}{2.1} & Primary technological equipment for solidification of the sludge: & & & \\
\hline & $\begin{array}{l}\text {-Availability of design documentation on non-standardized equipment of } \\
\text { the pilot facility }\end{array}$ & $\begin{array}{l}\text { Design documentation } \\
\text { has been developed }\end{array}$ & Subject to development & Subject to development \\
\hline & -Laboratory or pilot specimen of the facility is available & $\begin{array}{l}\text { Pilot specimen of the } \\
\text { facility is available }\end{array}$ & $\begin{array}{l}\text { Laboratory equipment is } \\
\text { available }\end{array}$ & $\begin{array}{l}\text { Laboratory equipment is } \\
\text { available }\end{array}$ \\
\hline \multirow[t]{3}{*}{2.2} & Primary transportation and technological equipment: & & & \\
\hline & -Availability of design documentation on non-standardized equipment & $\begin{array}{l}\text { Design documentation } \\
\text { on a container for } \\
\text { transporting a barrel with } \\
\text { solidified sludge }\end{array}$ & Subject to development & Subject to development \\
\hline & -Availability of pilot specimens & Not available & Not available & Not available \\
\hline \multirow[t]{3}{*}{2.3} & $\begin{array}{l}\text { Primary technological and transportation equipment for the temporary } \\
\text { storage facility }\end{array}$ & & & \\
\hline & -Availability of design documentation on non-standardized equipment & Subject to development & Subject to development & Subject to development \\
\hline & -Availability of pilot specimens & Not available & Not available & Not available \\
\hline 2.4 & $\begin{array}{l}\text { Necessity to modify area } 86 a \text { to establish a temporary storage facility for } \\
\text { solidified waste }\end{array}$ & 5 tanks & 2 tanks & 3 tanks \\
\hline 3. & \multicolumn{4}{|c|}{ Solidified Sludge Characteristics } \\
\hline 3.1 & Form of the solidified waste & Cement compound & Boron-silicate glass & Phosphate glass \\
\hline 3.2 & Content of plutonium, mg/l & $\sim 60$ & $\sim 1100$ & $\sim 620$ \\
\hline 3.3 & Specific activity, Ci/l & 1.78 & 265 & 152 \\
\hline 3.4 & Amount of the solidified sludge, $\mathrm{m}^{3}$ & 1573.0 & 544.0 & 949.0 \\
\hline 3.5 & Specific heat release, W/I & $<0.007$ & 1 & 0.59 \\
\hline 3.6 & Leachability, $\mathrm{g} \cdot \mathrm{cm}^{-2} \cdot$ day $^{-1}$ & $\mathrm{Cs}, \mathrm{Sr} \leq 10^{-3}$ & $\begin{array}{l}\mathrm{Cs} \leq 10^{-6}, \mathrm{Sr} \leq 10^{-1}, \mathrm{Pu} \leq \\
10^{-8}\end{array}$ & $\begin{array}{l}\mathrm{Cs} \leq 10^{-5}, \mathrm{Sr} \leq 10^{-6}, \mathrm{Pu} \leq \\
10^{-7}\end{array}$ \\
\hline 4. & \multicolumn{4}{|c|}{ Safety of Solidified Sludge Storage and Geologic Disposal } \\
\hline 4.1 & Excess of the surrounding massif's temperature over geothermal one, ${ }^{\circ} \mathrm{C}$ & Insufficient & $<9$ & $<9$ \\
\hline
\end{tabular}




\section{Technical/Economic Engineering Feasibility Study of Weapons Pu Sludge Immobilization at K-26}

\begin{tabular}{|c|c|c|c|c|}
\hline 4.2 & Rate of air feed to the storage facility, $\mathrm{m} / \mathrm{s}$ & $>0.02$ & $>0.1$ & $>0.02$ \\
\hline 4.3 & $\begin{array}{l}\text { Maximal advance of the concentration from a solidified waste container } \\
\text { along with fracture in rock, } m\end{array}$ & $\begin{array}{l}<160\left(\text { for } \mathrm{Sr}^{90}\right) \\
<110\left(\text { for } \mathrm{Pu}^{239}\right)\end{array}$ & 0.2 & 0.2 \\
\hline 4.4 & $\begin{array}{l}\text { Maximal advance of the concentration equal to APP from the solidified } \\
\text { waste storage along with fracture in rock, } m\end{array}$ & $<112\left(\right.$ for $\left.\mathrm{Sr}^{90}\right)$ & $\begin{array}{l}<10\left(\text { for } \mathrm{Cs}^{13 /}\right) \\
<10\left(\text { for } \mathrm{U}^{238}\right)\end{array}$ & $\begin{array}{l}<10\left(\text { for } \mathrm{Cs}^{131}\right) \\
<10\left(\text { for } \mathrm{U}^{238}\right)\end{array}$ \\
\hline 5. & \multicolumn{4}{|c|}{$\begin{array}{ll} & \text { Economic Data (000s US\$) } \\
\end{array}$} \\
\hline 5.1 & Investments in processing and storage of Pu-bearing sludge & $\$ 12,889.9$ & $\$ 17,116.4$ & $\$ 18,272.1$ \\
\hline 5.2 & Total operating costs for processing and storage of Pu-bearing sludge & $65,958.3$ & $61,138.7$ & $87,654.8$ \\
\hline 5.4 & Total operating costs for disposal of solidified sludge for 5 years & $206,285.0$ & $191,651.0$ & $263,583.0$ \\
\hline 5.5 & $\begin{array}{l}\text { Comparable total costs for processing, storage and disposal of Pu-bearing } \\
\text { sludge }\end{array}$ & $388,945.8$ & $337,719.6$ & $438,643.8$ \\
\hline
\end{tabular}




\section{Microwave Facility for Plutonium Immobilization in the "Hot" Cell at MCC [B347676]}

\section{K.G. Kudinov, A. Tretyakov, U.G. Krivitsky, A.V. Vasiliev, MCC}

To carry out testing during the feasibility study for plutonium immobilization at the Mining and Chemical Combine, we implemented a facility for solidification of radioactive waste in a hot cell at the Central Plant Laboratory. The facility includes:

- Microwave heater;

- Technological equipment for measuring out liquid reagents, preparing and feeding the mixture;

- Pipelines with check/control valves;

- Vapor and gas phase cooling and purification system;

- Check and sampling system.

The microwave heater was designed and developed by NIKIMT with the following performance characteristics:

\begin{tabular}{|c|c|}
\hline Power supply voltage, $\mathrm{V}$ & 220 \\
\hline Number of phases & 1 \\
\hline Frequency, $\mathrm{Hz}$ & 50 \\
\hline Total power consumption, kW & 12 \\
\hline Microwave power, kW & 5.0 \\
\hline Frequency, MHz & $2375-50$ \\
\hline Volume of cask-crucible, I & up to 20 \\
\hline Fill, \% & 80 \\
\hline Melt temperature, ${ }^{\circ} \mathrm{C}$ & $850-1100$ \\
\hline Type of vitrification & cyclic \\
\hline Water flow rate for solidification, $1 / \min$ & 10 \\
\hline Water temperature at inlet, ${ }^{\circ} \mathrm{C}$ & 13 \\
\hline Water temperature at outlet, ${ }^{\circ} \mathrm{C}$ & 40 \\
\hline
\end{tabular}

The portion of the microwave facility that includes the power source, magnetron, and circulator is placed in an operator room, and the waveguide and cask-crucible are located within a technological zone of the hot cell (Fig. 1). The following parameters were subject to control during microwave facility operation:

- Magnetron current;

- Voltage standing-wave ratio characterizing a portion of the microwave radiation reflected;

- Melt temperature by infrared pyrometer APIR-C;

- Cask wall temperature at three levels by a nickel-chromium-nickel-aluminum thermocouple;

- Gaseous phase temperature. 
Engineering Tests and Demonstrations at the K-26 Site

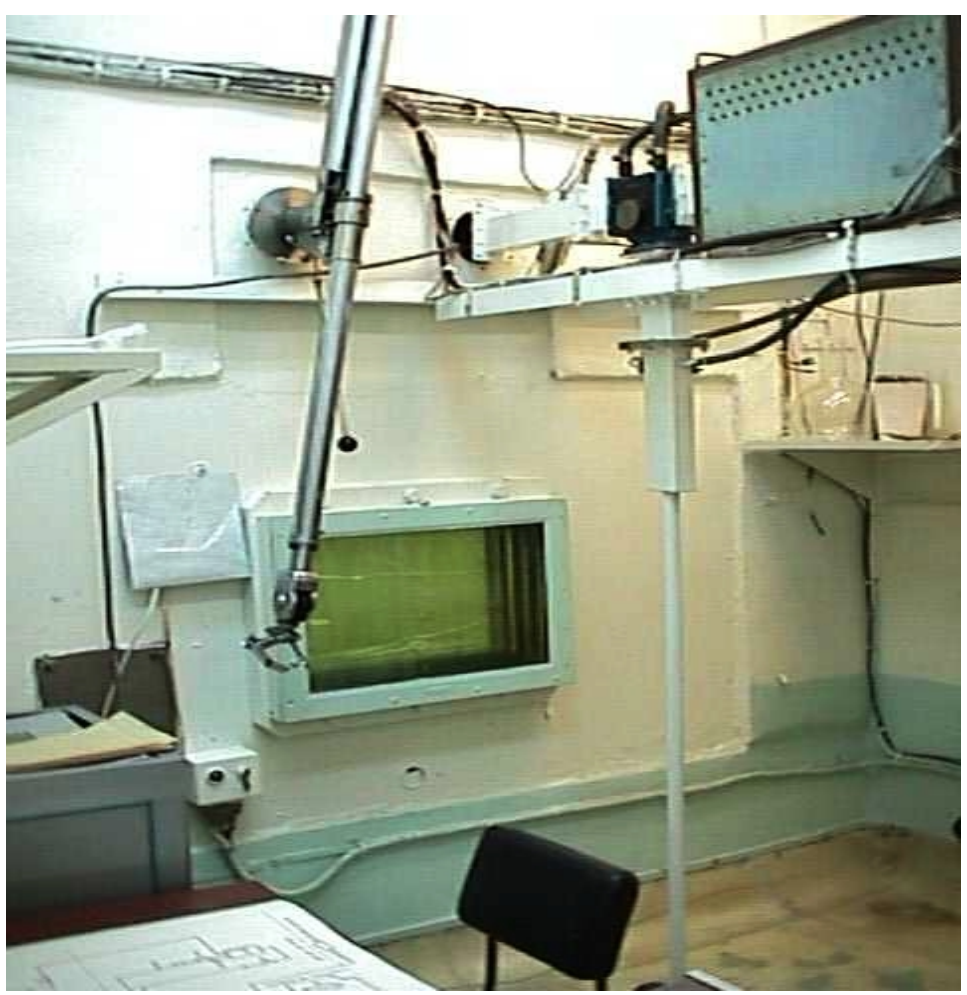

Figure 1a. The portions of the microwave facility in operator room of a hot cell.

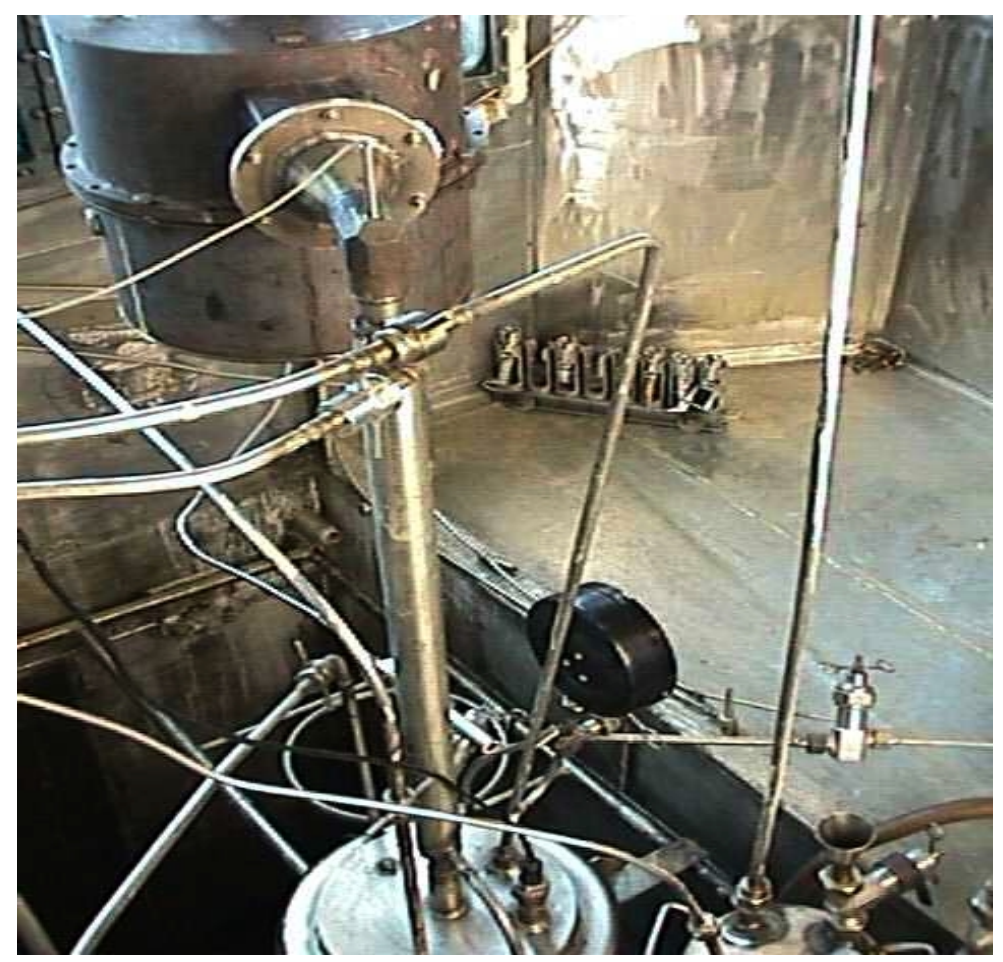

Figure $1 \mathrm{~b}$. The portions of the microwave facility in technological zone of the hot cell. 


\section{Russian Engineering and Industrial Site Plutonium Immobilization Contract Activities}

The experiments were carried out with a simulated sludge whose microcontent and physical and chemical properties are similar to that being retrieved from a storage tank. Plutonium was incorporated in the amount of $140 \mathrm{mg} / \mathrm{l}$, which corresponds to its average concentration in the solid phase of sludge accumulated at the Radiochemical Plant. Some experiments were carried out with a simulated sludge doped with a real one. Table 1 shows the content of the solid phase of actual sludge.

Table 1. Content of the solid phase of the sludge used for solidification.

\begin{tabular}{|l|l|c|}
\hline \hline \multicolumn{1}{|c|}{ Item/Parameter } & \multicolumn{1}{|c|}{ Unit } & Concentration \\
\hline Plutonium & $\mathrm{Mg} / \mathrm{l}$ & 142 \\
Uranium & $\mathrm{g} / \mathrm{l}$ & 9.6 \\
Iron & $\mathrm{g} / \mathrm{l}$ & 16.4 \\
Silicon Dioxide & $\mathrm{g} / \mathrm{l}$ & 0.3 \\
Aluminum & $\mathrm{g} / \mathrm{l}$ & 1.0 \\
Manganese & $\mathrm{g} / \mathrm{l}$ & 6.0 \\
Chromium & $\mathrm{g} / \mathrm{l}$ & 0.3 \\
Nickel & $\mathrm{g} / \mathrm{l}$ & 1.5 \\
Sludge density & $\mathrm{g} / \mathrm{cm}^{3}$ & 1.220 \\
Real density of solid phase particles & $\mathrm{g} / \mathrm{cm}^{3}$ & 3.168 \\
$\alpha$-activity, including: & $\mathrm{Ci} / \mathrm{l}$ & 0.7 \\
Strontium-90 & $\mathrm{Ci} / \mathrm{l}$ & 0.23 \\
Exposure Dose Rate, include: & $\mu \mathrm{R} / \mathrm{L} \cdot \mathrm{sec}$ & 2.9 \\
Cesium-137 & $\%$ & 82 \\
Cerium-144 & $\%$ & 7.0 \\
Antimony -125 & $\%$ & 6.0 \\
Ruthenium-106 & $\%$ & 5.0 \\
\hline
\end{tabular}

The sludge was solidified in modes recommended by VNIINM (phosphate glass matrix) and KRI (boronsilicate glass matrix). Figure 2 shows the radioactive waste solidification block-diagram. The experiments were carried out in several phases. At the beginning, with a simulated sludge (not bearing plutonium), the optimal solidification process parameters were determined. Next, a container was filled with glass $80 \%$ by volume in optimal mode. Then, a simulated sludge doped with plutonium was subjected to solidification. And finally, simulated sludge was added to a real sludge and solidified.

Based on the VNIINM technology, the experiments were carried out in a 13-I crucible. The optimal throughput for the initial sludge was $2 \mathrm{l} / \mathrm{hr}$. With the simulated sludge, we produced about $30 \mathrm{~kg}$ of plutonium-free phosphate glass, about $1 \mathrm{~kg}$ of phosphate glass bearing $0.046 \mathrm{wt} \%$ of plutonium dioxide, and $4.5 \mathrm{~kg}$ of phosphate glass bearing $0.047 \mathrm{wt} \%$ of plutonium dioxide with $0.04 \mathrm{Ci}(0.01 \mathrm{Ci} / \mathrm{kg})$ in total $\alpha$ activity.

Based on the KRI technology, solidification was carried out in a 3-I crucible. The optimal throughput for initial sludge was about $0.5 \mathrm{l} / \mathrm{hr}$. With the simulated sludge, we produced about $10 \mathrm{~kg}$ of plutonium-free boron-silicate glass, $0.5 \mathrm{~kg}$ of boron-silicate glass bearing $0.058 \mathrm{wt} \%$ of plutonium dioxide, and $1.5 \mathrm{~kg}$ of boron-silicate glass bearing $0.058 \mathrm{wt} \%$ of plutonium dioxide with $0.05 \mathrm{Ci}(0.03 \mathrm{Ci} / \mathrm{l})$ in $\alpha$-activity.

Table 2 provides the micro-component composition of phosphate and boron-silicate glasses. 
Table 2. Composition of phosphate and boron-silicate glasses produced for sludge solidification.

\begin{tabular}{|c|c|c|}
\hline \hline Component & $\begin{array}{c}\text { Phosphate glass } \\
\text { concentration, wt } \%\end{array}$ & $\begin{array}{c}\text { Boron-silicate glass } \\
\text { concentration, wt\% }\end{array}$ \\
\hline $\mathrm{UO}_{3}$ & 6.6 & 8.5 \\
\hline $\mathrm{P}_{2} \mathrm{O}_{5}$ & 56.6 & - \\
\hline $\mathrm{SiO}_{2}$ & 0.4 & 36.3 \\
\hline $\mathrm{B}_{2} \mathrm{O}_{3}$ & - & 7.0 \\
\hline $\mathrm{Na}_{2} \mathrm{O}$ & 23.6 & 14.9 \\
\hline $\mathrm{Fe}_{2} \mathrm{O}_{3}$ & 5.5 & 14.4 \\
\hline $\mathrm{Cr}_{2} \mathrm{O}_{3}$ & 0.8 & 1.9 \\
\hline $\mathrm{Al}_{2} \mathrm{O}_{3}$ & 1.2 & 3.1 \\
\hline $\mathrm{Li}_{2} \mathrm{O}$ & - & 7.0 \\
\hline $\mathrm{MnO}_{2}$ & 4.4 & 5.1 \\
\hline $\mathrm{NiO}$ & 0.9 & 1.1 \\
\hline
\end{tabular}

The dynamics of escape of volatile compounds during sludge vitrification have been determined. The main amount of carbonates and nitrates decompose to gaseous products at a temperature exceeding $400^{\circ} \mathrm{C}$. Plutonium is carried away as an aerosol in amounts not exceeding $1.3 \times 10^{-4} \%$ of the initial quantity in the sludge when immobilizing the plutonium into either phosphate or boron-silicate matrixes. Of the radionuclides in the sludge, the ruthenium-106 and cesium-137 discharge to the vapor-gas phase in significant quantities in both aerosol and vapor forms. A maximum ratio of the escape in these forms is 1:10000. Escape of ruthenium-106 and cesium-137 to the vapor-gas phase during immobilization into a phosphate matrix is equal to $14.03 \%$ and $15.63 \%$ of the initial quantity, respectively. The percentages of these radionuclides that escape during immobilization into a boron-silicate matrix is equal to $0.34 \%$ for Ru-106 and $0.40 \%$ for Cs- 137 .

We have studied the chemical stability of samples taken from the glass produced. The leaching rate of the components of the phosphate glass matrix and micro-components of the solidified sludge (uranium, manganese, nickel) when tested in distilled water under normal conditions $\left(25^{\circ} \mathrm{C}, 1 \mathrm{Atm}\right.$.) is higher than the leaching rates of the same components from boron-silicate glass. The leaching rates of radionuclides from the two types of glass are given in Table 3.

Table 3. Leaching rate of radionuclides from glass matrices.

\begin{tabular}{|l|c|c|}
\hline \multicolumn{1}{|c|}{ Radionuclide } & \multicolumn{2}{c|}{ Leaching rate, $\mathbf{g} / \mathrm{cm}^{2} /$ day } \\
\hline Plutonium & Phosphate glass & Boron-silicate glass \\
\hline Ruthenium-106 & $1.21 \times 10^{-7}$ & $1.26 \times 10^{-7}$ \\
\hline Cesium-137 & $1.87 \times 10^{-5}$ & $1.98 \times 10^{-5}$ \\
\hline
\end{tabular}

On average, the mechanical strength of samples ( $30 \mathrm{~mm}$ diameter and $10 \mathrm{~mm}$ height) when tested by pressing was equal to $3.5 \mathrm{MPa}$ for phosphate glass and $9.2 \mathrm{MPa}$ for boron-silicate glass. 


\section{FIG. 2. MICRO-WAVE FACILITY PRINCIPLE BLOCK DIAGRAM}

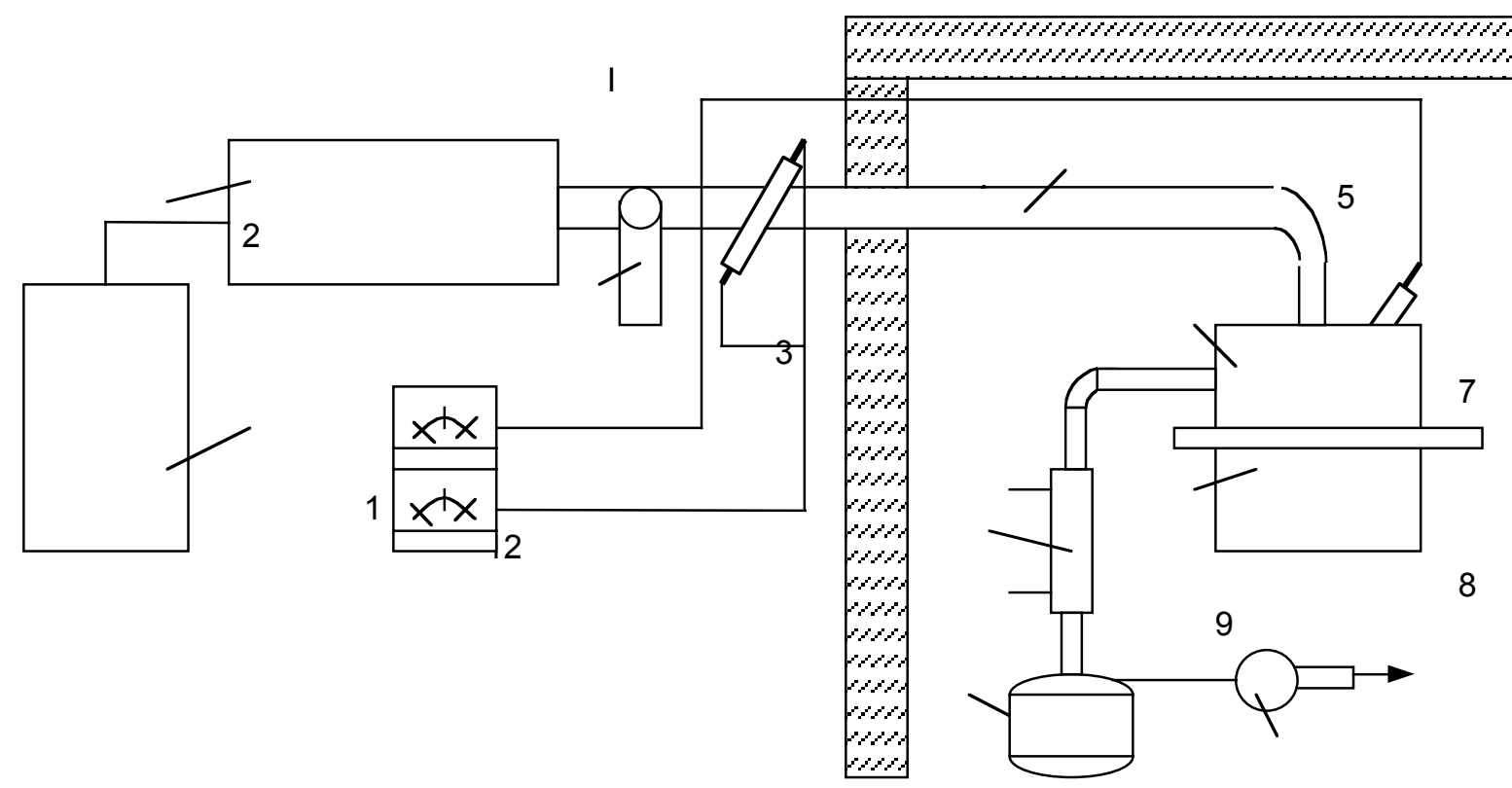

10

Technical Characteristics of the microwave heater

- power supply voltage, $\mathrm{V} \quad 220$

- number of phases 1

- frequency, $\mathrm{Hz}$

- total power consumption, 12

kVA

- micro-wave power, $\mathrm{kW} \quad 5.0$

- frequency, $\mathrm{MHz}$

- volume of cask-crucible, I up to

- fill, \%

80

- melt temperature, ${ }^{\circ}$

$850-$

1 - high voltage source;

7 - cask lid;

2 - magnetron;

8 - sack-crucible;

3 - circulator;

9 - gaseous phase condenser;

10 - condensate collector;

$\omega$

5 - waveguide

6 - pyrometer

11 - ejector;

12 - parameters reading panel;

I-operator room; II - hot cell technological zone. 


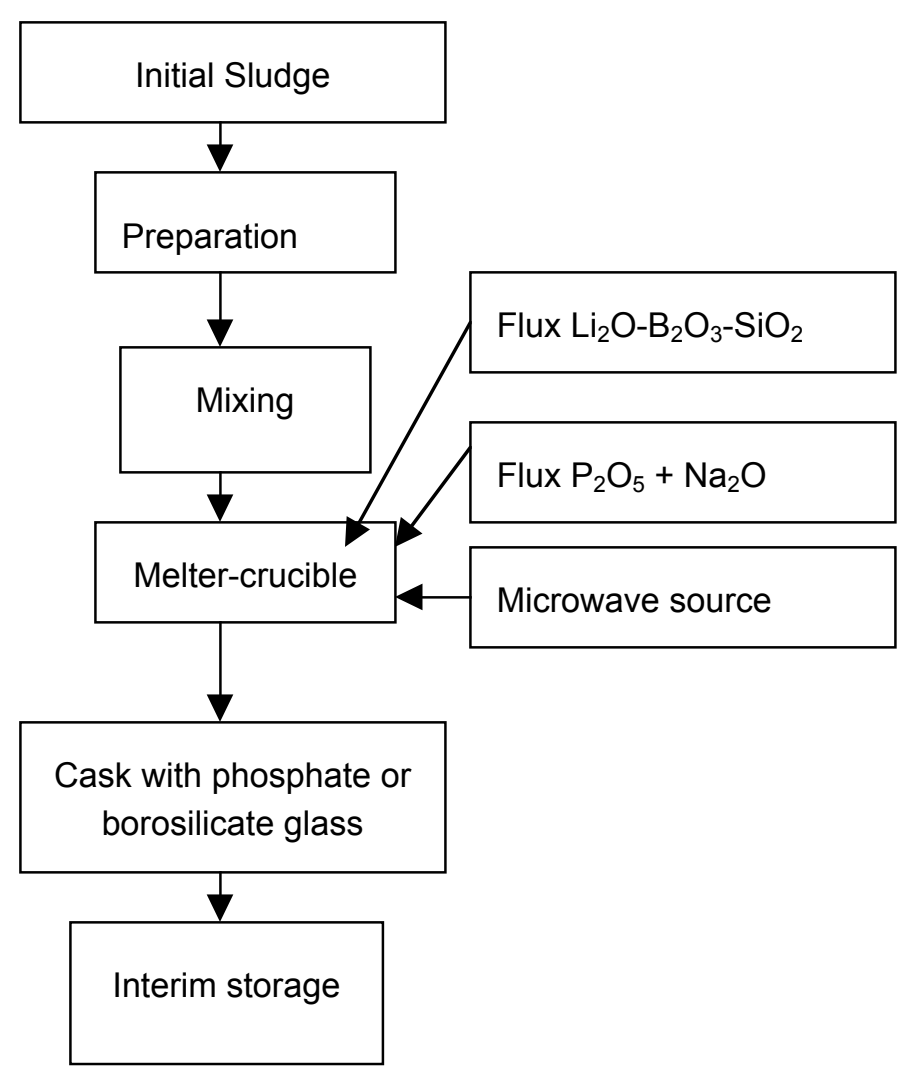

Figure 3. Radioactive Waste Vitrification Block Diagram.

\section{Conclusions}

Thus, under the contract with LLNL, a microwave heating facility for solidifying plutonium-bearing waste was installed in an MCC hot cell during May-June, 1999. Operating modes of immobilizing sludge into phosphate and boron-silicate matrixes have been verified, technological parameters of the process have been determined, and physical and chemical properties of the glasses produced have been studied.

The main drawback of the current microwave facility design is that it is not possible to control it remotely during operations. The next design will allow large-scale testing on a real sludge.

We have prepared proposals for modifications to be made to the facility, and these proposals will be implemented under a new contract.

To date, NIKIMT has fabricated a remotely served, thermally isolated melter-crucible, and we have designed and fabricated a unit for transporting the crucible within a technological zone of the hot cell.

We have also improved the technological, physical, and chemical characteristics of glass compositions, provided protection or remote replacement of sealing inserts on the waveguide, automated the microwave power control used during solidification, and modified a system that monitors the process parameters and controls measuring devices. 


\title{
Initial Data for the Engineering Feasibility Study on Pu-Bearing Radioactive Waste Immobilization at MCC [B347376]
}

\author{
A.C. Aloy, B.S. Kuznetsov, E.Yu. Ivanov, A.V. Trofimenko, KRI
}

\section{Assembly and Adjustment of the Microwave Facility in the Hot Cell}

According to the Work Plan, an experimental microwave facility from KRI was delivered to MCC and assembled in a hot cell (HC-9). Engineering specifications for the microwave (MW) facility and reports on work performed, including measurements of MW fields at work places, were considered by a special commission which concluded that:

- Control and power supply systems of the facility are in accordance with Operating Rules and Safety Regulations for electric facilities;

- Electromagnetic field levels are within permissible limits;

- A complete set of equipment and the condition of the melter meet the requirements of operation and maintenance for this type of facility.

Based on the final report of the commission, the facility was recognized as suitable for conducting start-up adjustment work as a part of the vitrification unit. At this stage, we installed the MW module, waveguide system, and crucible melter.

To conduct primary tests, provisional process regulations were developed for solidification of model sludges with the use of MW heating in $\mathrm{HC}-9$. The regulations include the following sections:

1. Description of technological process, sequence of operations;

2. Wiring diagram of the facility;

3. Physico-chemical characteristics of sludges subject to processing;

4. Characteristics of solidified product;

5. Standards for process conditions;

6. Process control;

7. Possible problems, emergency situations, their probable causes, and ways to eliminate them;

8. Basic rules for safe process management;

9. Ecology, environmental protection.

\section{Preparation and Investigation of Simulated Sludges}

To perform laboratory studies of MW vitrification for plutonium-containing sludges, model sludge samples were synthesized using the technique elaborated at MCC. To obtain a model sludge, nitric acid solutions were prepared which contained the basic cations present in actual sludge. The sludge was obtained using the procedure of reverse alkaline precipitation with mixing at $95 \pm 5^{\circ} \mathrm{C}$. This method was used to prepare sludges from solutions of the compositions shown in Table 1. 


\section{Engineering Tests and Demonstrations at the K-26 Site}

Table 1. Simulated sludge compositions.

\begin{tabular}{|l|l|l|l|}
\hline \hline \multirow{2}{*}{ Component } & \multicolumn{3}{|c|}{ Content, g/l } \\
\cline { 2 - 4 } & $\mathbf{1}$ & $\mathbf{2}$ & $\mathbf{3}$ \\
\hline $\mathrm{U}$ & 7.2 & 6.4 & 11.5 \\
\hline $\mathrm{Fe}$ & 5.1 & 7.1 & 1.3 \\
\hline $\mathrm{Mn}$ & 3.7 & - & 1.4 \\
\hline $\mathrm{Al}$ & 0.9 & 0.95 & 0.85 \\
\hline $\mathrm{Ni}$ & 0.9 & 0.65 & 0.28 \\
\hline $\mathrm{Cr}$ & 1.8 & 0.4 & 0.11 \\
\hline $\mathrm{SiO}_{2}$ & 0.56 & 1.8 & - \\
\hline $\mathrm{P}$ & 0.05 & - & 0.05 \\
\hline
\end{tabular}

After sludge aging, 150-180 g/l of sodium nitrate was introduced therein; the content of $\mathrm{NaOH}$ was about $15 \mathrm{~g} / \mathrm{l}$. After settling and washing with water, the content of sodium ion in sludge samples was 9-11 wt\% relative to the sum of cations of other metals. The settled sludge was thickened by filtration up to a solid phase content of 120-150 g/l.

The sludges obtained were studied by differential thermal analysis (DTA) and $x$-ray phase analysis. The results of DTA show the process of hydroxide dehydration at $\sim 150^{\circ} \mathrm{C}$ and sodium nitrate melting at $\sim 300^{\circ} \mathrm{C}$. The crystallization peak is observed at $680^{\circ} \mathrm{C}$.

The results of $\mathrm{x}$-ray phase analysis are shown in Fig. 1 in the form of diffractograms. These data show that the sludge is a mixture of roentgen-amorphous and crystalline phases represented by sodium nitrate and sodium diuranate.

In the process of sludge thermal treatment up to $1000^{\circ} \mathrm{C}$, first the compounds of sodium and iron interact forming $\mathrm{NaFeO}_{2}$, and second, diuranate is transformed into monouranate $\beta-\mathrm{Na}_{2} \mathrm{UO}_{4}$ which corresponds to data in the literature on thermal transformations in the system $\mathrm{Na}_{2} \mathrm{O}-\mathrm{UO}_{3}[1]$. 


\section{Russian Engineering and Industrial Site Plutonium Immobilization Contract Activities}

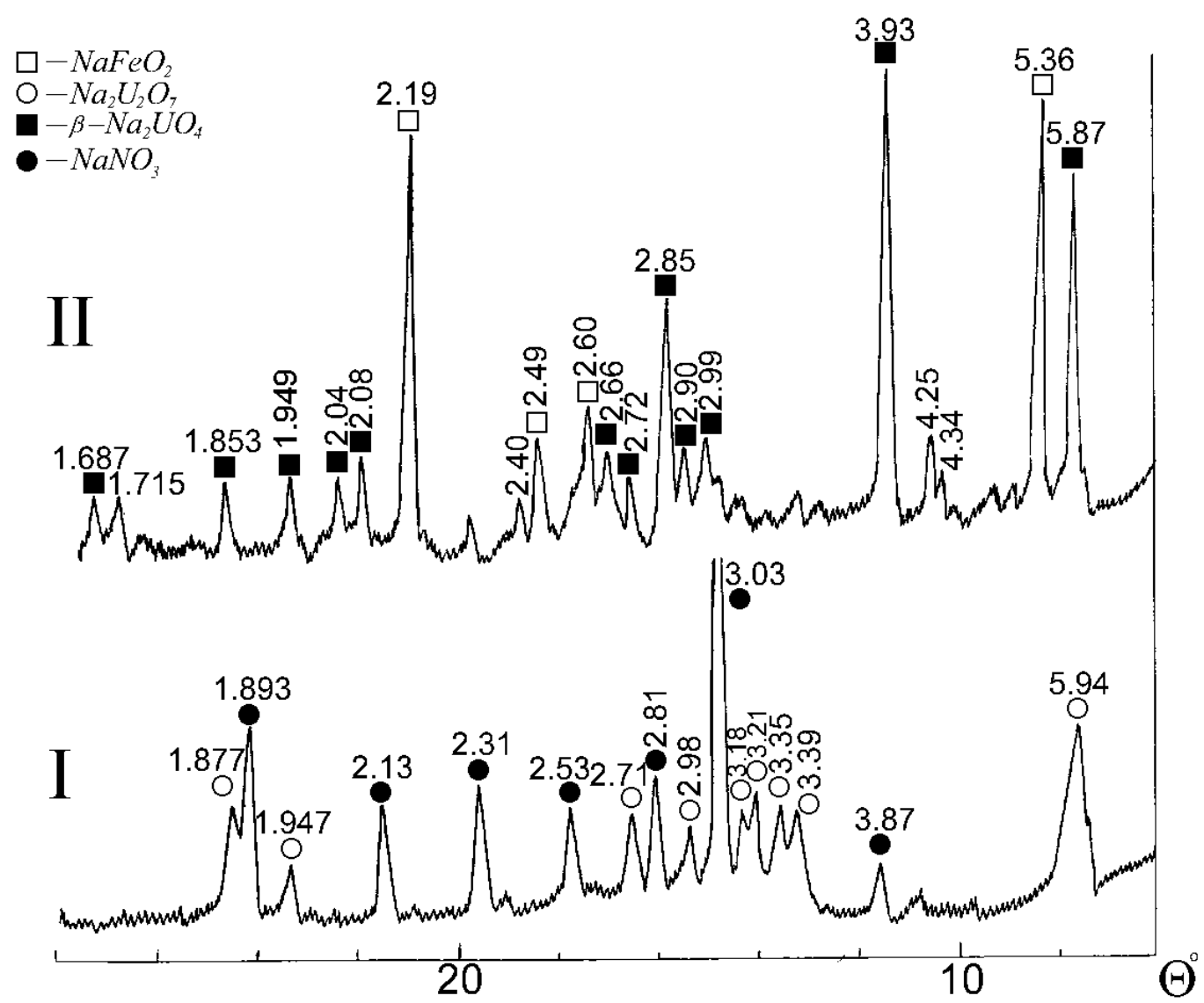

Fig. 1. (1) Diffractogram of sludge; (2) diffractogram of sludge after DTA.

\section{Investigation of Sludge Solidification Products}

To assess the behavior of real sludge during vitrification in the SXF facility, a series of fluxed model charge meltings was performed with model sludge to borosilicate flux ratios: (30:70), (40:60), (50:50), (60:40), and (70:30) mass\%. The composition of charge samples is shown in Table 2 . The phase composition of samples is given in Table 3 .

The blocks obtained were studied by $x$-ray phase analysis, electron probe microanalysis, and EMPA; in addition, their apparent density and porosity were determined.

Table 2. Content of oxides in charge.

\begin{tabular}{|l|l|l|l|l|l|l|l|l|l|}
\hline \hline \multirow{2}{*}{$\begin{array}{c}\text { Sludge:flux } \\
\text { (mass\%) }\end{array}$} & \multicolumn{8}{|c|}{ Oxides content in charge (mass \%) } \\
\cline { 2 - 11 } & $\mathbf{U O}_{2}$ & $\mathbf{S i O}_{2}$ & $\mathbf{F e}_{2} \mathbf{O}_{3}$ & $\mathbf{A l}_{2} \mathbf{O}_{3}$ & $\mathbf{C r}_{2} \mathbf{O}_{3}$ & $\mathbf{B}_{2} \mathbf{O}_{3}$ & $\mathbf{C e O}_{2}$ & $\mathbf{N a}_{2} \mathbf{O}$ & $\mathbf{L i}_{2} \mathbf{O}$ \\
\hline \hline $30: 70$ & 10.64 & 45.21 & 14.97 & 2.64 & 0.84 & 16.22 & 0.03 & 7.12 & 2.33 \\
\hline $40: 60$ & 14.18 & 39.17 & 19.96 & 3.52 & 1.12 & 13.90 & 0.04 & 6.11 & 2.00 \\
\hline $50: 50$ & 17.73 & 33.13 & 24.96 & 4.40 & 1.40 & 11.58 & 0.05 & 5.08 & 1.67 \\
\hline $60: 40$ & 21.27 & 27.08 & 29.95 & 5.27 & 1.68 & 9.27 & 0.07 & 4.08 & 1.33 \\
\hline $70: 30$ & 24.82 & 21.04 & 34.94 & 6.17 & 1.96 & 6.95 & 0.08 & 3.05 & 0.99 \\
\hline
\end{tabular}


Engineering Tests and Demonstrations at the K-26 Site

Table 3. Phase composition of samples after heating to $1000^{\circ} \mathrm{C}$.

\begin{tabular}{|c|l|}
\hline $\begin{array}{c}\text { Sludge composition } \\
\text { Sludge:flux (mass \%) }\end{array}$ & \multicolumn{1}{c|}{ Phase composition } \\
\hline $30: 70$ & Fully roentgen-amorphous (R/A) \\
\hline $40: 60$ & Fully (R/A) \\
\hline $50: 50$ & $\begin{array}{l}(\mathrm{R} / \mathrm{A}) \text { phase, solid solution } \mathrm{UO}_{2}, \mathrm{U}(\mathrm{Fe}, \mathrm{Cr}) \mathrm{O}_{4}, \\
\mathrm{Fe}^{+2} \mathrm{Me}^{+3}{ }_{2} \mathrm{O}_{4}\end{array}$ \\
\hline $60: 40$ & $\begin{array}{l}(\mathrm{R} / \mathrm{A}) \mathrm{phase}^{+} \mathrm{U}(\mathrm{Fe}, \mathrm{Cr}) \mathrm{O}_{4} \text { solid solution } \mathrm{UO}_{2}, \\
\mathrm{Fe}^{+2} \mathrm{Me}_{2}{ }_{2} \mathrm{O}_{4}\end{array}$ \\
\hline $70: 30$ & $\begin{array}{l}(\mathrm{R} / \mathrm{A}) \mathrm{phase}_{2} \text { solid solution } \mathrm{UO}_{2}, \mathrm{U}(\mathrm{Fe}, \mathrm{Cr}) \mathrm{O}_{4}, \\
\mathrm{Fe}{ }^{+2} \mathrm{Me}_{2}{ }_{2} \mathrm{O}_{4}\end{array}$ \\
\hline
\end{tabular}

X-ray phase analysis of samples was performed with diffractometer DRON-1,5 using $\mathrm{CuK}_{\alpha}$ radiation. Conditions on the $x$-ray tube were $U_{a}=32 \mathrm{kV}, \mathrm{l}_{\mathrm{a}}=16 \mathrm{~mA}$. Electron probe microanalysis was performed with $\mathrm{x}$-ray micro-analyzer CamScan (England).

The measurements of density and porosity were conducted according to State Standard [2]. The results obtained for apparent density are shown in Fig. 2. This graph shows that with the increase of oxide sum from 30 to $70 \%$, the density of samples increases from 2.83 to $3.70 \mathrm{~g} / \mathrm{cm}$. All samples have zero apparent porosity.

From the data, it follows that for the sludge oxide content in charge up to 40 mass $\%$, a roentgenamorphous material is formed. With increasing the oxide content up to 50 mass $\%$, along with roentgenamorphous phase, the compounds of spinel type, solid solutions based on uranium dioxide and compounds of the type $\mathrm{U}(\mathrm{Fe}, \mathrm{Cr}) \mathrm{O}_{4}$ are crystallized. The amount of crystalline phase in the samples increases with the growth of sludge oxide concentration.

All compositions of samples were analyzed by the EMPA technique. To determine uranium sedimentation, portions of samples were sawn out at different levels of glass blocks. The surfaces of sample melt were studied using the same procedure.

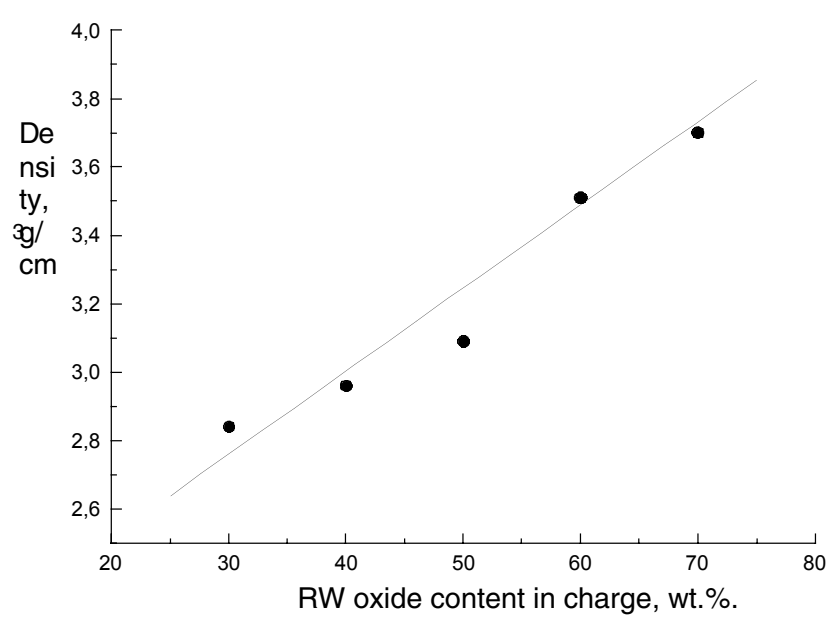

Fig. 2. Dependence of sample density on flux composition. 


\section{Results}

The main results of the investigation performed are as follows:

1. The matrix composition of samples with sludge content from 30 to 40 mass $\%$ in charge is close to that of charge for these samples and homogeneous in volume. All uranium is incorporated in the matrix. A small quantity of spinel inclusions with the composition $\mathrm{Fe}(\mathrm{Fe}, \mathrm{Cr})_{2} \mathrm{O}_{4}$. are present in the samples (Figs. 3, 4).

2. The matrix composition of samples containing 50,60 , and 70 mass $\%$ of oxides in charge has similar composition and, as compared to charge composition, it is enriched in silicon and aluminum oxides and depleted of iron and uranium oxides which form crystalline phases. The analysis of surface areas at different levels of glass blocks has not shown uranium sedimentation.

3. The distribution of crystalline phases in volume is uniform (Fig. 5).

4. In samples with oxide content in charge 50,60, and 70 mass $\%$, several phases are found: spinel of composition $\mathrm{Fe}(\mathrm{Fe}, \mathrm{Cr}, \mathrm{Al})_{2} \mathrm{O}_{4}$, needle-shaped dendrites, and star-shaped dendrites enriched with uranium (Fig. 6).

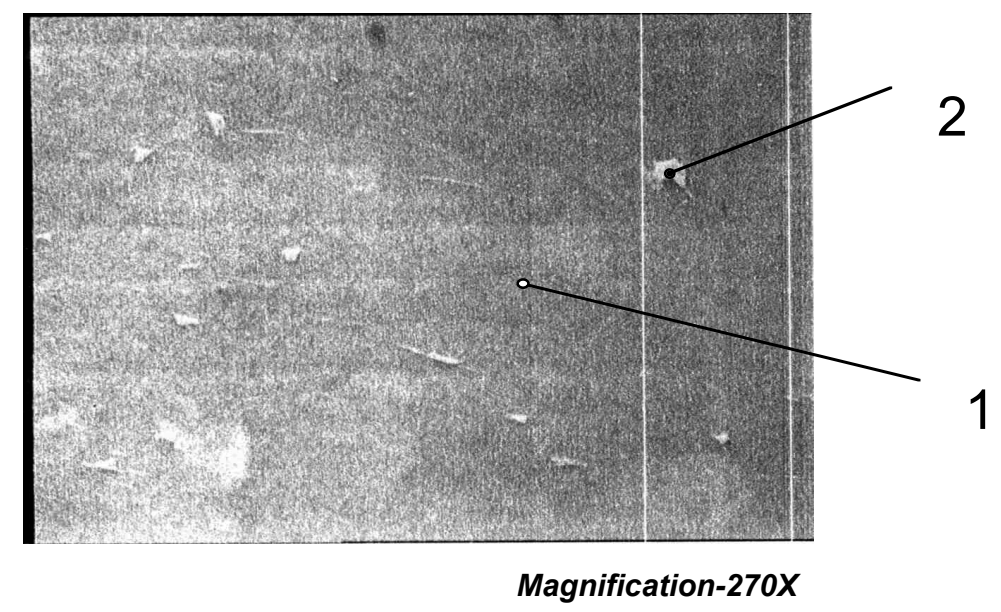

Fig. 3. Electronic photograph of sample; sludge:flux ratio=30:70 mass\%; (1) matrix, (2) spinel $\mathrm{FeCr}_{2} \mathrm{O}_{4}$. 
Engineering Tests and Demonstrations at the K-26 Site

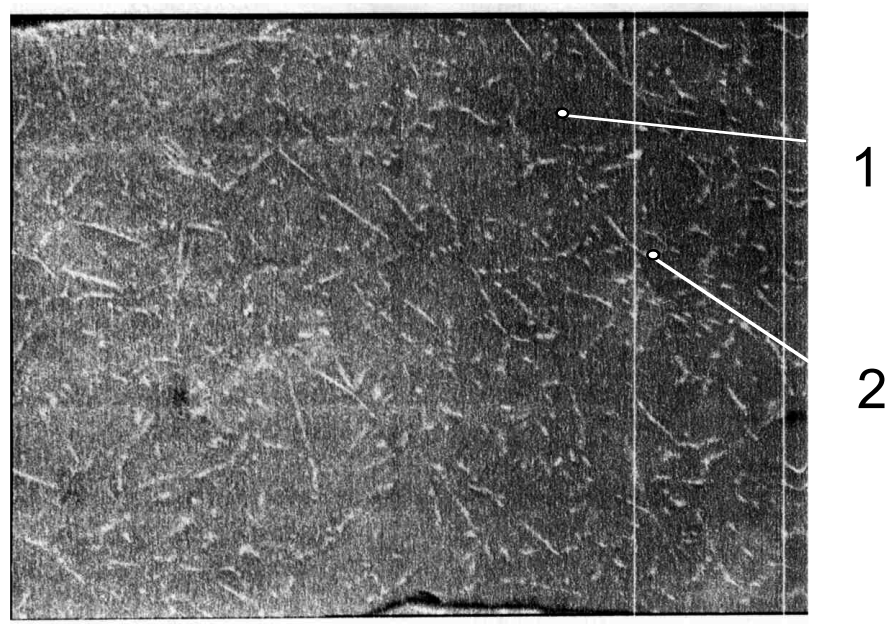

Magnification-430X

Fig. 4. Electronic photograph of sample; sludge:flux ratio=40:60 mass\%; (1) matrix, (2) spinel $\mathrm{Fe}(\mathrm{Fe}, \mathrm{Cr})_{2} \mathrm{O}_{4}$.

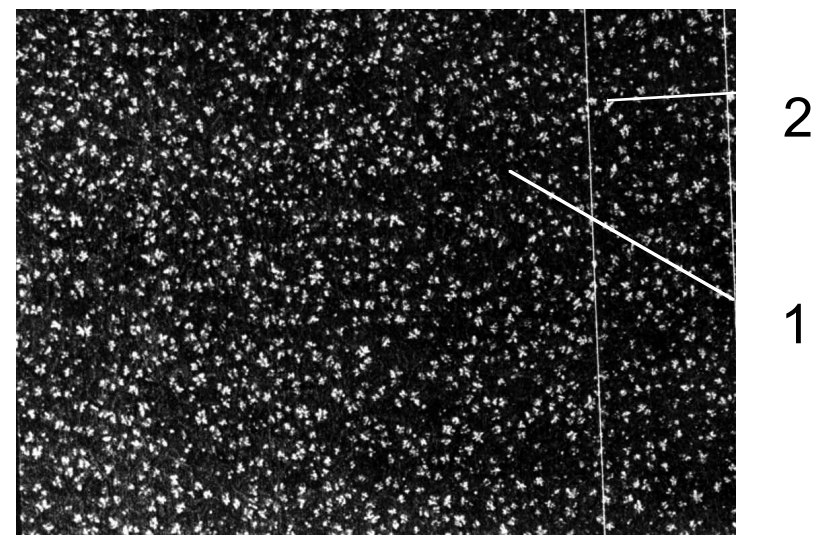

Magnification-137X

Fig. 5. Electronic photograph of sample; sludge:flux ratio=60:40 mass\%; (1) matrix, (2) crystalline phase. 


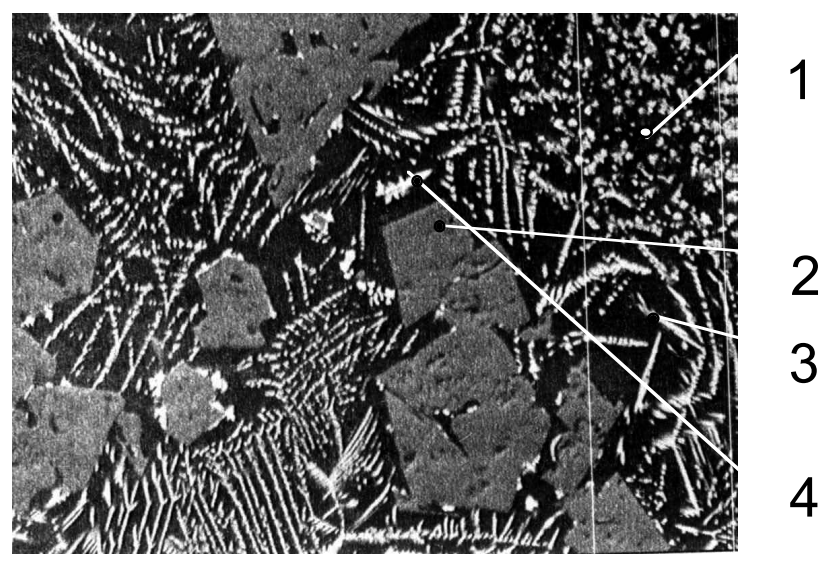

Magnification-440X

Fig. 6. Electronic photograph of sample; sludge:flux ratio=60:40 mass\%; (1) matrix, (2) spinel $\mathrm{Fe}(\mathrm{Fe}, \mathrm{Cr})_{2} \mathrm{O}_{4} ;(3)$ and (4) phases enriched with uranium.

\section{References}

1. Ippolitova E.A. et al. In "Studies on the Uranium Chemistry," Moscow, Moscow State University, 1987,. p. 63.

2. GOST 473.4-81. 
Viewgraphs

Preparing and gathering initial data for the engineering feasibility study on Plutonium-Bearing Radioactive Waste Immobilization at MCC

A.C. Aloy, B.S. Kuznetsov, E.Yu. Ivanov, A.V. Trofimenko

Khlopin Radium Institute, St. Petersburg, Russia. 


\section{Technological flow-sheet mass balances of the sludge solidification}

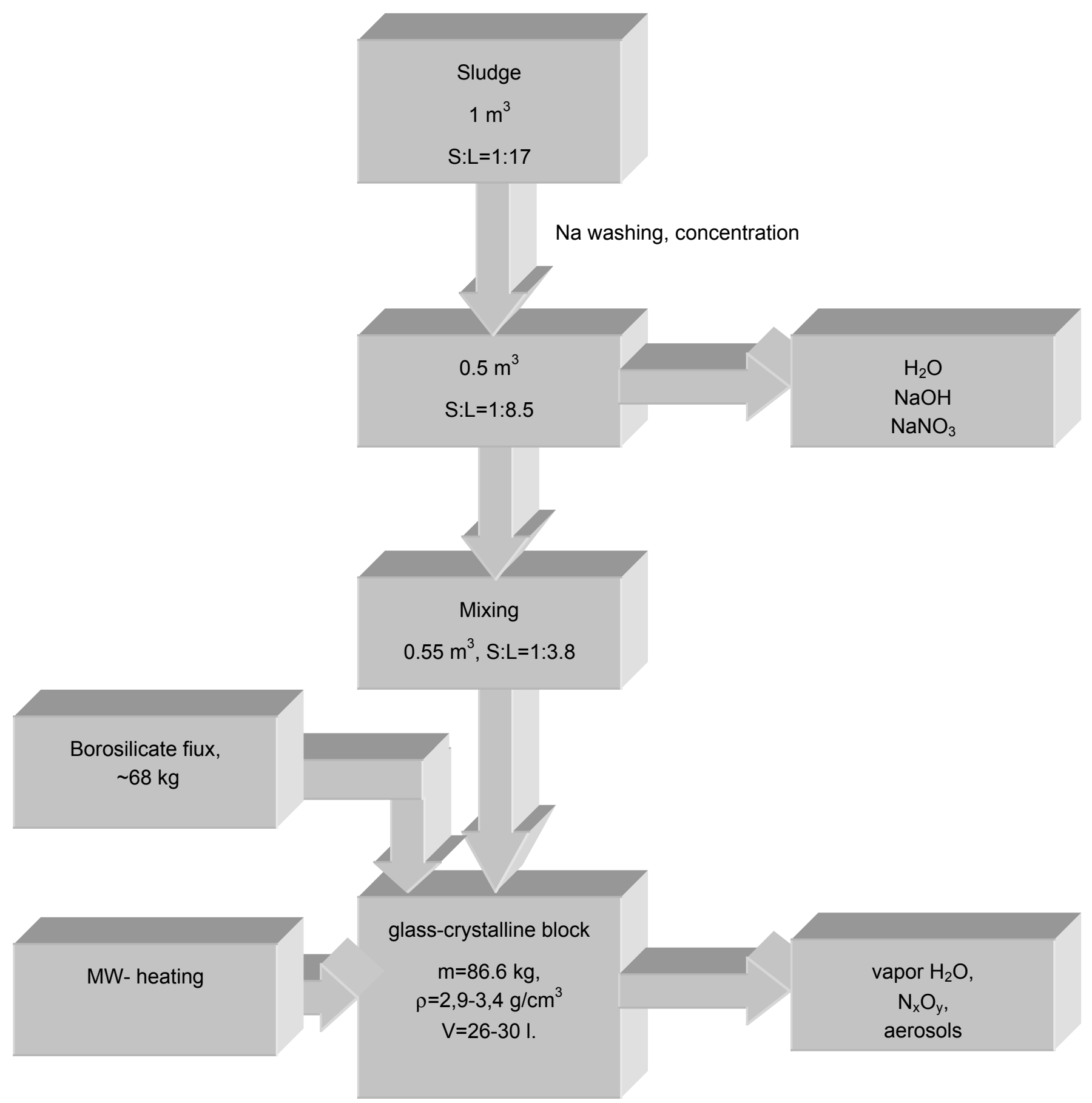

Volume reduction $\sim 35$ times. 
Engineering Tests and Demonstrations at the K-26 Site

The lab-scale MW-heating set block-scheme

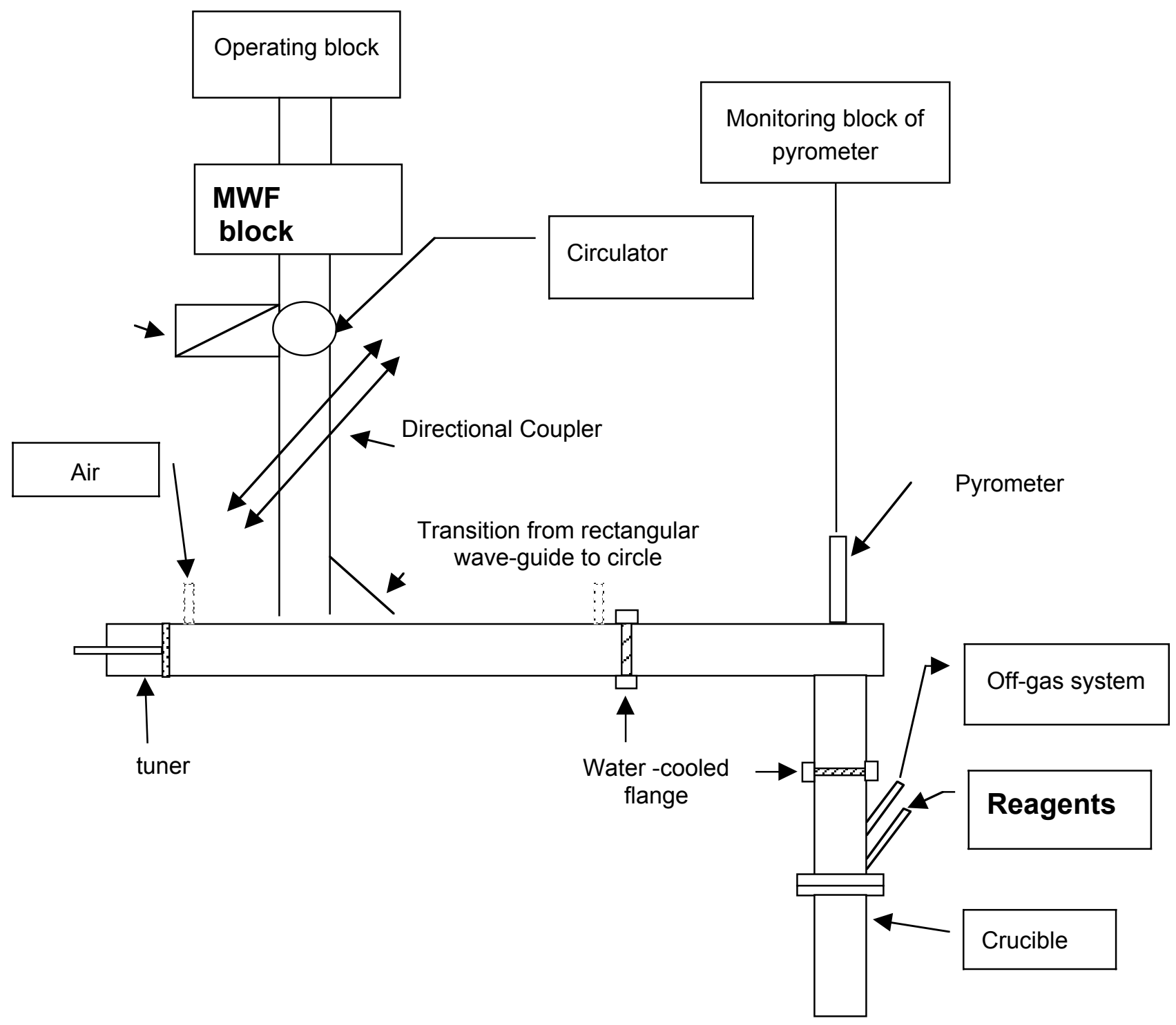




\section{Content of oxides in charge}

\begin{tabular}{|c|c|c|c|c|c|c|c|c|c|}
\hline \multirow{2}{*}{$\begin{array}{l}\text { Sludge: } \\
\text { flux } \\
\text { (wt. \%) }\end{array}$} & \multicolumn{9}{|c|}{ Oxides (wt.\%) } \\
\hline & $\mathrm{UO}_{2}$ & $\mathrm{CeO}_{2}$ & $\mathrm{Fe}_{2} \mathrm{O}_{3}$ & $\mathrm{Al}_{2} \mathrm{O}_{3}$ & $\mathrm{Cr}_{2} \mathrm{O}_{3}$ & $\mathrm{SiO}_{2}$ & $\mathrm{~B}_{2} \mathrm{O}_{3}$ & $\mathrm{Na}_{2} \mathrm{O}$ & $\mathrm{Li}_{2} \mathrm{O}$ \\
\hline $30: 70$ & 10.64 & 0.03 & 14.97 & 2.64 & 0.84 & 45.21 & 16.22 & 7.12 & 2.33 \\
\hline $50: 50$ & 17.73 & 0.05 & 24.96 & 4.40 & 1.40 & 33.13 & 11.58 & 5.08 & 1.67 \\
\hline $60: 40$ & 21.27 & 0.07 & 29.95 & 5.27 & 1.68 & 27.08 & 9.27 & 4.08 & 1.33 \\
\hline
\end{tabular}




\section{Dependence of sample density on flux composition}

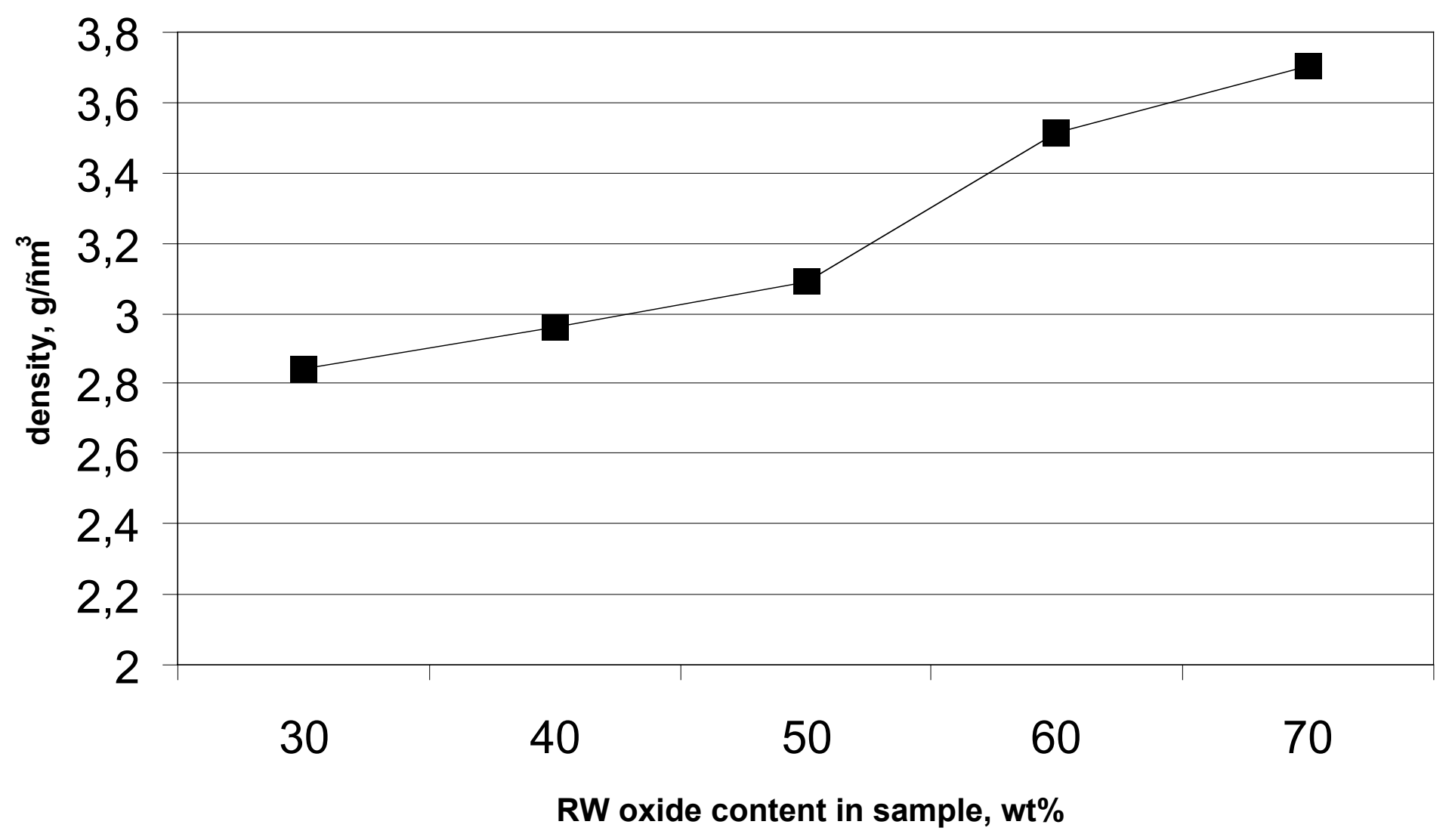


Phase composition of vitrified samples with different ratio sludge:flux

\begin{tabular}{|c|c|}
\hline $\begin{array}{c}\text { Ratio } \\
\text { Sludge:flux (mass \%) }\end{array}$ & Phase composition \\
\hline $30: 70$ & Fully roentgen-amorphous (R/A) \\
\hline $40: 60$ & Fully R/A \\
\hline $50: 50$ & R/A phase, $\mathrm{UO}_{2}, \mathrm{U}(\mathrm{Fe}, \mathrm{Cr}) \mathrm{O}_{4}, \mathrm{Fe}^{+2} \mathrm{Me}_{2}^{+3} \mathrm{O}_{4}$ \\
\hline $60: 40$ & $\mathrm{R} / \mathrm{A}$ phase, $\mathrm{U}(\mathrm{Fe}, \mathrm{Cr}) \mathrm{O}_{4}$ solid solution $\mathrm{UO}_{2}, \mathrm{Fe}^{+2} \mathrm{Me}_{2}^{+3} \mathrm{O}_{4}$ \\
\hline $70: 30$ & $\mathrm{R} / \mathrm{A}$ phase, solid solution $\mathrm{UO} \mathrm{O}_{2}, \mathrm{U}(\mathrm{Fe}, \mathrm{Cr}) \mathrm{O}_{4}, \mathrm{Fe}^{+2} \mathrm{Me}_{2}{ }_{2} \mathrm{O}_{4}$ \\
\hline
\end{tabular}




\section{Dependence of leach rates on flux composition} $t=90^{\circ} \mathrm{C}, 7$ day.

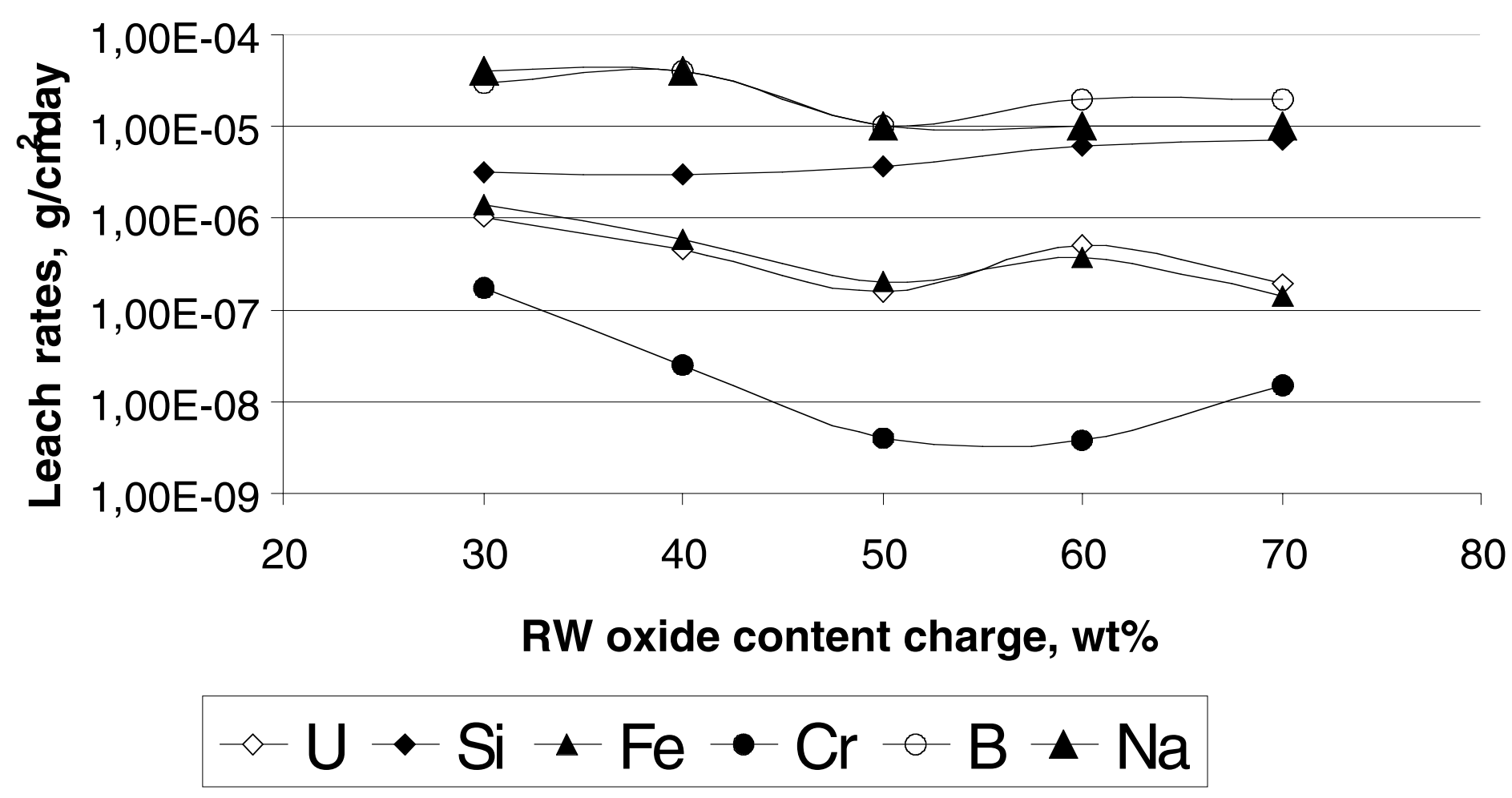


The pilot MW-heating set block-scheme at MCC hot cell

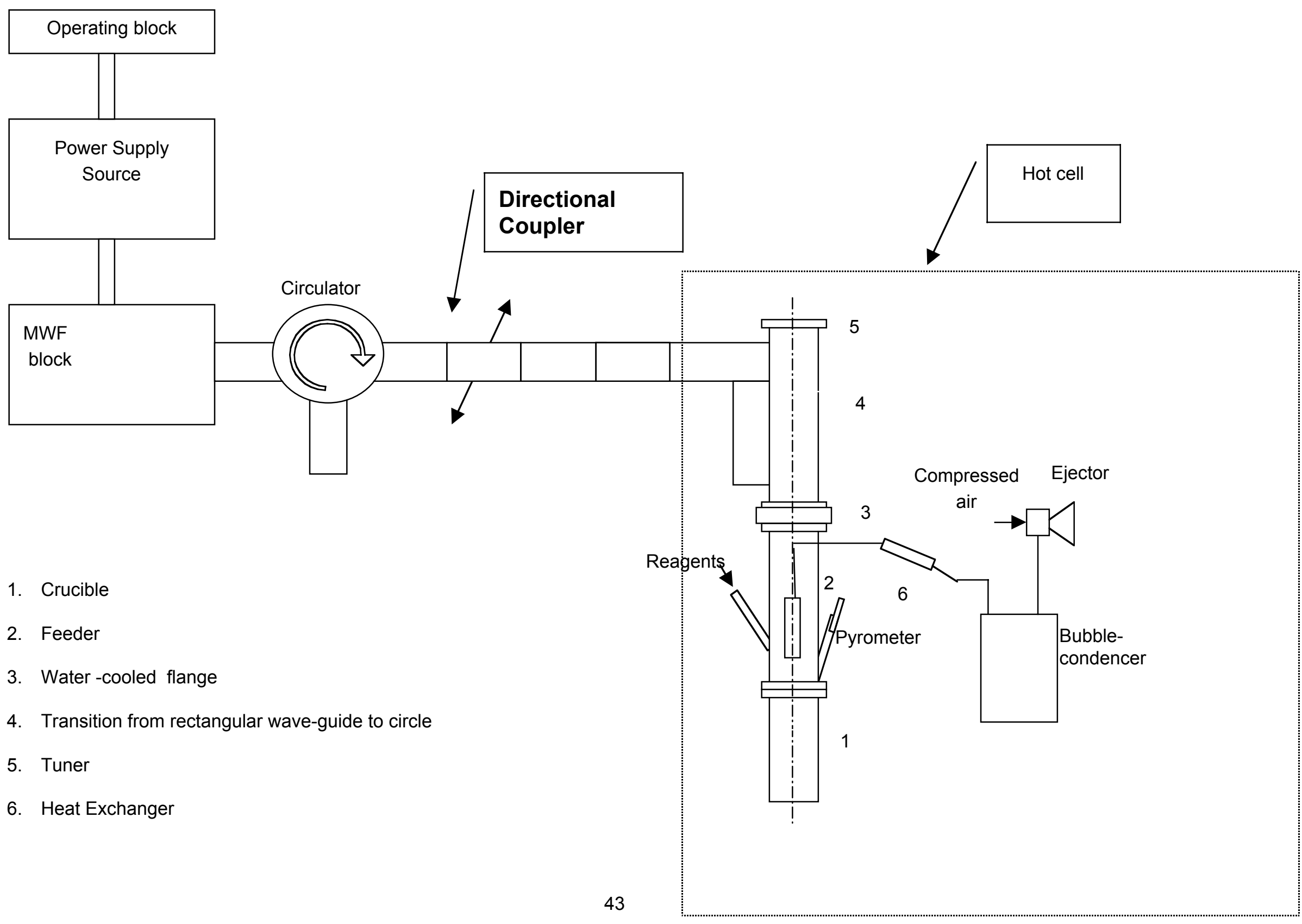


Composition and properties of the borosilicate glass, produced by pilot MW-heating set at MCC hot cell

Composition

\begin{tabular}{|c|c|c|c|c|c|c|c|c|c|c|}
\hline Component & $\mathrm{UO}_{3}$ & $\mathrm{Fe}_{2} \mathrm{O}_{3}$ & $\mathrm{MnO}_{2}$ & $\mathrm{Al}_{2} \mathrm{O}_{3}$ & $\mathrm{NiO}$ & $\mathrm{Na}_{2} \mathrm{O}$ & $\mathrm{Cr}_{2} \mathrm{O}_{3}$ & $\mathrm{SiO}_{2}$ & $\mathrm{Li}_{2} \mathrm{O}$ & $\mathrm{B}_{2} \mathrm{O}_{3}$ \\
\hline Content, wt\% & 12,0 & 10,1 & 8,1 & 2,1 & 1,6 & 14,6 & 1,4 & 36,1 & 7,0 & 7,0 \\
\hline
\end{tabular}

Property

\begin{tabular}{|c|c|c|c|}
\hline RW oxide content, wt $\%$ & \multicolumn{3}{|c|}{50} \\
\hline Compressive strength, $\mathrm{P}_{-}$ & \multicolumn{3}{|c|}{9.2} \\
\hline Density, g/_m $\mathrm{m}^{3}$ & \multicolumn{3}{|c|}{2.9} \\
\hline Phase composition & \multicolumn{3}{|c|}{ Fully roentgen-amorphous phase } \\
\hline \multirow{3}{*}{ Discharge of volatile elements, wt $\%$} & \multicolumn{3}{|c|}{$\mathrm{Pu}-2.0 \cdot 10^{-4}$} \\
\hline & \multirow{2}{*}{$\mathrm{Ru}, \mathrm{Cs}$} & Up to $300^{\circ}$ & $10^{-3}-10^{-4}$ \\
\hline & & Up to $900^{\circ}$ & $0.3-0.4$ \\
\hline
\end{tabular}

\begin{tabular}{|c|c|c|c|c|c|c|}
\hline Component & $\mathrm{U}$ & $\mathrm{Na}$ & $\mathrm{Mn}$ & $\mathrm{Cs}$ & $\mathrm{Ru}$ & $\mathrm{Pu}$ \\
\hline Leach rate g/_m $\mathrm{m}^{2}$.day $10^{5}$ & 0.1 & 0.8 & $<0.1$ & 2.4 & 2.1 & 0.01 \\
\hline
\end{tabular}




\section{SEM microphotographes of the glass-crystalline sample}

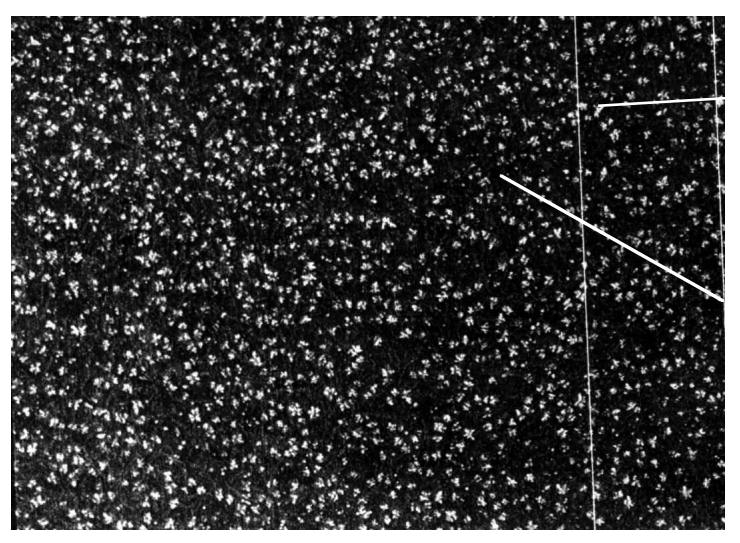

2

1

Magnification-137X

Sludge:Flux ratio $=60: 40$ mass. $\%$

1-matrix, 2-crystalline phase.

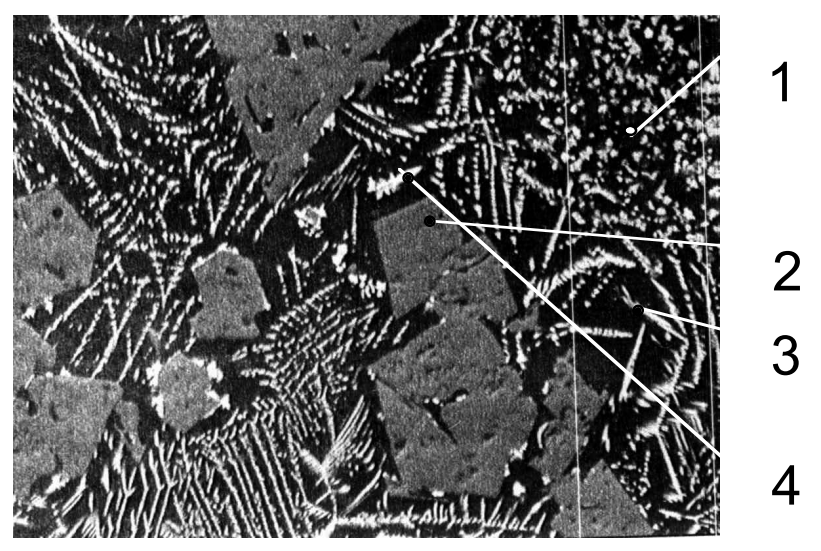

Magnification-440X

Sludge:Flux ratio=60:40 mass. $\%$

1-matrix, 2-spinel $\mathrm{Fe}(\mathrm{Fe}, \mathrm{Cr})_{2} \mathrm{O}_{4} ; 3$,4-phases enriched with uranium. 
Comparison data for phosphate and borosilicate matrixes properties according to MCC results

\begin{tabular}{|c|c|c|c|}
\hline & \multicolumn{2}{|c|}{ Borosilicate matrix } & $\begin{array}{c}\text { Phosphate } \\
\text { matrix }\end{array}$ \\
\hline $\begin{array}{l}\text { RW oxide content } \\
\text {, wt } \%\end{array}$ & & 50 & 43 \\
\hline Density, $\mathrm{g} / \mathrm{m}^{3}$ & & 2.9 & 3.3 \\
\hline $\begin{array}{l}\text { Compressive } \\
\text { strength, _P_ }\end{array}$ & & 9.2 & 3.5 \\
\hline \multirow[b]{2}{*}{$\begin{array}{c}\text { Discharge of } \\
\text { volatile elements, } \\
\text { wt } \%\end{array}$} & & $\mathrm{Pu}-2.0 \cdot 10^{-4}$ & $\mathrm{Pu}-1,4 \cdot 10^{-4}$ \\
\hline & $\begin{array}{l}\mathrm{Ru} \\
\text { Cs }\end{array}$ & $\begin{array}{l}\text { Up to } 300^{0} 10^{-3}- \\
10^{-4} \\
\text { Up to } 900^{0} 0.3-0.4\end{array}$ & $\begin{array}{c}\mathrm{Ru}, \mathrm{Cs} \sim 14- \\
15\end{array}$ \\
\hline
\end{tabular}


Leach rate, $\mathrm{g} / \mathrm{cm}^{2}$ day $10^{5}$

\begin{tabular}{|c|c|c|c|c|c|c|}
\hline Component & $\mathrm{U}$ & $\mathrm{Na}$ & $\mathrm{Mn}$ & $\mathrm{Cs}$ & $\mathrm{Ru}$ & $\mathrm{Pu}$ \\
\hline $\begin{array}{c}\text { Borosilicate } \\
\text { matrix }\end{array}$ & 0.1 & 0.8 & $<0.1$ & 2.4 & 2.1 & 0.01 \\
\hline $\begin{array}{c}\text { Phosphate } \\
\text { matrix }\end{array}$ & 3.0 & 8 & 9.6 & 1.4 & 3.1 & 0.01 \\
\hline
\end{tabular}


Engineering Tests and Demonstrations at the K-26 Site 


\title{
Study of the Process of Pu-containing Wastes Vitrification Using a Microwave Installation of 15 kW [B500995]
}

\author{
M. N. Molokhov, NIKIMT, and G. B. Borisov, A. V. Nazarov, VNIINM
}

Previous investigations of the interaction between microwave energy and model solutions of plutoniumcontaining sludges were made in microwave installation CM 1193 by NIKIMT. However, the conditions for Pu-containing sludge vitrification processes required us to modernize this microwave installation and add equipment for additional units and assemblies.

In order to process glasses with a melting temperature up to $950^{\circ} \mathrm{C}$, we added a 2.5-liter, thermoinsulated crucible made from radio-transparent material to the microwave chamber. To control the temperature of the surface of the melting glass, a device was made and installed on the lid of the microwave chamber. This device holds sensors for remote temperature control and eliminates microwave energy leakage from the chamber.

The modernized microwave installation has the following technical parameters (Table 1):

Table 1. Parameters for microwave installation.

\begin{tabular}{|l|c|}
\hline \hline Microwave energy power, $\mathrm{kW}$ & 15 \\
\hline Microwave energy frequency, $\mathrm{mHz}$ & 2375 \\
\hline Voltage, $\mathrm{V}$ & $220 / 380$ \\
\hline Electric power consumption, $\mathrm{kW}$ & 30 \\
\hline Melting temperature, ${ }^{\circ} \mathrm{C}$ & 1000 \\
\hline Volume of the chamber, $\mathrm{m}^{3}$ & 0.3 \\
\hline
\end{tabular}

During this investigation, we developed and tested the following procedures for experimental studies at the modernized microwave installation.

- Preparation of a flux simulated Pu-containing slurry of fixed composition;

- Preparation of an instruction manual for microwave operations;

- Vitrification of the simulated Pu-containing slurry according to the following steps:

1. $100-500 \mathrm{ml}$ of the flux slurry is fed into an empty crucible made from a radiotransparent material, e.g., quartz;

2. The crucible is put into the center of a container made from a radio-transparent material, e.g., quartz, and is thermally isolated, e.g., by kaolin cotton;

3. The container is put into the microwave chamber, then the chamber is closed by a lid, and the installation is switched on;

4. The slurry is evaporated and calcinated at $350-450^{\circ} \mathrm{C}$ at $5-10 \mathrm{~kW}$ of power just before obtaining a dry product (calcinate);

5. The processes of evaporation and calcination are repeated a few times by periodically pouring $100-$ to $500-\mathrm{ml}$ portions of slurry into the crucible before filling it with calcinate to approximately $80 \%$ of capacity. (During the pouring, the installation is turned off); 


\section{Engineering Tests and Demonstrations at the K-26 Site}

6. Melting of the calcinate is conducted at $900-950^{\circ} \mathrm{C}$ for $1-2$ hours;

7. The glass is sampled during the holding period at the melting point (during sampling, the installation is turned off);

8. After the end of the holding period, the crucible is taken off the container and cooled at room temperature;

9. After cooling, the crucible is broken off, and a visual assessment is made of the glass product to define its chemical stability and physico-chemical properties.

Temperatures of the surface of the calcinate and the glass are measured by means of a infrared pyrometer that can measure temperatures up to $1200^{\circ} \mathrm{C}$. Sampling the glass is done with a quartz rod. The chemical stability of the glass is assessed using the GOST-29114091 (IAEA analogue) leach method.

A vitrification test of the slurry was performed using the new procedure and the modernized microwave installation. The composition of the slurry was as follows (wt\%):

$$
\begin{aligned}
& \mathrm{Na}_{2} \mathrm{O} \text { - 16.8; } \mathrm{Fe}_{2} \mathrm{O}_{3}-24.8 \\
& \mathrm{Al}_{2} \mathrm{O}_{3}-6.8 ; \mathrm{MnO}_{2}-16.3 \\
& \mathrm{NiO}-3.8 ; \mathrm{U}_{3} \mathrm{O}_{8}-27.0 ; \\
& \mathrm{SiO}_{2}-2.3 ; \mathrm{Cr}_{2} \mathrm{O}_{3}-2.2
\end{aligned}
$$

A flux of the following composition was added to the frit $(100 \mathrm{~g})$ :

$$
\begin{aligned}
& \mathrm{Na}_{2} \mathrm{O}-45 \mathrm{~g} \text { in the form of } \mathrm{NaOH} \text {; } \\
& \mathrm{P}_{2} \mathrm{O}_{5}-140 \mathrm{~g} \text { in form of } 89 \% \mathrm{H}_{3} \mathrm{PO}_{4} \text {; } \\
& \mathrm{B}_{2} \mathrm{O}_{3}-20 \mathrm{~g} \text { in form of } \mathrm{H}_{3} \mathrm{BO}_{3} \text {. }
\end{aligned}
$$

The following glass was obtained (wt\%):

$$
\begin{aligned}
& \mathrm{Fe}_{2} \mathrm{O}_{3}-8.1 ; \mathrm{MnO}_{2}-5.3 ; \mathrm{Al}_{2} \mathrm{O}_{3}-2.2 ; \mathrm{NiO}-1.2 ; \mathrm{U}_{3} \mathrm{O}_{8}-8.9 ; \mathrm{SiO}_{2}-0.7 ; \mathrm{Cr}_{2} \mathrm{O}_{3}-0.7 \\
& \mathrm{Na}_{2} \mathrm{O}-20.3 ; \mathrm{P}_{2} \mathrm{O}_{5}-45.9 ; \mathrm{B}_{2} \mathrm{O}_{3}-6.6
\end{aligned}
$$

Vitrification of the simulated slurry can be described in the following way:

After installing the container (see Fig. 1, \#1) with thermal isolation (\#5) and the crucible (\#2) into the chamber (\#7), it was closed with the lid (\#6) using pneumocylinders (\#9), to put the edges of the lid into the hydro gate (\#13), thereby preventing leakage of the microwave energy to the outside. Then, three 5kW microwave generators (\#11) are turned on. Depending upon the volume of slurry in the crucible, one smoothly fixes the level of power needed to vitrify the slurry. The microwave energy is passed from the generator to the chamber on the waveguide (\#8). A steam-gas phase, which is generated during processing, is removed into a vent system via the holes (\#12).

The process can be divided into four stages: evaporation, calcination, vitrification, and holding. The end of evaporation can be determined by the decrease of fumes and the increase of a surface temperature of the material to be treated. At this moment, the microwave energy is turned off, the lid is opened, and one pours a portion of the slurry into the crucible. Following this method, one produces the calcinate in the crucible to the fill level (about $80 \%$ of its volume). After that, by increasing the power of the microwave 


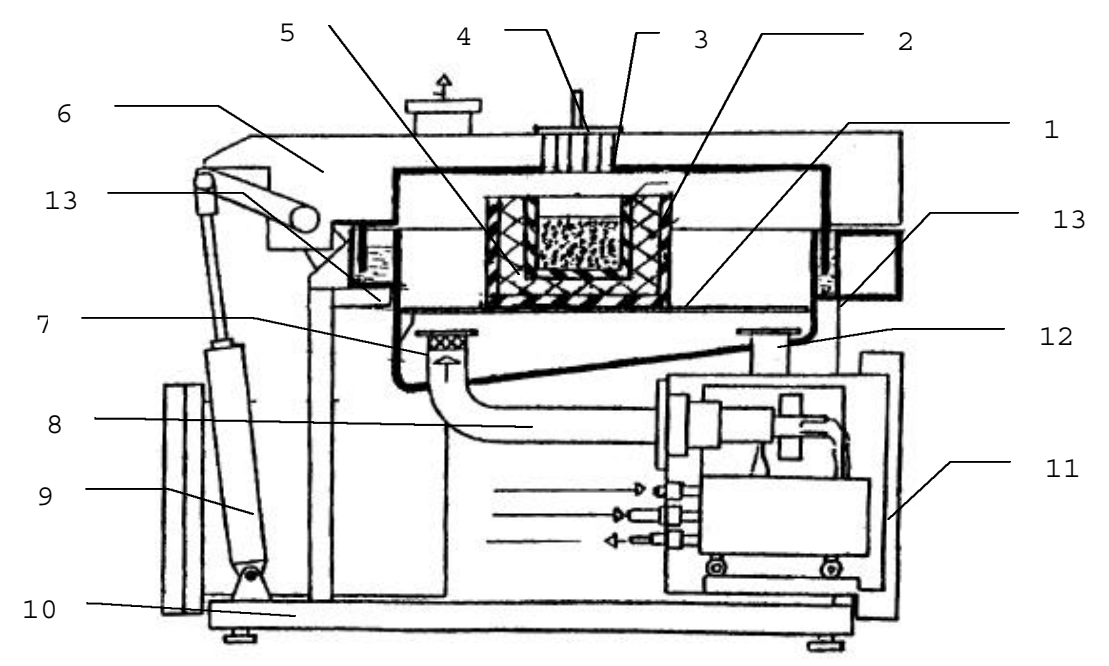

Fig. 1. Microwave facility to vitrify Pu-containing waste.

nergy, the temperature of the calcinate is raised to its melting point (approximately $900-950^{\circ} \mathrm{C}$ ) where the glass is held for a predefined time. During the holding period, the glass is sampled to define its quality. At the end of the holding period, the generators are turned off, the crucible is retrieved from the container, and cooled at room temperature.

\section{Conclusions}

1. In the course of the work, the Pu-containing phosphate and boro-phosphate glasses intended to vitrify the Pu-containing sludge have been melted and investigated.

2. At the stage of preparing the glass frit, we determined that Pu must be fed into the frit in the form of $\mathrm{PuO}_{2}$.

3. The glass samples we obtained were characterized to define homogeneity and the content of $\mathrm{Pu}$ in the matrix by two methods: $\gamma$-spectrometry and microprobe analysis. The results obtained by the two methods correlate with each other. By inclusion of up to $0.5 \mathrm{wt} \%$ of $\mathrm{PuO}_{2}$ into the phosphate and boro-phosphate glasses at $850-880^{\circ} \mathrm{C}$ and by holding the temperature for $30-40$ min., glasses with an equal distribution of Pu over the height of the glass block are formed. Plutonium is distributed within the volume of the glasses as separate tiny inclusions (1-4 microns) in the matrix enriched by plutonium and phosphor. To achieve more complete homogeneity of the glass, we recommend a longer holding period at the melting point. Further investigations will be focused on the definition of the marginal rate of Pu dissolution in the phosphate and borophosphate glasses proposed for immobilization of the Pu-containing sludge at MCC.

4. A procedure has been developed and tested to define the feasibility of vitrifying the simulated Pucontaining sludge using the modernized $15 \mathrm{~kW}$-microwave installation. 
Engineering Tests and Demonstrations at the K-26 Site 


\title{
Engineering Feasibility Study for Immobilization of Existing Sludges and Suspensions Containing Weapons-Grade Plutonium at PA Mayak [B506201]
}

\author{
Y. V. Glagolenko, S. Rovny, Mayak; L. Jardine, LLNL
}

\section{Introduction}

A preliminary engineering and economic feasibility study for the immobilization of materials containing weapons-grade plutonium was begun at PA Mayak in September 1999 under the auspices of the July 1998 agreement between the U.S. and the Russian Federation.

The Mayak Production Association (formerly the Mayak Chemical Combine) was formed in the late 1940s to produce weapons-grade plutonium and process fissile materials in order to achieve parity in the nuclear-weapons field. Later, civilian nuclear-fuel-cycle production facilities and facilities producing radioactive sources and preparations were set up at the enterprise on the basis of its well-developed infrastructure. In 1955, a radioactive-isotopes plant was placed in operation and, in 1976, a radiochemical plant to process spent nuclear fuel from nuclear power plants, transportation reactors, and research reactors was built. In 1986, the processing of irradiated blocks and the production of weapons-grade plutonium at the radiochemical plant were halted. A bit later, five commercial uranium-graphite reactors and a number of other defense-oriented production facilities were decommissioned.

In the course of the weapons plutonium production defense program, about 17,000 to $19,000 \mathrm{~m}^{3}$ of highlevel liquid radwaste and high-level alkaline slurries with a total radioactivity of 135 million $\mathrm{Ci}$ was accumulated at the Mayak Production Association. The chemical and radionuclide composition of the suspensions, slurries, and sediments is fairly complex, since solutions from the processing of various types of irradiated blocks and fuel elements (hydrates of aluminum, sulfide, and ferrocyanide precipitates) were concentrated by precipitation methods in storage tanks. Twenty storage tanks that have been operational since 1968 are used to hold the slurries of suspended materials of $\mathrm{Al}(\mathrm{OH})_{3}$ and ferrocyanides containing residual weapons grade plutonium. The tanks are concrete compartments measuring $19.5 \mathrm{~m} \times$ $9.5 \mathrm{~m} \times 7 \mathrm{~m}$ that are lined with stainless steel $(12 \times 18 \mathrm{H} 10 \mathrm{~T} 3)$ and have a working volume of $1170 \mathrm{~m}^{3}$. Twelve tanks have an internal cooling system with six different types of coils; all coils are horizontal. There are systems to monitor level, pressure, temperature, and gas evolution. Air is blown over the surface of the solutions to remove and dilute the hydrogen and methane evolved by radiolysis. These concrete tanks are on the surface on concrete slabs. Two tanks have $\sim 5 \mathrm{~m}$ of $\mathrm{Al}(\mathrm{OH})_{3}$ sediments. At one time, some tanks were $120^{\circ} \mathrm{C}$ at the bottom. Most tanks have $\sim 1 \mathrm{~m}$ of sediment. The quantity of weaponsgrade plutonium and uranium content is not known, but at this time, it is estimated that more that $1 \mathrm{MT}$ of weapons grade plutonium is in the tanks.

Mayak has developed some elements of the technology for plutonium extraction from HLW Pucontaining sludges and suspensions in storage tanks. Tests with real hydroxide-ferrocyanide solutions have included using equipment for mixing and extracting sludges and suspensions from tanks, dissolution of sludges and suspensions in acid mixtures, extracting plutonium, and partitioning cesium and strontium. The extraction of weapons-grade plutonium from the sludges and suspensions can be implemented at Mayak. However, the large amounts of secondary wastes, potential radiation exposures, and possible 
detriments to the environmental would result. Given the supply and expected demand for plutonium in Russia, options for direct immobilization without the extraction of plutonium are recognized as viable options for Mayak that merit assessment in an engineering feasibility study.

A technical team of Russian organizations was assembled by Mayak to perform this work. The organizations include but are not limited to VNIINM, KRI, and VNIPIET. Mayak is the lead organization and will approve all deliverables.

\section{Description of Work}

The engineering feasibility study is being conducted in two integrated phases over an 18-month period, Phase 1 is the data gathering (6 months) and Phase 2 is the detailed feasibility study. Limited experimental testing and demonstration experiments will also be conducted over the 18-month period to collect additional data as needed for the engineering feasibility study.

The engineering design organization VNIPIET is included in the Phase 1 activities to ensure that the data gathered can be effectively used in Phase 2 . The amount of experimental testing to collect additional engineering data will be kept to a minimum, but some testing with simulated (model) solutions of the tank sludges and suspensions is anticipated to validate sludge and suspension removal, solidified matrices, and equipment options for the engineering feasibility study.

Three processes for immobilization of weapons-grade, Pu-containing sludges and suspensions at Mayak will be evaluated and compared:

- Process \#1: The existing HLW sludges and suspensions in the 954 and 954A tanks at PA Mayak shall be removed and processed to extract, purify, and recover the weapons-grade Pu as oxide for storage. The residual solidified radionuclides, stable elements, and chemicals shall be immobilized into a glass-like form suitable for storage and geologic disposal at Mayak. Mayak shall be the lead organization for developing this process, and will be assisted by VNIPIET, VNIINM, and KRI, as appropriate.

- $\quad$ Process \#2: The existing HLW sludges and suspensions in the 954 and 954A tanks at PA Mayak shall be removed and immobilized into a glass-like solid using a "cold crucible" induction melting (CCIM) method without any extraction, purification, or recovery of the weapons-grade plutonium. Process options may include, but are not limited to, the use of direct flow evaporators or silica gel in the pretreatment steps. These solidified glass-like materials containing plutonium and other radionuclides shall be suitable for storage and geologic disposal at Mayak. VNIINM shall be the lead institute for developing this process and will be assisted by Mayak, VNIPIET, and KRI, as appropriate.

- Process \#3: The existing sludges and suspensions in the 954 and 954A tanks at PA Mayak shall be removed and immobilized into either glass-like or ceramic solid materials using partitioning methods available at the Mayak Radiochemical plant but without any extraction, purification, or recovery of the weapons-grade plutonium. Partitioning options may include, but are not limited to, the use of the EP500 melter or new ceramic processes. These solidified glass-like or ceramic materials containing plutonium and other radionuclides shall be suitable for storage and geologic disposal at Mayak. KRI shall be the lead institute for developing this process and will be assisted by Mayak, VNIPIET, and VNIINM, as appropriate. 


\section{Russian Engineering and Industrial Site Plutonium Immobilization Contract Activities}

\section{Phase 1. Initial Data Gathering}

Phase one, six months in duration, shall gather, generate, collect, and document the initial data needed for the follow-on, phase-two feasibility study. These initial data gathering tasks include assessing the 20 existing Mayak tanks in the Building 954 and 954A areas for their weapons-grade Pu content, and identifying the two or three tanks with the highest $\mathrm{Pu}$ inventories to be studied in the engineering feasibility study. We will perform additional sampling of the tanks to collect sludge and suspension samples for chemical analyses. New chemical analyses of recovered sludge and suspension samples will supplement existing Mayak weapons plutonium processing records. We will make tabulations of the specific content of the 20 tanks from all available Mayak data. These are all critical Phase 1 work activities. The removal methods for the sludges and suspensions are described below. Flowsheets and initial process descriptions will be developed in Phase 1 using existing technologies and existing Mayak facilities as much as possible.

\section{Phase 2. Detailed Feasibility Study}

Phase 2, up to 18 months in duration, consists of the detailed feasibility study. We will utilize the initial data, flowheets, and process descriptions developed and documented in Phase 1. The limited testing with simulated sludges and suspensions started in Phase 1 will be continued during Phase 2 to collect additional engineering data. That data will be integrated into the feasibility study. A geologic disposal concept for the Mayak site will be included in the engineering feasibility study.

The preliminary engineering feasibility study will compare the following two options:

1. Processing weapons-grade, Pu-containing sludges and suspensions at Mayak to extract, purify, and collect plutonium as oxide for storage and to solidify the radioactive wastes vs.

2. Direct immobilization processing of sludges and suspensions without any extraction, purification, and collection of plutonium.

All processes shall use existing technologies and existing Mayak facilities to the maximum extent possible and will produce solidified waste materials containing radionuclides that require geologic disposal.

\section{Deliverables}

The feasibility study will include comparisons of (1) costs, (2) time periods (schedules) for construction, start-up and processing operations, (3) radiation exposures of personnel, (4) secondary wastes and (5) contamination of (i.e., detriments to) the environment for the three processes. The results of the study, and the recommendations, will be presented to the Joint Steering Committee. 
Weapons Plutonium Sludge Immobilization at the Mayak Site 


\title{
VNIINM's Approach to Immobilize Pu-containing Wastes at PA Mayak [B506206]
}

\author{
A. S. Polyakov, P. P. Poluektov, G. B. Borisov, T. V. Smelova, A. V. Demin, VNIINM
}

\section{Introduction}

The Russian concept of the closed nuclear fuel cycle is based on the processing of spent nuclear fuel to recover uranium, plutonium, and neptunium as well as on the usage of weapons-grade Pu withdrawn from the nuclear defense program in MOX fuel production. Therefore, one needs to take into account issues related to the processing of radioactive wastes from the disposition of weapons-origin plutonium and to materials that cannot be reprocessed and require safe immobilization and eventual disposal.

\section{Pu-containing Sludges from Radiochemical Production}

About 17,000 to $19,000 \mathrm{~m}^{3}$ of high-level liquid radioactive wastes and high-level alkaline slurries from weapons-origin plutonium have been accumulated at PA Mayak in the course of the weapons plutonium production defense program. The wastes with residual weapons-grade plutonium are kept in storage tanks. These have concrete compartments lined with stainless steel (12X18H10T3), $19.5 \mathrm{~m} \& 9.5 \mathrm{~m} \theta$ $7 \mathrm{~m}$ with a working volume of $1170 \mathrm{~m}^{3}$. These concrete tanks are installed on concrete trays with a drain system in order to prevent any proliferation of the radioactive wastes in case of containment failure.

The following wastes, which have been generated as a result of the weapons-grade Pu production, are available in the tanks:

- Aluminum hydroxide slurries generated after decomposition of sodium aluminate;

- Aluminum hydroxide, iron, and nickel-potassium, ferrocyanide slurries generated as a result of decomposition of sodium aluminate with an eventual ferrocyanide treatment;

- Sludges after hydroxide sulfide-ferrocyanide purification of heated mother solutions.

Normative documents limit the concentration of $\mathrm{Pu}$ in liquid wastes being discharged at Mayak to $100 \mu \mathrm{g} / \mathrm{l}$. The availability of Pu-containing sludges and slurries in the tanks is needed to develop a technology for recovery of plutonium.

Since 1986 the storage tanks are under decommissioning. PA Mayak in cooperation with VNIPIET and SverdNIIChimmash (SNCM) have came up the development of processes and pilot equipment to remove the sludges from the tanks. Besides, integrated elements of the technology of extracting Pu from the highradioactive slurries and sludges accumulated in the tanks have been worked out at PA Mayak. Tests were made to dissolve the sludges in a mixture of acids, to recover $\mathrm{Pu}$ and to fractionate the wastes with obtaining cesium and strontium using real hydroxide-ferrocyanide solutions.

However, the realization of the scheme of Pu recovery up to its residual content in the wastes $100 \mu \mathrm{g} / \mathrm{l}$ is related to numerous technologic operations, which result in the generation of large amounts of secondary wastes and entail to considerable costs, which are incommensurable to the price of Pu. Besides, this one will bring to additional inventories of Pu. It is estimated (upon chemical sampling) that about $700-1500 \mathrm{~kg}$ of the weapons grade $\mathrm{Pu}$ is in the tanks. 
At an industrial scale a one-stage process of solidifying the wastes from processing of nuclear fuel in a ceramic melter EP-500 has been put into operation at PA Mayak. The output of the melter is $500 \mathrm{l} / \mathrm{h}$ upon the feeding solution and up to $2000 \mathrm{~kg} /$ day upon the glass. For six years of the non-stop exploitation of the melter EP-500/1p more then $12000 \mathrm{~m}^{3}$ of the liquid high-radioactive wastes has been included into the phosphate glass with the total activity of about 300 million $\mathrm{Ci}$.

There are two pilot facilities based on a cold-crucible inductive melting (CCIM) and located at the radiochemical and chemical-metallurgical productions of PA Mayak. A two-stage HLW solidification facility with the output of $100 \mathrm{l} / \mathrm{h}$ upon the feeding solution is being tested in a hot chamber of the radiochemical plant. At the first stage of the process a feeding material is calcinated in a direct-flow evaporator at 130$150^{\circ} \mathrm{C}$. After calcination, it is put into the cold crucible, where a final product is being synthesized. It is possible to use the CCIM facilities for both vitrification of HLW from nuclear fuel regeneration and immobilization of the Pu-containing wastes accumulated in the tanks as to incorporate them into chemically stable glass compositions and mineral-type matrices. In addition to increasing the environmental safety in the process of temporary storage and disposal, the usage of the mineral-type matrices (for example pyroxens, basalts) will also result in a decrease of volumes of the solidified products versus the phosphate and boronsilicate glasses on the account of boosting the rate of incorporation of the wastes into the structure of the compositions (as large as $50 \% \mathrm{wt}$ ).

VNIINM's approach to immobilize the Pu-containing sludges and slurries uses the two aforementioned technologies with the following options (Fig 1.):

Option 1 (base). The sludges and slurry removed from the tanks and mixed are sent to the stage of $\mathrm{Pu}$ recovering up to $100 \mu \mathrm{g} / \mathrm{l}$. Solutions after the processing are vitrified in the ceramic melter EP-500, but the plutonium is collected and stored for reuse.

Option 2. After removing from the tanks, the sludges are dissolved in a mixture of nitric and phosphorous acids. In this option two existing at PA Mayak processes are in use: vitrification in the ceramic melter EP500 and incorporation into mineral-type compositions at the CCIM facility. In this case the acceptance of a final decision is dependent upon the amount and a type of the accumulated sludges. One should bear in mind that the output of the CCIM melter is less then the one for the melter EP-500, but the former exceeds the ceramic melter in the range of the compositions of the wastes that can be processed.

Option 3. After removal from the tanks, the sludges, without preliminary dissolution, are transferred to a direct-flow evaporator and then to the CCIM facility located in a hot chamber. Here it is possible to remotely change equipment; for instance, the direct-flow evaporator in case it becomes plugged by the sludges.

Option 4. After removal from the tanks, the sludges are dissolved and sent to fractionating with the generation of two types of wastes: (1) fractions of trans-plutonic and rare-earth elements and (2) fractions of cesium and strontium. The first can be processed using the two-stage CCIM process to form mineraltype compositions similar to garnets (with incorporation of up to $30 \mathrm{wt} \%$ transplutonic oxides); the second one can be easily vitrified in the EP-500 ceramic melter to form phosphate glass. In addition, during fractionating, essentially intermediate level wastes are being generated, which also are processed using the EP-500 melter.

In all options, the eventual storage of the immobilized wastes is considered in a temporary storage facility under a HLW vitrification division prior to resolving the problem of constructing a geologic repository at PA Mayak. 


\section{Russian Engineering and Industrial Site Plutonium Immobilization Contract Activities}

Therefore, according to VNIINM's approach, all the Pu-containing sludges and slurries can be immobilized into glass compositions or mineral-type matrices using the ceramic melter and CCIM facilities that are available at PA Mayak.

\section{Pu-containing Wastes from MOX Fuel Production}

In the course of the operation of the Granat and Paket facilities at PA Mayak, different types of Pucontaining wastes are being generated. Incidentally, in the future, industrial-scale facilities will be exploited at PA Mayak to convert weapons-grade Pu and to produce MOX fuel in quantities of at least 2-5 t/year. These operations will also result in the generation of Pu-containing wastes.

In selecting an approach to processing, one needs to bear in mind the sources of waste generation. In general, all the Pu-containing wastes can be classified as follows: combustible (e.g., clothing, oils), noncombustible (e.g., unreprocessed residues, glass fibers, liquid wastes) and metallic wastes.

Two options for their immobilization can be assessed as follows (Fig. 2):

Option 1. Cementation of the Pu-containing wastes after preliminary recovery of Pu up to $100-150 \mathrm{mg} / \mathrm{kg}$ solids. $\mathrm{PuO}_{2}$ is stored for eventual reuse. The cemented wastes must be sent to a surface storage facility designed alike to the one for the Complex 300.

Option 2. Reprocessing of the wastes by CCIM. In this matter, the combustible wastes are burnt out (in a facility designed by SNCM), the liquid wastes after initial concentrating are melted with flux additions to form glass or mineral-type materials, and the solid non-metallic wastes are processed immediately in the CCIM facility. The metallic wastes are remelted by inductive-slag melting using the CCIM facility with purification of alpha-nuclides $>98 \%$. Purified and remelted metallic ingots are stored for possible reuse. Slags from remelting the metallic wastes and ashes from incinerating the combustible wastes together with the solid non-combustible wastes are sent to the CCIM facility for immobilization into glass or mineral-type compositions. Then, the solidified wastes are sent to the storage facility at a vitrification facility, and stored there prior to building a geologic repository at PA Mayak.

Therefore, to immobilize the Pu-containing wastes and residues from MOX fuel production, it is advisable to use the CCIM technology currently in place at PA Mayak.

\section{Conclusion}

VNIINM's philosophy is to apply an integrated option of immobilizing the Pu-containing slurry and MOX fuel production wastes and, at a maximum scale, to apply both existing and future equipment and techniques at PA Mayak.

The use of the CCIM will permit us to immobilize the Pu-containing sludges from radiochemical production and wastes from conversion and MOX fuel production into a highly stable, mineral-type composition (based on pyroxens or basalts) at an incorporation rate of up to $50 \mathrm{wt} \%$. Due to inductiveslag remelting, there will be an opportunity to purify and reuse a lot of the metallic wastes being generated from MOX fuel production.

Some of the Pu-containing wastes, as well as the secondary intermediate level wastes being generated from fractionation (option 4), can be vitrified in the EP-500 ceramic melter. 


\section{VNIINM's approach to immobilize the Pu-containing sludges of PA Mayak}

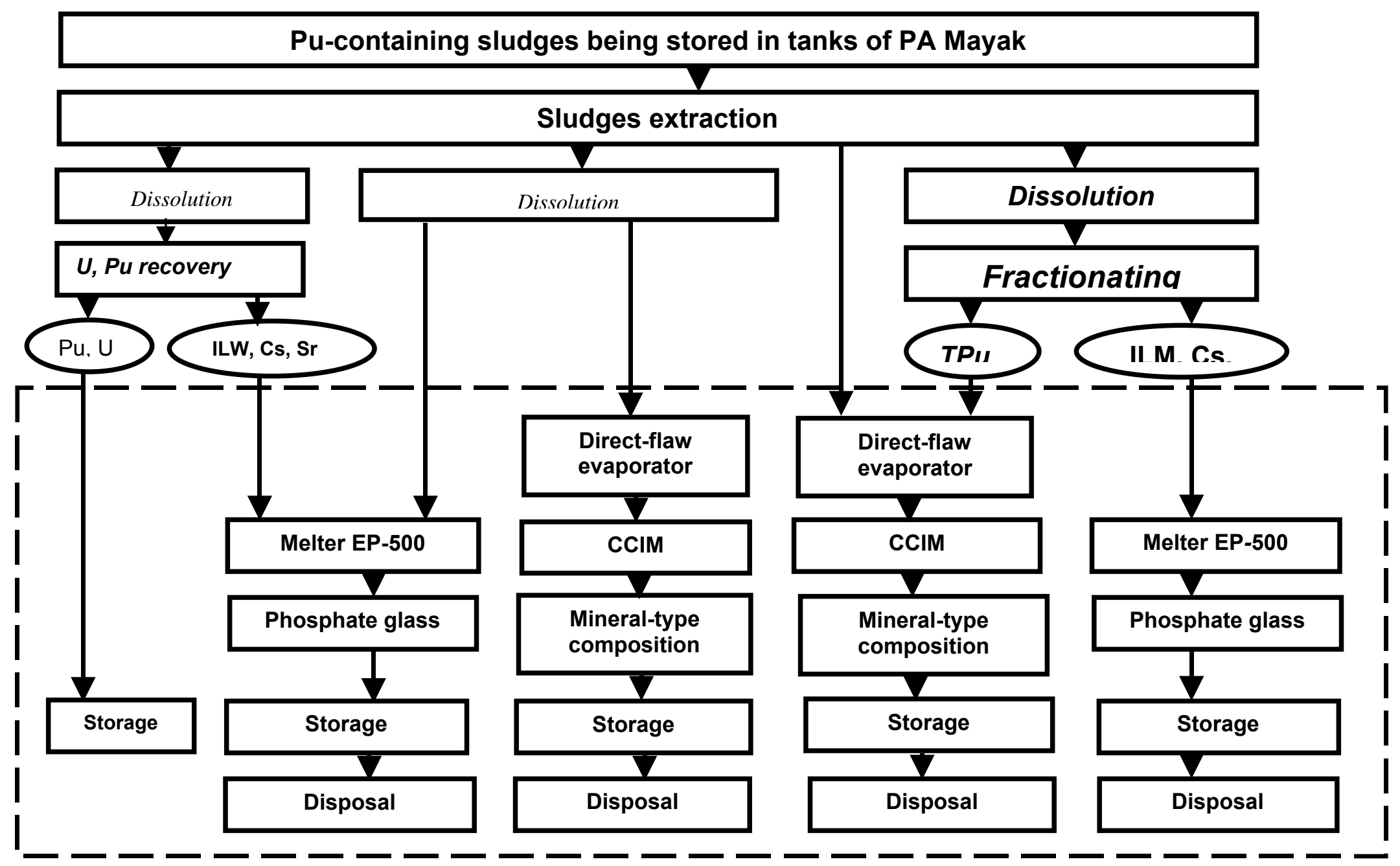


VNIINM's approach to immobilize the Pu-containing wastes from MOX fuel production at PA Mayak

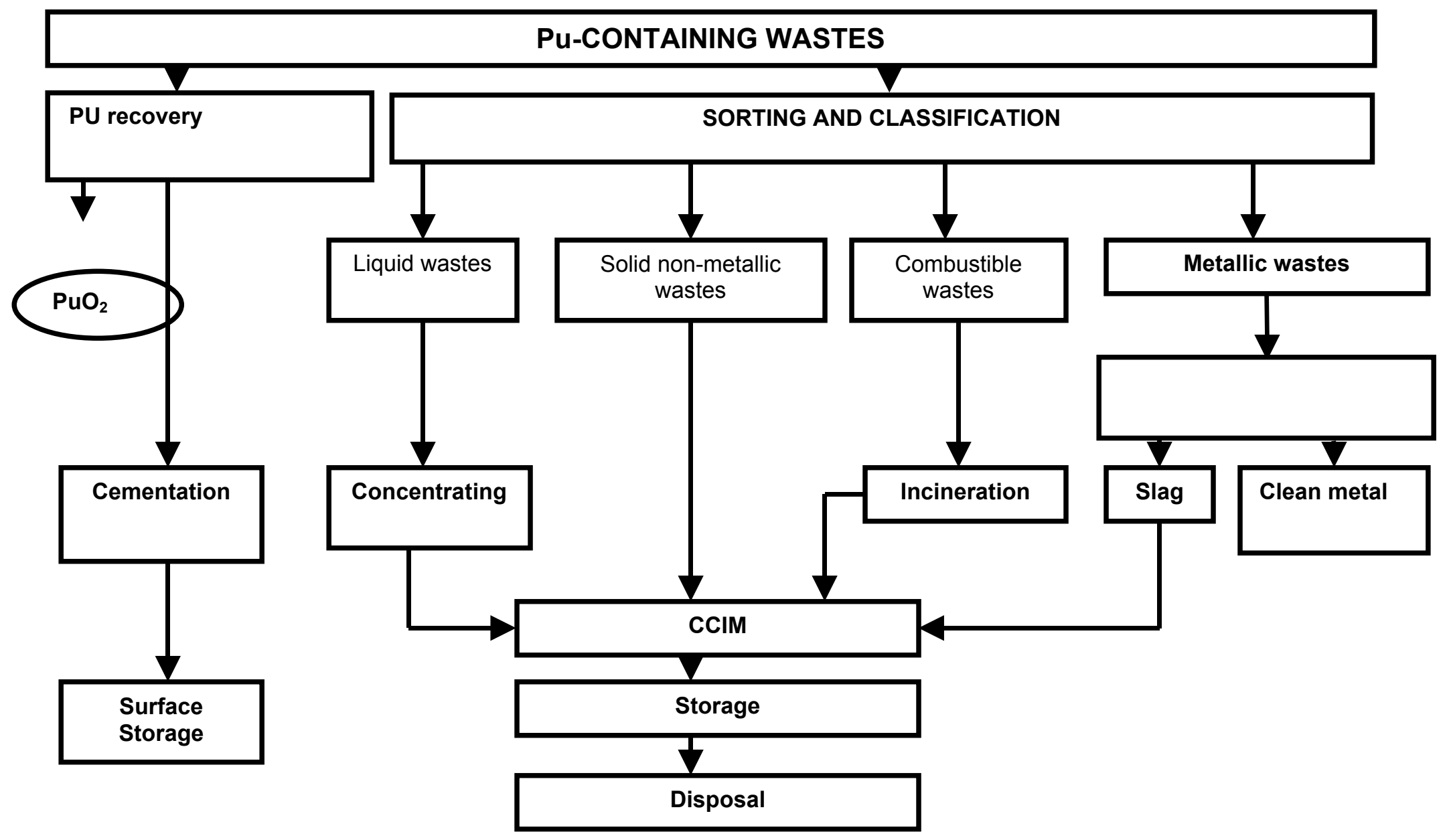


Weapons Plutonium Sludge Immobilization at the Mayak Site 


\title{
The KRI Approach for Developing Immobilization Technology for Plutonium Sludges at PA Mayak [B506209]
}

\author{
A. C. Aloy, B. S. Kuznetsov, A. V. Trofimenko, E. B. Anderson, B. E. Byrakov, V. N. \\ Romanovskiy, I. V. Smirnov, KRI
}

\section{Summary}

The main goal of this work in the frame of a general preliminary engineering feasibility study on Pubearing radioactive waste treatment at PA "Mayak" is to collect and prepare the initial data about KRI immobilization technologies and provide the design organization VNIPIET with these data.

The KRI approach for developing immobilization technologies shall include:

- Compositions of the glass-like and/or ceramic matrices;

- Processing descriptions of glass-like or ceramic solids (e.g., chemical reagents, process temperature, time periods required for the glass-like or ceramic materials to fill the containers, location points for critical process measurement devices);

- Types of confinement or hot cell structures required;

- Critical measurements of process equipment meters (existing and planned units);

- Any special equipment needed for preparation, pretreatment, solidification and transport of the solutions, sludges, and suspensions into the solidification equipment and containers;

- Designs for securing the lids of the containers;

- Methods for storage of the containers until geologic disposal is performed at Mayak;

- $\quad$ Systems needed for off-gas treatment requirements.

In addition, the description of the transport and technological treatment of containers filled with Pucontaining, glass-like or ceramic materials (i.e., hermetic sealing of the container, cleaning or decontamination of its exposed surfaces) and the methods of its transportation to the storage areas prior to geologic disposal, the designs and drawings of all equipment and its composition, as well as the list of emergency conditions, shall be supplied.

Because the composition of the Pu-containing alkaline sludges is not known with sufficient reliability, we will also perform additional sampling of the tanks to collect sludge and suspension samples to supplement existing Mayak weapons plutonium processing records. We will also tabulate the twenty specific tank contents from all available Mayak data. These steps are very important for the development of technology flowsheets and initial process descriptions.

KRI has significant experience and equipment for doing microwave melting of solids and sludges as well as for sintering different type of ceramics. Moreover, KRI is a lead scientific advisor for the industrial separation $\mathrm{Cs}$ and $\mathrm{Sr}$ technology flowsheet, which is available at Mayak.

Based on this experience, the KRI approach for immobilization of Pu-containing alkaline sludges consists of the following two options. 


\section{Option 1}

After removal of sludges and suspensions from tanks, they are washed out by water and the resulting solution is transmitted to the vitrification facility EP-500. The remaining solid part of the sludge is transferred to the microwave heating facility to solidify all plutonium in form of glass-crystalline product.

Option 2

After lifting sludge, the suspensions are dissolved in nitric acid. Then the solutions are filtered and Cs and Sr are separated from the filtrate.

After separation, REE and Pu precipitate with oxalate acid. This precipitate combines with insoluble residue after the filtration step, and monocite-type ceramic or garnet-perovskite ceramic can be produced.

Schematically, the two options are shown in Figure 1.

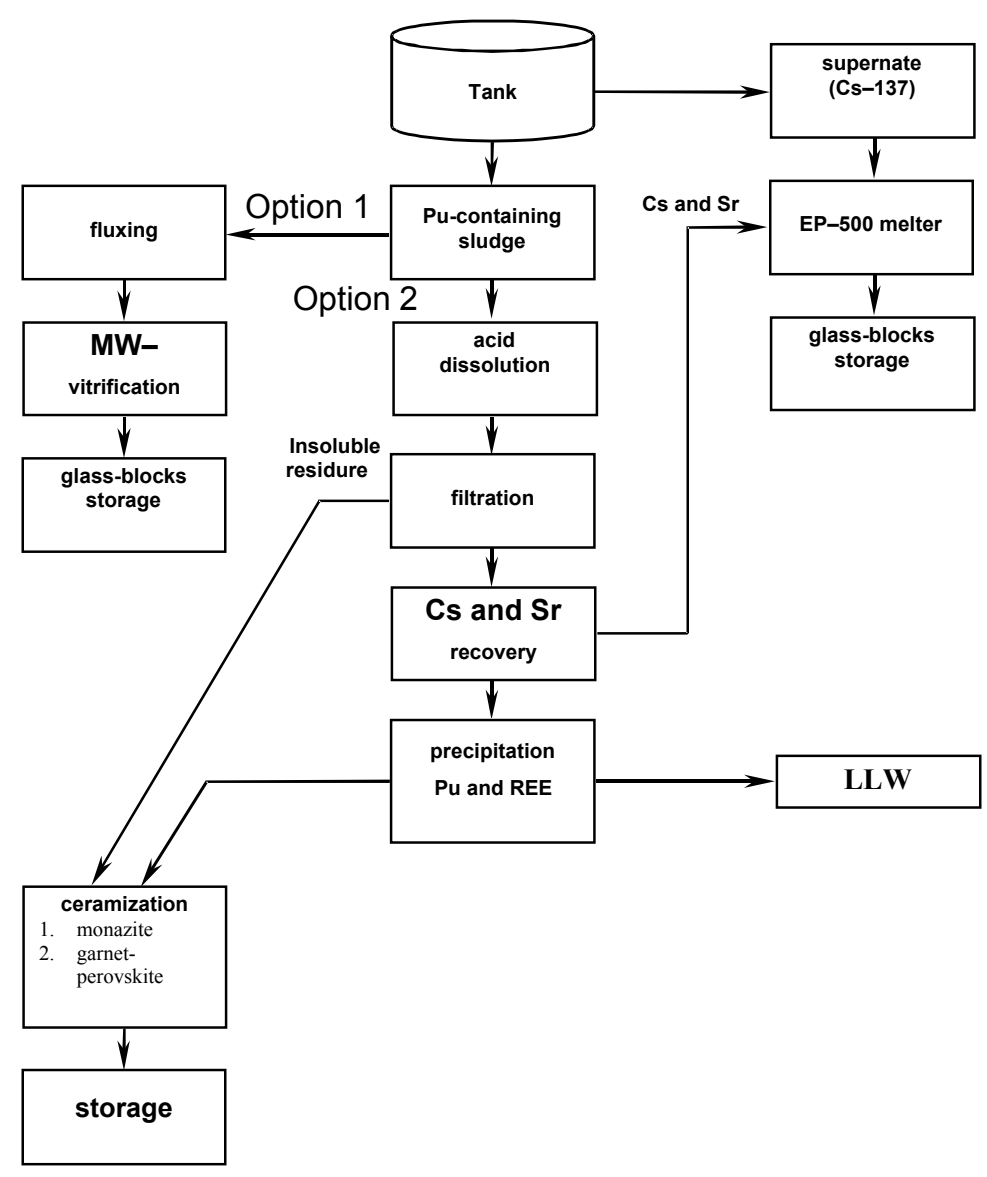

Figure 1. Two KRI options for immobilization of Pu-containing alkaline sludges.

Figure 2 demonstrates the $\mathrm{Cs}$ and $\mathrm{Sr}$ recovery process from dissolved sludge. Figure 3 shows the technological flowsheet and mass balance of raffinate reprocessing with monozite-type ceramic production. 
II. Russian Engineering and Industrial Site Plutonium Immobilization Contract Activities

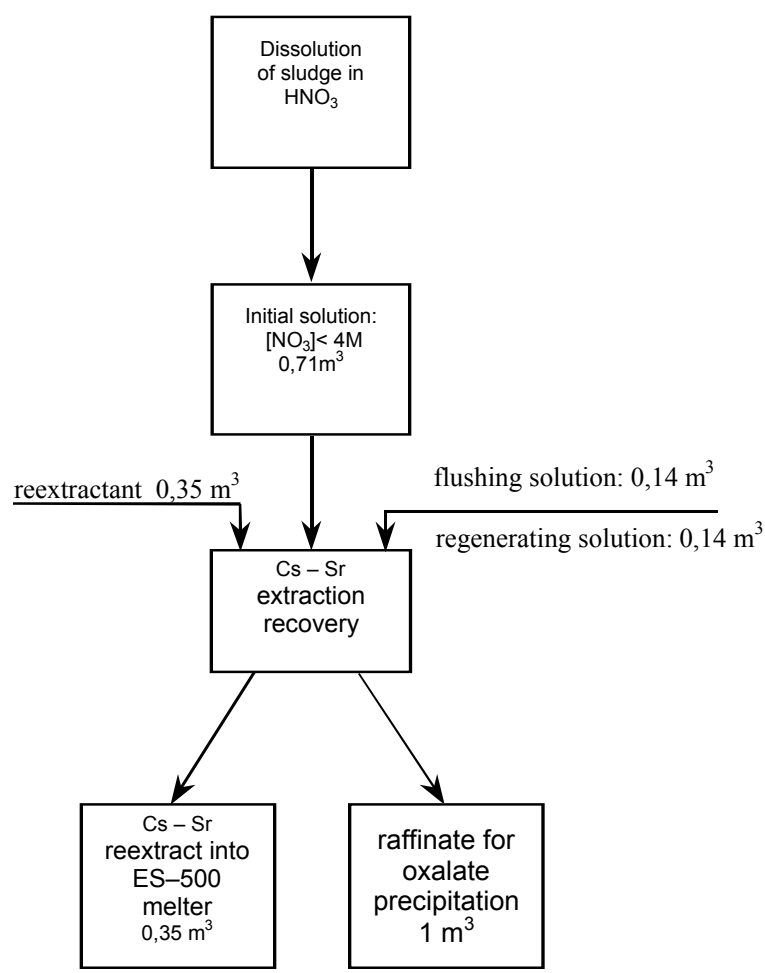

Figure 2. Cs and Sr recovery process from PA "Mayak" Pu-containing alkaline study.

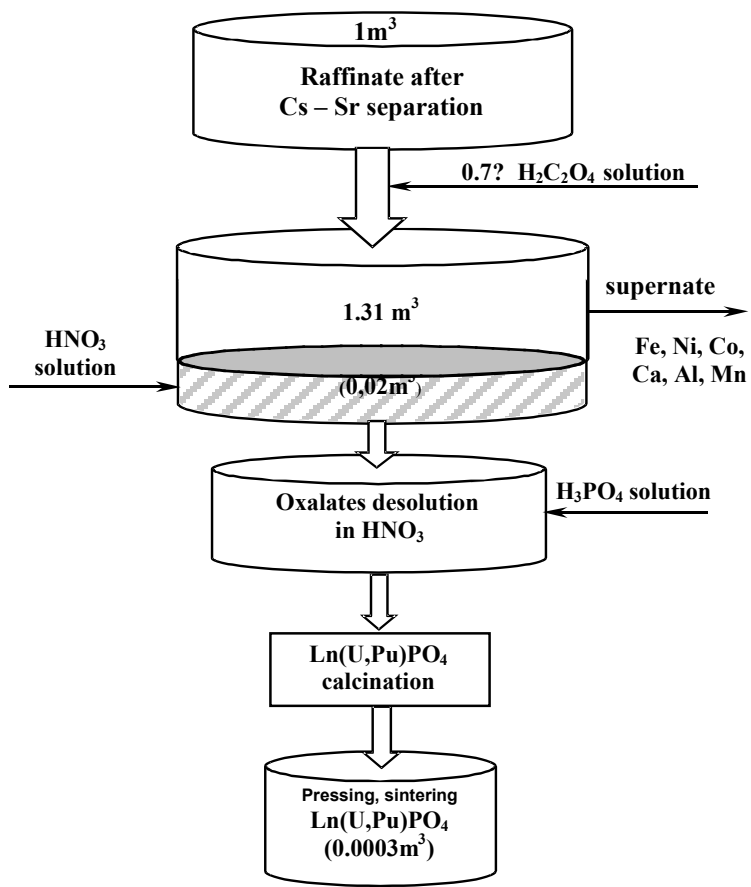

Figure 3. Technological flowsheet and mass balance of raffinate reprocessing with monozite-type ceramic production. 
Because some experimental data are not available at the start of the SOW, the bench-scale set GROM installed at Mayak will be used to generate additional information needed for the engineering feasibility study. A diagram of this data set is shown in Figure 4.

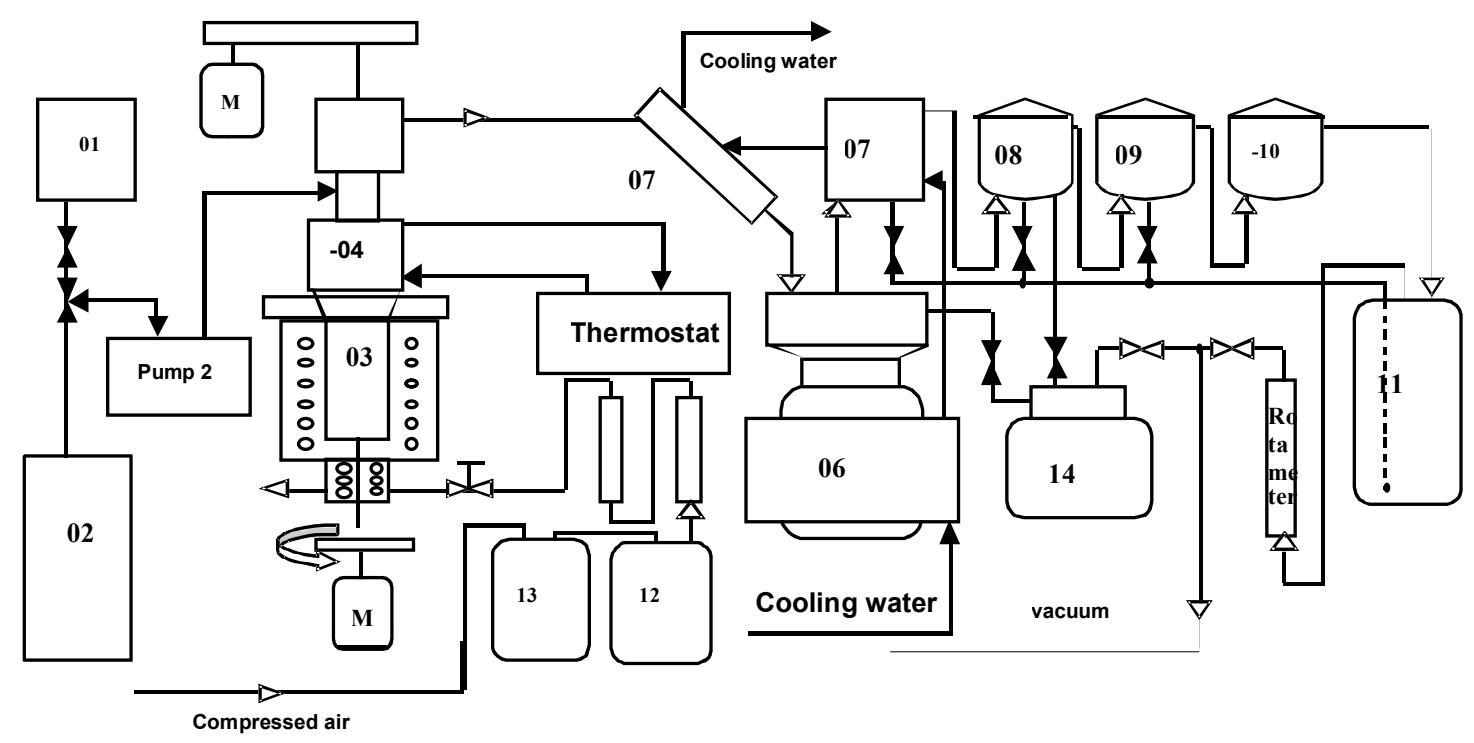

01-Tank for initial solution; 02-tank for flux solution; 03-crucible; 04-thin-film evaporator; 06-bubbler condenser; 07-water cooler; 08,09,10-offgas filters; 11-neutralizing tank; 12-tank for condensate; 13condensator; 14-accumulator-evaporator

Figure 4. Schematic flowsheet of GROM. 
Preparing and gathering initial data for the engineering feasibility study on Plutonium-Bearing Radioactive Waste Immobilization at PA "Mayak"

A.C. Aloy, B.S. Kuznetsov, A.V. Trofimenko, E.B. Anderson, B. E. Byrakov, V.N. Romanovskiy, I.V. Smirnov

Khlopin Radium Institute, St. Petersburg, Russia 


\section{The versions of reprocessing of PA «Mayak» alkali-type}

\section{plutonium-containing sludges as to RPA "Radium Institute" technology} $\begin{array}{ll}\text { Basic version } & \begin{array}{l}\text { The receipt of pure plutonium dioxide from } \\ \text { dissolved sludge. }\end{array}\end{array}$

Version 1 The direct MW- vitrification of sludge.

Version 2 was received from raffinate after recovery of cesium and strontium from dissolved sludge. 
II. Russian Engineering and Industrial Site Plutonium Immobilization Contract Activities

\section{Technological Flow-Sheet of PA "Mayak" HLW Solidification}

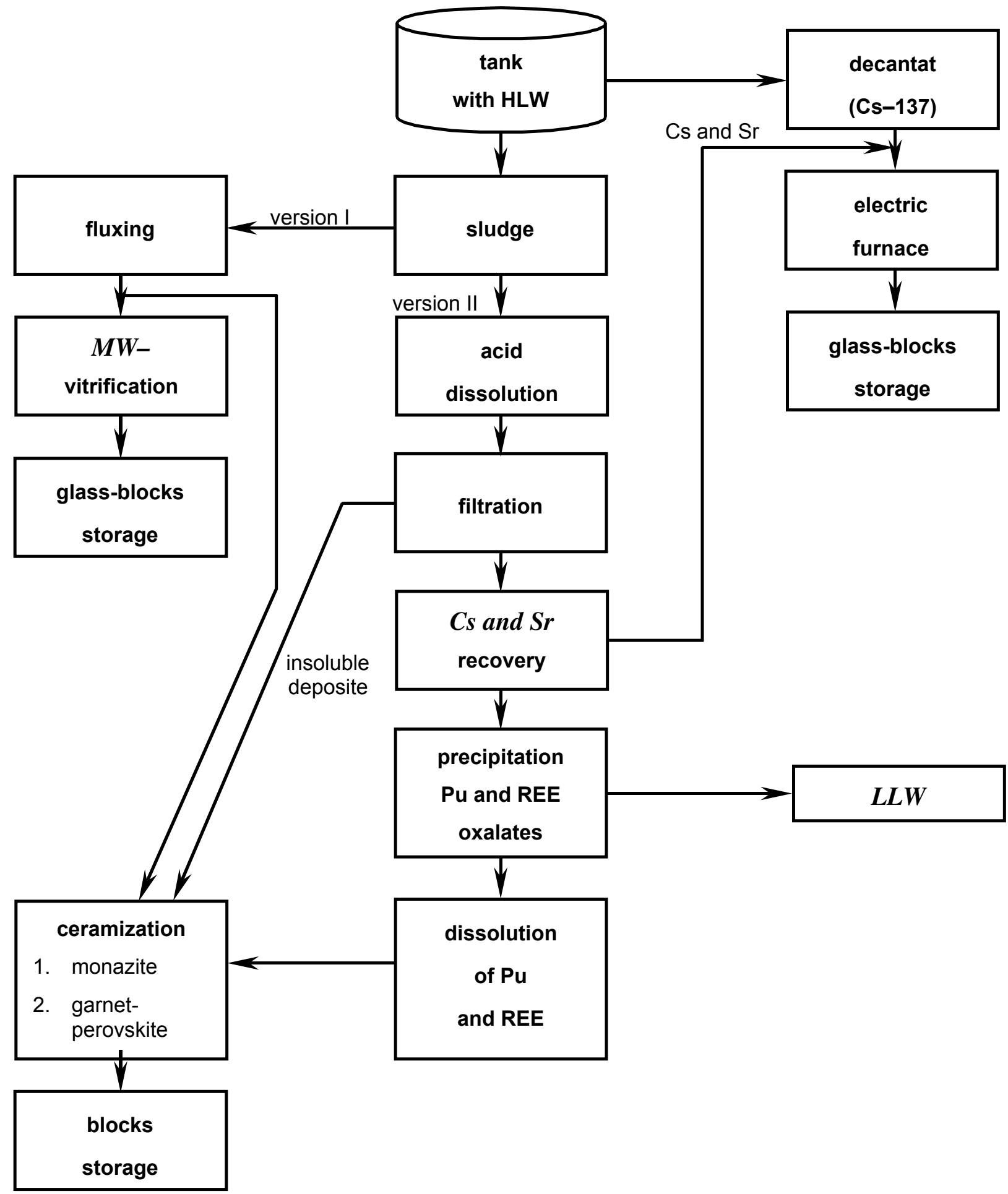




\section{Cs and Sr recovery from PA "Mayak" Pu-containing dissolving sludges using technology of Radium Institute}

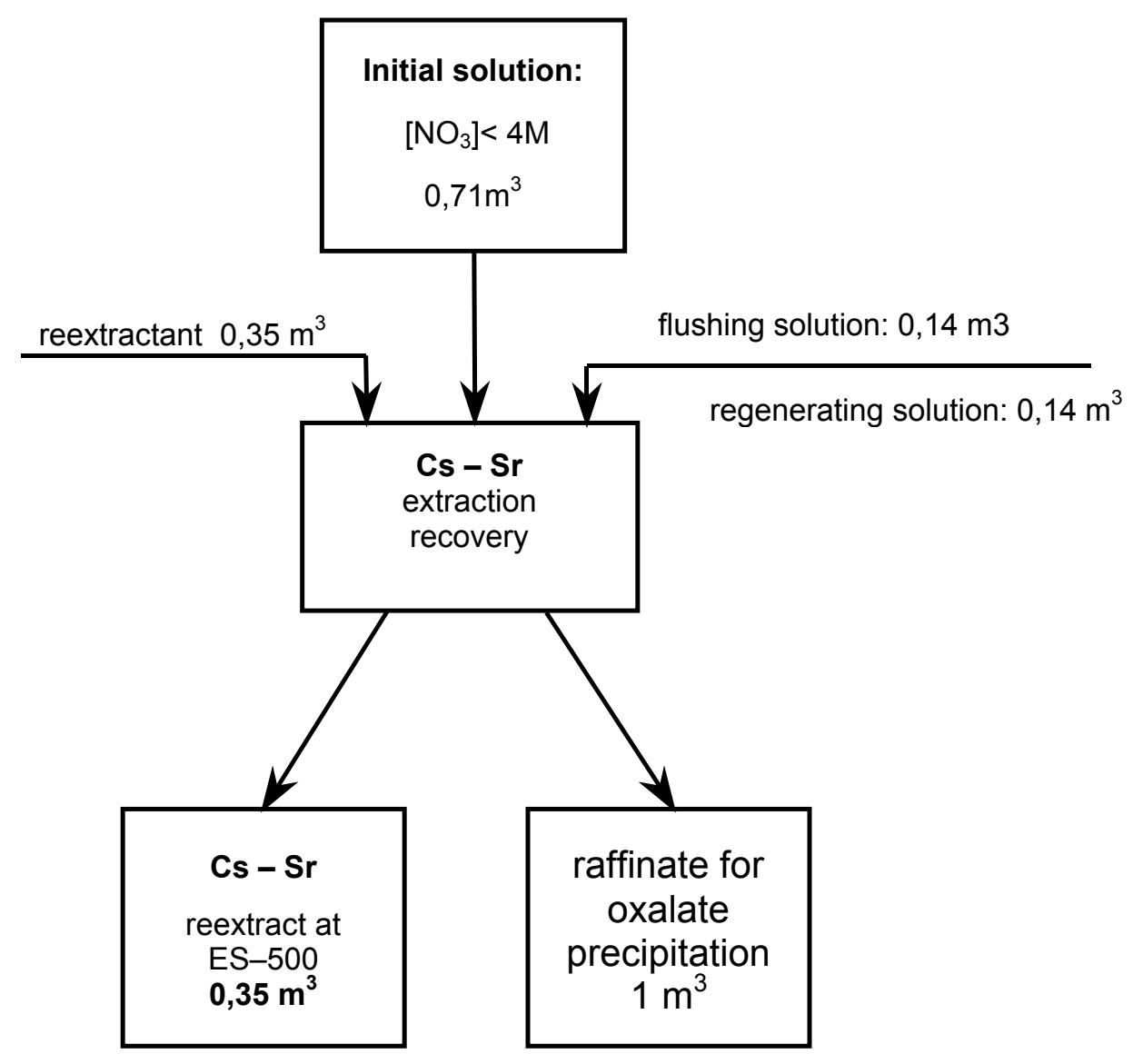


II. Russian Engineering and Industrial Site Plutonium Immobilization Contract Activities

\section{Technological scheme and the mass-scale balance of PA "Mayak" alkaline sludges reprocessing with the monazite ceramic receipt}

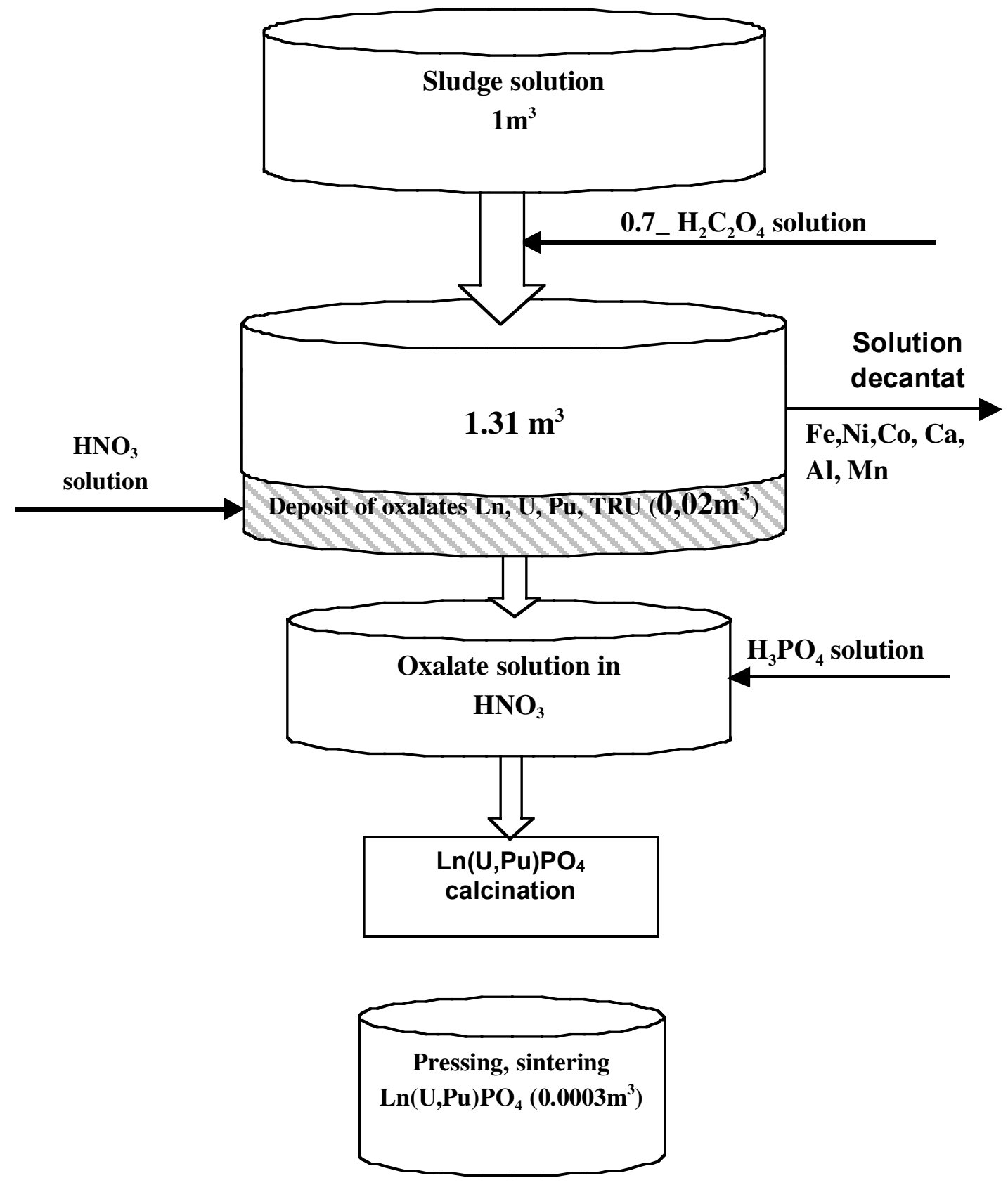




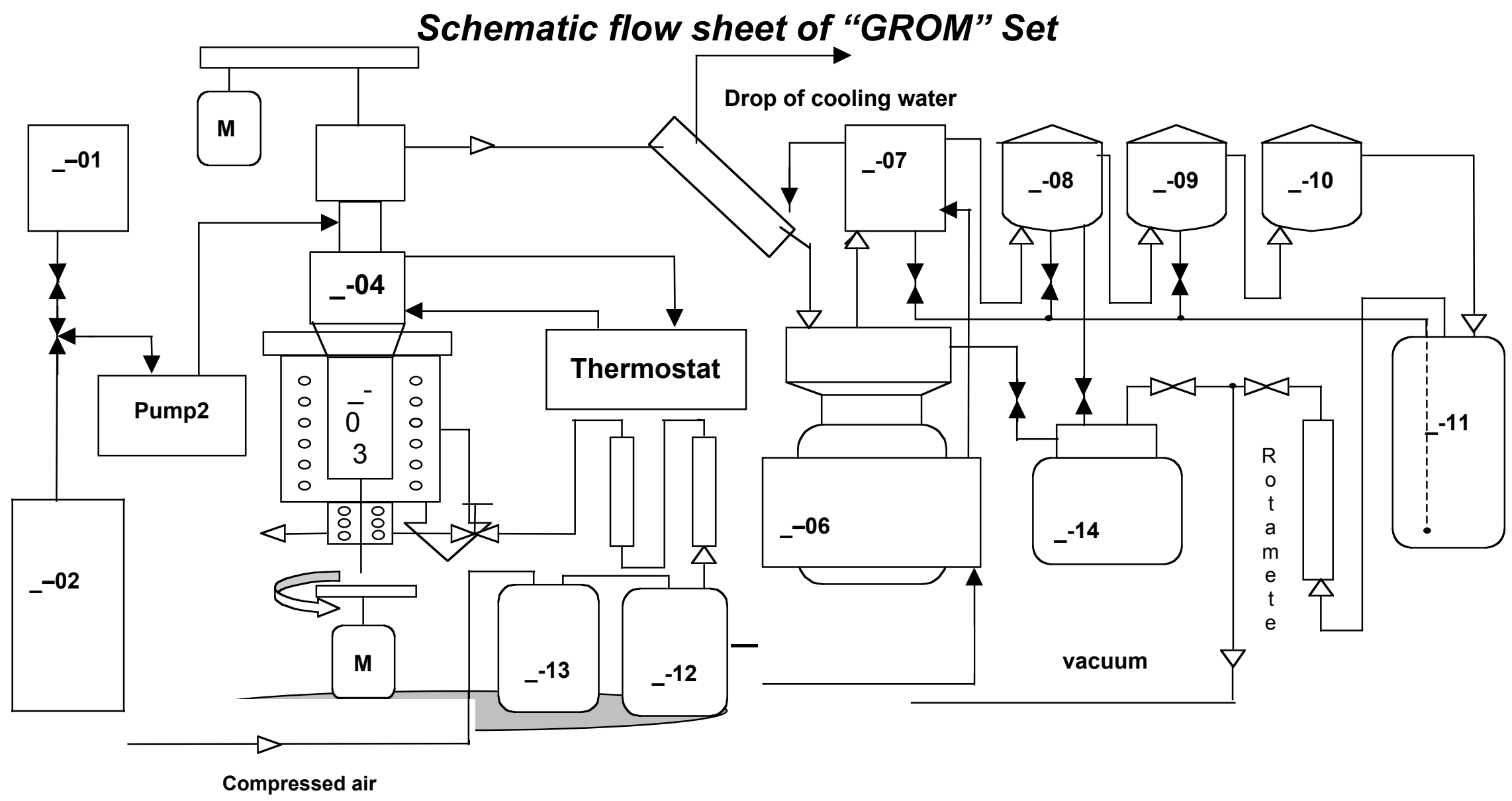

_-01 capacitance with initial solution _-02 capacitance with flushing solution. _-03 crucible. _-04 calciner-TRC. _-06 bubblier -08 percolator of coarse refining 1. -09 percolator of coarse refining $2_{-}{ }_{-}-10$ percolator of thin refining ${ }_{-}-11$ neutralizing tank ${ }_{-}-12$ accumulator of condensate . -13 condensator _-14 accumulator -evaporator. 


\title{
Engineering Feasibility Study for Immobilization of Weapons-Grade Plutonium-Containing Materials and Wastes from Future MOX and Conversion Facilities in Russia [Draft SOW]
}

\author{
Y. V. Glagolenko, S. Rovny, Mayak PA, and L. Jardine, LLNL
}

Ed. Note

New work will begin in early 2000 at PA Mayak to immobilize Pu-containing wastes and residues from future Russian MOX fabrication. A technical and economic feasibility study will be performed. Participants are Mayak, VNIPIET, GSPI, VNIINM, and KRI. Portions of the draft Statement of Work under discussion, but not final, are reproduced below.

\section{Draft Statement of Work}

A draft statement of work (SOW) defines a preliminary engineering feasibility study of immobilization of plutonium-containing materials and wastes containing weapons-grade plutonium generated from future MOX and conversion facilities in Russia. In addition, some limited testing and demonstration experiments required to collect initial engineering data required for the feasibility study is included in the SOW.

In the course of the weapons plutonium production defense program, the Mayak Production Association accumulated much experience with fabricating MOX fuel for fast reactors. Mayak is the only enterprise in the Russian Federation experienced both in production of MOX fuel and actual immobilization of the different radioactive waste types, including vitrification. Mixed-oxide fuel fabrication experience has been acquired at Mayak at both the pilot and semi-commercial industrial scale for fast-reactors. No commercialsize MOX operations have been performed at Mayak or elsewhere in Russia. Thus, Mayak is the best source of data and experience from which to design future MOX and conversion facilities and the immobilization systems required to treat secondary plutonium-containing wastes and materials generated during their operations.

For example, Mayak has had four types of plutonium fuel fabrication facilities on a semi-industrial scale over the years-Pilot Bay, Zhemchug, Granat, and Paket-from which they developed their experience base. Of these, only Paket is operational today. Mayak has developed and tested various fuel production processes, including (1) mechanical mixing or blending (stirring) of individual oxides and pelletizing, and (2) co-precipitation by both carbonate and ammonia processes and pelletizing, and (3) some limited solgel processes.

Pilot Bay was used in the 1960s and 1970s for manufacturing pellets and pilot fuel elements for fastreactor research ,processing about $\sim 1 \mathrm{Mt}$ of plutonium feed in both metal alloy and oxide forms.

Zhemchug manufactured MOX fuel assemblies for fast-reactors using sol-gel technology in 1986-87, and had a capacity of $\sim 35 \mathrm{~kg} / \mathrm{y}$ of plutonium. Both Granat and Paket became operational in 1988. Granat is no longer operational, but produced chemically co-precipitated $\mathrm{UO}_{2}-\mathrm{PuO}_{2} \mathrm{MOX}$ powders at $\sim 70-80 \mathrm{~kg} / \mathrm{y}$ for fabrication into pellets in the Paket facility. The Paket facility, modified in 1993, is still operational and can produce finished pelletized fuel rods and assemblies for fast-reactors using powders from either coprecipitated $\mathrm{PuO}_{2}-\mathrm{UO}_{2}$ processes from Granat or mechanical mixing processes of $\mathrm{PuO}_{2}$ and $\mathrm{UO}_{2}$. The capacity of Paket is $\sim 1 \mathrm{Mt} / \mathrm{y}$ of MOX, or 40 fuel assemblies.

In addition, based on all of Mayak's previous experience, Complex 300 was designed for the Mayak site in $\sim 1992$ to make $\sim 60 \mathrm{Mt} /$ year or 900 fuel assemblies of conventional pelletized MOX fuel for BN-800 fast-reactor fuel assemblies. Construction of Complex 300 was started at Mayak in 1984, but was 


\section{Weapons Plutonium Sludge Immobilization at the Mayak Site}

stopped in 1989 at the $50-60 \%$ completion point. Work on this complex provided additional experience to apply in executing a SOW.

Mayak will use and apply all of this past MOX fabrication and Pu-containing materials handling experience to execute the SOW.

\section{Description of Work}

\section{Objective}

The objective is to collect and generate the necessary initial technical data and information required to carry out a preliminary technical and economic engineering feasibility study (EFS) and to perform the EFS.

The preliminary EFS shall develop and compare the options for immobilizing the Pu-containing wastes and materials generated from future MOX and conversion processes and facilities in Russia.

Comparisons of immobilization options with and without the recovery of plutonium to residual levels of $200 \mathrm{mg} / \mathrm{kg}$ (200ppm) shall be included. All immobilization processes shall use existing technologies and existing Mayak facility experience to the maximum extent possible and shall produce solidified waste materials that require geologic disposal.

\section{Scope of Work}

A preliminary EFS shall be conducted on the basis of the data collected in this SOW. The organizations involved shall include Mayak and the sub-tier organizations (subcontractors), VNIINM, KRI, VNIPIET, and GSPI.

Substantial amounts of liquid and solid Pu-containing wastes and plutonium materials will be generated in the course of the operation of future MOX fuel fabrication and in the conversion of plutonium metal into dioxide. Alternatives to recovering the residual plutonium in the wastes and other materials to levels of $<200$ ppm shall be developed, evaluated, and compared, including processes for immobilization of weapons plutonium-containing wastes and materials.

- Process \#1: The Pu-containing wastes and materials estimated in this SOW shall be treated to recover the residual plutonium to levels of $<200 \mathrm{ppm}$ as required by current Russian practice and policy. Mayak shall be the lead organization for developing this process and will be assisted by VNIPIET, GSPI, VNIINM, and KRI as appropriate.

- Process \#2: The Pu-containing wastes and materials estimated in this SOW shall be treated to allow immobilization of the residual plutonium at levels of $>200 \mathrm{ppm}$. Process options may include, but are not limited to, use of direct flow evaporators or silica gel in the pretreatment steps and CCIM technology. Solidified glass-like materials containing plutonium and other radionuclides shall be suitable for storage and geologic disposal at Mayak. VNIINM shall be the lead institute for developing these process options and will be assisted by Mayak, VNIPIET, GSPI, and KRI as appropriate.

- Process \#3: The Pu-containing wastes and materials estimated in this SOW shall be treated to recover residual plutonium to levels of $>200 \mathrm{ppm}$. Process options may include, but are not limited to, the use of partitioning, the EP-500 melter, or new ceramic processes. These solidified glass-like or ceramic materials containing plutonium and other radionuclides shall be suitable for storage and geologic disposal at Mayak. KRI shall be the lead institute for developing this process and will be assisted by Mayak, VNIPIET, GSPI, and VNIINM as appropriate. 


\section{Russian Engineering and Industrial Site Plutonium Immobilization Contract Activities}

The engineering feasibility study shall be conducted over a 12-month period. Phase 1 is the data gathering period ( 4 months) and Phase 2 is the detailed feasibility study ( 8 months). Limited experimental testing shall be conducted over the 12-month period to collect additional data needed for the engineering feasibility study.

\section{Phase 1. Initial Data Gathering}

Phase 1, four months in duration, shall gather, generate, collect, and document the initial data needed to establish the inventories and categories of Pu-containing wastes and materials requiring treatment and assessments for the follow-on Phase 2 feasibility study. These initial data gathering tasks shall include assessing the inventories and types of Pu-containing materials and identifying solidification and treatment options. Initial flowsheets and process descriptions shall be developed in Phase 1 using existing data from past Mayak MOX and conversion experience from Paket, Granat, and other operations and existing technologies as much as possible for the three study options.

The engineering design organizations VNIPIET and GSPI shall be included in the Phase 1 activities to ensure that the data gathered can be effectively used in the Phase 2 feasibility studies. Phase 1 shall have a minimum amount of experimental testing done in Task 2 to collect additional engineering data. However, some testing with simulated (model) solutions of the plutonium containing wastes and materials is anticipated to validate plutonium handling and treatment options, solidified matrix compositions and equipment options for the engineering feasibility study.

\section{Phase 2. Detailed Feasibility Study}

Phase 2, eight months in duration, shall perform the detailed feasibility study using the initial data, flowsheets and process descriptions developed and documented in Phase 1. The limited testing with simulated industrial plutonium containing wastes and materials started in Phase 1 shall be continued in Task 2 during Phase 2 to collect additional engineering data. That data shall be integrated into the feasibility study. A geologic disposal concept for the Mayak site shall be included in the engineering feasibility study for solidified waste forms.

The preliminary feasibility study shall be carried out and comparisons made of (1) costs, (2) time periods (schedules) for construction, start-up and processing operations, (3) radiation exposures of personnel, (4) secondary wastes, and (5) contamination (or insults) of the environment for the three processes. The results of the study, and the recommendations, shall be presented to the Joint Steering Committee.

The work shall be organized and divided into four main tasks:

1. Preparing and gathering initial data for the preliminary engineering feasibility study.

2. Carrying out limited testing and demonstration experiments on the simulated and industrial plant plutonium containing wastes and materials.

3. Performing a preliminary feasibility study based on the initial data gathered in Task 1 and Task 2.

4. Developing a proposal work plan for possible follow-on work. 
Weapons Plutonium Sludge Immobilization at the Mayak Site 


\section{Russian Engineering and Industrial Site Plutonium Immobilization Contract Activities \\ Preliminary Feasibility Study: Plutonium-containing Pyrochemical Residues and Waste Treatment and Immobilization at RIAR [B506204]}

\section{L.G. Babikov and A.V. Bychkov, RIAR}

\section{Introduction}

For over 30 years, SSC RF RIAR has been performing research on plutonium involving the development of pyrochemical technology. In 1979, the pilot production of MOX fuel was first started for provisioning the BOR-60 reactor and later for the fabrication of $\mathrm{BN}-350$ and $\mathrm{BN}-600$ experimental fuel assemblies. At this time, a considerable amount of residue and waste containing about $56 \mathrm{~kg}$ of plutonium was formed. The isotope composition mainly corresponds to "power generating" plutonium. As the result of ${ }^{241} \mathrm{Pu}$ radioactive decay, a great amount of ${ }^{241} \mathrm{Am}$ has accumulated. Some of the residue and waste was also formed from the experimental reprocessing of $50 \mathrm{~kg}$ of metal weapons-grade plutonium.

The following materials are considered to be residue and waste:

- Plutonium dioxide, both alone and in a mixture of uranium dioxide, including the residues of unused fuel, sweep, sample returns, and oxide concentrates after salt regeneration;

- Phosphate concentrates;

- Salt-solvent ingots (after emergency shut-downs of technological process);

- $\quad$ Burned waste (pyrographite products, rags, films, filtering fabric).

There are $\sim 40 \mathrm{~kg}$ of waste involving $<1 \%$ plutonium mass fraction which can be subjected to immediate immobilization, whereas other waste is to be processed for plutonium removal and use in nuclear reactor fuel. A flowsheet for complex reprocessing of circulating products and pyrochemical technology waste was developed and some additional measures were proposed as early as 1986-90.

\section{Work Procedures}

The work flow utilizes the following procedures:

(a) Regeneration and salt recycling with separation of impurities and fuel component residues in the form of oxide or phosphate component. If plutonium mass fraction in the concentrate is less than $1 \%$, it can be vitrified;

(b) Calcination of combustible wastes involving pyrographite products, packing films, rags, filtering fabric from exhaust filter and others;

(c) Repeat concentrate reprocessing according to item (a) and ash according to (b) with plutonium recycling to fuel and formation of phosphate concentrates allowing their vitrification; 


\section{Preliminary Feasibility Study for Immobilizing Pu-containing Pyrochemical Salts at the RIAR Site}

(d) Decontamination of very contaminated equipment with removal of fuel components from solutions by both evaporation and ion-exchange and deposition methods with the following resin burning according to (b) and deposits reprocessing according to (c);

(e) Vitrification of phosphate and oxide wastes (concentrates).

Item (a) is implemented on the pilot production level. Concerning the other items, positive experimental results were obtained. The cost and labor estimates for their full implementation is a task in the forthcoming work, which is planned to be performed in the frame of the agreement between SSC RF RIAR and LLNL. 
II. Russian Engineering and Industrial Site Plutonium Immobilization Contract Activities

Ed. Note: Viewgraphs

\title{
Preliminary Engineering Feasibility Assessment: Treatment and Immobilization of Plutonium- Containing Pyrochemical Residues and Wastes at RIAR (Dimitrovgrad) [B506204]
}

\author{
L.G. Babikov and A.V. Bychkov
}

- For over 30 years, SSC RF RIAR has been performing research on the pyrochemical technology of plutonium fuel.

- In 1979, pilot production of MOX fuel was first started for the BOR-60 reactor and later for the fabrication of $\mathrm{BN}-350$ and $\mathrm{BN}-600$ fuel assemblies.

- In 1998, RIAR started demonstration work on the conversion of weapons plutonium to MOX fuel. 


\section{Objectives}

The objectives are to (1) establish an inventory and classification of the Pucontaining wastes at RIAR for use in the future assessments and selections of processing and immobilization methods for the RIAR site and (2) conduct a preliminary engineering feasibility for directly immobilizing, into an acceptable solid form for storage and geological disposal, the Pucontaining wastes streams of the RIAR, including those formed after the conversion of military origin Pu to MOX fuel.

- Task 1. Inventory of the existing pyrochemical Pu-containing waste inventories at the RIAR site;

- Task 2. Development of a process flowsheet for the direct immobilization of existing Pu-containing wastes;

- Task 3. Development of a process flowsheet for the direct immobilization of Pu-containing wastes formed after military Pu conversion in RIAR;

- Task 4. Development of a production scale flowsheet for the direct immobilization of Pu-containing wastes formed after military Pu conversion in RIAR. 


\section{Current Status}

- Considerable amount of residues and waste containing about $56 \mathrm{~kg}$ of plutonium were formed.

- The isotope composition mainly corresponds to the "power generating" plutonium. At the expense of the ${ }^{241} \mathrm{Pu}$ radioactive decay, a great amount of ${ }^{241} \mathrm{Am}$ is accumulated.

- Some amount of residues and waste was also formed after the experimental reprocessing of the $50 \mathrm{~kg}$ metal weapons-grade plutonium.

The following materials are considered as residues and waste:

- Plutonium dioxide both alone and as a mixture of uranium dioxide, including the residues of unused fuel, sweep, sample returns, oxide concentrates after salt regeneration;

- Phosphate concentrates;

- Salt-solvent ingots (after emergency shut-downs of technological process);

- Combustible waste (pyrographite products, rags, films, filtering fabric).

There are about $40 \mathrm{~kg}$ of waste containing $<1 \%$ plutonium mass fraction which can be subjected to immediate immobilization, whereas other waste can be processed for plutonium removal and use in nuclear reactor fuel. 


\section{The flowsheets for complex reprocessing of recycled products and pyrochemical waste were developed as early as 1986-90.}

They provide the following procedures:

a) Regeneration and salt recycling with separation of impurities and fuel component residues in the form of oxide or phosphate component. If plutonium mass fraction in the concentrate is $<1 \%$, it can be vitrified;

b) Burning of combustible wastes involving pyrographite products, packing films, rags, filtering fabric from exhaust filter and others;

c) Repeat concentrate reprocessing according to item a) and ash according to $b$ ) with plutonium recycling to fuel and formation of phosphate concentrates allowing their vitrification;

d) Decontamination of very contaminated equipment with removal of fuel components from solutions by both evaporation and ion-exchange and deposition methods with the following resin burning according to $b$ ) and deposits reprocessing according to $\mathrm{c}$ );

e) Vitrification of phosphate and oxide wastes (concentrates). 


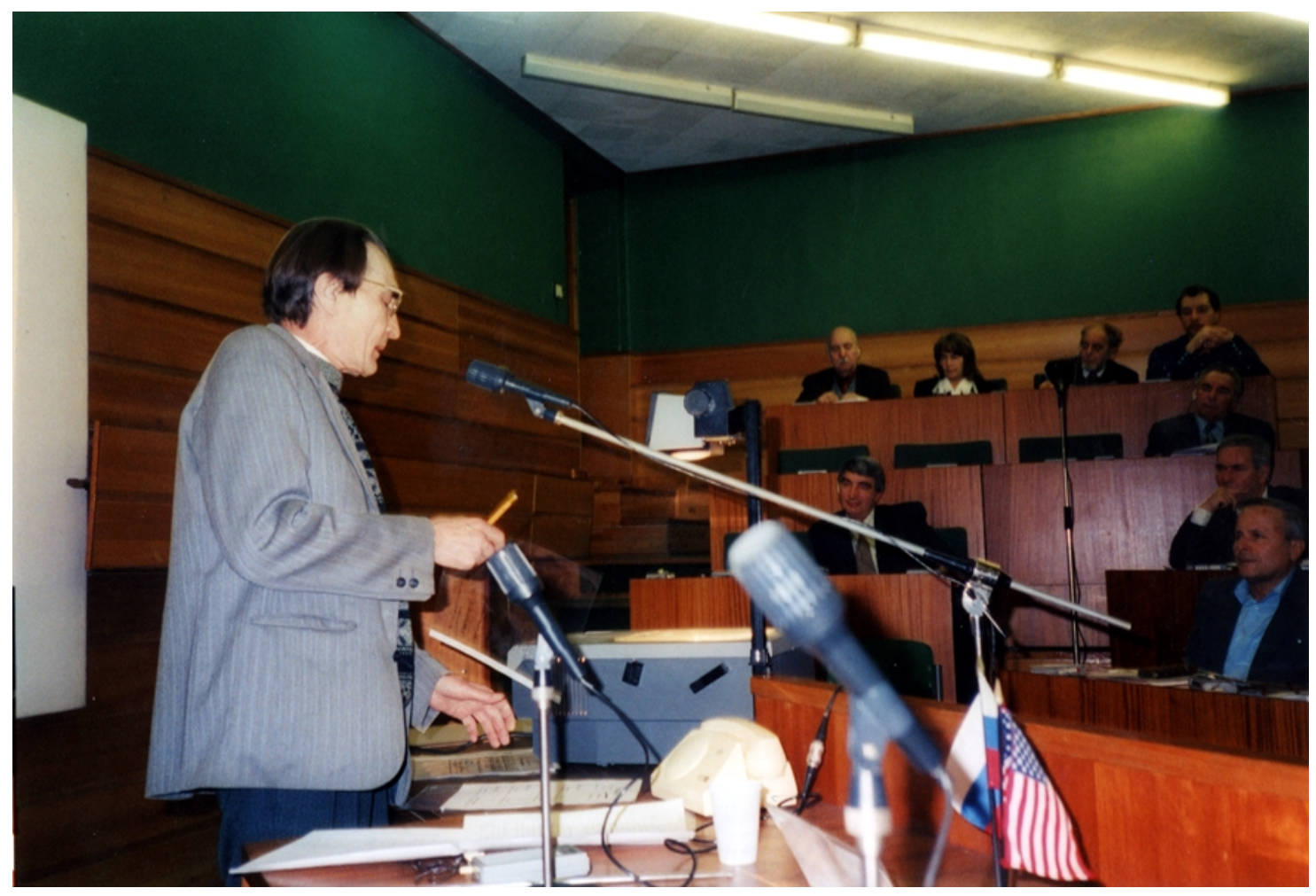

Y. Volkov, RIAR, making his presentation.

III. Research and Development Plutonium Immobilization Activities 



\section{Cold Crucible Induction Melter Study of Glasses and Ceramic Compositions for Immobilization of Pu-containing Materials [UTA 96-330-MOD-1]}

\section{Y. I. Matyunin, VNIINM}

Under the scope of the joint agreements between the US and the Russian Federation on the disposition of excess weapons-grade plutonium, the work described here has been carried out at VNIINM to study glasses intended for the immobilization of Pu-containing materials.

Studies have been made at VNIINM to immobilize simulated high-radioactive wastes using coldcrucible inductive melting (CCIM). A synthesis of different glass-type compositions with surrogates (cerium) and plutonium was made in lab-scale muffle furnaces and at a lab-scale CCIM installation manufactured and assembled at VNIINM (Figs. 1-4).
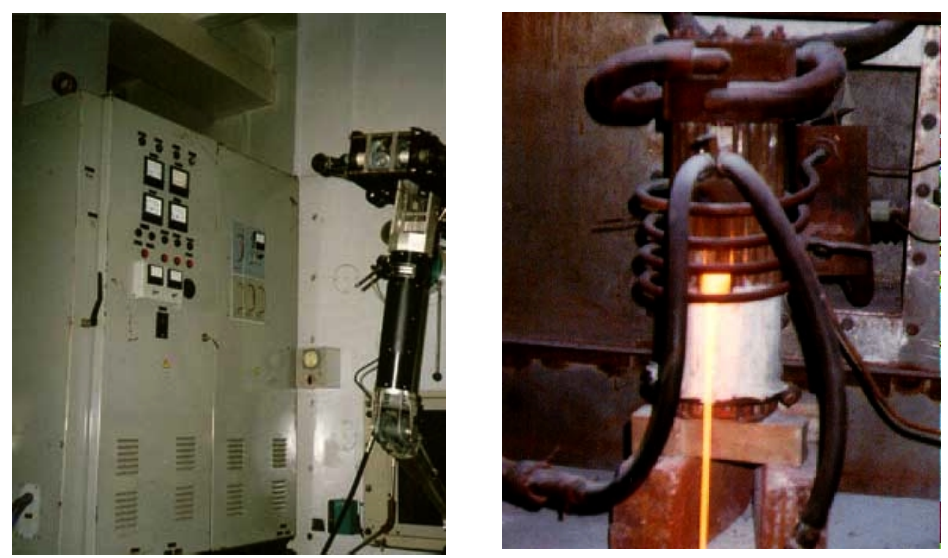

Fig. 1. Lab-scale installation CCIM-5.28; Crucible $d=100 \mathrm{~mm}, \mathrm{~h}=250 \mathrm{~mm}$, frequency=5.28 $\mathrm{MHz}$.
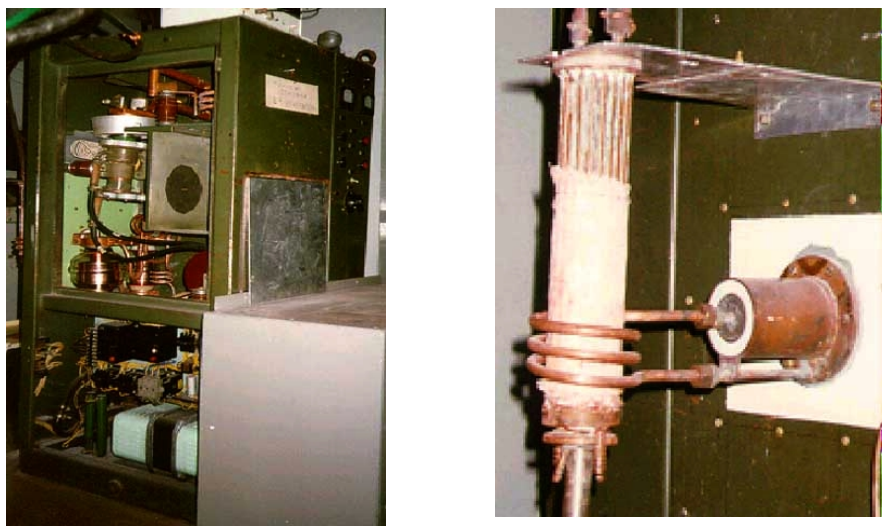


\section{Plutonium Glasses for Immobilization}

Fig. 2. Lab-scale installation CCIM-I-3; Crucible $d=50 \mathrm{~mm}, \mathrm{~h}=300 \mathrm{~mm}$, frequency=21 $\mathrm{MHz}$.
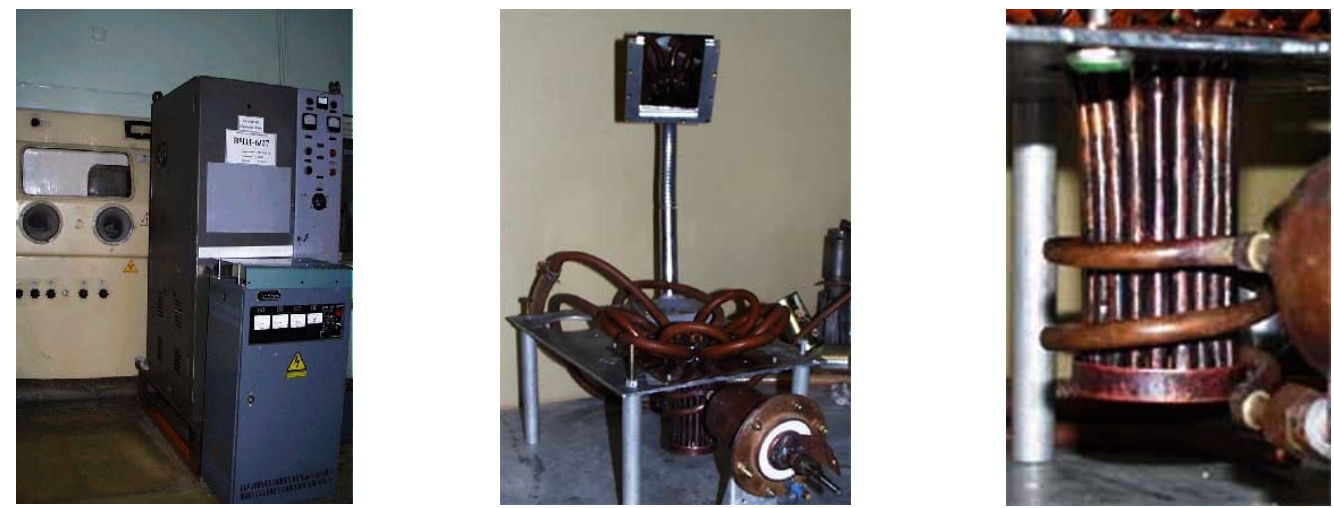

Fig. 3. Lab-scale installation CCIM-I-3; Crucible $d=50 \mathrm{~mm}, \mathrm{~h}=100 \mathrm{~mm}$, frequency=21 $\mathrm{MHz}$.
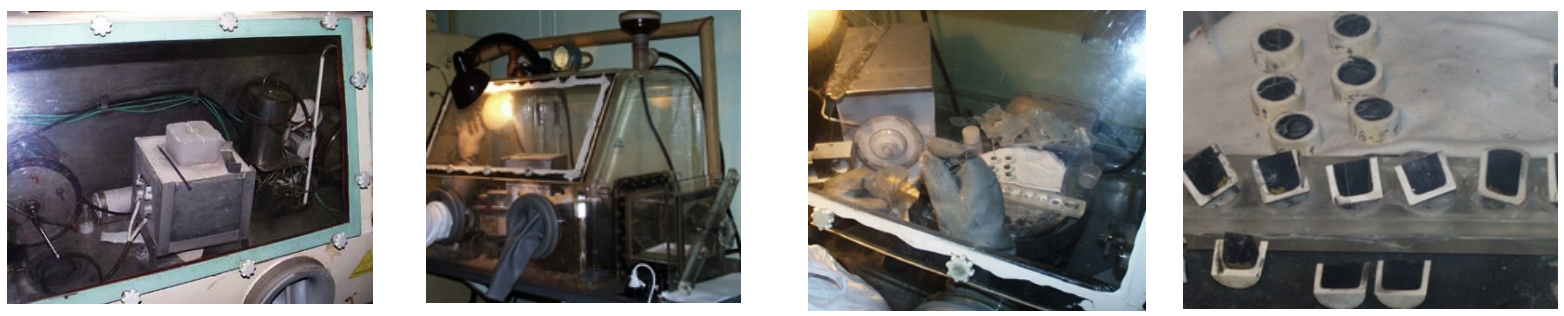

Fig. 4. A muffle furnace and equipment to synthesize and prepare Pu-containing materials for characterization studies.

According to the work plan, glasses based on LABS-glassfrit with different concentrations of lithium (up to $5 \mathrm{wt} \%$ ) and cerium (up to $20 \mathrm{wt} \%$ ) have been synthesized and investigated. The investigations used optical and electronic microscopy to delineate the equal distribution and complete incorporation of as much as $20 \mathrm{wt} \%$ cerium into the compositions. Adding lithium (up to $5 \mathrm{wt} \%$ ) into the matrix composition has reduced the viscosity of the melt more than three times and its specific resistance more than 20 times.

Studies of LABS compositions synthesized in the CCIM have shown that both an amorphous phase of the glass and crystal phases of zirconium oxide, rare-earth elements, and zirconium borides; and metallic silica are available in the samples.

Comparative studies of phosphate and boronsilicate compositions synthesized in the muffle furnace and in the CCIM installation (Tables 1 and 2) have shown that:

- In the course of the synthesis in the crucibles, simulated phosphate and boronsilicate glasses containing $\mathrm{Ce}$ (a surrogate of $\mathrm{Pu}$ ) have a limited rate of Ce solubility (by incorporation of $\mathrm{CeO}_{2}$ ). In case of exceeding the level of solubility in the glass (about 1.8.wt $\% \mathrm{CeO}_{2}$ for the phosphate glass and about $5.5 \mathrm{wt} \% \mathrm{CeO}_{2}$ for the boronsilicate glass), one can identify the release of dispersed crystal particles, forming sediment in the bottom part of the glass batch while holding at the melting temperature.

- In phosphate glasses with a high content of $\mathrm{Ce}$, crystal phases like monazite $\left(\mathrm{CePO}_{4}\right)$ with diminutive admixtures of other rare-earth elements $(\mathrm{Ce}, \mathrm{La}, \mathrm{Nd}) \mathrm{PO}_{4}$ have been identified. The 


\section{Research and Development Plutonium Immobilization Contract Activities}

availability of dispersed particles in the glass promotes crystallization of the glass with the formation of spherolites, in which the ratio of $\mathrm{Na:Al}: \mathrm{P}$ is similar to that of the given components in the matrix.

- In boronsilicate glasses with a high content of $\mathrm{Ce}$, a crystal phase cerianite $\left(\mathrm{CeO}_{2}\right)$ has been identified. In the bottom and in parietal layers of the glass batch (a contact zone between the melt and the crucible), a crystal-phase nepheline has been identified $\left(\mathrm{NaAISiO}_{4}\right)$

- In the phosphate and boronsilicate glasses synthesized in CCIM, the level of incorporation of $\mathrm{Ce}$ into the matrix compositions exceeds similar values for the materials synthesized in the crucibles. Crystal phases based on Ce have not been found in the samples studied.

Distribution of $\mathrm{Ce}$ in the glass batches is equal because of the considerable convection currents in the melt of the glass being synthesized in the CCIM.

The incorporation rate of $\mathrm{PuO}_{2}$ in the studied phosphate and boronsilicate glasses is insignificant. The level of dissolution of $\mathrm{PuO}_{2}$ in the phosphate and boronsilicate glasses synthesized in the crucibles is limited to within $0.15 \mathrm{wt} \%$ and $0.45 \mathrm{wt} \%$, respectively. Residual Pu in the form of dioxide insoluble in the glass matrix precipitates into the bottom part of the glass batch. The results of the characterization studies confirm the data obtained in earlier efforts.

Studies of Pu-containing glasses synthesized while melting glassfrit and plutonium dioxide in the $\mathrm{CCIM}$, as in the case with cerium, have shown practically equal distribution of $\mathrm{Pu}$ in the glass batch by content up to $0.5 \mathrm{wt} \%$. There were no crystal phases based on Pu in the glasses studied.

Table 1. Ce- and Pu-containing phosphate $(\mathrm{Ph})$ glasses.

\begin{tabular}{|l|l|l|l|l|l|}
\hline \multicolumn{1}{|c|}{ Type } & \multicolumn{5}{c|}{ Content of oxides, wt\% } \\
\hline & \multicolumn{1}{|c|}{$\mathrm{Na}_{2} \mathbf{O}$} & \multicolumn{1}{c|}{$\mathrm{Al}_{2} \mathrm{O}_{3}$} & \multicolumn{1}{c|}{$\mathbf{P}_{\mathbf{2}} \mathbf{O}_{\mathbf{5}}$} & \multicolumn{1}{c|}{$\mathbf{H L L W}{ }_{\text {ox }}{ }^{*}$} & $\mathbf{C e O}_{2} / \mathbf{P u O}_{2}$ \\
\hline $\mathrm{Ph}$ & 24.16 & 19.14 & 52.40 & 3.61 & 0.69 \\
\hline $\mathrm{Ph}-\mathrm{Ce}-3$ & 23.46 & 18.58 & 50.88 & 3.51 & 3.57 \\
\hline $\mathrm{Ph}-\mathrm{Ce}-5$ & 23.00 & 18.23 & 49.91 & 3.44 & 5.42 \\
\hline $\mathrm{Ph}-\mathrm{Pu}-0.2$ & 24.11 & 19.10 & 52.30 & 4.29 & 0.20 \\
\hline Ph-Pu-0.5 & 24.04 & 19.04 & 52.14 & 4.28 & 0.50 \\
\hline
\end{tabular}

*Without taking into account the content of Ce in HLLW

Table 2. Ce- and Pu-containing boronsilicate glasses.

\begin{tabular}{|l|l|l|l|l|l|l|l|l|}
\hline \hline \multicolumn{1}{|c|}{ Type } & \multicolumn{7}{c|}{ Content of oxides, wt. \% } \\
\hline & \multicolumn{1}{|c|}{$\mathbf{N a}_{\mathbf{2}} \mathbf{O}$} & $\mathbf{A l}_{\mathbf{2}} \mathbf{O}_{\mathbf{3}}$ & $\mathbf{B}_{\mathbf{2}} \mathbf{O}_{\mathbf{3}}$ & $\mathbf{C a O}$ & $\mathbf{F e}_{\mathbf{2}} \mathbf{O}_{\mathbf{3}}$ & $\mathbf{S i O}_{\mathbf{2}}$ & $\mathbf{H L L W}_{\text {ox }}{ }^{*}$ & $\mathbf{C e O}_{\mathbf{2}} / \mathbf{P u O}_{\mathbf{2}}$ \\
\hline GP-91 & 21.10 & 5.05 & 13.12 & 3.03 & 3.03 & 46.42 & 6.93 & 1.32 \\
\hline GP-91-Ce-3 & 20.49 & 4.90 & 12.74 & 2.94 & 2.94 & 45.07 & 6.73 & 4.19 \\
\hline GP-91-Ce-5 & 20.10 & 4.80 & 12.50 & 2.89 & 2.89 & 44.20 & 6.60 & 6.02 \\
\hline GP-91-Pu-0.2 & 21.06 & 5.04 & 13.10 & 3.02 & 3.02 & 46.33 & 8.23 & 0.20 \\
\hline GP-91-Pu-0.5 & 21.00 & 5.02 & 13.05 & 3.01 & 3.01 & 46.20 & 8.21 & 0.50 \\
\hline
\end{tabular}

*Without taking into account the content of $\mathrm{Ce}$ in $\mathrm{HLLW}_{\mathrm{ox}}$ 


\title{
Q VNIINM
}

Summary of the Agreement UTA96-330 MOD-1

\author{
RUSSIAN TESTING OF COLD \\ CRUCIBLE INDUCTION MELTER \\ (CCIM)
}




\section{Lab-scale CCIM installations}

\section{Lab-scale installation CCIM-5.28}

\section{Crucible $d=100 \mathrm{~mm}, \mathrm{~h}=\mathbf{2 5 0} \mathrm{mm}$, frequency $=5.28 \mathrm{MHz}$}
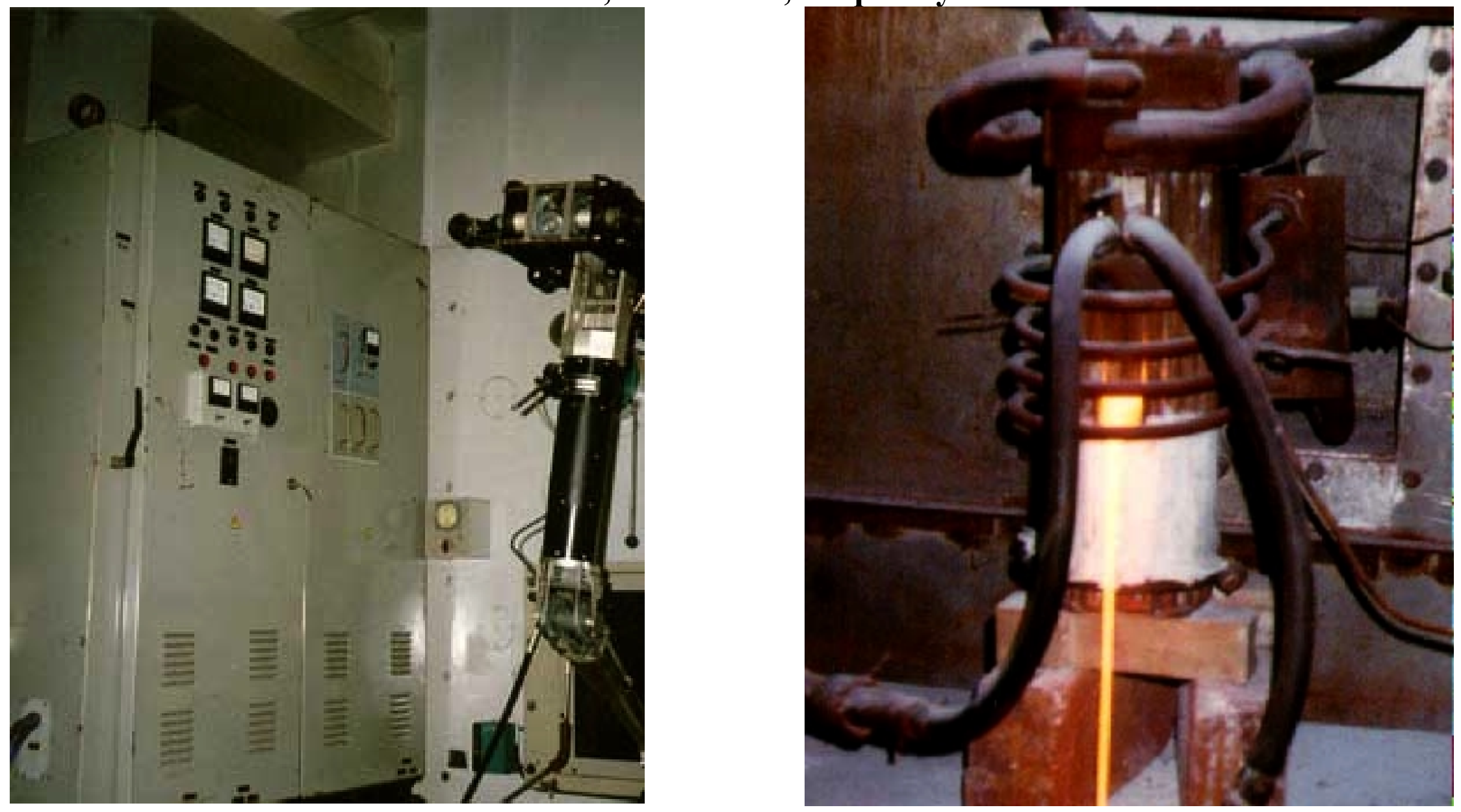


\section{Lab-scale CCIM installations \\ Lab-scale installation CCIM-I-3}

Crucible $\mathrm{d}=50 \mathrm{~mm}, \mathrm{~h}=300 \mathrm{~mm}$, frequency $=21 \mathrm{MHz}$
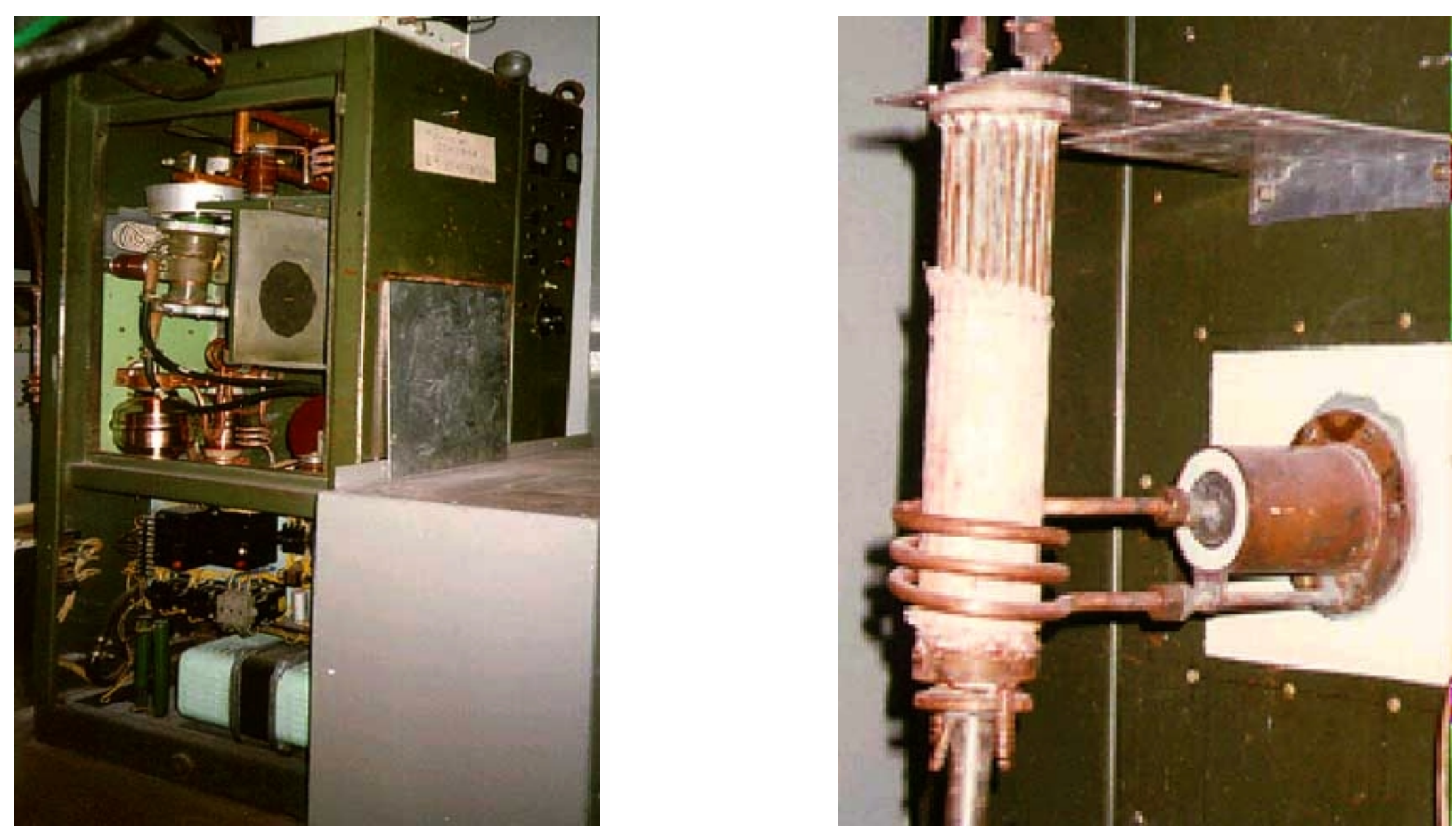


\section{Lab-scale CCIM installations}

\section{Lab-scale installation CCIM-Pu}

Crucible $\mathrm{d}=50 \mathrm{~mm}, \mathrm{~h}=100 \mathrm{~mm}$, frequency $=21 \mathrm{MHz}$
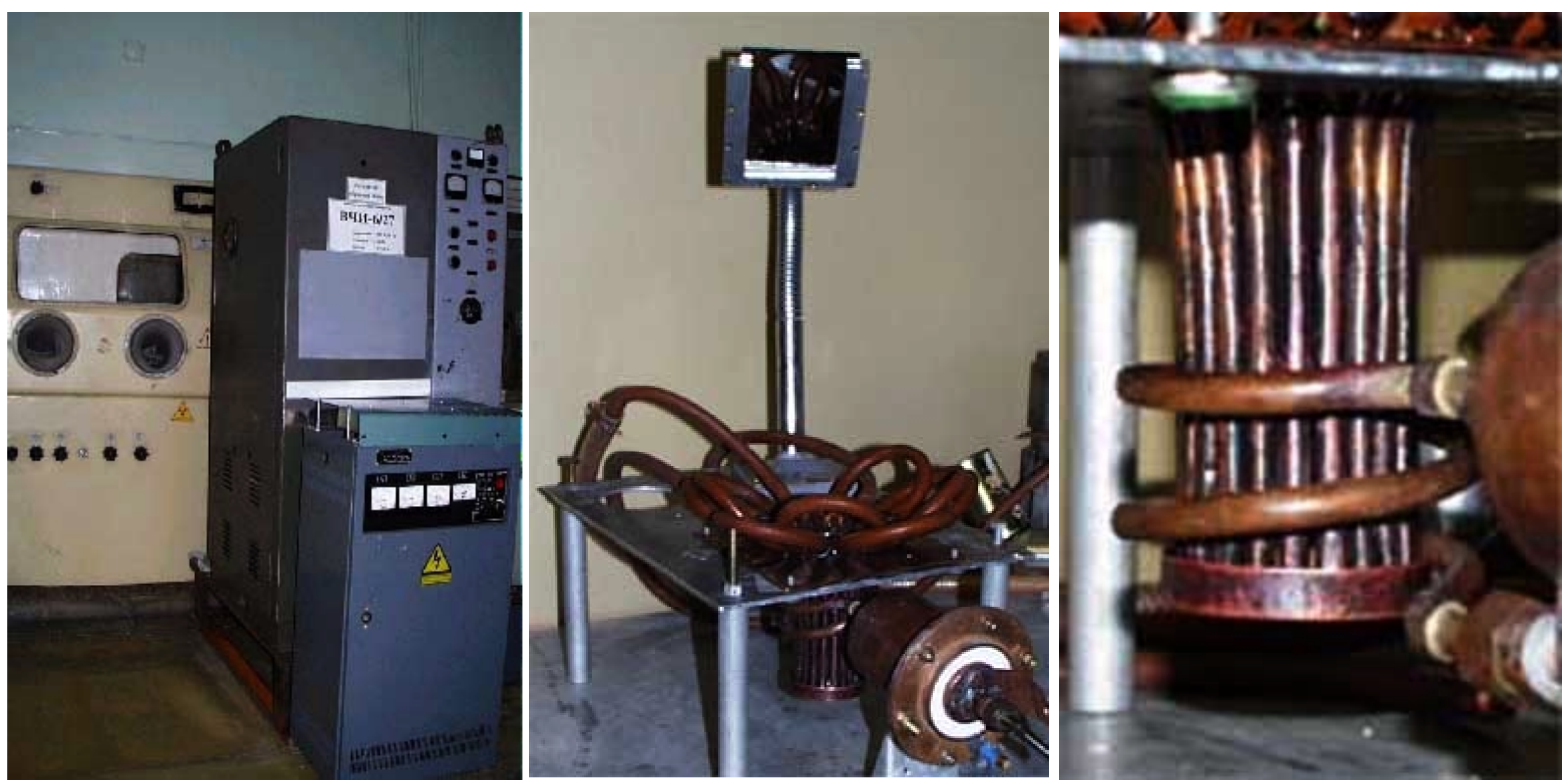


\section{LABS glasses \\ LABS-glasses based on a glassfrit (USA) \\ Muffle furnace}

LABS- glasses based on the glassfrit (USA) with a different content of Ce (10, 20\% wt)

LABS-Li glasses based on the glassfrit (USA) with a different content of $\mathrm{Li}(1,3,5 \% \mathrm{wt})$

LABS-Li-Ce glasses based on the glassfrit (USA) with a different content of Ce (7, 15\% wt)

Dependencies of viscosity and electrical conductivity of melts of the LABS-Li glasses from a temperature of the melt

\begin{tabular}{|c|c|c|c|c|c|c|}
\hline & \multicolumn{2}{|c|}{ LABS-frit } & \multicolumn{2}{c|}{ LABS-Li-1 } & \multicolumn{2}{c|}{ LABS-Li-5 } \\
\hline & $\mathbf{1 3 0 0}^{\circ} \mathrm{C}$ & $\mathbf{1 4 0 0}^{\circ} \mathrm{C}$ & $\mathbf{1 3 0 0}^{\circ} \mathrm{C}$ & $\mathbf{1 4 0 0}^{\circ} \mathrm{C}$ & $\mathbf{1 4 0 0}^{\circ} \mathrm{C}$ & $\mathbf{1 4 0 0}^{\circ} \mathrm{C}$ \\
\hline Viscosity, dPa s & 185 & $\mathbf{6 5}$ & $\mathbf{8 0}^{\circ}$ & $\mathbf{3 5}$ & $\mathbf{5 5}$ & $\mathbf{2 2}$ \\
\hline Specific Resistance, Om cm. & $\mathbf{2 3 0}$ & 67 & 12 & 5,5 & 4 & 2,5 \\
\hline
\end{tabular}

During the work homogeneity of Ce in the synthesized LABS compositions has been studied Results of optical and electron microscopy point out the homogeneity and complete inclusion of Ce into the structure up to $20 \%$ wt. 


\section{LABS glasses \\ LABS-glasses based on the glassfrit (USA) CCIM}

$L_{-} B S^{4}$ (start-up at SiC with an addition of metallic Aluminum)

$L_{-} B S^{5}$ (start-up at Aluminum).
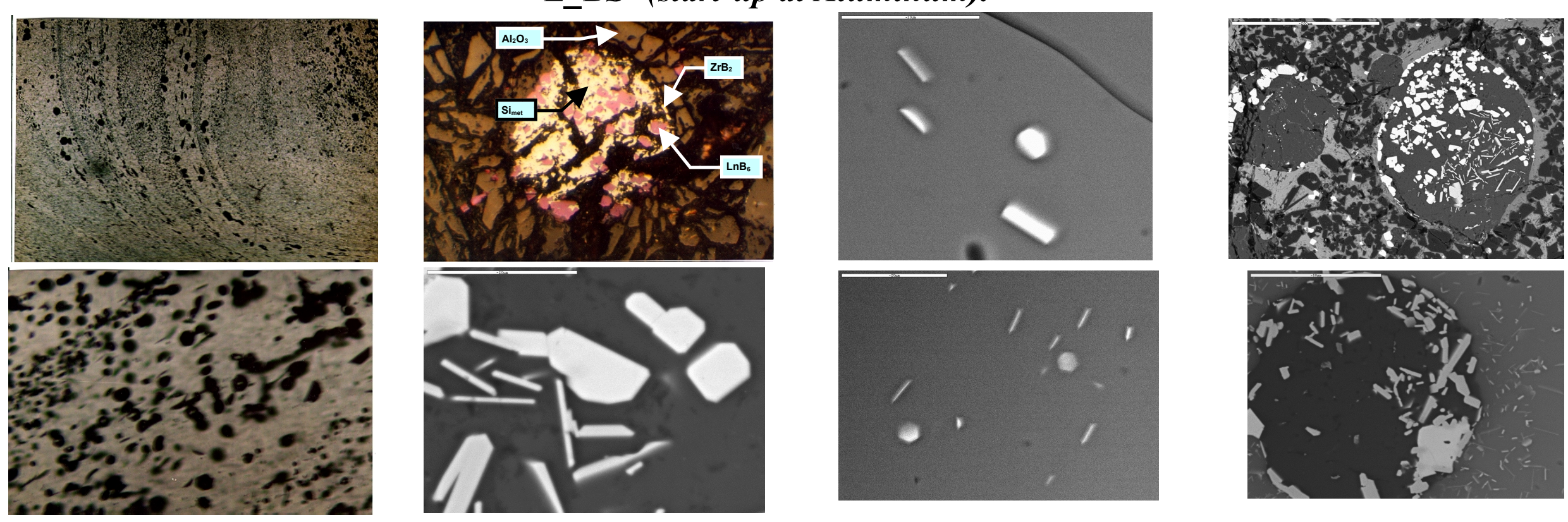

According to results of SEM/EDS and XRD characterization methods there are both an amorphous phase of the glass LABS and crystal phases of Zirconium oxide $\left(\mathrm{ZrO}_{2}\right)$, borides of rare-earth elements $\left(\operatorname{LnB}_{6}\right)$, and Zirconium $\left(\mathrm{ZrB} B_{2}\right)$, metallic silica $\left(S i_{\text {met }}\right)$ 


\section{Synthesis of glass-type materials Phosphate and boronsilicate glasses}

Ce-containing phosphate and boronsilicate glasses

\begin{tabular}{|c|c|c|c|c|c|}
\hline Type & \multicolumn{5}{|c|}{ Content of oxides, wt. \% } \\
\cline { 2 - 6 } & $\mathrm{Na}_{2} \mathrm{O}$ & $\mathrm{Al}_{2} \mathrm{O}_{3}$ & $\mathrm{P}_{2} \mathrm{O}_{5}$ & $\mathrm{HLLW}_{\text {ox }}{ }^{*}$ & $\mathrm{CeO}_{2}$ \\
\hline $\mathrm{Ph}$ & 24.16 & 19.14 & 52.40 & 3.61 & 0.69 \\
\hline $\mathrm{Ph}-\mathrm{Ce}-3$ & 23.46 & 18.58 & 50.88 & 3.51 & 3.57 \\
\hline $\mathrm{Ph}-\mathrm{Ce}-5$ & 23.00 & 18.23 & 49.91 & 3.44 & 5.42 \\
\hline
\end{tabular}

\begin{tabular}{|c|c|c|c|c|c|c|c|c|}
\hline \multirow{2}{*}{ Type } & \multicolumn{7}{|c|}{ Content of oxides, wt. \% } \\
\cline { 2 - 9 } & $\mathrm{Na}_{2} \mathrm{O}$ & $\mathrm{Al}_{2} \mathrm{O}_{3}$ & $\mathrm{~B}_{2} \mathrm{O}_{3}$ & $\mathrm{CaO}$ & $\mathrm{Fe}_{2} \mathrm{O}_{3}$ & $\mathrm{SiO}_{2}$ & $\mathrm{HLLW}_{\text {ox }}{ }^{*}$ & $\mathrm{CeO}_{2}$ \\
\hline GP-91 & 21.10 & 5.05 & 13.12 & 3.03 & 3.03 & 46.42 & 6.93 & 1.32 \\
\hline GP-91-Ce-3 & 20.49 & 4.90 & 12.74 & 2.94 & 2.94 & 45.07 & 6.73 & 4.19 \\
\hline GP-91-Ce-5 & 20.10 & 4.80 & 12.50 & 2.89 & 2.89 & 44.20 & 6.60 & 6.02 \\
\hline
\end{tabular}

${ }^{*}$ - - without taking into account the content of Ce in $\mathrm{HLLW}_{\mathrm{ox}}$ 


\section{Synthesis of glass-type materials}

\section{Phosphate and boronsilicate glasses}

Pu-containing phosphate and boronsilicate glasses

\begin{tabular}{|c|c|c|c|c|c|}
\hline \multirow{2}{*}{ Type } & \multicolumn{5}{|c|}{ Content of oxides, wt. \% } \\
\cline { 2 - 6 } & $\mathrm{Na}_{2} \mathrm{O}$ & $\mathrm{Al}_{2} \mathrm{O}_{3}$ & $\mathrm{P}_{2} \mathrm{O}_{5}$ & $\mathrm{HLLW}_{\text {ox }}$ & $\mathrm{PuO}_{2}$ \\
\hline $\mathrm{Ph}$ & 24.16 & 19.14 & 52.40 & 4.30 & - \\
\hline $\mathrm{Ph}-\mathrm{Pu}-0.2$ & 24.11 & 19.10 & 52.30 & 4.29 & 0.20 \\
\hline $\mathrm{Ph}-\mathrm{Pu}-0.5$ & 24.04 & 19.04 & 52.14 & 4.28 & 0.50 \\
\hline
\end{tabular}

\begin{tabular}{|c|c|c|c|c|c|c|c|c|}
\hline \multirow{2}{*}{ Type } & \multicolumn{7}{|c|}{ Content of oxides, wt. \% } \\
\cline { 2 - 10 } & $\mathrm{Na}_{2} \mathrm{O}$ & $\mathrm{Al}_{2} \mathrm{O}_{3}$ & $\mathrm{~B}_{2} \mathrm{O}_{3}$ & $\mathrm{CaO}$ & $\mathrm{Fe}_{2} \mathrm{O}_{3}$ & $\mathrm{SiO}_{2}$ & $\mathrm{HLLW}_{\text {ox }}$ & $\mathrm{PuO}_{2}$ \\
\hline GP-91 & 21.10 & 5.05 & 13.12 & 3.03 & 3.03 & 46.42 & 8.25 & - \\
\hline GP-91-Pu-0.2 & 21.06 & 5.04 & 13.10 & 3.02 & 3.02 & 46.33 & 8.23 & 0.20 \\
\hline GP-91-Pu-0.5 & 21.00 & 5.02 & 13.05 & 3.01 & 3.01 & 46.20 & 8.21 & 0.50 \\
\hline
\end{tabular}




\section{Synthesis of glass-type materials Phosphate and boronsilicate glasses}

\section{Ce- and Pu-containing phosphate and boronsilicate glasses}

\section{Muffle furnace}

Synthesis of Ce-Pu-containing glasses prepared from a mixture of the glassfrit with Cerium oxide $\left(\mathrm{CeO}_{2}\right)$ or $\mathrm{Pu}\left(\mathrm{PuO}_{2}\right)$ was made in a lab-scale muffle furnace under the following temperature conditions

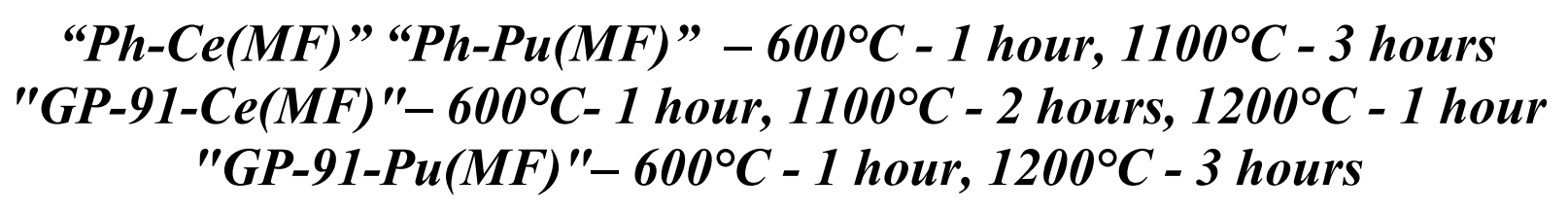

\section{CCIM}

Synthesis of Ce-and Pu-containing glasses was made at the lab-scale installation «CCIM-I3». A portion of the glassfrit $(150 \mathrm{~g})$ and a start-up material (powder of metallic Aluminum, 1-2 g) were loaded into the crucible. After formation of the basin of the melt (5-10 min) step-by-step (2-3 loadings) a mixture of the glassfrit $(50 \mathrm{~g})$ with Cerium $(3,6 \mathrm{~g})$ or Plutonium $(0.2$ or $0.5 \mathrm{~g})$ dioxide was put onto the surface of the melt. After loading of the last portion of the mixture, the melt was kept during 3 hours and then cooled together with a crucible. 


\section{Characterization of the synthesized materials}

\section{Used characterization methods:}

\section{Optical microscopy}

Electron microscopy (SEM/EDS)

XRD analysis

$$
\text { Alpha radiography }
$$

Alpha- and gamma spectrometry

Gamma-spectrometry

Atomic adsorption spectrometry 


\section{Characterization of the synthesized materials}

\section{Ce-containing phosphate and boronsilicate glasses}

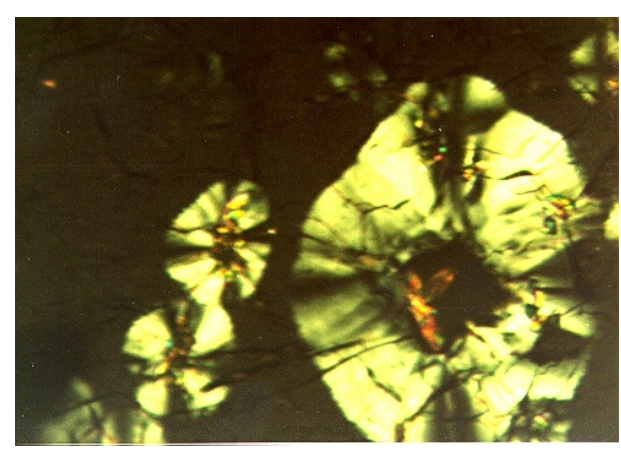

$\mathrm{Ph}-\mathrm{Ce}-3(\mathrm{MF})$

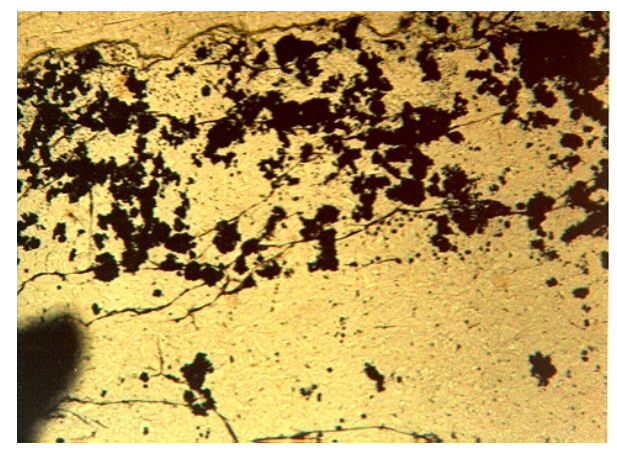

GP91-Ce-5(MF)

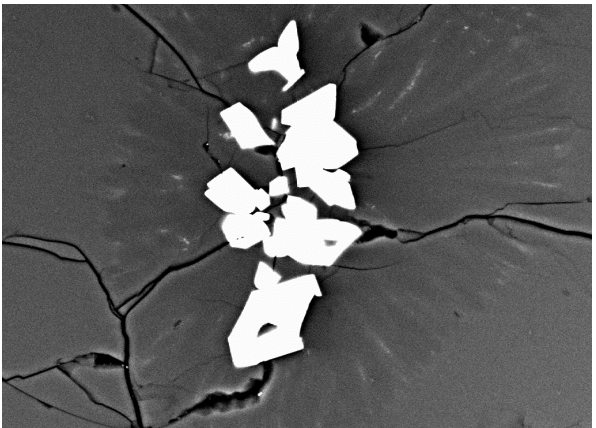

Ph-Ce-3(MF)

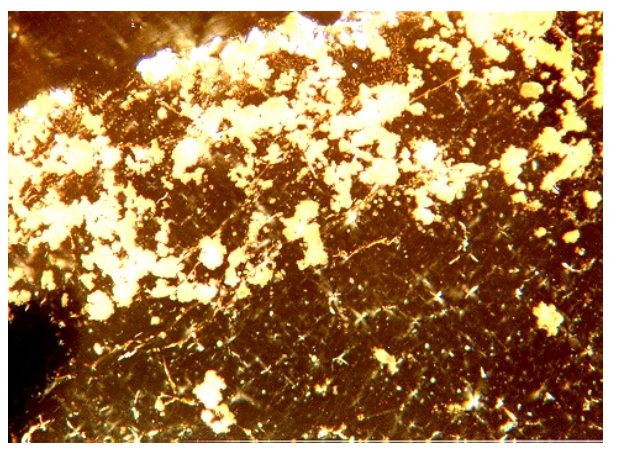

GP91-Ce-5(MF)

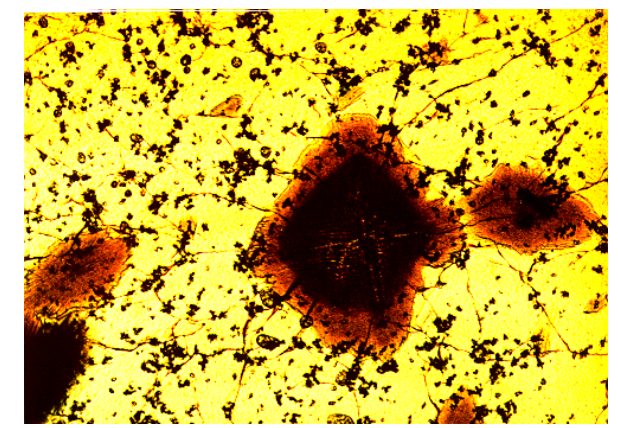

$\mathrm{Ph}-\mathrm{Ce}-5(\mathrm{MF})$

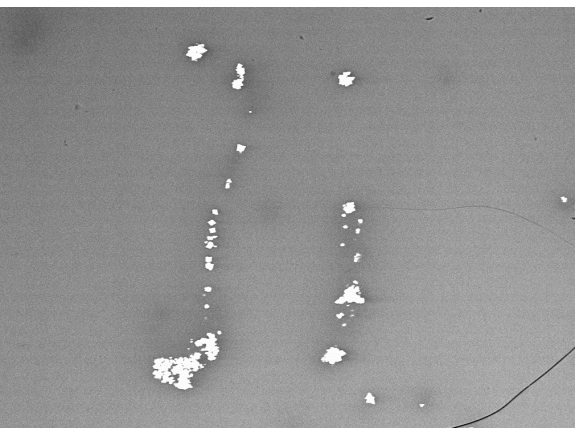

GP91-Ce-5(MF)

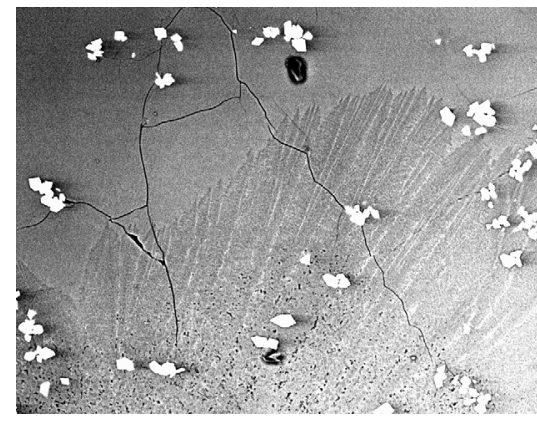

$\mathrm{Ph}-\mathrm{Ce}-5(\mathrm{MF})$

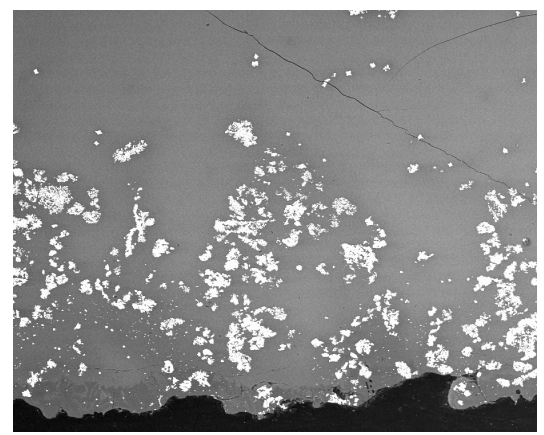

GP91-Ce-5(MF) 


\section{Characterization of the synthesized materials}
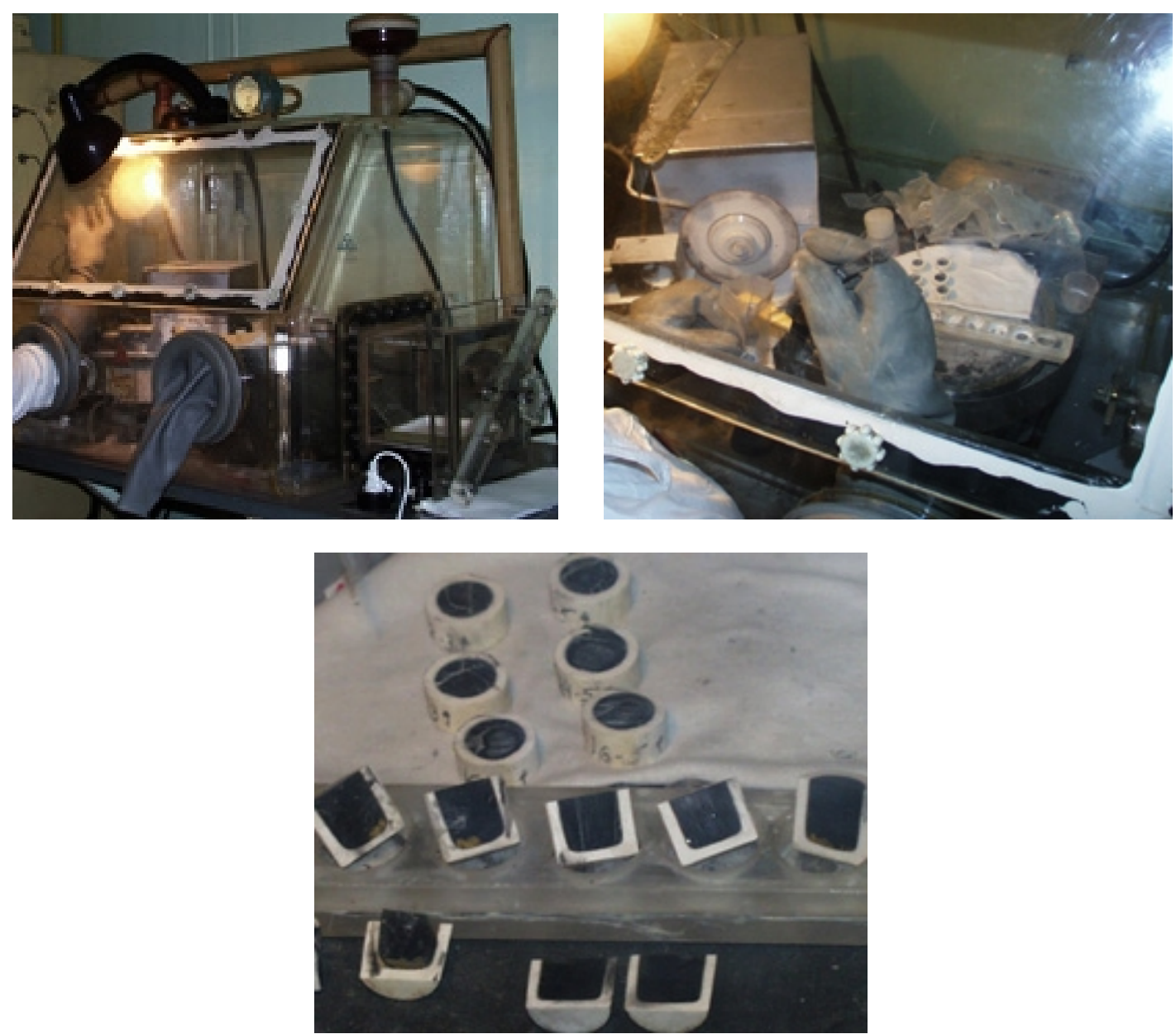

A protective box with equipment for fabrication of samples and some samples for characterization studies 


\section{Characterization of the synthesized materials}

\section{Pu-containing phosphate and boronsilicate glasses}
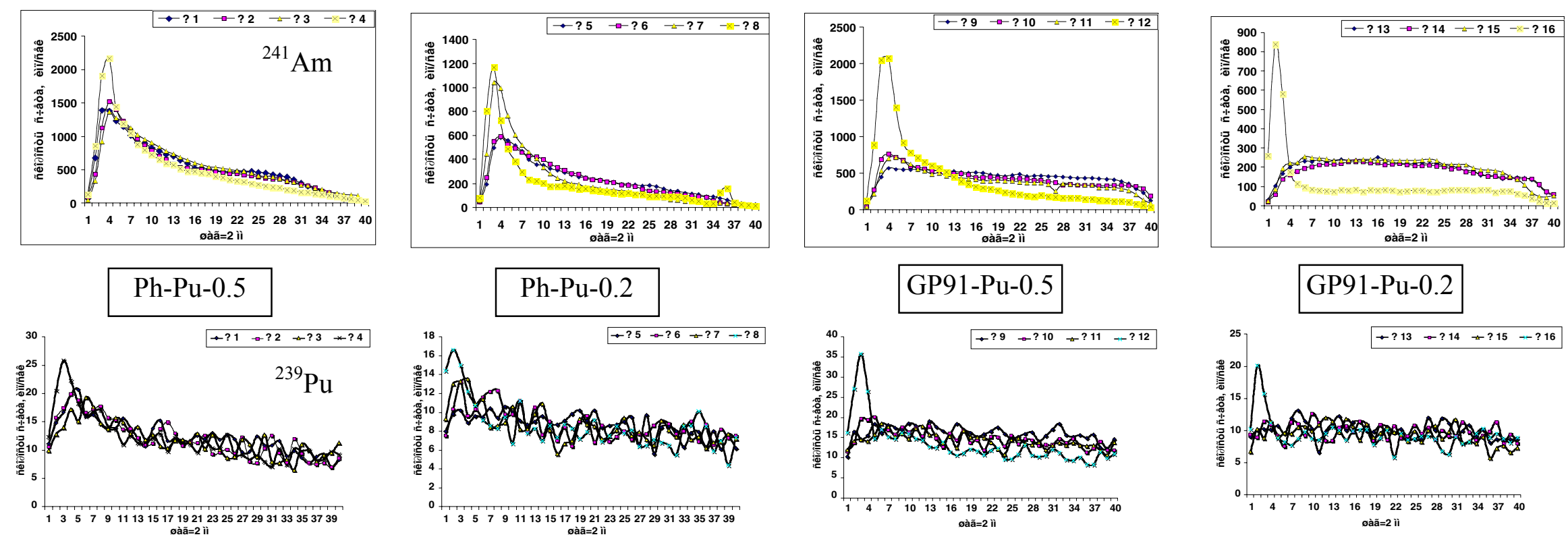

Distribution of Pu and Am upon the height of the synthesized glass batches (data of gamma-scanning) 


\section{Characterization of the synthesized materials}

\section{Pu-containing phosphate and boronsilicate glasses}

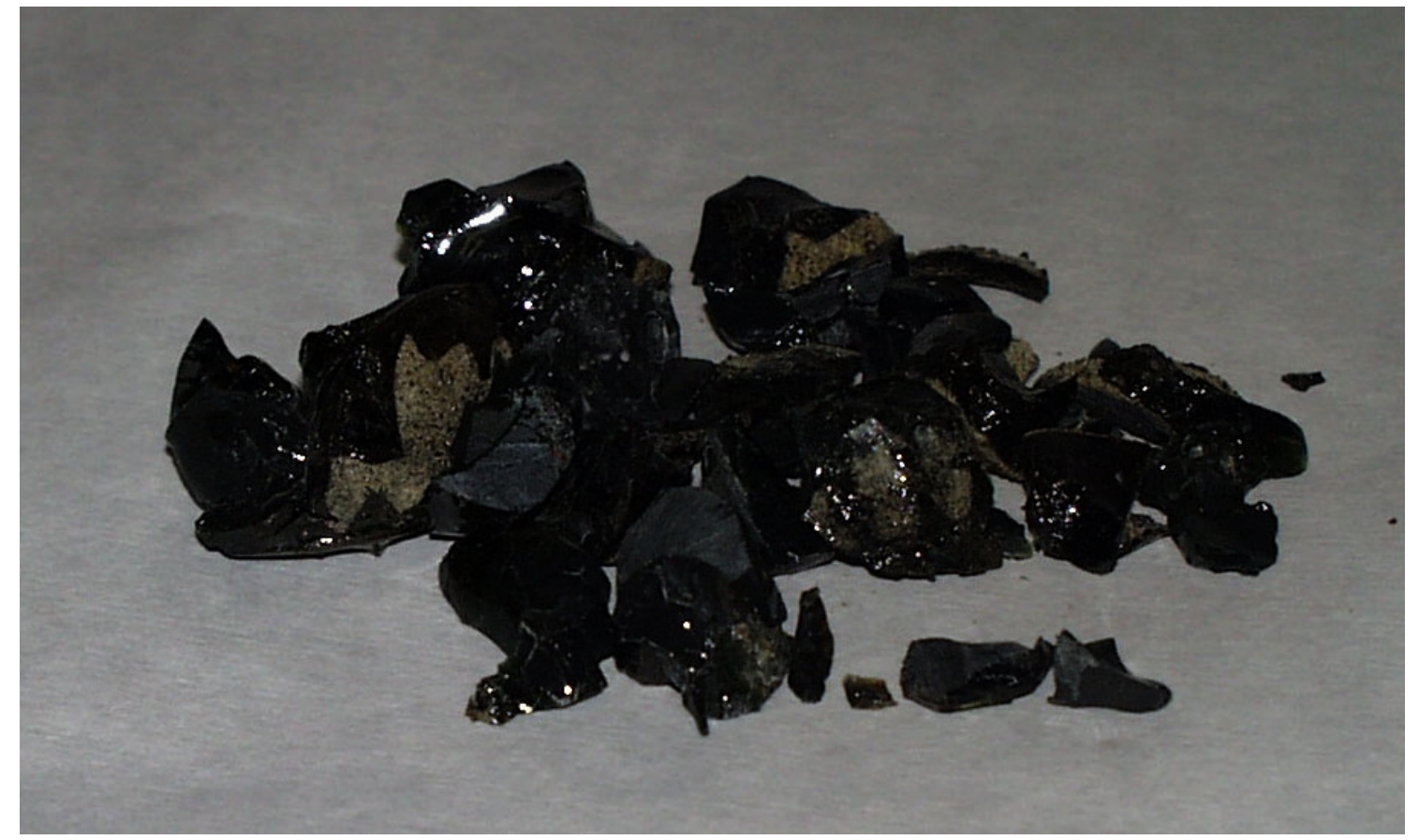

Specimens of the Pu-containing boronsilicate glass synthesized in CCIM 


\section{Characterization of the synthesized materials}

\section{Pu-containing phosphate and boronsilicate glasses}

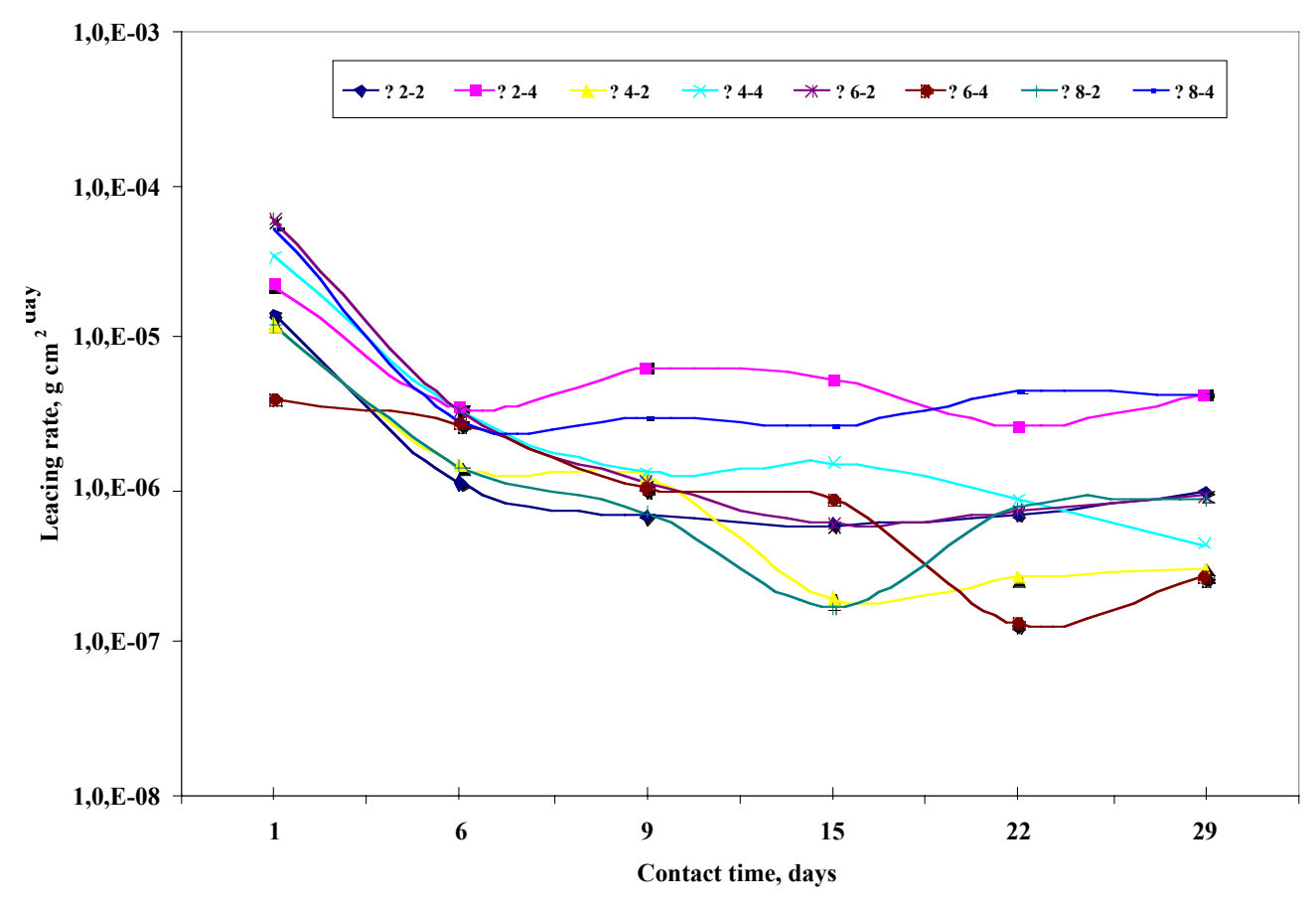

Ph

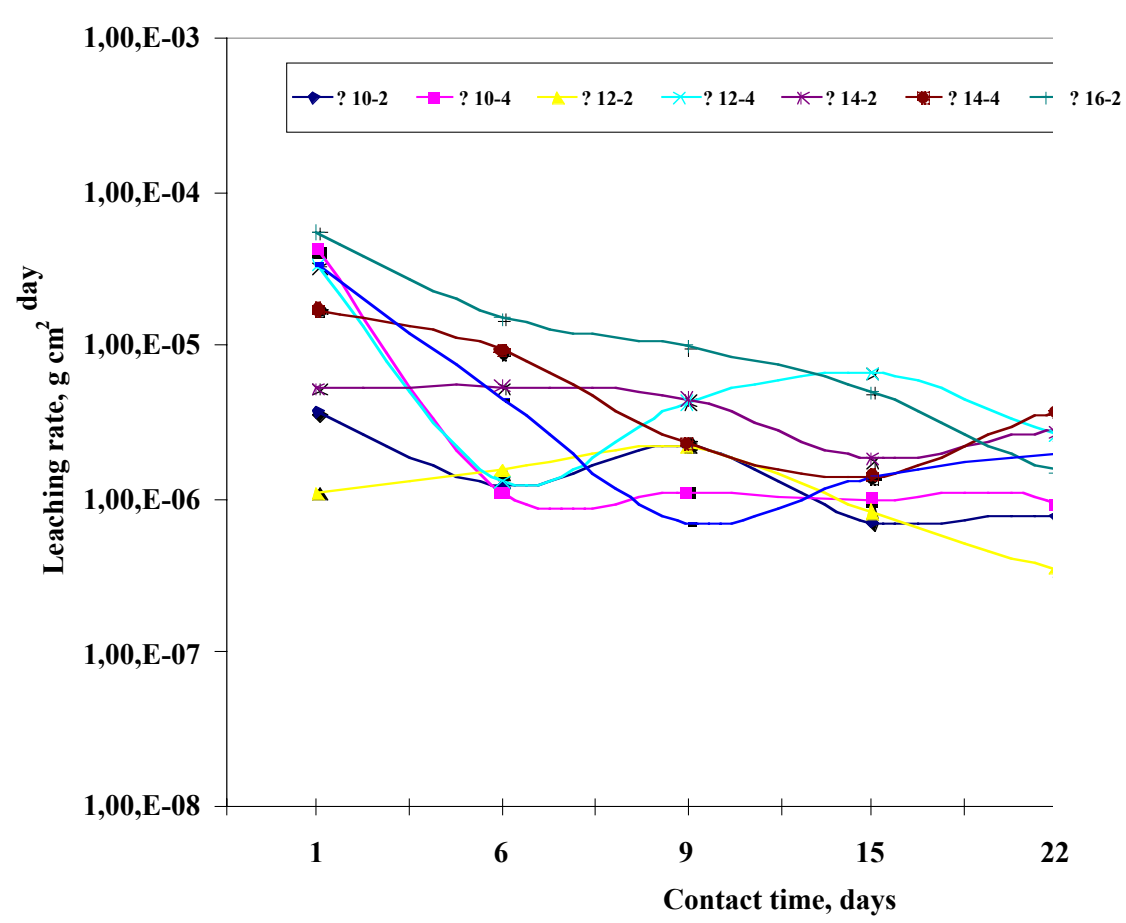

GP-91

Leach rate of $\mathrm{Pu}$ from the synthesized glasses. 


\section{CONCLUSIONS}

1. Distribution of Ce in the LABS glass synthesized in a muffle furnace at up to $1500^{\circ} \mathrm{C}$ is equal with its content as large as $20 \%$ wt.

2. While melting the LABS glass in CCIM it was identified the formation of dispersed crystal phases equally distributed upon the bulk of the glass batch.

3. In the course the synthesis in crucibles simulated phosphate and boronsilicate glasses, containing $\mathrm{Ce}$ (surrogate of $\mathrm{Pu}$ ) have limited solubility of $\mathrm{Ce}$ (by incorporation of $\mathrm{CeO}_{2}$ ). In case of exceeding the level of solubility (about $1.8 . \%$ wt $\mathrm{CeO}_{2}$ for phosphate glass and about $5.5 \% \mathrm{wt} \mathrm{CeO}_{2}$ for boronsilicate glass) in the glass one can identify release of dispersed crystal particle, sedimenting to the bottom part of the glass batch while keeping the melt.

4. In phosphate glasses with the high content of Ce crystal phases like monazite ( $\left.\mathrm{CePO}_{4}\right)$ with diminutive admixtures of other rare-earth elements (Ce, $\mathrm{La}, \mathrm{Nd}) \mathrm{PO}_{4}$ have been identified. The availability of dispersed particles in the glass promotes crystallization of the glass with formation of spherolites, in which the ratio of Na:Al:P is similar to the one of the given components in the matrix. 
5. In boronsilicate glasses with the high content of $\mathrm{Ce}$ a crystal phase Cerianite (CeO $\mathrm{C}_{2}$ has been identified. In bottom and parietal layers of the glass batch (a contact zone between the melt and the crucible) a crystal phase nepheline has been identified ( $\left.\mathrm{NaAlSiO}_{4}\right)$

6. In phosphate and boronsilicate glasses synthesized in CCIM, the level of incorporation of Ce into the matrix compositions exceeds similar values for the materials synthesized in the crucibles. Crystal phases based on Ce have not been found out in the studied samples. Distribution of Ce in the glass batches is equal that is caused by considerable convection streams in the melt of the glass being synthesized in CCIM.

7. Incorporation rate of $\mathrm{PuO}_{2}$ in phosphate and boronsilicate glasses of the studied compositions is insignificant. The level of dissolution $\mathrm{PuO}_{2}$ in the phosphate and boronsilicate glasses synthesized in crucibles is limited within $0.15 . \%$ wt and $0.45 \% \mathrm{wt}$, respectively. Excessive Pu in form of dioxide insoluble in the glass matrix precipitates into the bottom part of the glass batch. The results of the characterization studies approve data obtained at earlier works.

8. Studies of Pu-containing glasses synthesized while melting the glassfrit and Plutonium dioxide in CCIM, as in case with Cerium, have shown practically equal distribution of $P u$ in the glass batch by its content up to $0.5 \%$ wt. There were no crystal phases based on Pu in the studied glasses distinguished. 


\section{Development of Glass Compositions for Immobilization of Pu-containing Wastes at PA Mayak [B501119]}

\section{Y. I. Matyunin, VNIINM}

This work was performed under the framework of an agreement between the US and the Russian Federation to develop glass compositions for the immobilization of Pu-containing wastes. In this paper, we describe several approaches to developing matrix compositions needed to immobilize hard-todissolve residues:

- A maximal rate of incorporation of alpha-radioactive wastes into the matrix for the joint immobilization of all types of Pu-containing waste - hard-to-dissolve residues, hydrate-sludge slurry and aqueoustailing solutions using the components of the wastes to synthesize the matrix;

- An increase of radioactivity of the hard-to-dissolve residues by means of their joint immobilization with the evaporated high-level aqueous-tailing wastes that will complicate the possibility of recovering $\mathrm{Pu}$ from the wastes for reuse.

At VNIINM under the framework of this agreement, efforts are also being made to study the immobilization of high-level radioactive wastes using the CCIM. A synthesis of different glass compositions with plutonium and plutonium surrogates are being carried out in lab-scale muffle furnaces and at the CCIM installations that have been manufactured and assembled at VNIINM (see Figs. 3 and 4; previous article).

Boron-basalt compositions made with cerium [BZ-Ce-15mf $\left.\left(15 \% \mathrm{CeO}_{2}\right)\right]$, hafnium [BZ-Hf-10mf $(10 \%$ $\left.\mathrm{HfO}_{2}\right)$ ], uranium [BZ-U-10mf $\left(10 \% \mathrm{U}_{3} \mathrm{O}_{8}\right)$ ] and plutonium [BZ-Pu-5mf $\left(5 \% \mathrm{PuO}_{2}\right)$ ] have been synthesized in a muffle furnace and studied.

Table 1 shows different compositions with $\mathrm{Ce}, \mathrm{U}$, and Pu synthesized in the muffle furnace.

Table 1. Boron-basalt compositions with components simulating the wastes.

\begin{tabular}{|c|c|c|c|c|c|c|c|c|}
\hline \multirow{2}{*}{$\begin{array}{l}\text { Oxide, } \\
\text { wt } \% \\
\end{array}$} & \multicolumn{2}{|l|}{ BZ } & \multicolumn{2}{|c|}{ BZ-Ce-15 } & \multicolumn{2}{|c|}{ BZ-Hf-10 } & \multicolumn{2}{|c|}{ BZ-U-10 } \\
\hline & SEM & Chem. & SEM & chem. & SEM & chem. & SEM & chem. \\
\hline $\mathrm{Na}_{2} \mathrm{O}$ & 2.42 & 1.87 & 1.92 & 1.53 & 1.95 & 1.66 & 1.79 & 2.00 \\
\hline $\mathrm{MgO}$ & 2.70 & 2.66 & 1.95 & 2.23 & 2.45 & 2.44 & 2.33 & 2.50 \\
\hline $\mathrm{Al}_{2} \mathrm{O}_{3}$ & 12.52 & 11.4 & 17.51 & 13.8 & 11.17 & 12.5 & 11.42 & 15.40 \\
\hline $\mathrm{SiO}_{2}$ & 37.26 & 34.2 & 28.67 & 27.3 & 36.10 & 31.3 & 33.11 & 29.50 \\
\hline $\mathrm{P}_{2} \mathrm{O}_{5}$ & 0.10 & $\mathrm{~N} /$ & 0.21 & $\mathrm{~N} /$ & 0.26 & $\mathrm{~N} /$ & 0.07 & $\mathrm{~N} /$ \\
\hline $\mathrm{K}_{2} \mathrm{O}$ & 0.58 & 0.58 & 0.59 & 0.54 & 0.66 & 0.57 & 0.56 & 0.64 \\
\hline $\mathrm{CaO}$ & 16.54 & 16.8 & 12.90 & 13.4 & 15.19 & 14.8 & 14.36 & 13.10 \\
\hline $\mathrm{TiO}_{2}$ & 0.76 & 0.69 & 0.73 & 0.54 & 0.57 & 0.60 & 0.68 & 0.76 \\
\hline $\mathrm{MnO}^{*}$ & 0.12 & 0.18 & 0.03 & 0.16 & 0.13 & 0.18 & 0.02 & 0.16 \\
\hline $\mathrm{Fe}_{2} \mathrm{O}_{3}$ & 5.52 & 6.28 & 4.32 & 5.23 & 5.23 & 6.71 & 5.15 & 5.50 \\
\hline $\mathrm{Ce}_{2} \mathrm{O}_{3}$ & $\mathrm{~N} /$ & $\mathrm{N} /$ & 14.72 & 14.7 & $\mathrm{~N} /$ & 0.69 & $\mathrm{~N} /$ & $\mathrm{N} /$ \\
\hline $\mathrm{HfO}_{2}$ & $\mathrm{~N} /$ & $\mathrm{N} /$ & $\mathrm{N} /$ & $\mathrm{N} /$ & 7.02 & 6.71 & $\mathrm{~N} /$ & $\mathrm{N} /$ \\
\hline $\mathrm{U}_{3} \mathrm{O}_{8}$ & $\mathrm{~N} /$ & $\mathrm{N} /$ & $\mathrm{N} /$ & $\mathrm{N} /$ & $\mathrm{N} /$ & N/_ & 4.06 & 5.80 \\
\hline $\mathrm{B}_{2} \mathrm{O}_{3}$ & $\mathrm{~N} /$ & 24.6 & $\mathrm{~N} /$ & 20.4 & $\mathrm{~N} /$ & 21.6 & $\mathrm{~N} /$ & 21.30 \\
\hline Total & 78.52 & 99.26 & 83.55 & 99.83 & 80.73 & 99.76 & 73.55 & 96.66 \\
\hline
\end{tabular}




\section{Plutonium Glasses for Immobilization}

Table 2. Boron-basalt composition with $\mathrm{PuO}_{2}$.

\begin{tabular}{|c|c|c|c|c|c|}
\hline$\#$ & Code & Weight, g. & $\mathrm{Pu}, \mathrm{mg}$ & $\mathrm{PuO}_{2}, \mathrm{mg}$ & $\%$ \\
\hline \multicolumn{2}{|c|}{ Calculation } & & & & 5,07 \\
\hline 1 & -3 & 1,4280 & 99,4 & 112,8 & 7,9 \\
\hline 2 & $-3-2$ & 2,1948 & 97,5 & 110,6 & 5,0 \\
\hline 3 & $=-3-1$ & 1,6178 & 66,8 & 75,8 & 4,7 \\
\hline 4 & -3 & 1,5088 & 64,5 & 73,1 & 4,8 \\
\hline 5 & -2 & 1,5194 & 74,6 & 84,6 & 5,6 \\
\hline 6 & -2 & 1,4929 & 54,6 & 61,9 & 4,1 \\
\hline 7 & -2 & 1,3729 & 54,6 & 61,9 & 4,5 \\
\hline 8 & -1 & 1,4741 & 73,1 & 82,8 & 5,6 \\
\hline 9 & -1 & 1,6574 & 76,2 & 86,4 & 5,2 \\
\hline 10 & -1 & 1,3341 & 58,5 & 66,3 & 5,0 \\
\hline \multicolumn{2}{|c|}{ Bottom } & \multirow{3}{*}{$\Sigma$} & \multirow[t]{3}{*}{ 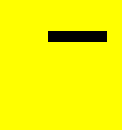 } & & 6,37 \\
\hline \multirow{2}{*}{\multicolumn{2}{|c|}{ Middle }} & & & & 4,74 \\
\hline & Upper & & & & 4,75 \\
\hline
\end{tabular}

a - Bottom of the glass batch

$\mathrm{b}$ - Middle of the glass batch

c - Upper of the glass batch

Comparative investigations of the compositions synthesized in the CCIM-Pu installation have been carried out [BZ-Na-Ce $\left.\left(15 \% \mathrm{CeO}_{2}\right)\right]$, [BZ-Na-U $\left.\left(10 \% \mathrm{U}_{3} \mathrm{O}_{8}\right)\right]$. Table 3 contains the results of chemical and SEM analyses of the simulated boron-basalt composition.

Table 3. Results of chemical and SEM analyses of simulated boron-basalt composition.

\begin{tabular}{|l|l|l|}
\hline Oxides & Chem & SEM \\
\hline $\mathrm{Fe}_{2} \mathrm{O}_{3}$ & 3.91 & 2.78 \\
\hline $\mathrm{TiO}_{2}$ & 0.67 & 0.61 \\
\hline $\mathrm{CaO}$ & 9.33 & 11.31 \\
\hline $\mathrm{SiO}{ }_{2}$ & 29.50 & 34.40 \\
\hline $\mathrm{K}_{2} \mathrm{O}$ & 0.55 & 0.59 \\
\hline $\mathrm{Na}_{2} \mathrm{O}$ & 4.94 & 2.78 \\
\hline $\mathrm{Al}_{2} \mathrm{O}_{3}$ & 11.80 & 15.97 \\
\hline $\mathrm{MgO} \mathrm{O}$ & 2.44 & 2.29 \\
\hline $\mathrm{Ce}_{2} \mathrm{O}_{3}$ & - & - \\
\hline $\mathrm{CeO}_{2}$ & 17.60 & - \\
\hline $\mathrm{UO}_{2}$ & - & 8.24 \\
\hline $\left.\mathrm{B}_{2} \mathrm{O}_{3}{ }^{*}\right)$ & 18.90 & 21.96 \\
\hline $\mathrm{Total}^{*}$ & 99.64 & 100.93 \\
\hline
\end{tabular}

In the CCIM-Pu installation, mineral-type matrices based on pyroxenes and andradites with cerium (15 wt\%), uranium (10 wt\%) and plutonium (5 wt\%) have been also synthesized as follows:

Pyroxenes, wt\% $\mathrm{SiO}_{2}(42) ; \mathrm{MgO}$ (16); $\mathrm{Al}_{2} \mathrm{O}_{3}$ (8); $\mathrm{CaO}$ (14); $\mathrm{Fe}_{2} \mathrm{O}_{3}$ (12); $\mathrm{Na}_{2} \mathrm{O}$ (8).

Andradites, wt\% $\mathrm{SiO}_{2}$ (38); $\mathrm{MgO}$ (8); $\mathrm{Al}_{2} \mathrm{O}_{3}$ (12); $\mathrm{CaO}$ (11); $\mathrm{Fe}_{2} \mathrm{O}_{3}$ (26); $\mathrm{NiO}$ (1); $\mathrm{Cr}_{2} \mathrm{O}_{3}$ (2); $\mathrm{MnO}_{2}(2)$. 


\section{Research and Development Plutonium Immobilization Contract Activities}

\section{Conclusions}

At present, work is going on to study the synthesized compositions using different characterization methods.

On the basis of the results to date, one can make the following conclusions:

- The studied boron-basalt compositions are capable of dissolving considerable amounts of wastes, including at least $15 \%$ of cerium oxide and $10 \%$ of hafnium and uranium oxides.

- In the bottom part of the samples synthesized in the crucibles that contain hafnium and uranium, crystal phases of elements have been identified. Their formation is related to decreasing solubility of the melt due to the increased content of aluminum oxide. This is caused by enrichment of the melt by aluminum oxide as a result of dissolving an alundrum crucible, leading to polymerization of the structure and decreasing the solubility of $\mathrm{Hf}^{4+}$ and $\mathrm{U}^{4+}$.

- Materials synthesized in the CCIM have more equal distribution of elements in the bulk of the batches versus the materials synthesized in the crucibles.

- The level of incorporation of the elements into the compositions synthesized in CCIM is higher than the analogous values obtained during the synthesis of the materials by the usual method.

- The results obtained show the possibility of fabricating materials (including the hard-to-dissolve residues, hydrate-sludge slurry, and aqueous-tailing solutions) in the CCIM. For the first two types of wastes, pyroxens have been proposed. In the case of the aqueous-tailing solutions, this would be garnet. Preliminary studies of the structure of the fabricated materials have shown its resemblance to the proposed minerals.

- Work is proceeding toward the synthesis of matrices with real components of the wastes and the study of their physico-chemical properties. 
(9)

VNIINM

Summary of the Agreement 501119

\section{Development of Glass Compositions Required for Immobilization of Plutonium Wastes at "Majak"}




\section{Selection of matrix compositions for study}

During the development of the matrix compositions needed to immobilize hard-to-dissolve residues approaches have been selected as follows:

- A maximal rate of incorporation of alpha-radioactive waste into the matrix on the account of joint immobilization of all types of the Pucontaining waste - hard-to-dissolve residues, hydrate-sludge slurry and aqueous-tailing solutions with the purpose of using its components to synthesize the matrix

- Transfer of the hard-to-dissolve residues to be immobilized of into high-radioactive materials by means of its joint immobilization with the evaporated aqueous-tailing waste that will complicate the possibility of recovering $\mathrm{Pu}$ from the waste for reuse 


\section{Installation CCIM-Pu}

Crucible d $=50 \mathrm{~mm}, \mathrm{~h}=100 \mathrm{~mm}$, Frequency $=21 \mathrm{MHz}$

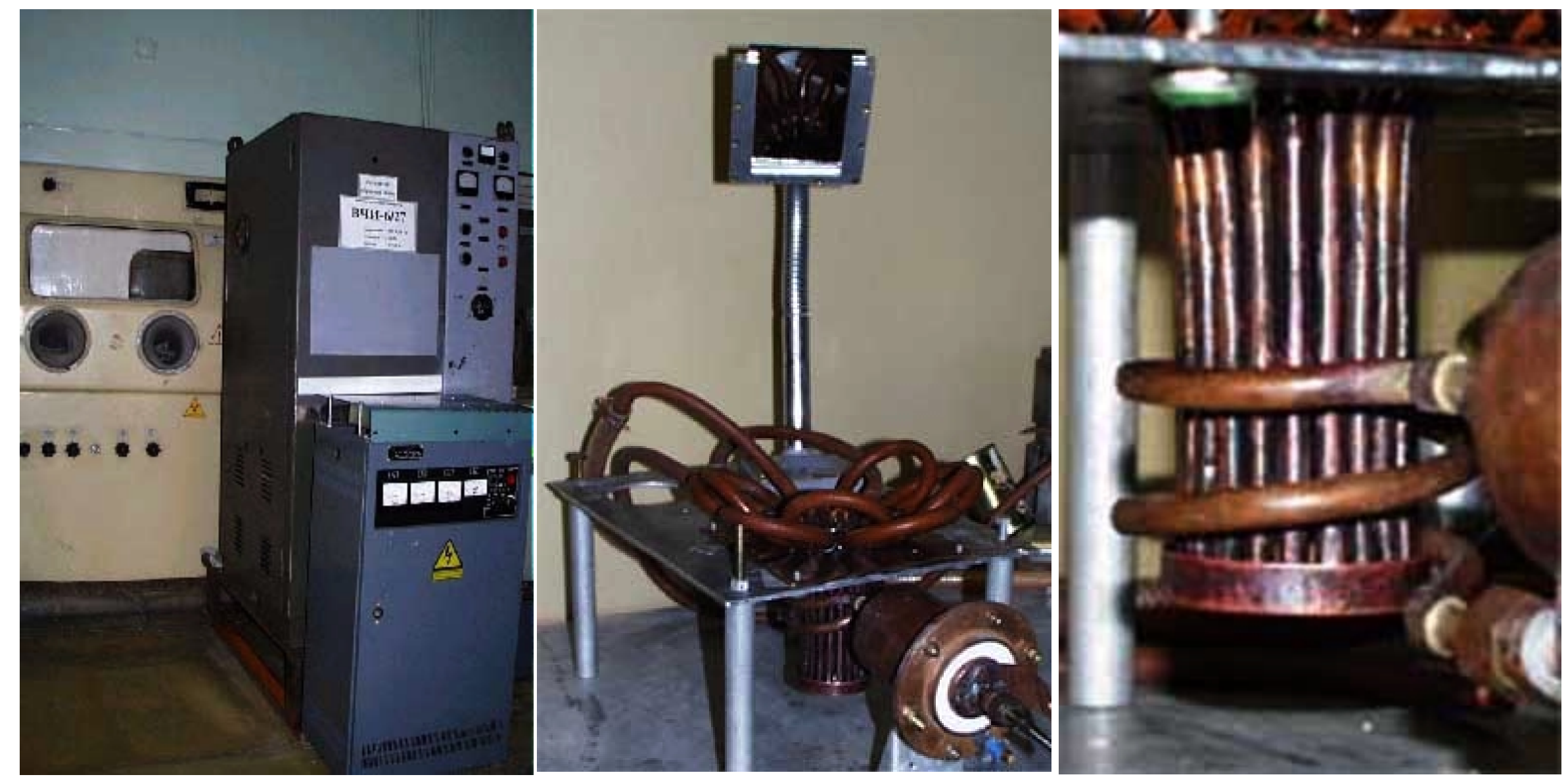

Overall view of the installation «CCIM-Pu» 


\section{Synthesis of boronbasalt compositions (MF)}

- Synthesis of calcium tetraborate $-\mathrm{CaO} \times 2 \mathrm{~B}_{2} \mathrm{O}_{3}$ [melting at $1200^{\circ} \mathrm{C}$ of calcium oxide $(\mathrm{CaO})$ and boric acid $\left.\left(\mathrm{H}_{3} \mathrm{BO}_{4}\right)\right]$.

- Additions of a flux of calcium borate permits to reduce the melting temperature and viscosity of a melt on the account of changing its composition and structure.

- The boronbasalt composition has been synthesized from the mixture of dispersed powders of natural basalt and calcium tetraborate in ratio of 40:60 by its melting at $1200^{\circ} \mathrm{C}$ in alundum crucibles in air. 


\section{Synthesis of boronbasalt compositions (MF)}

Boronbasalt compositions with components simulating the waste.

Synthesis of the glass-type compositions

- With cerium* [BZ-Ce-15 (15\% CeO2)],

- With hafnium* [BZ-Hf-10 (10\% HfO2)],

- With uranium [BZ-U-10 (10\% U3O8)]

- With plutonium [BZ-Pu-5 (5\% PuO2)]

by weight of $100 \mathrm{~g}$ was carried out in alundum crucibles by melting of a boronbasalt glassfrit with oxides of respective nuclides $\left(1250-1300^{\circ} \mathrm{C}, 3\right.$ hours).

*Enforced mixing in the process of the synthesis. 


\section{Study of boronbasalt compositions (MF)}

Boronbasalt compositions with components simulating the waste.

Compositions of the synthesized glasses

\begin{tabular}{|c|c|c|c|c|c|c|c|c|}
\hline \multirow{2}{*}{$\begin{array}{l}\text { Oxide, } \\
\text { wt.\% }\end{array}$} & \multicolumn{2}{|c|}{ BZ } & \multicolumn{2}{|c|}{ BZ-Ce-15 } & \multicolumn{2}{|c|}{ BZ-Hf-10 } & \multicolumn{2}{|c|}{ BZ-U-10 } \\
\hline & SEM & chem. & SEM & chem. & SEM & chem. & SEM & chem. \\
\hline $\mathrm{Na}_{2} \mathrm{O}$ & 2.42 & 1.87 & 1.92 & 1.53 & 1.95 & 1.66 & 1.79 & 2.00 \\
\hline $\mathrm{MgO}$ & 2.70 & 2.66 & 1.95 & 2.23 & 2.45 & 2.44 & 2.33 & 2.50 \\
\hline $\mathbf{A l}_{2} \mathbf{O}_{3}$ & 12.52 & 11.4 & 17.51 & 13.8 & 11.17 & 12.5 & 11.42 & 15.40 \\
\hline $\mathrm{SiO}_{2}$ & 37.26 & 34.2 & 28.67 & 27.3 & 36.10 & 31.3 & 33.11 & 29.50 \\
\hline $\mathbf{P}_{2} \mathbf{O}_{5}{ }^{*}$ & 0.10 & $\mathrm{~N} /$ & 0.21 & $\mathrm{~N} /$ & 0.26 & $\mathrm{~N} /$ & 0.07 & $\mathbf{N} /$ \\
\hline $\mathrm{K}_{2} \mathrm{O}$ & 0.58 & 0.58 & 0.59 & 0.54 & 0.66 & 0.57 & 0.56 & 0.64 \\
\hline $\mathrm{CaO}$ & 16.54 & 16.8 & 12.90 & 13.4 & 15.19 & 14.8 & 14.36 & 13.10 \\
\hline $\mathrm{TiO}_{2}$ & 0.76 & 0.69 & 0.73 & 0.54 & 0.57 & 0.60 & 0.68 & 0.76 \\
\hline $\mathrm{MnO}^{*}$ & 0.12 & 0.18 & 0.03 & 0.16 & 0.13 & 0.18 & 0.02 & 0.16 \\
\hline $\mathrm{Fe}_{2} \mathrm{O}_{3}$ & 5.52 & 6.28 & 4.32 & 5.23 & 5.23 & 6.71 & 5.15 & 5.50 \\
\hline $\mathrm{Ce}_{2} \mathrm{O}_{3}$ & N/ & N/ & 14.72 & 14.7 & N/ & 0.69 & N/ & N/ \\
\hline $\mathrm{HfO}_{2}$ & N/ & $\mathrm{N} /$ & N/ & N/ & 7.02 & 6.71 & N/ & N/ \\
\hline $\mathbf{U}_{3} \mathbf{O}_{8}$ & N/ & N/ & N/ & N/ & N/ & N/ & 4.06 & 5.80 \\
\hline $\mathbf{B}_{2} \mathbf{O}_{3}$ & N/ & 24.6 & N/ & 20.4 & N/ & 21.6 & N/ & 21.30 \\
\hline Total & 78.52 & 99.26 & 83.55 & 99.83 & 80.73 & 99.76 & 73.55 & 96.66 \\
\hline
\end{tabular}




\section{Study of boronbasalt compositions (MF)}

Boronbasalt compositions with components simulating the waste.

\begin{tabular}{|c|c|c|c|c|c|}
\hline \multirow{2}{*}{$\begin{array}{l}\text { Oxide, } \\
\text { Wt.\% }\end{array}$} & \multicolumn{5}{|c|}{ BZ-Ce-15 } \\
\hline & 1 & 2 & 3 & 4 & $=$ \\
\hline $\mathrm{Na}_{2} \mathrm{O}$ & 1.91 & 1.87 & 1.63 & 2.26 & 1.92 \\
\hline MgO & 1.85 & 1.91 & 2.19 & 1.85 & 1.95 \\
\hline $\mathrm{Al}_{2} \mathrm{O}_{3}$ & 17.85 & 17.54 & 17.00 & 17.66 & 17.51 \\
\hline $\mathrm{SiO}_{2}$ & 29.32 & 29.05 & 27.39 & 28.93 & 28.67 \\
\hline $\mathbf{P}_{2} \mathbf{O}_{5}{ }^{*}$ & 0.18 & 0.12 & 0.37 & 0.18 & 0.21 \\
\hline $\mathrm{K}_{2} \mathrm{O}$ & $\mathbf{0 . 5 3}$ & 0.70 & 0.55 & 0.58 & 0.59 \\
\hline $\mathrm{CaO}$ & 12.81 & 13.00 & 12.99 & 12.82 & 12.90 \\
\hline $\mathrm{TiO}_{2}$ & 0.58 & 0.86 & 0.79 & 0.70 & 0.73 \\
\hline $\mathrm{MnO}^{*}$ & 0.09 & 0.00 & 0.03 & 0.01 & 0.03 \\
\hline $\mathrm{Fe}_{2} \mathrm{O}_{3}$ & 4.04 & 4.38 & 4.63 & 4.21 & 4.32 \\
\hline $\mathrm{Ce}_{2} \mathrm{O}_{3}$ & 14.04 & 14.83 & 13.90 & 15.68 & 14.72 \\
\hline Total & 83.60 & 84.27 & 81.48 & 84.90 & 83.55 \\
\hline
\end{tabular}

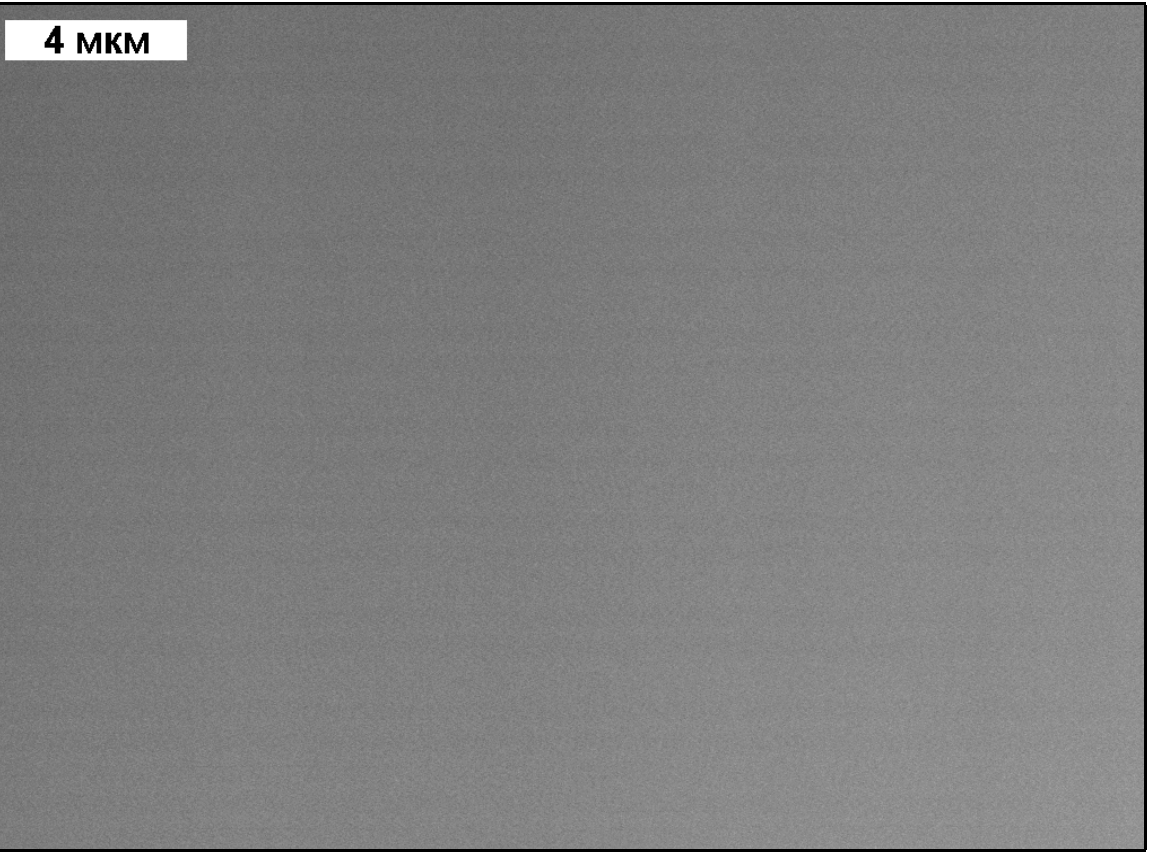




\section{Study of boronbasalt compositions (MF)}

Boronbasalt compositions with components simulating the waste.

\begin{tabular}{|c|c|c|c|c|c|}
\hline \multirow{2}{*}{$\begin{array}{l}\text { Oxide, } \\
\text { Wt.\% }\end{array}$} & \multicolumn{5}{|c|}{ BZ-Hf-10 } \\
\hline & 1 & 2 & 3 & 4 & . \\
\hline $\mathrm{Na}_{2} \mathrm{O}$ & 1.74 & 1.91 & 1.93 & 2.21 & 1.95 \\
\hline MgO & 2.26 & 2.24 & 2.70 & 2.59 & 2.45 \\
\hline $\mathrm{Al}_{2} \mathrm{O}_{3}$ & 10.93 & 10.79 & 11.37 & 11.58 & 11.17 \\
\hline $\mathrm{SiO}_{2}$ & 35.61 & $\mathbf{3 7 . 5 0}$ & 35.26 & 36.01 & 36.10 \\
\hline $\mathbf{P}_{2} \mathbf{O}_{5}^{*}$ & 0.00 & 0.29 & 0.15 & 0.58 & 0.26 \\
\hline $\mathrm{K}_{2} \mathrm{O}$ & 0.59 & 066 & 0.60 & 0.82 & 0.66 \\
\hline $\mathrm{CaO}$ & 14.81 & 14.94 & 15.57 & 15.43 & 15.19 \\
\hline $\mathrm{TiO}_{2}$ & 0.73 & 0.25 & 0.69 & 0.62 & 0.57 \\
\hline $\mathrm{MnO}^{*}$ & 0.35 & 0.02 & 0.01 & 0.17 & 0.13 \\
\hline $\mathrm{Fe}_{2} \mathrm{O}_{3}$ & 4.91 & 5.22 & 5.37 & 5.41 & 5.23 \\
\hline $\mathrm{HfO}_{2}$ & 7.67 & 7.56 & 6.30 & 6.57 & 7.02 \\
\hline Total & 79.61 & 81.38 & 79.94 & 81.99 & 80.73 \\
\hline
\end{tabular}
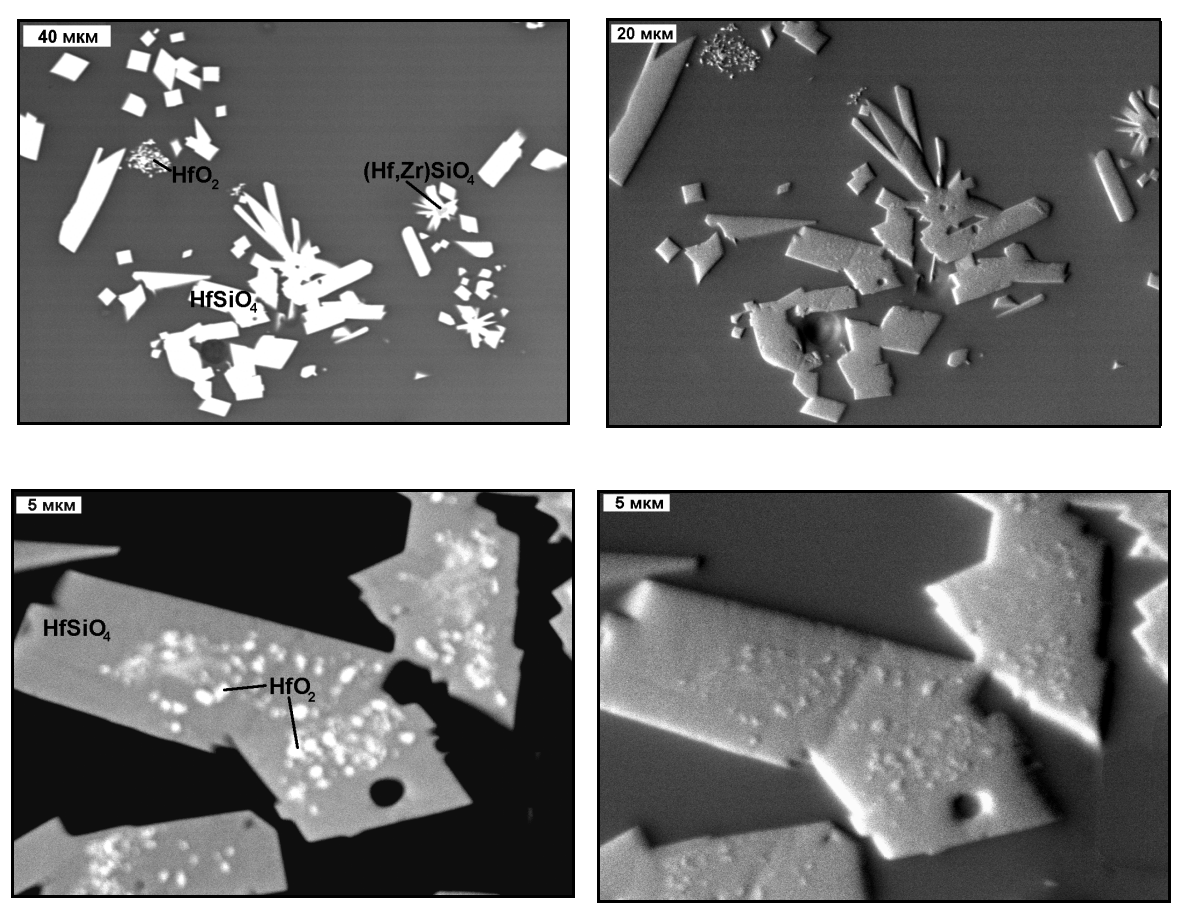


\section{Study of boronbasalt compositions (MF)}

Boronbasalt compositions with components simulating the waste

\begin{tabular}{|c|c|c|c|c|c|}
\hline \multicolumn{2}{|l|}{ Oxide } & \multicolumn{3}{|c|}{ BZ-U-10 } & \\
\hline Wt.\% & 1 & 2 & 3 & 4 & . \\
\hline $\mathrm{Na}_{2} \mathrm{O}$ & 1.88 & 2.00 & 1.58 & 1.69 & 1.79 \\
\hline MgO & 2.29 & 2.55 & 2.21 & 2.28 & 2.33 \\
\hline $\mathrm{Al}_{2} \mathrm{O}_{3}$ & 11.32 & 10.67 & 11.45 & 12.23 & 11.42 \\
\hline $\mathrm{SiO}_{2}$ & 33.70 & 33.21 & 31.74 & 33.90 & 33.11 \\
\hline $\mathbf{P}_{2} \mathbf{O}_{5}{ }^{*}$ & 0.16 & 0.00 & 0.00 & 0.12 & 0.07 \\
\hline $\mathrm{K}_{2} \mathrm{O}$ & 0.62 & 0.68 & 0.52 & 0.43 & 0.56 \\
\hline $\mathrm{CaO}$ & 14.29 & 14.19 & 13.99 & 14.97 & 14.36 \\
\hline $\mathrm{TiO}_{2}$ & 0.55 & 0.79 & 0.67 & 0.70 & 0.68 \\
\hline $\mathrm{MnO}^{*}$ & $\mathbf{0 . 0 0}$ & 0.05 & 0.02 & 0.00 & 0.02 \\
\hline $\mathrm{Fe}_{2} \mathrm{O}_{3}$ & 5.12 & 5.00 & 5.21 & 5.25 & 5.15 \\
\hline $\mathrm{UO}_{2}$ & 4.14 & 3.63 & 4.26 & 4.21 & 4.06 \\
\hline Total & 74.07 & 72.66 & 71.67 & 75.80 & 73.55 \\
\hline
\end{tabular}
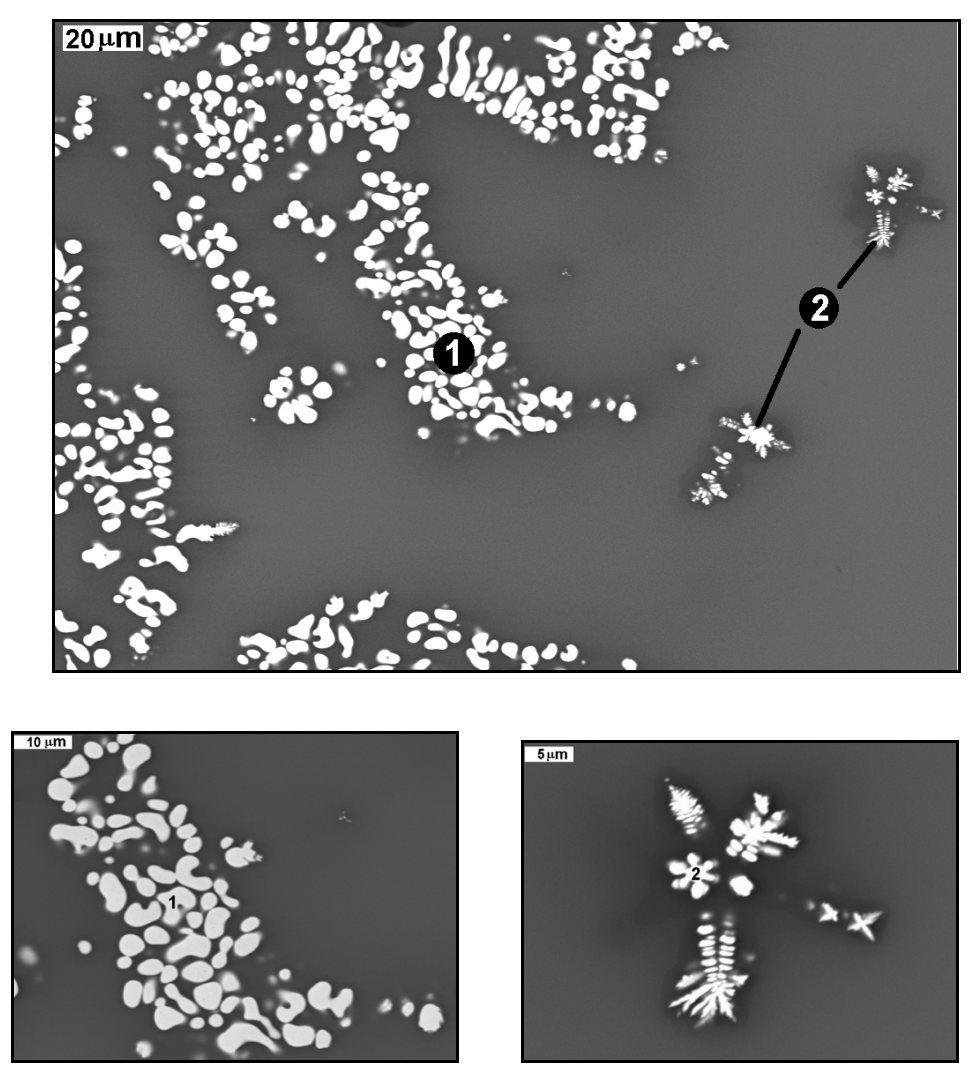


\section{Study of boron-basalt compositions (MF)}

Boronbasalt compositions with components simulating the waste.

(BZ-U-10)

\begin{tabular}{|c|c|c|c|c|c|c|c|c|c|}
\hline Oxide & $1^{*}$ & $2^{*}$ & $3^{*}$ & $4^{*}$ & $5^{*}$ & $6^{*}$ & $7^{*}$ & Bottom** & Upper ${ }^{* \star}$ \\
\hline $\mathrm{Na}_{2} \mathrm{O}$ & 1.58 & 1.98 & 2.35 & 2.15 & 2.01 & 1.76 & 1.79 & 2.01 & 2.00 \\
\hline $\mathrm{MgO}$ & 2.48 & 2.36 & 2.03 & 2.52 & 2.45 & 2.30 & 2.33 & 2.50 & 2.50 \\
\hline $\mathrm{Al}_{2} \mathrm{O}_{3}$ & 17.32 & 15.50 & 15.46 & 15.90 & 12.25 & 11.65 & 11.42 & 14.40 & 15.40 \\
\hline $\mathrm{SiO}_{2}$ & 25.40 & 30.55 & 32.11 & 29.13 & 32.78 & 32.52 & 33.11 & 29.90 & 29.50 \\
\hline $\mathrm{P}_{2} \mathrm{O}_{5}$ & 0.03 & 0.37 & 0.32 & 0.14 & 0.00 & 0.18 & 0.07 & 1 & 1 \\
\hline $\mathrm{K}_{2} \mathrm{O}$ & 0.46 & 0.66 & 0.75 & 0.60 & 0.69 & 0.58 & 0.56 & 0.68 & 0.64 \\
\hline $\mathrm{CaO}$ & 12.95 & 14.27 & 14.23 & 14.46 & 13.81 & 14.65 & 14.36 & 13.10 & 13.10 \\
\hline $\mathrm{TiO}_{2}$ & 0.99 & 0.74 & 0.77 & 0.51 & 0.72 & 0.61 & 0.68 & 0.78 & 0.76 \\
\hline $\mathrm{MnO}$ & 0.00 & 0.00 & 0.00 & 1.09 & 0.00 & 0.10 & 0.02 & 0.15 & 0.16 \\
\hline $\mathrm{Fe}_{2} \mathrm{O}_{3}$ & 4.02 & 4.56 & 4.76 & 4.27 & 5.19 & 5.25 & 5.15 & 5.50 & 5.50 \\
\hline $\mathrm{UO}_{2}$ & 9.57 & 7.07 & 6.26 & 5.81 & 5.47 & 4.27 & 4.06 & 8.00 & 5.80 \\
\hline $\mathrm{B}_{2} \mathrm{O}_{3}$ & 1 & 1 & 1 & 1 & 1 & 1 & 1 & 22.20 & 21.30 \\
\hline Total & 74.81 & 78.07 & 79.03 & 75.59 & 75.37 & 73.85 & 73.55 & 99.31 & 96.66 \\
\hline
\end{tabular}

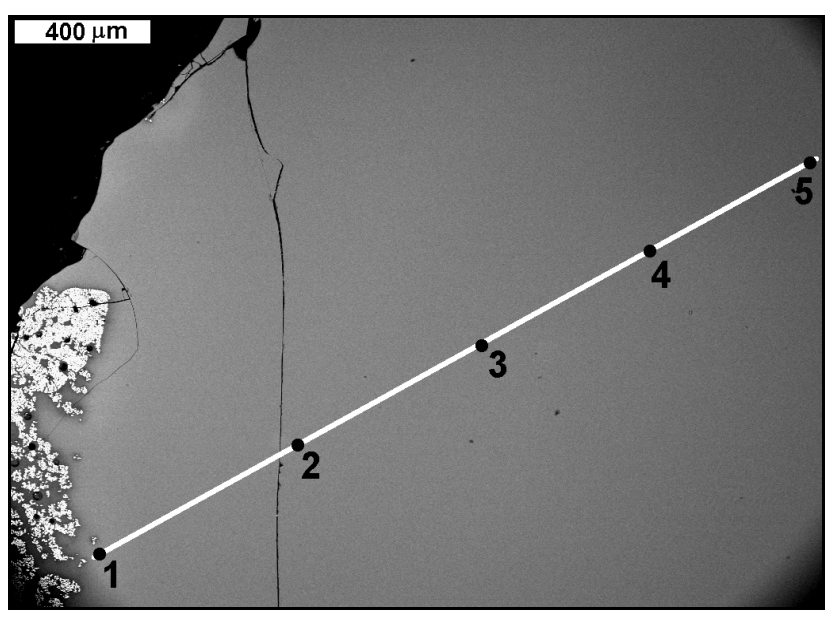

* - SEM/EDS,

** - chemical analysis 


\section{Study of boron-basalt compositions (MF)}

Boron-basalt compositions with components simulating the waste.

(BZ-Pu-5)

\begin{tabular}{|c|c|c|c|c|c|}
\hline & Code & Weight, $\mathrm{g}$. & $\mathrm{Pu}, \mathrm{mg}$ & $\mathrm{PuO}_{2}, \mathrm{mg}$ & $\%$ \\
\hline \multicolumn{2}{|c|}{ Calculation } & \multicolumn{4}{|r|}{5,07} \\
\hline 1 & -3 & 1,4280 & 99,4 & 112,8 & 7,9 \\
\hline 2 & $-3-2$ & 2,1948 & 97,5 & 110,6 & 5,0 \\
\hline 3 & $-3-1$ & 1,6178 & 66,8 & 75,8 & 4,7 \\
\hline 4 & -3 & 1,5088 & 64,5 & 73,1 & 4,8 \\
\hline 5 & -2 & 1,5194 & 74,6 & 84,6 & 5,6 \\
\hline 6 & -2 & 1,4929 & 54,6 & 61,9 & 4,1 \\
\hline 7 & -2 & 1,3729 & 54,6 & 61,9 & 4,5 \\
\hline 8 & -1 & 1,4741 & 73,1 & 82,8 & 5,6 \\
\hline 9 & -1 & 1,6574 & 76,2 & 86,4 & 5,2 \\
\hline 10 & -1 & 1,3341 & 58,5 & 66,3 & 5,0 \\
\hline \multicolumn{2}{|c|}{ Bottom } & \multirow{3}{*}{\multicolumn{3}{|c|}{$\Sigma$}} & 6,37 \\
\hline \multicolumn{2}{|c|}{ Middle } & & & & 4,74 \\
\hline \multicolumn{2}{|c|}{ Upper } & & & & 4,75 \\
\hline
\end{tabular}

- - Bottom of the glass batch

_ - Middle of the glass batch

_- Upper of the glass batch
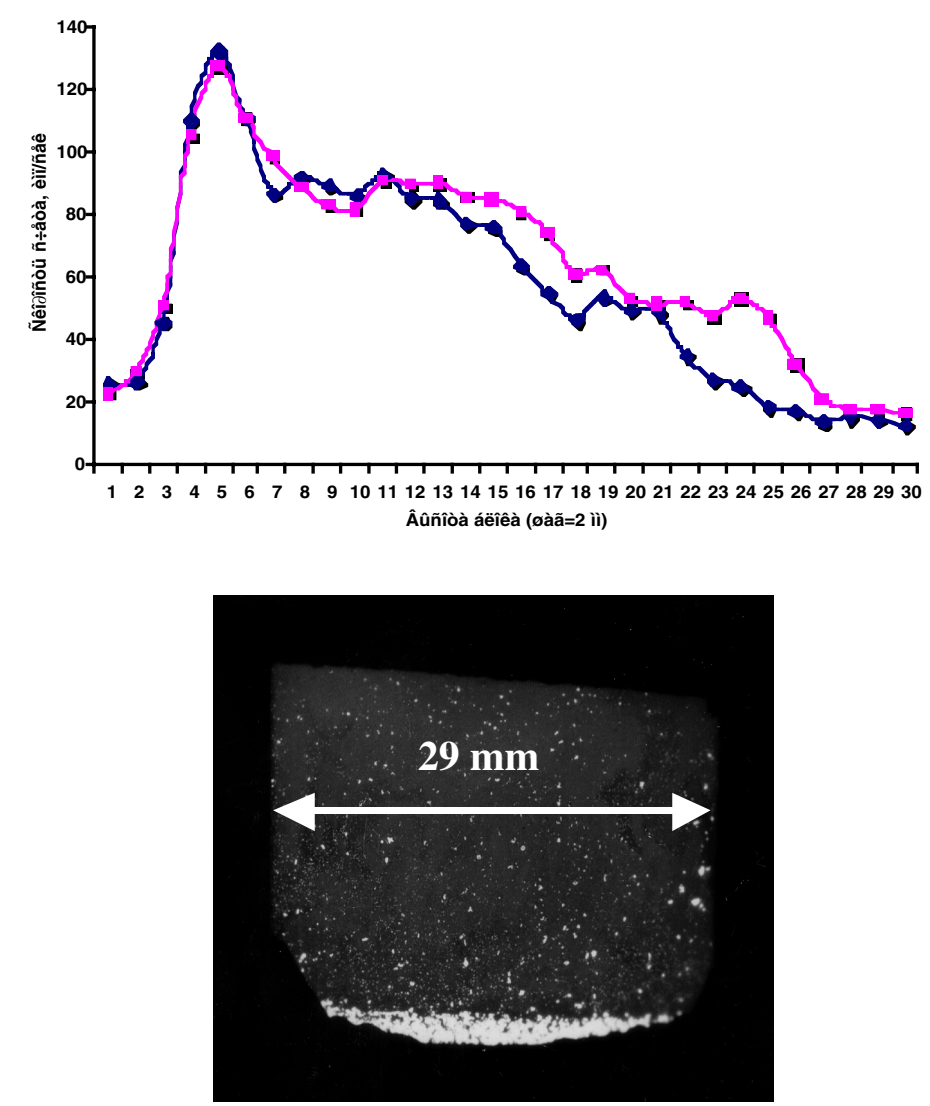


\section{Study of boron-basalt compositions (MF)}

Matrix composition BZ

The conducted tests to remelt the composition BZ at the installation CCIM-Pu have shown that there are some difficulties related to obtaining of the basin of the melt and stable melting of the material at the given temperature, which connected to low electrical conductivity of the melt at $1200-1300^{\circ} \mathrm{C}$.

An increase of the temperature of the melt provides the growth of its electrical conductivity, however considerably increases the volatility of the components of the matrix (Boron) and respectively results in changing the composition of the matrix and the melt

Therefore, a decision has been made to correct the composition of the matrix BZ-0 with the purpose of increasing electrical conductivity of the melt. Sodium has been selected as a component, which increases electrical conductivity of the melt. 


\section{Synthesis of boron-basalt compositions (CCIM)}

\section{Matrix composition Bz-Na}

Melting of an oxide-salt mixture to synthesize the glassfrit BZ-Na was made in alundum crucibles in a muffle furnace (synthesis temperature of the glass $-1200-1250^{\circ} \mathrm{C}$, duration of keeping the melt - 2-3 hours). Upon the end of melting the melt was poured out into a metallic tray and crashed after cooling.

\begin{tabular}{|l|l|}
\hline \multicolumn{2}{|l|}{ Calculated composition } \\
\hline Oxide & $\%$ wt \\
\hline $\mathrm{Na}_{2} \mathrm{O}$ & 6.0 \\
\hline $\mathrm{MgO}$ & 3.0 \\
\hline $\mathrm{Al}_{2} \mathrm{O}_{3}$ & 10.0 \\
\hline $\mathrm{SiO}_{2}$ & 35.0 \\
\hline $\mathrm{K}_{2} \mathrm{O}$ & 1.0 \\
\hline $\mathrm{CaO}$ & 15.0 \\
\hline $\mathrm{TiO}_{2}$ & 1.0 \\
\hline $\mathrm{Fe}_{2} \mathrm{O}_{3}$ & 6.0 \\
\hline $\mathrm{B}_{2} \mathrm{O}_{3}$ & 23.0 \\
\hline
\end{tabular}




\section{Synthesis of boronbasalt compositions (CCIM)}

\section{Matrix composition Bz-Na}

Remelting of the synthesized glassfrit BZ-Na was performed at the installation -Pu with a crucible at a diameter of $50 \mathrm{~mm}$. Preliminary loading of the glass frit to melt the basin of the melt was 100-150 g. Start-up heating and melting of the glass frit was carried out by silite heaters $(\mathrm{SiC})$ put into the crucible with the glass frit.

After formation of the basin of the melt a start-up heater was removed and the glassfrit was dozed onto the basin (portions by 10-15 g).

Further portions of the glassfrit were dosed after complete melting of the former ones. After ending the dosing of 50-100 $\mathrm{g}$ of the glassfrit, the melt was keeping within 0.5-1.0 hours and the obtained glass was cooling together with the crucible.

After cooling up to a room temperature, the synthesized glass batch was got rid off from the crucible and subjected to sampling for eventual investigations.

The experiments conducted to remelt the composition BZ-Na at installation CCIM-Pu have shown that the process of remelting of the given composition is under more optimal conditions. This one permits carrying on the synthesis of the compositions based on BZ-Na with components simulating the waste of PA "Mayak". 


\section{Synthesis of boron-basalt compositions (CCIM)}

\section{Boronbasalt compositions with components simulating the waste.}

- Synthesis of glass-type compositions

- With Cerium [BZ-Na-Ce $\left.\left(15 \% \mathrm{CeO}_{2}\right)\right]$,

- With Uranium [BZ-Na-U $\left.\left(10 \% \mathrm{U}_{3} \mathrm{O}_{8}\right)\right]$

Synthesis of the boronbasalt compositions was made at the installation CCIM-Pu at a diameter of $50 \mathrm{~mm}$. An initial loading of the glassfrit BZ-Na to melt the basin of the melt was $150 \mathrm{~g}$. Start-up heating and melting of the glassfrit was performed by silite heaters ( $\mathrm{SiC})$, put into the crucible with the glassfrit.

After formation of the basin of the melt, the material of the start-up heater was removed from the melt After formation of the basin of the melt a start-up heater was removed and a mixture of the glassfrit BZ-Na (50 g) and an oxide of Cerium (25 g) or Uranium (12 g) was dozed onto the basin (portions by 10-15 g). After the end of dosing of the mixture, the melt was keeping within $0.5-1.0$ hour and the obtained glass was cooled together with the crucible. 


\section{Synthesis of boron-basalt compositions (CCIM)}

Matrix boronbasalt composition (Bz-Na)

\begin{tabular}{|l|l|l|l|l|l|l|l|l|l|}
\hline Oxide & Chem & $\mathbf{1}$ & $\mathbf{2}$ & $\mathbf{3}$ & $\mathbf{4}$ & $\mathbf{5}$ & $\mathbf{6}$ & $\mathbf{7}$ & Average \\
\hline $\mathrm{Fe}_{2} \mathrm{O}_{3}$ & 4.28 & 3.78 & 3.55 & 3.46 & 3.67 & 3.25 & 3.56 & 3.43 & 3.53 \\
\hline $\mathrm{CaO}$ & 11.20 & 11.30 & 11.37 & 11.42 & 11.63 & 11.26 & 11.02 & 11.77 & 11.40 \\
\hline $\mathrm{SiO}_{2}$ & 35.30 & 38.16 & 38.67 & 39.44 & 40.00 & 39.57 & 39.83 & 40.06 & 39.39 \\
\hline $\mathrm{Na}_{2} \mathrm{O}$ & 6.10 & 5.70 & 5.70 & 5.18 & 5.19 & 5.15 & 5.35 & 5.27 & 5.36 \\
\hline $\mathrm{TiO}_{2}$ & 0.85 & 0.75 & 0.92 & 0.93 & 0.92 & 0.83 & 0.83 & 0.75 & 0.85 \\
\hline $\mathrm{Al}_{2} \mathrm{O}_{3}$ & 13.60 & 12.72 & 12.85 & 12.49 & 13.59 & 13.72 & 12.94 & 13.97 & 13.18 \\
\hline $\mathrm{MgO}$ & 2.65 & 2.72 & 2.60 & 2.50 & 2.67 & 2.64 & 2.66 & 2.67 & 2.64 \\
\hline $\mathrm{K}_{2} \mathrm{O}$ & 0.73 & 0.70 & 0.66 & 0.55 & 0.52 & 0.54 & 0.53 & 0.53 & 0.57 \\
\hline $\mathrm{B}_{2} \mathrm{O}_{3}$ & 22.60 & $\left.22.60^{*}\right)$ & 22.60 & 22.60 & 22.60 & 22.60 & 22.60 & 22.60 & 22.60 \\
\hline$\Sigma$ & 97.31 & 98.43 & 98.92 & 98.57 & 100.79 & 99.56 & 99.32 & 101.05 & 99.52 \\
\hline
\end{tabular}

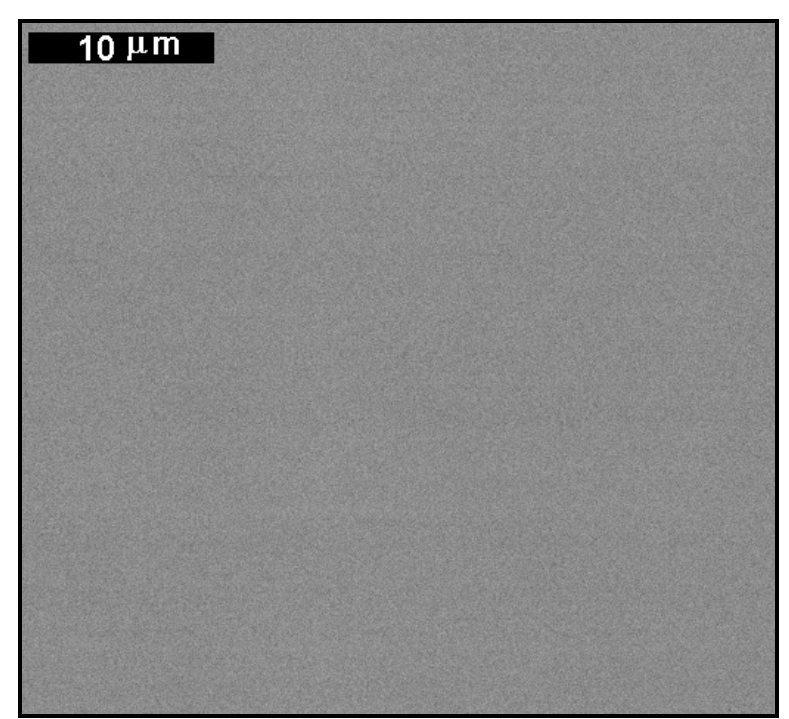




\section{Study of boron-basalt compositions (CCIM)}

\section{Boronbasalt compositions with components simulating the waste.}

\section{(Bz-Na-Ce)}

\begin{tabular}{|c|c|c|c|c|}
\hline Oxides & Chem & $\begin{array}{l}\text { Lower part } \\
\text { of batch }\end{array}$ & $\begin{array}{l}\text { Central part } \\
\text { of the batch }\end{array}$ & $\begin{array}{l}\text { Upper part } \\
\text { of the batch }\end{array}$ \\
\hline $\mathrm{Fe}_{2} \mathrm{O}_{3}$ & 3.91 & 2.88 & 3.03 & 3.07 \\
\hline $\mathrm{TiO}_{2}$ & 0.67 & 0.69 & 0.67 & 0.71 \\
\hline $\mathrm{CaO}$ & 9.33 & 9.98 & 9.89 & 9.95 \\
\hline $\mathrm{SiO}_{2}$ & 29.50 & 35.06 & 34.25 & 34.61 \\
\hline $\mathrm{K}_{2} \mathrm{O}$ & 0.55 & 0.66 & 0.55 & 0.46 \\
\hline $\mathrm{Na}_{2} \mathrm{O}$ & 4.94 & 5.07 & 4.98 & 4.41 \\
\hline $\mathrm{Al}_{2} \mathrm{O}_{3}$ & 11.80 & 11.86 & 12.00 & 12.04 \\
\hline $\mathrm{MgO}$ & 2.44 & 2.33 & 2.30 & 2.32 \\
\hline $\mathrm{Ce}_{2} \mathrm{O}_{3}$ & - & 12.63 & 15.31 & 15.94 \\
\hline $\mathrm{CeO}_{2}$ & 17.60 & F & - & - \\
\hline $\left.\mathrm{B}_{2} \mathrm{O}_{3}{ }^{*}\right)^{\prime}$ & 18.90 & 18.90 & 18.90 & 18.90 \\
\hline Total & 99.64 & 100.06 & 101.88 & 102.41 \\
\hline
\end{tabular}
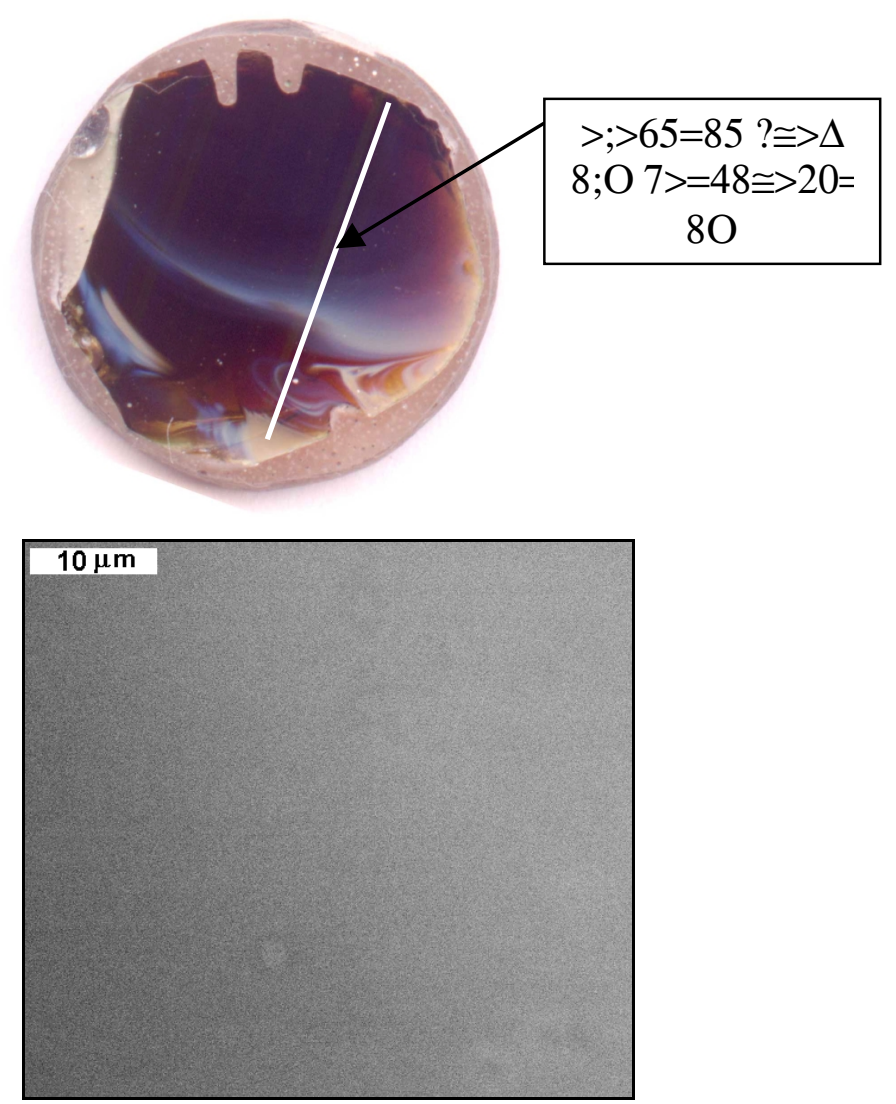


\section{Study of boron-basalt compositions (CCIM)}

Boronbasalt compositions with components simulating the waste.

(Bz-Na-Ce)

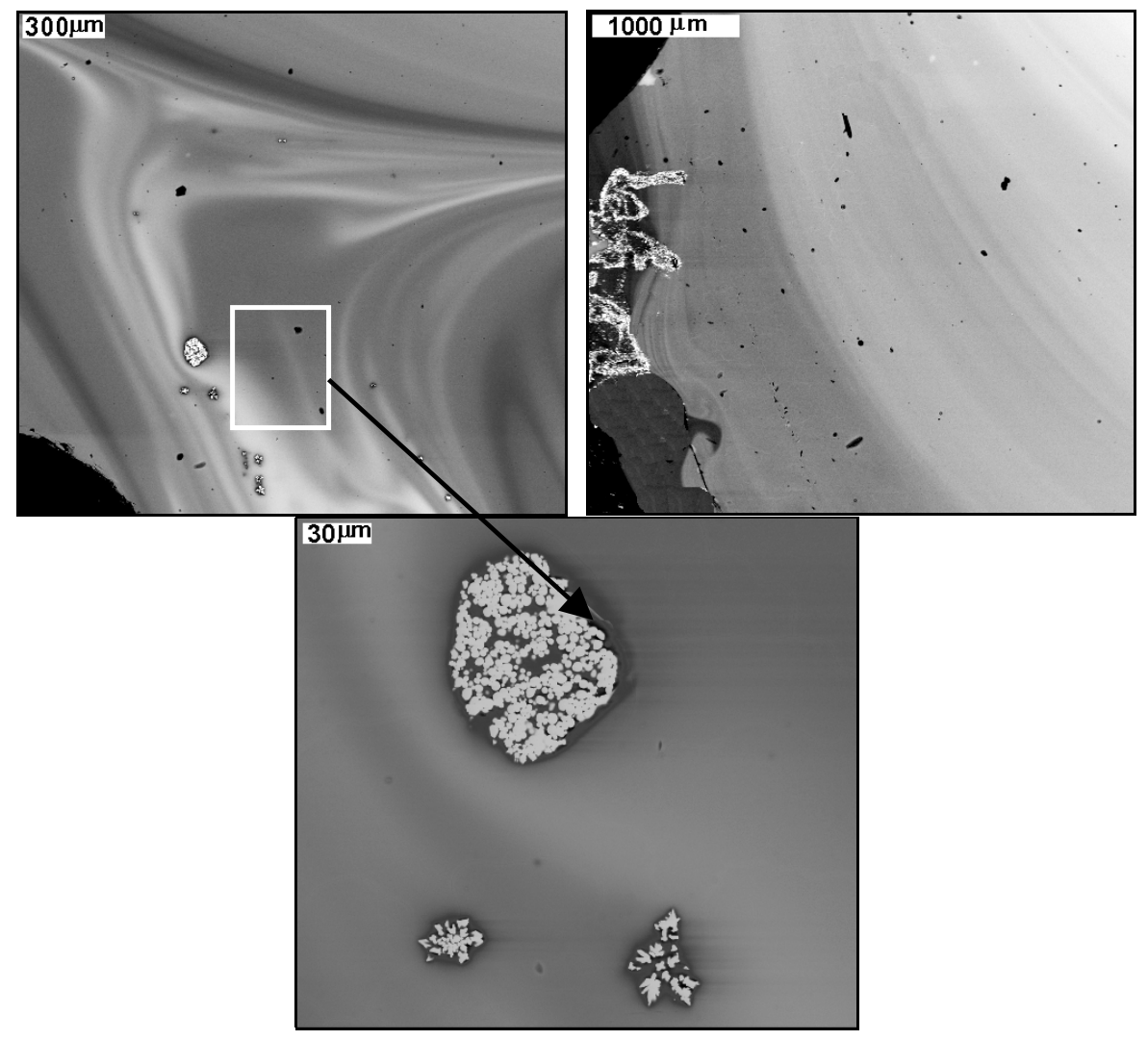




\section{Study of boron-basalt compositions (CCIM)}

\section{Boronbasalt compositions with components simulating the waste.}

\section{(Bz-Na-U)}

\begin{tabular}{|l|l|l|l|l|l|l|l|}
\hline Oxides & 1 & 2 & 3 & 4 & 5 & 6 & Average \\
\hline $\mathrm{Fe}_{2} \mathrm{O}_{3}$ & 2.82 & 2.73 & 2.90 & 2.82 & 2.78 & 2.69 & 2.78 \\
\hline $\mathrm{TiO}_{2}$ & 0.57 & 0.68 & 0.60 & 0.63 & 0.58 & 0.58 & 0.61 \\
\hline $\mathrm{CaO}$ & 11.28 & 11.16 & 11.30 & 11.36 & 11.33 & 11.42 & 11.31 \\
\hline $\mathrm{SiO}_{2}$ & 34.22 & 34.22 & 34.70 & 34.95 & 33.97 & 34.35 & 34.40 \\
\hline $\mathrm{K}_{2} \mathrm{O}$ & 0.66 & 0.57 & 0.59 & 0.58 & 0.58 & 0.58 & 0.59 \\
\hline $\mathrm{Na}_{2} \mathrm{O}$ & 2.89 & 2.58 & 2.52 & 3.00 & 2.97 & 2.71 & 2.78 \\
\hline $\mathrm{Al}_{2} \mathrm{O}_{3}$ & 16.00 & 15.95 & 15.90 & 15.37 & 16.08 & 16.54 & 15.97 \\
\hline $\mathrm{MgO}$ & 2.29 & 2.14 & 2.29 & 2.26 & 2.56 & 2.22 & 2.29 \\
\hline $\mathrm{U}_{2} 2$ & 8.21 & 8.18 & 8.06 & 8.17 & 8.43 & 8.38 & 8.24 \\
\hline $\mathrm{B}_{2} \mathrm{O}_{3}{ }^{*}{ }^{2}$ & 21.96 & 21.96 & 21.96 & 21.96 & 21.96 & 21.96 & 21.96 \\
\hline Total & 100.90 & 100.17 & 100.82 & 101.10 & 101.24 & 101.43 & 100.93 \\
\hline
\end{tabular}

$\left.\mathrm{B}_{2} \mathrm{O}_{3}{ }^{*}\right)$ - included upon the data of the chemical analysis.

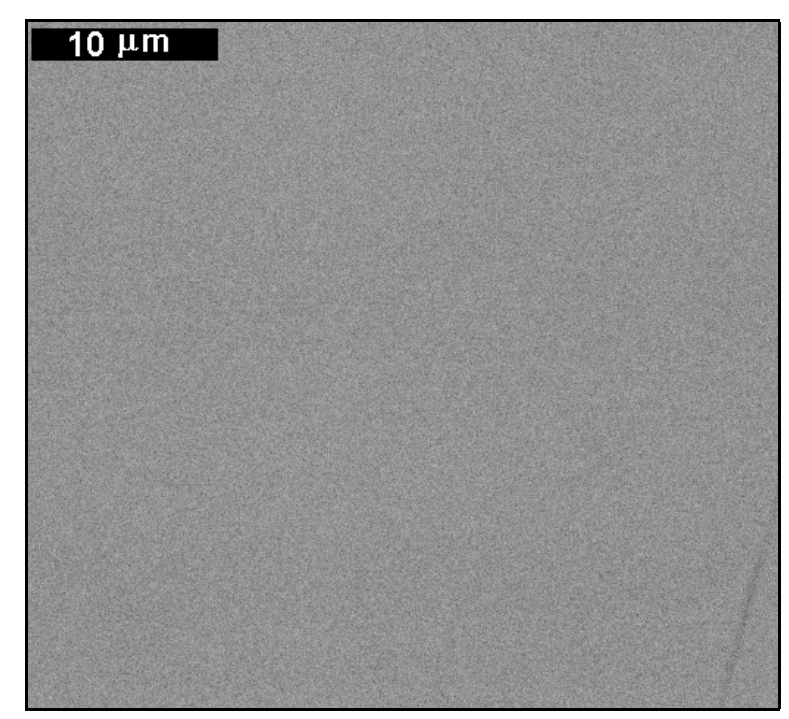




\section{Synthesis of mineral-type compositions}

\section{Synthesis of matrix pyroxen (GED) and andradite $(\cup$ compositions and Cerium-containing compositions GED-Ce and A-Ce}

Experiments to synthesize mineral-type compositions GED, A GED-Ce and A-Ce were carried out at the installation CCIM-Pu in a water-cooled crucible with an internal diameter of $50 \mathrm{~mm}$. Silica carbide (SiC) was used as a material of start-up heating. Formation of the basin of the melt in CCIM was made using the glassfrit of oxide-salt mixtures.

\begin{tabular}{|c|c|c|c|c|c|c|c|c|c|c|}
\hline \multirow{2}{*}{$\begin{array}{l}\text { Type of the } \\
\text { material }\end{array}$} & \multicolumn{10}{|c|}{ Compositions of initial oxide-salt mixtures, $\mathbf{g}$} \\
\hline & $\mathrm{SiO}_{2}$ & MgO & $\mathrm{Al}_{2} \mathrm{O}_{3}$ & $\mathrm{CaO}$ & $\mathrm{Fe}_{2} \mathrm{O}_{3}$ & $\mathrm{NiO}$ & $\mathrm{Cr}_{2} \mathrm{O}_{3}$ & $\mathrm{MnO}_{2}$ & $\mathrm{Na}_{2} \mathrm{CO}_{3}$ & $\mathrm{CeO}_{2}$ \\
\hline GED & 210 & 80 & 40 & 70 & 60 & - & - & - & 68.4 & - \\
\hline GED-Ce & 105 & 40 & 20 & 35 & 30 & - & - & - & 34.2 & 43.8 \\
\hline$A$ & 190 & 40 & 60 & 55 & 130 & 5 & 10 & 10 & - & - \\
\hline $\mathrm{A}-\mathrm{Ce}$ & 95 & 20 & 30 & 27.5 & 65 & 2.5 & 5 & 5 & - & 43.8 \\
\hline
\end{tabular}

After formation of the basin of the melt and removal of the start-up heater, the glassfrit was dosed into the crucible by portions at 10-15 g so, as the mass of a final batch of the material to be synthesized of would not exceed $200^{\circ} \mathrm{C}$. Eventual portions of the glassfrit were dosed after complete melting the former ones. The obtained melt was keeping in the "cold" crucible within 60 minutes (after inserting last portion of the glassfrit) and then was cooling directly in the crucible. 


\section{Synthesis of mineral-type compositions}

\section{Synthesis of the frit of the matrix compositions GED and A}

In experiments to fabricate Uranium - and Plutonium-containing compositions a frit the compositions GED and A preliminarily prepared has been used as initial materials.

The usage of the glassfrit allowed to decrease dust-formation and to reduce the overall contamination of the internal volume and surface of a glove-box.

Frits GED-F and A-F were prepared by melting the oxide-salt mixtures in alundum crucibles in a muffle furnace (synthesis temperature $-1450-1600^{\circ} \mathrm{C}$, duration of keeping the melt $-1-2$ hours). Upon the end of meting, the melt was poured out onto a metallic tray.

\begin{tabular}{|l|c|c|c|c|c|c|c|c|c|}
\hline \multirow{2}{*}{ Type of material } & \multicolumn{8}{|c|}{ Compositions of initial oxide-salt mixtures, } \\
\cline { 2 - 11 } & $\mathrm{SiO}_{2}$ & $\mathrm{MgO}$ & $\mathrm{Al}_{2} \mathrm{O}_{3}$ & $\mathrm{CaO}$ & $\mathrm{Fe}_{2} \mathrm{O}_{3}$ & $\mathrm{NiO}$ & $\mathrm{Cr}_{2} \mathrm{O}_{3}$ & $\mathrm{MnO}_{2}$ & $\mathrm{Na}_{2} \mathrm{CO}_{3}$ \\
\hline GED-F & 210 & 80 & 40 & 70 & 60 & - & - & - & 68.4 \\
\hline A-F & 190 & 40 & 60 & 55 & 130 & 5 & 10 & 10 & - \\
\hline
\end{tabular}




\section{Synthesis of mineral-type compositions Synthesis of the compositions A-U and GED-U}

Synthesis of Uranium-containing compositions were made at the installation CCIM-Pu. An initial loading of the frit to obtain the basin of the melt was $150 \mathrm{~g}$. Start-up heating and melting of the glassfrit was performed using a rod made from Silica carbide $(\mathrm{SiC})$, put into the crucible with the frit.

After formation of the basin of the melt and removal of the start-up heater, a mixture of the glassfrit (50 g) and Uranium oxide ( $12 \mathrm{~g}$ of $\left.\mathrm{U}_{3} \mathrm{O}_{8}\right)$ thoroughly blended was dosed into the crucible by portions at 10-15 g. Eventual portions of the glassfrit were dosed after complete melting the former ones. The obtained melt was keeping in the "cold" crucible within 60 minutes (after inserting last portion of the glassfrit) and then was cooling directly in the crucible.

After cooling up to a room temperature, the synthesized glass batch was removed from the crucible and subjected to sampling for eventual studies. 


\section{Synthesis of mineral-type compositions with Plutonium (CCIM)}

Synthesis of plutonium-containing compositions GEDBZ-Pu and GED-Pu were made at the installation CCIM-Pu. An initial loading of the frit to obtain the basin of the melt was $150 \mathrm{~g}$. Start-up heating and melting of the glassfrit was performed using a rod made from Silica carbide (SiC), put into the crucible with the frit.

After formation of the basin of the melt and removal of the start-up heater, a mixture of the glassfrit BZ$\mathrm{Na}(50 \mathrm{~g})$ or GED (50 g) and Plutonium oxide $(6 \mathrm{~g})$ thoroughly blended was dosed into the crucible by portions at 10-15 g. Eventual portions of the glassfrit were dosed after complete melting the former ones. The obtained melt was keeping in the "cold" crucible within 60 minutes (after inserting last portion of the glassfrit) and then was cooling directly in the crucible.

After cooling up to a room temperature, the synthesized glass batch was removed from the crucible and subjected to sampling for eventual studies. 


\section{Synthesis of mineral-type compositions (GED-Ce)}

\begin{tabular}{|l|l|l|l|l|l|}
\hline Oxides & Chem. & \multicolumn{2}{l|}{ Under aggregate } & \multicolumn{2}{l|}{ Over aggregate } \\
\cline { 3 - 6 } & average & $\mathbf{1}$ & $\mathbf{2}$ & $\mathbf{3}$ & $\mathbf{4}$ \\
\hline $\mathrm{Fe}_{2} \mathrm{O}_{3}$ & 9.83 & 5.66 & 5.89 & 8.26 & 8.11 \\
\hline $\mathrm{CaO}$ & 9.73 & 9.50 & 9.85 & 10.24 & 10.20 \\
\hline $\mathrm{SiO} \mathrm{N}_{2}$ & 42.60 & 46.82 & 45.07 & 42.42 & 43.14 \\
\hline $\mathrm{Na}_{2} \mathrm{O}$ & 6.00 & 5.70 & 5.99 & 6.03 & 5.78 \\
\hline $\mathrm{CeO}_{2}$ & 15.40 & - & - & - & - \\
\hline $\mathrm{Ce}_{2} \mathrm{O}_{3}$ & - & 11.50 & 12.84 & 14.20 & 14.30 \\
\hline $\mathrm{Al}_{2} \mathrm{O}_{3}$ & 8.16 & 7.15 & 7.03 & 7.35 & 7.07 \\
\hline $\mathrm{MgO}$ & 8.10 & 11.95 & 11.79 & 12.10 & 12.35 \\
\hline Total & 99.82 & 98.18 & 98.46 & 100.60 & 100.95 \\
\hline
\end{tabular}
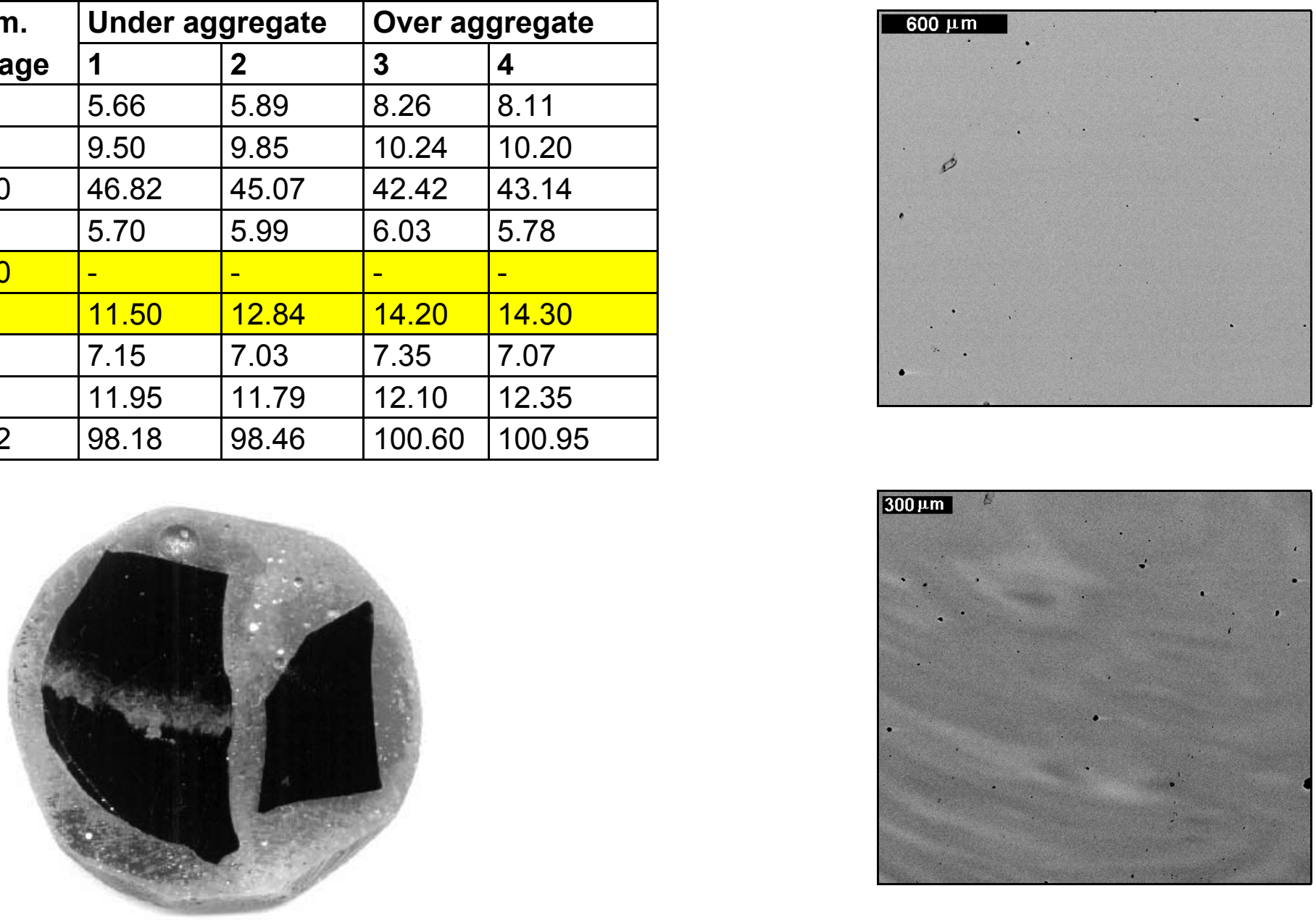


\section{Synthesis of mineral-type compositions (GED-U)}
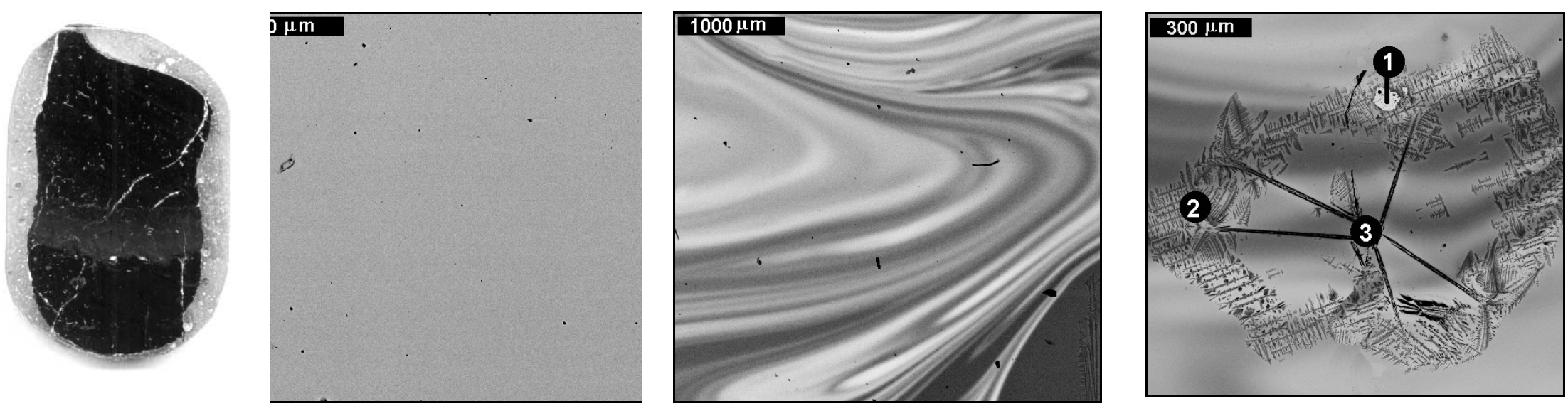

\begin{tabular}{|c|c|c|c|c|c|c|c|c|c|c|c|c|c|}
\hline \multirow{2}{*}{ Oxides } & \multicolumn{8}{|c|}{ Under crystal aggregate } & \multicolumn{2}{|c|}{ Among crystals } & \multicolumn{3}{|c|}{ Over crystal aggregate } \\
\hline & 1 & 2 & 3 & 4 & 5 & 6 & 7 & 8 & 1 & 2 & 1 & 2 & 3 \\
\hline $\mathrm{Na}_{2} \mathrm{O}$ & 4.21 & 4.10 & 3.90 & 3.60 & 3.38 & 4.30 & 4.00 & 3.91 & 4.39 & 4.68 & 4.15 & 3.95 & 3.90 \\
\hline $\mathrm{MgO}$ & 13.46 & 15.44 & 15.06 & 14.39 & 16.46 & 14.14 & 11.61 & 13.33 & 4.33 & 9.65 & 14.23 & 14.77 & 14.57 \\
\hline $\mathrm{Al}_{2} \mathrm{O}_{3}$ & 9.26 & 5.82 & 7.09 & 6.83 & 7.09 & 7.20 & 7.88 & 8.58 & 9.19 & 11.47 & 10.96 & 10.72 & 10.96 \\
\hline $\mathrm{SiO}_{2}$ & 48.92 & 47.53 & 47.49 & 47.10 & 44.88 & 44.13 & 46.93 & 46.54 & 43.83 & 44.68 & 46.74 & 45.30 & 45.80 \\
\hline $\mathrm{CaO}$ & 11.92 & 11.79 & 12.03 & 12.16 & 12.21 & 10.70 & 11.07 & 11.51 & 14.31 & 13.28 & 11.35 & 11.54 & 11.72 \\
\hline $\mathrm{Fe}_{2} \mathrm{O}_{3}$ & 8.46 & 8.70 & 8.09 & 8.57 & 8.66 & 8.39 & 8.78 & 8.90 & 9.50 & 9.21 & 8.67 & 8.40 & 8.86 \\
\hline $\mathrm{UO}_{2}$ & 1.74 & 4.25 & 6.06 & 7.83 & 8.64 & 9.57 & 10.29 & 11.48 & 11.70 & 10.38 & 8.79 & 8.44 & 8.51 \\
\hline Total & 97.97 & 97.63 & 99.72 & 100.48 & 101.32 & 98.43 & 100.56 & 104.25 & 97.25 & 103.35 & 104.89 & 103.12 & 104.32 \\
\hline
\end{tabular}




\section{Synthesis of mineral-type compositions (GEDBZ-Pu)}

\section{Short characteristic of samples of the batch of the compositions GEDBZ-Pu}

\begin{tabular}{|c|c|c|c|c|c|}
\hline \multirow[b]{2}{*}{-} & \multirow{2}{*}{ Place of sampling } & \multirow{2}{*}{ Weight, g } & \multicolumn{2}{|l|}{ Content, mg } & \multirow{2}{*}{$\begin{array}{l}\text { Content } \mathrm{PuO}_{2} \text {, } \\
\%\end{array}$} \\
\hline & & & $\mathrm{Pu}$ & $\mathrm{PuO}_{2}$ & \\
\hline 1 & Surface & 1,3758 & 67,1 & 76,1 & 5,53 \\
\hline 2 & Surface & 0,4018 & 24,1 & 27,3 & 6,80 \\
\hline 3 & Volume with the surface & 0,7299 & 36,8 & 41,7 & 5,72 \\
\hline 4 & Volume with the side skulk & 1,7540 & 87,2 & 98,9 & 5,64 \\
\hline 5 & Volume with a crystallization zone & 2,9938 & 51,6 & 58,5 & 1,95 \\
\hline 6 & Volume with the side skulk & 3,6236 & 188,8 & 214,1 & 5,91 \\
\hline 7 & Volume & 3,1520 & 170,9 & 193,8 & 6,15 \\
\hline 8 & Volume with the skulk & 1,2997 & 65,9 & 74,7 & 5,75 \\
\hline 9 & Volume & 1,1858 & 59,9 & 67,9 & 5,73 \\
\hline 10 & Volume with the skulk & 1,4302 & 53,4 & 60,5 & 4,23 \\
\hline 11 & Volume & 1,8239 & 83,7 & 94,9 & 5,20 \\
\hline 12 & Volume with three zones & 2,9115 & 39,6 & 44,9 & 1,54 \\
\hline 13 & Large volume & 7,1585 & 398,5 & 451,8 & 6,31 \\
\hline 14 & Volume with a crystallization zone & 2,8847 & background & - & - \\
\hline 15 & Volume & 3,3655 & 138,7 & 157,3 & 4,67 \\
\hline
\end{tabular}




\section{Synthesis of mineral-type compositions(GED-Pu)}

Short characteristic of samples of the batch of the compositions GEDBZ-Pu

\begin{tabular}{|l|l|l|l|l|l|}
\hline \multirow{2}{*}{ Place of sampling } & \multirow{2}{*}{ Weight, } & \multicolumn{2}{l}{ Content, $\mathrm{mg}$} & Content $\mathrm{PuO}_{2}, \%$ \\
\cline { 5 - 6 } & & & $\mathrm{Pu}$ & $\mathrm{PuO}_{2}$ & \\
\hline 1 & Surface & 0,8438 & 38,8 & 44,0 & 5,21 \\
\hline 2 & Surface & 0,3940 & 15,7 & 17,8 & 4,52 \\
\hline 3 & Upper half-batch & 2,4971 & 98,2 & 111,3 & 4,46 \\
\hline 4 & Upper half-batch & 3,2112 & 119,9 & 135,9 & 4,23 \\
\hline 5 & Upper half-batch & 1,0224 & 35,3 & 40,0 & 3,91 \\
\hline 6 & Upper half-batch & 0,8855 & 35,9 & 40,7 & 4,60 \\
\hline 7 & Upper half-batch with the crystallization zone & 7,4534 & 301,3 & 341,6 & 4,58 \\
\hline 8 & and skulk & & & & \\
\hline 9 & Material with the side skulk & 1,8147 & 69,9 & 79,2 & 4,37 \\
\hline 10 & Crysterial with the side skulk & 1,4291 & 56,1 & 63,6 & 4,45 \\
\hline 11 & Three zones with the skulk & 0,8745 & 38,4 & 43,5 & 4,98 \\
\hline 12 & Upper half-batch & 2,7959 & 80,3 & 91,0 & 3,26 \\
\hline 13 & Upper half-batch & 0,7848 & 34,3 & 38,9 & 4,96 \\
\hline 14 & Upper half-batch & 0,7425 & 32,5 & 36,8 & 4,96 \\
\hline 15 & Upper half-batch & 1,1401 & 42,9 & 48,6 & 4,27 \\
\hline
\end{tabular}




\section{Conclusions}

The boron-basalt compositions studied are capable of dissolving considerable amounts of waste, including at least $15 \%$ of cerium oxide and $10 \%$ of hafnium and uranium oxides.

In the bottom part of the samples synthesized in crucibles and containing hafnium and uranium, crystal phases of elements have been identified. Their formation is related to a decreasing solubility of the melt regarding high-charge cations due to increasing the content of aluminum oxide. This last result is caused by enrichment of the melt by aluminum oxide as a result of dissolving an alundum crucible, leading to the polymerization of the structure and decreasing the solubility of $\mathrm{Hf}^{4+}$ and $\mathrm{U}^{4+}$.

Materials synthesized in the CCIM have a flatter distribution of elements upon the bulk of batches versus the materials synthesized in crucibles.

The level of incorporation of the elements into the compositions synthesized in CCIM is a higher values analogous to those obtained from the synthesis of the materials by a usual method. 


\section{Conclusions (continued)}

The results obtained state the possibility of fabricating materials (including the hard-todissolve residues, hydrate-sludge slurry, and aqueous-tailing solutions) in the CCIM. For the first two types of waste, pyroxens have been proposed; for the aqueous-tailing solutions garnet. Preliminary studies of the structure of the fabricated materials have shown its resemblance to the proposed minerals.

The work is proceeding towards an additional synthesis of the matrices with real components of waste and a study of physico-chemical properties of the compositions. 


\title{
Synthesis of Borosilicate and Phosphate Glasses Containing ${ }^{239} \mathrm{Pu}$ and Study of Their Properties [B338247]
}

\author{
A.S. Aloy, V.Z. Belov, O.A. Iskhakova, A.V. Trofimenko, RPA, KRI
}

\section{Introduction}

Based on the study of physico-chemical properties of borosilicate and phosphate glasses as well on the theoretical assessment of thermodynamic behavior of plutonium dioxide in borosilicate and phosphate melts, glass matrices were selected for the immobilization of Pu-239 [1,2,3].

The particle size of plutonium dioxide powder added to the batch did not exceed 100 microns and in each case, its weight was equal to 5 mass $\%$.

After synthesis of the borosilicate glass, SEM analyses indicated the formation of a crystalline phase of plutonium silicate in the bottom layers with inclusions that were about 3-5 microns in size. The concentration of plutonium dissolved in homogeneous glass was equal to 2.67 mass $\%$ in terms of oxide.

In the case of phosphate glass, only small particles of pure plutonium dioxide were found in the bottom layer, whereas the main part of glass mass was homogeneous. The concentration of plutonium there was 4.46 mass $\%$ corresponding to the solubility of $\mathrm{PuO}_{2}$.

After preparation of the borosilicate and phosphate glasses with $2.67 \mathrm{wt} \%$ plutonium in the borosilicate glass and $4.46 \mathrm{wt} \%$ plutonium in the phosphate glass, their water durability was evaluated by the standard MCC- 1 static test at $25^{\circ} \mathrm{C}$ and $90^{\circ} \mathrm{C}$.

\section{Synthesis of borosilicate and phosphate glasses containing ${ }^{239} \mathrm{Pu}$ in the form of plutonium oxide}

To produce borosilicate glasses, the oxides of corresponding elements, i.e., modifiers, nitrates, or carbonates of sodium and cesium, were used as batch components, and silicon oxides and boric acid as glass formers.

Initial components were thoroughly ground, then the necessary weight amount of plutonium dioxide was added to the mixture obtained, and the mixture was homogenized once more. The particle size of plutonium dioxide powder in the batch did not exceed 100 microns.

The amount of plutonium dioxide introduced corresponded to 5.0 mass $\%$ in terms of final product.

The synthesis of plutonium-containing phosphate glasses was performed based on preliminarily melted $\left(1100^{\circ} \mathrm{C}, 2\right.$ hours) and comminuted glass frit of corresponding composition. Glass frit was obtained by melting a mixture of nitrates of elements, modifiers, and phosphoric acid. After preliminary preparation, plutonium dioxide powder in weight amount of 5.0 mass $\%$ was added to comminuted glass frit, and the mixture was transferred into an alumina crucible which was placed in a resistance furnace of special construction for glass melting.

The furnace scheme is shown in Fig. 1. 


\section{Plutonium Glasses for Immobilization}

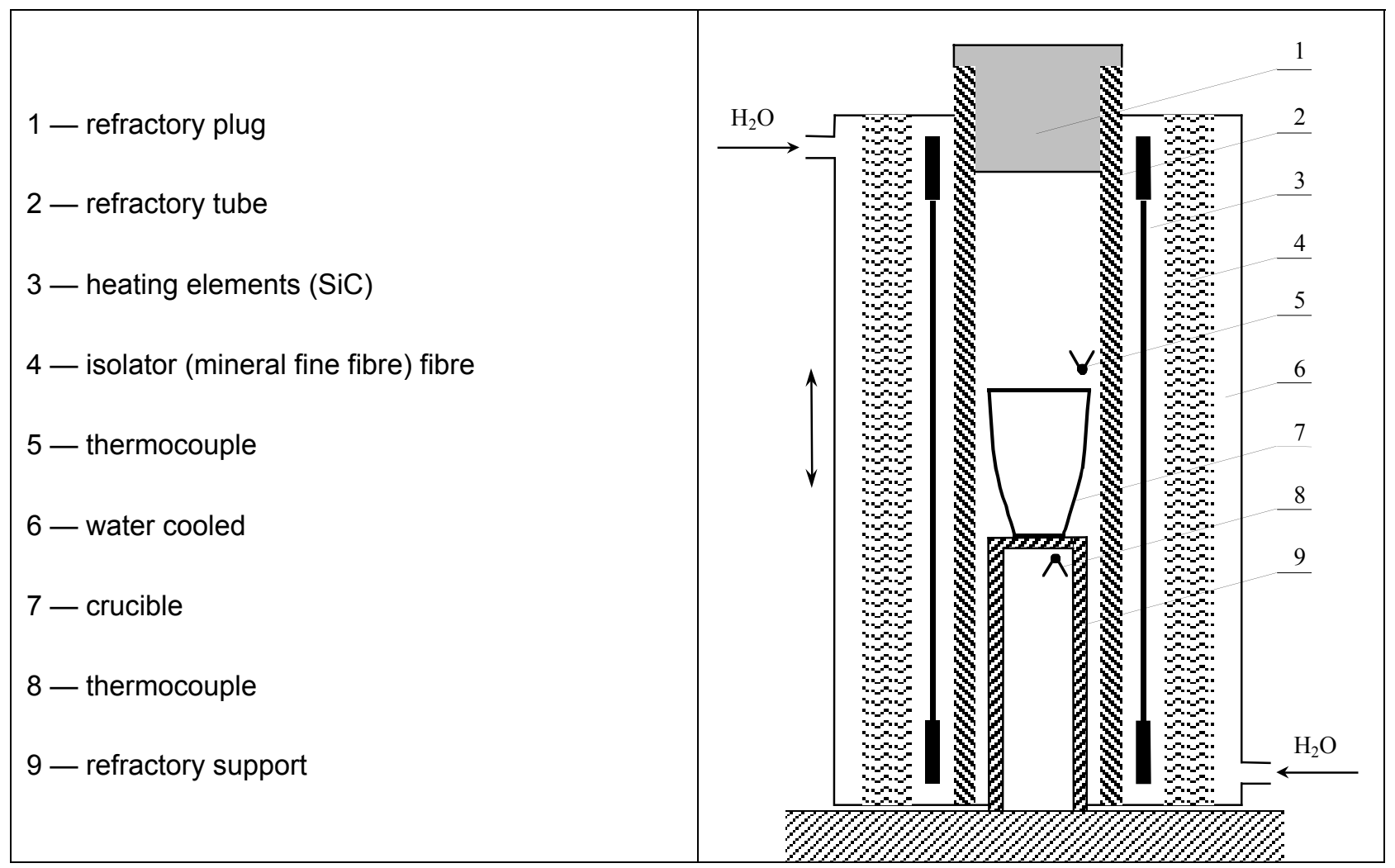

Fig.1. Laboratory furnace to produce glasses with high concentration of plutonium.

Borosilicate glasses were synthesized at $1150^{\circ} \mathrm{C}$ for 2 hours; phosphate glasses at $1100^{\circ} \mathrm{C}$ with melt exposure during 2 hours without stirring.

Gadolinium was introduced in glass composition as a neutron absorber.

Compositions of glasses, their specific activities and the content of plutonium oxide dissolved in a glass matrix determined by gamma spectrometry are shown in Tables 1 and 2 .

Table 1. Borosilicate glass composition producing with plutonium oxide in the initial batch (whiteformulation, gray-analysis)

\begin{tabular}{|c|c|c|c|c|c|c|c|c|c|c|}
\hline Component & $\mathrm{SiO}_{2}$ & $\mathrm{~B}_{2} \mathrm{O}_{3}$ & $\mathrm{Na}_{2} \mathrm{O}$ & $\mathrm{Al}_{2} \mathrm{O}_{3}$ & $\mathrm{Cs}_{2} \mathrm{O}$ & Zno & $\mathrm{BaO}$ & $\mathrm{Fe}_{2} \mathrm{O}_{3}$ & $\mathbf{G d}_{2} \mathbf{O}_{3}$ & $\mathrm{PuO}_{2}$ \\
\hline $\begin{array}{l}\text { Concentration } \\
\text { (mass\%) }\end{array}$ & $42 ., 40$ & 16.90 & 20.50 & 2.05 & 2.05 & 5.10 & 4.10 & 3.10 & 1.03 & 2,67 \\
\hline
\end{tabular}




\section{Research and Development Plutonium Immobilization Contract Activities}

Table 2. Phosphate glass composition producing with plutonium oxide in the initial batch (whiteformulation, gray-analysis).

\begin{tabular}{|l|l|l|l|l|l|l|l|l|l|}
\hline Component & $\mathbf{P}_{\mathbf{2}} \mathbf{O}_{\mathbf{5}}$ & $\mathbf{N a}_{\mathbf{2}} \mathbf{O}$ & $\mathbf{A l}_{\mathbf{2}} \mathbf{O}_{\mathbf{3}}$ & $\mathbf{C s}_{\mathbf{2}} \mathbf{O}$ & $\mathbf{Z n O}$ & $\mathbf{B a O}$ & $\mathbf{F e}_{\mathbf{2}} \mathbf{O}_{\mathbf{3}}$ & $\mathbf{G d}_{\mathbf{2}} \mathbf{O}_{\mathbf{3}}$ & $\mathbf{P u O}_{\mathbf{2}}$ \\
\hline $\begin{array}{l}\text { Concentration } \\
\text { (mass\%) }\end{array}$ & 59.90 & 10.15 & 8.15 & 3.04 & 4.08 & 3.05 & 2.05 & 5.09 & 4.48 \\
\hline Specific activity & $(9.18 \pm 0.3) \cdot 10^{4}(\mathrm{~Bq} / \mathrm{mg})$ \\
\hline
\end{tabular}

The measurements were conducted by means of the detector EGPC 20P11A, made of ultrapure germanium with a well, the Schlumberger amplified 7147. The Canberra AccuSped-A built-in chip with the encoder of Wilkinson type for $100 \mathrm{MHz}$ and $32 \mathrm{~KB}$ memory (8,192 channels) was used as a pulse analyzer. To estimate the peak area, the background lower than the peak was approximated by a polynomial.

The peak shape was identified by a Gaussian curve. The peak characteristics (area, simi-width and the position of the peak center), as well as the background characteristics, were calculated by iteration method of least squares.

The time span for the measurements resulted from the fact that the most intense lines had $a \pm 1 \%$ error in the peak areas.

The obtained borosilicate and phosphate glasses were studied by electron microprobe analysis to determine their homogeneity and/or the presence of crystalline phases. Results are shown in Figs. 2-5. From these figures, the following conclusions can be made. In borosilicate glass, where 5 mass $\%$ of plutonium oxide was introduced, a crystalline phase of plutonium silicate was found in bottom layers. The size of crystalline inclusions did not exceed 3-5 microns. As a rule, these have rectangular form. The image of inclusions was obtained in absorbed electrons and in characteristic x-rays of plutonium and silicon. Quantitative x-ray spectral analysis of inclusions has been attempted, but the results are not sufficiently correct due to the small size of inclusions. According to available assessments, plutonium content in these inclusions is 72.6 mass $\%$ and silicon content $\sim 8.4$ mass $\%$. The glass matrix in the middle part of the crucible does not contain any crystalline phases or inclusions and is homogeneous (Fig. 2). The concentration of plutonium dissolved in it was 2.67 mass $\%$ in terms of oxide.

It can be assumed that during 2 hours of glass melting, the largest particles of plutonium oxide did not have time to dissolve in the bulk of melt and reacted with silicon dioxide, forming refractory plutonium silicate.

In the case of phosphate glass, plutonium dioxide was found in the bottom layer (Fig. 5), whereas the upper part of the glass mass was homogeneous. Plutonium dioxide concentration was 4.48 mass\%, corresponding to the solubility of plutonium oxide in phosphate matrix of given composition under selected melting conditions. 


\begin{tabular}{|c|c|}
\hline 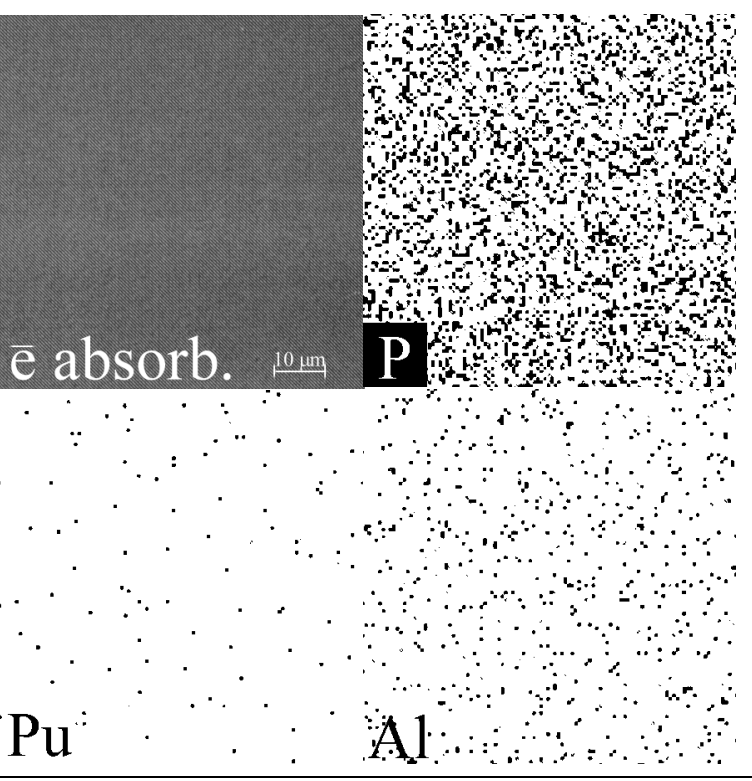 & 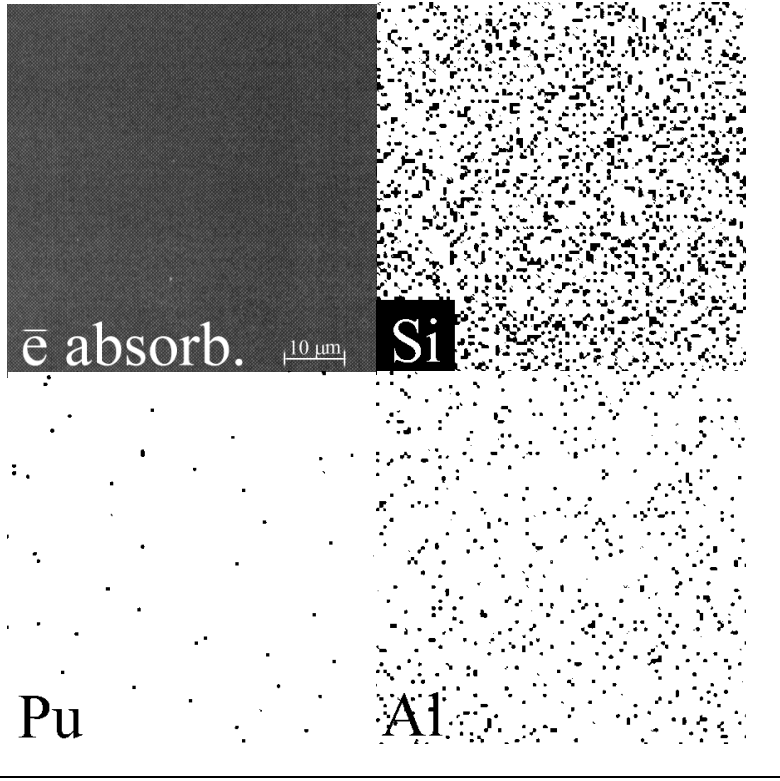 \\
\hline Fig. 2. SEM micrographs of phosphate glass. & Fig. 3. SEM micrographs of borosilicate glass. \\
\hline
\end{tabular}
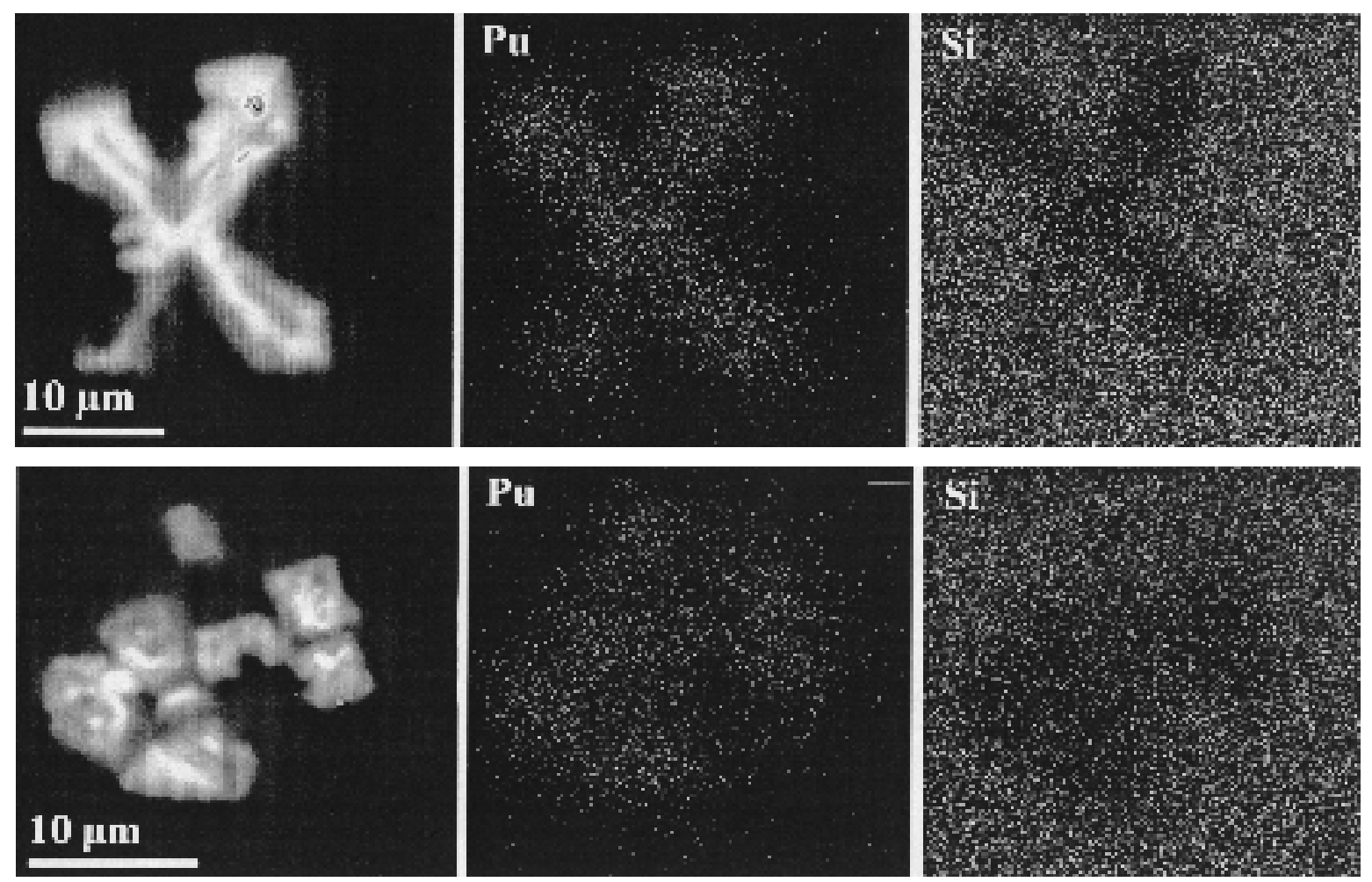

Fig. 4. Inclusions in borosilicate glass. SEM micrographs show the inclusions and elements maps. 

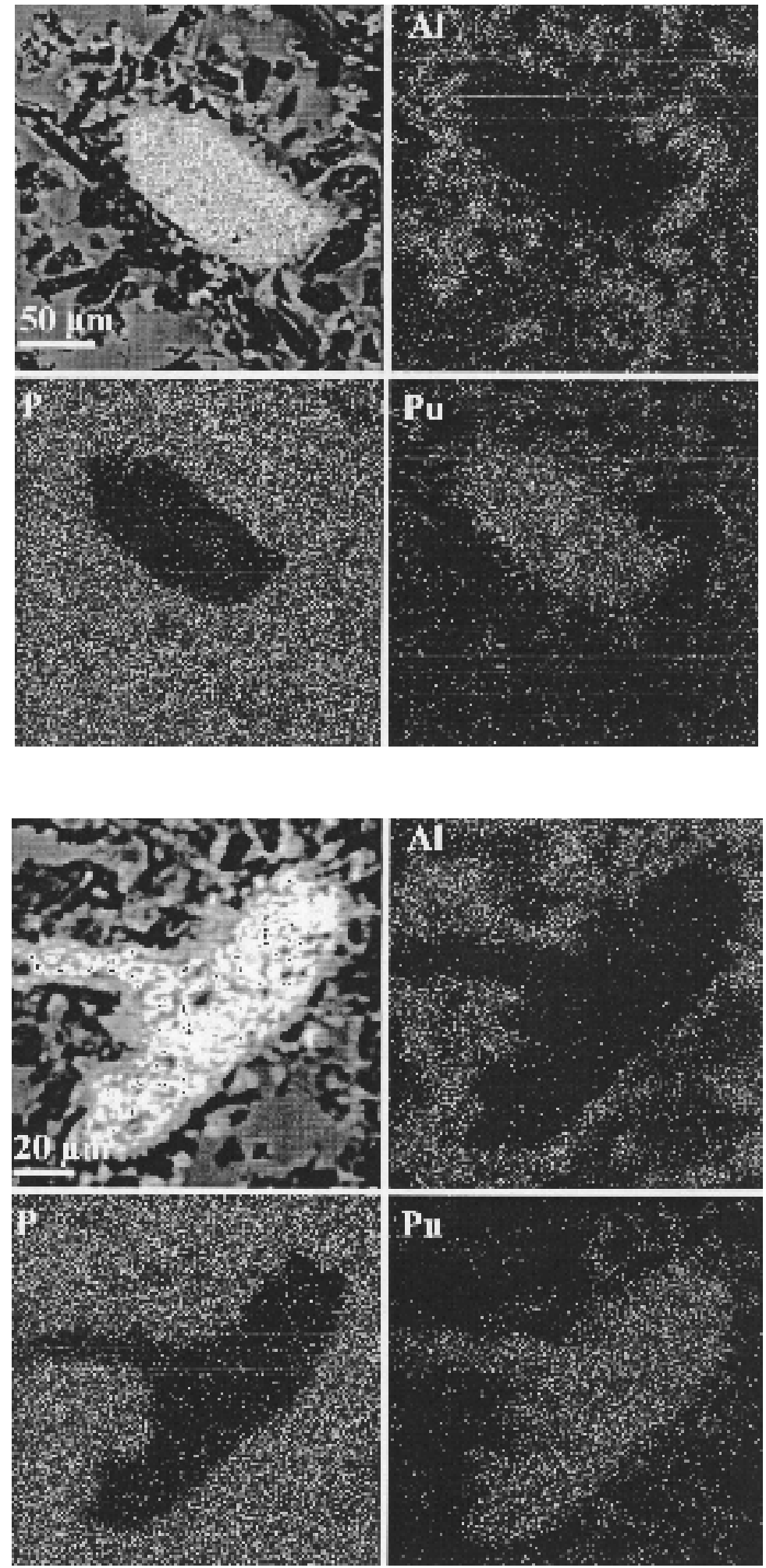

Fig. 5. Inclusions in phosphate glass. SEM micrographs show the inclusions and elements map. 


\section{Plutonium Glasses for Immobilization}

\section{Study of plutonium sedimentation in borosilicate and phosphate melts}

To study the process of plutonium sedimentation in glass melts under conditions of long aging, borosilicate and phosphate glasses were synthesized with plutonium dioxide concentration of 2.16 and 3.10 mass $\%$, respectively (Tables 3,4 ).

Table 3. Borosilicate glass composition containing Pu-239.

\begin{tabular}{|l|l|l|l|l|l|l|l|l|l|l|}
\hline \hline Component & $\mathrm{SiO}_{2}$ & $\mathrm{~B}_{2} \mathrm{O}_{3}$ & $\mathrm{Na}_{2} \mathrm{O}$ & $\mathrm{Al}_{2} \mathrm{O}_{3}$ & $\mathrm{Cs}_{2} \mathrm{O}$ & $\mathrm{ZnO}$ & $\mathrm{BaO}^{\prime}$ & $\mathrm{Fe}_{2} \mathrm{O}_{3}$ & $\mathbf{G d}_{2} \mathrm{O}_{3}$ & $\mathrm{PuO}_{2}$ \\
\hline $\begin{array}{l}\text { Concentration } \\
\text { (mass\%) }\end{array}$ & 42.7 & 17.0 & 20.6 & 2.10 & 2.10 & 5.10 & 4.10 & 3.10 & 1.04 & 2.16 \\
\hline
\end{tabular}

Table 4. Phosphate glass composition containing Pu-239.

\begin{tabular}{|l|l|l|l|l|l|l|l|l|l|}
\hline \hline Component & $\mathbf{P}_{2} \mathrm{O}_{5}$ & $\mathrm{Na}_{2} \mathbf{O}$ & $\mathrm{Al}_{2} \mathrm{O}_{3}$ & $\mathbf{C s}_{2} \mathrm{O}$ & $\mathrm{ZnO}$ & $\mathrm{BaO}^{\prime}$ & $\mathrm{Fe}_{2} \mathrm{O}_{3}$ & $\mathbf{G d}_{2} \mathrm{O}_{3}$ & $\mathrm{PuO}_{2}$ \\
\hline $\begin{array}{l}\text { Concentration } \\
\text { (mass } \%)\end{array}$ & 60.60 & 10.35 & 8.35 & 3.10 & 4.20 & 3.15 & 2.10 & 5.05 & 3.10 \\
\hline \multicolumn{7}{|l|}{ Specific activity $=(6.38 \pm 0.3) \cdot 10^{4}(\mathrm{~Bq} / \mathrm{mg})$} \\
\hline
\end{tabular}

According to data of electron microprobe analysis, such glasses represent homogeneous formations (Figs. 2 and 3) and do not contain crystalline phases or inclusions that could form sediments or initiate plutonium sedimentation.

The process of sedimentation was studied as follows.

Comminuted borosilicate and phosphate glasses were placed in a platinum crucible having a die in the form of pipe for production of granules by free dropping outflow of glass mass.

The crucible was placed in a granulator whose construction is shown in Fig. 6. 


(1- plugging device $(\mathrm{Pt})$

Fig. 6. Laboratory setup to study sedimentation process in the melts.

The die of the crucible had a platinum shutoff device. Borosilicate and phosphate glasses were melted and melt-aged for 8 hours at 1050 and $1000^{\circ} \mathrm{C}$, respectively, without mixing. The height of melt column for borosilicate glass was $4.8 \mathrm{~cm}$ (glass mass volume $11.25 \mathrm{~cm}^{3}$ ) and $4.2 \mathrm{~cm}$ (glass volume $9.85 \mathrm{~cm}^{3}$ ) for phosphate glass.

After 8-hour aging, the shutoff device opened and drops of melt fell on a massive rotating heated disk. The glass granulation was conducted up to full outflow of glass mass. After annealing and cooling of granules on disk the series of granules were taken from upper, middle, and lower parts of crucible-melter and sent for measurement of their activity.

Experimental values of specific activity for a series of granules are presented in Tables 5 and 6.

The analysis of results obtained has shown that both in borosilicate and in phosphate melts under given temperature-time conditions, plutonium sedimentation (plutonium phase separation throughout the height of melt) is not observed. The values of specific activities for different layers of melt are close and fall within the range of sample activity measurement error (not exceeding 6\%) (Fig. 7). 


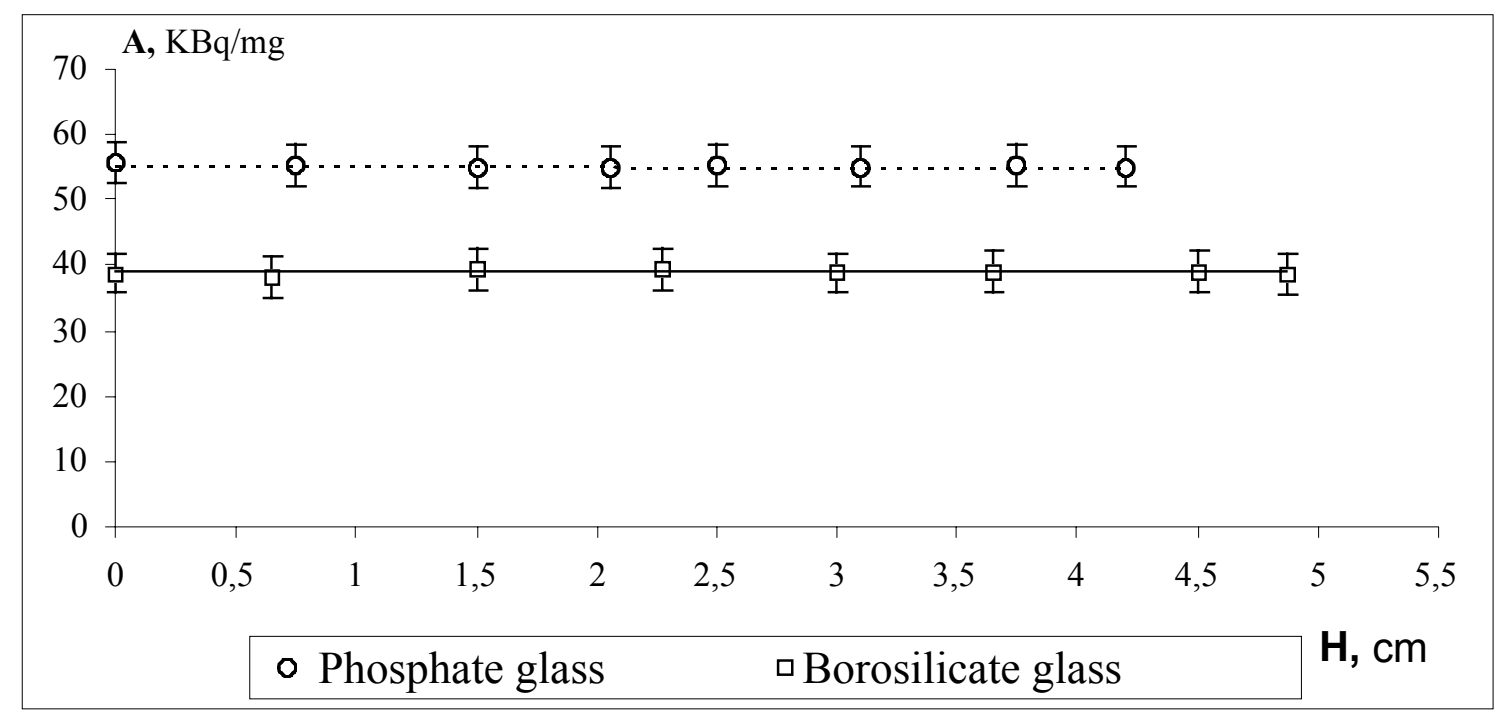

Fig. 7. Effect of the melt's level on the specific activities of the glass beads after 8 hours exposure of the melts.

Table 5. Specific activities of borosilicate beads after granulation of the melt held $8 \mathrm{~h}$ at $1050^{\circ} \mathrm{C}$.

\begin{tabular}{|l|l|l|l|l|}
\hline $\begin{array}{l}\text { \# portion } \\
\text { of beads }\end{array}$ & Melt's zone & $\begin{array}{l}\text { Average mass of bead in } \\
\text { portion }(\mathbf{m g})\end{array}$ & $\begin{array}{l}\text { Average activity of } \\
\text { bead (MBq) }\end{array}$ & $\begin{array}{l}\text { Specific activity of bead } \\
\text { (KBq/mg) }\end{array}$ \\
\hline 1 & \multirow{2}{*}{ Bottom layer } & 217.85 & 8.41 & $38.76 \pm 3.10$ \\
2 & 216.95 & 8.39 & $38.25 \pm 3.08$ \\
\hline 3 & 215.10 & 8.45 & $39.28 \pm 3.12$ \\
4 & & 8.34 & $39.22 \pm 3.14$ \\
5 & Medium layer & 212.60 & 8.13 & $38.78 \pm 3.10$ \\
6 & 209.65 & 8.05 & $38.99 \pm 3.12$ \\
\hline 7 & 206.45 & 7.78 & $38.90 \pm 3.11$ \\
8 & & 7.68 & $38.57 \pm 3.08$ \\
\hline
\end{tabular}

Table 6. Specific activities of phosphate beads after granulation of the melt held $8 \mathrm{~h}$ at $1000^{\circ} \mathrm{C}$.

\begin{tabular}{|l|l|l|l|l|}
\hline $\begin{array}{l}\text { \# portion } \\
\text { of beads }\end{array}$ & Melt's zone & $\begin{array}{l}\text { Average mass of bead in } \\
\text { portion }(\mathbf{m g})\end{array}$ & $\begin{array}{l}\text { Average activity of } \\
\text { bead } \mathbf{( M B q})\end{array}$ & $\begin{array}{l}\text { Specific activity of } \\
\text { bead (KBq/mg) }\end{array}$ \\
\hline 1 & Bottom layer & 130.85 & 7.28 & $55.64 \pm 3.34$ \\
2 & 130.45 & 7.22 & $55.35 \pm 3.32$ \\
\hline 3 & 128.60 & 7.07 & $54.98 \pm 3.30$ \\
4 & & 6.96 & $54.73 \pm 3.28$ \\
5 & Medium layer & 127.15 & 6.87 & $55.29 \pm 3.32$ \\
6 & 124.25 & 6.80 & $55.04 \pm 3.30$ \\
\hline 7 & 123.55 & 6.83 & $55.38 \pm 3.32$ \\
8 & & 6.78 & $55.08 \pm 3.30$ \\
\hline
\end{tabular}




\section{Effect of changing the form of introduced plutonium on its solubility in borosilicate and phosphate glass matrices}

In the beginning of this report, we described experimental data for plutonium-containing glasses where plutonium was introduced in the form of oxide. In this section, we present data showing the variation of plutonium solubility in glass, if plutonium is introduced in nitrate form (Tables 7,8 ).

Table 7. Borosilicate glass composition producing with plutonium nitrate in the initial batch (white-formulation, gray-analysis).

\begin{tabular}{|l|l|l|l|l|l|l|l|l|l|l|}
\hline Component & $\mathrm{SiO}_{2}$ & $\mathrm{~B}_{2} \mathrm{O}_{3}$ & $\mathrm{Na}_{2} \mathrm{O}$ & $\mathrm{Al}_{2} \mathrm{O}_{3}$ & $\mathrm{Cs}_{2} \mathrm{O}$ & $\mathrm{ZnO}$ & $\mathrm{BaO}$ & $\mathrm{Fe}_{2} \mathrm{O}_{3}$ & $\mathbf{G d}_{2} \mathrm{O}_{3}$ & $\mathrm{PuO}_{2}$ \\
\hline $\begin{array}{l}\text { Concentration } \\
\text { (mass\%) }\end{array}$ & 41.60 & 16.50 & 20.00 & 2.05 & 2.05 & 5.05 & 4.05 & 3.03 & 1.02 & 4.65 \\
\hline Specific activity $(9.51 \pm 0.3) \cdot 10^{4}(\mathrm{~Bq} / \mathrm{mg})$ \\
\hline
\end{tabular}

Table 8. Phosphate glass composition producing with plutonium nitrate in the initial batch (whiteformulation, gray-analysis).

\begin{tabular}{|l|l|l|l|l|l|l|l|l|l|}
\hline \hline Component & $\mathbf{P}_{2} \mathrm{O}_{5}$ & $\mathrm{Na}_{2} \mathrm{O}$ & $\mathrm{Al}_{2} \mathrm{O}_{3}$ & $\mathrm{Cs}_{2} \mathrm{O}$ & $\mathrm{ZnO}$ & $\mathrm{BaO}$ & $\mathrm{Fe}_{2} \mathrm{O}_{3}$ & $\mathbf{G d}_{2} \mathrm{O}_{3}$ & $\mathrm{PuO}_{2}$ \\
\hline $\begin{array}{l}\text { Concentration } \\
\text { (mass\%) }\end{array}$ & 60.00 & 10.00 & 8.00 & 3.00 & 4.00 & 3.00 & 2.00 & 5.00 & 5.00 \\
\hline
\end{tabular}

At the first stage, plutonium oxide used in previous experiments was converted into nitrate form in a sand bath by concentrated nitric acid in the presence of a catalyst. The deep green color of the solution obtained confirmed the formation of plutonium (IV) nitrate. Specific activity of the plutonium nitrate solution was determined using an approved technique described earlier. The relative error was $<10 \%$.

The synthesis of borosilicate glass was carried out as follows.

Portions introduced a calculated volume of plutonium nitrate into thoroughly ground mixture consisting of nitrates of elements-modifiers and glass-formers. The mixture was evaporated to dry residue and the formation of cake in a platinum crucible. Then the cake was calcined at $400^{\circ} \mathrm{C}$. After cooling, the calcinate was thoroughly ground to particle size of 1-5 microns and was transferred into an Alundum crucible which was placed in a melting furnace. The amount of plutonium nitrate introduced corresponds to 5.0 mass $\%$ of plutonium oxide in terms of final product.

Glass melting was carried out satisfying the conditions of synthesis established for previous glasses.

The measured specific activity of homogeneous part of glass after melting was $9.51 \times 10^{4} \mathrm{~Bq} / \mathrm{mg}$, which corresponds to a plutonium oxide concentration of 4.65 mass $\%$. Thus, for a borosilicate glass matrix used to incorporate ${ }^{239} \mathrm{Pu}$ in nitrate form it, is possible to obtain a homogeneous glass in which plutonium solubility increases significantly from 2.67 to 4.65 mass $\%$.

The synthesis of phosphate plutonium-containing glass where plutonium nitrate was introduced was conducted in the same manner as the borosilicate glass synthesis. The distinction was in batch preparation. Plutonium nitrate was poured in a solution of nitrate salt components of phosphate glass 


\section{Plutonium Glasses for Immobilization}

containing phosphoric acid with subsequent evaporation of solution to dry residue and its calcination at $400^{\circ} \mathrm{C}$.

Conditions of synthesis and the amount of introduced plutonium (5 mass\%) in terms of final product corresponded to the experiment already described.

The phosphate glass obtained represented a homogeneous composition in which no crystalline phases and heterogeneities were observed (Table 8). Specific activity of the glass was $10.29 \times 10^{4} \mathrm{~Bq} / \mathrm{mg}$.

Thus, all plutonium introduced in the form of nitrate was completely dissolved in the phosphate matrix, but saturation level was not achieved.

\section{Chemical durability study of borosilicate and phosphate glasses with high content of plutonium by MCC-1 method}

After preparation of the borosilicate and phosphate glasses with plutonium content of $2.67 \mathrm{wt} \%$ and 4.48 $w t \%$, respectively, their water durability was evaluated by the standard MCC- 1 static test under $25^{\circ} \mathrm{C}$ and $90^{\circ} \mathrm{C}$.

The ratio of the surface area (SA) of the active glass specimen to the leachant (distilled water) volume (V) was approximately $S A / V=0.1 \mathrm{~cm}^{-1}$.

All of the leachants were sampled after intervals of 3,14 , and 28 days and the concentration of leached inactive elements were analyzed by inductively coupled plasma atomic emission spectrometry (ICP-AES) after plutonium and americium separation with resin.

The leachants activity measurements, as well as glass specimens before and after leaching, were conducted using gamma spectroscopy. The data are shown in Table 10.

Table 10. Normalize loss mass phosphate and borosilicate glasses (MCC-1, g/m ${ }^{2}$ ).

\begin{tabular}{|c|c|c|c|c|c|c|c|}
\hline \multirow{2}{*}{ Type } & \multirow{2}{*}{$t\left(C^{\circ}\right)$} & \multirow{2}{*}{ Days } & \multicolumn{5}{|c|}{ Element } \\
\hline & & & Gd & $\mathrm{Na}$ & $\mathbf{P}$ & Al & Pu-239 \\
\hline \multirow{6}{*}{$\mid \begin{array}{l}\mathrm{PH}-54.46 \\
\mathrm{PuO}_{2}\end{array}$} & \multirow{3}{*}{90} & 3 & 0.12 & 58.28 & 24.81 & 9.23 & 0.94 \\
\hline & & 14 & 0.31 & 79.81 & 69.34 & 19.31 & 1.89 \\
\hline & & 28 & 0.53 & 179.12 & 149.79 & 30.03 & 1.98 \\
\hline & \multirow{3}{*}{25} & 3 & 0.02 & 0.60 & 0.59 & 0.02 & 0.01 \\
\hline & & 14 & 0.06 & 0.78 & 0.78 & 0.06 & 0.02 \\
\hline & & 28 & 0.08 & 1.49 & 1.51 & 0.06 & 0.03 \\
\hline \multirow{2}{*}{ Type } & \multirow{2}{*}{$t\left(C^{\circ}\right)$} & \multirow{2}{*}{ Days } & \multicolumn{5}{|c|}{ Element } \\
\hline & & & Gd & $\mathrm{Na}$ & $B$ & $S i$ & Pu-239 \\
\hline \multirow{6}{*}{$\mid \begin{array}{l}\mathrm{BS}-52.67 \\
\mathrm{PuO}_{2}\end{array}$} & \multirow{3}{*}{90} & 3 & 0.08 & 12.63 & 18.69 & 22.02 & 0.11 \\
\hline & & 14 & 0.13 & 32.90 & 80.78 & 95.90 & 0.53 \\
\hline & & 28 & 0.20 & 48.79 & 122.14 & 105.92 & 0.87 \\
\hline & \multirow{3}{*}{25} & 3 & 0.05 & 0.10 & 0.15 & 0.28 & 0.02 \\
\hline & & 14 & 0.05 & 0.39 & 0.49 & 0.73 & 0.07 \\
\hline & & 28 & 0.05 & 0.44 & 1.03 & 1.01 & 0.08 \\
\hline
\end{tabular}

In the range of 25 to $90^{\circ} \mathrm{C}$, the normalized mass losses plutonium for phosphate glasses are 0.03 to 1.98 $\mathrm{g} / \mathrm{m}^{2}$ and for borosilicate glasses are 0.08 to $0.87 \mathrm{~g} / \mathrm{m}^{2}$. 


\section{Research and Development Plutonium Immobilization Contract Activities}

\section{Absorption spectra of $\mathrm{Pu}$ in the borosilicate and phosphate glasses}

In this work, we studied absorption spectra of Pu in the borosilicate glass, as well as absorption spectra of $\mathrm{Pu}$ in phosphate glass. The compositions of the glasses are given in Tables 1 and 2 .

Absorption spectra of Pu were measured on an SF-8 recording spectrophotometer (manufactured in Russia) over the 400- to 2500-nm region. The instrument, which was modified by analogy with the Cary$17 \mathrm{H}$ (USA), has practically the same performance characteristics. The instrument was equipped with accessories enabling measurements in the temperature range of 12 to $1100 \mathrm{~K}\left(-260\right.$ to $\left.830^{\circ} \mathrm{C}\right)$. Samples for spectroscopic measurements were in the form of nearly plane-parallel plates. The spectra were measured against air.

Absorption spectra of $\mathrm{Pu}$ in borosilicate and phosphate glasses at different temperatures are shown in Figs. 8 and 9, and the wavelengths of the principal maxima in the spectra are given in Table 9. Although the glass used in this work differs in composition from that in [4] (in particular, it is lower in Si and higher in B), the room-temperature spectrum in Fig. 1 is quite similar to the corresponding spectrum in [4]. In accordance with the findings by Karraker [6] and Eller et al. [7], we can conclude that at room temperature plutonium exists in our borosilicate glass as $\mathrm{Pu}(\mathrm{IV})$.

As for the phosphate glass, absorption features characteristic of $\mathrm{Pu}(\mathrm{III})$ (the maxima at 1530 and $1380 \mathrm{~nm}$ and enhanced absorption near $555 \mathrm{~nm}$ ) are clearly seen from the spectra, along with the strong $\mathrm{Pu}(\mathrm{IV})$ bands. As seen from Fig. 9, the features assigned by us to $\mathrm{Pu}(\mathrm{III})$, especially the maxima at 1530 and $1380 \mathrm{~nm}$, strengthen with lowering the temperature. Notably, the latter maxima are observed in the spectral region $1300-1600 \mathrm{~nm}$, where no optical transitions belonging to $\mathrm{Pu}(\mathrm{IV})$ can appear in accordance with the Carnall's energy level scheme [5] given in the top of the figure. We observed the intense absorption in the $1300-1600 \mathrm{~nm}$ region earlier for $\mathrm{Pu}(\mathrm{III})$ spectra in chloride and fluoride melts.

It should also be emphasized that the spectra of $\mathrm{Pu}(\mathrm{IV})$ in phosphate glass (Fig. 9) strikingly resemble its spectrum in fluoride melt, which we obtained earlier and have reproduced from [7].

It follows from the spectra studied that in the borosilicate glass, plutonium exists as $\mathrm{Pu}(\mathrm{IV})$; whereas, in the phosphate glass, the presence of appreciable amounts of $\mathrm{Pu}(\mathrm{III})$ may be inferred, with $\mathrm{Pu}(\mathrm{IV})$ prevailing.

For the both glasses, in the wide temperature range studied, no substantial changes in the coordination state of $\mathrm{Pu}$ can be inferred from the comparison analysis of the spectra. 
Plutonium Glasses for Immobilization

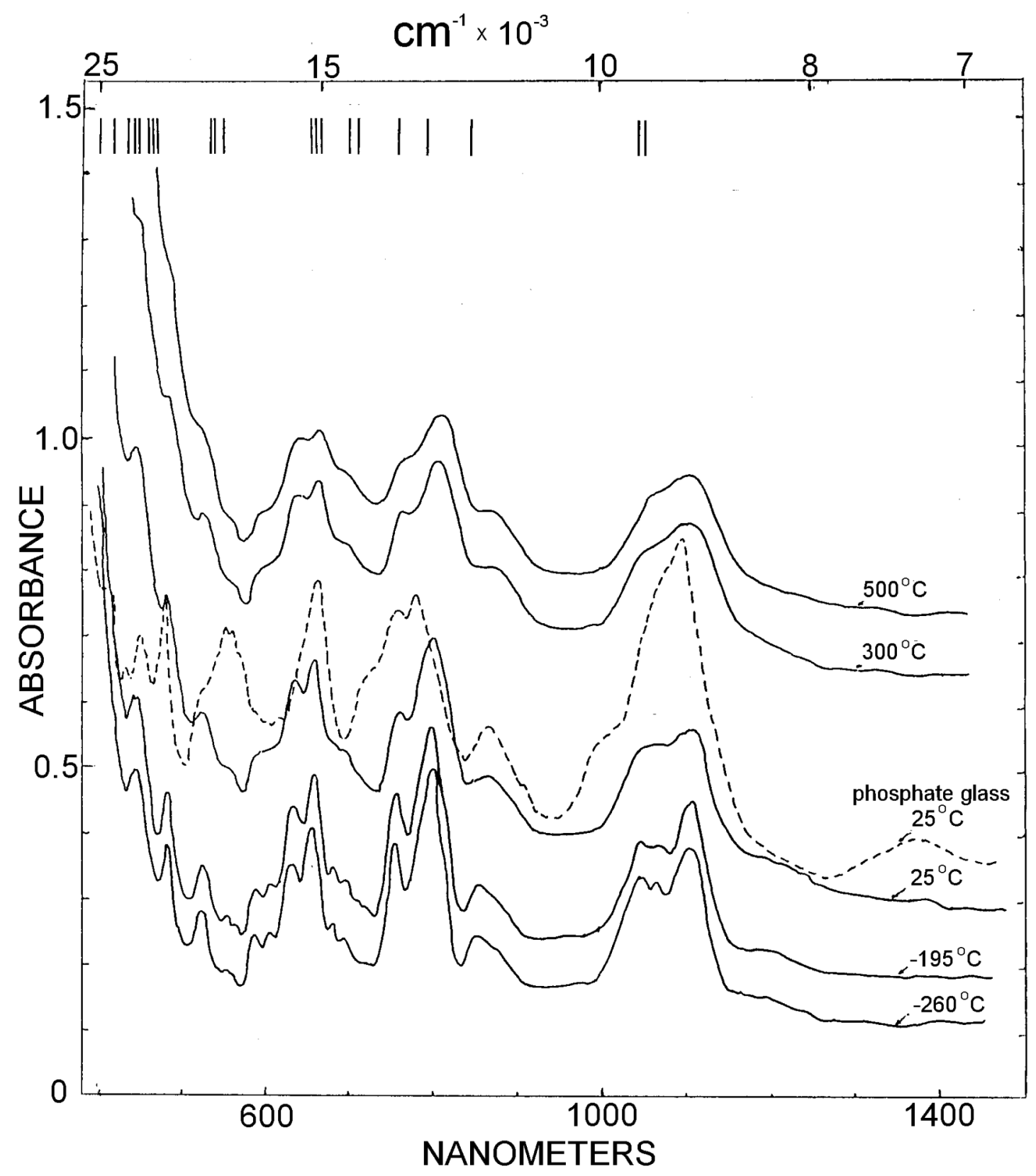

Fig. 8. Absorption spectra of $\mathrm{Pu}$ in borosilicate glass. For comparison, a part of the Pu spectrum in phosphate glass at $25^{\circ} \mathrm{C}$ is also reproduced (dashed line). 


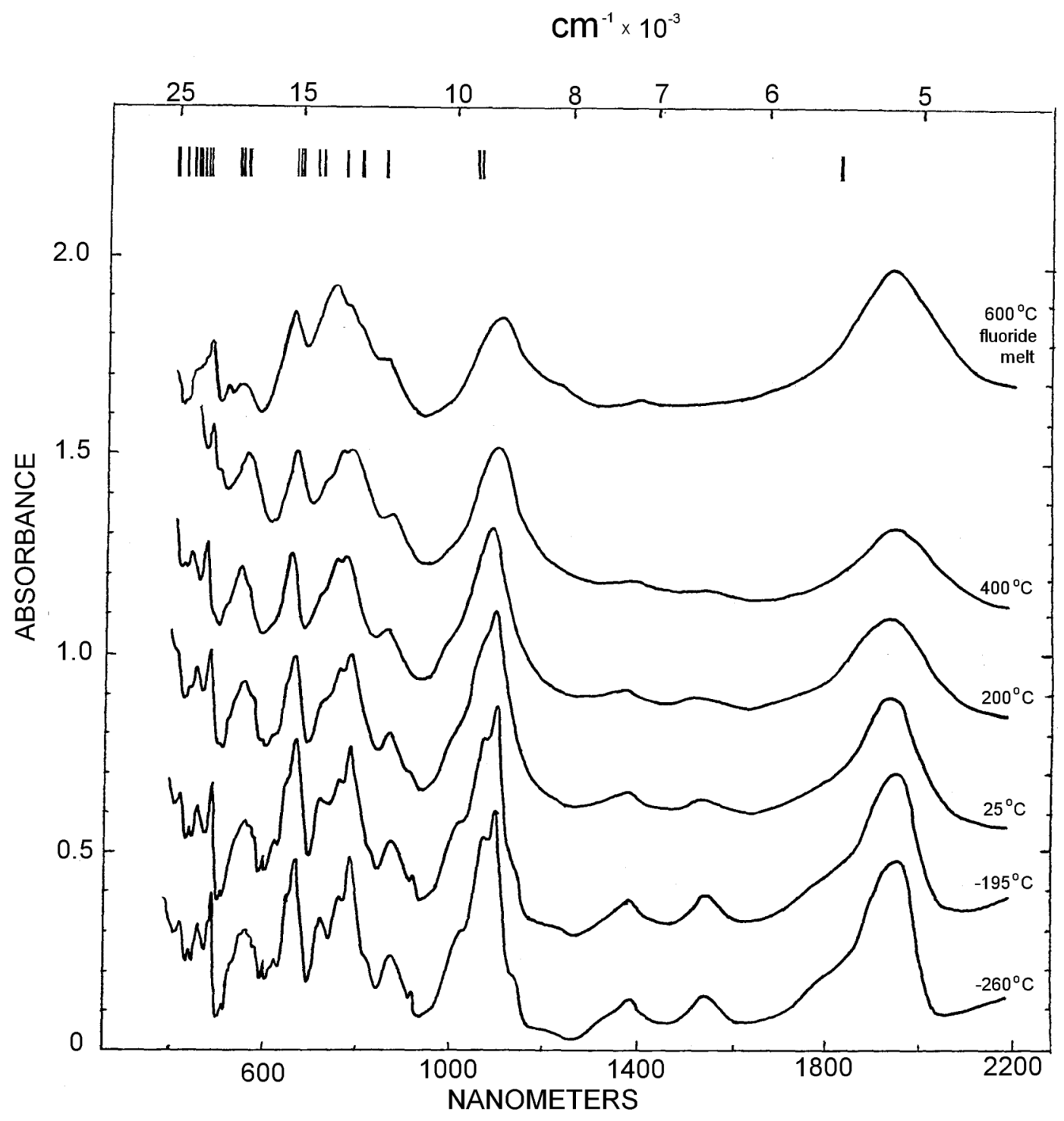

Fig. 9. Absorption spectra of $\mathrm{Pu}$ in phosphate glass. For comparison, the absorption spectrum of $\mathrm{Pu}(\mathrm{IV})$ in LiF-NaF-KF (46.5-11.5-42 mol\%) eutectic melt at $600^{\circ} \mathrm{C}$ [7] is also presented (upper line). 


\section{Appendix A. Modeling of the Solubility of $\mathrm{CeO}_{2}$ and $\mathrm{PuO}_{2}$ in Oxide Melts and Glasses}

\section{B.Shachmatkin, Inst. Of Silicate Chemistry RAN, St. Petersburg}

A thermodynamic analysis of reactions proceeding in oxide systems together with a modeling of the detailed composition of the resulting melts and a modeling of the solubility curves of $\mathrm{CeO}_{2}$ and $\mathrm{PuO}_{2}$ in oxide systems (the latter is equivalent to the modeling of the relevant liquidus curves) allows us to make the conclusions below.

First, $\mathrm{CeO}_{2}$ cannot be considered as an ideal simulator of $\mathrm{PuO}_{2}$ for studying the solubility of the latter, which is due to a considerable difference in the melting temperatures and the enthalpies of melting of both oxides. Fig. 10 shows the temperature dependencies of the solubility of $\mathrm{CeO}_{2}$ and $\mathrm{PuO}_{2}$ (i.e., the liquidus curves) which have been modeled on the assumption of ideal behavior of the oxides in a liquid phase. As is seen, a noticeable difference in the limiting values of solubility of $\mathrm{CeO}_{2}$ and $\mathrm{PuO} 2$ become less pronounced as temperature decreases. However, even at $1127^{\circ} \mathrm{C}$, this difference is still noticeable (cf. $2.8 \mathrm{~mol} \% \mathrm{CeO}_{2}$ and $4.4 \mathrm{~mol} \% \mathrm{PuO}_{2}$ which corresponds to 7.3 mass $\% \mathrm{CeO}_{2}$ and 16.6 mass $\% \mathrm{PuO}_{2}$ ).

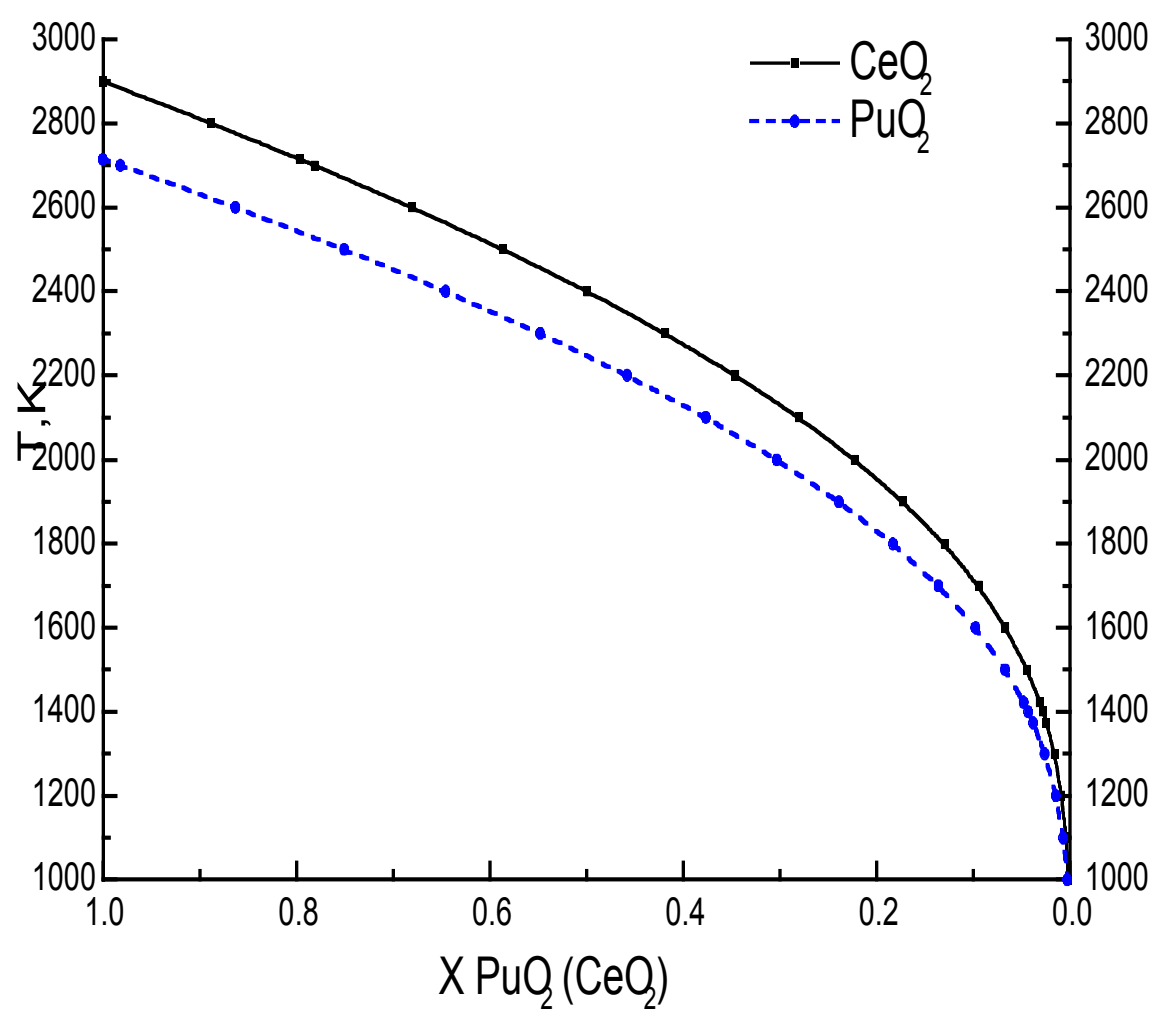

Fig. 10. The liquidus curves of $\mathrm{CeO}_{2}$ and $\mathrm{PuO}_{2}$ modeled on the assumption of ideal behavior of the oxides in a liquid phase. 


\section{Research and Development Plutonium Immobilization Contract Activities}

An appreciable difference is also observed between the thermal effects of the reactions into which the oxides $\mathrm{CeO}_{2}$ and $\mathrm{PuO}_{2}$ are involved. Thus, the enthalpy of formation of plutonium sulfate, $\mathrm{Pu}\left(\mathrm{SO}_{4}\right)_{2}$, is $-62.8 \mathrm{kcal} / \mathrm{mol}$, while that of cerium sulfate, $\mathrm{Ce}\left(\mathrm{SO}_{4}\right)_{2}$, reaches $-112.1 \mathrm{kcal} / \mathrm{mol}$, i.e., as compared to plutonium dioxide, $\mathrm{CeO}_{2}$ has a considerably more basic nature.

Fig. 11 shows changes in the run of the liquidus curve depending on the degree of deviation from ideal behavior of $\mathrm{PuO}_{2}$. It is seen that a chemical interaction between $\mathrm{PuO}_{2}$ and components of the melt leads to a decrease in the activity coefficient of the oxide (this corresponds to a change in the $Q$ value from 0 for ideal behavior of $\mathrm{PuO}_{2}$ to -10 ) which means that the solubility of $\mathrm{PuO}_{2}$ becomes larger.

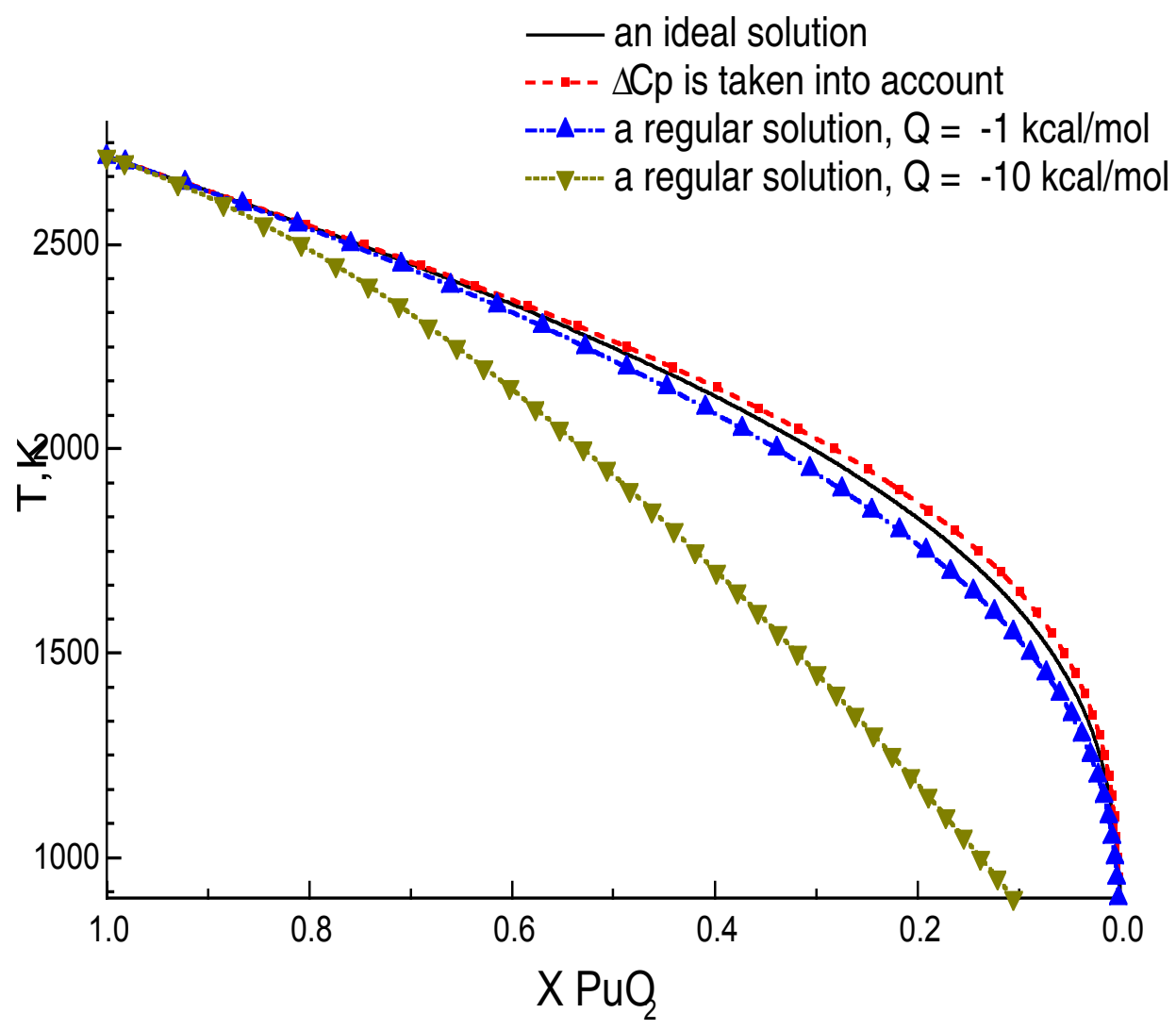

Fig. 11. The liquidus curve of $\mathrm{PuO}_{2}$ modeled with regard to the degree of deviation from the ideal behavior of $\mathrm{PuO}_{2}$.

Second, we can conclude that a reasonably good agreement of the model solubility of $\mathrm{CeO}_{2}$ with relevant experimental data (cf. in borosilicate glass: 7.3 mass $\%$, model and 4-5 mass $\%$, experiment; in phosphate glass: 4 mass $\%$, model and 7-10 mass $\%$, experiment) indicates that the behavior of $\mathrm{CeO}_{2}$ insignificantly deviates from ideal behavior. It should be noted that the difference between the experimental and calculated solubility observed in the borosilicate composition is due to a minor positive deviation, while that observed in the phosphate composition results from a negative deviation.

The results of modeling the chemical structure of two glass frits are given in Tables 11-13. 


\section{Plutonium Glasses for Immobilization}

Table 11. The chemical structure of the BS- 5 borosilicate glass.

\begin{tabular}{|l|l|l|l|l|l|}
\hline \hline Substance & $\mathrm{SiO}_{2}$ & $\mathrm{Na}_{2} \mathbf{O} \cdot 4 \mathrm{~B}_{2} \mathrm{O}_{3}$ & $\mathbf{N a}_{2} \mathrm{O} \cdot 2 \mathbf{S i O}_{2}$ & $\mathrm{Na}_{2} \mathrm{O} \cdot \mathrm{Al}_{2} \mathbf{O}_{3} \cdot 6 \mathbf{S i O}_{2}$ & $\mathbf{N a}_{2} \mathbf{O} \cdot 4 \mathrm{BaO} \cdot 10 \mathbf{S i O}_{2}$ \\
\hline Mol. \% & 26.3 & 10.9 & 52.56 & 1.98 & 8.24 \\
\hline
\end{tabular}

Table 12. The chemical structure of the PH-5 phosphate glass.

\begin{tabular}{|l|l|l|l|l|l|}
\hline \hline Substance & $\mathbf{P}_{2} \mathrm{O}_{5}$ & $\mathrm{Na}_{2} \mathbf{O} \cdot \mathbf{P}_{2} \mathrm{O}_{5}$ & $\mathrm{ZnO} \cdot \mathbf{P}_{2} \mathrm{O}_{5}$ & $\mathrm{Al}_{2} \mathbf{O}_{3} \cdot \mathbf{P}_{2} \mathbf{O}_{5}$ & $\mathrm{Na}_{2} \mathbf{O} \cdot 2 \mathrm{BaO}_{3} \mathbf{P}_{2} \mathbf{O}_{5}$ \\
\hline Mol. \% & 17.7 & 43.07 & 13.57 & 21.73 & 3.93 \\
\hline
\end{tabular}

From the data given above, we see that in the former composition $\mathrm{CeO}_{2}$ can interact only with the oxide $\mathrm{SiO}_{2}$. However, it is known that cerium silicates are very unstable and decompose above $800^{\circ} \mathrm{C}$. In the latter composition, interaction between $\mathrm{CeO}_{2}$ and $\mathrm{P}_{2} \mathrm{O}_{5}$ results in the formation of rather stable compounds, $\tilde{\mathrm{Na}} \mathrm{O}_{2} \cdot \mathrm{P}_{2} \mathrm{O}_{5}$ and $3 \mathrm{~N}^{2} \mathrm{O}_{2} \cdot 2 \mathrm{P}_{2} \mathrm{O}_{5}$. This leads to a decrease in the activity coefficient of $\mathrm{CeO}_{2}(\mathrm{a}$ negative deviation from ideal behavior), and hence to an increase in the solubility of $\mathrm{CeO}_{2}$.

It is interesting to note that the modeling of the chemical structure of the glass composition developed in Moscow (26 mass \% Na $\mathrm{Na}_{2} \mathrm{O} 23$ mass $\% \mathrm{Al}_{2} \mathrm{O}_{3}$ and 50 mass $\% \mathrm{P}_{2} \mathrm{O}_{5}$ ) gives the following results.

Table 13. The chemical structure of the P-1 phosphate glass (Contract UTA96-0330 MOD-1).

\begin{tabular}{|l|l|l|l|l|}
\hline \hline Substance & $\mathbf{A l}_{2} \mathbf{O}_{3}$ & $\mathbf{3} \mathrm{Na}_{\mathbf{2}} \mathbf{O} \cdot \mathbf{P}_{2} \mathbf{O}_{5}$ & $\mathbf{A l}_{\mathbf{2}} \mathbf{O}_{3} \cdot \mathbf{P}_{\mathbf{2}} \mathbf{O}_{5}$ & $3 \mathrm{Na}_{\mathbf{2}} \mathbf{O} \cdot \mathbf{2} \mathbf{A l}_{\mathbf{2}} \mathbf{O}_{3} \cdot \mathbf{3} \mathbf{P}_{2} \mathbf{O}_{5}$ \\
\hline Mol. \% & 8.7 & 21.96 & 0.001 & 69.34 \\
\hline
\end{tabular}

As is seen, $\mathrm{Al}_{2} \mathrm{O}_{3}$ is the only active component in this composition. However, its interaction with $\mathrm{CeO}_{2}$ is extremely weak. This means that the solubility of $\mathrm{CeO}_{2}\left(\mathrm{PuO}_{2}\right)$ in this glass is considerably less as compared to that in the above compositions.

Thus, the results obtained confirm that, even being performed in a rough approximation, the modeling of the chemical structure of glasses enables an adequate description of the solubility of $\mathrm{PuO}_{2}\left(\mathrm{CeO}_{2}\right)$ in various glasses to be made. 


\section{Research and Development Plutonium Immobilization Contract Activities}

\section{Conclusions}

1. Borosilicate and phosphate glasses have been obtained in which ${ }^{239} \mathrm{Pu}$ solubility in the form of plutonium dioxide corresponded to 2.66 and 4.46 mass $\%$.

2. Incorporation of ${ }^{239} \mathrm{Pu}$ in the form of nitrate allowed us to increase its solubility in borosilicate matrix to 4.65 mass $\%$ and in phosphate matrix to 5.0 mass $\%$.

3. After aging of glass melts for 8 hours at $1000^{\circ} \mathrm{C}$ for phosphate glass and at $1050^{\circ} \mathrm{C}$ for borosilicate glass, plutonium sedimentation was not observed.

4. In the glasses only $\mathrm{Pu}(4+)$ was detected by optical spectroscopy at room temperature.

5. In borosilicate melts, the precipitated phase consists of plutonium silicate both in oxidizing and reducing conditions. In phosphate melts, the precipitated phase consists mainly of plutonium dioxide.

6. It follows from the spectra studied that, in the borosilicate glass, plutonium exists as $\mathrm{Pu}(\mathrm{IV})$, whereas in the phosphate glass the presence of appreciable amounts of $\mathrm{Pu}(\mathrm{III})$ may be inferred, with $\mathrm{Pu}(\mathrm{IV})$ prevailing.

7. In the range $25-90^{\circ} \mathrm{C}$, the normalized mass losses plutonium for phosphate glasses are in the range $0.02-1.90 .0 \mathrm{~g} / \mathrm{m}^{2}$ and for borosilicate glasses are in the range $0.07-0.90 \mathrm{~g} / \mathrm{m}^{2}$.

\section{References}

1. Savanna River Actinide Glass Program W.G. Ramsey Presentation to Russian Delegation, June 20, 1995

2. K. Scheffler, U.Riege and C.T. Walker: "Chemical Compatibility of HLW Borosilicate Glasses with Actinides: Solubilities and Segregation Processes",German Report KfK 2552 and EUR-5750 e (1978)

3. Hj. Matzke and J. van Geel "Incorporation of Pu and other actinides in borosilicate glass and in waste ceramics" EUR.COM., Joint Research Centre,ITE, Postfach 2340, D-76125 Karlsruhe,FRG, 1995

4. P.G. Eller, G.D. Jarvinen, J.D. Purson, R.A. Penneman, R.R. Ryan, F.W. Lytle, and R.B. Gregor. Actinide valences in borosilicate glass. Radiochimica Acta 39 (1985) 17 -22

5. N.A. Stump, R.G. Haire, S. Dai. Spectroscopic investigations of neptunium's and plutonium's oxidation states in sol-gel glasses as function of initial valence and thermal history. Mat. Res. Soc. Symp. Proc. 465 (1997) 47. Materials Research Society.

6. D.G. Karraker. Actinide valences in borosilicate glass. J. Am. Ceram. Soc. 65 (1982) 53

7. A.S. Aloy, O.A. Iskhakova, A.V. Trofimenko. et al. "Chemical durability of borosilicate and phosphate glasses with high content of plutonium" International Topical Meeting, Radioactive waste management: commitment to the future environment. Antwerp, Belgium. 10-14 October 1999,V II. 


\section{Plutonium Glasses for Immobilization}




\title{
Characterization of Borosilicate Compositions Developed for the Immobilization of Plutonium-containing Sludges at MCC [B501118]
}

\author{
A.S. Aloy, V.Z. Belov, O.A. Iskhakova, A.V. Trofimenko, RPA, KRI \\ Introduction
}

The report presents the results of the investigation of physico-chemical characteristics of borosilicate compositions developed for the immobilization of plutonium-containing sludges, which has been accumulated within a series of years at the Mining Chemical Combine (MCC) Krasnoyarsk-26. Taking into consideration the complexity of the chemical composition of the sludge, containing weapons plutonium, uranium, strontium-90, cesium-137 and other elements, the solidified forms should be able to incorporate possibly maximum amounts of sludge components and provide safety criteria as well as the quality of final materials.

In this work, the glass-crystalline compositions, glasses, and devitrified glasses obtained in a number of experiments for solidification of plutonium-containing sludge, prepared according to the method developed by the MCC Central Plant Laboratory $(\mathrm{CPL})$ in Krasnoyarsk-26, are analyzed; their contents and elements ratio are very close to real sludge. To immobilize plutonium-containing sludge, a lowalkaline area of compositions within the following limits was chosen: silicon oxide, 56-68 wt\%; boron oxide 14-21 wt\%; sodium oxide, 5-10 wt\%; lithium oxide, 4-6 wt\%. It was done on the basis of theoretical criteria of glass formation (crystallization) and melting coefficients of the corresponding oxides for the temperature zone $1200-1400^{\circ} \mathrm{C}$ in accordance with technologies described in the works [1,2] and also recommendations on designing vitroceramic materials [3].

The physico-chemical parameters of glass-crystalline compositions, glasses and the products of their crystallization were compared to choose the most satisfying composition for realization of solidification process in MW facility with real pulps in Krasnoyarsk under industrial conditions.

\section{Methods of composition analysis for plutonium-containing sludge solidification}

Glass-crystalline, glass-like compositions and devitrified glasses were analyzed by the following methods:

- X-ray phase analysis was performed using diffractometer DRON-UM1 with radiation; $x$-ray tube characteristics: $32 \mathrm{kV}, 16 \mathrm{~mA}$.

- Differential-thermal analysis (DTA) was performed using a derivatograph; the rate of sample heating in the temperature interval $20-10000 \mathrm{C}$ was $100 / \mathrm{min}$.

- X-ray spectral microanalysis (EMPA) was performed at the x-ray microanalyses of the CamScan type.

- Optical spectrometry was performed at the spectra-photometer SF-8 in the range of 350-2500 nm.

- Mossbauer spectroscopy was performed by Mossbauer Spectrometer MS $1101 \mathrm{E}$. 


\section{Plutonium Glasses for Immobilization}

- The apparent density and porosity were assessed in accordance with GOST 473.4-81 Chemically resistant and heat resistant ceramic wears. The method for determination of apparent density and apparent sponginess.

- The chemical stability of the compositions was studied in accordance with MCC-1.

- Atom-emission method and mass-spectrometry with inductive-coupled plasma (ICP-AES) were used to analyze the non-active part of leachates. The data error did not exceed $10 \%$.

- Gamma-spectrometry was used to determine the activity of the initial solid samples and liquid leachate samples. The measurements were performed according to the standard method with the application of a detector made of ultrapure germanium supplied by a Schlumberger cell, model EG PC 20 P11A. The Canberra matrix Accu Spec A inserted into PC was used as an impulse analyzer.

- Scintillation method in liquid was applied to measure low alpha-activities. The method is allowed to identify units of beckerel in a sample.

\section{Analysis of glass-crystalline composition characteristics for sludge immobilization}

The average data on the composition of waste sludge are given in Table 1 according to the information of the Mining and Chemical Combine. Within the limits of the given concentrations, we chose compositions to reflect a wide range of the possible contents and ratios of elements in real sludge, which are presented for oxides in Table 2.

As a result of test melting and investigation of technological and physico-chemical characteristics of the melts, and also on the basis of the calculations of thermodynamical functions of complex oxide systems at high temperatures for the fixation of plutonium-containing sludge, the following frit composition was defined ( $w t \%)$ :

silicon oxide - 64.0; boron oxide -20.8 ; sodium oxide -9.2 ; lithium oxide -6.0 .

Glass-crystalline compositions, where the ratio of sludge oxide contents to borosilicate flux was 50:50 mass $\%$, were obtained by melting the batch in alumina crucibles by microwave heating at $1300^{\circ} \mathrm{C}$ for 1 hour. The sludge compositions calculated in terms of oxides are given in Table 2.

The sludges were synthesized by the Central Plant Laboratory MCC method. Table 3 shows the compositions of glass-crystalline compounds.

All samples had zero apparent porosity.

The values of apparent density depend on the content of uranium in the sludge and grow higher with increasing $U$ content ( $3.02 \mathrm{~g} / \mathrm{cm}^{3}$ for the composition K-15, $3.13 \mathrm{~g} / \mathrm{cm}^{3}$ for K-25 and $3.22 \mathrm{~g} / \mathrm{cm}^{3}$ for K-35).

The results of $x$-ray phase analysis showed that the obtained compositions are glass-crystalline forms. Together with the $\mathrm{x}$-ray amorphous phase they contain crystals in the form of solid solutions on the basis of uranium dioxide, compounds of the spinel type, and $\mathrm{U}(\mathrm{Fe}, \mathrm{Cr}) \mathrm{O}_{4}$. The phase composition of glasscrystalline compounds is presented in Table 4. 
Table 1. Concentrations of elements.

\begin{tabular}{|l|l|}
\hline \hline Element & Concentration $\mathbf{( g / l})$ \\
\hline $\mathrm{Pu}$ & $0,024-0,309$ \\
\hline $\mathrm{U}$ & $12,70-76,80$ \\
\hline $\mathrm{Fe}$ & $0,70-14,20$ \\
\hline $\mathrm{Cr}$ & $0,30-0,80$ \\
\hline $\mathrm{Ni}$ & $0,30-1,90$ \\
\hline $\mathrm{Mn}$ & $2,00-8,70$ \\
\hline $\mathrm{Al}$ & $1,10-5,60$ \\
\hline $\mathrm{SiO}_{2}$ & $1,20-7,30$ \\
\hline $\mathrm{Sr}$ & $0,40-4,20$ \\
\hline $\mathrm{Ce}$ & $0,30-0,70$ \\
\hline $\mathrm{Zr}$ & $0,30-0,80$ \\
\hline $\mathrm{Cs}$ & $0,10-0,30$ \\
\hline $\mathrm{Na}$ & $1,20-7,50$ \\
\hline $\mathrm{K}$ & $0,40-1,00$ \\
\hline
\end{tabular}

Table 2. Sludge compositions in terms of oxides (wt\%).

\begin{tabular}{|l|l|l|l|}
\hline \hline \multirow{2}{*}{ Oxides } & \multicolumn{2}{|l|}{ Sludge types } \\
\cline { 2 - 4 } & $\mathbf{P}-\mathbf{1}$ & $\mathbf{P}-\mathbf{2}$ & $\mathbf{P}-\mathbf{3}$ \\
\hline $\mathrm{PuO}_{2}$ & 0.20 & 0.20 & 0.20 \\
\hline $\mathrm{UO}_{2}$ & 22.68 & 29.42 & 50.74 \\
\hline $\mathrm{Fe}_{2} \mathrm{O}_{3}$ & 18.10 & 41.38 & 9.50 \\
\hline $\mathrm{Cr}_{2} \mathrm{O}_{3}$ & 1.16 & 2.40 & 0.76 \\
\hline $\mathrm{NiO}$ & 3.36 & 3.34 & 1.74 \\
\hline $\mathrm{MnO}_{2}$ & 17.98 & 6.44 & 10.76 \\
\hline $\mathrm{Al}_{2} \mathrm{O}_{3}$ & 13.34 & 7.32 & 7.84 \\
\hline $\mathrm{SiO}_{2}$ & 9.56 & 2.46 & 5.90 \\
\hline $\mathrm{SrO}^{\mathrm{CeO}}$ & 6.66 & 0.96 & 3.60 \\
\hline $\mathrm{ZrO}_{2}$ & 1.12 & 0.76 & 0.84 \\
\hline $\mathrm{Cs}_{2} \mathrm{O}$ & 1.42 & 0.84 & 0.96 \\
\hline $\mathrm{Na}_{2} \mathrm{O}$ & 0.44 & 0.22 & 0.26 \\
\hline $\mathrm{K}_{2} \mathrm{O}$ & 2.64 & 3.30 & 5.90 \\
\hline & 1.34 & 0.98 & 1.00 \\
\hline
\end{tabular}




\section{Plutonium Glasses for Immobilization}

Table 3. Precursors for the synthesis of glass-crystalline products in the presence of low alkaline oxides.

\begin{tabular}{|c|c|c|c|}
\hline \multirow{2}{*}{ Oxide } & \multicolumn{3}{|c|}{ Type of matrices } \\
\hline & 15 & 25 & 35 \\
\hline $\mathrm{PuO}_{2}$ & 0,10 & 0,10 & 0,10 \\
\hline $\mathrm{UO}_{2}$ & 11,34 & 14,71 & 25,38 \\
\hline $\mathrm{Fe}_{2} \mathrm{O}_{3}$ & 9,05 & 20,69 & 4,75 \\
\hline $\mathrm{Cr}_{2} \mathrm{O}_{3}$ & 0,58 & 1,20 & 0,39 \\
\hline $\mathrm{NiO}$ & 1,58 & 1,68 & 0,88 \\
\hline $\mathrm{MnO}_{2}$ & 8,99 & 3,22 & 5,39 \\
\hline $\mathrm{Al}_{2} \mathrm{O}_{3}$ & 6,56 & 3,66 & 3,93 \\
\hline $\mathrm{SiO}_{2}$ & 4,77 & 1,23 & 2,95 \\
\hline $\mathrm{SrO}$ & 3,23 & 0,48 & 1,80 \\
\hline $\mathrm{CeO}_{2}$ & 0,56 & 0,38 & 0,42 \\
\hline $\mathrm{ZrO}_{2}$ & 0,71 & 0,42 & 0,48 \\
\hline Cs2O & 0,21 & 0,11 & 0,13 \\
\hline $\mathrm{Na}_{2} \mathrm{O}$ & 1,32 & 1,65 & 2,95 \\
\hline $\mathrm{K}_{2} \mathrm{O}$ & 0,67 & 0,49 & 0,50 \\
\hline \multirow[t]{2}{*}{$\begin{array}{l}\text { Content of sludge } \\
\text { oxides in the matrix }\end{array}$} & 50,0 & 50,0 & 50,0 \\
\hline & \multicolumn{3}{|l|}{ Frit composition } \\
\hline $\mathrm{SiO}_{2}$ & 32,0 & 32,0 & 32,0 \\
\hline $\mathrm{B}_{2} \mathrm{O}_{3}$ & 10,4 & 10,4 & 10,4 \\
\hline $\mathrm{Na}_{2} \mathrm{O}$ & 4,6 & 4,6 & 4,6 \\
\hline $\mathrm{Li}_{2} \mathrm{O}$ & 3,0 & 3,0 & 3,0 \\
\hline Synthesis temperature, ${ }^{\circ} \mathrm{C}$ & 1300 & 1300 & 1300 \\
\hline Time of synthesis & 3 hours & 3 hours & 3 hours \\
\hline Product & Glass-crystalline & Glass-crystalline & Glass-crystalline \\
\hline
\end{tabular}

Table 4. Phase composition of the glass-crystalline products.

\begin{tabular}{|c|c|c|c|}
\hline Charge composition & 15 & 25 & 35 \\
\hline Phase composition & $\begin{array}{l}\mathrm{U}(\mathrm{Fe}, \mathrm{Cr}) \mathrm{O}_{4} ; \\
\text { Solid solution } \mathrm{UO}_{2+x} ; \\
\mathrm{Fe}(\mathrm{Fe}, \mathrm{Cr})^{+3} \mathrm{O}_{4} \text { amorphous } \\
\text { phase }(70-75 \text { vol. } \%)\end{array}$ & $\begin{array}{l}\text { Solid solution } \mathrm{UO}_{2+x} \\
\mathrm{Fe}(\mathrm{Fe}, \mathrm{Cr})_{2} \mathrm{O}_{4} \\
\mathrm{UFeO}_{4} \text { amorphous phase } \\
(45-50 \text { vol.\%) }\end{array}$ & $\begin{array}{l}\mathrm{Na}_{2} \mathrm{U}_{2} \mathrm{O}_{7} ; \\
\text { Solid solution } \mathrm{UO}_{2+\mathrm{x}} ; \\
\mathrm{U}(\mathrm{Fe}, \mathrm{Cr})_{2} \mathrm{O}_{4} \text { amorphous } \\
\text { phase }(20-25 \text { vol. } \%)\end{array}$ \\
\hline
\end{tabular}

The additional heating of glass-crystalline compositions in the temperature interval $20-1000^{\circ} \mathrm{C}$ with the speed of heating $(10 \% \mathrm{~min})$ did not lead to the change of phase composition, which witnesses to the fact that the final solidified forms were thermally stable.

The homogeneity of crystalline phase distribution throughout the composition volume for $\mathrm{K}-25$ was assessed by the EMPA method. For this purpose, different parts of the ingot were sampled. The electronic photo of a sample is given in Fig. 1. 


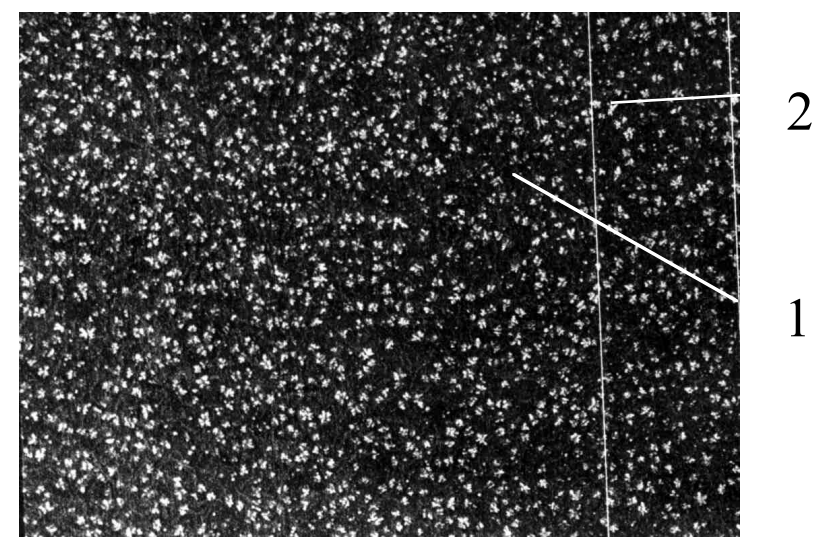

Magnification - 137x

Fig. 1. Electron photograph of sample K-25 with pulp: flux ratio 50:50 (mass. \%). (1) amorphous phase, (2) crystalline phase.

The data analysis showed that the composition of a glass matrix is enriched with silicon and aluminum for the glass-crystalline compositions K-25, containing 50 mass $\%$ of sludge oxides, and at the same time it is depleted in iron and uranium which form crystalline phases.

Uranium sedimentation was not found and crystalline phases are evenly distributed throughout the volume.

\section{Analysis of the Glass-Like Compositions on the Sludge Basis.}

To obtain a fully glassy-like matrix containing 50 mass $\%$ of sludge oxides, the compositions of the borosilicate frit was changed in accordance with thermodynamic calculations.

In comparison with the composition of fluxing additives, when glass-crystalline compositions were being obtained, the amount of the sum of lithium and sodium oxides was increased up to 15 mass $\%$, and the amount of glass-forming elements was decreased: silicon dioxide to 28 mass $\%$ and boron oxide to 7 mass $\%$.

The data on the glass compositions and synthesis conditions are given in Table 5. X-ray analysis data showed that the obtained glasses are $\mathrm{x}$-ray amorphous.

The glass density increases with the increase of the amount of uranium in sludge compositions; it reaches the value of $2,99 \mathrm{~g} / \mathrm{cm}^{3}$ for the composition $\mathrm{K}-15 \mathrm{G}$ and the value of $3,17 \mathrm{~g} / \mathrm{cm}^{3}$ for the composition K-35G. The density values of glass and glass-crystalline compositions, incorporating 50 mass $\%$ of sludge oxides, show very similar numbers.

\section{Crystallization of Glasses}

The assessment of glass stability to devitrification was performed by DTA method. The temperature values of exothermic effects caused by the crystallization process for the compositions K-15G, K-25G, K$35 \mathrm{G}$ were 700,680 , and $650^{\circ}$ correspondingly. The glass samples were thermally treated at the temperatures somewhere in the range of $650-700^{\circ} \mathrm{C}$ for 6 hours for their crystallization. The phase structure of the compounds formed in the process of crystallization is presented in Table 6. 


\section{Plutonium Glasses for Immobilization}

Table 5. Glass compositions.

\begin{tabular}{|c|c|c|c|}
\hline \multirow{2}{*}{ Oxides } & \multicolumn{3}{|c|}{ Matrix types } \\
\hline & $\mathrm{K}-15 \mathrm{G}$ & K-25G & K-35G \\
\hline $\mathrm{PuO}_{2}$ & 0.10 & 0.10 & 0.10 \\
\hline $\mathrm{UO}_{2}$ & 11.34 & 14.71 & 25.38 \\
\hline $\mathrm{Fe}_{2} \mathrm{O}_{3}$ & 9.05 & 20.69 & 4.75 \\
\hline $\mathrm{Cr}_{2} \mathrm{O}_{3}$ & 0.58 & 1.20 & 0.39 \\
\hline $\mathrm{NiO}$ & 1.58 & 1.68 & 0.88 \\
\hline $\mathrm{MnO}_{2}$ & 8.99 & 3.22 & 5.39 \\
\hline $\mathrm{Al}_{2} \mathrm{O}_{3}$ & 6.56 & 3.66 & 3.93 \\
\hline $\mathrm{SiO}_{2}$ & 4.77 & 1.23 & 2.95 \\
\hline $\mathrm{SrO}$ & 3.23 & 0.48 & 1.80 \\
\hline $\mathrm{CeO}_{2}$ & 0.56 & 0.38 & 0.42 \\
\hline $\mathrm{ZrO} 2$ & 0.71 & 0.42 & 0.48 \\
\hline $\mathrm{Cs}_{2} \mathrm{O}$ & 0.21 & 0.11 & 0.13 \\
\hline $\mathrm{Na}_{2} \mathrm{O}$ & 1.32 & 1.65 & 2.95 \\
\hline $\mathrm{K}_{2} \mathrm{O}$ & 0.67 & 0.49 & 0.50 \\
\hline \multirow[t]{2}{*}{$\begin{array}{l}\text { Content of sludge oxides in } \\
\text { the matrix }\end{array}$} & 50.0 & 50.0 & 50.0 \\
\hline & \multicolumn{3}{|c|}{ Glass frit (flux) } \\
\hline $\mathrm{SiO}_{2}$ & 28.0 & 28.0 & 28.0 \\
\hline $\mathrm{B}_{2} \mathrm{O}_{3}$ & 7.0 & 7.0 & 7.0 \\
\hline $\mathrm{Na}_{2} \mathrm{O}$ & 8.0 & 8.0 & 8.0 \\
\hline $\mathrm{Li}_{2} \mathrm{O}$ & 7.0 & 7.0 & 7.0 \\
\hline Temperature of synthesis, ${ }^{0} \mathrm{C}$ & 1200 & 1200 & 1200 \\
\hline Time of synthesis & 3 hours & 3 hours & 3 hours \\
\hline Product & Glass & Glass & Glass \\
\hline
\end{tabular}

$\mathrm{X}$-ray-phase analysis data show that 6 -hour heating of the samples at the temperatures equaling exothermic peaks leads to complete crystallization.

The prolongation of heating to 72 hours did not change the diffraction peaks shown in x-ray spectra, which bears witness to completion of the process of crystalline phase formation.

One can see from Table 6 that the phase composition of crystallization products of all glasses is practically identical.

Compounds with spinel structures, lithium silicate, and sodium diuranate are formed in glasses as basic crystalline phases. Depending on the composition of solidified sludge, only the quantitative ratio of these compounds changes. 


\section{Research and Development Plutonium Immobilization Contract Activities}

Table 6. Phase composition of the devitrified glasses.

\begin{tabular}{|c|c|c|c|c|c|}
\hline $\begin{array}{c}\text { Heat } \\
\text { treatment } \\
\text { condition }\end{array}$ & $\begin{array}{l}\text { Initial } \\
\text { sample }\end{array}$ & $\begin{array}{l}650^{\circ} \mathrm{C} \\
6 \text { hours }\end{array}$ & $\begin{array}{l}680^{\circ} \mathrm{C} \\
6 \text { hours }\end{array}$ & $\begin{array}{l}700^{\circ} \mathrm{C} \\
6 \text { hours }\end{array}$ & $\begin{array}{c}650-700^{\circ} \mathrm{C} \\
72 \text { hours }\end{array}$ \\
\hline Sample \# & \multicolumn{5}{|c|}{ Phase composition (the main phase is underlined) } \\
\hline $\mathrm{K}-15 \mathrm{G}$ & $\begin{array}{l}\text { X-ray } \\
\text { amorphous }\end{array}$ & $\begin{array}{l}\text { X-ray amorphous } \\
\text { phase, traces of } \\
\text { spinel structure } \\
\text { compound }\end{array}$ & $\begin{array}{l}\text { X-ray amorphous } \\
\text { phase, } \underline{\mathrm{Li}}_{2} \underline{\mathrm{SiO}}_{3} \\
\text { compound with spinel } \\
\text { structure }{ }_{2} \mathrm{Na}_{2} \mathrm{U}_{2} \mathrm{O}_{7}\end{array}$ & $\begin{array}{l}\underline{\mathrm{Li}}_{2} \underline{\mathrm{SiO}}_{3}{ }_{2} \text { compound } \\
\text { with spinel structure } \\
\underline{\mathrm{Na}_{2}} \underline{\mathrm{U}}_{2} \underline{\mathrm{O}}_{7}\end{array}$ & $\begin{array}{l}\mathrm{Li}_{2} \underline{\mathrm{SiO}}_{3}, \\
\text { compound with spinel } \\
\text { structure_Na } \mathrm{Na}_{2} \mathrm{U}_{2} \mathrm{O}_{7}\end{array}$ \\
\hline $\mathrm{K}-25 \mathrm{G}$ & $\begin{array}{l}\text { X-ray } \\
\text { amorphous }\end{array}$ & $\begin{array}{l}\text { X-ray-amorphous } \\
\text { phase, compound } \\
\text { with spinel } \\
\text { structure, } \mathrm{Li}_{2} \mathrm{SiO}_{3}\end{array}$ & $\begin{array}{l}\text { Compound with spinel } \\
\frac{\text { structure, } \mathrm{Na}_{2} \mathrm{U}_{2} \mathrm{O}_{7}}{\mathrm{Li}_{2} \mathrm{SiO}_{3}}\end{array}$ & $\begin{array}{l}\frac{\text { Compound with }}{\text { spinel structure, }} \\
\frac{\mathrm{Na}_{2} \mathrm{U}_{2} \mathrm{O}_{7}, \mathrm{Li}_{2} \mathrm{SiO}_{3}}{}\end{array}$ & $\begin{array}{l}\mathrm{Li}_{2} \mathrm{SiO}_{3}, \text { compound } \\
\text { with spinel structure } \\
\mathrm{Na}_{2} \mathrm{U}_{2} \mathrm{O}_{7}\end{array}$ \\
\hline $\mathrm{K}-35 \mathrm{G}$ & $\begin{array}{l}\text { X-ray } \\
\text { amorphous }\end{array}$ & $\begin{array}{l}\underline{\mathrm{Na}_{2}} \underline{\mathrm{U}_{2}} \underline{\mathrm{O}}_{2} \underline{\mathrm{O}}_{7_{2}} \\
\mathrm{Li}_{2} \mathrm{SiO} \\
\text { with spinel structure }\end{array}$ & $\begin{array}{l}\frac{\mathrm{Na}_{2}}{\mathrm{Li}_{2}} \underline{\mathrm{U}_{2}} \underline{\mathrm{S}}_{3} \underline{\mathrm{O}}_{z_{2}}, \text { compound with } \\
\text { spinel structure }\end{array}$ & $\begin{array}{l}\underline{\mathrm{Na}_{2}} \underline{\mathrm{U}}_{2} \underline{\mathrm{O}}_{7} \underline{\mathrm{O}}_{2} \\
\mathrm{Li}_{2} \mathrm{SiO}_{3}, \text { compound } \\
\text { with spinel structure }\end{array}$ & $\begin{array}{l}\underline{\mathrm{Na}_{2}} \underline{\mathrm{U}}_{2} \underline{\mathrm{O}}_{7} \underline{\mathrm{O}}_{2} \\
\mathrm{Li}_{2} \mathrm{SiO}_{3}, \text { compound } \\
\text { with spinel structure }\end{array}$ \\
\hline
\end{tabular}

\section{Spectrophotometric study of redox state of uranium in glasses for Pu immobilization}

To determine the redox state of uranium in the developed glass compositions (and thus to characterize in part the redox conditions in the corresponding systems), absorption spectra were measured for some of the compositions over the 350-2500 nm region. As follows from the work by Calas [4], who studied uranium oxidation states in magmatic silicate glasses in this spectral region, $\mathrm{U}(\mathrm{VI}), \mathrm{U}(\mathrm{V})$, and $\mathrm{U}(\mathrm{IV})$ can be reliably determined depending on the redox conditions. The following features were taken as the most characteristic [4]: a maximum at $424 \mathrm{~nm}$ and a shoulder near $490 \mathrm{~nm}$ for $\mathrm{U}(\mathrm{VI})$, maxima near 1400 and $1600 \mathrm{~nm}$ for $\mathrm{U}(\mathrm{V})$, and those near 1000 and $1850 \mathrm{~nm}$ for U(IV). Similar data were reported for U(VI) and $\mathrm{U}(\mathrm{V})$ in borosilicate glasses by Karraker [5] and Eller et al. [6].

The compositions studied in this work are shown in Tables 3 and 5.

Because of the high content of colorful elements in the batches ( $\mathrm{U}, \mathrm{Mn}, \mathrm{Fe}, \mathrm{Cr}$ ), the glasses are virtually not transparent in the visible and near infrared. Thus, samples for spectrophotometric measurements were prepared in the form of suspensions of finely ground pieces of the corresponding simulated compositions in Vaseline oil. The suspensions were placed between two plates of optical glass, thus forming a thin uniform layer. Absorption spectra of $U$ were measured at room temperature on an SF-8 spectrophotometer manufactured in Russia. The instrument, which was modified by analogy with Cary$17 \mathrm{H}$ (USA), has practically the same performance characteristics. The spectra of $U$ in the simulated compositions were measured either against air or against the samples of the corresponding compositions free of $U$.

In Fig. 2, the absorption spectrum of the glass-like composition developed in this work $K-35(G)$ is compared with $\mathrm{U}(\mathrm{VI})$ spectra in borosilicate glass [6], magmatic silicate glass [4], and in chloride melt. Comparison of the principal features of the spectrum of $\mathrm{K}-35(\mathrm{G})$ composition in Fig.2 (a maximum at 420 $\mathrm{nm}$ ) and a shoulder near $505 \mathrm{~nm}$ with those for borosilicate glass (416 and $485 \mathrm{~nm}$ ) and albite (424 and $490 \mathrm{~nm}$ ) suggests the redox state $\mathrm{VI}$ for uranium in our composition. Less pronounced features for $\mathrm{U}(\mathrm{VI})$ were observed for the $\mathrm{K}-25(\mathrm{G})$ composition, and no characteristic absorption bands were seen in the spectrum of $K-15(G)$. No features typical of $U(V)$ and/or $U(I V)$ were observed over the $500-2500 \mathrm{~nm}$ region for the compositions $\mathrm{K}-35(\mathrm{G}), \mathrm{K}-25(\mathrm{G})$, and $\mathrm{K}-15(\mathrm{G})$. 


\section{Plutonium Glasses for Immobilization}

An attempt was also made to measure the absorption spectra of $U$ in the glass-crystalline compositions $\mathrm{K}-35, \mathrm{~K}-25$, and $\mathrm{K}-15$ (see Table 3). No detectable amounts of either $\mathrm{U}(\mathrm{VI})$ or $\mathrm{U}(\mathrm{V}) \& \mathrm{U}(\mathrm{IV})$ were evidenced by the absorption spectra in the corresponding regions. It can be suggested that $\mathrm{U}(\mathrm{VI})$ is actually absent. The presence of $\mathrm{U}(\mathrm{V})$ and/or $\mathrm{U}(\mathrm{IV})$, whose molar absorptivities are an order of magnitude lower [5], cannot be excluded. As we know, there have been no successful attempts to measure the absorption spectra of crystalline uranium oxides, although the importance of such studies is well understood.

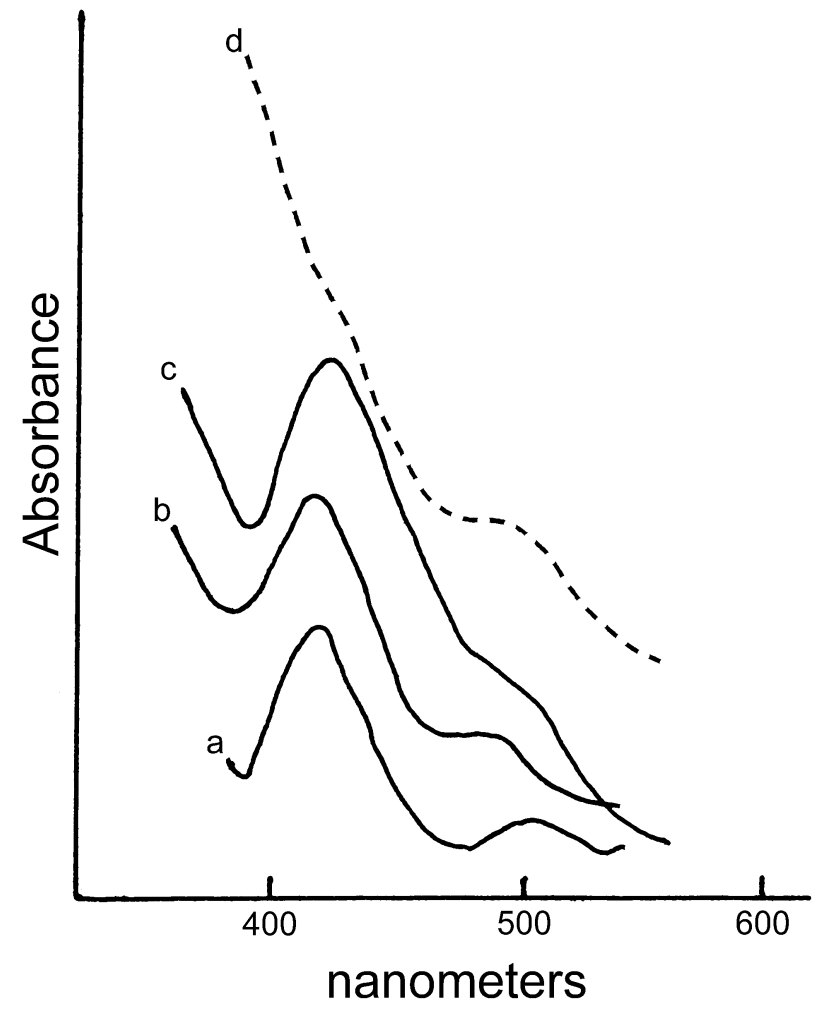

Fig. 2. Absorption spectra of uranium in glass-like systems: composition K-35G developed in this work (a), borosilicate glass [6] (b), albite [4] (c), and (for comparison) our data for U(VI) in LiCl$\mathrm{NaCl}-\mathrm{KCl}$ melt at $600^{\circ} \mathrm{C}(\mathrm{d})$.

\section{The influence of organics on the glass redox state}

The redox state of a sintered glasses was investigated by means of the iron redox ratio, $\mathrm{Fe}^{2+} / \mathrm{Fe}^{\text {total }}$, determined by Mossbauer Spectrometer MS $1101 \mathrm{E}$, under a regime of constant accelerations with the help of a gamma-resonance couple $\left[{ }^{57} \mathrm{Co}(\mathrm{Cr})\right.$ course] RSD 112 detector (convector $\mathrm{K}_{2} \mathrm{Mg}^{57} \mathrm{Fe}(\mathrm{CN})_{6}$ ) at room temperature.

Samples were prepared by pressing in the low-pressure polyethylene at $95^{\circ} \mathrm{C}$. The sample density is $1 \mathrm{mg} / \mathrm{cm}^{2}$ on Fe of natural isotope composition. Data treatment was carried out under a standard data treatment program with a Lorents line form. 
To produce oxidizing conditions, the main raw materials were taken in nitrate form, $\mathrm{H}_{3} \mathrm{BO}_{3}, \mathrm{H}_{3} \mathrm{PO}_{4}, \mathrm{SiO}_{2}$ and melted in air.

The reducing conditions were achieved by the use of carbonates for batch as well as ethylenglicol, which is industrially used at the PA Mayak vitrification plant.

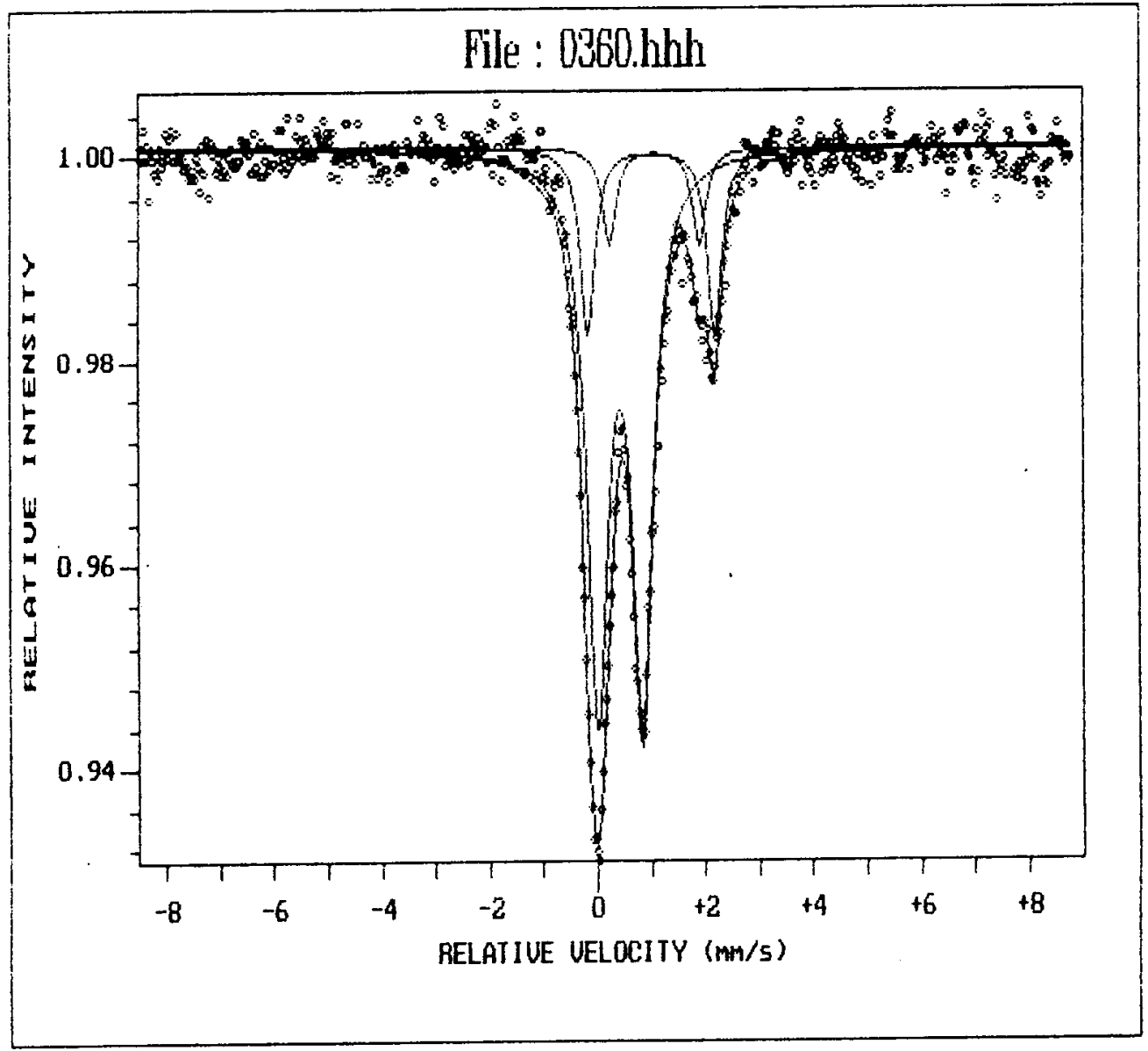

Fig. 3. The Mossbauer's spectrum of K-25 glass melted in the present of ethylenglicol. $\left(\mathrm{SP}-1, \mathrm{~V}=200, \mathrm{Fe}^{2+} / \mathrm{Fe}^{3+}=0,25\right)$.

The only Fe(III) was detected in the glass samples which were prepared from nitrates and carbonates. As it can be seen from Fig. 2, in the presence of ethylenglicol, the ratio $\mathrm{Fe}^{2+} / \mathrm{Fe}^{3+}$ was changed and the redox state became more reduced.

On the basis of analysis of the redox-state, glasses and their phase compositions, we showed that uranium in reducing conditions occurs in the form of $\left(\mathrm{UO}_{2}\right)^{2+}$, while in fully oxidizing conditions, it forms uranate or diuranate anions.

Basically, from the point of water durability glasses, the first case is more preferable. 


\section{Plutonium Glasses for Immobilization}

\section{The Chemical Stability of Borosilicate Compositions for Plutonium-Containing Sludge Immobilization.}

The most important parameter of safety and reliability is that of chemical stability of the compositions under investigation in reference to aqueous media,. This, to a great extent, is determined by the degree of immobilization of radioactive and/or stable elements in solidified forms.

Leachability tests were performed according to the MCC-1 [7] method.

The leaching was performed in deionized water at temperatures $25^{\circ} \mathrm{C}$ and $90^{\circ} \mathrm{C}$. The water was changed in 3,14 , and 28 days. The correlation of the square surface of the sample and the volume of the leachate was $1 / 10$.

At $90^{\circ} \mathrm{C}$, leaching was performed in stainless steel autoclaves with Teflon installed containers. The loss of water through their walls did not exceed $0.01 \mathrm{ml}$ per 24 hours. The tests at $25^{\circ} \mathrm{C}$ were performed in Teflon hermetic containers.

Leachate aliquots were sampled after each change of water. They were analyzed to estimate the amount of the basic components and $\mathrm{pH}$.

Special attention in the work was paid to the sorption of plutonium and uranium on the solid surfaces of the Teflon capsules, which is connected with the hydrolysis of these elements in a broad range of $\mathrm{pH}$.

In every case, conditions were chosen to perform complete desorption of radionuclides from the walls of the Teflon capsules, so that there might not be any loss of these elements and one might provide the quantitative transfer of uranium and plutonium into the leachate to measure its total activity. Thus, plutonium desorption was realized by applying 6-molar nitric acid solution with the addition of hydrogen dioxide $\left(\mathrm{H}_{2} \mathrm{O}_{2}\right)$ at $70^{\circ} \mathrm{C}$ in the course of 24 hours.

The study of the chemical stability of the compositions with similar concentration of sludge elements to be fixed allows us to compare the obtained data most accurately; this is done in order to identify the most stable compositions for their further application in real sludge solidification under production conditions.

When the normalized losses mass were calculated, an amendment was made for plutonium and uranium sorption.

Plutonium-239 in the form of oxide was introduced into the glass-crystalline compositions, as they are the most chemically stable ones. The specific activity of the samples for all compositions had the value of $14,47 \cdot 10^{4} \mathrm{Bk} / \mathrm{mg}$.

The values of the normalized loss mass of the elements in the compositions under study on the $28^{\text {th }}$ at $25^{\circ} \mathrm{C}$ and $90^{\circ} \mathrm{C}$ are presented as histograms in Figs. 4 and 5 .

The general tendency in the leaching process is the fact that uranium and plutonium are fixed more firmly than elements formed the network of glasses of all types at $25^{\circ} \mathrm{C}$ as well as at $90^{\circ} \mathrm{C}$. The values of normalized losses mass in the interval of $25-90^{\circ} \mathrm{C}$ for matrix elements as a rule differ by two orders of magnitude; whereas, these differences for uranium and plutonium comprise up to 5-10 times.

The obtained experimental values of leachability rates for both network elements and uranium and plutonium confirm the impact of the temperature effect, in that the rates increase by 2-100 times when the temperature of the leaching agent is increased from 25 to $90^{\circ} \mathrm{C}$ [8]. 


\section{Research and Development Plutonium Immobilization Contract Activities}

The behavior of uranium in the process of leaching differs considerably from matrix elements, and is determined by its valence state and its present chemical form in amorphous or crystalline compounds.

Glass-crystalline compositions in comparison with glasses and crystallized glasses have the lowest values of normalized losses of mass for uranium (Figs. 4,5). This phenomenon is connected to the fact that in glass-crystalline compositions, uranium may be found in the structure of compounds as $U(\mathrm{IV})$ and $\mathrm{U}(\mathrm{V})$, whereas in glasses it may be found mainly in $\mathrm{U}(\mathrm{VI})$. The main part of uranium in crystallized glasses enters the structure of sodium diuranate, which is a soluble enough compound; that is why its leachability rate in crystallized glasses has the greatest value.

The elements of variable valence, such as $\mathrm{Fe}, \mathrm{Cr}, \mathrm{Ni}, \mathrm{Mn}$, are fixed most firmly in glass-crystalline compositions, as they enter the structure of crystalline compounds of the $\mathrm{U}(\mathrm{FeCr})_{2} \mathrm{O}_{4}$ type and spinels (Figs. 4,5).

The process of plutonium-239 transfer to the leachate has its distinctive features. The normalized mass losses and plutonium leachability rates in glass-crystalline compounds of all compositions at $25^{\circ} \mathrm{C}$ are in the range of $(2-8) \cdot 10^{-3} \mathrm{~g} / \mathrm{m}^{2}$ and $(0.5-2.3) \cdot 10^{-4} \mathrm{~g} / \mathrm{m}^{2}$ day; at $90^{\circ} \mathrm{C}$, these values increase only by two times. Thus, plutonium discharge depends on the temperature of leaching and the composition of the sludge inconsiderably.

Based on the results obtained, one can see that the values of the plutonium mass losses in glasscrystalline compositions have the same level of magnitudes as the different types of ceramics used for the solidification of plutonium-containing waste $[9,10]$. 
Plutonium Glasses for Immobilization
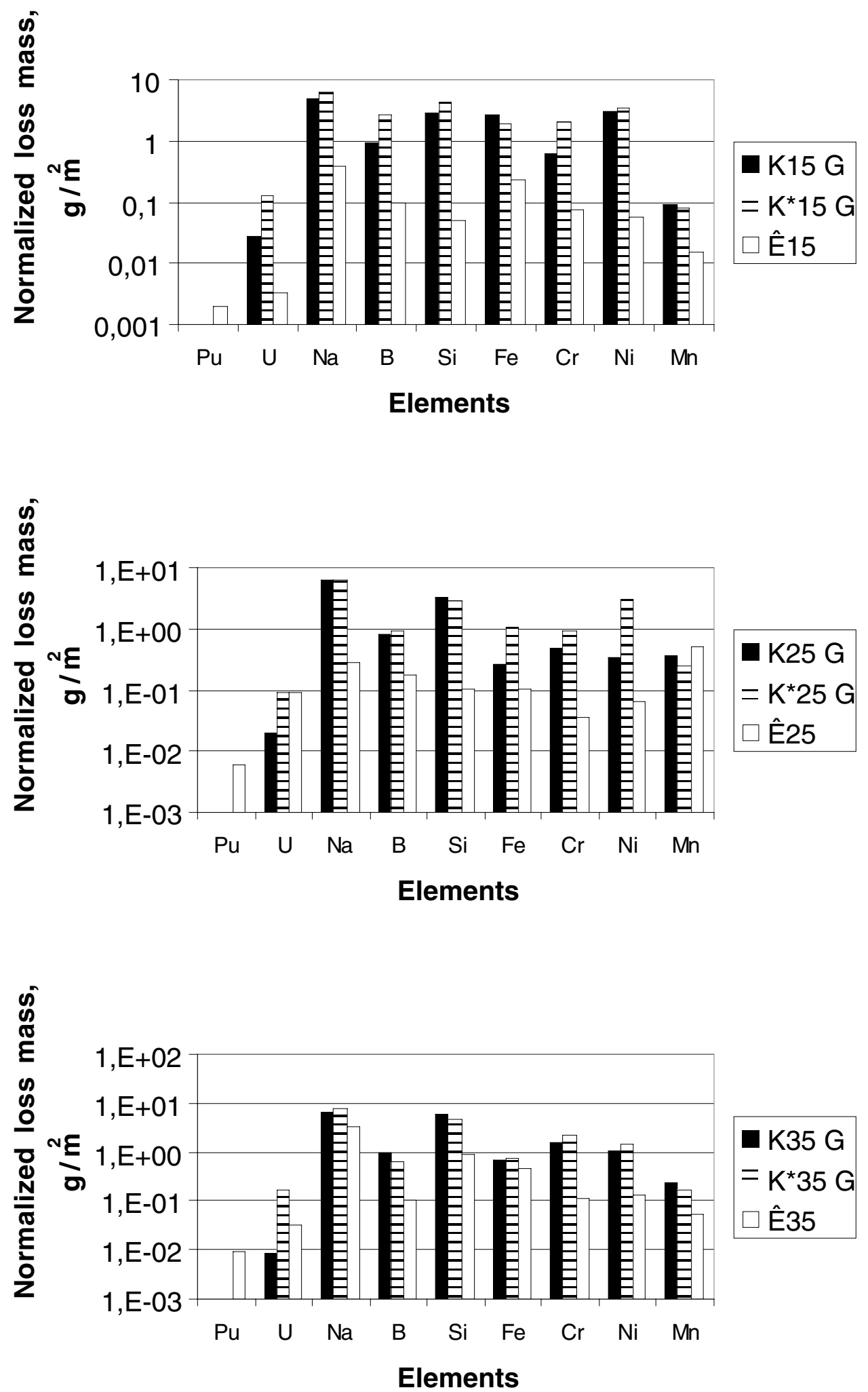

Fig. 4. The normalized release $\left(\mathrm{g} / \mathrm{m}^{2}\right)$ of elements from glass $\left(y_{0}\right)$, devitrified glass (三) and glasscrystalline $(\mathrm{m})$ during a leaching experiment carried out at a temperature of $25^{\circ} \mathrm{C}$. 

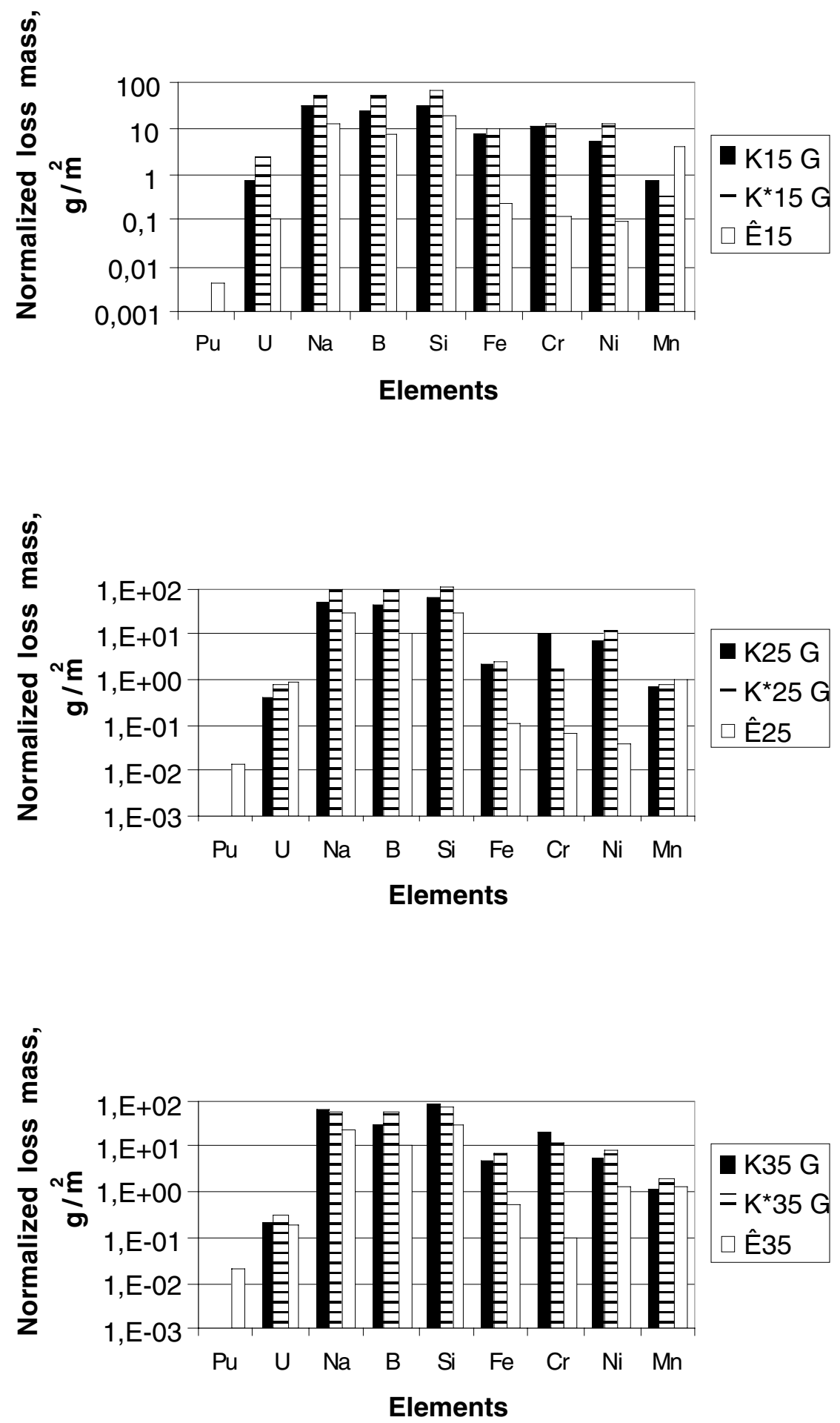

Fig. 5. The normalized release $\left(\mathrm{g} / \mathrm{m}^{2}\right)$ of elements from glass $\left(y_{0}\right)$, devitrified glass $\equiv$ and glass-crystalline $(\mathrm{m})$ during a leaching experiment carried out at a temperature of $90^{\circ} \mathrm{C}$. 


\section{Plutonium Glasses for Immobilization}

\section{Conclusions}

1. In glass-crystalline compositions uranium mainly enters the structure of chemically stable crystalline compounds which are evenly distributed throughout the volume of the sample.

2. All glass-like compositions are thermally stable up to $650^{\circ} \mathrm{C}$.

3. Uranium enters in the form $\mathrm{U}(\mathrm{VI})$ into a network in glass-like compositions, and it is evenly distributed in the volume.

4. The formation of compounds where uranium may be found as $U(I V)$ and $U(V)$ is characteristic of glass-crystalline compositions. Sodium diuranate and $\mathrm{U}(\mathrm{VI})$ state are formed during devitrification of glasses.

5. The chemical stability of the solidified form increases in the line devitrified glasses - glasses - glasscrystalline compositions.

6. The discharge of uranium from the compositions in the process of leaching is determined by its valence state.

7. The discharge of plutonium in the process of leaching depends on the temperature of leaching and sludge composition only inconsiderably.

8. The chemical stability of glass compositions can be compared with analogous values for different types of ceramics used for the solidification of plutonium-containing sludge.

\section{References}

1. A.A. Appen. Glass Chemistry. Khimiya Publishing House, p.18, 1974 (in Russian).

2. L.I.Demkina. Glass and Ceramics, \#10, 22, 1960 (in Russian).

3. R.M.Pavlushkin. Fundamentals of Sytalls Technology. Moscow, 303, 1970 (in Russian).

4. Calas G. // Geochimica et Cosmochimica Acta. 1979. Vol 43, P. 1521 - 1531.

5. Karraker D.G. // J. Am. Ceram. Soc. 1982. Vol. 65, N 1. P. 53-55.

6. Eller P.G., Jarvinnen G.D., Purson J.G., Penneman R.A., Ryan R.R., Lytle.

7. ASTM C1220-92, «Standard Test Method for Static Leaching of Monolithic Waste Forms for Disposal of Radioactive Waste», Annual Book of ASTM Standards.

8. Marples J.A.C., communication at IAEA Coordination Research Programme Meeting, Richland, Washington, June 1977.

9. J.D.Vienna, P.Hrma, M.J.Schweiger, and M.H.Langowski,\#Compositional Dependence of Elemental Release from HLW Glasses by the Product Consistency Test a One Component at-a Time Study\# in Ceram.Trans. in press 1997.

10. Jostsons A.,Vance E.R., Day R.A., Hart K.P.,Proc.of Int. Topic meeting on nuclear and hazardous waste management, 18-23 Aug., 1996, Seattle, USA. 


\section{Summary of Pu Ceramics Developed for Pu Immobilization [B338247, B501118]}

\section{B.E. Burakov, E.B. Anderson, KRI}

\section{Introduction: Part I [B338247]}

The V.G. Khlopin Radium Institute (KRI) has been carrying out investigations on radioactive waste management for many years, based upon the Russian technology of high-level wastes (HLW) partitioning [1-3]. This technology uses retention vitrification as a method for handling the Cs-Sr fraction of HLW and creates the conditions for more efficacious immobilization of the actinide (TRU) fraction using durable ceramics. There are also actinide-containing wastes of complex chemical composition that were formed as a result of nuclear weapons production in Russia and the US. These wastes can not be converted directly into ceramics, but the crystalline form can be used for their immobilization. Since 1990, the Radium Institute has researched different types of crystalline host-phases acceptable for the immobilization of TRU and other long-lived radionuclides, reserving vitrification technology for treatment of the Cs-Sr fraction of HLW (Fig. 1, [25]).

Theoretical and experimental investigations identified zircon, $(\mathrm{Zr}, \mathrm{An}) \mathrm{SiO}_{4}$ (where $\mathrm{An}=\mathrm{U}, \mathrm{Pu}, \mathrm{Np}, \mathrm{Am}, \mathrm{Cm}$ ), as one of the most durable host-phases for actinide immobilization; in particular, weapons-grade $\mathrm{Pu}$ [6$9,11-13,15,16,20]$. Moreover, it was found that amorphous zirconium hydrosilicate (AZHS) used as a precursor for zircon synthesis through the sol-gel method is also a chemically durable material that has a stable natural analogue, "gel-zircon" [17,18]. Therefore, in some cases, interim stabilization of actinide wastes can be provided during the stage of initial precursor preparation. Another actinide host-phase, zirconia, $(\mathrm{Zr}, \mathrm{An}, \ldots) \mathrm{O}_{2}$, was selected by the Radium Institute on the basis of published data $[4,5,8-10,13-$ 16]. The fourth type of crystalline ceramic, based upon garnet/perovskite $(\mathrm{Y}, \mathrm{Gd}, \mathrm{Ca}, \mathrm{Fe}, \ldots)_{3}$ $(\mathrm{Al}, \mathrm{Ga}, \mathrm{Fe}, \ldots)_{5} \mathrm{O}_{12} /\left(\mathrm{Y}, \mathrm{Gd}, \mathrm{Ca}\right.$..) $(\mathrm{Al}, \mathrm{Ga}, \mathrm{Fe}, \ldots) \mathrm{O}_{3}$ host-phases [21,22], is under consideration at $\mathrm{KRI}$ for immobilization of actinide-containing wastes of complex chemical composition. These wastes may contain from 30 to $88 \mathrm{wt} \%$ of $\mathrm{Pu}, 20 \mathrm{wt} \% \mathrm{U}$, and $5 \mathrm{wt} \%$ each of $\mathrm{Am}$ and Th. Other contents of the wastes include $\mathrm{Al}, \mathrm{Ca}, \mathrm{C}, \mathrm{Cr}, \mathrm{Ga}, \mathrm{Cl}, \mathrm{Fe}, \mathrm{K}, \mathrm{Na}, \mathrm{Ni}, \mathrm{Si}, \mathrm{Sr}, \mathrm{Ta}, \mathrm{W}$, and $\mathrm{Zn}$ in different proportions [22]. It is suggested that the combination of garnet with perovskite provides the possibility of incorporation in their lattices of almost all multivalent actinides and most of the non-radioactive elements, avoiding the formation of separated actinide phases. An additional attractive feature of garnet/perovskite ceramic is that it can be synthesized by the melting method instead of hot pressing. A summary of KRI activity in the field of actinide waste immobilization is shown in Fig. 2 [25]. It is necessary to note that at present the Russian Ministry of Atomic Energy (Minatom) does not consider weapons- zirconia-based grade Pu as a "waste" and requires its immobilization as a nuclear fuel. Therefore, this may provide, in the future, a possible universal application of ceramic-like Pu-fuel as well as a waste form. In the framework of Agreement B338247 (1997/98), the Radium Institute has carried out the synthesis and investigation of the following ceramic samples doped with $10 \mathrm{wt} \%{ }^{239} \mathrm{Pu}$ : zircon/zirconia (80 wt\% ( $\left.\left.\mathrm{Zr}, \mathrm{Pu}\right) \mathrm{SiO}_{4} / 20 \mathrm{wt} \%(\mathrm{Zr}, \mathrm{Pu}) \mathrm{O}_{2}\right)$; monozirconia, $(\mathrm{Zr}, \mathrm{Gd}, \mathrm{Pu}) \mathrm{O}_{2}$; and the US-type ceramic based on pyrochlore, $\mathrm{Ca}(\mathrm{Gd}, \mathrm{Hf}, \mathrm{Zr}, \mathrm{U}) \mathrm{Ti}_{2} \mathrm{O}_{7}$.

The three main goals of that research are to:

- Adapt previous experience of ceramic synthesis using actinide surrogates (e.g., Ce, Eu) for experiments with $\mathrm{Pu}$ and $\mathrm{Am}$; 


\section{Plutonium Ceramics for Immobilization}

- Determine the optimal formulation and synthesis conditions for Pu-doped zircon/zirconia and monozirconia ceramics;

- Obtain samples (0.5-1.5 g each) of Pu-doped ceramics (zircon/zirconia; mono-zirconia, and pyrochlore) and compare their features using scanning electron microscopy (SEM), x-ray powder diffraction (XRD), leach testing, and Pu recovery tests at KRI and VNIINM.

In the first year, this work will be done with the existing KRI glove box equipment. Additional equipment such as a high-temperature $\left(1500^{\circ} \mathrm{C}\right)$ furnace, low-temperature $\left(900^{\circ} \mathrm{C}\right)$ calcining furnace, cold press, etc., should be acquired and installed in the glove-boxes.

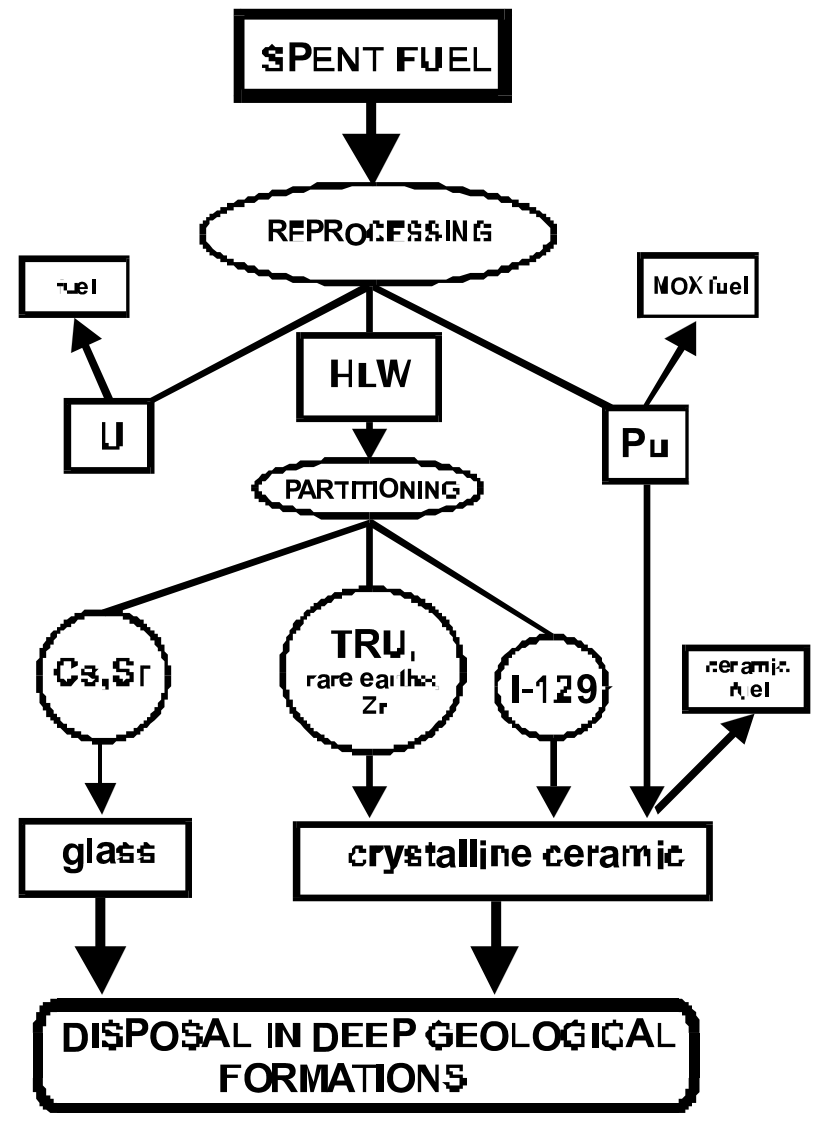

Fig. 1. Simplified version of the KRI approach to immobilization of HLW [25]. 


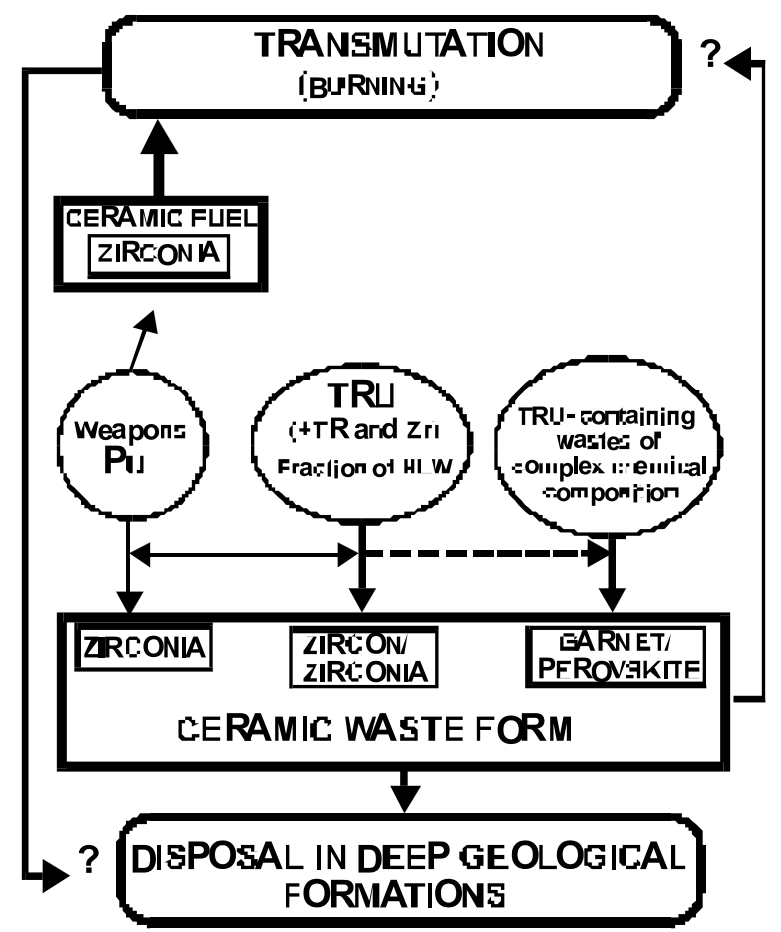

Fig. 2. General schedule of ceramic application for immobilization of actinide (TRU) wastes [25].

\section{Experimental}

The main difficulty in the fabrication of a doped ceramic is to avoid the formation of separated actinide phases while at the same time providing acceptable mechanical durability of the designed ceramic. It is required that all the actinide be incorporated into the crystalline structure of the mineral host-phases in the form of substitutional solid solution. An additional problem is that there are special restrictions concerning $\mathrm{Pu}$ handling and, therefore, selection of the synthesis methods is limited. Because of these reasons, in the first stage of experiments using Pu-surrogates, we have considered different precursors and various synthesis conditions (Table 1) to obtain samples of zircon/zirconia and mono-zirconia ceramics through appropriate methods. The features of the formulation and fabrication of US-type pyrochlore-based ceramics were presented to Dr. Burakov by the US specialists during his visit to LLNL in November 1997. Samples of Ce-doped pyrochlore ceramic and non-radioactive components of precursor were received from LLNL, also.

Results of experiments with Pu-surrogates allowed us to select optimal conditions for the synthesis of Pudoped samples. We decided to use sol-gel precursor for the fabrication of zircon/zirconia ceramic (Fig.3b); co-precipitated Zr-Gd-Pu oxalates for the synthesis of mono-zirconia ceramic; and a mixture of oxide powders (non-radioactive part of the precursor delivered from $\mathrm{LLNL} ; \mathrm{UO}_{2}$ and $\mathrm{PuO}_{2}$ provided by $\mathrm{KRI})$ for pyrochlore ceramic. All samples were obtained through sintering of cold pressed pellets in air (Tables 2-6) in a special furnace (Fig. 4).

In the experiments carried out in 1987-88, the use of the previous LLNL blend caused melting of final Pudoped pyrochlore ceramic. Melting commenced at $1310^{\circ} \mathrm{C}$ and complete melting was observed at $1380^{\circ} \mathrm{C}$ (Sample P-2). Only at $1280^{\circ} \mathrm{C}$, which is $70^{\circ} \mathrm{C}$ less than required in the LLNL 


\section{Plutonium Ceramics for Immobilization}

Table 1. The features of experiments on ceramic synthesis using Pu-surrogates.

\begin{tabular}{|c|c|c|}
\hline Type of ceramic & Precursor & Method of synthesis \\
\hline \multirow[t]{2}{*}{ 1. $(\mathrm{Zr}, \mathrm{U}) \mathrm{SiO}_{4}+(\mathrm{Zr}, \mathrm{U}) \mathrm{O}_{2}$} & $\mathrm{Zr}_{\text {metal }}, \mathrm{U}_{3} \mathrm{O}_{8}, \mathrm{SiO}_{2}$ amorph & $\begin{array}{l}\text { Cold pressing, sintering in air, } \\
\mathrm{T}=1500^{\circ} \mathrm{C}, \mathrm{t}=1 \text { hour }\end{array}$ \\
\hline & $\mathrm{Zr}_{\text {metal }}, \mathrm{CeO}_{2}, \mathrm{SiO}_{2}$ amorph & $\begin{array}{l}\text { Hot pressing in air } \\
\mathrm{T}=1300,1400,1500^{\circ} \mathrm{C} \\
\mathrm{P}=25 \mathrm{MPa}, \mathrm{t}=1 \text { hour }\end{array}$ \\
\hline \multirow[t]{2}{*}{$\begin{array}{l}\text { 2. }(\mathrm{Zr}, \mathrm{Ce}) \mathrm{SiO}_{4}+ \\
(\mathrm{Zr}, \mathrm{Ce}) \mathrm{O}_{2}\end{array}$} & Sol-gel $(\mathrm{Zr}, \mathrm{Ce}) \mathrm{SiO}_{\mathrm{x}}$ & $\begin{array}{l}\text { Sintering in air, } \\
T=1300,1400,1500,1600,1620^{\circ} \mathrm{C}, \\
t=1 \text { hour }\end{array}$ \\
\hline & $\begin{array}{l}\text { Co-precipitated } \\
\mathrm{Zr}-\mathrm{Ce} \text { oxalates } \\
\text { after plasma calcination, } \\
\mathrm{SiO}_{2 \mathrm{amorph}}\end{array}$ & $\begin{array}{l}\text { Cold pressing, sintering in air, } \\
\mathrm{T}=1600^{\circ} \mathrm{C}, \mathrm{t}=1 \text { hour }\end{array}$ \\
\hline $\begin{array}{l}\text { 3. }(\mathrm{Zr}, \mathrm{Gd}) \mathrm{SiO}_{4}+ \\
(\mathrm{Zr}, \mathrm{Gd}) \mathrm{O}_{2}\end{array}$ & Sol-gel $(\mathrm{Zr}, \mathrm{Gd}) \mathrm{SiO}_{\mathrm{x}}$ & $\begin{array}{l}\text { Sintering in air, } \\
T=1300,1400,1500,1600,1620^{\circ} \mathrm{C} \\
t=1 \text { hour }\end{array}$ \\
\hline 4. $(\mathrm{Zr}, \mathrm{Ce}) \mathrm{O}_{2}$ & $\begin{array}{l}\text { Co-precipitated } \\
\text { Zr-Ce oxalates }\end{array}$ & $\begin{array}{l}\text { Plasma-calcination } \\
\text { (+ hot pressing ) }\end{array}$ \\
\hline 5. $(\mathrm{Zr}, \mathrm{Gd}) \mathrm{O}_{2}$ & $\begin{array}{l}\text { Co-precipitated } \\
\text { Zr-Gd oxalates }\end{array}$ & $\begin{array}{l}\text { Cold pressing, sintering in air, } \\
\mathrm{T}=1000^{\circ} \mathrm{C}, \mathrm{t}=1 \text { hour }\end{array}$ \\
\hline
\end{tabular}

recipe, were acceptable ceramic samples obtained (Sample P-1). Despite the final amount of ceramic, there were enough samples (Fig. 6) for all necessary investigations, including the recovery tests at KRI and VNIINM. We recognized that additional samples would be very useful to verify the results of both Institutes in the frame of the next Agreement. Particular attention should be paid to understand the reason for pyrochlore melting.
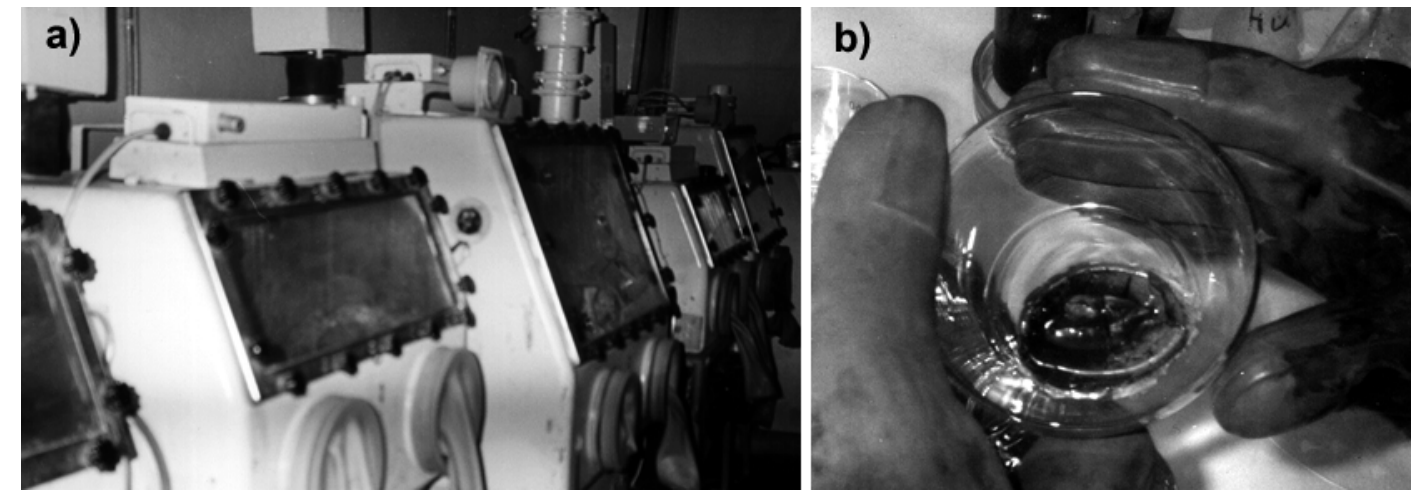

Fig. 3. (a) Glove-box chain for precursor preparation and synthesis of Pu-doped ceramic samples; (b) solidified gel containing $\sim 1 \mathrm{~g}$ of ${ }^{239} \mathrm{Pu}$ (calculated on metal) for the synthesis of zircon/zirconia ceramics. 

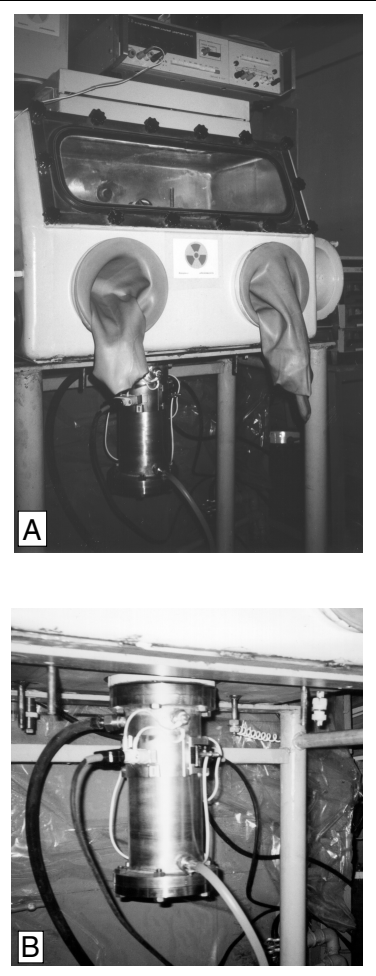

Fig. 4. Furnace \#1 attached to glove-box for ceramic synthesis by sintering in air: (a) general view; (b) detailed image. It contains graphite close to the high-temperature zone that places $\mathrm{CO}$ in contact with the ceramic pellets during synthesis.

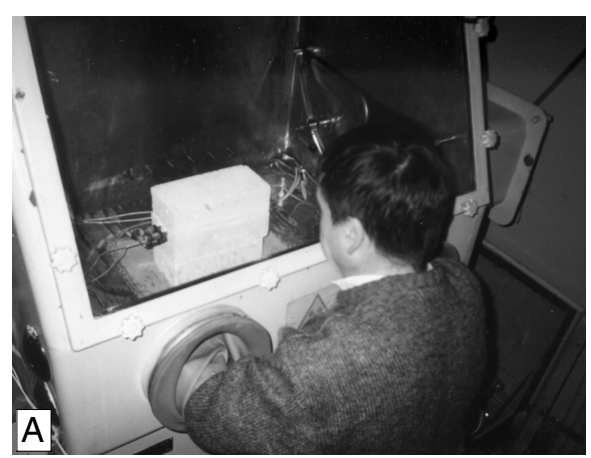

Fig. 5. Furnace \#2 made of porous alumina for ceramic synthesis bu sintering in air: (a) general view; (b) furnace is open and 7 pellets of Pu ceramics are seen on the Pt foil.

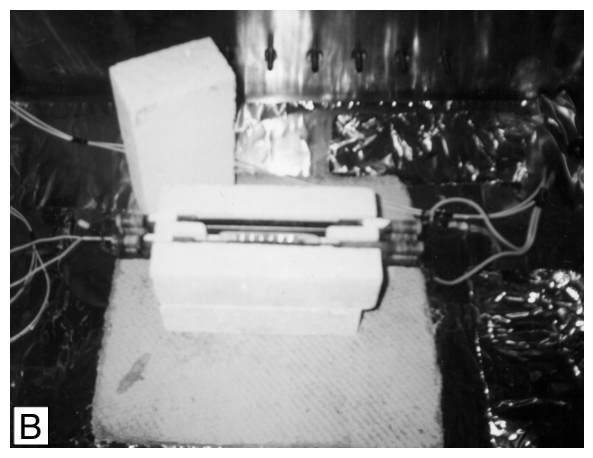




\section{Plutonium Ceramics for Immobilization}

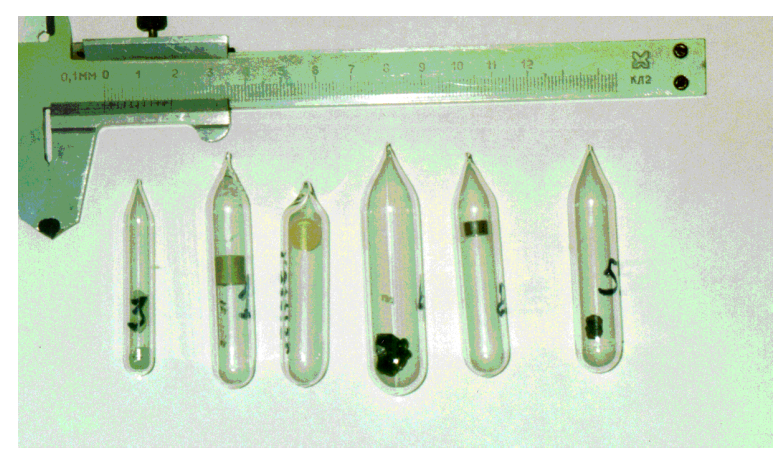

$\begin{array}{llllll}1 & 2 & 3 & 4 & 5 & 6\end{array}$

Fig. 6. Some samples of Pu-doped ceramics obtained in the framework of B338247: (1), (2) zircon/zirconia (ZIR-1 and ZIR-3); (3) ismono-zirconia (Z-1); (4) solidified calcined gel (amorphous zirconium hydrosilicate, the starting precursor for the synthesis of zircon/zirconia ceramic); (5) pyrochlore (P-1); and (6) melted pyrochlore (P-2).

\section{Introduction: Part II [B501118]}

\section{Experimental}

We decided to carry out synthesis of pyrochlore ceramic from old and new precursors in the new furnace made of porous alumina (Fig. 5). In comparison with the previous one (Fig. 4), this furnace does not contain any graphite close to the heating elements. The presence of heated graphite in the first furnace below the crucible (out from the high temperature zone) does not provide completely reducing conditions under sintering in air because the system is open. However, this can be considered like oxidationreduction buffer (CO) preventing complete oxidation of $\mathrm{U}^{4+}$ (from $\mathrm{UO}_{2}$ used in precursor) to $\mathrm{U}^{6+}$. Additional samples of zircon/zirconia and mono-zirconia ceramics doped with $10 \mathrm{wt} \%{ }^{239} \mathrm{Pu}$ were also obtained through sintering in new furnace (Tables 2, 3, 6, 7). In comparison with previous samples, new ones of zircon/zirconia ceramic were formulated on a higher amount of the zircon phase to understand the actual zircon structure capacity to incorporate plutonium. Also, we doubled (from 10 to $20 \mathrm{~mol} \%$ ) the $\mathrm{Gd}$ contents in the precursor of mono-zirconia ceramic to provide stabilization of the $100 \%$ cubic zirconia phase with fluorite-type structure. 
Table 2. Features of $\mathrm{Pu}$-doped zircon/zirconia $(\mathrm{Zr}, \mathrm{Pu}) \mathrm{SiO}_{4} /(\mathrm{Zr}, \mathrm{Pu}) \mathrm{O}_{2}$ ceramic samples synthesized by sintering in air.

\begin{tabular}{|c|c|c|c|c|c|c|c|c|c|}
\hline \multirow[t]{2}{*}{ \# } & \multicolumn{2}{|c|}{ Sintering conditions } & \multirow[t]{2}{*}{$\begin{array}{c}\text { Ceramic } \\
\text { density, } \\
\text { g/cm }\end{array}$} & \multicolumn{5}{|c|}{$\begin{array}{c}\text { Yield in wt\% } \\
\text { (MZ - monoclinic zirconia, } \\
\text { TZ - tetragonal zirconia) }\end{array}$} & \multirow[t]{2}{*}{$\begin{array}{l}\text { Zircon cell } \\
\text { parameters, } \\
\text { angstroms }\end{array}$} \\
\hline & time & $\mathbf{T},{ }^{\circ} \mathbf{C}$ & & Zircon & $\mathrm{PuO}_{2}$ & $\mathrm{SiO}_{2}$ & MZ & TZ & \\
\hline ZIR-1 & 1 hour & 1490 & $3.1-3.2$ & 10-20 & - & 20 & 40 & 20 & $\begin{array}{l}a=6.597 \pm 0.005 \\
c=5.972 \pm 0.006\end{array}$ \\
\hline ZIR-2 & 1 hour, 30 min & 1500 & 3.3 & 75 & $8-10 ?$ & 5 & \begin{tabular}{|l} 
less \\
1 \\
\end{tabular} & 10 & $\begin{array}{l}a=6.609 \pm 0.004 \\
c=5.984 \pm 0.004\end{array}$ \\
\hline ZIR-3 & 3 hours, $15 \mathrm{~min}$ & 1490 & 3.7 & 80 & $\begin{array}{l}\mathrm{Pu}_{0.5} \mathrm{Zr}_{0.5} \mathrm{O}_{2} ? \\
1-3\end{array}$ & - & $1-3$ & 15 & $\begin{array}{l}a=6.615 \pm 0.004 \\
c=5.990 \pm 0.004\end{array}$ \\
\hline ZIR-4 & $\begin{array}{l}4 \text { hours } \\
3 \text { hours, } 15 \mathrm{~min}\end{array}$ & $\begin{array}{l}1450 \\
1500\end{array}$ & 3.4 & $96-98$ & $2-3$ & - & $\begin{array}{l}\text { less } \\
0.5\end{array}$ & $\begin{array}{l}\text { less } \\
0.5\end{array}$ & $\begin{array}{l}a=6.636 \pm 0.003 \\
c=5.994 \pm 0.003\end{array}$ \\
\hline
\end{tabular}

Table 3. Features of $\mathrm{Pu}$-doped mono-zirconia $(\mathrm{Zr}, \mathrm{Gd}, \mathrm{Pu}) \mathrm{O}_{2}$ ceramic samples synthesized by sintering in air.

\begin{tabular}{|c|c|c|c|c|c|c|c|c|}
\hline \multirow[t]{2}{*}{ \# } & \multirow[t]{2}{*}{$\begin{array}{c}\text { Gd } \\
\text { contents, } \\
\text { mol\% }\end{array}$} & \multicolumn{2}{|c|}{ Sintering conditions } & \multirow[t]{2}{*}{$\begin{array}{c}\text { Ceramic } \\
\text { density, } \\
\text { g/cm }\end{array}$} & \multicolumn{4}{|c|}{$\begin{array}{c}\text { Yield (in wt\%) of zirconia: } \\
\text { CZ - cubic, MZ - monoclinic } \\
\text { TZ - tetragonal }\end{array}$} \\
\hline & & time & $\mathbf{T},{ }^{\circ} \mathbf{C}$ & & $\mathrm{CZ}$ & TZ & MZ & $\mathrm{PuO}_{2}, \mathrm{Gd}_{2} \mathrm{O}_{3}$ \\
\hline Z-1 & 10 & $2 \mathrm{~h}$ & 1300 & 4.6 & $40-45$ & 50 & $5-10$ & - \\
\hline Z-2 & 20 & $\begin{array}{l}4 \mathrm{~h} \\
3 \mathrm{~h}, 15 \mathrm{~min}\end{array}$ & $\begin{array}{l}1450 \\
1500\end{array}$ & 5.6 & 100 & - & - & - \\
\hline
\end{tabular}

Table 4. Features of US-Pyrochlore ceramic samples synthesized by sintering in air (in the presence of $\mathrm{CO}$ and not).

\begin{tabular}{|c|c|c|c|c|c|c|c|c|c|}
\hline \multirow[t]{2}{*}{ \# } & \multicolumn{2}{|c|}{ Sintering conditions } & \multirow{2}{*}{$\begin{array}{l}\text { Ceramic } \\
\text { density } \\
\mathrm{g} / \mathrm{cm}^{3}\end{array}$} & \multicolumn{6}{|c|}{ Yield in wt. \% ( Bran. -brannerite, Pyr.-pyrochlore) } \\
\hline & time & $\begin{array}{l}\mathrm{T},{ }^{\circ} \mathrm{C} \\
\text { precursor }\end{array}$ & & Bran & $\mathrm{UO}_{2}$ & $\mathrm{PuO}_{2}$ & Pyr. & $\begin{array}{l}\left(\mathrm{U}_{0.72} \mathrm{Pu}_{0.28}\right) \mathrm{O}_{2-\mathrm{x}} \\
\text { close to } \mathrm{PuO}_{2}\end{array}$ & $\mathrm{TiO}_{2}$ \\
\hline $\mathbf{P}-1$ & $4 \mathrm{~h}$ & $\begin{array}{l}1280 \\
\text { «old» precursor } \\
\text { in presence of } \mathrm{CO}\end{array}$ & 4.7 & 1 & - & - & $95-97$ & less 1 & $1-3$ \\
\hline $\begin{array}{l}\mathbf{P}-\mathbf{2} \\
\text { melted }\end{array}$ & $4 \mathrm{~h}$ & $\begin{array}{l}1380 \\
\text { «old» precursor } \\
\text { in presence of } \mathrm{CO}\end{array}$ & $?$ & 5 & $5-7$ & $3-5$ & 75 & - & $<1$ \\
\hline P-3 & $4 \mathrm{~h}$ & $\begin{array}{l}1350 \\
\text { «old» precursor } \\
\text { no CO }\end{array}$ & 5.0 & $3-5$ & - & + & $90-95$ & 3-5 (or $\mathrm{PuO}_{2}$ ) & traces \\
\hline P-4 & $4 \mathrm{~h}$ & $\begin{array}{l}1350 \\
\text { «new» precursor } \\
\text { no CO }\end{array}$ & 4.9 & $1-3$ & - & + & $90-95$ & $1-3\left(\right.$ or $\left.\mathrm{PuO}_{2}\right)$ & $1-3$ \\
\hline
\end{tabular}




\section{Plutonium Ceramics for Immobilization}

Table 5. Average chemical composition (from microprobe analysis) of pyrochlore phase in different ceramic samples (in wt/at\%).

\begin{tabular}{|l|c|l|l|l|l|l|l|}
\hline \hline \multicolumn{1}{|c|}{$\#$} & Hf & Ca & Gd & \multicolumn{1}{c|}{ Pu } & Ti & U & O \\
\hline P-1 & $9.3 / 2.3$ & $7.7 / 8.5$ & $7.5 / 2.1$ & $15.4 / 2.8$ & $18.6 / 17.1$ & $18.4 / 3.4$ & $23.2 / 63.8$ \\
\hline $\begin{array}{l}\text { P-2 } \\
\text { Melted }\end{array}$ & $9.3 / 2.0$ & $7.7 / 7.4$ & $5.3 / 1.3$ & $9.0 / 1.4$ & $25.8 / 20.9$ & $16.5 / 2.7$ & $26.4 / 64.2$ \\
\hline P-3 & $7.1 / 1.7$ & $8.2 / 8.9$ & $7.4 / 2.1$ & $10.7 / 1.9$ & $19.0 / 17.4$ & $23.1 / 4.2$ & $23.3 / 63.7$ \\
\hline P-4 & $8.1 / 2.0$ & $8.1 / 8.7$ & $7.6 / 2.1$ & $9.0 / 1.6$ & $19.7 / 17.7$ & $23.1 / 4.2$ & $23.6 / 63.6$ \\
\hline
\end{tabular}

\section{Summary of Results and Discussion [B338247 and B501118]}

\section{Zircon/zirconia, $(\mathrm{Zr}, \mathrm{Pu}) \mathrm{SiO}_{4} /(\mathrm{Zr}, \mathrm{Pu}) \mathrm{O}_{2}$}

- Samples ZIR-1,2,3 (Agreement B338247). Designed as $80 \mathrm{wt} \%$ zircon/20 wt\% zirconia;

- Sample ZIR-4 (Agreement B501118) - designed as more then $99 \mathrm{wt} \%$ zircon and the rest as zirconia.

The main features of the zircon/zirconia ceramics are summarized in Table 2.

Small grain size $(<2 \mu \mathrm{m})$ of single phases in Pu-doped samples ZIR-1, -2 , and -3 made EPMA difficult. However, Pu (in metal estimation) from 12.1 to $15.0 \mathrm{wt} \%$ was measured in some aggregates of zirconia in sample ZIR-3. Zircon grains in the matrix of Sample ZIR-4 had sizes ranging from 35 to 20-30 $\mu$ m, which allowed correct microprobe analysis: Zr-45.4 wt\%; Pu-6.9 wt\%; and Si-15.2 wt\%. This means that the sintering temperature of $1500^{\circ} \mathrm{C}$ was not optimal for $10 \mathrm{wt} \% \mathrm{Pu}$ incorporation into the zircon structure; this caused the conversion of part of the $\mathrm{Pu}$ to separate into $\mathrm{PuO}_{2}$ inclusions. Leach test data (Tables 5, 6) show the highest $\mathrm{Pu}$ loss for zircon/zirconia ceramics, confirming the presence of separate form of $\mathrm{Pu}$ in the ceramic matrices. Probably, the zirconia phase in the zircon/zirconia ceramic is an important component, not only for trivalent actinides incorporation, but also, in some cases, it can increase the limit of Pu loading. Additional study of the zircon lattice capacity to incorporate Pu is required.

\section{Mono-zirconia, $(\mathrm{Zr}, \mathrm{Gd}, \mathrm{Pu}) \mathrm{O}_{2}$}

- Sample Z-1 (Agreement B338247). Designed as $100 \mathrm{wt} \%$ cubic zirconia stabilized by $10 \mathrm{~mol} \%$ Gd;

- Sample Z-2 (Agreement B501118). Designed as $100 \mathrm{wt} \%$ cubic zirconia stabilized by $20 \mathrm{~mol} \%$ Gd.

The main features of mono-zirconia ceramics are summarized in Table 3. As we found, $20 \mathrm{~mol} \% \mathrm{Gd}$ is optimal for stabilization of the cubic (fluorite type) zirconia phase. The lack of $\mathrm{Gd}$ (sample Z-1) caused the formation of two zirconia phases: tetragonal and cubic. However, the matrices of both samples obtained were characterized as homogeneous. No separate Pu- or Gd-phases were found in their matrices. And also, higher temperature and longer sintering decreased ceramic porosity. 


\section{Research and Development Plutonium Immobilization Contract Activities}

Table 6. Leach test (MCC-1, modified, in deionized water at $\mathrm{T}=90^{\circ} \mathrm{C}$ ) data for Pu-doped ceramic samples.

\begin{tabular}{|c|c|c|c|c|}
\hline \multirow{2}{*}{$\begin{array}{l}\text { Designed formulation } \\
\text { ( 10 wt\% Pu loading) }\end{array}$} & \multirow{2}{*}{$\begin{array}{c}\text { Precursor and } \\
\text { syntesis conditions }\end{array}$} & \multirow[t]{2}{*}{ Days } & \multicolumn{2}{|c|}{$\mathrm{NL}\left(\mathrm{g} / \mathrm{m}^{2}\right)$} \\
\hline & & & ${ }^{239} \mathrm{Pu}$ & ${ }^{241} \mathrm{Am}$ \\
\hline \multicolumn{5}{|c|}{ Obtained in the frame of Material Support Agreement \#B338247 } \\
\hline Sample ZIR-1 & sol-gel, & 3 & $1,4 \mathrm{E}-01$ & $9,5 \mathrm{E}-01$ \\
\hline$(\mathrm{ZrPu}) \mathrm{SiO}_{4} /(\mathrm{Zr}, \mathrm{Pu}) \mathrm{O}_{2}$ & nonmilled & 14 & $2,0 \mathrm{E}-01$ & $6,9 \mathrm{E}+00$ \\
\hline in wt\% : 80/20 & $1490^{\circ} \mathrm{C} / 1 \mathrm{~h}$ & 28 & $2,2 \mathrm{E}-01$ & $9,3 \mathrm{E}+00$ \\
\hline Sample ZIR-2 & sol-gel, & 3 & $5,3 \mathrm{E}-02$ & $4,7 \mathrm{E}+00$ \\
\hline$(\mathrm{ZrPu}) \mathrm{SiO}_{4} /(\mathrm{Zr}, \mathrm{Pu}) \mathrm{O}_{2}$ & milled, cold pressed & 14 & $3,4 \mathrm{E}-02$ & $7,4 \mathrm{E}+00$ \\
\hline in wt $\%: 80 / 20$ & $1500^{\circ} \mathrm{C} / 1,5 \mathrm{~h}$ & 28 & $3,5 \mathrm{E}-01$ & $7,6 \mathrm{E}+00$ \\
\hline Sample ZIR-3 & sol-gel & 3 & $2,7 \mathrm{E}-02$ & $1,8 \mathrm{E}+00$ \\
\hline$(\mathrm{ZrPu}) \mathrm{SiO}_{4} /(\mathrm{Zr}, \mathrm{Pu}) \mathrm{O}_{2}$ & milled, cold pressed & 14 & $2,7 \mathrm{E}-01$ & $1,9 \mathrm{E}+00$ \\
\hline in wt $\%: 80 / 20$ & $1490^{\circ} \mathrm{C} / 3 \mathrm{~h} 15 \mathrm{~min}$ & 28 & $3,1 \mathrm{E}-01$ & $5,3 \mathrm{E}+00$ \\
\hline Sample Z-1 & co-precipitated & 3 & $<1,9 \mathrm{E}-03$ & $1,2 \mathrm{E}-01$ \\
\hline$(\mathrm{Zr}, \mathrm{Pu}, \mathrm{Gd}) \mathrm{O}_{2}$ & Zr-Gd-Pu-oxalates, milled, cold pressed & 14 & $<5,0 \mathrm{E}-03$ & 2,6E-01 \\
\hline $10 \mathrm{~mol} \% \mathrm{Gd}$ & $1300^{\circ} \mathrm{C} / 2 \mathrm{~h}$ & 28 & $<6,7 \mathrm{E}-03$ & $3,9 \mathrm{E}-01$ \\
\hline Sample P-2 & «old» US precursor $+\mathrm{PuO}_{2}, \mathrm{UO}_{2}$ & 3 & $<1,9 \mathrm{E}-03$ & $2,1 \mathrm{E}-03$ \\
\hline \multirow[t]{2}{*}{ (Ca,Gd,Pu,Hf)-pyrochlore } & milled, cold pressed & 14 & $<5,0 \mathrm{E}-03$ & $4,8 \mathrm{E}-03$ \\
\hline & $1380^{\circ} \mathrm{C} / 4 \mathrm{~h}$ (melted), presence of $\mathrm{CO}$ & 28 & $<7,5 \mathrm{E}-03$ & $5,9 \mathrm{E}-03$ \\
\hline Sample P-1 & «old» US precursor $+\mathrm{PuO}_{2}, \mathrm{UO}_{2}$ & 3 & $<1,5 \mathrm{E}-03$ & $5,4 \mathrm{E}-03$ \\
\hline \multirow[t]{2}{*}{ (Ca,Gd,Pu,Hf)-pyrochlore } & milled, cold pressed & 14 & $<3,8 \mathrm{E}-03$ & $1,4 \mathrm{E}-02$ \\
\hline & $1280^{\circ} \mathrm{C} / 4 \mathrm{~h}$, presence of $\mathrm{CO}$ & 28 & $<5,1 \mathrm{E}-03$ & $1,5 \mathrm{E}-02$ \\
\hline \multicolumn{5}{|c|}{ Obtained in the frame of Material Support Agreement \# B501118 } \\
\hline Sample ZIR-4 & sol-gel & 3 & $5, \mathrm{E}-02$ & $4, \mathrm{E}-01$ \\
\hline \multirow[t]{2}{*}{$(\mathrm{Zr}, \mathrm{Pu}) \mathrm{SiO}_{4}$} & milled, cold pressed & 14 & 2,E-01 & $2, \mathrm{E}+00$ \\
\hline & $1450^{\circ} \mathrm{C} / 4 \mathrm{~h} ; 1500^{\circ} \mathrm{C} / 3 \mathrm{~h} 15 \mathrm{~min}$ & 28 & 2,E-01 & $2, E+00$ \\
\hline Sample Z-2 & co-precipitated & 3 & $5, \mathrm{E}-03$ & $2, \mathrm{E}-02$ \\
\hline$(\mathrm{Zr}, \mathrm{Pu}, \mathrm{Gd}) \mathrm{O}_{2}$ & Zr-Gd-Pu-oxalates, milled, cold pressed & 14 & 2,E-02 & $5, \mathrm{E}-01$ \\
\hline $10 \mathrm{~mol} \% \mathrm{Gd}$ & $1450^{\circ} \mathrm{C} / 4 \mathrm{~h} ; 1500^{\circ} \mathrm{C} / 3 \mathrm{~h} 15 \mathrm{~min}$ & 28 & $4, \mathrm{E}-02$ & $1, \mathrm{E}+00$ \\
\hline Sample P-3 & «old» US precursor $+\mathrm{PuO}_{2}, \mathrm{UO}_{2}$ & 3 & $4, \mathrm{E}-04$ & $2, \mathrm{E}-03$ \\
\hline \multirow[t]{2}{*}{$(\mathrm{Ca}, \mathrm{Gd}, \mathrm{Pu}, \mathrm{Hf})$-pyrochlore } & milled, cold pressed & 14 & $9, E-04$ & $8, \mathrm{E}-03$ \\
\hline & $1350^{\circ} \mathrm{C} / 4 \mathrm{~h}$ in air (no CO) & 28 & 9,E-04 & $1, \mathrm{E}-02$ \\
\hline Sample P-4 & «new» US precursor $+\mathrm{PuO}_{2}, \mathrm{UO}_{2}$ & 3 & 2,E-04 & $2, \mathrm{E}-03$ \\
\hline \multirow[t]{2}{*}{ (Ca,Gd,Pu,Hf)-pyrochlore } & milled, cold pressed & 14 & 1,E-03 & $9, \mathrm{E}-03$ \\
\hline & $1350^{\circ} \mathrm{C} / 4 \mathrm{~h}$ in air (no CO) & 28 & 1,E-03 & $1, \mathrm{E}-02$ \\
\hline
\end{tabular}




\section{Plutonium Ceramics for Immobilization}

Table 7. Leach test (MCC-1, modified, in deionized water at $\mathrm{T}=25^{\circ} \mathrm{C}$ ) data for Pu-doped ceramic samples.

\begin{tabular}{|c|c|c|c|c|}
\hline \multirow{2}{*}{$\begin{array}{l}\text { Designed formulation } \\
\text { ( 10 wt\% Pu loading) }\end{array}$} & \multirow{2}{*}{$\begin{array}{c}\text { Precursor and } \\
\text { syntesis conditions }\end{array}$} & \multirow[t]{2}{*}{ 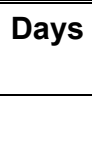 } & \multicolumn{2}{|c|}{${ }^{*} \mathrm{NL}\left(\mathrm{g} / \mathrm{m}^{2}\right)$} \\
\hline & & & ${ }^{239} \mathrm{Pu}$ & ${ }^{241} \mathrm{Am}$ \\
\hline \multicolumn{5}{|c|}{ Obtained in the frame of Material Support Agreement \# B501118 } \\
\hline Sample P-3 & «old» US precursor $+\mathrm{PuO}_{2}, \mathrm{UO}_{2}$ & 3 & $4, E-04$ & $8, E-04$ \\
\hline \multirow[t]{2}{*}{$(\mathrm{Ca}, \mathrm{Gd}, \mathrm{Pu}, \mathrm{Hf})$-pyrochlore } & milled, cold pressed & 14 & 1,E-03 & 3,E-03 \\
\hline & $1350^{\circ} \mathrm{C} / 4 \mathrm{~h}$, in air (no CO) & 28 & $1, \mathrm{E}-03$ & 3,E-03 \\
\hline Sample P-4 & «new» US precursor $+\mathrm{PuO}_{2}, \mathrm{UO}_{2}$ & 3 & 2,E-03 & 1,E-02 \\
\hline \multirow[t]{2}{*}{ (Ca,Gd,Pu,Hf)-pyrochlore } & milled, cold pressed & 14 & 2,E-03 & 1,E-02 \\
\hline & $1350^{\circ} \mathrm{C} / 4 \mathrm{~h}$, in air (no CO) & 28 & $3, E-03$ & 1,E-02 \\
\hline Sample ZIR-4 & & 3 & $8, E-03$ & 3,E-01 \\
\hline \multirow[t]{2}{*}{$(\mathrm{ZrPu}) \mathrm{SiO}_{4}$} & sol-gel & 14 & $3, E-02$ & 9,E-01 \\
\hline & $1450^{\circ} \mathrm{C} / 4 \mathrm{~h} ; 1500^{\circ} \mathrm{C} / 3 \mathrm{~h} 15 \mathrm{~min}$ & 28 & $4, E-02$ & 9,E-01 \\
\hline Sample Z-2 & co-precipitated & 3 & 4,E-03 & $4, \mathrm{E}-02$ \\
\hline$(\mathrm{Zr}, \mathrm{Pu}, \mathrm{Gd}) \mathrm{O}_{2}$ & Zr-Gd-Pu-oxalates, milled, cold pressed & 14 & $8, E-03$ & 2,E-01 \\
\hline $20 \mathrm{~mol} \% \mathrm{Gd}$ & $1450^{\circ} \mathrm{C} / 4 \mathrm{~h} ; 1500^{\circ} \mathrm{C} / 3 \mathrm{~h} 15 \mathrm{~min}$ & 28 & $9, \mathrm{E}-03$ & 2,E-01 \\
\hline
\end{tabular}

\section{US-pyrochlore, (Ca,Pu,Gd,Hf) $\mathrm{T}_{2} \mathrm{O}_{7}$}

For all samples - US-precursor (64.4 wt\%)+ $\mathrm{PuO}_{2}(11.9 \%), \mathrm{UO}_{2}(23.7 \%)$ :

- Sample P-1,2 (Agreement B338247) - «old» US-precursor (from first delivery);

- Sample P-3 (Agreement B501118) - «old» US-precursor;

- Sample P-4 (Agreement B501118) - «new» US-precursor (from second delivery).

The main features of all pyrochlore ceramic samples obtained in the framework of Agreements B338247 and B501118 are summarized in Tables 4-7. The matrix of sample P-2 (melted at $1300^{\circ} \mathrm{C}$ in the presence of $\mathrm{CO}$ ) contains elongated crystals of, presumably, the brannerite phase of the following average compositions (from microprobe analysis): $\mathrm{Hf}-6.6$ wt\%; Ca-0.6 wt\%, Gd-5.9 wt\%; Pu-18.4 wt\%; and Ti-21.4 wt\%. 


\section{Research and Development Plutonium Immobilization Contract Activities}

\section{Conclusions}

The results obtained allow us to make the following conclusions:

1. All ceramics: zircon/zirconia, mono-zirconia, and US-pyrochlore show high durability to Pu leaching by deionized water despite the fact that some of them contain separate Pu phases in their matrices. Zirconia and US-pyrochlore ceramics have almost the same leach rate at $25^{\circ} \mathrm{C}$ and are similar at $90^{\circ} \mathrm{C}$

2. As was found, the greatest Pu incorporation into zircon matrix did not exceed $6.9 \mathrm{wt} \%$. This means that $10 \mathrm{wt} \%$ Pu loading to zircon/zirconia ceramic consists of mainly zircon, which is not optimal. An excess of $\mathrm{Pu}$ is converted to separate $\mathrm{PuO}_{2}$ inclusions that significantly increase the Pu leach rate in comparison with other types of ceramic. Additional study is required to estimate zircon lattice capacity to incorporate Pu and to optimize synthesis conditions, avoiding formation of separate Pu-phases and decreasing porosity of final ceramic.

3. Ceramics have different features concerning Am release under leach testing. Pyrochlore ceramic is characterized at the lower level, and zircon/zirconia ceramic has the higher level. Detailed additional study of the reasons is required.

4. The presence of $\mathrm{CO}$ in the synthesis of US-pyrochlore ceramic causes melting starting from $1310^{\circ} \mathrm{C}$ (to complete melting at $1380^{\circ} \mathrm{C}$ ). However, low temperature $\left(1280^{\circ} \mathrm{C}\right)$ pyrochlore ceramic samples contain significantly fewer separate Pu-phases in comparison with ceramics obtained under regular conditions (no CO, $1350^{\circ} \mathrm{C}$ ). Therefore, the additional study of US-pyrochlore ceramic synthesis under low temperature in the presence of $\mathrm{CO}$ would be useful.

\section{References}

1. Galkin, B.Ya, Yessimantovskiy, V.M, Lazarev, L.N. et. al. (1988) Extraction of Cesium and Strontium, REE and TRU from Liquid Volatile Waste by Means of an Extractant Based on Dicarboxylate of Cobalt. Proceedings of International Solvent Extraction Conference ISEC-88, Moscow, Russia.

2. Law,J.D, Brewer,K.N, Smirnov,I.V, Dzekun,E.G, Herbst,R.S, Romanovskiy,V.N, Babain,V.A, Todd,T.A, Esimantovskiy,V.M, Zaitsev,B.N. (1996) Collaborative Flowsheet Development Studies Using Cobalt Dicarbollide and Phosphine Oxide for the Partitioning of Radionuclides from Idaho Chemical Processing Plant High-Activity Liquid Waste with Centrifugal Contactors. Proceedings of the International Topical Meeting on Nuclear and Hazardous Waste Management SPECTRUM-96, Seattle, Washington, USA, 18-23/08/1996, 2308-2313.

3. Todd,T.A, Brewer,K.N, Law,J.D, Wood,D.J, Herbst,R.S, Romanovskiy, V.N, Esimantovskiy,V.M, Smirnov,I.V, Babain,V.A. (1998) Development of Universal Solvent for the Decontamination of Acidic Liquid Radioactive Wastes. Booklet of Abstracts, 13th International Radiochemical Conference RADIOCHEMIE-98, Marianske Lazne-Jachymov, Czech Republic, 19-24/04/1998, p.379.

4. Carroll,D.F. (1963) The System $\mathrm{PuO}_{2}-\mathrm{ZrO}_{2}$, Journal of The American Ceramic Society - Discussions and Notes, vol.46, No. 4, 194-195.

5. Heimann,R.B, Vandergraaf,T.T. (1988) Cubic Zirconia as a Candidate Waste Form for Actinides: Dissolution Studies, Journal of Materials Science Letters 7, 583-586. 


\section{Plutonium Ceramics for Immobilization}

6. Anderson,E.B, Burakov,B.E, Pazukhin,E.M. (1993) High-Uranium Zircon from "Chernobyl Lavas", Radiochimica Acta 60, 149-151.

7. Burakov,B.E. (1993) A Study of High-Uranium Technogenous Zircon ( $\mathrm{Zr}, \mathrm{U}) \mathrm{SiO}_{4}$ from Chernobyl "Lavas" in Connection with the Problem of Creating a Crystalline Matrix for High-Level Waste Disposal. Proceedings of International Conference SAFE WASTE -93., 13-18/06/1993, Avignon, France, v.2, 19-28.

8. Anderson,E.B, Burakov,E.B, Vasiliev,V.G. (1993) A Creation of Crystalline Matrix for Actinide Waste in Khlopin Radium Institute. Proceedings of International Conference SAFE WASTE-93, 1318/06/1993, Avignon, France, Vol.2, 29-33.

9. Anderson,E.B, Burakov,B.E, Galkin,B.Ya. etc . (1995) UK-Russian Collaboration High Level Waste Immobilization Studies. Proceedings of the International Conference Global -95, Versailles, France, 11-14/09/1995, Vol.1, 216-223.

10. Kuramoto,K-I, Makino, Y, Yanagi,T, Muraoka,S, Ito,Y. (1995) Development of Zirconia- and AluminaBased Ceramic Waste Forms for High Concentrated TRU Elements. Proceedings of the International Conference Global-95, Versailles, France, 11-14/09/1995, Vol.2, 1838-1845.

11. Ewing,R.C, Lutze,W, Weber,W.J (1995) Zircon: A Host-Phase for the Disposal of Weapons Plutonium. Journal of Material Research 10, 243-246.

12. Ewing,R.C, Weber,W.J, Lutze,W. (1996) Crystalline Ceramics: Waste Forms for the Disposal of Weapons Plutonium. Eds. E.R.Merz and C.E.Walter Disposal of Weapon Plutonium , 65-83, Kluwer Academic Publishers, Dordrecht.

13. Burakov,B.E, Anderson,E.B, Galkin,B.Ya, Starchenko,V.A,Vasiliev,V.G. (1996) The Crystalline HostPhases for Immobilization of Weapons Plutonium and Waste Actinides. Eds.E.R.Merz and C.E.Walter Disposal of Weapon Plutonium, 85-89, Kluwer Academic Publisher, Dordrecht .

14. Furuya,H, Muraoka,S, Muromura,T. (1996) Feasibility of Rock-Like Fuel and Glass Waste Form for Disposal of Weapons Plutonium. Eds.E.R.Merz and C.E.Walter Disposal of Weapon Plutonium, Kluwer Academic Publisher, Dordrecht, 107-121.

15. Burakov, B.E, Anderson, E.B, Shabalev,S.I. (1998) A Search of the Most Optimal Forms of the Solidification of High-Level Waste Geologically Compatible with Hosting Granitoid Rocks. Defence Nuclear Waste Disposal in Russia, Eds. M.J.Stenhouse and V.I.Kirko, Kluwer Academic Publishers, Dordrecht, 59-68.

16. Burakov, B.E, Anderson, E.B, Rovsha, S.I, Ushakov,S.V, Ewing,R.C, Lutze,W, Weber,W.J.(1996) Synthesis of Zircon for Immobilization of Actinides. Materials Research Society Symposium Proceedings Scientific Basis for Nuclear Waste Management XIX, Vol.412, 33-39.

17. Helean,K.B, Burakov,B.E, Anderson,E.B, Strykanova,E.E, Ushakov,S.V, Ewing,R.C. (1997). Mineralogical and Microtextural Characterization of "Gel-Zircon" from the Manibay Uranium Mine, Kazakhstan. Materials Research Society Symposium Proceedings Scientific Basis for Nuclear Waste Management XX, Vol.465, 1219-1226.

18. Burakov, B.E, Helean,K.B, Anderson, E.B, Ewing, R.C,(1997) Amorphous Zirconium Hydrosilicate ( AZHS ) - a Prospective Material for Plutonium Fixation. Transactions of the International Conference Plutonium Futures - the Science, Santa-Fe, New-Mexico, USA, 25-27/08/1997, p.21. 


\section{Research and Development Plutonium Immobilization Contract Activities}

19. Burakov,B.E, Helean,K.B, Korolev,V.A, Ewing,R.C, Anderson,E.B, Shpunt,L.B, Strykanova,E.E. (1998) Synthesis of Actinide-Doped Zirconia by Plasma Calcination. Material Research Society Symposium Proceedings Scientific Basis for Nuclear Waste Management XXI, Vol.506, 95-100.

20. Ushakov,S.V, Burakov,B.E, Garbuzov,V.M, Anderson,E.B, Strykanova,E.E, Yagovkina,M.M, Helean,K.B, Guo,Y.X, Ewing,R.C, Lutze,W.(1998) Synthesis of Ce-Doped Zircon by a Sol-Gel Process. Material Research Society Symposium Proceedings Scientific Basis for Nuclear Waste Management XXI, Vol.506, 281-288.

21. Burakov, B.E, Strykanova, E.E. (1998) Garnet Solid Solution of $\mathrm{Y}_{3} \mathrm{Al}_{5} \mathrm{O}_{12}-\mathrm{Gd}_{3} \mathrm{Ga}_{5} \mathrm{O}_{12}-\mathrm{Y}_{3} \mathrm{Ga}_{5} \mathrm{O}_{12}(\mathrm{YAG}-$ GGG-YGG) as a Prospective Crystalline Host-Phase for Pu Immobilization in the Presence of Ga. Proceedings of the International Conference Waste Management'98, Tucson, Arizona, USA, 15/03/1998, CD version, http://localhost:6017/html/sess34/34-05/34-05.htm.

22. Burakov,B.E, etc. (1999) Ceramic Forms for Immobilizing Pu Using Zr, Y, Al Metal Additives. Environmental Issues and Waste Management Technologies IV, 349-356.

23. Degueldre, C., Heimgartner, P., Ledergerber, G., Sasajima, N., Hojou, K., Muromura, T., Wang, L., Gong, W., Ewing, R. (1997) Behaviour of Zirconia Based Fuel Material under Xe Irradiation. Material Research Society Symposium Proceedings Scientific Basis for Nuclear Waste Management XX, Vol.439, 625-632.

24. Kinoshita, H., Kuramoto, K., Uno, M., Yamanaka, S. Mitamura, H., Banba, T. (1998) Phase Stability and Mechanical Property of Yttria-Stabilized Zirconia Form for Partitioned TRU Wastes. Proceedings of the $2^{\text {nd }}$ NUCEF International Symposium NUCEF'98, 16-17/11/98, Hitachinaka, Ibaraki, Japan, JAERI-Conf.99-004 (Part I), 307-326.

25. Burakov, B.E, Anderson, E.B. (1998) Development of Crystalline Ceramic for Immobilization of TRU Wastes in V.G. Khlopin Radium Institute. Proceedings of the $2^{\text {nd }}$ NUCEF International Symposium NUCEF'98, 16-17/11/98, Hitachinaka, Ibaraki, Japan, JAERI-Conf.99-004 (Part I), 295-306.

26. Gong, W.L, Lutze, W, Ewing, R.C. (1998) Zirconia - a Ceramic for Excess Weapons Plutonium Wastes. Material Research Society Symposium Proceedings Scientific Basis for Nuclear Waste Management (in press). 


\section{Plutonium Ceramics for Immobilization}




\title{
Study of Properties of Ceramics Based on Zircon and Zirconia [B338243]
}

\author{
G. B. Borisov, O. A. Mansourov, O. A. Alexeyev, V.S. Gorbunov, VNIINM
}

\section{Introduction}

In Russia, boronsilicate and phosphate glasses and mineral-type compositions, containing up to several percent of $\mathrm{Pu}$, are under consideration to immobilize plutonium-containing waste.

The Khlopin Radium Institute (KRI) carries on the work to develop and synthesize ceramic materials based on zircon and zirconia, containing up to $10 \mathrm{wt} \% \mathrm{PuO}_{2}$.

VNIINM studied the basic physical-chemical properties of the ceramics fabricated at the initial stage of development at KRI: porosity, density, homogeneity of plutonium distribution in the matrix, phase composition, leach rates of basic elements, composing the matrix of the materials.

\section{Materials to be studied}

During the work, ceramic materials made by $\mathrm{KRI}$ on a ground of zircon and zirconia containing both cerium and plutonium were under study. Amorphous zirconium hydrosilicate (AZHS) with incorporation of $\mathrm{Ce}, \mathrm{Pu}$, and $\mathrm{Gd}$ was used as a precursor during fabrication of the ceramics. Before fabrication, ceriumcontaining specimens of solidified sol-gel $(\mathrm{Zr}, \mathrm{Ce}) \mathrm{SiO}_{4}$ were calcinated in a plasma jet at a speed of $40-$ $60 \mathrm{~g} / \mathrm{h}$ in an argon gas medium. Then ceramic samples were fabricated by hot isostatic pressing at $1400^{\circ} \mathrm{C}$ and $200 \mathrm{MPa}$ for 1 hour in an argon medium. The difference between that and other types of the ceramic samples was in the use of cold pressing. The pressing was made at $25 \mathrm{MPa}$, but sintering at $1250^{\circ} \mathrm{C}$ during $2-5$ hours in air. Fabrication of cerium-containing zirconia samples was made at $1400^{\circ} \mathrm{C}$ within 1 hour.

Plutonium-containing samples of zircon were fabricated also using the amorphous zirconium hydrosilicate at the sintering temperature $1490-1500^{\circ} \mathrm{C}$ during 3 hours and $15 \mathrm{~min}$. Zirconia samples were synthesized from co-precipitated oxalates of $\mathrm{Pu}, \mathrm{Gd}, \mathrm{Zr}$ at the sintering temperature $1450^{\circ} \mathrm{C}$ during 3 hours.

\section{Applied characterization methods}

\section{Hydrolitical stability of the materials (leachibility)}

In the process of work, leach rates of $\mathrm{Ce}, \mathrm{Zr}, \mathrm{Pu},{ }^{241} \mathrm{Am}$ from the matrix of investigated materials were measured by methods MCC-1 and IAEA under the following conditions:

- MCC-1 method: type of the material - monolithic, duration of the experiment -3 days, the surfacearea-to-volume ratio $\sim 10 \mathrm{~m}^{-1}$.

- IAEA method: duration of the experiment - 10 days with a periodical change of a leachate, temperature $\sim 20^{\circ} \mathrm{C}$, the surface-area-to-volume ratio $\sim 10 \mathrm{~m}^{-1}$.

The way of implementing the experiments and also its features are given in progress report \# 2 . 


\section{Plutonium Ceramics for Immobilization}

To define the content of $\mathrm{Ce}$ and $\mathrm{Zr}$ in the leachate, an ICP analysis was applied (accuracy $\pm 10 \%$ ).

Determination of concentrations of $\mathrm{Pu}$ and ${ }^{241} \mathrm{Am}$ was performed using combined alpha-spectrometric and alpha-radiometric methods. The combined analysis was used to measure an overall activity of the sample by the alpha-radiometric method, plutonium and ${ }^{241} \mathrm{Am}$ activities from the overall activity of the sample by the alpha-spectrometric method, and to establish the masses of plutonium and americium using a specific activity of plutonium evaluated going from an isotopic composition.

\section{Homogeneity of the ceramic compositions}

Homogeneity was assessed by means of a microprobe analysis (JEOL JXA-8600S) with preliminary work on ceramography.

Preparation of $\mathrm{Pu}$-containing slices required specific measures of precaution. Accordingly, cutting and polishing of the samples were done in glove boxes, and loading of the slices into a microanalyzator was carried out using special containers in order to eschew possible contamination of internal walls of the set. On Pu-containing samples, the study was made at a voltage of $12 \mathrm{kV}$. The beam current was about 10 nA. Qualitative analysis of different phases of the structure was conducted upon a standard program that uses special corrections "Oxide ZAF". The chemical composition of each phase was defined in 10-15 points with the aim of assessing the real error of measuring by a focused beam (diam. $<2$ micron) while there are fluctuations of the composition and the influence of the under-surface layers.

\section{Definition of porosity of the samples}

Porosity of the samples was assessed using microprobe analysis. Upon the surface of the sample, a random secant with diam. $1 \mathrm{~mm}$ was drawn. In toto, 501 points were measured along this line. Porosity was defined using a surface area of the peaks. Conditions of the analysis: voltage $-15 \mathrm{kV}$, beam current $-10 \mathrm{nA}$.

\section{Results of the experiments and its discussion}

\section{Definition of leach rates}

As a result of the experiments conducted, satisfactory data on hydrolitical stability of the ceramics made in KRI were obtained.

In the course of study of cerium-containing specimens, high values of leachability were accomplished (from $2^{*} 10^{-2}$ to $5^{\star} 10^{-3} \mathrm{~g} / \mathrm{m}^{2}$ day for Ce and about $10^{-3} \mathrm{~g} / \mathrm{m}^{2}$ day for $\mathrm{Zr}$ according to the IAEA method). Perhaps, it was linked to insufficiency of elaborated regimes of the synthesis of the ceramics.

During study of plutonium-containing samples by the MCC-1 method, a leach rate of plutonium from zircon was within $1.8^{*} 10^{-3} \mathrm{~g} / \mathrm{m}^{2}$ day, but from zirconia the rate was $5.4^{*} 10^{-3} \mathrm{~g} / \mathrm{m}^{2}$ day. A leach rate of

${ }^{241} \mathrm{Am}$, respectively, was $1.6 * 10^{-2}$ and $1.2^{*} 10^{-3} \mathrm{~g} / \mathrm{m}^{2}$ day.

Table 1 summarizes data on leachability of $\mathrm{Pu}$ and ${ }^{241} \mathrm{Am}$ from the materials studied. 


\section{Research and Development Plutonium Immobilization Contract Activities}

Table 1. Leach rates of $\mathrm{Pu}$ and ${ }^{241} \mathrm{Am}$ from the ceramic materials.

\begin{tabular}{|c|c|c|}
\hline Type of material & $\begin{array}{l}\text { Leach rate of plutonium, } \mathrm{g} / \mathrm{m}^{2} \\
\text { day }\end{array}$ & $\begin{array}{c}\text { Leach rate of americium, } \mathrm{g} / \mathrm{m}^{2} \\
\text { day }\end{array}$ \\
\hline \multicolumn{3}{|l|}{ 1st day } \\
\hline $\begin{array}{l}\text { Zircon } \\
\text { Zirconia }\end{array}$ & $\begin{array}{l}3.80 * 10^{-4} \\
2.86 * 10^{-4}\end{array}$ & $\begin{array}{l}3.25^{*} 10^{-3} \\
1.28^{*} 10^{-3}\end{array}$ \\
\hline \multicolumn{3}{|l|}{ 2nd day } \\
\hline $\begin{array}{l}\text { Zircon } \\
\text { Zirconia }\end{array}$ & $\begin{array}{l}2.51 * 10^{-4} \\
3.97 * 10^{-4}\end{array}$ & $\begin{array}{l}8.79 * 10^{-4} \\
4.36 * 10^{-4}\end{array}$ \\
\hline \multicolumn{3}{|l|}{ 3rd day } \\
\hline $\begin{array}{l}\text { Zircon } \\
\text { Zirconia }\end{array}$ & $\begin{array}{l}5.50^{*} 10^{-5} \\
8.34 * 10^{-4}\end{array}$ & $\begin{array}{l}2.82 * 10^{-3} \\
2.12 * 10^{-4} \\
\end{array}$ \\
\hline \multicolumn{3}{|l|}{ 4th day } \\
\hline $\begin{array}{l}\text { Zircon } \\
\text { Zirconia }\end{array}$ & $\begin{array}{l}7.90^{*} 10^{-5} \\
5.05^{*} 10^{-5}\end{array}$ & $\begin{array}{l}1.62 * 10^{-3} \\
5.70^{*} 10^{-5}\end{array}$ \\
\hline \multicolumn{3}{|l|}{ 7th day } \\
\hline $\begin{array}{l}\text { Zircon } \\
\text { Zirconia }\end{array}$ & $\begin{array}{l}3.50^{*} 10^{-5} \\
2.07 * 10^{-5}\end{array}$ & $\begin{array}{l}3.48 * 10^{-4} \\
1.07 * 10^{-4}\end{array}$ \\
\hline \multicolumn{3}{|l|}{ 10th day } \\
\hline $\begin{array}{l}\text { Zircon } \\
\text { Zirconia }\end{array}$ & $\begin{array}{l}8.3^{*} 10^{-5} \\
6.89^{*} 10^{-5}\end{array}$ & $\begin{array}{l}1.51^{*} 10^{-4} \\
1.13^{*} 10^{-4}\end{array}$ \\
\hline
\end{tabular}

As one see from the results, the leach rates of elements from the ceramics decrease with time and reach a level where parameters of leachability do not change from duration of exposing the samples in a leachant. Leachability of americium is an order of magnitude more than for plutonium. This fact can be explained by high chemical activity and mobility of its ions in the matrix of the ceramics and in an aqueous solution.

\section{Definition of homogeneity of elements in the ceramics}

Figures 1 and 2 give images of the studied materials made by the microprobe analyzator.

As one can see from the images of surfaces of the specimens, there are definite differences in homogeneity of the matrices of zircon and zirconia. In zircon, it is possible to notice obvious nonhomogeneity of the matrix, which consists of two phases: gray phase, depleted of plutonium (about 0.003 $w t \%)$ and the grain-type one with a content of $\mathrm{Pu} \sim 7-8 \mathrm{wt} \%$. In the latter phase, however, there are also deviations in homogeneity of the components (to say, $\mathrm{SiO}_{2}$ ). In the case with zirconia, homogeneity of the components is more equal. The matrix is a grain-type structure, where the content of Pu ranges within 7$8.65 \mathrm{wt} \%$. 


\section{Plutonium Ceramics for Immobilization}

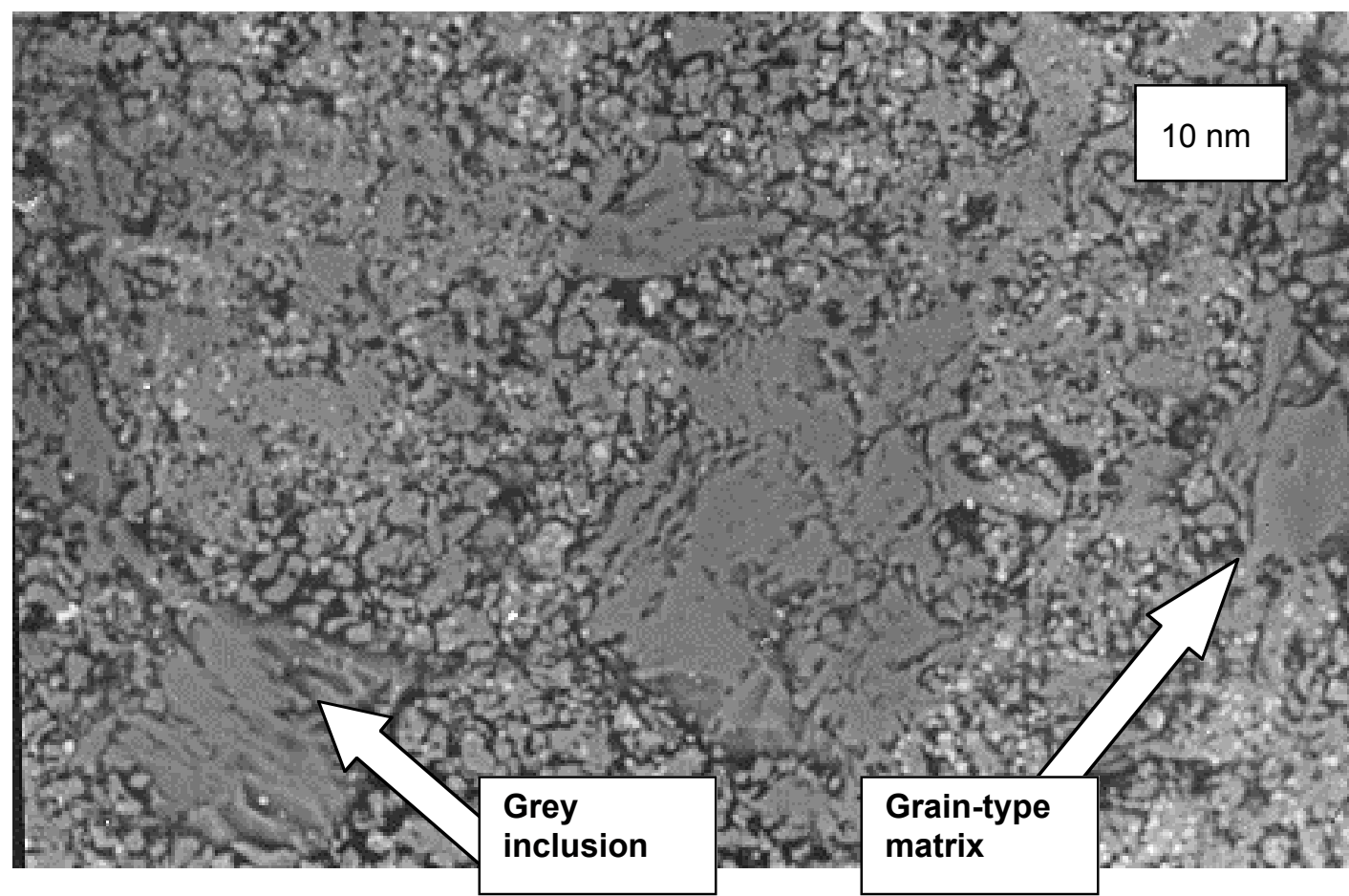

Fig. 1. Image of the surface of the zircon sample made by $500-x$ magnification.

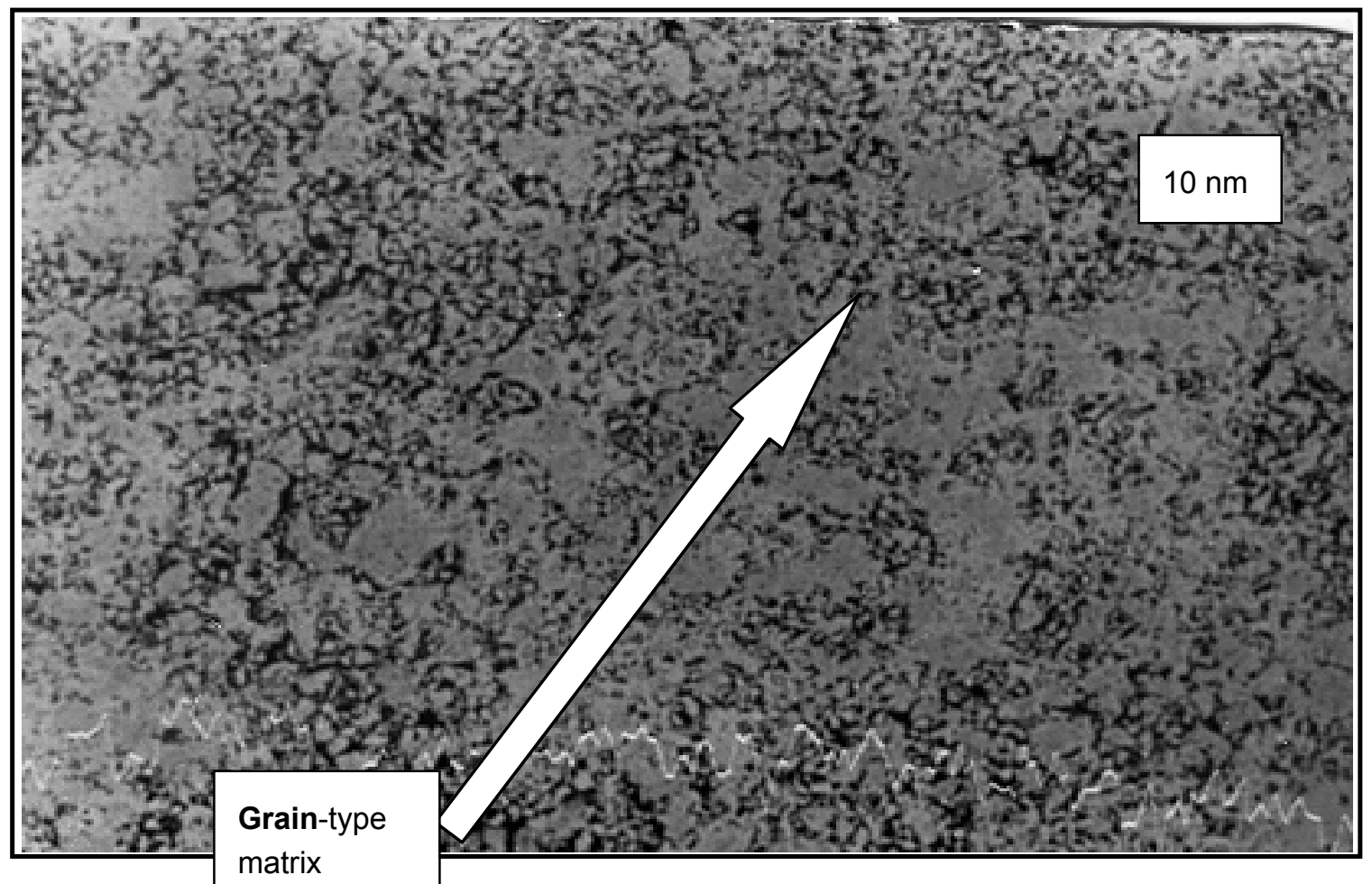

Fig. 2. Image of the surface of the zirconia sample made by $500-x$ magnification. 


\section{Research and Development Plutonium Immobilization Contract Activities}

With the help of a non-focused beam (up to diam. 300 micron) and additionally by a network of points scattered from each other on 600 micron (vertical) and 870 micron (horizontal), an average content of the components of the matrix was identified. The calculated value of cerium dioxide content corresponds to the average one for the gray phase, and accuracy in this case characterizes the distribution of cerium in this sample. Results of the analysis are given below:

\section{Zircon}

Gray phase, wt\%: $\mathrm{PuO}_{2}-0.0037 \pm 0.045 ; \mathrm{SiO}_{2}-32.46 \pm 3.74$;

Grain-type phase, wt \%: $\mathrm{PuO}_{2}-7.67 \pm 1.80 ; \mathrm{SiO}_{2}-26.20 \pm 8.84$.

\section{Zirconia}

Grain-type matrix, wt\%: $\mathrm{PuO}_{2}-7.92 \pm 0.61 ; \mathrm{SiO}_{2}-0.26 \pm 0.40$.

By the way, open porosity of the specimens was measured by dint of the microprobe analyzator (the method of defining is described above). Open porosity for zircon $-14 \%$; for zirconia $-7 \%$.

Therefore, from the data obtained, one can infer that a leach rate of Pu from zircon is nearly similar to one from zirconia. Hydrolitical stability of the materials is rather high and falls within $3.8^{*} 10^{-4}-8.3^{*} 10^{-5} \mathrm{~g} / \mathrm{m}^{2}$ /day. With regard to homogeneity of $\mathrm{Pu}$ in the matrix, zircon versus zirconia has an utterly nonhomogeneous structure. The content of Pu in different phases varies from 0.00 up to $9.88 \mathrm{wt} \%$. It can be elucidated by insufficiency of working out regimes of fabricating the ceramics at the initial stage of the process: poor homogeneity of precursors during blending of precipitated plutonium and zirconium oxalates with silica, a low temperature of sintering.

\section{Conclusions}

- During the work in VNIINM, basic physico-chemical properties of ceramic compositions based on zircon $\left(\mathrm{ZrSiO}_{4}\right)$ and zirconia $\left(\mathrm{ZrO}_{2}\right)$ with up to $10 \mathrm{wt} \%$ Pu developed by KRI were defined.

- Leach rates of cerium, plutonium, and americium were identified by the MCC-1 and IAEA methods. With regard to plutonium, leach rates of $\mathrm{Pu}$ from two types of the ceramics are insignificant and vary within $3.8^{*} 10^{-4}-8.4^{*} 10^{-5} \mathrm{~g} / \mathrm{m}^{2}$ day depending upon the duration of the analysis (1-10 days). A leach rate of ${ }^{241} \mathrm{Am}$ from zircon and zirconia is approximately $1.6^{*} 10^{-2}-1.2^{*} 10^{-3} \mathrm{~g} / \mathrm{m}^{2}$ day and grounded by its diffusion from the matrix to the leachant.

- The ceramics synthesized is non-homogeneous on distribution of plutonium: the content of Pu in zircon differs from 0.00 to $9.88 \%$ wt; the content of Pu in zirconia differs from 7.00 to 8.65 wt\%. Porosity of the materials are as follows: $14 \%$ for zircon and $7 \%$ for zirconia.

- It is necessary to conduct an additional complex of work to improve properties and durability of the ceramics. 


\section{Plutonium Ceramics for Immobilization}




\title{
Study of Properties of the US-specified Ceramics Made Using the Expertise of MOX Fuel Production [B503009]
}

\author{
V. A. Astafiev, A. E. Glushenkov, V. M. Sidelnikov, G. B. Borisov, O. A. \\ Mansourov, VNIINM, Moscow
}

\section{Introduction}

At present, under the auspices of the USA/Russia agreements, joint works are under way to dispose of plutonium-containing materials. It is proposed to use a "dual approach," i.e., production of mixed plutonium-uranium fuel for its further burn-up in different nuclear reactors and immobilization of plutonium-containing materials into ceramic and glass-type matrices with its safe storage and eventual disposal.

The plutonium immobilization work includes development of compositions (glasses, mineral-type matrices or ceramics), their characterization, definition of the chemical stability of the matrix of the materials, development and manufacturing of necessary equipment, and technological lines to fabricate immobilization forms. By the way, development of a homogeneous and stable composition with the aim of incorporating $\mathrm{Pu}$ at a maximum scale and equally distributed upon the bulk of the matrix; and development of a technological process, which would be reliable and met to the nonproliferation requirements to fissile materials are one of the basic criteria.

Ceramics based on pyrochlore and developed by specialists of Lawrence Livermore National Laboratory (LLNL) is one of the possible matrices that can be used with the purpose of Pu immobilization [1]. It is based on calcium and titanium compounds with additions of gadolinium and hafnium as neutron absorbers and is capable of encapsulating up to $10 \mathrm{wt} \% \mathrm{PuO}_{2}$ and $23 \mathrm{wt} \% \mathrm{UO}_{2}$.

The immobilization technology using pyrochlore ceramics was also developed by LLNL, and is based on preliminary blending of the components by needed homogeneity, pressing and high-temperature sintering of batches. Then, the batches are considered to encapsulate by a high-radioactive glass and "can-incanister" assemblies made by such a manner are sent for disposal.

A flow-sheet, for instance at a stage of synthesizing the batches, is rather complicated and includes a lot of operations $(\sim 16)$ and the usage of aqueous binders that is not desirable from the standpoint of nuclear criticality.

It is advisable to use the experience of producing MOX fuel in the processes of immobilizing Pu into the ceramics. In the world practice of MOX fuel fabrication, technological principles have been defined in general. The absence of humidity (aqueous stages) is one of those. By the way, at MOX-fuel fabrication facilities that are being designed throughout the world (for instance, at BNFL), one strives for reduction of industrial procedures especially related to dust-formation of powders.

Two technological schemes (immobilization and MOX fuel fabrication) have definite similarities at the stages of preliminary mixing (homogenization of a feeding material), pressing and sintering of pellets. This one can be applied in the future, for example while resolving the problem of wastes generated in the course of MOX fuel production [5]. The given approach will allow the minimization of costs related to 


\section{Plutonium Ceramics for Immobilization}

development and running of a technology of treating the wastes, building of new technological lines, construction, etc.

The paper describes work fulfilled to define the basic physico-chemical properties of the US specified ceramics made using an expertise of pelletized MOX-fuel fabrication. Precursors as well as all necessary documentation (recommended specifications and procedures to fabricate the ceramics) have been procured by LLNL [2].

\section{Fabrication of Ceramic Pellets}

\section{Characteristics of feeding materials}

To fabricate ceramic pellets, feeding materials were used as follows:

- LLNL-delivered precursor - a mixture of oxides of $\mathrm{Ca}, \mathrm{Ti}, \mathrm{Hf}, \mathrm{Gd}$ of the following composition: $\mathrm{CaO}_{2-}-15,45 \mathrm{wt} \% ; \mathrm{HfO}_{2}-16,54 \mathrm{wt} \%$;

$\mathrm{Gd}_{2} \mathrm{O}_{3}-12,34 \mathrm{wt} \% ; \mathrm{TiO}_{2}-55,67 \mathrm{wt} \%$.

- Uranium dioxide powder, prepared by ADU method;

- Plutonium dioxide powder, prepared by oxalate precipitation.

Characteristics of the precursors were defined using the following methods:

- Tap density (with and without shaking). The tap density without shaking was measured by means of a volumenometer and calculated by values of a volume and weight of a sample. Accuracy of the method is within $\pm 0.05 \mathrm{~g} / \mathrm{cm}^{3}$. The tap density with shaking was measured by the same method. The powder was compacted manually before cessation of changing its volume.

- Theoretical density. The theoretical density was calculated on the base of density of components and its mass.

- Specific surface area. The specific surface area was defined by a method of the low-temperature sorption of argon under the condition of the generation of a monomolecular sorption layer. The amount of argon was determined by chromatography. The specific surface area was evaluated upon the mass of the sample and the amount of argon. Accuracy of the method is within $20-30 \%$.

Characteristics of the feeding materials are presented in Table 1.

Table 1. Characteristics of the feeding materials.

\begin{tabular}{|l|l|l|l|}
\hline \hline \multirow{2}{*}{ Parameter } & \multicolumn{3}{|l|}{ Material } \\
\cline { 2 - 4 } & $\mathrm{PuO}_{\mathbf{2}}$ & $\mathbf{U O}_{\mathbf{2}}$ & Ceramics \\
\hline Tap density without shaking, $\mathrm{g} / \mathrm{cm}^{3}$ & 1,94 & 2,32 & 0,86 \\
\hline Tap density with shaking, $\mathrm{g} / \mathrm{cm}^{3}$ & 2,30 & 3,13 & 1,07 \\
\hline Theoretical density, $\mathrm{g} / \mathrm{cm}^{3}$ & 11,46 & 10,96 & 5,34 \\
\hline Specific surface area, $\mathrm{m}^{2} / \mathrm{g}$ & 15,05 & 2,62 & 10.0 \\
\hline
\end{tabular}




\section{Research and Development Plutonium Immobilization Contract Activities}

\section{Fabrication of ceramics containing uranium dioxide}

Ceramic samples containing uranium dioxide as an surrogate of plutonium have been made to work off regimes of the fabrication of a material containing plutonium dioxide. This part of the work was focused on the definition of the possibility of pressing pellets with maximal density that is very important during a solid-phase synthesis, and the establishment of optimum regimes of sintering, which can be realized using equipment for the pelletized MOX fuel fabrication.

\section{Fabrication of ceramics containing plutonium dioxide}

Based on data used while fabricating the pellets containing Uranium dioxide, samples containing Plutonium dioxide have been made.

To remove water sorbed in the precursors as well as water, which is included in $\mathrm{Ca}(\mathrm{OH})_{2}$, the precursors were firstly calcinated. The process was carried out in a furnace VTP-06 at $750^{\circ} \mathrm{C}$ during 1 hour. Weighing of a powder before and after the calcination was done using a Sartorius ${ }^{\circledR}$ balance with the

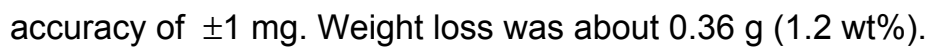

The tap density of the precursors after the calcinating was defined according to a standard method. The following meanings of the tap density were obtained: without shaking $-0.81 \mathrm{~g} / \mathrm{cm}^{3}$, with shaking -1.03 $\mathrm{g} / \mathrm{cm}^{3}$.

Weight of a batch for mixing was $33.33 \mathrm{~g}$, including the precursor of the ceramics $-30 \mathrm{~g}$ (90 wt\%), Uranium dioxide $-3.33 \mathrm{~g}(10 \mathrm{wt} \%)$.

Mixing of the components was performed during $4 \mathrm{~min}$ in a electromagnetic blender ABC-150 [3] used to fabricate MOX fuel. The ratio between the components and a grinding media was 1:1 [4]. Separation of the grinding media was carried out on a tray with the size of a cell -300 microns.

After mixing, the tap densities without/with shaking of the powder were defined and theoretical density of the obtained mixture was calculated taking into account densities of the components and its mass.

Characteristics of the mixture are given in the Table 2.

Table 2. Characteristics of the powder of the ceramics containing uranium dioxide.

\begin{tabular}{|l|l|}
\hline \hline Tap density without shaking, $\mathrm{g} / \mathrm{cm}^{3}$ & 0,80 \\
\hline Tap density with shaking, $\mathrm{g} / \mathrm{cm}^{3}$ & 1,56 \\
\hline Theoretical density, $\mathrm{g} / \mathrm{cm}^{3}$ & 7,25 \\
\hline
\end{tabular}

The pressing was made using a lab-scale facility IK-4155. A diameter of a press-mold is $9.07 \mathrm{~mm}$.

To define an optimum regime of pressing the pellets, they have been made using three pressures -3.0 , 4.0 , and $4.5 \mathrm{t} / \mathrm{cm}^{3}$. An eventual decrease of pressure resulted in the formation of over-pressing cracks. A pressure $3 \mathrm{t} / \mathrm{cm}^{3}$ has been selected as the optimum one.

After pressing, characteristics of "green" pellets have been fixed (see Table 3). 


\section{Plutonium Ceramics for Immobilization}

Table 3. Characteristics of the "green" pellets.

\begin{tabular}{|l|l|l|l|l|l|}
\hline \hline Pressure, $\mathbf{t} / \mathbf{c m}^{2}$ & Weight, $\mathbf{g}$ & $\begin{array}{c}\text { Diameter, } \\
\mathbf{~ m m}\end{array}$ & Height, $\mathbf{~ m m}$ & Density, $\mathbf{g} / \mathbf{c m}^{\mathbf{3}}$ & $\begin{array}{c}\text { \% of the } \\
\text { theoretical }\end{array}$ \\
\hline 3,0 & 1,494 & 9,19 & 7,25 & 3,11 & 42,90 \\
\hline 3,0 & 1,568 & 9,20 & 7,47 & 3,19 & 44,00 \\
\hline 4,0 & 2,134 & 9,19 & 9,62 & 3,34 & 46,07 \\
\hline 4,5 & 1,733 & 9,19 & 7,73 & 3,38 & 46.62 \\
\hline 4,5 & 1,392 & 9,20 & 6,07 & 3,45 & 47,59 \\
\hline 4,5 & 2,083 & 9,22 & 8,97 & 3,48 & 48,00 \\
\hline
\end{tabular}

To sinter the samples, a vacuum shaft inductive furnace SSVE-1.31/16 at 0.02 MPa under an argon media was applied. The sintering was made in a molybdenum container on a tungsten tray under the conditions selected on the ground of studies with the surrogate $\mathrm{UO}_{2}$ :

- Heating up to $1320^{\circ} \mathrm{C}$ at $600^{\circ} \mathrm{C} /$ hour;

- Keeping at $1320^{\circ} \mathrm{C}$ during 3 hours;

- Cooling to room temperature at $600^{\circ} \mathrm{C} / \mathrm{hour}$.

Total time of the process $\sim 7$ hours.

The density of the sintered pellets was measured using the hydrostatic method. Weighing of the pellets in air and water was made at the Sartorius ${ }^{\circledR}$ balance with a complementary set for measuring the hydrostatic density.

Characteristics of the sintered pellets are given in the Table 4.

Table 4. Characteristics of the sintered pellets.

\begin{tabular}{|l|l|l|}
\hline \multicolumn{1}{|c|}{ Pressure, $\mathbf{t} / \mathbf{c m}^{\mathbf{2}}$} & \multicolumn{1}{|c|}{$\begin{array}{c}\text { Density of "green" } \\
\text { pellets, } \mathbf{g} / \mathbf{c m}^{\mathbf{3}}\end{array}$} & \multicolumn{1}{|c|}{$\begin{array}{c}\text { Hydrostatic density, } \\
\mathbf{g} / \mathbf{c m}^{\mathbf{3}}\end{array}$} \\
\hline 3,0 & 3,11 & 5,16 \\
\hline 3,0 & 3,19 & 5,15 \\
\hline 4,0 & 3,34 & 5,20 \\
\hline 4,5 & 3,38 & 5,23 \\
\hline 4,5 & 3,45 & 5,22 \\
\hline 4,5 & 3,48 & 5,20 \\
\hline
\end{tabular}




\section{Research and Development Plutonium Immobilization Contract Activities}

\section{Characterization of the synthesized pellets}

The pellets were studied by XRD and microprobe characterization methods.

\section{XRD analysis}

The study was made using a difractometer DRON-2 with a monochromatic $\mathrm{Cu} \mathrm{K}_{\beta}$ - irradiation. Diffraction maximums were analyzed in an interval of diffraction angles $10-60^{\circ}$ at $2 \theta$.

A phase analysis made upon the program "XPI" has shown that basically the matrix is composed of compounds like $\mathrm{Gd}_{2} \mathrm{Ti}_{2} \mathrm{O}_{7}$ (related to pyrochlores). The performed analysis of the diffraction maximums has indicated that $\mathrm{Gd}_{2} \mathrm{Ti}_{2} \mathrm{O}_{7}$ is identified as a face centered lattice with a period a=10.20 $\AA$ (a space group $\left.\hat{I}_{h}^{7}-\mathrm{Fd} 3 \mathrm{~m}\right)$.

One can also see a few of weak diffraction maximums at a diffractogram that are not related to the phase $\mathrm{Gd}_{2} \mathrm{Ti}_{2} \mathrm{O}_{7}$. The amount of this phase is approximately $5 \mathrm{wt} \%$.

Ceramographics and microprobe analyses of the microstructure were carried out using a scanning microscope CAMEBAX at $20 \mathrm{kV}$ and $3 \mathrm{nA}$.

As a result of the study of an etched slice, it was identified that the surface is consisted of a matrix (Fig.1a) embracing gray grains (2-10 microns) and porous (2-5 microns) with inclusions of the following zones:

1. With the size of 50-60 microns and composing of equal-axis dark grains (Fig $1 \mathrm{~b}$ );

2. With the size of 20-50 microns and composing of grains of a prolonged unequal form (5-10 microns) (Fig 2a);

3. With the size of 20-30 microns and composing of grains of a prolonged form (1-8 microns) (Fig 2b). 

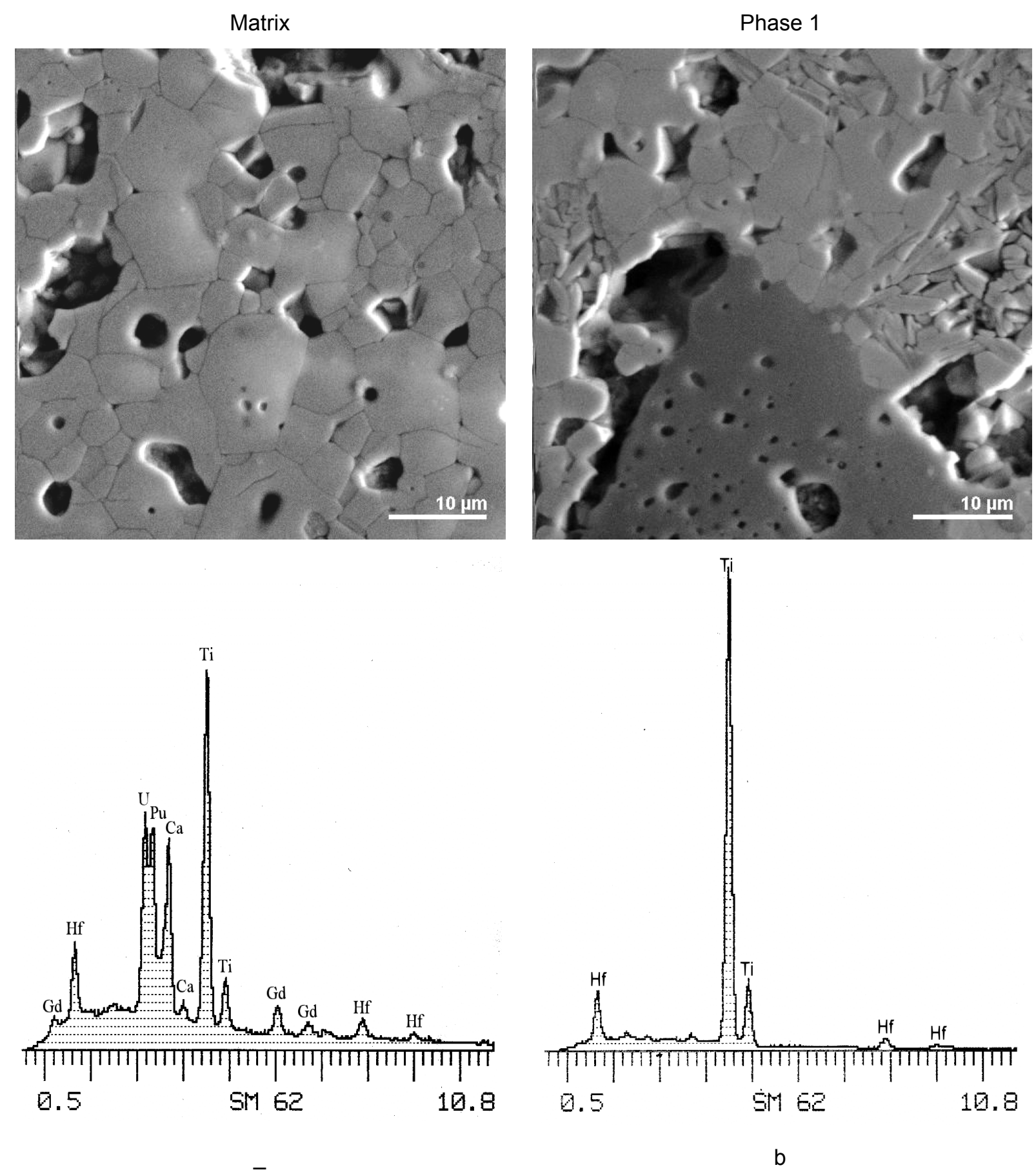

Fig 1. SEM images of the matrix and phase 1. 
Phase 2
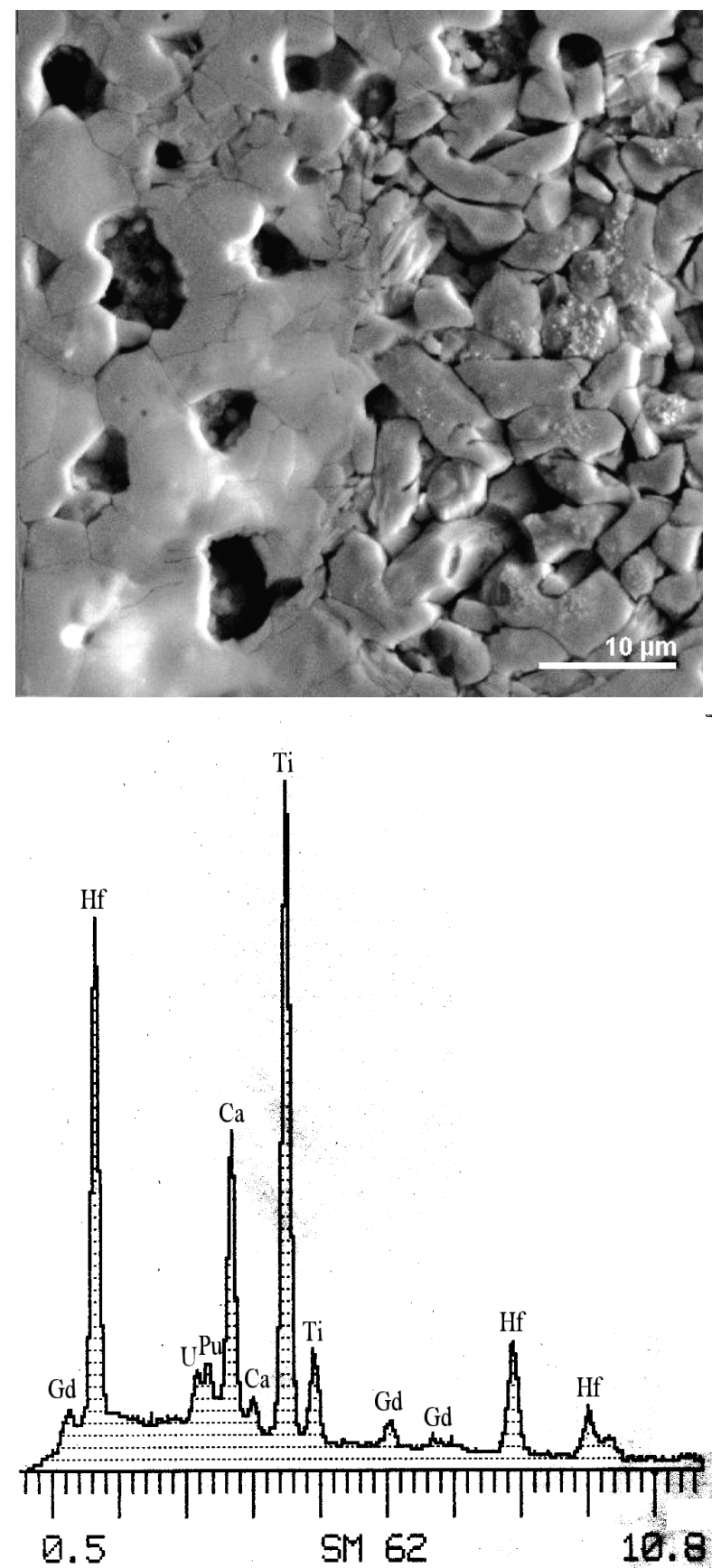

Phase 3
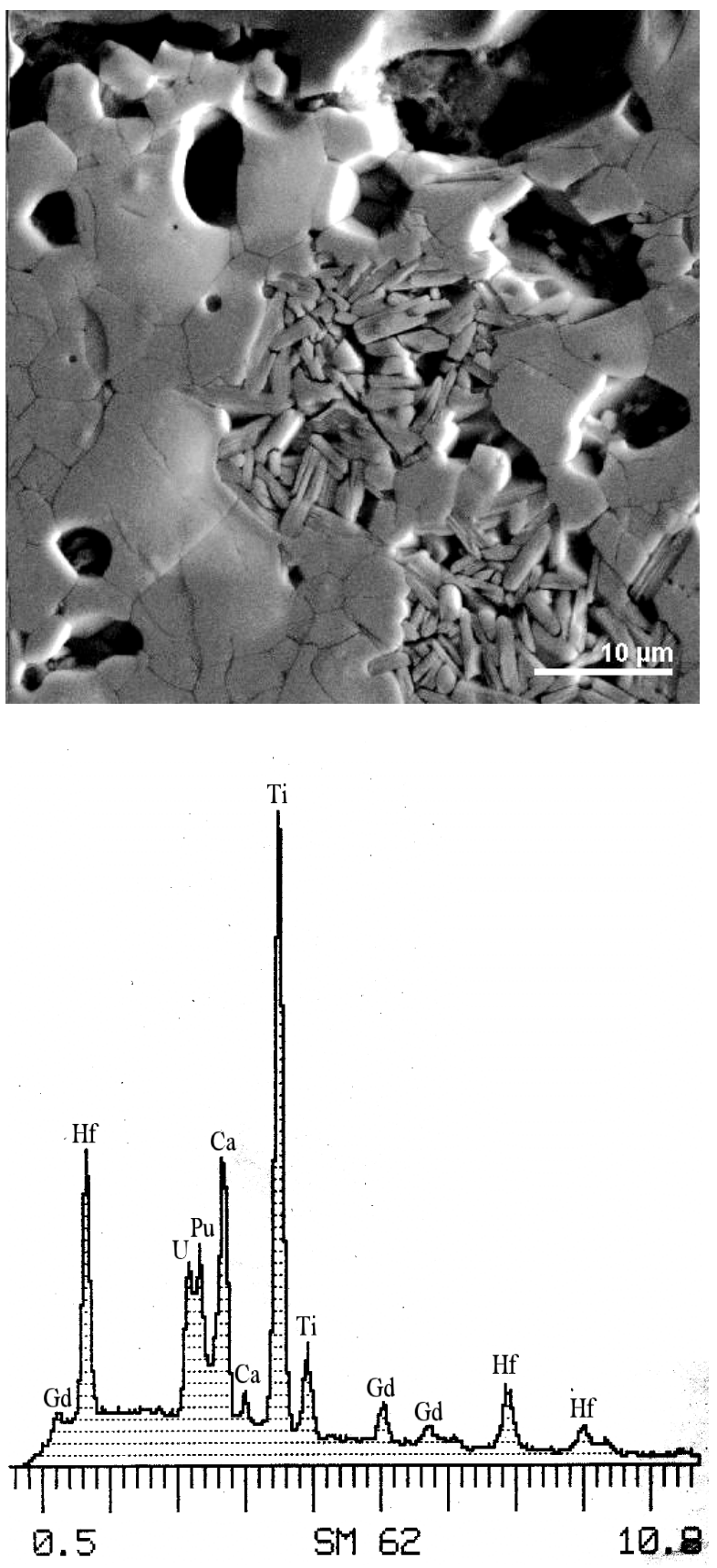

b

Fig 2. SEM images of phase 2 and phase 3.

On the ground of the results, compositions of the phases have been calculated. 


\section{Plutonium Ceramics for Immobilization}

Table 5. A phase composition of the ceramics based on pyrochlore.

\begin{tabular}{|l|l|l|l|l|l|}
\hline \hline & Precursors & Matrix & Phase 1 & Phase 2 & Phase 3 \\
\hline $\mathbf{H f O}_{2}$ & $11,08 \%$ & $9,5 \%$ & $11 \%$ & $51 \%$ & $25 \%$ \\
\hline $\mathbf{P u O}_{2}$ & $10,00 \%$ & $12 \%$ & & $3,5 \%$ & $7,5 \%$ \\
\hline $\mathrm{TiO}_{2}$ & $37,30 \%$ & $34 \%$ & $88 \%$ & $30 \%$ & $39 \%$ \\
\hline $\mathbf{U O}_{2}$ & $23,00 \%$ & $27 \%$ & & $3 \%$ & $12,5 \%$ \\
\hline $\mathrm{CaO}_{2}$ & $10,35 \%$ & $10 \%$ & & $10 \%$ & $11 \%$ \\
\hline $\mathbf{G d}_{2} \mathbf{O}_{3}$ & $8,27 \%$ & $7,5 \%$ & \multicolumn{2}{|l}{} \\
\hline
\end{tabular}

A balance between the precursors and phases allowed to evaluate the content of the phases in the sample.

Matrix $\sim 89 \mathrm{wt} \%$, phase $1 \sim 4 \mathrm{wt} \%$, phase $2 \sim 3 \mathrm{wt} \%$, phase $3 \sim 4 \mathrm{wt} \%$.

The analysis of the phases of the sample also permitted to consider that the matrix, phase 2, phase 3 can own a similar structure like pyrochlore. These estimations are approved by the XRD analysis.

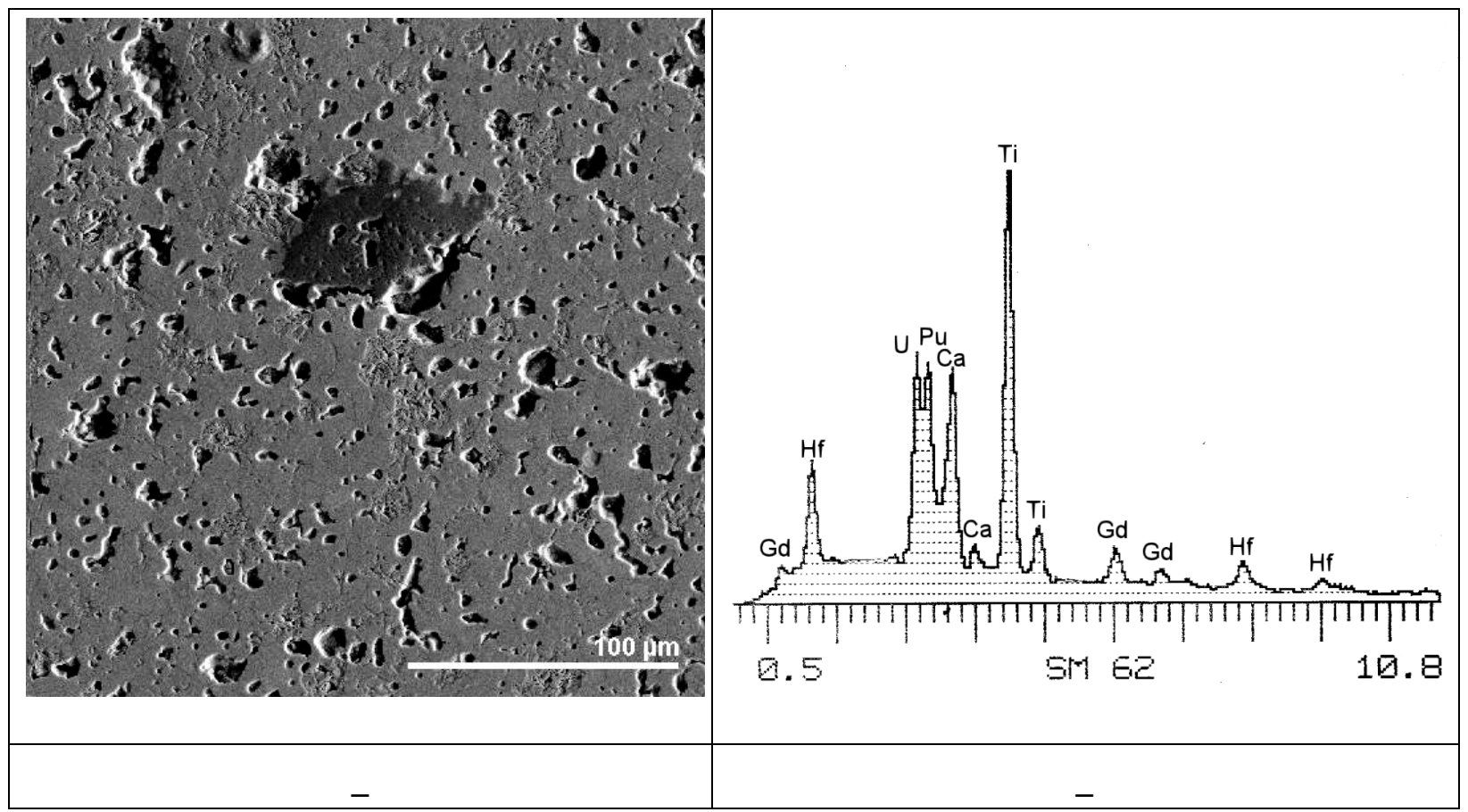

Fig 3. Typical fragment of microstructure of sample with all identified phases.

Figure 3 demonstrates a typical fragment of the microstructure of the obtained sample that includes all identified phases. During characterization of the sample there were no any zones containing "free" uranium and plutonium dioxides.

Figure 4 illustrates an image of a slice of the sample, containing three phases having, upon our opinion, the structure of the pyrochlore, as well as images of the given slice made in characteristic $x$-ray radiation upon $\mathrm{Pu}, \mathrm{U}, \mathrm{Hf}$. Due to the difficulty to register weak maximums of $\mathrm{Ca}, \mathrm{Ti}$, and $\mathrm{Gd}$, images of these elements in characteristic $x$-ray radiation have not been managed. 

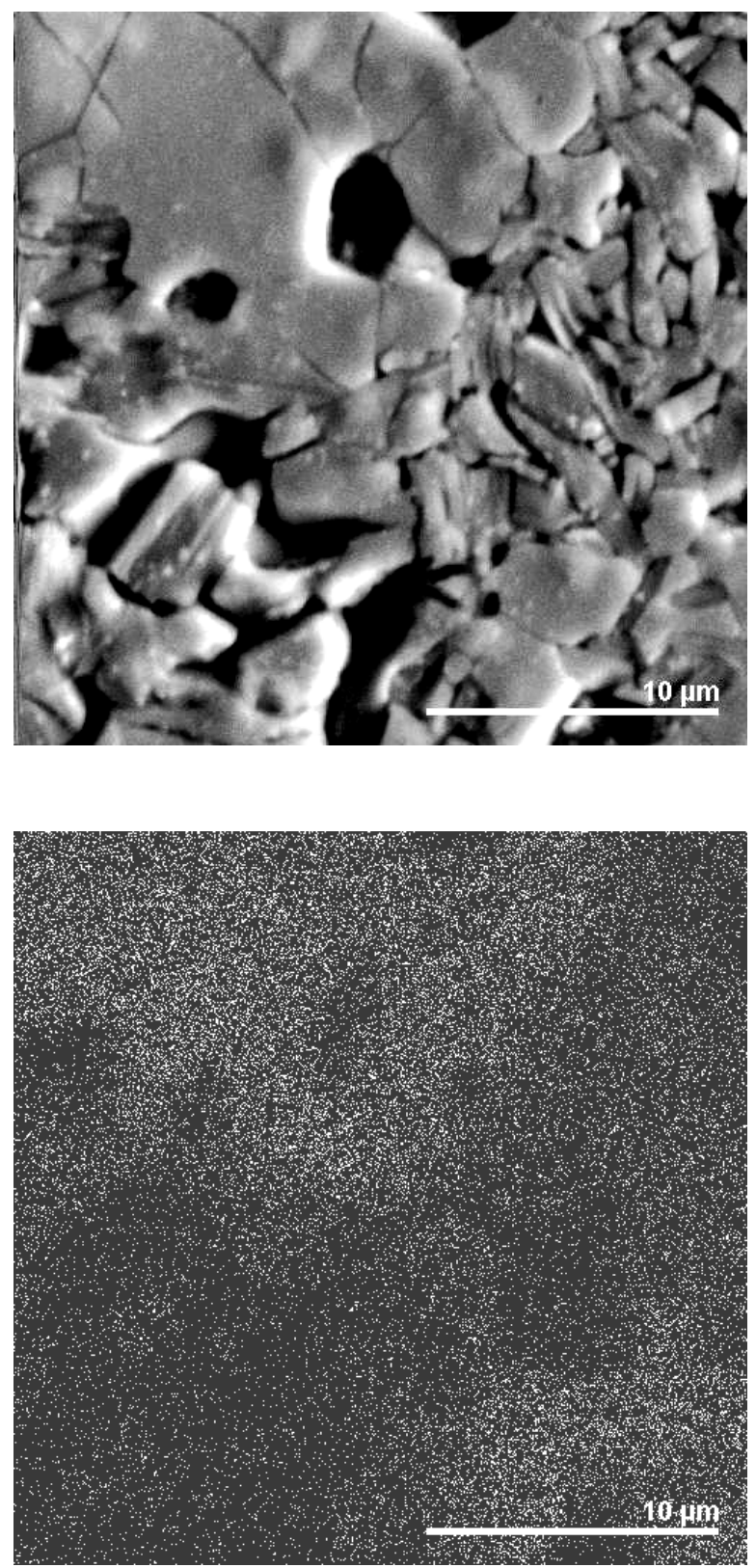

$U$

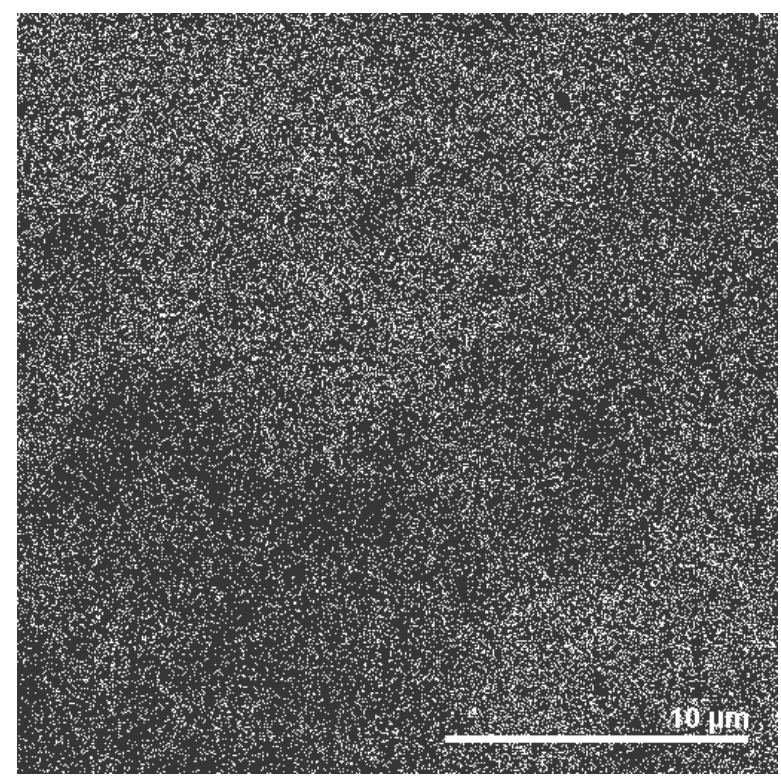

$\mathrm{Pu}$

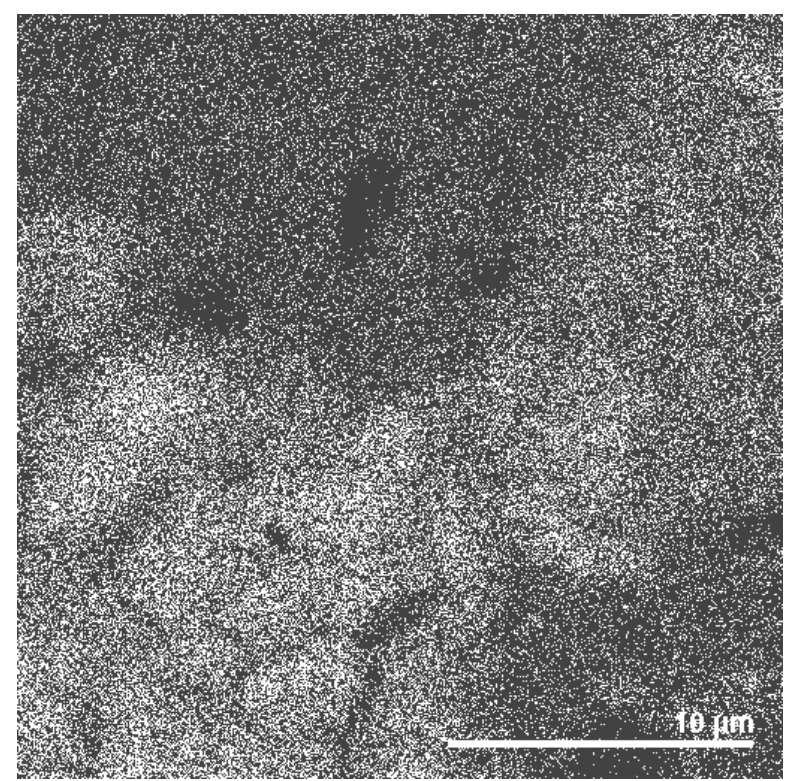

$\mathrm{Hf}$

Fig. 4. Image of a slice of the sample. 


\section{Plutonium Ceramics for Immobilization}

\section{Conclusions}

As a result of the work, we have shown that:

1. It is feasible to use the equipment and approaches of MOX fuel production for the fabrication of the ceramics proposed for immobilization of the Pu-containing materials. Conditions of synthesis of the ceramics by solid-phase reactions have been established and confirmed.

2. An application of a high-effective circulating blender has allowed us to obtain a mixture of powders with a high rate of homogeneity and dispersal.

3. An application of standard equipment and pressing regimes developed for MOX fuel (pressing without binders or with lubricating press equipment by a dry stuff such as Zinc stearate) has allowed us to obtain dense pellets (i.e., porosity measured by ceramography was about 5-6\%).

4. Sintering of such mixtures during 6-7 hours results in the complete synthesis of pyrochlore that was confirmed by $\mathrm{x}$-ray and microprobe analyses.

5. Microprobe studies have confirmed the synthesis of pyrochlore for $96-97 \%$. The presence of three phases similar to the pyrochlore, but with a different element ratio, can be explained by some fluctuation of the components while blending or by insufficient sintering time.

6. In the course of structural studies, inclusions of pure plutonium or its phases have not been identified. This is due to the high rate of homogenization and the presence of a solid solution based on the pyrochlore.

7. Final conclusions to fabricate the ceramics using equipment and an expertise of MOX fuel production are possible only after additional investigations of large batches (including definition of leach rates of $\mathrm{Pu}, \mathrm{U}$, and other components).

\section{References}

- Cochran S., Dunlop W., Edmunds T., Maclean L., Gould T., "Fissile Material Disposition Program Final Immobilization Form Assessment and Recommendation". LLNL UCRL-ID-128705, October 23, 1997.

- Procedures to fabricate pellets from LLNL-prepared US Precursor. LLNL. April 19, 1999.

- Menshikova T.S., Antipov S.A., Astafiev V.A. Patent \# 2122247, priority from 10.06.97.

- Menshikova T.S., Astafiev V.A. "Study of a technology to fabricate MOX fuel with the high content of Plutonium”. VANT collection. Material guidance section. Issue 1 (54), 1997, p 6.

- Armantrout, G.A. and Jardine, L. J. , "Disposition of Excess Plutonium Using 'Off-Spec' MOX pellets as a Sintered Ceramic Waste Form," Waste Management 96 Conference, Tucson, AZ, UCRL-JC121830, Feb. 25-29, 1996. 


\title{
Summary of Plutonium Sorption on Rocks and Materials of Destruction of Engineered Barriers at Normal Pressure and Elevated Temperature [UTA-331]
}

\section{T. Gupalo, V. Beygul, VNIPIPT}

\begin{abstract}
A complex of laboratory studies on physical and chemical processes of plutonium solutions interactions with hard rock of biotite gneiss type and the materials of engineered barriers at normal pressure and elevated temperature has been carried out. These studies simulate the accelerated mode of real processes of slow destruction of the multi-barrier system elements in the borehole repository for vitrified plutonium by ground water, and retaining most of the plutonium leached from glass logs in the repository near zone.
\end{abstract}

\section{Goal}

To undertake the laboratory studies to evaluate the plutonium sorption on hard rock and the products of destruction of engineered barriers at normal pressure and elevated temperature.

\section{Technical Approach}

To carry out the laboratory experiments in investigation of destruction processes in sample rock and the materials of engineered barriers (i.e., boron silicate glass, steel, bentonite) in the process of interaction with the model water close in its contents to the ground water at great depths in crystalline hard rock cores. Experiments were carried out with plutonium solutions in order to study the plutonium sorption on hard rock and the materials of destruction of engineered barriers, separately and in various combinations.

\section{Technical Results}

1. In 1997, a complex of laboratory studies on physical and chemical processes of plutonium solutions interactions with the materials of engineered barriers and hard rock was carried out. These studies simulate the accelerated mode of real processes of slow destruction of the multi-barrier system elements in the borehole repository for vitrified plutonium by ground water and retaining most of the plutonium leached from glass logs in the repository near zone (Fig. 1).

2. The following materials simulating engineered barriers have been used in the laboratory experiments: boron silicate glass (glass logs), bentonite (bentonite backfilling in the boreholes), steel (casing, container). Crushed samples of glass and steel were used in the experiments to enlarge the surface involved in the reaction and to accelerate the processes of interaction with the model ground water.

3. The parameters of the model ground water contents are assumed to be within the limits of their possible values at the depths of $2000-5000 \mathrm{~m}$, in hard rock masses: 


\section{Geologic Disposal of Immobilized Plutonium}

$$
\mathrm{M}_{50}^{\prime} \frac{\mathrm{Cl} 99.1 \quad \mathrm{SO}_{4} 0.9}{\mathrm{Na} 71.5 \quad \mathrm{Ca} 23 \quad \mathrm{Mg} 5.5}, p H=7.0-7.5
$$

Disks from gneiss samples corresponding to the hard rock cores under investigation were used in the experiments. The samples were selected in three different areas of hard rock cores, and are marked by the following mineralogical contents: quartz $-25-40 \%$, feldspar $-20-40 \%$, biotite $-25-35 \%$, chlorite $-5-10 \%$.

4. The laboratory experiments were carried out under static conditions, assuming that in the zones of hard rock fracturing at 2000-5000 m depth, the velocities of ground water, according to the data on drilling the deep and super-deep boreholes, amount to millimeters or centimeters a year.

The experiments were carried out at a temperature of $80^{\circ} \mathrm{C}$, which corresponds to possible temperature in the near zone of the repository taking into account the heat release from the vitrified plutonium.

5. Experiments have been carried out to investigate processes of plutonium leaching from cement matrices at normal pressures and temperatures, plutonium sorption on gneiss samples and its desorption from the hard rock. According to the results of experiments, 89.1-97.7\% of plutonium from the solution was sorbed on the gneiss, and only $1.45 \%$ of the sorbed plutonium was desorbed, i.e., plutonium sorption on the rock is virtually irreversible.

6. It was discovered that in process of interaction of gneiss and the model ground water the hard rock is gradually destroyed, and a deposit appears on the disk surface demonstrating a high fixation capacity with regard to plutonium $\mathrm{K}_{\mathrm{d}}=1800 \mathrm{~cm}^{3} / \mathrm{g}$.

In the course of experiments, the desorption of plutonium by the ground water, which was retained both by the gneiss surface and the deposit formed on its surface, came only to $2.5 \%$ of initially sorbed amount. Plutonium is fixed on the gneiss surface selectively by individual minerals; chloritized biotite, in particular, is characterized by an enhanced capability of fixing plutonium.

7. Neogenesises resulting from the interaction of glass and ground water have a high sorption capacity for plutonium. Products of steel corrosion have significantly high capacity for fixation of plutonium. In the process of interaction of bentonite and the ground water, it is divided in two fractions, with both having high sorption capabilities with respect to plutonium:

$$
\mathrm{K}_{\mathrm{d}}=8.1 \cdot 10^{3} \mathrm{~cm}^{3} / \mathrm{g} \text { and } 1.7 \cdot 10^{5} \mathrm{~cm}^{3} / \mathrm{g} \text {. }
$$

8. The graphs illustrating the results of laboratory experiments carried out in accordance with the VNIPIPT assignment, are introduced in the report of Ms. E. Zakharova (Institute of Physical Chemistry, Russian Academy of Science, Moscow), the fourth report in this section.

9. The final report on the contract is 105 pages long, including 61 graphs with the results of experiments, and 6 radiographs of the sample hard rock sites. It is entitled "Laboratory scale tests to establish near-field transport, migration, and sorption of Pu isolated in hard rock geologic formations." The fixed-price agreement UTA-331 was dated 09/01/96 between the University of Texas at Austin and All-Russian Research and Design Institute of Production Engineering. Moscow, 1997. 


\section{Conclusion}

The processes of plutonium interaction in ground water solutions with the materials of engineered barriers in various combinations and hard rock have been studied. The stability of plutonium in all samples was proved to be decreasing, contributing to retention of dissolved plutonium in the near zone of the repository.

In the future, it would be advisable to proceed with the laboratory experiments, taking into account the expected pressure for the rock mass at a depth of 2000-5000 m.

In the course of future experiments, it would be advisable to pay specific attention to investigation of plutonium behavior in solutions and mass transfer of colloid, pseudo-colloid forms, and micro-dispersed particles. They are potentially capable of contributing to plutonium transfer along the fracturing zones to farther distances compared to purely ionic forms in solutions. 
Investigations on plutonium sorption on rocks and destruction materials of engineered barriers under normal pressure and high temperature (UTA-331, 1997)

\section{Laboratory scale test support}

\begin{tabular}{|c|}
\hline $\begin{array}{c}\text { Substantiation of laboratory scale } \\
\text { test conditions }\end{array}$ \\
\hline $\begin{array}{c}\text { Development of investigation } \\
\text { techniques for Pu sorption on rocks } \\
\text { and destruction materials of } \\
\text { engineered barriers under } \\
\mathrm{P}=0.1 \mathrm{MPa}, \mathrm{T}=80^{\circ} \mathrm{C}\end{array}$ \\
\hline Preparation of model water \\
\hline Core sampling in host rock, \\
preparation of rock samples \\
\hline
\end{tabular}

Execution of laboratory scale tests under $\mathrm{P}=0.1 \mathrm{MPa} . \mathrm{T}=20^{\circ} \mathrm{C}$ and $80^{\circ} \mathrm{C}$

Laboratory scale tests on leaching $\mathrm{Pu}$ and $\mathrm{Cs}$ from cement compositions under $\mathrm{P}=0.1 \mathrm{MPa}, \mathrm{T}=20^{\circ} \mathrm{C}, \mathrm{Pu}$ and $\mathrm{Cs}$ sorption on rocks, $\mathrm{Pu}$ and $\mathrm{Cs}$ desorption from rock samples

Laboratory scale tests on Pu sorption on rocks and destruction materials of engineered barriers separately and in different combinations under $\mathrm{P}=0.1 \mathrm{MPa}, \mathrm{T}=80^{\circ} \mathrm{C}$ 


\title{
Summary of Plutonium Sorption-Desorption on Rock Samples at Elevated Pressure and Temperature [B338273]
}

\author{
T. Gupalo, V. Beygul, VNIPIPT
}

\begin{abstract}
The analysis of the published results of experiments to investigate the interaction of plutonium and uranium solutions with the crystalline rocks was carried out. The data on possible migration of plutonium and uranium in ionic and colloid forms along the heightened fracturing zones of the hard rock cores in terms of geological disposal was summarized. The estimation of potential possibility of plutonium critical mass accumulation in the contour zone of the repository for immobilized Pu-materials was considered.

The methodology of investigation on solidity of radionuclides fixation on the rocks in fracturing zones at elevated temperature and pressure was developed. The laboratory experiments were conducted to investigate the plutonium, neptunium, americium sorption-desorption processes in conditions possible in terms of the geological disposal of the immobilized Pu-materials, i.e., temperature of $80^{\circ} \mathrm{C}$ and pressure of $30 \mathrm{MPa}$. As a result of experiments, it was discovered that the pressure rise significantly reduces the fixation stability of plutonium, neptunium, and americium isotopes on the rock.
\end{abstract}

\section{Goal}

To carry out the laboratory investigations on evaluation of parameters of the processes of plutonium transfer, sorption and desorption from the rock in terms of disposal in geological formations.

\section{Technical Approach}

Laboratory experiments were conducted with plutonium isotope solutions at elevated temperatures and pressures equal to those existing at a great depth, in the crystalline hard rock. We utilized sample rock from the heightened fracturing zones of the real crystalline hard rock, and analyzed and summarized the published results of the experiments in hydro-geochemistry of plutonium and uranium under geological disposal. An estimation of potential possibility of nuclear criticality during creation of the repository for immobilized Pu-materials was also prepared.

\section{Technical Results}

1. In the course of contractual work, the comprehensive analysis of isolating properties of the natural barrier-poorly fracturing crystalline hard rock-during geological disposal of immobilized Pu-materials was carried out. The main directions of the conducted investigations were as follows (see Figs. 1-3).

2. In fracturing zones of poorly permeable crystalline hard rock of the old folded areas, at a depth of more than $1000 \mathrm{~m}$, the ground waters will be characterized by $\mathrm{pH}$ values of $>7$ and $\mathrm{Eh}<0$, i.e., alkalescent and regenerating conditions. Low permeability of the rocks, regenerating conditions and rather low velocities of ground water flow contribute to geochemical isolation of disposed radionuclides, specifically, of plutonium, uranium, neptunium, and americium. 


\section{Geologic Disposal of Immobilized Plutonium}

3. Based on a large amount of the results of laboratory investigations and mathematical simulation accumulated for the time being, the distribution coefficient $\mathrm{K}_{d}(\mathrm{Pu})$ for the dissolved plutonium while migration in fracturing zones of the crystalline hard rock at a depth of $1000 \mathrm{~m}$ can amount to $5000 \mathrm{ml} / \mathrm{g}$.

It is worth mentioning that the stipulated results were obtained in the experiments at normal pressure conditions. In reality, at a depth of more than 2000-3000 m, pressure can reach $30 \mathrm{MPa}$.

4. In neutral water and regenerating environment, the dissolved plutonium can exist mainly in a tetravalent form and very low concentrations.

Based on the analysis of the published results of experiments, the main portion of plutonium can migrate in colloid form with contaminated ground water. The measurements of colloid particles are mainly less than $100^{-10}$ meters. They are badly retained by rock. However in time, the contents of colloids in ground water decreases gradually. In terms of the observed rather low velocity of ground water flow in crystalline hard rock, at a great depth, the colloids stick together, enlarge and precipitate on fracture surfaces in the process of aging. The contents of colloids in the ground water in crystalline mass existing in permanent condition is rather low. Besides, the bentonite engineered barrier can intensively retain plutonium colloids.

5. Based on theoretical estimations of American and Russian scientists, the minimum necessary condition for occurrence of spontaneous chain reaction in the repository contour zone, with a two-times safety reserve, will be the presence of channels with over $100 \mathrm{~cm}^{2}$ cross-section; cavities with over $17 \mathrm{~cm}$ diameter existing within a long-term period and filled with water and plutonium; or accumulation of plutonium rocks in the massif cavities, with plutonium concentration not less than $6.6 \mathrm{~g} / \mathrm{l}$. The existence of these conditions is not likely for the crystalline hard rock at a great depth. A risk of existence or occurrence of such structural heterogeneity in the future should be considered in process of siting a repository for Pu-materials in each individual hard rock cores. The work sets forth the realization of these estimations.

Moreover, to accumulate highly anomalous concentrations of plutonium in local zones, the presence of contrast regeneration barriers on the border of the areas with oxidizing conditions or creation of exclusive conditions for plutonium mechanical carrying out of the repository working zone, and plutonium local accumulation in anomalous cavities should be necessary.

These situations are, in practice, unlikely for the crystalline hard rock at a great depth, but should also be considered in terms of creation of a repository for Pu-materials.

6. In the course of the contract work, the laboratory experiments have been carried out for investigation of sorption properties of gneiss-type rocks in connection with plutonium, neptunium, and americium isotopes dissolved in the model ground water under conditions possible for the hard rock at a depth of more than $1000 \mathrm{~m}$, and at a temperature of $80^{\circ} \mathrm{C}$, and pressure of $30 \mathrm{MPa}$. The samples of two rock types different in their mineralogical contents and selected in the zones with tectonic disturbances in the metamorphic complex of Pre-Paleozoic rocks were used in the experiments. 


\section{Research and Development Plutonium Immobilization Contract Activities}

To conduct the experiments for investigation on behavior of long-lived radionuclide solutions at elevated pressures and temperatures, the modification of the laboratory installation primarily created for study on rock permeability by water and gas have been carried out.

7. The methodology of laboratory studies on parameters of radionuclides sorption-desorption processes on the sample rock surfaces at elevated pressures and temperatures has been developed.

The laboratory experiments were carried out with the selected gneiss disks system imitating the hard rock cores fracturing zone existing in conditions of the all-round compression. The parameters of processes of plutonium sorption on the rocks, plutonium desorption from contaminated surfaces, and migration of dissolved plutonium from the system with the contaminated model water solution have been determined in the experiments.

Similar experiments were carried out with neptunium and americium solutions.

8. Based on the series of conducted experiments, a preliminary conclusion on significant stirring up of the process of plutonium desorption from the rock surfaces at a pressure increase to $30 \mathrm{MPa}$ was made.

In this connection, the stability of plutonium and neptunium fixation on the rock at incresed pressure reduces, in practice, to a similar extent. In the course of experiments, the influence of pressure increase on americium stability reduction was significantly lower than for plutonium and neptunium.

The experimental graphs illustrating the alteration of parameters of plutonium, neptunium, americium sorption-desorption from the rock are introduced in the report on results of laboratory experiments for VNIPIpromtechnologii (VNIPIPT), Moscow, Russia (see the report of E. Zakharova, Institute of Physical Chemistry, RAS, later in this section).

9. The final report on the contract is on 90 pages long, and includes 27 photographs of a microstructure and radiograph of the sites of the studied rock samples, 9 graphs with the results of experiments, and 3 schemes. The title of the technical final report is "Plutonium laboratory scale tests to establish near-field transport, migration, and sorption of Pu isolated in hard rock geologic formations".

The fixed-price material support agreement number B338273 dated 09/25/97 between the Regents of the University of California and VNIPIPT, Moscow, 1998.

\section{Conclusion}

1. The results of laboratory experiments on plutonium, neptunium, americium sorption-desorption in terms of interaction with the gneiss-type rocks at elevated pressures and temperatures could be applied for substantiation of safety and design of the systems for geological disposal of immobilized Pu-materials in the crystalline hard rock.

2. In the future, it would be advisable to proceed with the studies on influence of the pressure increase on the processes of long-lived radionuclides sorption-desorption on the rocks, including the modification of experimental methodology. 
Plutonium sorption-desorption tests in the near-field zone of disposal for plutonium-containing materials in crystalline rock mass B3382273, 1998)

- Analysis of possible conditions in near-field zone of disposal for plutonium-containing materials;

- Laboratory scale tests support for $\mathrm{Pu}, \mathrm{Np}, \mathrm{Am}$ sorption-desorption under high pressures and temperatures ;

- Laboratory scale tests on $\mathrm{Pu}, \mathrm{Np}, \mathrm{Am}$ sorption-desorption under $\mathrm{P}=30 \mathrm{MPa}, \mathrm{T}=80^{\circ} \mathrm{C}$. 


\section{Analysis of possible conditions in zone of plutonium-containing disposal (B338273, 1998)}

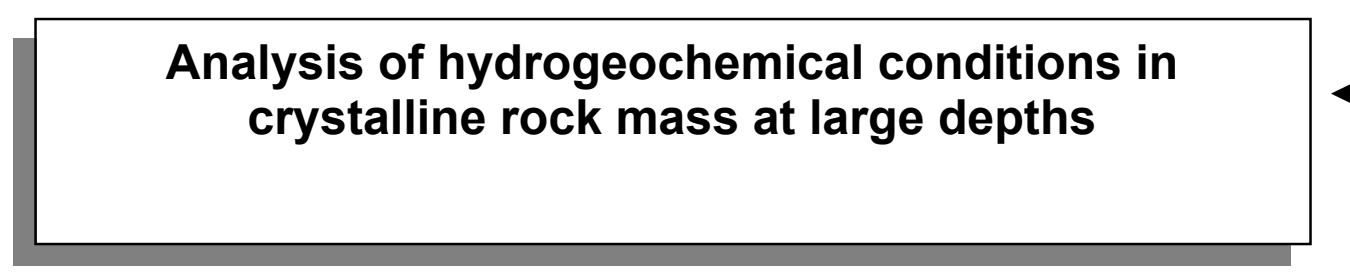

, Eh, compositions of
underground waters

Analysis of hydrogeochemical properties of $\mathrm{U}$ and $\mathrm{Pu}$

- theoretical assessments;

- generalization of experimental results;

- data on natural analogies of transuranium elements disposal.

\section{Analysis of formation mechanisms and migration ability of Pu colloids}

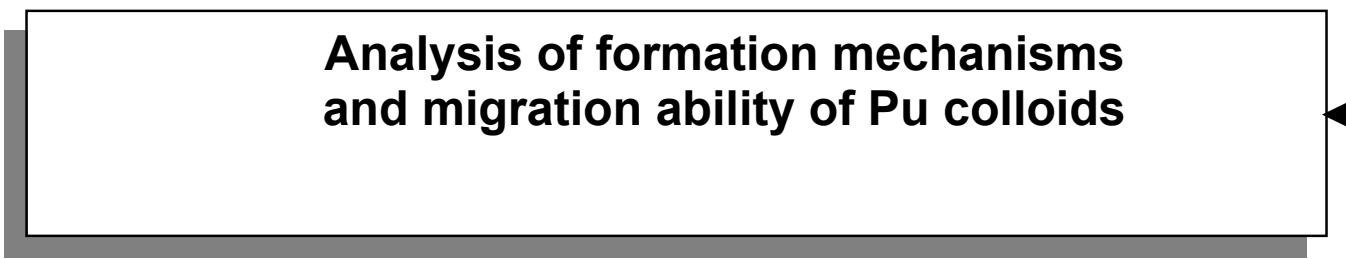

potential solubility of $\mathrm{U}$ and $\mathrm{Pu}$ in underground waters; distribution coefficients on rocks and materials

Analysis of possibility of nuclear criticality occurrence at geological disposal

limiting conditions of nuclear of plutonium-containing materials

conditions of migration danger limitations for Pu colloid forms 
Laboratory scale tests on sorption-desorption of $\mathrm{Pu}, \mathrm{Np}, \mathrm{Am}$ from rocks under high pressure and temperature|

(B338273, 1998)

\section{Laboratory scale test support}

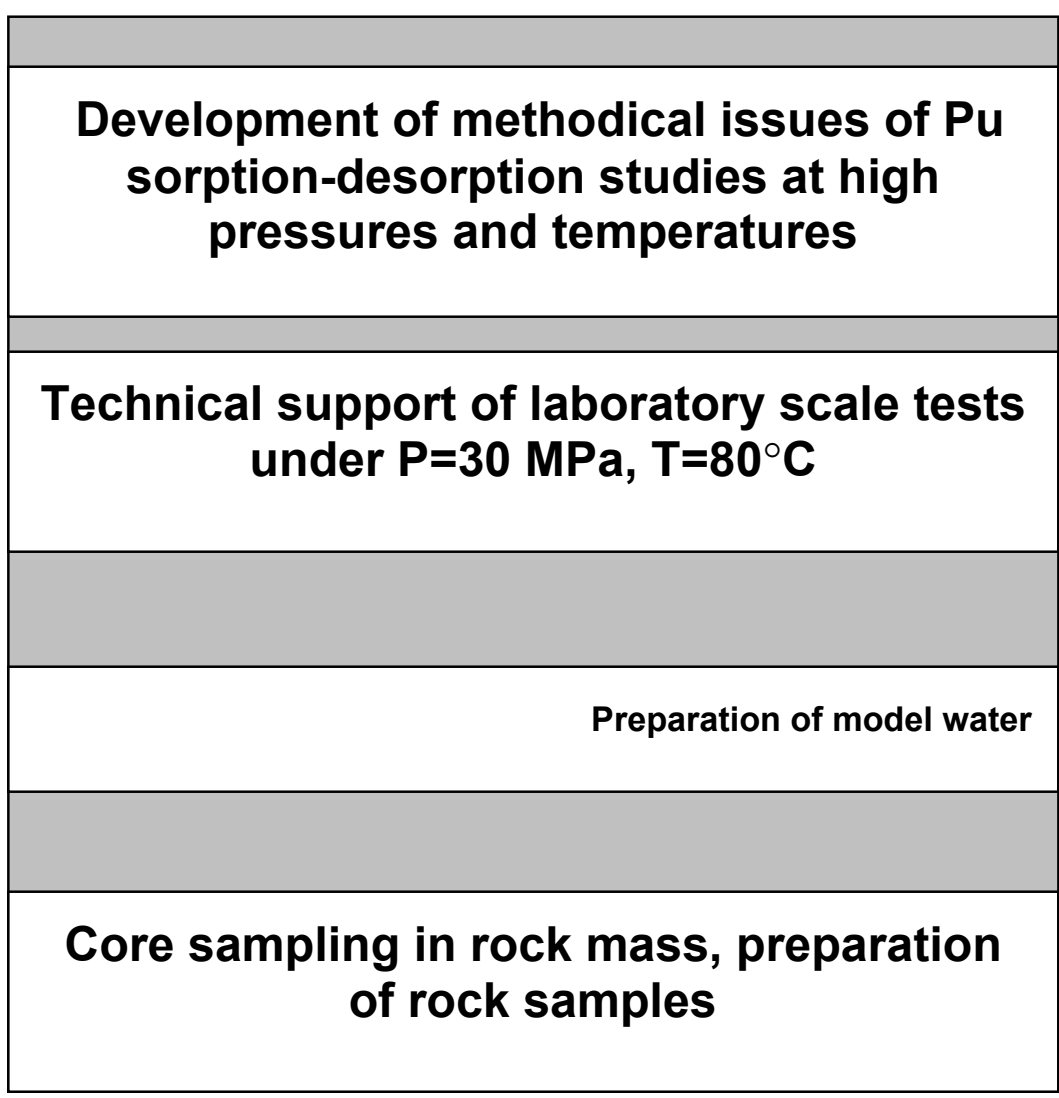

\section{Execution of laboratory scale tests} under $\mathrm{P}=30 \mathrm{MPa}, \mathrm{T}=80^{\circ} \mathrm{C}$

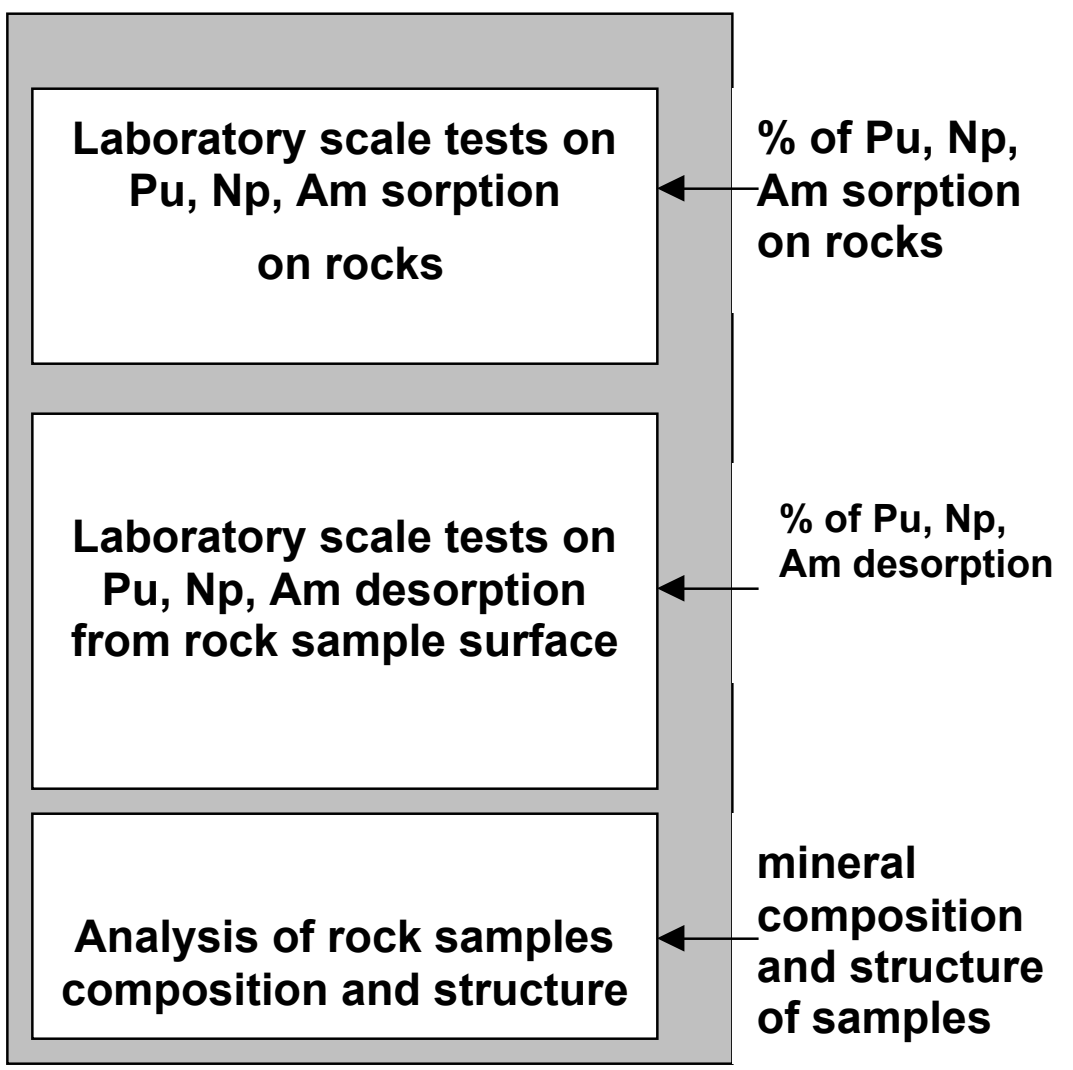




\title{
Comparison of K-26 Glass Properties and Plutonium Sorption on Hard Rock Cores at Elevated Temperature and Pressure [B501120]
}

\author{
T. Gupalo, V. Beygul, VNIPIPT; A.A.Tretyakov, S.A.Manakov, MCC
}

\begin{abstract}
The laboratory experiments for investigation on physical and chemical properties of the three types of phosphate and borosilicate glass originating from K-26 were carried out with plutonium imitator, with real sludges, and with sludge and plutonium dioxide with plutonium mass contents of $0.5 \%$. The experiments were conducted with model (simulated) water of two types: (1) analogous to the ground water in the K-26 hard rock core and (2) similar to water at a depth of more than $1500 \mathrm{~m}$. Temperatures and pressures in these experiments were $\mathrm{T}=80^{\circ} \mathrm{C}, \mathrm{P}=0.1 \mathrm{MPa}$, and $\mathrm{T}=80^{\circ} \mathrm{C}$ and $\mathrm{P}=15 \mathrm{MPa}$, accordingly. Moreover, the experiments for investigation on plutonium sorption on the rock and the products of engineered barriers destruction, and plutonium desorption from the rock and the products of glass destruction have been carried out under the similar conditions and with the same water.
\end{abstract}

The tests on mechanical stability of the samples of phosphate and borosilicate glass originating from K-26 were conducted.

Based on the preliminary results, the comparison of the properties of the glass produced at K-26 for immobilization of the waste from weapon plutonium production has been carried out.

\section{Goal}

To investigate and compare at elevated pressure and temperature the physical and chemical properties of phosphate and borosilicate glass produced at K-26 for the purpose of comparative evaluation of their possible utilization for immobilization of Pu-materials during geological disposal in the crystalline hard rock cores.

\section{Technical Approach}

The K-26 equipment produces samples of phosphate and borosilicate glass of three types: (1) an imitation of the real sludge from weapon plutonium production; the real sludge; and plutonium dioxide and sludge imitator.

The samples are preliminary kept at a temperature of $80^{\circ} \mathrm{C}$, with no water contact. Then, these samples are utilized for laboratory experiments for definition of plutonium and uranium radionuclides leaching velocities for conditions possible in terms of geological disposal at a depth of 250-350 m (model water with radionuclide contents of $0.4 \mathrm{~g} / \mathrm{l}$, pressure of $0.1 \mathrm{MPa}$, temperature of $80^{\circ} \mathrm{C}$ ), and $1500-2000 \mathrm{~m}$ (model water with radionuclide contents of $50 \mathrm{~g} / \mathrm{l}$, pressure of $15 \mathrm{MPa}$, temperature of $80^{\circ} \mathrm{C}$ ).

Afterwards, laboratory experiments are carried out to investigate plutonium sorption on the products of destruction of two types of glass, on the products of steel corrosion, on the hard rock, are carried out; and then, plutonium desorption from the sample rock at elevated pressure and temperature is studied. 


\section{Geologic Disposal of Immobilized Plutonium}

The tests on mechanical stability of phosphate and borosilicate glass originating from K-26 under compression and strain are carried out.

\section{Technical Results}

1. In the course of the contract work, laboratory investigations on physical and mechanical properties of phosphate and borosilicate glass originating from K-26 and the evaluation of their possible utilization for immobilization of K-26 radioactive sludge were carried out.

The main directions and stages of the completed works are shown on Figs. 1-2.

2. The contract considers phosphate and borosilicate glass designed for immobilization of radioactive sludge from weapon plutonium production at K-26. The experimental production of these types of glass has been launched at K-26 based on the methodology developed in VNIINM (Moscow) and the Radium Institute (St. Petersburg), accordingly.

In the experiments to investigate the chemical stability and mechanical stability of the glass, plutonium and uranium sorption-desorption on the hard rock the three types of samples of K-26 phosphate and borosilicate glass have been utilized: with real sludge imitator, real sludge (Table 1), with sludge imitator and plutonium dioxide with plutonium mass contents of $0.5 \%$ (Table 2 ).

3. Preliminarily, all the glass samples were kept aside for 40 days at a temperature of $90^{\circ} \mathrm{C}$, with no water contact.

4. Then, the samples with pulp imitator interacted with the distilled water at a temperature of $25^{\circ} \mathrm{C}$ and $90^{\circ} \mathrm{C}$, and a pressure of $0.1 \mathrm{MPa}$. In the process, the glass dissolution velocities and velocities of the main elements' exit from matrix have been assessed: (1) from phosphate glass-uranium, phosphorus, sodium, chrome, silicon, iron, aluminum, nickel, and manganese; (2) from borosilicate glass-uranium, boron, sodium, chrome, silicon, iron, aluminum, and manganese.

5. The analysis of possible conditions has been carried out for an intermediate storage location depth $(250-350 \mathrm{~m})$ and a depth location for a repository for immobilized radioactive sludge from weapon plutonium production (1500-2000 m).

The composition of two types of water for laboratory experiments was determined based on the data on the ground water chemical analysis at a depth of the K-26 underground facilities (hydrocarbonaceous calcium-sodium-magnesium water, mineralized - $0.4 \mathrm{~g} / \mathrm{l}$, and $\mathrm{pH}=7.5-8.5$ ), and the earlier summarized data on drilling the deep and super-deep boreholes in the former USSR and abroad (neutral chloride sodium-calcium-magnesium water, mineralized - $50 \mathrm{~g} / \mathrm{l}$ ). For these conditions, the following temperature and pressure values were accepted for the experiments: $\mathrm{T}=80^{\circ} \mathrm{C}, \mathrm{P}=0.1 \mathrm{MPa}$ and $15 \mathrm{MPa}$, accordingly. Hereinafter, the above water types will be referred to as the model water of $1^{\text {st }}$ and $2^{\text {nd }}$ types. 
Table 1. Composition of borosilicate and phosphate glass, with imitator of radioactive sludge from weapon plutonium production.

\begin{tabular}{|l|l|l|}
\hline \hline Component & \multicolumn{2}{|l|}{ Contents of components in glass, mass \% } \\
\hline & Borosilicate (BI) & Phosphate (Phl) \\
\hline $\mathrm{MnO}_{2}$ & 5.8 & 4.3 \\
\hline $\mathrm{Al}_{2} \mathrm{O}_{3}$ & 3.1 & 1.1 \\
\hline $\mathrm{NiO}$ & 1.0 & 0.9 \\
\hline $\mathrm{Fe}_{2} \mathrm{O}_{3}$ & 14.5 & 5.4 \\
\hline $\mathrm{Cr}_{2} \mathrm{O}_{3}$ & 1.9 & 1.0 \\
\hline $\mathrm{Na}_{2} \mathrm{O}$ & 14.9 & 23.3 \\
\hline $\mathrm{Li}_{2} \mathrm{O}$ & 7.0 & - \\
\hline $\mathrm{SiO}_{2}$ & 36.4 & 0.3 \\
\hline $\mathrm{B}_{2} \mathrm{O}_{3}$ & 7.0 & - \\
\hline $\mathrm{P}_{2} \mathrm{O}_{5}$ & - & 56.8 \\
\hline
\end{tabular}

Table 2. Composition of borosilicate and phosphate glass, with imitator and plutonium.

\begin{tabular}{|l|l|l|}
\hline Component & \multicolumn{2}{|l|}{ Contents of components in glass, mass \% } \\
\hline & Borosilicate (BP) & Phosphate (PhP) \\
\hline $\mathrm{PuO}_{2}$ & 0.5 & 0.5 \\
\hline $\mathrm{UO}_{3}$ & 8.4 & 6.5 \\
\hline $\mathrm{MnO}_{2}$ & 5.8 & 4.4 \\
\hline $\mathrm{Al}_{2} \mathrm{O}_{3}$ & 3.1 & 1.1 \\
\hline $\mathrm{NiO}$ & 1.0 & 0.9 \\
\hline $\mathrm{Fe}_{2} \mathrm{O}_{3}$ & 14.4 & 5.5 \\
\hline $\mathrm{Cr}_{2} \mathrm{O}_{3}$ & 1.9 & 6.5 \\
\hline $\mathrm{Na}_{2} \mathrm{O}$ & 14.8 & 23.4 \\
\hline $\mathrm{Li}_{2} \mathrm{O}$ & 7.0 & - \\
\hline $\mathrm{SiO}_{2}$ & 36.1 & 0.4 \\
\hline $\mathrm{B}_{2} \mathrm{O}_{3}$ & 7.0 & - \\
\hline $\mathrm{P}_{2} \mathrm{O}_{5}$ & - & 56.4 \\
\hline & & \\
\hline
\end{tabular}

6. Samples of phosphate and borosilicate glass with the real K-26 sludge were interacting with the $1^{\text {st }}$ type model water $(0.4 \mathrm{~g} / \mathrm{l})$ at a temperature of $90^{\circ} \mathrm{C}$, and pressure of $0.1 \mathrm{MPa}$. The leaching velocity graphs for $\mathrm{Pu}, \mathrm{U}$ and major glass ingredients (i.e., phosphorus and silicon, for the glass of PhR and BR types) are shown in Figs. 3, 4.

As the result of the laboratory experiments, the glass dissolution velocities and the velocities of plutonium and uranium leaching have been determined (Table 3; preliminary results). 
Table 3. Preliminary properties of K-26 phosphate and borosilicate glass containing plutonium and radioactive waste of weapon plutonium production.

\begin{tabular}{|c|c|c|c|}
\hline \multirow[t]{2}{*}{ Indicators } & \multirow[t]{2}{*}{ Units } & \multicolumn{2}{|c|}{$\begin{array}{l}\text { Experimental conditions for study on glass physical } \\
\text { and chemical properties }\end{array}$} \\
\hline & & $\begin{array}{l}\mathrm{P}=0.1 \mathrm{MPa}, \mathrm{T}=90^{\circ} \mathrm{C}, \text { salt } \\
\text { contents in water, } 0.4 \mathrm{~g} / \mathrm{l}, \\
\text { glass with real sludge }\end{array}$ & $\begin{array}{l}\mathrm{P}=15 \mathrm{MPa}, \mathrm{T}=80^{\circ} \mathrm{C}, \text { salt } \\
\text { contents in water, } 50 \mathrm{~g} / \mathrm{l}, \\
\text { glass with imitator and } \\
\mathrm{PuO}_{2}\end{array}$ \\
\hline $\begin{array}{l}\text { Dissolution velocities } \\
\text { For main glass components }\end{array}$ & $\begin{array}{l}\mathrm{g} / \mathrm{cm}^{2} / \\
\text { day }\end{array}$ & & \\
\hline $\begin{array}{l}\text { 1.1. Phosphate glass } \\
\text { Phosphorus }\end{array}$ & & $6.3 \cdot 10^{-3}$ & $3.2 \cdot 10^{-5}$ \\
\hline $\begin{array}{l}\text { 1.2. Borosilicate glass } \\
\text { Boron } \\
\text { Silicon } \\
\end{array}$ & & $\begin{array}{l}2.8 \cdot 10^{-4} \\
5.1 \cdot 10^{-5}\end{array}$ & $\begin{array}{l}4.9 \cdot 10^{-7} \\
2.81 \cdot 10^{-6}\end{array}$ \\
\hline $\begin{array}{l}\text { Radionuclides } \\
\text { Leaching velocities }\end{array}$ & $\begin{array}{l}\mathrm{g} / \mathrm{cm}^{2} / \\
\text { day }\end{array}$ & & \\
\hline $\begin{array}{r}\text { 2.1. Phosphate glass } \\
\text { Plutonium } \\
\text { Uranium }\end{array}$ & & $\begin{array}{l}1.0 \cdot 10^{-5} \\
4.3 \cdot 10^{-3}\end{array}$ & $\begin{array}{l}2.3 \cdot 10^{-8} \\
2.3 \cdot 10^{-6}\end{array}$ \\
\hline $\begin{array}{r}\text { 2.2. Borosilicate glass } \\
\text { Plutonium } \\
\text { Uranium }\end{array}$ & & $\begin{array}{l}2.1 \cdot 10^{-8} \\
7.6 \cdot 10^{-7}\end{array}$ & $\begin{array}{l}7.1 \cdot 10^{-7} \\
2.4 \cdot 10^{-5}\end{array}$ \\
\hline $\begin{array}{l}\text { Sample stability limits, } \\
\text { For compression and strain }\end{array}$ & $\mathrm{MPa}$ & & \\
\hline $\begin{array}{l}\text { 3.1. Phosphate glass } \\
\text { compression } \\
\text { strain }\end{array}$ & & $\begin{array}{l}11-14 \\
2-8\end{array}$ & \\
\hline $\begin{array}{l}\text { 3.2. Borosilicate glass } \\
\text { compression } \\
\text { strain }\end{array}$ & & $\begin{array}{l}15-25 \\
5-17\end{array}$ & \\
\hline $\begin{array}{l}\text { Thermoconductivity of } \\
\text { Phosphate and Borosilicate glass }\end{array}$ & $\mathrm{W} / \mathrm{m} \cdot{ }^{\circ} \mathrm{C}$ & 1.2 & \\
\hline
\end{tabular}

7. Samples of phosphate and borosilicate glass with sludge imitator and plutonium dioxide have interacted with the $2^{\text {nd }}$ type model water, at a temperature of $T=80^{\circ} \mathrm{C}$ and pressure of $\mathrm{P}=15 \mathrm{MPa}$ (Figs. 5,6). As a result of experiments, the glass dissolution velocities and plutonium and uranium leaching velocities have been defined (Table 3; preliminary results).

8. The tests on mechanical stability of the phosphate and borosilicate glass samples have been conducted; the stability limits of the samples for compression and strain were defined (Table 3; preliminary results). The glass samples of $30 \mathrm{~mm}$ diameter and $30 \mathrm{~mm}$ height were utilized for the tests.

9. The laboratory experiments for investigation on plutonium sorption on the hard rock and glass and steel destruction products have been carried out: with the $1^{\text {st }}$ type model water at $T=80^{\circ} \mathrm{C}$ 


\section{Research and Development Plutonium Immobilization Contract Activities}

and $P=0.1 \mathrm{MPa}$, the $2^{\text {nd }}$ type model water at $\mathrm{T}=80^{\circ} \mathrm{C}$ and $\mathrm{P}=15 \mathrm{MPa}$. The results of the experiments show that plutonium is strongly sorbed on the hard rock under conditions similar to a great depths, i.e., at a pressure of $15 \mathrm{MPa}$ and the model water with high salt contents.

The laboratory experiments for investigation on plutonium desorption from the hard rock and the glass destruction products at $\mathrm{T}=80^{\circ} \mathrm{C}, \mathrm{P}=0.1 \mathrm{MPa}$ and $\mathrm{T}=80^{\circ} \mathrm{C}, \mathrm{P}=15 \mathrm{MPa}$ were carried out.

The results of experiments assigned by VNIPIPT on plutonium sorption and desorption on the rocks and the products of engineered barriers' destruction are introduced in the report of $\mathrm{E}$. Zakharova (Institute of Physical Chemistry, RAS, Moscow) later in this section.

\section{Conclusion}

1. The studies of the main physical and chemical properties of K-26 newly produced Pu-phosphate and Pu-borosilicate glass for immobilization of radioactive sludge from weapon plutonium production were carried out. As far as the preliminary results are concerned, it is necessary to point out that on the basis of the study of the experimental glass samples produced at K-26, at elevated pressure and temperature the $\mathrm{Pu}$ and $\mathrm{U}$ leaching velocities for phosphate and borosilicate glass are of practically similar type, and at normal pressure, are differ three-times in favor of the borosilicate glass. Besides, the phosphate glass was destroyed faster upon its contact with water, than the boronsilicate. The laboratory experiments for investigation on plutonium sorption and desorption from the hard rock were conducted.

2. To substantiate the priorities in utilizing the glass produced for immobilization and further underground disposal of the K-26 radiochemical production waste, it would be necessary to carry out a safety evaluation and a feasibility financial study of corresponding options of the multibarrier systems for intermediate storage and geological disposal of waste; and conduct a comparison of the above according to a comprehensive "risk-benefit" criteria. 
Laboratory scale tests support for study of K-26 phosphate and borosilicate glass properties during immobilization of weapon plutonium production wastes

(B501120, 1999)
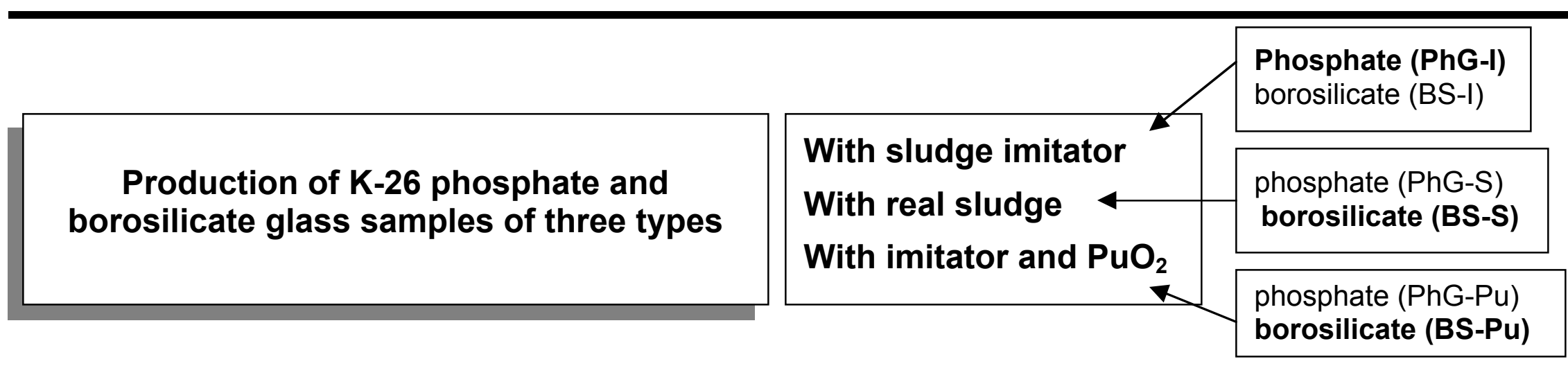

Determination of laboratory test conditions for leaching and sorption-desorption experiments under normal and high pressure

Model water $1, \mathrm{P}=0 \mathrm{MPa}, \mathrm{T}=90^{\circ} \mathrm{C}$

Model water $2, \mathrm{P}=15 \mathrm{MPa}, \mathrm{T}=\mathbf{8 0}^{\circ} \mathrm{C}$

Development of test technique for radionuclide leaching from glasses

Assembly and starting operation of K-26 laboratory installation for leaching from glasses under normal and high pressures and temperatures

For 0.1 MPa pressure

For high pressures 
Laboratory scale tests for study of K-26 phosphate and borosilicate glass properties under storage and geological disposal of immobilized weapon plutonium production wastes (B501120,1999)

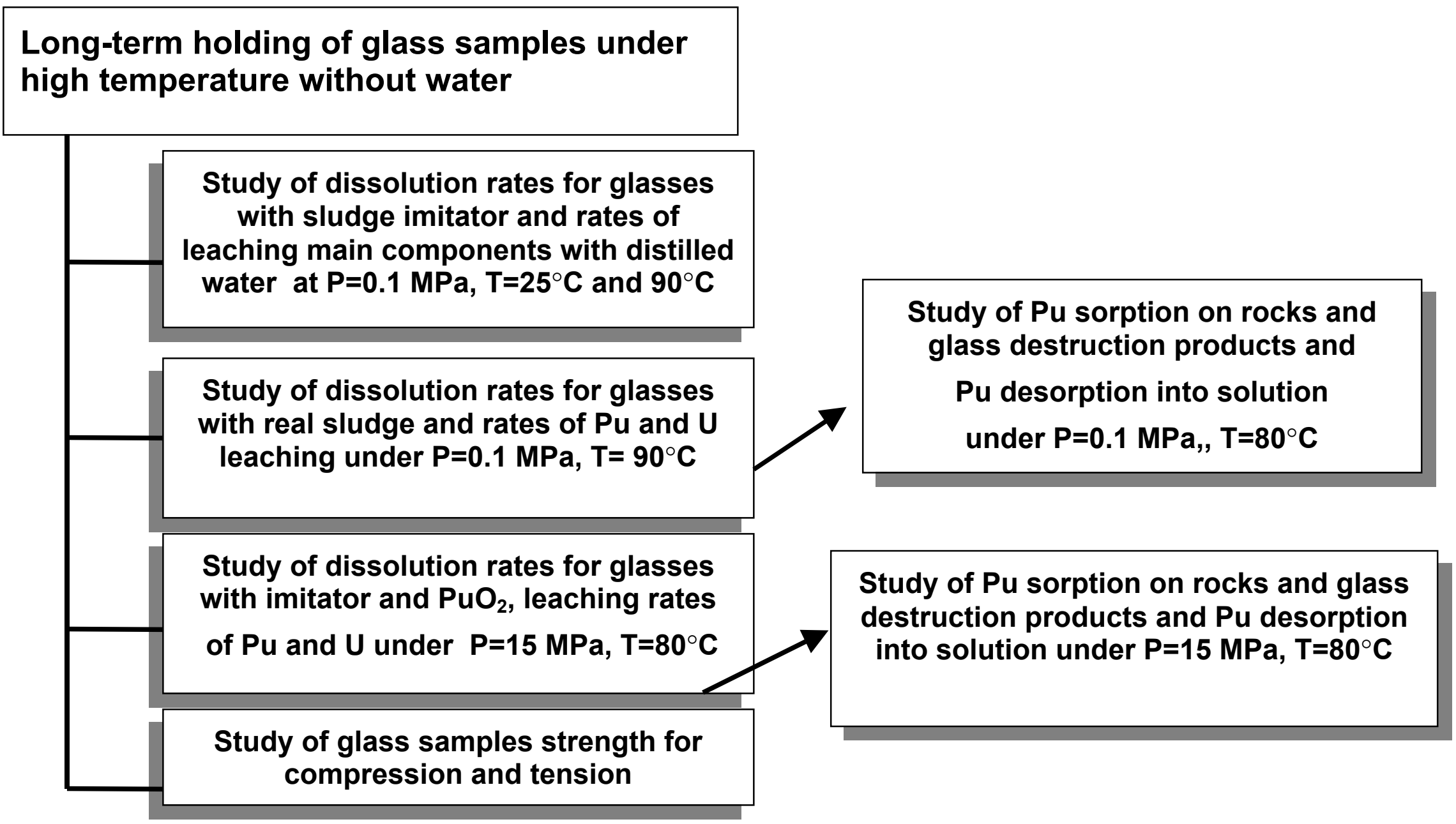


Geologic Disposal of Immobilized Plutonium 


\section{Laboratory Studies on the Behavior of Plutonium in the Solidified Radioactive Waste Repositories Located in the Low Fractured Rock Masses [B338273, B501120]}

\section{E.V. Zakharova, A.A.Menyailo, K.A.Menyailo, S.I.Ushakov, Institute of Physical Chemistry RAS (IPC RAS)}

Underground disposal safety of the solidified plutonium should be based on forecasting the behavior of plutonium released into the geological media through the repository boundaries, as the engineered barrier resistance could not be guaranteed for the time span of the order of the thousands of years. The forecast should be based on the experimental data on the behavior of plutonium after the decomposition of the matrix and the other engineered barrier elements followed by the release of plutonium through the boundaries of a repository. To determine the factors both accelerating and retarding the migration of plutonium, separate phases of the processes occurred in the course of the repository deterioration were simulated in the experiments with the allowance for the complexity of those processes. In the presented study the hypothetical data were used on the hydrogeological and geochemical characteristics of a rock mass intended for location of a repository. Hence, results of the studies allow to evaluate just the direction and the extent to which the behavior of plutonium is affected by the physicochemical processes occurred in the course of the repository deterioration.

It is supposed that the repository under study is located in a low-permeable rock mass at the depth over $1000 \mathrm{~m}$ at the underground water flow velocity below $10 \mathrm{~mm} /$ year. For the rock used for location of the repository, the metamorphous gneiss rock is selected consisting basically of quartz, micas (muscovite, biotite), and feldspar (orthoclase, plagioclase).

Rock masses represented by gneiss are characterized by chloride-sodium type brines with the salt bearing up to $50 \mathrm{~g} / \mathrm{l}$, at the $\mathrm{pH}$ of $6.7-7.7$. Chemical composition of the underground water simulant was obtained by summarizing data available on the underground water composition in gneiss masses at low depth (see Table 1).

Table 1. Chemical composition of the underground water simulant.

\begin{tabular}{|l|l|l|l|l|l|}
\hline \hline Component & $\mathrm{NaCl}$ & $\mathrm{Na}_{2} \mathrm{SO}_{4}$ & $\mathrm{CaCl}_{2}$ & $\mathrm{MgCl}_{2}$ & $\mathrm{pH}$ \\
\hline Concentration, g/L & 36.017 & 0.566 & 11.147 & 2.271 & 6.70 \\
\hline
\end{tabular}

Warm-up within the repository location zone is expected to be $80^{\circ} \mathrm{C}$. Experiments were run under pressure of $0.1,15$, and $30 \mathrm{MPa}$.

As the gneiss samples were taken from the practically water-free mass, the interaction between the gneiss and the underground water should be considered as the interaction of a rock with the underground water penetrating from an another water-bearing horizon. 


\section{Geologic Disposal of Immobilized Plutonium}

\section{Part I, Year 1997}

At the first phase of the studies the task was to evaluate the behavior of plutonium is affected by the following processes:

- Interaction of the repository-containing rock with the underground water under non-equilibrium conditions;

- Deterioration of the engineered barrier elements in contact with the underground water.

At this phase the experiments were run under the temperature of $80^{\circ} \mathrm{C}$ and the pressure of $0.1 \mathrm{MPa}$. Rock gneiss discs sawed from the core were used for the experiments..

It's been found that in the course of the rock and underground water contact the $\mathrm{pH}$ of the solution changes, the content of calcium and magnesium in the solution decreases, and the appearance of silicon in the solution is detected.

In the process of the rock - underground water the rock deteriorates, and a precipitate is formed consisting of the fine rock particles and fluid flakes, and besides, a coat of the very fine particles is formed on the surface of the rock itself.

According to the data of the X-ray phase analysis, the products of gneiss deterioration are a mixture of micas, mixed-layered minerals, and montmorillonite. As in the initial samples both the mixed-layered minerals and montmorillonite are not present, the appearance of those is attributed to the transformation under the hydrothermal conditions of the tri-octahedron micas consisting primarily of the biotite. All those processes associated with the rock transformation should make some effect on the behavior of plutonium.

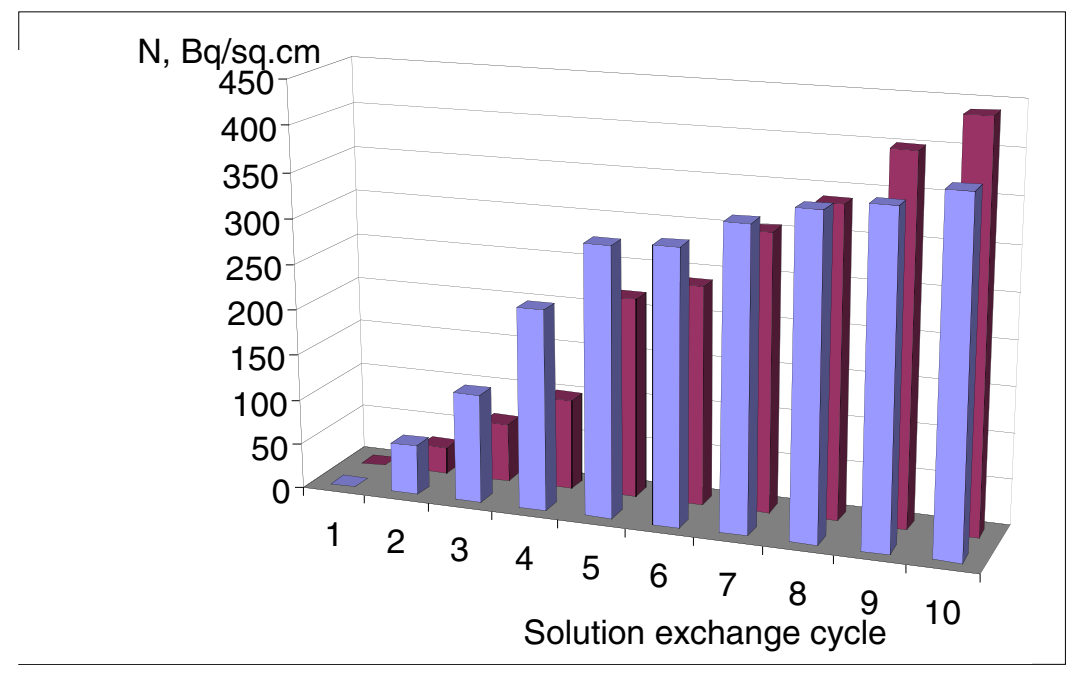

Fig. 1. Accumulation of plutonium on two gneiss disc surfaces during sorption from the underground water simulant.

Process of plutonium accumulation on the gneiss surface is presented in Fig. 1. In the experiment the content of $\mathrm{Pu}(\mathrm{IV})$ in the feed solution was $0.1 \mathrm{mg} / \mathrm{L}\left(3.75 \cdot 10^{5} \mathrm{~Bq} / \mathrm{L}\right)$. In the interaction process of the rock 
and plutonium-containing underground water the plutonium is distributed among the three phases of the rock, solution, and the precipitate. Distribution of plutonium between the gneiss surface and the precipitate is shown in Fig. 2 . By the $10^{\text {th }}$ cycle the plutonium quantities immobilized on the precipitate and on the gneiss surface are practically equal.

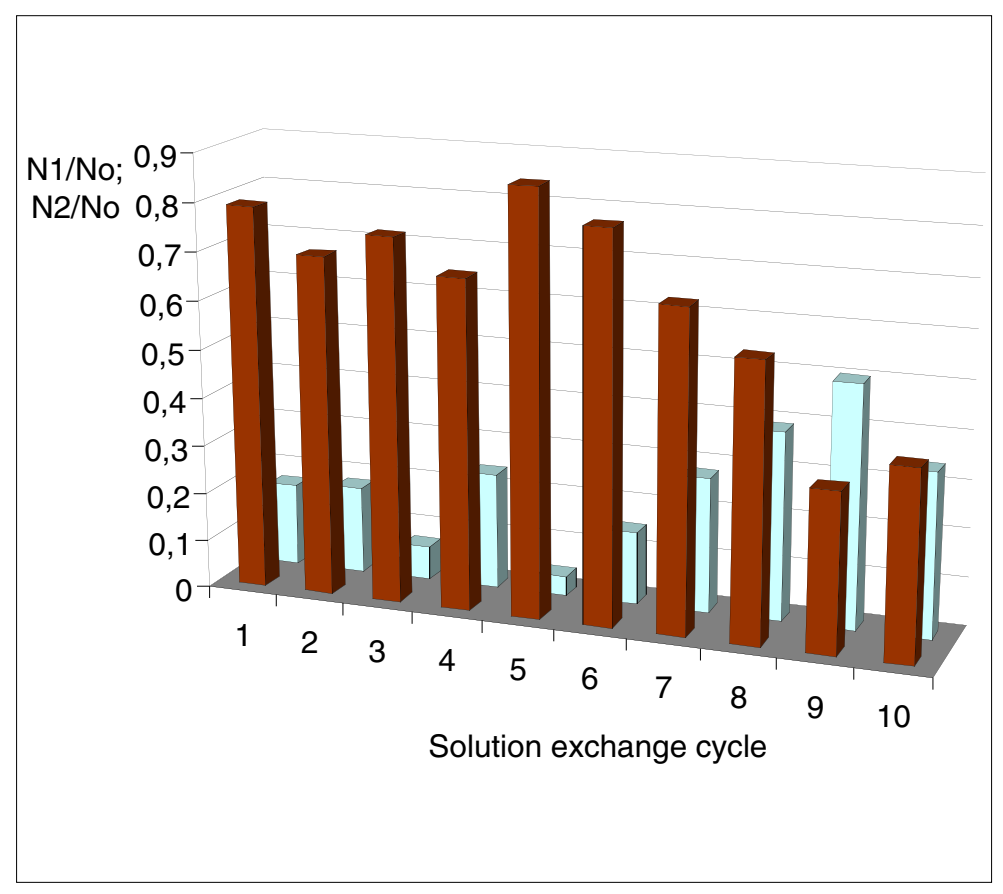

Fig. 2. Distribution of plutonium on the rock (dark columns) and on the precipitate (light columns) during sorption from the underground water simulant:

$$
\begin{aligned}
& N_{1} \text { - amount of plutonium, immobilized on the entire disc surface; } \\
& N_{2} \text { - amount of plutonium captured by the precipitate; } \\
& N_{0} \text { - amount of plutonium in the feed. }
\end{aligned}
$$

Then the coat from the disc was removed, the coat contained $54 \%$ of the gross plutonium quantity immobilized on the entire disc. Residual plutonium quantities adsorbed on both disc surfaces amounted 177 and $187 \mathrm{~Bq} / \mathrm{cm}^{2}$, merely $2.5 \%$ of the plutonium adsorbed on gneiss surface being stripped by the underground water under $0.1 \mathrm{MPa}$.

To determine a part played by different minerals in the plutonium immobilization, the experiment was performed with two mirror discs sawed from the gneiss core. One disc was used to prepare a polished section for determining the mineralogical rock composition. The other was used for plutonium sorption followed by imaging the both butt-end disc surfaces by radiography. Radiographic images were used to locate the area of the most widely spread plutonium immobilization, the area of the elevated plutonium immobilization capacity, as well as the areas containing big and small fractures of 0.5 and $0.15 \mathrm{~mm}$ width, respectively. Surfaces of the fractures also showed the elevated plutonium content. 


\section{Geologic Disposal of Immobilized Plutonium}

For each of those areas selected according to the radiographic data, the corresponding areas on the polished section surface were located, and the mineralogical composition of the rock in the area was determined.

It has been found that in the most widely spread plutonium immobilization area the presence of the sericite mineral in small quantities is observed which witnesses the secondary hydrothermal rock transformation. The area of the elevated plutonium immobilization capacity was enriched by the chlorinated biotite formed as a result of the hydrothermal impact on the biotite. The big fracture is enriched by biotite. Biotite particle size in the fracture is much smaller than in the rock which witnesses its secondary origin. In the big fracture the presence of muscovite and quartz of the secondary hydrothermal origin. The small fracture is of later origin and is filled by calcite. Those data witness the fact that the rock was exposed to the two basic hydrothermal impacts. An earlier one, when the big fracture was filled with the secondary micas and quartz, and the following one, when the biotite in the rock was partially chlorinated, and the feldspars were exposed to sericitization.

Another factor capable to affect the distribution of plutonium beyond the repository boundaries is the interaction of the released plutonium with the deterioration products of the engineered barrier.

Deterioration products of the first engineered barrier element are hydrated ferric oxides (hematite). As it was found, the hematite is a good plutonium sorbent, the $K_{d}$ of plutonium on the hematite being equal to $2.4 \cdot 10^{5} \mathrm{~cm}^{3} / \mathrm{g}$ (see Fig. 3).

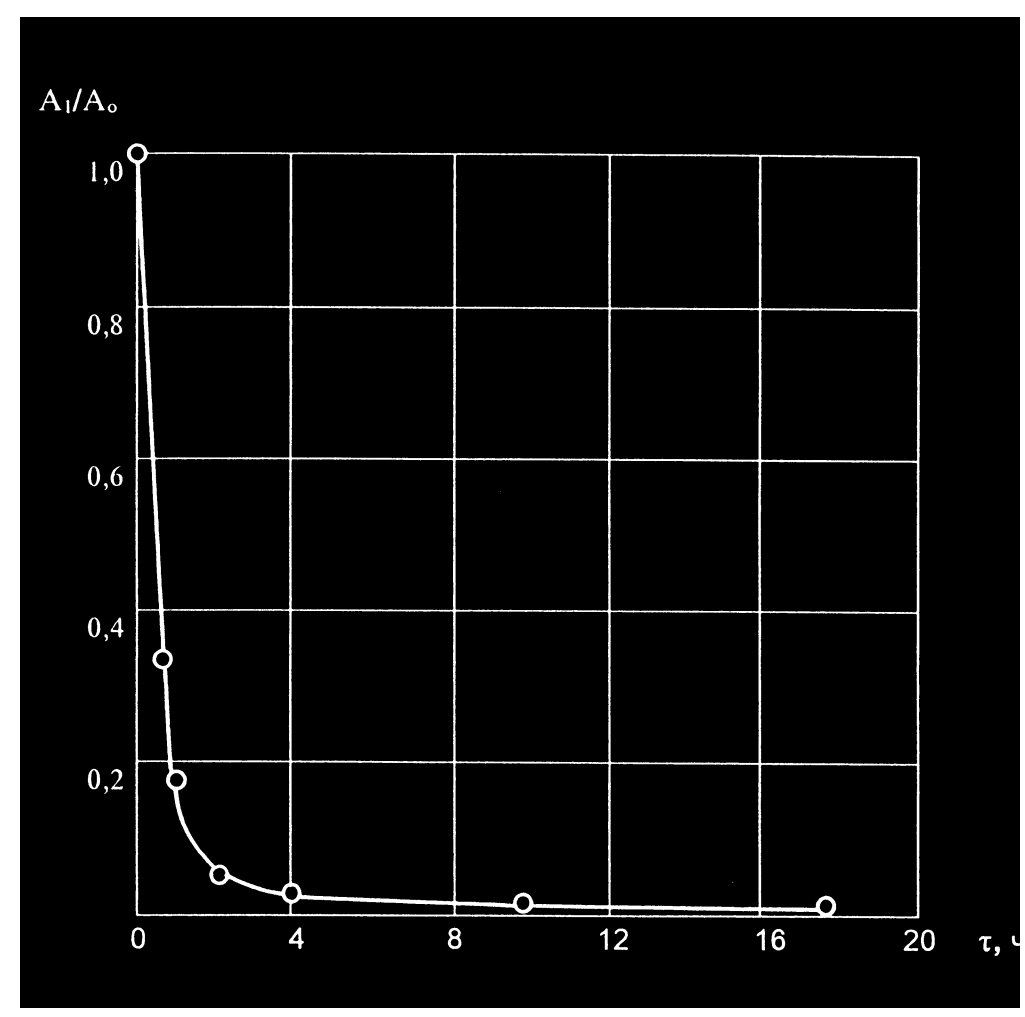

Fig. 3. Variations in the underground water plutonium content $\left(A_{1} / A_{0}\right)$ with time at $\left(80+3^{\circ} \mathrm{C}\right)$ under contact with hematite 
The next engineered barrier element is the bentonite filler. It is found that during the interaction of bentonite and underground water under hydrothermal conditions the former is stratified into two layers, different in properties. The layers possess elevated sorption capacity with regard to plutonium as compared with the initial bentonite (see Fig. 4). Distribution coefficient $\left(K_{d}\right)$ of plutonium for the initial bentonite amounts $825 \mathrm{~cm}^{3} / \mathrm{g}$, and for the hydrothermal-treated bentonite fraction the $\mathrm{K}_{\mathrm{d}}$ is equal to 17300 and $8105 \mathrm{~cm}^{3} / \mathrm{g}$.

From the results of the first phase of the research it follows that if water from another aquifer penetrate the repository-containing horizon or the temperature rises in the given zone of the rock mass, the interaction is possible between the underground water and the repository-surrounding rock. Thus, the interaction of rock and underground water under hydrothermal conditions may lead to the formation of minerals possessing high sorption capabilities.

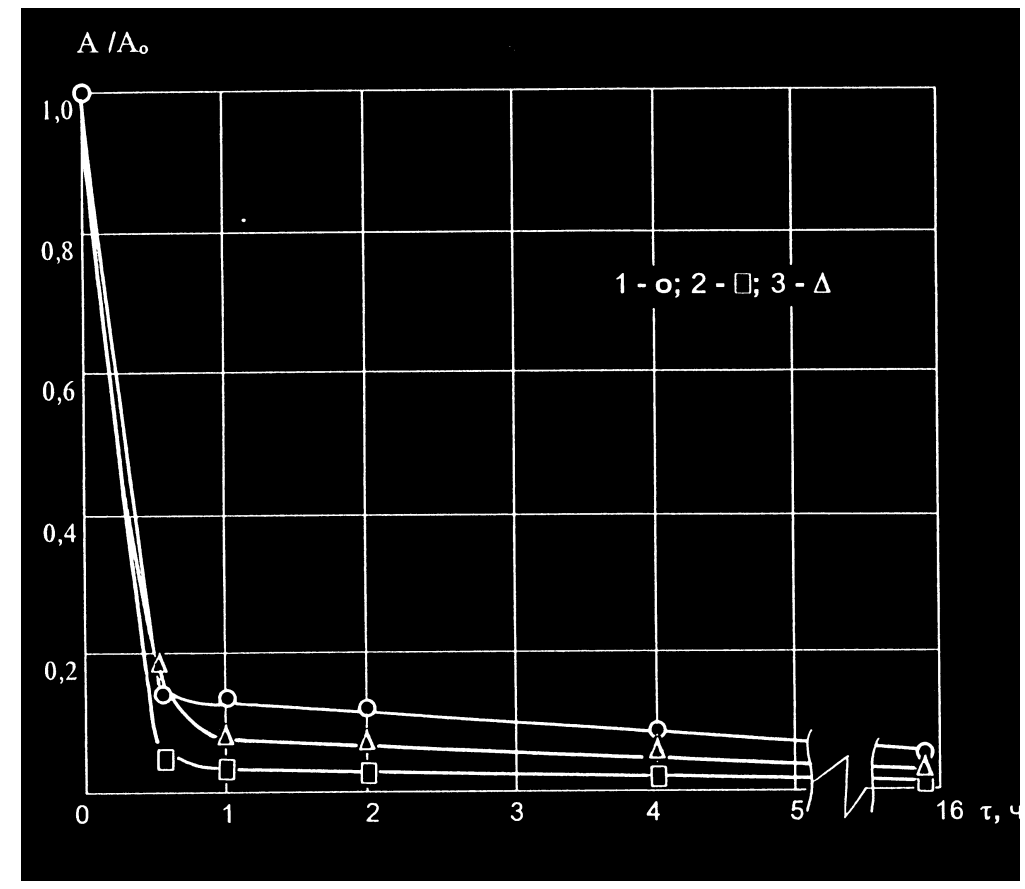

Fig. 4. Variations in the underground water plutonium content $\left({ }_{1} / A_{0}\right)$ with time at $\left(80+3^{\circ} \mathrm{C}\right)$ under contact with bentonite (1) and its fractions $(2,3)$.

It was found that immobilization of plutonium on the rock surface occurs the most intensely in those surface areas where a transformation of the rock-forming minerals under the hydrothermal conditions happened to occur during the previous geological ages. Therefore, it is evident that when choosing a repository location one should select the mountain masses consisting of rock types that were either exposed earlier to the hydrothermal impact or are capable to transform under the warm-up occurred in the repository.

Study of the interaction of the separate engineered barrier elements (steel, bentonite) with the underground water showed the interaction to cause deterioration of the each, as well as the stability variations of the underground water being in contact with those elements. As a result of the each 


\section{Geologic Disposal of Immobilized Plutonium}

engineered barrier element deterioration, new species possessing high sorption properties with regard to plutonium are formed. All the above mentioned decreases the stability of plutonium in the underground water. In addition, it was found that mixing of the underground water portions that were in contact with different engineered barrier elements also gives decrease in the stability of water and in the plutonium stability in the water.

\section{Part II, Year 1998}

One of the possibilities for increasing reliability of the vitrified radioactive plutonium-containing waste disposal, is the disposal thereof in the wells low depths. However, in the last case the repository is also going to be deteriorated in time, and the possibility of plutonium release beyond the repository boundaries still exists. Under the circumstances, it is necessary to evaluate the part of the every parameter of the geological media that is capable to affect the low depth plutonium disposal safety, the pressure being one of those parameters.

In this phase of the research the task was to evaluate the effect of the pressure and temperature on the strength of plutonium immobilization on the rocks and on the plutonium migration with the mineralized underground water through the simulated and natural fractures.

Experiments were performed on the gneiss discs under the temperature of $80^{\circ} \mathrm{C}$ and the pressure of 30 $\mathrm{MPa}$. For comparison the experiments were also run under $0.1 \mathrm{MPa}$. Underground water composition is given in Table 1.

The lack of data on the parameters of the geochemical and physicochemical processes occurred in the zone of the supposed repository location does not allow to obtain the reliable information on the species of plutonium existence and on the quantitative characteristics of the latter in the underground water transferring the plutonium from the deteriorated repository. Hence, the plutonium species most closely related to the actual species of plutonium existence in the underground water shall be those formed during the transfer of plutonium into the solution after a contact of the latter with the surface of a contaminated rock. Taking that as a starting point, the studies of the behavior were performed at the elevated temperature and pressure for the plutonium immobilized on the rock surface under $0.1 \mathrm{MPa}$ prior to the experiment.

Behavior of plutonium after the release of the latter from the deteriorated repository shall be governed by the fact that the plutonium exists in the low fractured media with the retarded water flow of not less than $10 \mathrm{~mm} /$ year. Thus, the process of plutonium immobilization on the fracture surface and the process of its stripping from there shall occur, for practical purposes, under the batch conditions.

To investigate the behavior of plutonium under the high pressure and the elevated temperature the conventional facility was used, basically intended for the core permeability studies. Technical specifications of the facility are as follows: maximum core diameter of $30 \mathrm{~mm}$, core height of $50 \mathrm{~mm}$, maximum pressure simulating the mountain (geostatic) pressure of $600 \mathrm{~kg}-\mathrm{f} / \mathrm{cm}^{2}$, the temperature control limit of $80^{\circ} \mathrm{C}$.

Instead of a core, three gneiss discs were placed into the facility. In the center, between the two, the disc with pre-immobilized plutonium in the amount of $1100 \mathrm{~Bq} / \mathrm{cm}^{2}$ was located. Underground water simulant film was located in the slits between the adjacent disc surfaces. Experiments were run under the temperature of $80^{\circ} \mathrm{C}$ and the hydrostatic squeezing pressure of $30 \mathrm{MPa}$. Holding time for the above set of discs under the described conditions was 2.5 hours to provide sufficient time to attain the equilibrium. 


\section{Research and Development Plutonium Immobilization Contract Activities}

After the experiment was completed, $\alpha$-activity on the surface of each disc was determined. Several cycles of plutonium stripping were performed.

In Figs 5 and 6 the redistribution of plutonium is shown in the system with the central disc containing plutonium on the surface and two clean discs, as well as the quantity of plutonium removed from the simulated fracture.

Comparison of curves presented in Fig. 6 (under $30 \mathrm{MPa}$ and $80^{\circ} \mathrm{C}$ ) with the analogous curves obtained under hydrothermal conditions under the atmospheric pressure (see Fig. 5) proves the fact that, the general regularities of the plutonium redistribution being equal, the process of plutonium stripping is intensified under the pressure of $30 \mathrm{MPa}$. Under such a pressure, a negligible sorption of plutonium is observed on the clean rock surface, the adsorbed plutonium being transferred back into the solution rather quickly.

Elevation of pressure under the hydrothermal conditions also activates the sorption - stripping processes for americium and neptunium, the effect for americium being less apparent. 
$A_{1} / A_{o} ; A_{2} / A_{o} ; A_{3} / A_{\circ}$

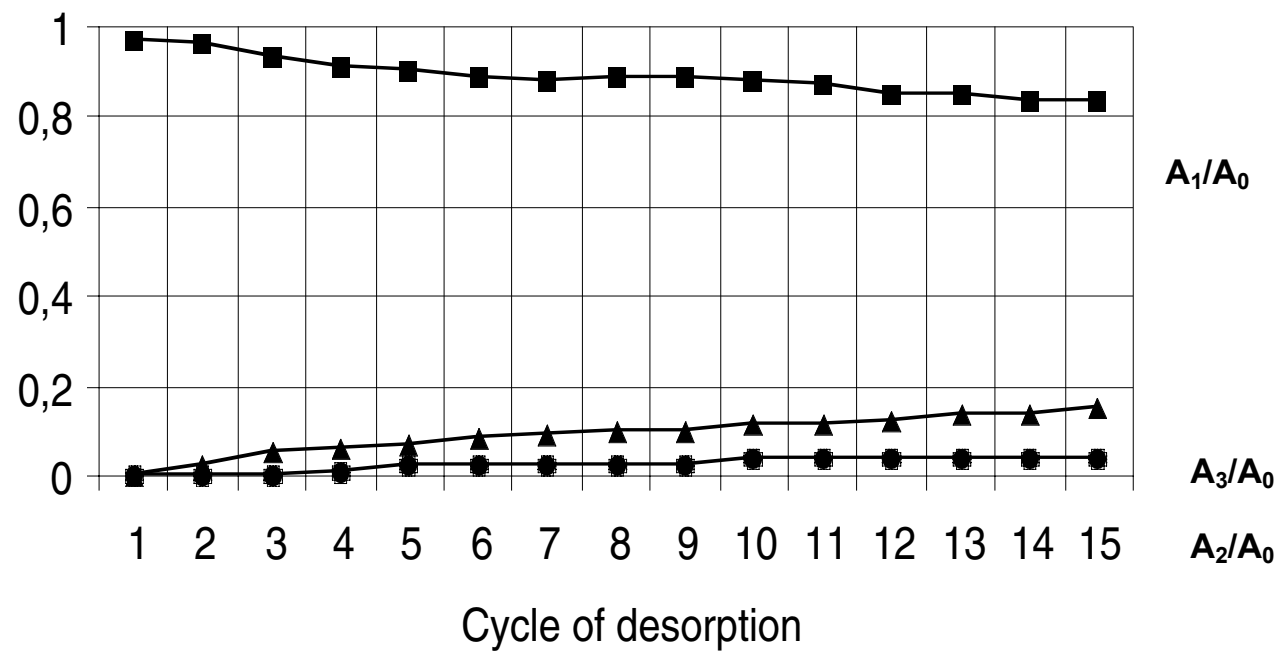

Fig. 5. Distribution of plutonium $\left(80^{\circ} \mathrm{C} ; 0,1 \mathrm{MPa}\right)$ in the fractured rock simulating system during desorption $\mathrm{Pu}$ by the underground water (A1/Ao), sorption (A2/Ao) and migration after desorption (A3/Ao).

$$
A_{1} / A_{\circ} ; A_{2} / A_{\circ} ; A_{3} / A_{\circ}
$$

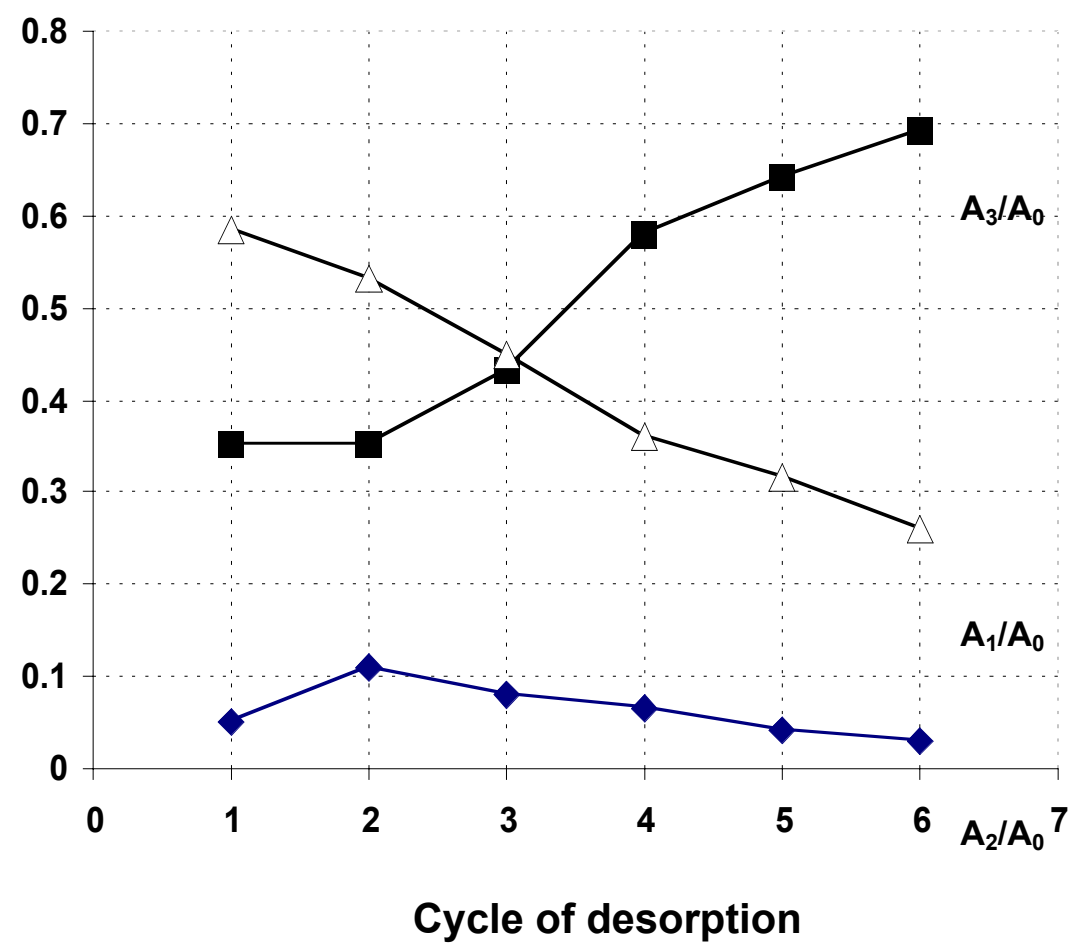

Fig. 6. Distribution of plutonium $\left(80^{\circ} \mathrm{C} ; 30 \mathrm{MPa}\right)$ in the fractured rock simulating system during desorption $\mathrm{Pu}(\mathrm{A} 1 / \mathrm{Ao})$, sorption (A2/Ao) and migration after desorption (A3/Ao). 
Investigation of the effect of natural fractures on the transfer of plutonium has been performed. Plutonium was adsorbed on one of the disc surfaces divided by a fracture. Experiments with the disc were run on the facility according to the technique described earlier (under $30 \mathrm{MPa}$ and $80^{\circ} \mathrm{C}$ ). As one can see from the curves shown in Fig. 7, the process of plutonium stripping and removal from the system is sharply slowed down under the presence of a natural fracture in the rock. For instance, if $35 \%$ of the feed plutonium adsorbed on the central disc is removed during the first cycle from the rock disc without a fracture, merely $10.5 \%$ is removed from a fractured disc.

$$
A_{1} / A_{o} ; A_{2} / A_{o} ; A_{3} / A_{o} ; A_{4} / A_{0}
$$

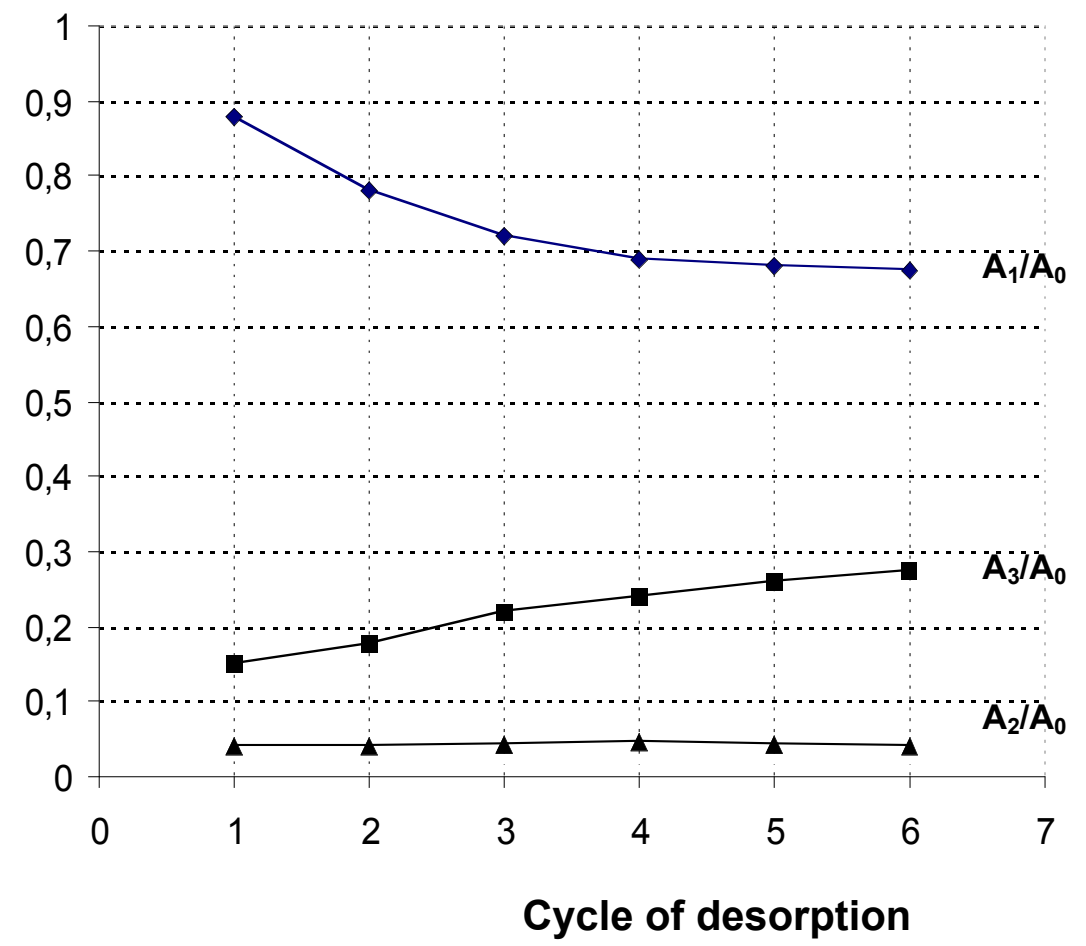

Fig. 7. Distribution of plutonium $\left(80^{\circ} \mathrm{C} ; 30 \mathrm{MPa}\right)$ in the fractured rock simulating system with a natural fracture in the gneiss during desorption $\mathrm{Pu}$ by the underground water (A1/Ao), sorption (A2/Ao) and migration after desorption (A3/Ao).

Thus, the availability of rock fractures located across the fractures engaged in the flow of plutonium transfer with the underground water shall slow down the transfer.

After the second phase of the research was completed, it was found that the strength of plutonium immobilization on the gneiss surface is decreased under the pressure of $30 \mathrm{MPa}$ and the temperature of $80^{\circ} \mathrm{C}$ as compared to the immobilization strength under $30 \mathrm{MPa}$ and $80^{\circ} \mathrm{C}$.

Natural fractures may play the part of a barrier inhibiting the migration of plutonium. 


\section{Geologic Disposal of Immobilized Plutonium}

\section{Part III, Year 1999}

In the final phase the behavior of glass matrix materials was investigated under the elevated pressure and temperature corresponding to the actual ones in the repository location.

Construction of a repository in a given point of a mountain mass gives rise to the disturbance of the geochemical equilibrium existed before the repository construction. Gradual sequential deterioration of the separate repository elements represents the restoration process of the disturbed equilibrium. Disposal safety of the radionuclides incorporated into a matrix could be markedly increased if the products of the matrix deterioration would become the incorporate part of the secondary engineered geochemical barrier preventing the distribution of plutonium.

This phase of the studies was aimed at the comparison of the absorbing properties of the deterioration products of the phosphate and boron - silicate glass (see Table 2).

Table 2. Phosphate and boron - silicate glass composition.

\begin{tabular}{|c|c|c|}
\hline \multirow[t]{2}{*}{ Component } & \multicolumn{2}{|c|}{ Content in glass, $\%$ by mass } \\
\hline & Boron - silicate & Phosphate \\
\hline $\mathrm{CeO}_{2}$ & 0.5 & 0.5 \\
\hline $\mathrm{UO}_{2}$ & 8.4 & 6.5 \\
\hline $\mathrm{MnO}_{2}$ & 5.8 & 4.4 \\
\hline $\mathrm{Al}_{2} \mathrm{O}_{3}$ & 3.1 & 1.1 \\
\hline $\mathrm{NiO}$ & 1.0 & 0.9 \\
\hline $\mathrm{Fe}_{2} \mathrm{O}_{3}$ & 14.4 & 5.5 \\
\hline $\mathrm{Cr}_{2} \mathrm{O}_{3}$ & 1.9 & 6.5 \\
\hline $\mathrm{Na}_{2} \mathrm{O}$ & 14.8 & 23.4 \\
\hline $\mathrm{Li}_{2} \mathrm{O}$ & 7.0 & - \\
\hline $\mathrm{SiO}_{2}$ & 36.1 & 0.4 \\
\hline $\mathrm{B}_{2} \mathrm{O}_{3}$ & 7.0 & - \\
\hline $\mathrm{P}_{2} \mathrm{O}_{5}$ & - & 56.4 \\
\hline
\end{tabular}

Process of the glass deterioration in a repository is a long-term process. To accelerate it, the experiments were run in autoclaves at the considerable increase in the solid to liquid phase ratio as compared to those parameters under actual conditions. Crushed glass was used of the fraction particle size within the range of $0.25-0.5 \mathrm{~mm}$.

Interactions were studied for the phosphate or boron - silicate glass with the underground water simulant for low depth horizons (salt bearing $50 \mathrm{~g} / \mathrm{L}$, see Table 1) and for phosphate glass with the surface water simulant of the Krasnoyarsk rock mass (salt bearing $0.4 \mathrm{~g} / \mathrm{L}$, see Table 3 ).

Table 3. Chemical composition of the surface water simulant (Krasnoyarsk).

\begin{tabular}{|l|l|l|l|l|l|l|}
\hline \hline Component & $\mathrm{Na}^{+}$ & $\mathrm{Mg}^{2+}$ & $\mathrm{Ca}^{2+}$ & $\mathrm{Cl}^{-}$ & $\mathrm{SO}_{4}{ }^{2-}$ & $\mathrm{HCO}_{3}{ }^{-}$ \\
\hline Concentration, $\mathrm{mg} / \mathrm{L}$ & 125.0 & 1.7 & 3.0 & 133.7 & 12.0 & 134.2 \\
\hline
\end{tabular}

Preliminary experiments simulating the cooling of the glass prior to disposal (performed at $80^{\circ} \mathrm{C}$ at 0.1 $\mathrm{MPa}$ ) showed that no structural changes were observed in the boron - silicate glass samples after 40 days, but the phosphate glass samples show the initial signs of the crystalline structure formation. 


\section{Research and Development Plutonium Immobilization Contract Activities}

After the contact of the boron - silicate glass samples with the underground water of low depth horizons (under $80^{\circ} \mathrm{C}$ and $0.1 \mathrm{MPa}$ for 40 days and under $150^{\circ} \mathrm{C}$ and $0.5 \mathrm{MPa}$ for 13 days) practically no decrease in the weight samples was detected. Fine dispersed precipitate formed in the process consisted of the needle-point crystals and was close in structure to the riversidite mineral. Precipitate mass after 40 days amounted less than $2 \%$ of the initial glass sample mass. Under those conditions the transfer of uranium into the solution is observed. Uranium is not immobilized by the rock but is distributed between the new species and the underground water.

Sorption of plutonium was studied on the new species formed in the process of the interaction of boron silicate glass with underground water under the hydrothermal conditions, and on the glass after the hydrothermal treatment. It was found that for the new species obtained at $80^{\circ} \mathrm{C}$ the $\mathrm{K}_{\mathrm{d}}$ amounted $1.0210^{4}$ $\mathrm{cm}^{3} / \mathrm{g}$, and for $150^{\circ} \mathrm{C}$ the $\mathrm{K}_{\mathrm{d}}$ value was $2.87 \cdot 10^{5} \mathrm{~cm}^{3} / \mathrm{g}$. Increase in the sorption capacity of the new species formed at the elevated temperature is probably associated with the ordering in the crystalline structure thereof. For glass hydrothermally pretreated at $80^{\circ} \mathrm{C}$ the $\mathrm{K}_{d}$ value amounts $350 \mathrm{~cm}^{3} / \mathrm{g}$, and for $150^{\circ} \mathrm{C}$ the $\mathrm{K}_{\mathrm{d}}$ value is $1080 \mathrm{~cm}^{3} / \mathrm{g}$.

Crushed glass with the adsorbed plutonium (the layer thickness of $1 \mathrm{~mm}$ ) after the hydrothermal treatment was placed between the two gneiss discs. Underground water was introduced into the pore space between the glass particles and the obtained block was held at $80^{\circ} \mathrm{C}$ under $30 \mathrm{MPa}$. It was found that there was practically no sorption of plutonium on the gneiss surface, $38 \%$ of the initial plutonium quantity was retained by glass, and $60.6 \%$ of plutonium adsorbed on the initial glass migrated out of the system.

Process of the plutonium stripping from a glass sample also occurs intensely after the pressure was lowered to $15 \mathrm{MPa}$ at $80^{\circ} \mathrm{C}$ (see Fig. 8).

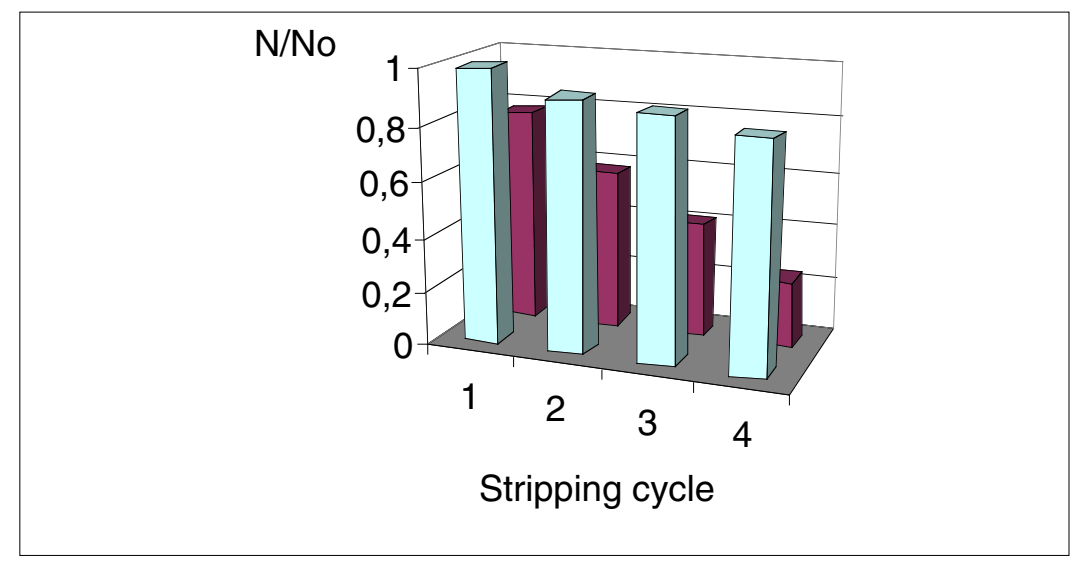

Fig. 8. Stripping of plutonium at $80^{\circ} \mathrm{C}$ under $15 \mathrm{MPa}$ from the phosphate (light columns) and boron - silicate glass (dark columns).

Decomposition of the phosphate glass was performed in the surface and underground water simulants in autoclaves at $110^{\circ} \mathrm{C}$ and at $150^{\circ} \mathrm{C}$. Loss of the phosphate glass sample weight after treatment at $110^{\circ} \mathrm{C}$ is negligible and amounts $0.7-1.6 \%$ (experiment duration -- 20 days). At $150^{\circ} \mathrm{C}$ the process of the phosphate glass deterioration is intensified (see Table 4). 
Table 4. Specifications of the "phosphate glass - surface water" and "phosphate glass underground water" systems after treatment at $150^{\circ} \mathrm{C}$ for 13 days.

\begin{tabular}{|l|l|l|}
\hline \hline \multicolumn{1}{|c|}{ Parameters } & \multicolumn{2}{c|}{ Water } \\
\cline { 2 - 3 } & \multicolumn{1}{c|}{$\begin{array}{c}\text { Surface } \\
\text { (Krasnoyarsk) }\end{array}$} & \multicolumn{1}{c|}{ Low depth } \\
\hline Quantity of the hydrothermally pretreated glass, \% & 26.2 & 32.9 \\
\hline Quantity of the glass deterioration products, \% & 14.7 & 19.3 \\
\hline Quantity of uranium in the solution, \% & 0.04 & 0.03 \\
\hline Quantity of uranium in the hydrothermally pretreated glass, \% & 34.8 & 35.2 \\
\hline Quantity of uranium in the glass deterioration products, \% & 65.1 & 64.7 \\
\hline Solution pH after the experiment is completed & 6.24 & 5.38 \\
\hline
\end{tabular}

Table 5. Sorption of plutonium at $80^{\circ} \mathrm{C}$ under $0.1 \mathrm{MPa}$ on the solid phases separated after hydrothermal treatment of the phosphate glass.

\begin{tabular}{|l|l|l|}
\hline \hline \multicolumn{1}{|c|}{ Distribution coefficient, $\mathbf{c m}^{\mathbf{3}} / \mathbf{g}$} & \multicolumn{2}{c|}{ Water } \\
\cline { 2 - 3 } & \multicolumn{1}{|c|}{$\begin{array}{c}\text { Surface } \\
\text { (Krasnoyarsk) }\end{array}$} & \multicolumn{1}{c|}{ Low depth } \\
\hline On the hydrothermally pretreated glass & 76 & 1810 \\
\hline On the glass deterioration products & 47 & 330 \\
\hline
\end{tabular}

Hydrothermal treatment of the phosphate glass at $150^{\circ} \mathrm{C}$ lead to the formation of the mix consisting of the deeply leached glass particles and the fine dispersed phase. Obtained mix was divided into two fractions by separating the glass particles after the hydrothermal treatment from the fine dispersed phase - the deterioration products.

As one can see from the data given in Table 4, the glass deteriorates. In this case the content of uranium in the hydrothermally pretreated glass and the deterioration products increase as compared to the content of uranium in the initial glass.

Fractions of the phosphate glass after the hydrothermal treatment were used for sorption of plutonium at $80^{\circ} \mathrm{C}$ under $0.1 \mathrm{MPa}$ from the surface and underground water (see Table 5). As it is seen from the data given, the phosphate glass deterioration products possess worse sorption properties as compared to the leached glass. The hydrothermally pretreated glass leached in the simulated underground water solution and the deterioration products thereof possess higher sorption properties as compared to the glass and the deterioration products thereof that passed the hydrothermal treatment.

After the sorption of plutonium on the leached phosphate glass was completed, the stripping of plutonium was studied at $80^{\circ} \mathrm{C}$ under $15 \mathrm{MPa}$. Stripping was performed according to the technique similar to that used for stripping from the leached boron - silicate glass. As it is seen from the curve given in Fig. 8 , during the first cycle the stripping of plutonium does not practically occur. In the following cycles the quantity of plutonium stripped from the phosphate glass is much less than from the boron - silicate one.

Thus, it has been found that in the experiments simulating the deep underground disposal of the vitrified waste, the boron-silicate glass reveals higher chemical resistance as compared to the phosphate glass. Deterioration products of the boron-silicate glass also have the higher sorption capacity with regard to plutonium. However, the stripping of plutonium from the leached boron-silicate glass under the elevated 
temperature and pressure conditions $\left(80^{\circ} \mathrm{C}\right.$ and $\left.15 \mathrm{MPa}\right)$ occurs much more intensely than from the phosphate glass after the hydrothermal treatment.

Summarizing the data obtained, one may conclude that to obtain reliable data on the behavior of the glass-like or any other matrix materials in the course of disposal, one must use the actual information about the geological and geochemical parameters of the rock mass where a repository is to be located and about the composition of the matrix materials with the radioactive waste incorporated therein. 
Geologic Disposal of Immobilized Plutonium 


\title{
Production and Study of U.S. Ceramics for Plutonium Immobilization [B501111]
}

\author{
Yu. F. Volkov, A. N. Lukinykh, V. I. Spiryakov, S. V. Tomilin and A. V. Bychkov, \\ SSC RF RIAR
}

\begin{abstract}
Specimens of oxide ceramics containing cerium, uranium, and plutonium were prepared using the solidphase synthesis in the temperature range $1250-1400^{\circ} \mathrm{C}$. The composition and method of ceramics preparation were defined by the LLNL program.
\end{abstract}

The peculiar features of phase formation were investigated in three types of ceramics: $\mathrm{Hf}-\mathrm{Ce}-\mathrm{Ce}, \mathrm{Hr}-\mathrm{Ce}-\mathrm{U}$ and Hf-Pu-U.

The x-ray analysis showed that the mineral composition of specimens depends essentially on the ceramics type as well as on the sintering temperature and gas medium.

\section{Introduction}

The US-accepted concept on excess plutonium conversion was based on its immobilization in oxide ceramics of a special chemical and mineral composition [1,2]. The main component of ceramics is the cubic phase of pyrochlore mineral type. The presence of other mineral-like phases is acceptable, such as: zirconolite, brannerite or perovskite and rutile. It should be noted that according to the data available in literature, the perovskite phase is less stable in aqueous solutions than other additional phases.

Therefore, perovskite presence in ceramics in relatively large quantities is undesirable. At the same time the presence of zirconolite, brannerite and rutile is acceptable in large quantities (20-50 vol\%) [2]. In particular, the titanite ceramics containing up to $85 \%$ of zirconolite is proposed for immobilization of actinides: $\mathrm{U}, \mathrm{Np}, \mathrm{Pu}, \mathrm{Am}$ and $\mathrm{Cm}[3]$.

The plutonium content in pyrochlore-based ceramics is $10.5 \%$ [1, et al.]. As a result of $\alpha$-decay, ${ }^{239} \mathrm{Pu}$ $\left(T_{1 / 2}=24 \cdot 100\right.$ years) ceramics will be subjected to radiation and transit to the metamict state in time. It should be assumed that the accumulation of radiation damage influences the physical-chemical properties of ceramics, as well as the strength of plutonium fixation and other ecologically hazardous radionuclides.

The task involves the obtaining of experimental data defining ceramics for long-term plutonium immobilization. For this purpose, it is planned to prepare and study the ceramic specimens containing the applicable quantity of ${ }^{238} \mathrm{Pu}\left(\mathrm{T}_{1 / 2}=87.7\right.$ years $)$ and ${ }^{244} \mathrm{Cm}\left(\mathrm{T}_{1 / 2}=18.1\right.$ years $)$ as accelerators of radiation defects. Using the short-lived actinide isotopes allows shortening the time of metamictization up to several months. This allows us to carry out the investigations related to $\alpha$-decay and to predict the radiation damages and ceramic properties to substantiate the long-term immobilization of plutonium with less specific activity.

The investigation results of ceramic specimens containing cerium, uranium-238 and plutonium-239 are given in the present report. The information obtained on the synthesis and phase formation properties of 


\section{Accelerated Radiation Damage Studies of the US Pu Ceramic Formulation}

the inactive and low-active ceramic specimens are necessary to solve the main task concerned with investigation of radiation damages in ceramics containing the high-active actinide isotopes.

\section{Preparation of ceramic specimens}

The oxide composition of charge which was used for U.S. ceramics synthesis is given in Table 1 in accordance with data described elsewhere [4].

Table 1. Initial charge composition.

\begin{tabular}{|c|c|c|c|c|c|}
\hline \multirow[b]{2}{*}{$\begin{array}{c}\text { Ceramics } \\
\text { type }\end{array}$} & \multirow[b]{2}{*}{ Designations } & \multicolumn{4}{|c|}{ Mass Fraction, \% } \\
\hline & & Base* $^{*}$ & $\mathrm{CeO}_{2}$ & $\mathrm{UO}_{2}$ & $\mathrm{PuO}_{2}$ \\
\hline $\mathrm{Hf}-\mathrm{Ce}-\mathrm{Ce}$ & 1 & 73,90 & 26,02 & - & - \\
\hline $\mathrm{Hf}-\mathrm{Ce}-\mathrm{U}$ & 2 & 67,34 & 7,89 & 24,77 & - \\
\hline Hf-Pu-U & 3 & 64,42 & - & 23,69 & 11,89 \\
\hline
\end{tabular}

${ }^{*}$ Composition of base, \%: $\mathrm{CaO}-15,45$;

$\mathrm{HfO}_{2}-16,54 ; \mathrm{Gd}_{2} \mathrm{O}_{3}-12,34 ; \mathrm{TiO}_{2}-55,67$.

The technique for preparation of the ceramic specimens of 1-3 types corresponds to the principal scheme proposed by LLNL (Fig. 1, hereinafter see Appendix). However, there are some variations from the rigorous procedure. The main difference is that the manual method of powder grinding, mixing and impregnating with cerium and plutonium nitrate solutions was used instead of wet charge grinding in a ball mill. This is due to preparation of the small quantities of test specimens ( $5 \mathrm{~g}$ charge mass) and radiation safety in operation with high-active actinide isotopes. The methodical features of the charge preparation, fabrication of pellets and their sintering have been described in detail in reports $[5,6]$. The main information necessary for a further description of the results is presented in the given paper.

The peculiarities for preparation of the charge and ceramic specimens (1) and (2) are shown in scheme shown in Fig. 2. The charge for each type of ceramics was prepared by two methods: (1) mixing the LLNL base with cerium and uranium ceramics; (2) impregnating the powders with cerium nitrate solution. After calcination at $750^{\circ} \mathrm{C}$, the charge was divided into two parts, one of which was ground with water and the obtained suspension was dried at the temperature of $125^{\circ} \mathrm{C}$.

The above methodical changes were made to detect a possible effect of the charge preparation conditions on the sintered charge properties. Such a necessity is proved by the fact that the methodical features are very important at all stages of ceramics preparation $[2,4,7]$. Therefore, it was necessary to find out the determining factors for preparation of so-called proper ceramics.

After operation with inactive ceramics of types (1) and (2), the preparation of the ceramic charge of type (3) was essentially simplified (Fig. 3). The prepared powder mixture of base and uranium oxide was placed in a quartz tube and impregnated with plutonium nitrate solution. (The plutonium preparation is developed and certificated by research workers of the Analytical department). The tube with suspension was placed in a quartz cell and the solution was evaporated by temperature increasing from 100 to $300^{\circ} \mathrm{C}$. Decomposition of nitrates occurred at 400-500_C. Then the temperature was gradually increased to $750^{\circ} \mathrm{C}$ and calcination was carried out during $1 \mathrm{~h}$. The obtained charge was carefully ground and mixed. All the operations on preparation of the charge were carried out in the tube.

The pellets of 5,9 and $13 \mathrm{~mm}$ in diameter were prepared from the obtained charge (1-3) at a pressure of about $1000 \mathrm{~kg} / \mathrm{cm}^{2}$. The thermal treatment of specimens (Figs. 2 and 3) was generally conducted in air by using the sequential step-by-step sintering in the range of temperatures from 1250 to $1400^{\circ} \mathrm{C}$ and holding 


\section{Research and Development Plutonium Immobilization Contract Activities}

for $1 \mathrm{~h}$. For comparison, a one-stage sintering of some specimens was carried out at 1350 or $1400^{\circ} \mathrm{C}$ for $2 \mathrm{~h}$. The experiments were performed under various atmosphere: in air under standard conditions, in air flux with forced supply to the sintering area and in flux of argon-hydrogen mixture.

\section{Results}

All the synthesized ceramic specimens of type 1-3 were analyzed by $\mathrm{x}$-ray and the geometrical density was calculated.

\section{X-ray analysis}

X-ray patterns were taken by photomethod using a camera of Debaja-Sherrera type as well as a difractometer of DRON-3M type. In the first case, the discrete powder samples were analyzed, in the second case, the pellets with polished surface were analyzed. As a result, the information on the phase formation peculiar features depending on the ceramics type, methods of charge preparation, sintering temperature and gas medium was obtained [8].

\section{Hf-Ce-Ce type ceramics}

The peculiar feature of cerium ceramics consists in the fact that the phase composition essentially depends on the synthesis conditions (Table 2). When sintering in air under normal conditions, the specimens always consist of two phases related to the structure of pyrochlore and perovskite type. (Hereinafter the principal phases are given only). A relative phase content depends very much on the different factors (Table 1). However, the following tendency is observed: with increasing temperature, the amount of the perovskite phase increases and the amount of the pyrochlore phase decreases, in contrast. After sintering at $1450^{\circ} \mathrm{C}$, the perovskite is the prevailing phase and all the methodical peculiarities of the charge preparation are of no importance.

Table 2. X-ray analysis results of Hf-Ce-Ce ceramics (RIAR specimens, photography).

\begin{tabular}{|l|l|l|l|}
\hline \hline \multicolumn{2}{|c|}{ Sintering mode* } & \multicolumn{1}{c|}{ Specimen } & \multicolumn{1}{c|}{ Main phases } \\
\hline \multicolumn{1}{|c|}{${ }^{\circ}{ }^{\circ} \mathbf{C}$} & \multicolumn{1}{|c|}{ Atmosphere } & \multicolumn{1}{c|}{ designation } & \multicolumn{1}{c|}{ Aftering ${ }^{* *}$} \\
\hline 1250 & & $1.1(\mathrm{a})$ & Perovskite (70), pyrochlore (30) \\
\hline & Air without & $1.2(\mathrm{a})$ & The same \\
\hline & forced supply & $1.1(\mathrm{~b})$ & Perovskite (50), pyrochlore (50) \\
\hline & & $1.2(\mathrm{~b})$ & The same \\
\hline 1350 & & $1.1(\mathrm{a})$ & Perovskite (80), pyrochlore (20) \\
\hline & The same & $1.2(\mathrm{a})$ & The same \\
\hline & & $1.1(\mathrm{~b})$ & Perovskite (80), pyrochlore $(20)$ \\
\hline 1450 & & $1.2(\mathrm{~b})$ & The same \\
\hline 1250 & & $1.1(\mathrm{a})$ & Perovskite (90), pyrochlore (10) \\
\hline 1350 & The same & $1.2(\mathrm{a})$ & The same \\
\hline 1350 & forced supply & $1.1(\mathrm{~b})$ & Pyrochlore (>95) \\
\hline
\end{tabular}

* Sintering duration at the specified temperatures is $1 \mathrm{~h}$.

${ }^{* *}$ A rough approximate phase content is shown in percent in brackets. 


\section{Accelerated Radiation Damage Studies of the US Pu Ceramic Formulation}

Such behavior of ceramics is likely to be accounted for by a deficiency of oxygen in formation of the pyrochlore structure. For this purpose, the experiments were performed to provide the ceramics sintering under conditions of continuous air supply. A one-hour thermal treatment of raw pellets at 1250 and $1350^{\circ} \mathrm{C}$ allowed obtaining ceramics incorporating almost $100 \%$ of pyrochlore phase type; the perovskite phase was observed in the trace quantities. The thermal treatment of raw pellets in argon or in argonhydrogen mixture, on the contrary, leads to an obvious increase of the perovskite phase and to a reduction of the perovskite phase, correspondingly (Table 2).

Experiments on the phase transition of the sintered ceramics under thermal treatment are very demonstrative. A repeated sintering under the changed synthesis conditions leads to the reversible phase transition:

pyrochlore $\Leftrightarrow$ perovskite.

Thus, the phase composition of $\mathrm{Hf}-\mathrm{Ce}-\mathrm{Ce}$ ceramics type depends very much on the conditions in which sintering takes place. However, the value of oxygen partial pressure is apparently the determining factor in formation of two competitive phases of pyrochlore and perovskite.

Figures 4 and 5 show schemes of the most typical $x$-ray patterns of the cerium ceramic specimens obtained in different synthesis conditions.

\section{Hf-Ce-U type ceramics}

The main results of the X-ray analysis of the obtained specimens are presented in Table 3. Uraniumcontaining ceramics has its peculiar features of the phase formation, and in this respect it differs from purely cerium ceramics. The sintering of raw pellets in air under standard conditions showed that the mineral composition depends on the charge preparation technique and sintering temperature. In this case the obtained ceramics usually incorporated about $90-95 \%$ of the pyrochlore phase, while a large number of perovskite phases formed in the cerium ceramics under the same conditions. However, there are some instances when, under similar conditions of sintering, uranium-containing ceramics are the monophase ceramics incorporating the oxide compounds of pyrochlore, fluorite, and perovskite (Table 3).

It is typical that with increasing sintering temperature, the amount of pyrochlore phase increases rather than decreases, unlike the cerium ceramics. From this it follows that fluorite and perovskite phases are metastable, because they appeared, as a rule, at low temperatures of synthesis.

The change of atmosphere on sintering leads to the change of the phase compound. However, unlike the specimens of cerium ceramics, there are some peculiar features. After thermal treatment of raw pellets in air flux as well as in $\mathrm{Ar}+1.57 \% \mathrm{H}_{2}$ atmosphere, the ceramic formed. It is mainly composed of pyrochlore and additional phases of brannerite or perovskite type (Table 3 ). Thus, the presence of uranium essentially influences a mechanism of phase formation and stabilizes the pyrochlore structure.

Figures 6 and 7 show the typical $\mathrm{x}$-ray patterns of $\mathrm{Hf}-\mathrm{Ce}-\mathrm{U}$ ceramic specimens obtained under different synthesis conditions. 
Table 3. X-ray analysis results of Hf-Ce-U (SSC RIAR specimens, photography).

\begin{tabular}{|c|l|l|l|}
\hline \hline \multicolumn{2}{|c|}{ Sintering mode* } & \multicolumn{1}{c|}{ Specimen } & \multicolumn{1}{c|}{ Main phases } \\
\hline $\mathbf{T},{ }^{\circ} \mathbf{C}$ & \multicolumn{1}{|c|}{ Atmosphere } & designation & \multicolumn{1}{c|}{ After sintering ${ }^{* *}$} \\
\hline & & $2.1(\mathrm{a})$ & Pyrochlore(95), rutile(5) \\
\hline & Air without & $2.2(\mathrm{a})$ & Pyrochlore (90), perovskite (5), rutile (5) \\
\hline 1250 & forced supply & $2.1(\mathrm{~b})$ & Pyrochlore (45), fluorite (45), perovskite (10) \\
\hline & & $2.2(\mathrm{~b})$ & Pyrochlore (40), fluorite (40), perovskite (20) \\
\hline & & $2.1(\mathrm{a})$ & Pyrochlore (95), rutile (5) \\
\hline 1350 & & $2.2(\mathrm{a})$ & Pyrochlore (90), perovskite (5), rutile (5) \\
\hline & The same & $2.1(\mathrm{~b})$ & Pyrochlore (90), perovskite (10) \\
\hline 1450 & The same & $2.2(\mathrm{~b})$ & Pyrochlore (80), fluorite(10), perovskite (10) \\
\hline & & $2.1(\mathrm{a})$ & Pyrochlore (95), rutile (5) \\
\hline 1250 & Air with forced supply & $2.2(\mathrm{a})$ & The same \\
\hline 1350 & Ar+1.57\% $\mathrm{H}_{2}$ & $2.2(\mathrm{a})$ & Pyrochlore (90), brannerite(10) \\
\hline
\end{tabular}

* Sintering duration at the specified temperatures is $1 \mathrm{~h}$

** A rough approximate phase content is shown in per cent in brackets.

\section{$\mathrm{Hf}_{-}{ }^{239} \mathrm{Pu}-\mathrm{U}$ type ceramics}

Table 4 shows the main data on the plutonium-containing ceramics. It was prepared six specimens that differed in mass, diameter and thermal treatment conditions. As in a case of (1) and (2) type ceramics, the sintering was performed in air under standard conditions with the forced air supply in the reduced atmosphere. However, the phase composition of plutonium ceramics is practically independent on the sintering atmosphere, unlike (1) and (2) type ceramics. In all the cases, a pyrochlore forms as a base phase, while brannerite is an additional phase, as a rule (Fig. 8).

Table 4. Ceramic specimens of $\mathrm{Hf}_{-}^{239} \mathrm{Pu}-\mathrm{U}$ type.

\begin{tabular}{|l|l|l|l|l|l|}
\hline \hline Specimen, \# & \multicolumn{1}{|c|}{ Mass, $\mathbf{g}$} & Diameter $\varnothing, \mathbf{~ m m}$ & \multicolumn{1}{|c|}{$\mathbf{T ,}{ }^{\circ} \mathbf{C}$} & \multicolumn{1}{c|}{$\mathbf{t}, \mathbf{h}$} & \multicolumn{1}{c|}{$\mathbf{g} / \mathbf{c m}^{\mathbf{3}}$} \\
\hline $1 *$ & 0,131 & 3,7 & 1380 & 1 & 5,3 \\
\hline $2 * *$ & 0,363 & 4,0 & $1250-1380$ & $1+1+1$ & $4,7-5,4$ \\
\hline $3 *$ & 0,495 & 7,1 & 1400 & $1+1$ & $5,3-5,4$ \\
\hline $4 *$ & 0,839 & 10,2 & 1400 & $1+1$ & $5,5-5,7$ \\
\hline $5 *$ & 1,918 & 10,4 & 1400 & 2 & 5,3 \\
\hline $6 *$ & 1,068 & 10,1 & 1400 & 2 & 5,4 \\
\hline
\end{tabular}

*Air sintering without forced supply.

** Air sintering with forced supply and in $\mathrm{Ar}+4,98 \% \mathrm{H}_{2}$ atmosphere.

\section{Cubic phases}

The pyrochlore crystal structure is known to have a lot in common with perovskite and fluorite ones [ 9 and others]. Hence, their co-existence and mutual transition are quite a general phenomena. All the three phases have cubic symmetry. The specimens of (1) and (2) type ceramics have parameters of crystal lattices that are given in Table 5.

The perovskite phase formed differs from typical orthorhombic structure of $\mathrm{CaTiO}_{3}$ mineral and a greater extent corresponds to strontium titanate $\mathrm{SrTiO}_{3}$ and synthetic loparite $\mathrm{Ce}_{1.33} \mathrm{Ti}_{2} \mathrm{O}_{5.8}$. 


\section{Accelerated Radiation Damage Studies of the US Pu Ceramic Formulation}

Table 5. The parameter values of cubic phase lattices.

\begin{tabular}{|l|l|l|l|l|}
\hline \hline $\begin{array}{l}\text { Ceramics } \\
\text { type }\end{array}$ & Specimen & $\begin{array}{l}\text { Sintering } \\
\text { temperature, }{ }^{\circ} \mathbf{C}\end{array}$ & Phase types & a, $\AA$ \\
\hline & & & Pyrochlore & $10,178(4)$ \\
\hline Hf-Ce-Ce & $1.1(\mathrm{~b})$ & 1250 & Perovskite & $3,85(1)$ \\
\hline & $1.2(a)$ & 1350 & Pyrochlore & $10,139(3)^{\star}$ \\
\hline & & & Pyrochlore & $10,174(5)$ \\
\hline & $2.2(\mathrm{~b})$ & 1250 & Perovskite & $3,86(1)$ \\
\hline & & & Fluorite & $5,436(5)$ \\
\hline & & & Pyrochlore & $10,173(4)$ \\
\hline & $2.2(a)$ & 1250 & Perovskite & $3,84(1)$ \\
\hline & $2.2(a)$ & 1350 & Pyrochlore & $10,1769(6)^{\star}$ \\
\hline
\end{tabular}

* - The values were defined from the diffraction photographs; other values from the x-ray photographs of powders.

Fluorite phase was detected firstly for some $\mathrm{Hf}-\mathrm{Ce}-\mathrm{U}$ ceramic specimens after their sintering at 1250 and $1350^{\circ} \mathrm{C}$. Later this phase was recorded in x-ray patterns of $\mathrm{Hf}-\mathrm{Ce}-\mathrm{Ce}$ ceramic specimens after their sintering at $1000-1200^{\circ} \mathrm{C}$.

The parameter of pyrochlore lattice is unstable and changes within the definite range.

The parameter of perovskite remains constant for various specimens. The parameter of fluorite phase lattice is between the lattice parameter values of $\mathrm{CeO}_{2}$ and $\mathrm{UO}_{2}$.

Study of plutonium ceramics found that the change in sintering atmosphere leads to the marked change in ceramic colour and parameter of pyrochlore phase (Table 6). However, as it has been already noticed, no appreciable changes in phase composition were observed. The same change in color and parameter of the pyrochlore cubic lattice was observed and recorded in study of (1) and (2) type ceramics.

Table 6. Atmosphere influence on ceramic properties.

\begin{tabular}{|l|l|l|}
\hline \hline \multicolumn{1}{|c|}{$\begin{array}{c}\text { Sintering } \\
\text { atmosphere }\end{array}$} & \multicolumn{1}{|c|}{$\begin{array}{c}\text { Parameter a of } \\
\text { pyrochlore phase, } \AA\end{array}$} & \multicolumn{1}{|c|}{ Color of ceramic powder } \\
\hline Air sintering with forced supply & $10.1615-10.1806$ & yellowish \\
\hline Air sintering without forced supply & $10.1423-10.1485$ & brown \\
\hline $\mathrm{Ar}+4,98 \% \mathrm{H}_{2}$ & 10.1475 & bright brown \\
\hline
\end{tabular}

\section{Ceramic density}

Tables 7 and 8 show the value of geometrical density of (1) and (2) type ceramic pellets prior to and after thermal treatment. According to the data, the density of specimens regularly increases with increasing sintering temperature. The value of maximum density that was achieved during step-by-step sintering is $4.9-5.0 \mathrm{~g} / \mathrm{cm}^{3}$.

The density of the plutonium-containing ceramics (Table 4) is within the range $5.3-5.7 \mathrm{~g} / \mathrm{cm}^{3}$, i.e., it is noticeably above that of the density of (1) and (2) type ceramic specimens. 
Table 7. Density values of Hf-Ce-Ce ceramic specimens as a function of sintering temperature and charge preparation conditions.

\begin{tabular}{|c|c|c|c|c|c|}
\hline \multicolumn{2}{|c|}{ Sintering mode } & \multicolumn{4}{|c|}{ Specimen density* ${ }^{*} \mathrm{~g} / \mathrm{cm}^{3}$} \\
\hline $\mathbf{T}^{\circ} \mathbf{C}$ & $t, h$ & 1.1(a) & $1.2(a)$ & $1.1(\mathrm{~b})$ & $1.2(b)$ \\
\hline \multicolumn{2}{|c|}{ Before sintering } & 2,6 & 2,8 & 2,7 & 2,7 \\
\hline 1250 & 1 & 3,5 & 4,2 & 4,2 & 4,7 \\
\hline 1350 & 1 & 4,8 & 4,8 & 4,6 & 4,6 \\
\hline 1450 & 1 & 4,9 & 4,9 & - & - \\
\hline
\end{tabular}

*Definition error is $\pm 0,1 \mathrm{~g} / \mathrm{cm}^{3}$.

Table 8. Density values of $\mathrm{Hf}-\mathrm{Ce}-\mathrm{U}$ ceramic specimens as a function of sintering temperature and preparation method of the original charge.

\begin{tabular}{|l|l|l|l|l|l|}
\hline \hline \multicolumn{2}{|l|}{ Sintering mode } & \multicolumn{4}{l|}{ Specimen density*, $\mathrm{g} / \mathrm{cm}^{3}$} \\
\hline $\mathrm{T},{ }^{\circ} \mathrm{C}$ & $\mathrm{t}, \mathrm{h}$ & $2.1(\mathrm{a})$ & $2.2(\mathrm{a})$ & $2.1(\mathrm{~b})$ & $2.2(\mathrm{~b})$ \\
\hline Before sintering & 1 & 3,1 & 3,0 & 3,1 & 3,0 \\
\hline 1250 & 1 & 4,2 & 4,3 & 4,3 & 4,6 \\
\hline 1350 & 1 & 4,9 & 5,0 & 5,0 & 4,9 \\
\hline 1450 & 4,9 & 5,0 & - & - \\
\hline
\end{tabular}

*Definition error is $\pm 0,1 \mathrm{~g} / \mathrm{cm}^{3}$.

\section{Discussion}

Results of synthesis and investigations of $\mathrm{Hf}-\mathrm{Ce}-\mathrm{Ce}, \mathrm{Hf}-\mathrm{Ce}-\mathrm{U}$, and $\mathrm{Hf}_{-}{ }^{239} \mathrm{Pu}-\mathrm{U}$ show that the most important factors of the phase composition are temperature and atmosphere of sintering, changing them it is possible to obtain the ceramic specimens with reproducible results. Besides, it was demonstrated that a phase composition depends on the properties of cerium, uranium and plutonium atoms.

We consider in greater detail the characteristic features of phase formation mechanism of each ceramic type.

\section{Hf-Ce-Ce type ceramics}

If sintering is performed in conditions with limited air supply, the most stable is the perovskite phase. The pyrochlore phase is metastable under these conditions, since with increasing sintering temperature, its quantity decreases at the expense of increase of the perovskite phase quantity. Thus, the transition occurs by scheme:

\section{Pyrochlore Perovskite}

$$
\text { (Ca, Gd, Ce, } \mathrm{Hf} \mathrm{Ti}_{2} \mathrm{O}_{7} \Leftrightarrow(\mathrm{Ca}, \mathrm{Gd}, \mathrm{Ce}, \mathrm{Hf}) \mathrm{Ti}_{2} \mathrm{O}_{6}
$$

This gives evidence to a loss of oxygen on heating, and that is quite explainable in terms of crystalline chemistry. The pyrochlore structure is known [9] to be a three-dimensional frame made of distorted $\mathrm{TiO}_{6}$ octahedrons united by common oxygen tops. The seventh oxygen atom together with the cations of group A (common formula $\mathrm{A}_{2} \mathrm{~B}_{2} \mathrm{O}_{7}$ ) locates in space between octahedron and its bonding strength is not so strong as those of other oxygen atoms that form polymer frame.

If specimens are sintered in air flux, the reverse transition takes place: 


\title{
Accelerated Radiation Damage Studies of the US Pu Ceramic Formulation
}

\author{
Perovskite Pyrochlore \\ (Ca, Gd, Ce, $\mathrm{Hf}) \mathrm{Ti}_{2} \mathrm{O}_{6} \Leftrightarrow(\mathrm{Ca}, \mathrm{Gd}, \mathrm{Ce}, \mathrm{Hf}) \mathrm{Ti}_{2} \mathrm{O}_{7}$
}

This indicates to the fact that perovskite structure is able to absorb oxygen easily.

In our opinion, the main reason of the phase formation with perovskite structure consists in the fact that pyrochlore structure without the seventh oxygen atom is unstable. Such behavior seems to be determined by the nature of cerium atoms.

\section{Hf-Pu-U type ceramics}

Proceeding to $\mathrm{Hf}-\mathrm{Pu}-\mathrm{U}$ ceramics, the following assumption can be made. In similar synthesis conditions the ceramics is also able to lose reversibly and to absorb oxygen by scheme:

\section{Pyrochlore Pyrochlore}

$$
\text { (Ca, Gd, Hf, U, Pu) } \mathrm{Ti}_{2} \mathrm{O}_{7} \Leftrightarrow(\mathrm{Ca}, \mathrm{Gd}, \mathrm{Hf}, \mathrm{U}, \mathrm{Pu}) \mathrm{Ti}_{2} \mathrm{O}_{6}
$$

Unlike purely cerium ceramics, the pyrochlore structure thanks to uranium and plutonium atoms is stable, even though the seventh atom of oxygen is absent. It is for this reason that a significant difference is absent in phase composition on changing the sintering atmosphere and only considerable change in color and lattice parameter of pyrochlore phase gives indirect evidence to changing the ceramics composition. Therefore, it should be assumed that depending on sintering mode and conditions, the ceramics composition relative to the oxygen content may be unstable and presented by general formula $(\mathrm{Ca}, \mathrm{Gd}$, $\mathrm{Hf}, \mathrm{U}, \mathrm{Pu}) \mathrm{Ti}_{2} \mathrm{O}_{7-\mathrm{x}}$ or $(\mathrm{Ca}, \mathrm{Gd}, \mathrm{Hf}, \mathrm{U}, \mathrm{Pu}) \mathrm{Ti}_{2} \mathrm{O}_{6+x}$, where $0<\mathrm{x}<1$. Thus, the phase formation with perovskite structure is not likely to take place in plutonium-containing ceramics. However, the ceramic composition and properties are also changed. Therefore, it should be taken into account in experiments.

\section{Hf-Ce-U type ceramics}

This ceramics type takes an intermediate position between cerium and plutonium ceramics in terms of the phase formation with pyrochlore and perovskite structures.

With relation to the above phase transitions the point of oxidation state of cerium, uranium and plutonium atoms is very important. It is evident that a special investigation is needed to provide a qualified opinion on the existence of tri- and tetravalent cerium (plutonium) and tetra- and hexavalent uranium.

\section{Conclusion}

- As a result of the performed experiments the technique is developed for preparation of the research ceramic specimens with pyrochlore structure.

- The step-by-step sintering showed that the mechanism of phase formation is complicated as a whole. At the same time the peculiar features of preparation of ceramic specimens were defined which can be attributed to the chemical and crystal-chemical properties of cerium, uranium and plutonium atoms.

- The phase composition of cerium ceramics depends greatly on the sintering atmosphere. Depending on the oxygen partial pressure two main phases are formed: pyrochlore and perovskite in the various proportions. 


\section{Research and Development Plutonium Immobilization Contract Activities}

- It was demonstrated that the complex oxides of pyrochlore and perovskite type are formed at relatively low temperature $\left(1250-1350^{\circ} \mathrm{C}\right)$ during a short-term sintering $(1-2 \mathrm{~h})$.

- It was defined that on repeated thermal treatment of sintered ceramics the reverse transitions of pyrochlore $\Leftrightarrow$ perovskite type are easy to implement changing the synthesis conditions.

- Specimens of cerium-uranium ceramics in the intermediate sintering steps may be heterogeneous, composed of the phase mixture of pyrochlore, perovskite and fluorite type. However, at the temperatures of $1350-1400^{\circ} \mathrm{C}$ ceramics is formed with pyrochlore structure prevailing.

- Ceramics containing plutonium and uranium is not so strongly sensitive to change of synthesis conditions relative to phase composition. The main stable phases are pyrochlore and bronnerite. The perovskite phase is not typical of plutonium ceramics.

- It was demonstrated that step-by-step sintering of ceramic specimens of all the three types does not lead to any abnormal effects concerning change in the phase composition. On the contrary, the ceramics behavior is normal, since at the repeated sintering the pyrochlore phase quantity and density value increase.

- It was demonstrated that the mineral composition of ceramics depends, finally, on temperature and oxidation-reduction medium. Other methodical peculiarities related to the preparation of charge and to sintering temperature mode, although they are important, are not determining factors for obtaining ceramics of pyrochlore structure.

\section{References}

1. Richard A. Van Konynenburg. Expected Radiation Effects in Plutonium Immobilization Ceramic, LLNL, U.S., 1977, 29 pp.

2. Bart Ebbinghaus. Ceramic Formulation and Process. U.S.-Russian Experts Workshop. LLNL, U.S., February, 1999.

3. Vance, E. R., Ball, C. J., Dayetoll, R. A. Actinide and rare incorporation into zirconolite. Actinides-93, Proceedings of the international conference on actinides Sante Fe, New Mexico, U.S., September 1924, 1993, p. 409.

4. Procedure for Fabricating Pellets from the U.S. Precursor. SMP-52-98. LLNL, U.S., 1999.

5. Radiation damages study of plutonium ceramics. Contract \#501111. Production of $\mathrm{Hf}-\mathrm{Ce}-\mathrm{Ce}$ and $\mathrm{Hf}-$ Ce-U type ceramic specimens. SSC RF RIAR, Dimitrovgrad, Progress report (02), 1999, 9 pp.

6. Radiation damages study of plutonium ceramics. Contract B501111. Production of Hf-Pu-U type ceramic specimens. SSC RF RIAR. Dimitrovgrad, Progress report (03), 1999, 8 pp.

7. Deis M. Strachah. Radiation Damage Studies at Pacific National Laboratory. U.S.-Russion Experts Workshop. LLNL, U.S., February, 1999.

8. Radiation damages study of plutonium ceramics. Contract \#501111. Study of Hf-Ce-Ce and Hf-Ce-U type ceramic specimens. SSC RF RIAR. Dimitrovgrad, Progress report (05), 1999, 18 pp.

9. Wells A. Structural Inorganic Chemistry: in 3 volumes: translated from English/edited by M.A. PorayKoshitza. I.:Mir, 1997-1998. 


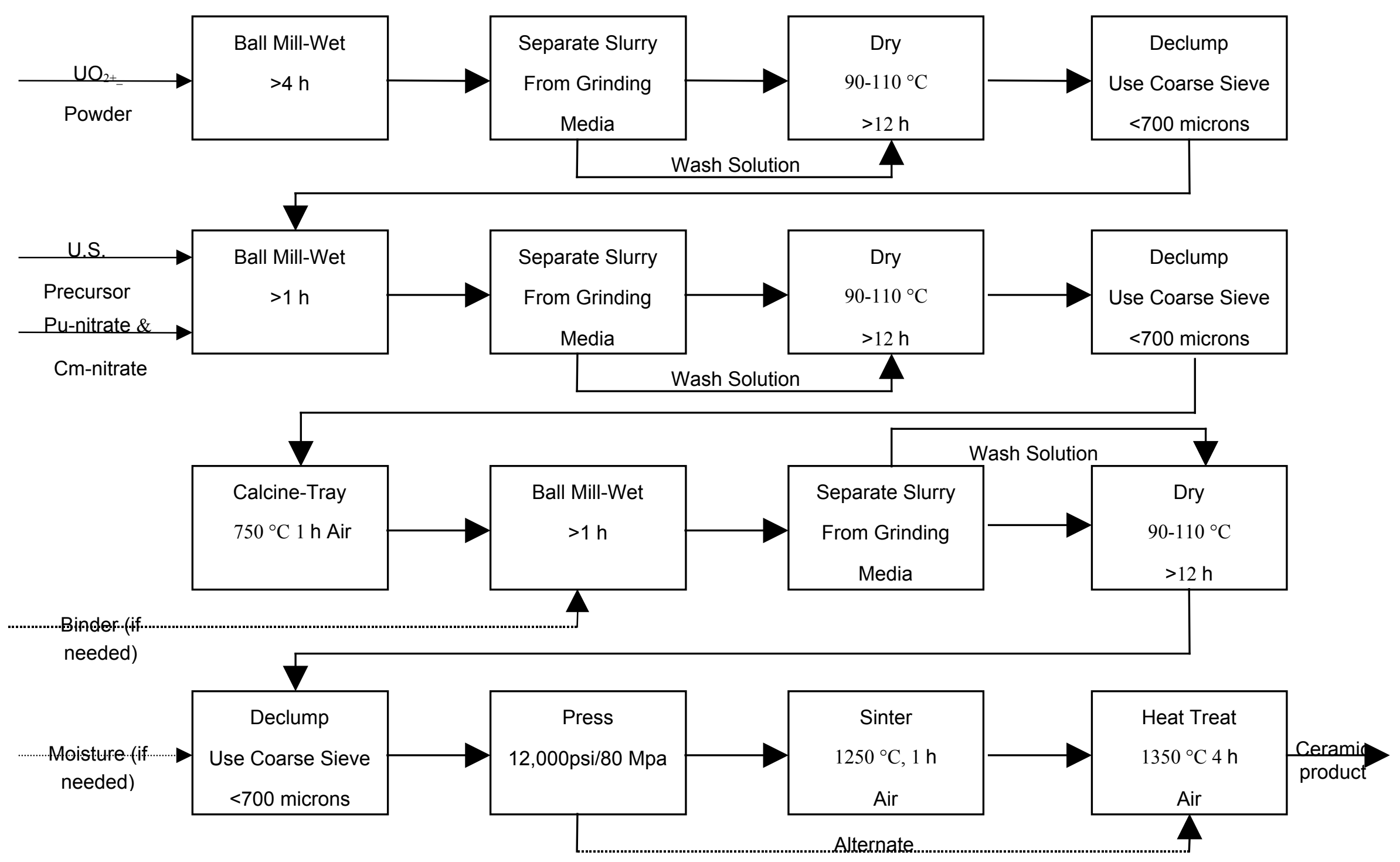

Fig. 1. LLNL process flow diagram. 


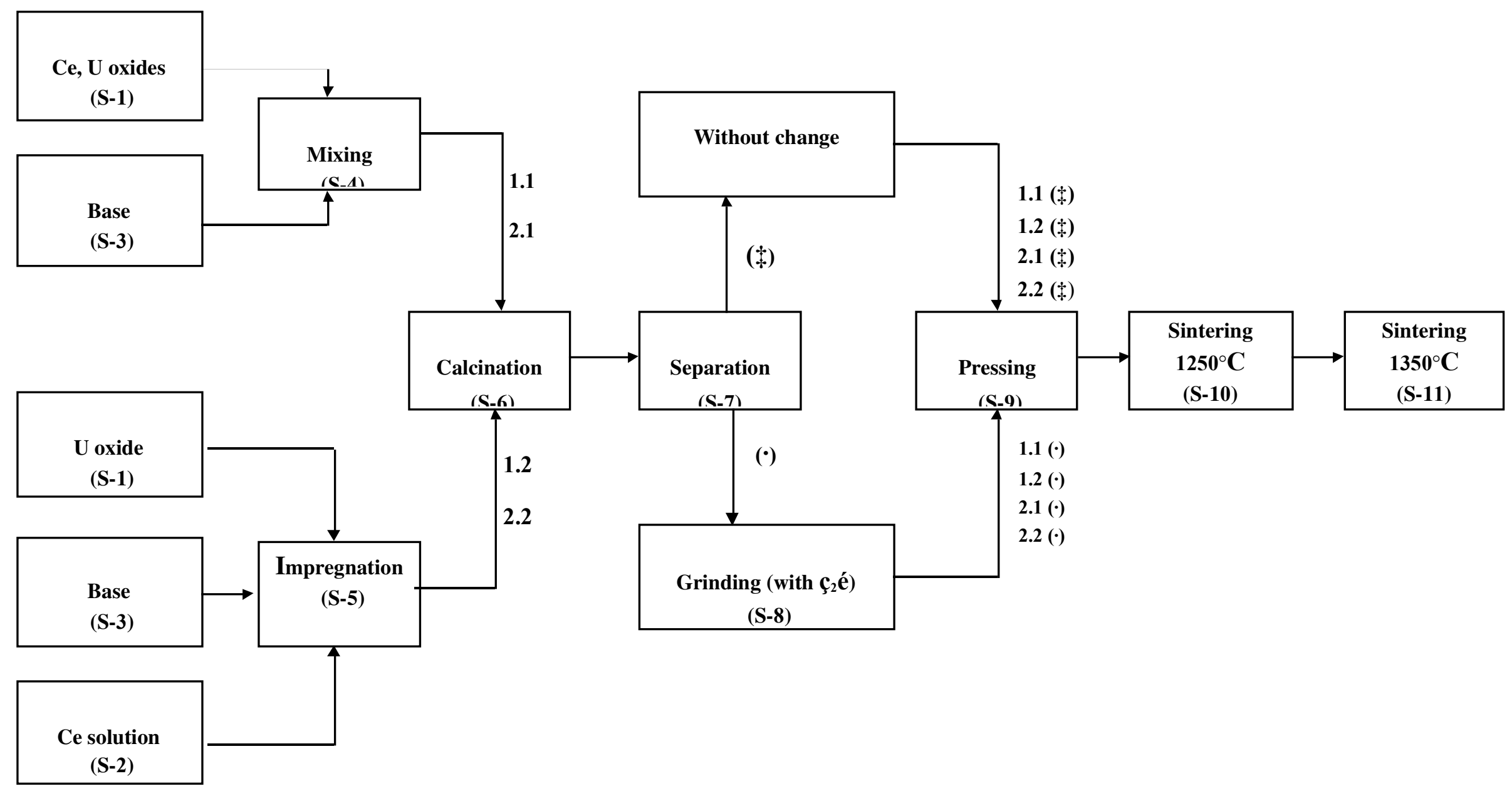

Fig. 2. Block diagram of $\mathrm{Hf}-\mathrm{Ce}-\mathrm{Ce}$ and $\mathrm{Hf}-\mathrm{Ce}-\mathrm{U}$ type ceramic pellet production. 


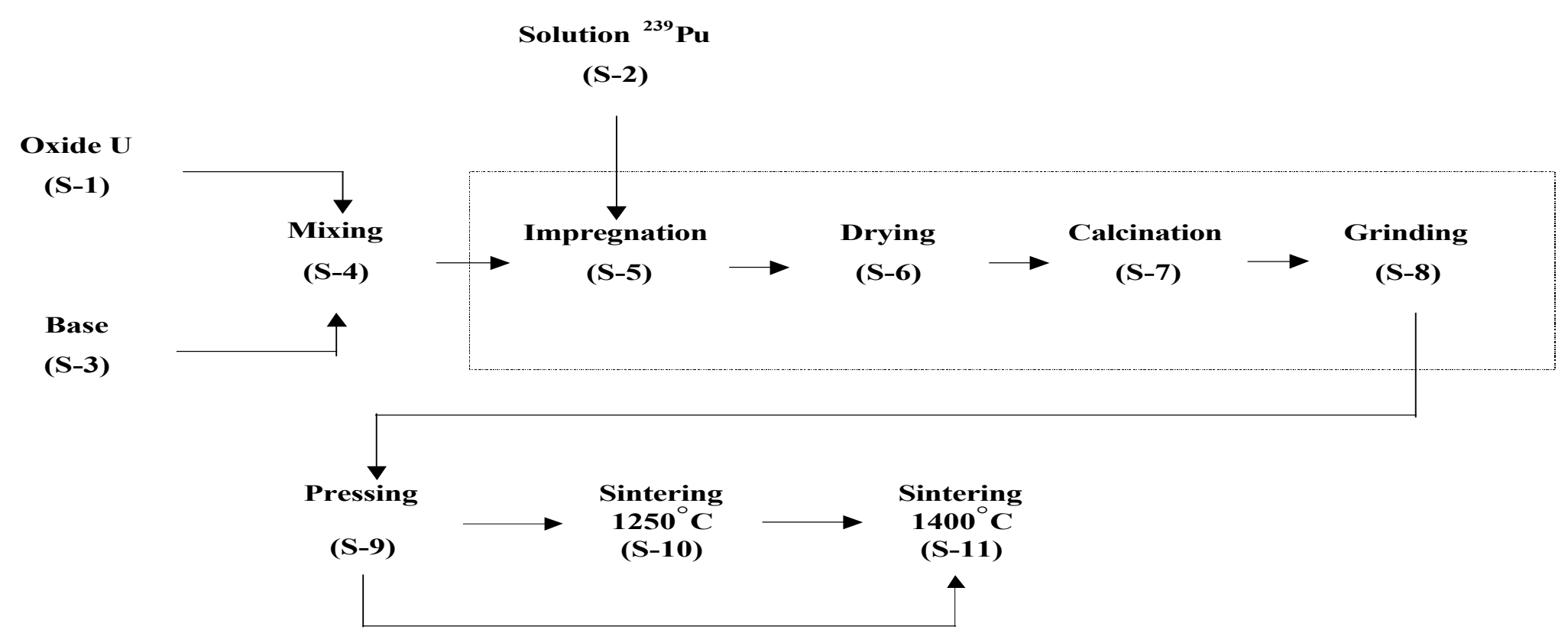

Fig. 3. Block-diagram of $\mathrm{Hf}-{ }^{239} \mathrm{Pu}-\mathrm{U}$ type ceramic pellet production

Fig. 3. Block diagram of $\mathrm{Hf}_{-}{ }^{239} \mathrm{Pu}-\mathrm{U}$ type ceramic pellet production. 

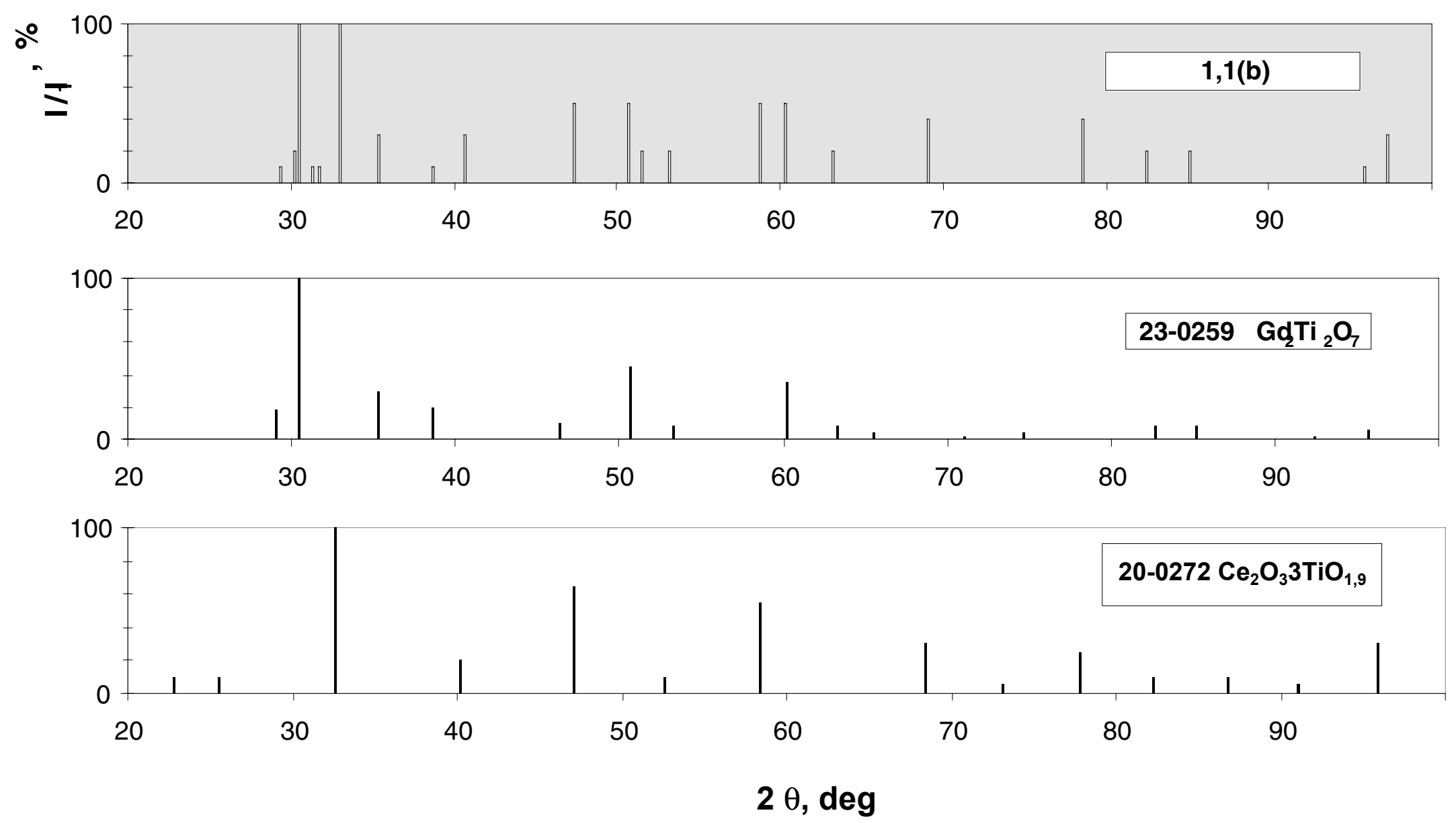

Fig. 4. X-ray photograph scheme of HF-Ce-Ce ceramic specimen after sintering at $1250^{\circ} \mathrm{C}$ without forced air supply and interpretation of the phase composition. 

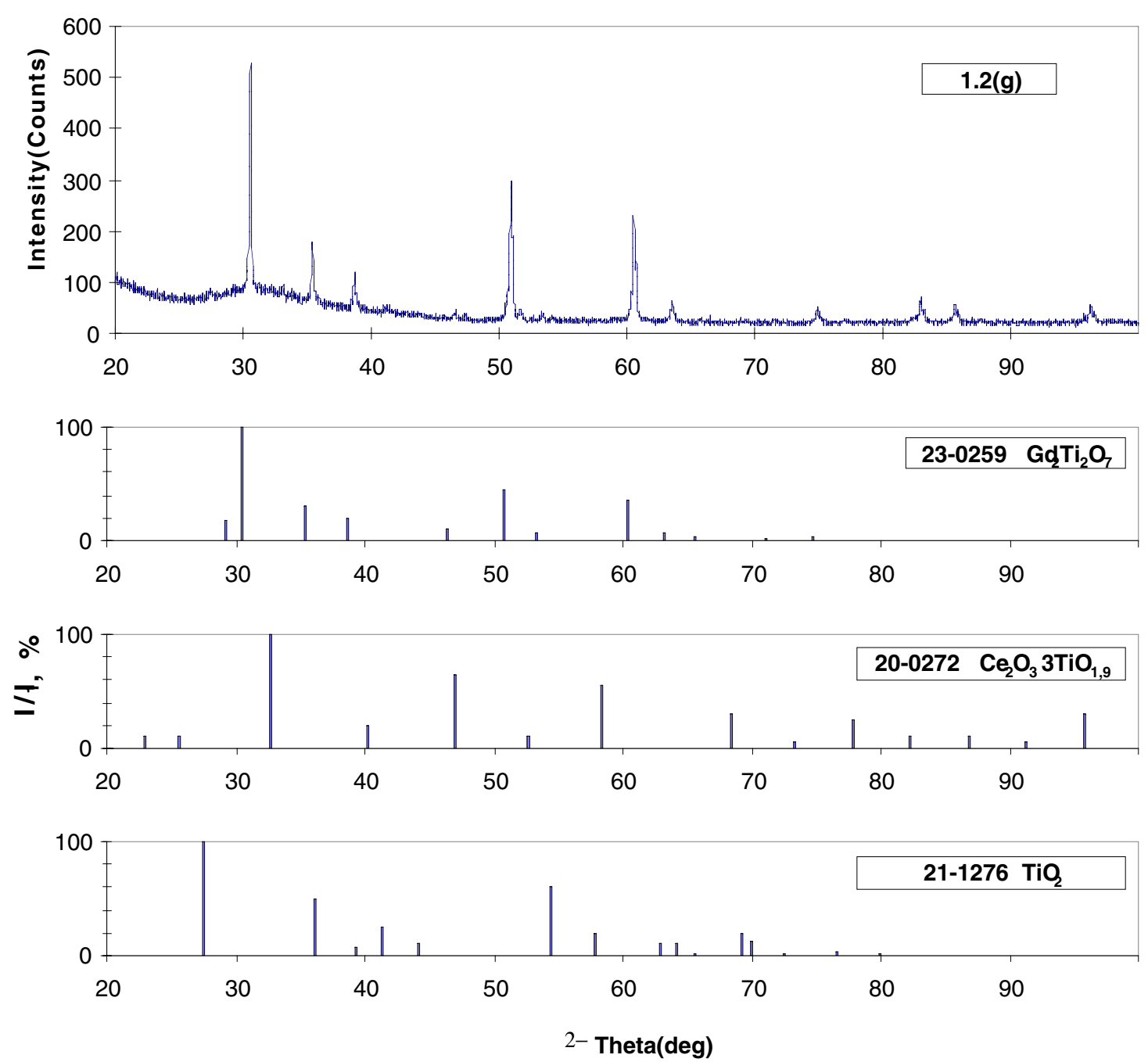

Fig. 5. Diffraction photograph of $\mathrm{Hf}-\mathrm{Ce}-\mathrm{Ce}$ ceramic specimen after sintering at $1350^{\circ} \mathrm{C}$ in air flow and interpretation of the phase composition. 

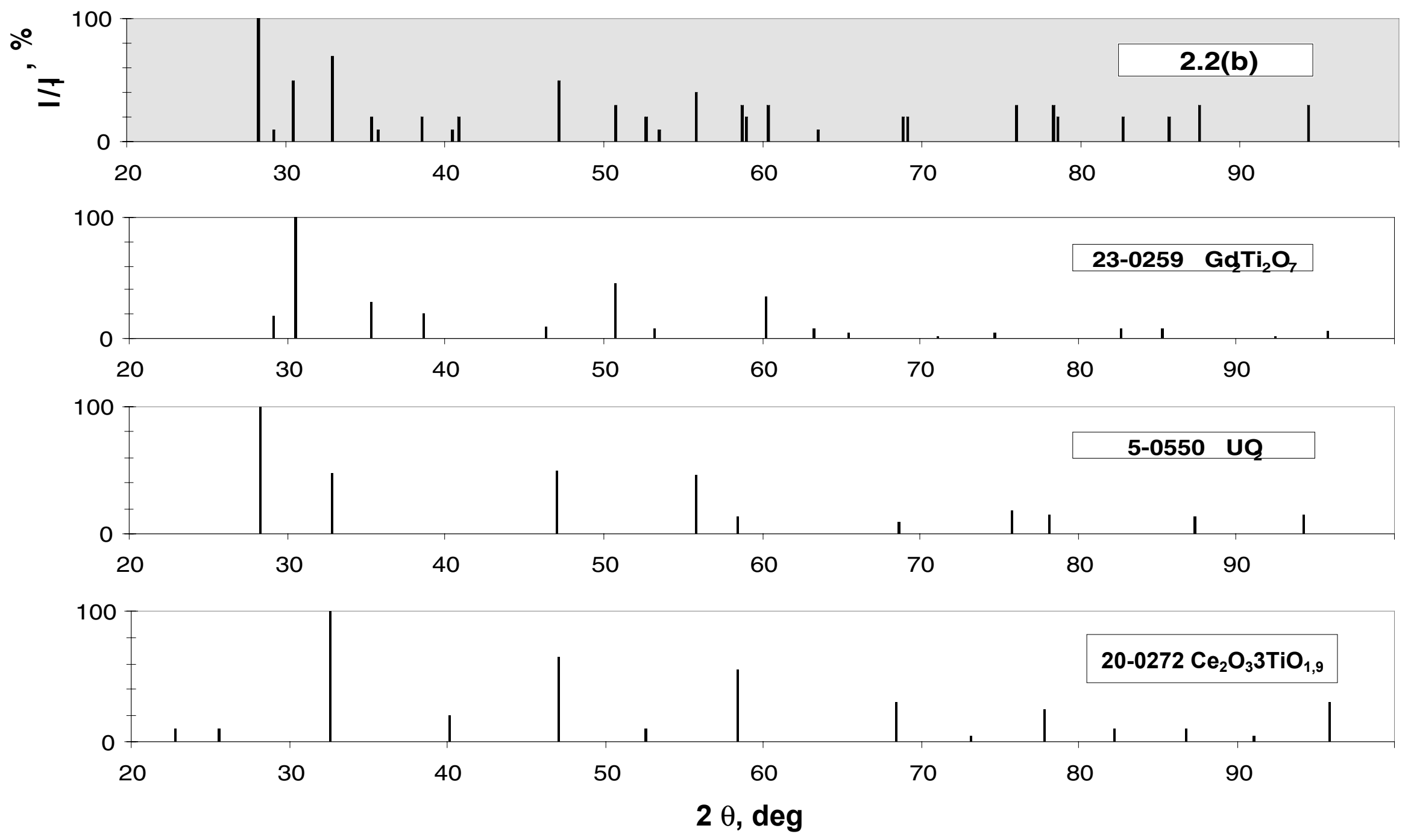

Fig. 6. X-ray photograph scheme of HF-Ce-U ceramic specimen after sintering at $1250^{\circ} \mathrm{C}$ without forced air supply and interpretation of the phase composition. 

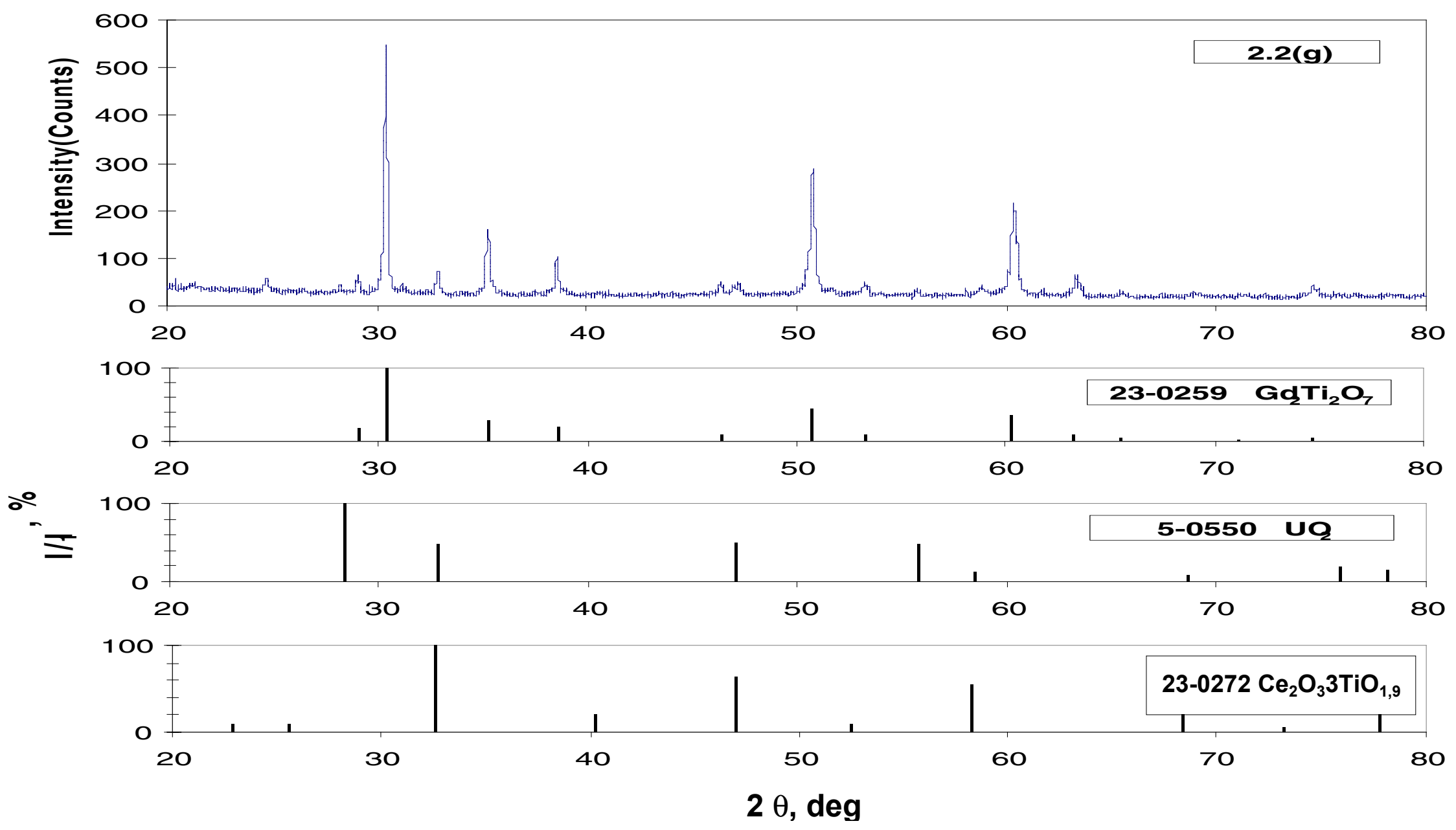

Fig. 7. Diffraction photograph of $\mathrm{Hf}-\mathrm{Ce}-\mathrm{U}$ ceramic specimen after sintering at $1350^{\circ} \mathrm{C}$ in $\mathrm{Ar}+1,57 \% \mathrm{H}_{2}$ atmosphere and interpretation of the phase composition. 

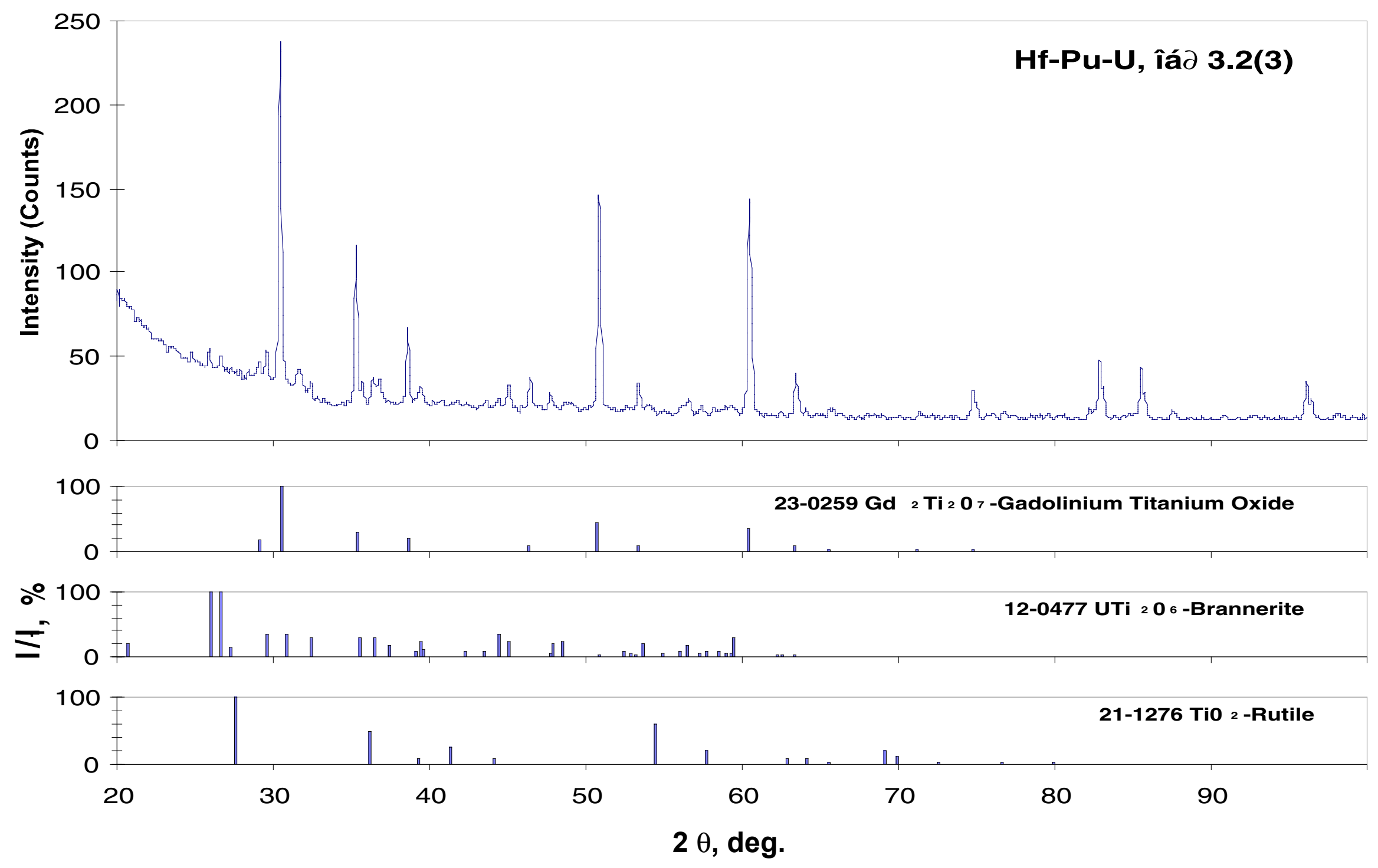

Fig. 8. Diffraction photograph of $\mathrm{Hf}-\mathrm{Pu}-\mathrm{U}$ ceramic specimen after sintering at $1400^{\circ} \mathrm{C}$ in air and interpretation of the phase composition. 
Accelerated Radiation Damage Studies of the US Pu Ceramic Formulation 


\section{Some Aspects of Study of Radiation Damages in Ceramics Intended for Pu-containing Materials Immobilization [B506205]}

\section{O.A. Alexeyev, VNIINM}

\section{Summary of Work}

One of the principal problems in Pu-containing materials immobilization is the radiation stability of a material doped by plutonium.

Above all, one should give preliminary deliberations regarding radiation damage and then describe experiments that will be implied during a joint work with Lawrence Livermore National Laboratory.

A basic source of radiation damage in Pu-containing ceramics is the effect of alpha particles at $5 \mathrm{MeV}$. The path of the alpha particles in an oxide matrix, along which they lose energy by elastic and inelastic collisions with surrounding atoms, is typically 10-15 microns long. In addition, the matrix undergoes the interaction of recoil atoms at $90 \mathrm{keV}$ within $50 \mathrm{~nm}$ of the path. Another aspect is that as a result of every alpha decay, an atom of helium is incorporated into the matrix.

Thus, every act of alpha-decay forms approximately 100 Frenkel pairs and almost 10 times more of displaced atoms; withal in $1 \mathrm{~g}$ of ${ }^{239} \mathrm{Pu}$ and ${ }^{238} \mathrm{Pu}$ there are $2.3^{*} 10^{9}$ and $1.1^{*} 10^{11}$ decays for $1 \mathrm{~s}$, respectively. Excessive vacancies and displaced atoms emerged are annihilated, partially migrate towards stocks and partially form stable complexes.

Compositions that have utility for Pu immobilization are thermodynamically non-equilibrium systems. Therefore, radiation damage must cause the failures in the structure and stimulate migration processes, which occur at a diminutive speed in case of the absence of irradiation. As a result, one can expect amorphization of the material, and formation of exclusions of a new phase. Incidentally, such exclusions can appear and in non-saturated solid solutions on account of selective enrichment of the stocks by one of the components. With regard to over-saturated solid solutions, diffusion speeded by irradiation will be promoting the growth of particles of the new phase and an increase of migration of the components, which at low temperatures and in the absence of irradiation are not identified.

As an illustration, one can give a joint graph by Arrenius for thermally activated and irradiated diffusions of uranium and plutonium in $\mathrm{UO}_{2}$ and in MOX fuel.

To prepare this graph, published data for radiation and lab-scale tests of oxide nuclear fuel were summarized and averaged. It allows us to get an approximate equation of uranium and plutonium diffusions under the reactor conditions at $1000-1400^{\circ} \mathrm{C}$ and by the density of intervals $\mathrm{F}=5^{\star} 10^{12}$ intervals $/ \mathrm{cm}^{-3} \mathrm{c}^{-1}$ :

$$
D_{R}{ }^{U, P u} \sim 1.66^{*} 10^{-13} \exp [(-0.8 \pm 0.3 \mathrm{R}) / \mathrm{kT}]
$$

A similar equation got upon the averaged data of lab-scale tests is as follows:

$$
D_{T}{ }^{U, P u} \sim 1.50 * 10^{-2} \exp [(-4.33 \pm 0.85 \mathrm{R}) / \mathrm{kT}]
$$

Therefore, $\mathrm{R}$, a parameter of radiation acceleration of the diffusion of actinides in the matrix of oxide nuclear fuel, can be expressed: 


$$
\mathrm{R}=\mathrm{D}_{\mathrm{R}} / \mathrm{D}_{\mathrm{T}} \sim 1.1^{* 1} 10^{-11} \exp \left[(13.6 \pm 2.1) \mathrm{T}_{\mathrm{m}} / \mathrm{T}\right]
$$

where: $T_{m}$ is the melting temperature of fuel set to $3000 \mathrm{~K}$.

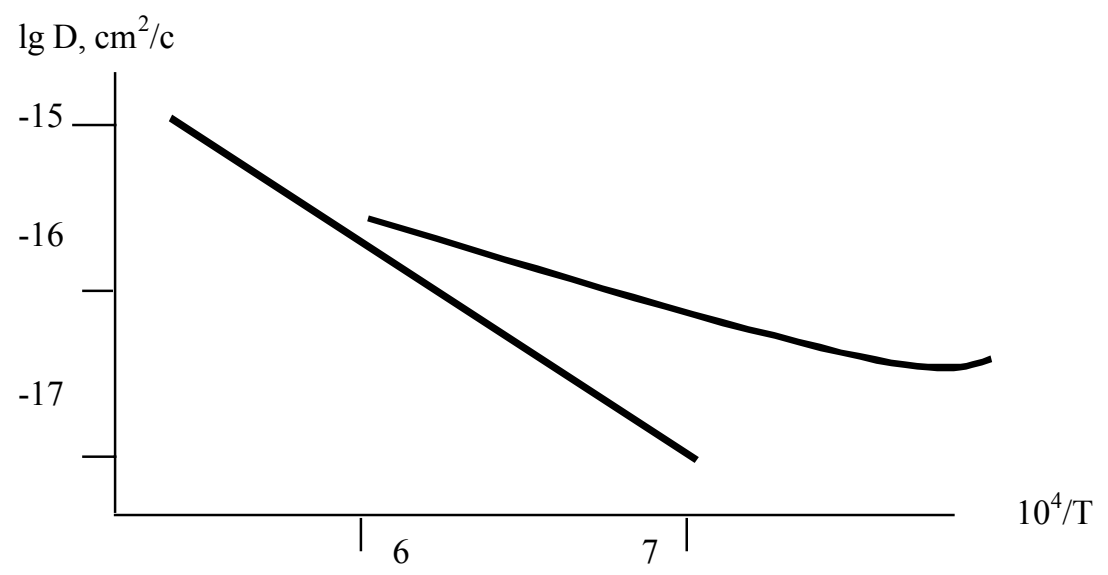

Fig. 1. Temperature dependencies of thermally activated and irradiated diffusions of uranium and plutonium in $\mathrm{UO}_{2}$ and in MOX fuel.

If one can put the same dependency for metals, for which there are more reliable and numerous data, in the graph of a temperature dependency, so it turns out that both approximate dependencies are correlated.

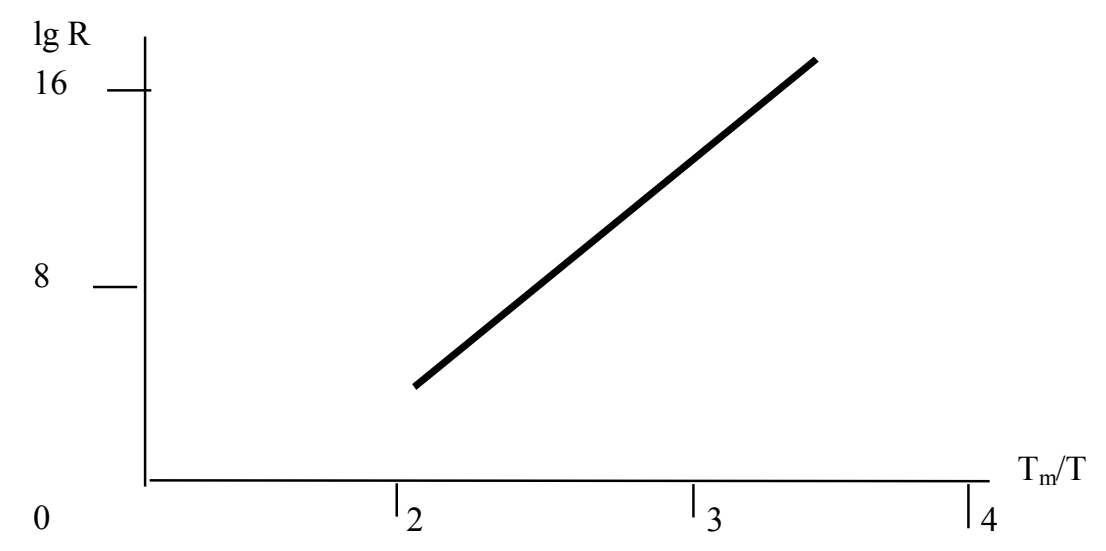

Fig. 2. A temperature dependency of a parameter of radiation acceleration of the diffusion in metals (thin line) and in oxide nuclear fuel.

From our standpoint, this assumption gives the opportunity to assess accelerated diffusion processes under the influence of irradiation. One can see that by a temperature close to $400 \mathrm{~K}$, the parameter of radiation acceleration of the diffusion is $10^{27}$. 


\section{Research and Development Plutonium Immobilization Contract Activities}

Without a doubt, such an assessment must be proved by additional experiments. But this outlines the necessity for painstaking study of the radiation damage in materials intended for Pu-containing materials immobilization.

The following investigations of samples delivered by RIAR are relevant to the mutual work with LLNL to study the US-specific ceramics based on pyrochlore at VNIINM:

1. Measurement of dimensions and weight to assess the changes of density and cracking;

2. Study of the structure of initial and irradiated samples by ceramography;

3. Definition of homogeneity and a phase composition as well determine the amorphous components of the structure;

4. X-ray analysis to identify internal tensions, changes of the phase composition, amorphization;

5. Electron Spin Resonance analysis of the initial and irradiated samples to clarify the nature of the damages;

6. Positron Annihilation analysis with the purpose of defining the accumulation of helium and character of its incorporation into the matrix;

7. Definition of leach rates of the initial and irradiated samples to assess its radiation stability;

8. Measurement of plutonium diffusion rate in the ceramics at $1000,1100,1200,1300^{\circ} \mathrm{C}$ in order to figure a temperature dependency, to identify boundary diffusion, and to determine the diffusion coefficient at low temperatures by means of extrapolation of data.

Items 1-7 will be repeated during intervals of time. The cumulative dose of irradiation for every sample would be $10^{18}$ alpha-particles at the end. 
Accelerated Radiation Damage Studies of the US Pu Ceramic Formulation 


\section{KRI Studies of the US Pu Ceramics [B506203]}

\section{B. Burakov, KRI}

\section{Introduction}

The US-specified plutonium ceramic compositions shall be prepared, fabricated in RIAR, and sent to the KRI. KRI will obtain from RIAR two samples (total weight 1-2 gram each) of the US-specified ceramic compositions Zirconolite/Pyrochlore $\mathrm{Ca}(\mathrm{Zr}, \mathrm{Hf}, \mathrm{Pu}, \mathrm{Cm}) \mathrm{Ti}_{2} \mathrm{O}_{7}$ :

1. One sample (5-6 pellets) doped with 9.24 wt $\%$ of ${ }^{238} \mathrm{PuO}_{2}\left(10.5 \%\right.$ of $\mathrm{PuO}_{2} ; 88 \%$ of ${ }^{238} \mathrm{Pu}$; and $12 \%$ of ${ }^{239,40} \mathrm{Pu}$ );

2. One sample (5-6 pellets) doped with 10.5 wt $\%$ of ${ }^{239} \mathrm{PuO}_{2}$ for comparison with ${ }^{238} \mathrm{Pu}$-doped ceramic.

The ceramics samples containing ${ }^{238} \mathrm{Pu},{ }^{239} \mathrm{Pu}$ shall be characterized for phase and chemical compositions, physical and chemical features. Measurements of radiation damage will include: (1) $x$-ray diffraction (to determine degree of metamictization), (2) optical and scanning electron microscopy (of metamict samples to determine if microcracking has occurred), (3) density measurements (to determine amount of swelling), and (4) MCC-1 leach test for $\mathrm{Pu}, \mathrm{U}$, and $\mathrm{Ca}$.

\section{Experimental}

The work is organized for 1.5 years. Every three months, the radiation damage of the same samples is to be observed by described methods. The main attention shall be paid to the radiation safety of this research. Recently KRI has developed a special cassette (Fig. 1), which allows us to make safe XRD analyses of ${ }^{238-239} \mathrm{Pu}$-doped samples, hermetically covered to protect equipment from contamination. At the same time, this cassette provides safe keeping of even damaged samples over a long time spans for periodic XRD analysis. KRI has prepared glove boxes and other equipment for work with ${ }^{238} \mathrm{Pu}$-doped samples in the near future. New Pu aerosol filters were installed and all necessary supplies were made or purchased. 
Accelerated Radiation Damage Studies of the US Pu Ceramic Formulation

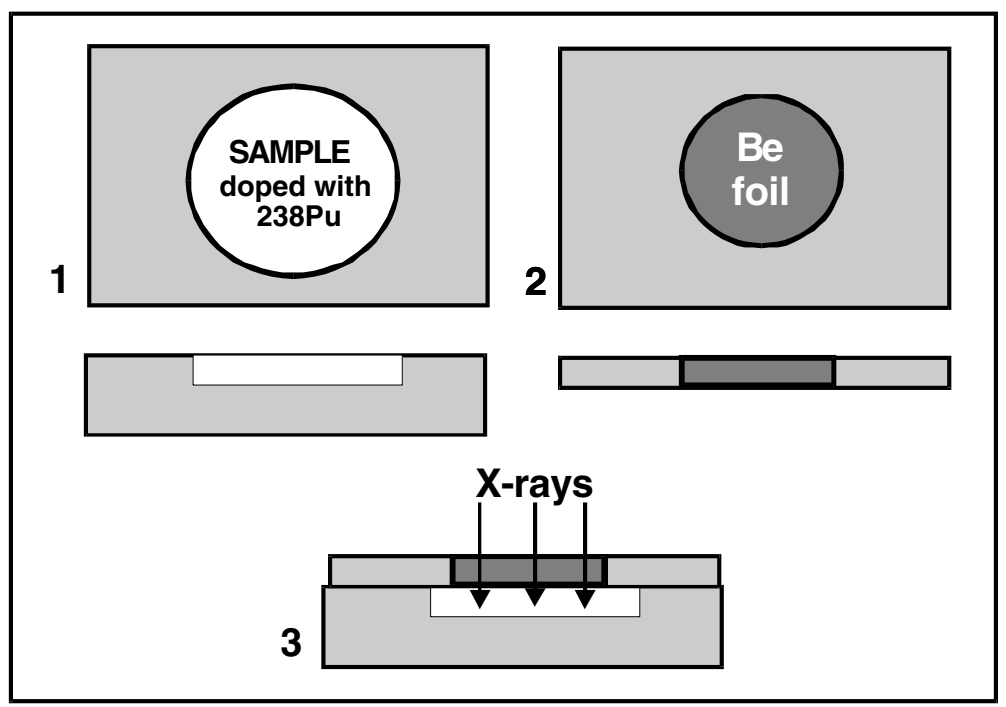

Fig. 1. Special cassette developed in V.G.Khlopin Radium Institute for XRD analysis of Pu-doped samples and for keeping samples containing ${ }^{238} \mathrm{Pu}$ over long time: (1) regular sample handler made of aluminum or copper; (2) protection cover with Be-window transparent for X-rays; (3) cross section of whole cassette. 


\title{
Recovery of Plutonium from Vitreous and Ceramic Materials Used for Waste Immobilization [B344864]
}

\author{
L. N. Lazarev, S.A. Bartenev, V.B. Gevirts, E.A. Kolobov, S.A. Strelkov, and \\ N.G. Firsin, KRI
}

\section{Introduction}

The objective of this scientific and basic research study is to establish:

1. The effectiveness of plutonium incorporation into ceramics and glass compositions that could potentially be used as a barrier to unauthorized future use of fissile nuclear materials.

2. The potential difficulty of plutonium dissolution or recovery from plutonium-containing glass and ceramic immobilization forms.

The study of plutonium dissolution or recovery by simple technological methods should provide an answer to the study objective. Stability of glass and ceramic compositions under development is evaluated predominantly from the standpoint of containment of plutonium for long-term storage or geologic disposal. There is a need to determine the feasibility of technical methods for decomposition of glass and ceramic (ore-like) matrix materials with the aim of recovering plutonium within the matrix.

The restrictions to be taken into account in development of processes for industrial plants of host nations for production are not of importance in the event of illegal theft of plutonium by terrorist or non-host nation groups. Thus, restrictions such as incomplete recovery of plutonium, formation of large volumes of wastes, application of toxic and corrosive reagents, workers receiving large radiation exposures, use of non-commercial industry equipment, etc., are assumed acceptable approaches to the recovery of plutonium for the purposes of this study. The feasibility of such rough technology methods was kept in mind when studying the nonproliferation problems.

To conduct studies on recovery of plutonium from glass and ceramics, it is necessary to possess standard samples. These may be pellets, granules or powder with plutonium content on the order of 5$10 \%$. Three types of ceramics (two Russian and one U.S. specified composition) and two types of Russian glasses were studied.

All glass and ceramic samples were obtained from laboratories at the Radium Institute. Initially, some pellets and granules of a non-plutonium simulator, namely cerium, were obtained. After a minimum of non-plutonium samples were tested to develop the plutonium test procedures, the samples containing plutonium were obtained and tested.

When studying the recovery of plutonium, KRI considered the possibilities for both direct dissolution of plutonium ceramic and glass compositions and preliminary chemical transformations of the materials followed by subsequent dissolution. For the purification of plutonium recovered from the ceramic and glass forms and its recovery from solutions, the sorption on ion-exchange resins was used. 


\section{Results of Test on Processing of Vitreous Compositions Containing Plutonium}

\section{Characterization of plutonium-containing vitreous compositions}

To test the decomposition processes, two lots of granulated aluminophosphate and borosilicate glasses containing plutonium were produced at the laboratory of Dr. A. S. Aloy. The chemical composition of the glasses is shown in Table 1.

According to data of electron microprobe analysis, the samples of aluminophosphate and borosilicate glass granules were completely homogeneous and did not contain any crystalline phases and inclusions.

Each sample of plutonium-containing compositions was analyzed for plutonium content.

\section{Process equipment and analytical control system}

Tests of processes for decomposition of Pu-containing vitreous compositions by acid and alkaline solutions were carried out using an autoclave installed in a glove box.

A fluoroplastic flask with a spring-loaded lid was used as a reaction vessel. This construction allows us to carry out the process of glass decomposition both in acid and in alkaline solutions at temperatures up to $200^{\circ} \mathrm{C}$ without any discharge of vapours and aerosols.

The degree of plutonium passage into solution in the process of decomposing the samples of vitreous compositions after their chemical treatment was determined from specific activity of solution separated from a precipitate, if it is formed. At a lower Pu content in solution compared to that of a processed glass granule, the secondary chemical treatment of precipitate was performed for additional recovery of plutonium.

Plutonium content in all samples of vitreous compositions was determined by gamma-spectrometric method.

\section{Verification of processes for plutonium recovery from borosilicate and aluminophosphate vitreous compositions}

To decompose borosilicate glasses and recover plutonium both acid and alkaline reagents have been used (Table 2).

\section{Glass solution processing by sorption}

In a glass matrix, plutonium is most likely present in quadrivalent state. However, after glass decomposition and treatment by strong solutions of acid, Pu (IV) can be oxidized to Pu (VI). Our experience on sorption of actinide shows that they can be sorbed on phosphonic acid cationite from moderately acid solutions both in quadrivalent and in hexavalent state. The use of this sorbent for plutonium recovery allows us to avoid an additional operation for stabilization of plutonium quadrivalent state. Therefore, all experiments were carried out on phosphonic acid cationite KRF.

The structural formula of elementary link is presented below: 

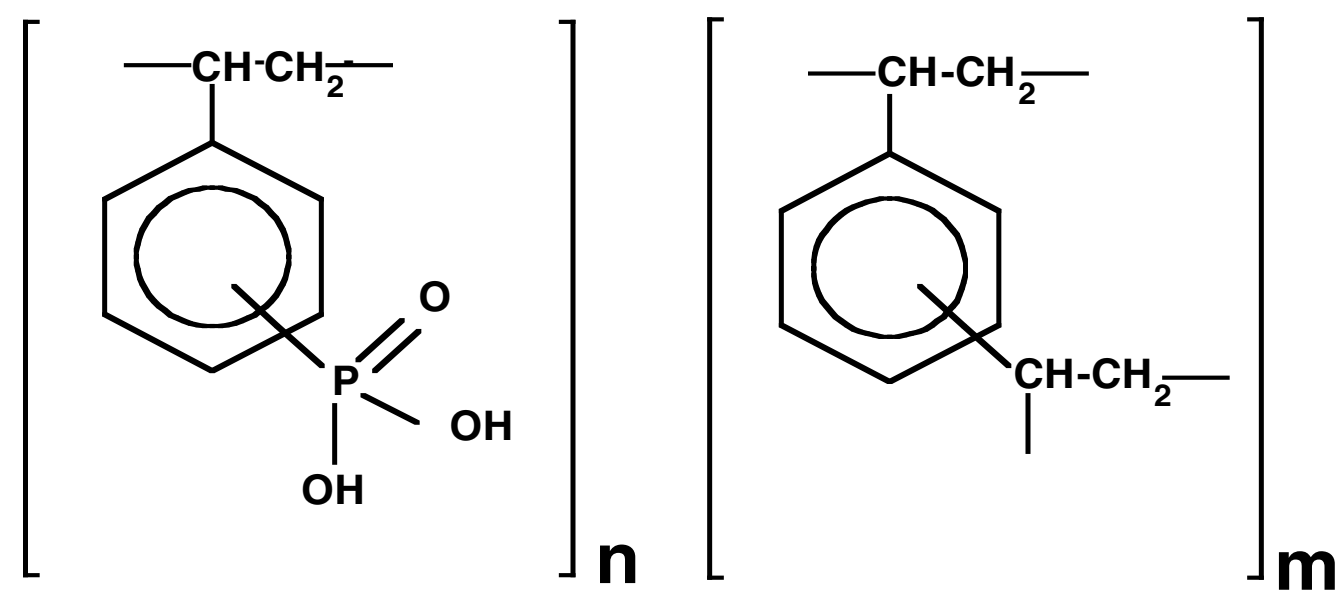

On recovery from aluminophosphate glass solutions, plutonium was sorbed from solutions. Sorption was practically complete. Total losses of plutonium in filtrates did not exceed $4.3 \%$ from initial amount and, in washing, no more than $1.5 \%$. The solutions containing nitrates and acid were used for desorption. The plutonium balance was 80 to $113 \%$.

\section{Inference}

The work carried out on plutonium recovery from aluminophosphate and borosilicate glasses has shown that:

- Decomposition of plutonium-containing matrices and plutonium passage in solution can be achieved by glass treatment with acid solutions. The best results have been obtained when treating the glass with subsequent additional dissolution of plutonium in strong acid.

- Plutonium recovery from solution has been carried out on phosphonic acid cationite KRF. Plutonium yield in desorbate for both types of glasses exceeds $90 \%$. Plutonium balance is close to $100 \%$.

- Vitreous compositions can be recommended for plutonium immobilization in temporary storage with provision of adequate measures for its security. Plutonium incorporation in vitreous compositions will not create an insurmountable barrier against unauthorized plutonium recovery.

\section{Results of Tests on Processing of Ceramic Compositions Containing Plutonium}

The attack on three types of compositions was studied: compositions based on zirconium dioxide, zircon, and pyrochlore. We had at our disposal a very small number of samples of these materials.

Relying on the test results with the use of simulators, the test schemes were chosen for plutonium separation from real specimens of ceramics and subsequent recovery of plutonium from solutions. 


\section{Nonproliferation Studies of Pu Recovery from Pu Glass and Pu Ceramic Immobilization Forms}

\section{Characteristics of plutonium-containing ceramic compositions}

For testing the decomposition processes at the Radium Institute in the laboratory headed by Prof. E. B. Anderson, there were manufactured specimens of three types of simulated and plutonium-containing ceramics on the basis of zirconium dioxide, a mixture of zircon and zirconium dioxide, and pyrochlore The composition of the latter ceramics and the method of their synthesis was suggested by LLNL. Weight content of plutonium amounted to $10 \%$ on conversion to dioxide in all the samples.

Tables 4-6 present data on synthesis conditions and characteristics of ceramics used in experiments on plutonium recovery. All the specimens were synthesized in the air.

Each specimen of all ceramic types used in the tests on plutonium recovery consisted of a broken piece of mechanically-destructed pellet of the material.

\section{Process equipment and analytical control system for ceramics decomposition processes}

The processes for decomposition of Pu-containing ceramics were conducted using an autoclave and electric furnace installed in a glove box

When processing the ceramics by acids, a glass or fluoroplastic test tube placed in a protective fluoroplastic guard tube with a spring-loaded lid was used as a reaction vessel.

The procedure of ceramics decomposition by melting was conducted in an electric furnace. Alkaline melting of ceramics was conducted.

Plutonium content was determined in all initial samples of ceramic compositions

\section{Plutonium recovery by sorption from solutions of ceramics}

On the basis of data obtained previously, phosphonic acid cationite KRF was chosen as a sorbent for plutonium recovery from ceramics solutions. Plutonium was sorbed from acid solutions of ceramics.

\section{Inference}

As a result of experiments performed, it has been shown that plutonium can be recovered from all three ceramics under study. However, ceramics are chemically more stable than glasses.

For decomposing all the types of ceramic materials under study, four methods of chemical action were used.

Plutonium exists in ionic form in solutions obtained after decomposition of ceramics. This is confirmed by the possibility of its efficient recovery with sorbents used in Russian practice.

\section{Conclusion}

The investigation performed should have provided the answer to the question of whether plutonium incorporation into vitreous or ceramic compositions could create an additional barrier in the nonproliferation system.

The results reported have shown that plutonium incorporation into the studied compositions is a poor obstacle against its unauthorized use. 


\section{Research and Development Plutonium Immobilization Contract Activities}

Plutonium glasses, in particular those of aluminophosphate type, are readily decomposed by acid. Precipitates formed in this case do not retain plutonium. Plutonium can be efficiently recovered by sorption from solutions obtained in glass processing by acids and washing solutions joined with them. A skilled chemist experienced in the field of radiochemical technology can implement such process of plutonium recovery from vitreous compositions. The choice of acid as decomposing agent and the use of sorption for plutonium recovery are rather obvious methods described in accessible literature.

Thus, the protective function of glass for the purpose of nonproliferation can be fulfilled only in combination with other techniques making difficult the management of immobilization products. For this purpose, there was a proposal to include high-level waste (HLW) into vitreous compositions.

The studied ceramic compositions are more stable than glasses. But ceramics can be decomposed by chemical means for plutonium recovery. The feasibility of such a process has been shown in this report.

When elaborating the plutonium-containing ceramics, the matrix material is chosen based on the analogy with minerals having the highest chemical stability. A specialist who will be charged with plutonium recovery from synthesized materials can use the methods for decomposition of natural raw materials. In the literature, there is comprehensive information on analytical and technological methods for recovery of valuable components from natural ores.

The improvement of protective properties of plutonium-containing ceramics can be achieved in two ways:

- Elaboration of ceramics with higher chemical stability;

- Incorporation of HLW into ceramic composition.

The density of plutonium ceramics, which we had at hand, was far from the maximum attainable. The decrease of porosity will make the ceramics more stable. The best results in this direction could have been obtained with the use of hot gasostatic synthesis. The Technological Division of the Radium Institute carries out investigations on the use of gasostatic method for solidification of HLW in ceramic form. This experience may be used to solve the problem of plutonium immobilization.

In studies described in this report, different methods of chemical action on ceramics were used. They were chosen according to specific features of each ceramic. To compare the stability of different ceramics, a restricted number of decomposition methods should be chosen (e.g., reagent, temperature, duration). The use of such standard testing methods will allow us to compare protective properties of different plutonium-containing materials,

The introduction of HLW into the composition of ceramics will make it very difficult to recover plutonium. However, this will require the elaboration of new compositions capable of fixing strongly a great number of chemical elements. At the Radium Institute, the investigations in this direction began at the laboratory of Dr. E. Anderson. He proposed to use, for example, ceramics of the garnet-perovskite type.

Thus, we think it advisable to focus subsequent plutonium immobilization studies on the creation of more stable and difficult to process ceramics. The assessment of results achieved will be made by using standard methods of testing for plutonium recovery feasibility. 
Nonproliferation Studies of Pu Recovery from Pu Glass and Pu Ceramic Immobilization Forms

Table 1. Chemical composition (wt\%) of aluminophosphate and borosilicate glasses.

\begin{tabular}{|l|c|c|}
\hline \hline \multirow{2}{*}{ Components } & \multicolumn{2}{|c|}{ Pu-containing compositions } \\
\cline { 2 - 3 } & Borosilicate glass & Aluminophosphate glass \\
\hline $\mathrm{Na}_{2} \mathrm{O}$ & 20.60 & 10.35 \\
\hline $\mathrm{Al}_{2} \mathrm{O}_{3}$ & 2.10 & 8.35 \\
\hline $\mathrm{Cs} 2 \mathrm{O}$ & 2.10 & 3.10 \\
\hline $\mathrm{BaO}$ & 4.10 & 3.15 \\
\hline $\mathrm{ZnO}$ & 5.10 & 4.20 \\
\hline $\mathrm{Fe}_{2} \mathrm{O}_{3}$ & 3.10 & 2.10 \\
\hline $\mathrm{P}_{2} \mathrm{O}_{5}$ & - & 60.6 \\
\hline $\mathrm{B}_{2} \mathrm{O}_{3}$ & 17.00 & - \\
\hline $\mathrm{SiO}_{2}$ & 42.60 & - \\
\hline $\mathrm{Gd}_{2} \mathrm{O}_{3}$ & - & 5.05 \\
\hline $\mathrm{CeO}_{2}$ & 1.04 & - \\
\hline $\mathrm{PuO}_{2}$ & 2.26 & 3.10 \\
\hline
\end{tabular}


Table 2. Results of experiments on chemical treatment of Pu-containing borosilicate glasses.

\begin{tabular}{|c|c|c|c|c|c|c|c|c|c|c|c|}
\hline \multirow[b]{2}{*}{ 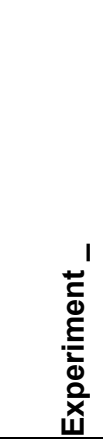 } & \multicolumn{2}{|c|}{ Sample } & \multicolumn{3}{|c|}{$\begin{array}{l}\text { Sample chemical treatment } \\
\text { conditions }\end{array}$} & \multirow{2}{*}{ 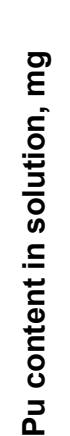 } & \multicolumn{3}{|c|}{$\begin{array}{l}\text { Precipitate chemical treatment } \\
\text { conditions }\end{array}$} & \multirow{2}{*}{ 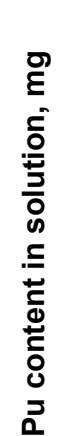 } & \multirow{2}{*}{ 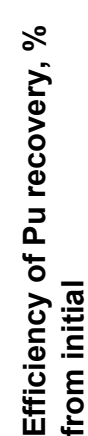 } \\
\hline & $\begin{array}{l}\underset{x}{0} \\
\stackrel{0}{\underline{0}} \\
\end{array}$ & 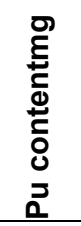 & Reagent & $\mathbf{T},{ }^{\circ} \mathbf{C}$ & Time, $\mathrm{h}$ & & Reagent & $\mathbf{T},{ }^{\circ} \mathbf{C}$ & Time, $\mathrm{h}$ & & \\
\hline 1 & A-59 & 3.11 & & & & & & & & & \\
\hline 2 & A-60 & 3.10 & & & & & & & & & \\
\hline 3 & A-62 & 3.00 & & & & & & & & & \\
\hline 4 & A-61 & 3.37 & & \multicolumn{6}{|c|}{ Details removed by Editor } & & \\
\hline 5 & A-63 & 3.29 & & & & & & & & & \\
\hline 6 & A-65 & 3.10 & & & & & & & & & \\
\hline 7 & A-64 & 3.29 & & & & & & & & & \\
\hline 8 & $\begin{array}{l}\text { A-66, } \\
\text { A-67 }\end{array}$ & 6.55 & & & & & & & & & \\
\hline
\end{tabular}

Note. In all experiments, the $\mathrm{S}: \mathrm{L}$ ratio was $1: 10 \mathrm{~g} / \mathrm{ml}$. 


\section{Nonproliferation Studies of Pu Recovery from Pu Glass and Pu Ceramic Immobilization Forms}

Table 3. Results of experiments on chemical treatment of Pu-containing aluminophosphate glasses.

\begin{tabular}{|c|c|c|c|c|c|c|c|c|c|c|c|}
\hline \multirow[b]{2}{*}{ 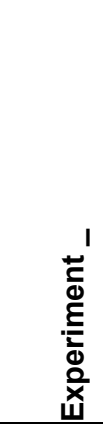 } & \multicolumn{2}{|l|}{ Sample } & \multicolumn{3}{|c|}{ Sample chemical treatment conditions } & \multirow{2}{*}{ 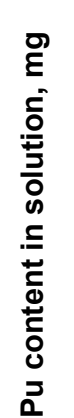 } & \multicolumn{3}{|c|}{$\begin{array}{l}\text { Precipitate chemical } \\
\text { treatment conditions }\end{array}$} & \multirow{2}{*}{ 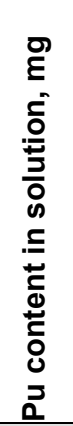 } & \multirow{2}{*}{ 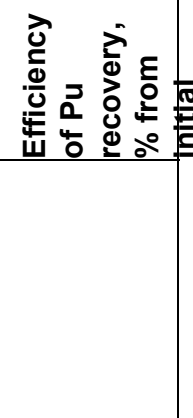 } \\
\hline & 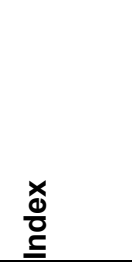 & 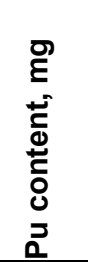 & Reagent & $\mathbf{T},{ }^{\circ} \mathbf{C}$ & Time, $\mathbf{h}$ & & Reagent & $\mathbf{T},{ }^{\circ} \mathbf{C}$ & $\begin{array}{l}\text { Time, } \\
\text { h }\end{array}$ & & \\
\hline 1 & $\mathrm{~A}-30$ & 2.94 & & & & & & & & & \\
\hline 2 & $\begin{array}{l}\text { A-31, A- } \\
33\end{array}$ & 5.65 & & & & & & & & & \\
\hline 3 & $\begin{array}{l}\text { A-36, A- } \\
37\end{array}$ & 5.89 & & & Det: & s ren & by Editor & & & & \\
\hline 4 & A-32 & 2.92 & & & & & & & & & \\
\hline 5 & A-35 & 3.15 & & & & & & & & & \\
\hline 6 & A-38 & 2.82 & & & & & & & & & \\
\hline 7 & A-34 & 3.12 & & & & & & & & & \\
\hline
\end{tabular}

Note. In all experiments the $S: L$ ratio was $-1: 10 \mathrm{~g} / \mathrm{ml}$. 
Table 4. Characteristics and synthesis conditions of ceramics based on zirconium dioxide (Zr, Gd, $\mathrm{Pu}) \mathrm{O}_{2}$ with immobilized plutonium.

\begin{tabular}{|c|c|c|c|c|c|c|c|}
\hline \multirow{2}{*}{ 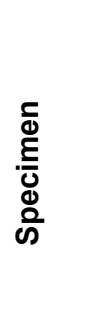 } & \multirow{2}{*}{ 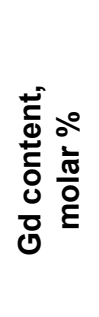 } & \multicolumn{2}{|c|}{$\begin{array}{l}\text { Sintering } \\
\text { conditions }\end{array}$} & \multirow{2}{*}{ 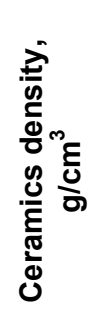 } & \multicolumn{3}{|c|}{$\begin{array}{l}\text { Yield (wt\%) of zirconium dioxide } \\
\text { (CZ-cubic, MZ-monoclinic, TZ-tetragonal) }\end{array}$} \\
\hline & & Time & $\mathbf{T}^{\circ} \mathbf{C}$ & & CZ & $\mathrm{TZ}$ & MZ \\
\hline DOZ-1 & 10 & $2 \mathrm{~h}$ & 1300 & 4.6 & $40-45$ & 50 & $\begin{array}{l}5-10 \\
-\end{array}$ \\
\hline \multirow[t]{2}{*}{ DOZ-2 } & \multirow[t]{2}{*}{20} & $4 \mathrm{~h}$ & 1450 & 5.6 & 100 & - & $\begin{array}{l}- \\
-\end{array}$ \\
\hline & & $\begin{array}{l}3 \mathrm{~h} \\
15 \\
\mathrm{~min}\end{array}$ & 1500 & & & & \\
\hline
\end{tabular}

Table 5. Characteristics and synthesis conditions of ceramics based on zircon/zirconium dioxide $(\mathrm{Zr}, \mathrm{Gd}, \mathrm{Pu}) \mathrm{O}_{2}$ with immobilized plutonium.

\begin{tabular}{|c|c|c|c|c|c|c|c|c|}
\hline \multirow[t]{2}{*}{ 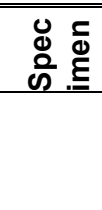 } & \multicolumn{2}{|c|}{$\begin{array}{l}\text { Sintering } \\
\text { conditions }\end{array}$} & \multirow{2}{*}{ 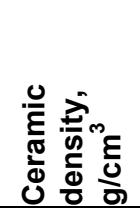 } & \multicolumn{5}{|c|}{$\begin{array}{l}\text { Yield (wt\%) } \\
\text { (MZ-monoclinic, TZ-tetragonal) }\end{array}$} \\
\hline & Time & $\mathbf{T}^{\circ} \mathbf{C}$ & & Zircon & $\mathrm{PuO}_{2}$ & $\mathrm{SiO}_{2}$ & MZ & TZ \\
\hline ZR-1 & $\begin{array}{l}3 \mathrm{~h} \\
15 \mathrm{~min}\end{array}$ & 1490 & 3.72 & 80 & $\begin{array}{l}\mathrm{Pu}_{0.5} \mathrm{Zr}_{0.5} \mathrm{O}_{2} \\
1-3\end{array}$ & - & $1-3$ & 15 \\
\hline \multirow[t]{2}{*}{ ZR-2 } & $4 \mathrm{~h}$ & 1450 & 3.40 & $96-98$ & $2-3$ & - & $<0.5$ & $<0.5$ \\
\hline & $\begin{array}{l}3 \mathrm{~h} \\
15 \mathrm{~min}\end{array}$ & 1500 & & & & & & \\
\hline
\end{tabular}

Table 6. Characteristics and synthesis conditions of pyrochlore ceramic.

\begin{tabular}{|c|c|c|c|c|c|c|c|c|c|}
\hline \multirow[b]{2}{*}{$\begin{array}{l}\bar{\Phi} \\
\frac{\Xi}{U} \\
\Phi \\
\text { के }\end{array}$} & \multicolumn{2}{|c|}{$\begin{array}{l}\text { Sintering } \\
\text { conditions }\end{array}$} & \multirow[b]{2}{*}{ 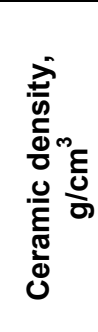 } & \multicolumn{6}{|c|}{ Yield (wt\%) } \\
\hline & Time & $\mathbf{T}^{\circ} \mathbf{C}$ & & 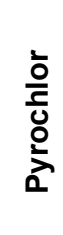 & $\begin{array}{l}\text { UO } \\
2\end{array}$ & $\mathrm{PuO}_{2}$ & 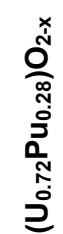 & 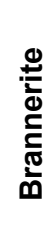 & $\mathrm{TiO}_{2}$ \\
\hline PC-1 & $\begin{array}{l}\mathrm{h} \mathrm{h} \\
10 \mathrm{~min}\end{array}$ & 1280 & 4.67 & 95 & - & - & $<1$ & 1 & $1-3$ \\
\hline
\end{tabular}


Nonproliferation Studies of Pu Recovery from Pu Glass and Pu Ceramic Immobilization Forms

Table 7. Results of plutonium recovery from ceramics by mineral acids.

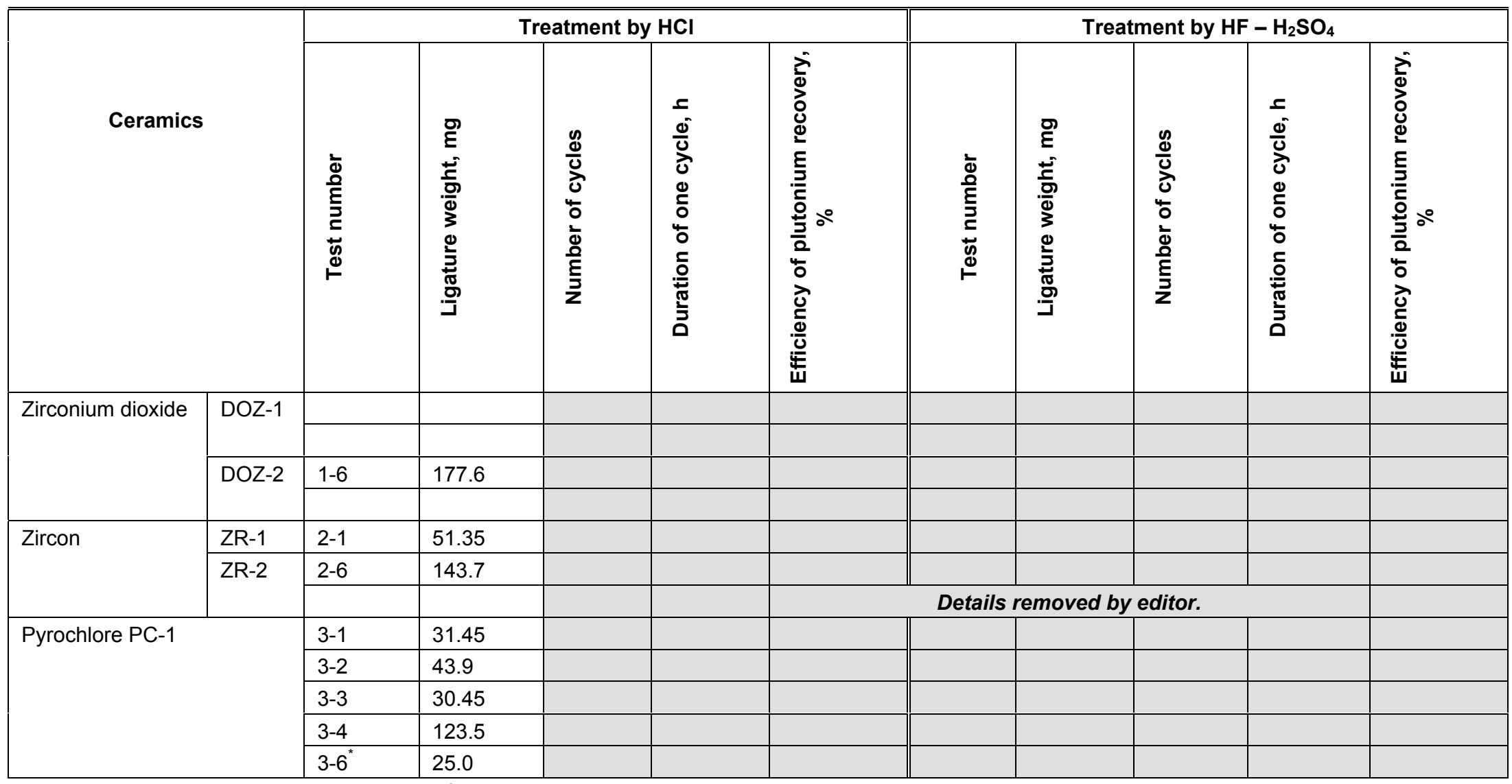

* Decomposition at atmospheric pressure and $100^{\circ} \mathrm{C}$. 
Table 8. Results of plutonium recovery from ceramics by alloying technique.

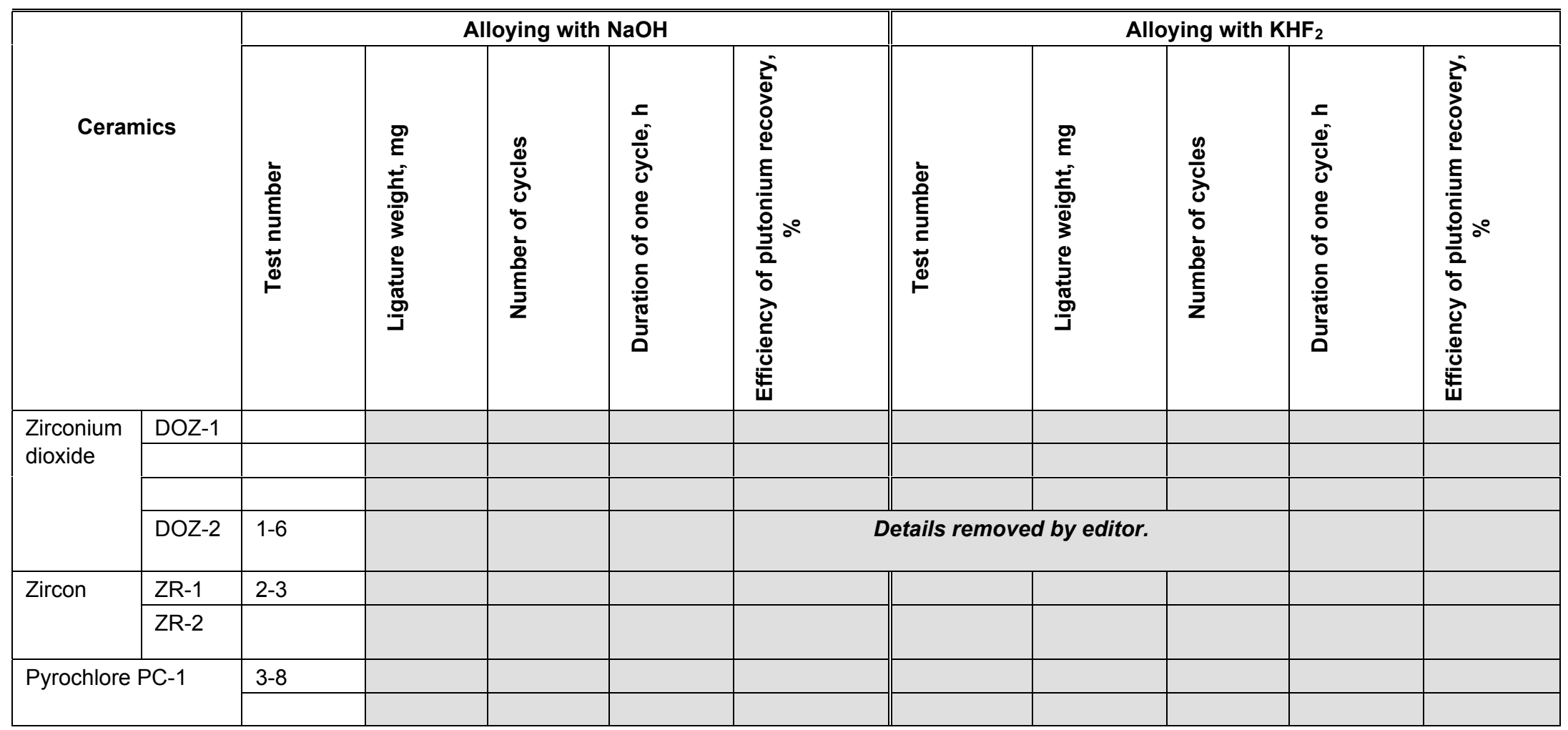

Fig. 1 removed by Editor

Fig. 2 removed by Editor

Fig. 3 removed by Editor 
Nonproliferation Studies of Pu Recovery from Pu Glass and Pu Ceramic Immobilization Forms 


\title{
Study of Recovery of Plutonium from Ceramic and Glass-type Materials [B344863]
}

\author{
V. S. Ilyashenko, V. F. Gorbunov, O. A. Mansourov, VNIINM \\ Introduction
}

VNIINM has vast experience in the field of developing and putting into operation different processes of reprocessing plutonium from solid waste of the metallic plutonium production as well as regeneration of spent nuclear fuel. The given waste is not uniform in chemical composition and is composed of hard-todissolve residues, ashes, sludges, and sediments from different technological operations. Their chemical composition is similar to natural ores, minerals, silica glasses, and ceramics.

To decompose such wastes, two methods are being used: (1) dissolution in acids; (2) melting of the hardto-dissolve residues. These techniques of reprocessing have different efficiency and predominantly are dependent upon the type or the composition of the material to be studied.

The acid treatment provides the Pu recovery into an acid solution within $90 \mathrm{wt} \%$. The use of a more severe method melting allows us to achieve the rate of dissolution of the matrix up to $98-99 \mathrm{wt} \%$.

Taking into account the composition of the materials studied under the framework of the agreement, and to assess their use as immobilization forms, it was decided to apply the methods described above (which also are used to recover valuable components from natural ores and minerals); namely: dissolution in mineral acids and melting with diverse fusing agents.

\section{Characteristics of Materials Studied}

During the implementation of the effort, the following materials have been studied:

- Phosphate glass. Composition, wt\%: $\mathrm{Na}_{2} \mathrm{O}-24.04, \mathrm{Al}_{2} \mathrm{O}_{3}-19.24, \mathrm{P}_{2} \mathrm{O}_{5}-52.14$, simulators of waste (oxides) $-4.08, \mathrm{PuO}_{2} \sim 0.3$.

- Borosilicate glass. Composition, wt\%: $\mathrm{Na}_{2} \mathrm{O}-21.00, \mathrm{Al}_{2} \mathrm{O}_{3}-5.02, \mathrm{~B}_{2} \mathrm{O}_{3}-13.05, \mathrm{CaO}-3.01$, $\mathrm{Fe}_{2} \mathrm{O}_{3}-3.01, \mathrm{SiO}_{2}-46.20$, simulators of waste (oxides) $-8.21, \mathrm{PuO}_{2} \sim 0.3$.

- Russian-specific ceramics based on $\mathrm{ZrO}_{2}$ and $\mathrm{ZrSiO}_{4}$ with content of $\mathrm{Pu}$ up to $10 \mathrm{wt} \%$. Conditions of fabrication: preliminary blending, calcination, pressing, sintering at $1400-1500^{\circ} \mathrm{C}$ during 3 hours.

- The US-specific ceramics based on pyrochlore with a content of Pu about $10 \mathrm{wt} \%$. Two groups of ceramic samples have been studied; with densities of 4.6 and $5.2 \mathrm{~g} / \mathrm{cm}^{3}$. Conditions of fabrication: preliminary blending, calcination, pressing at $3-5 \mathrm{t} / \mathrm{cm}^{2}$, sintering at $\sim 1350^{\circ} \mathrm{C}$ for $3 \mathrm{~h}$. 


\section{Nonproliferation Studies of Pu Recovery from Pu Glass and Pu Ceramic Immobilization Forms Discussion of Results}

Treatment of ceramic and glass-type materials, containing cerium

At the initial stage of the work, powdered and monolithic Cerium-containing samples were studied with the purpose of selecting and mastering the procedures of dissolving the Pu-containing materials.

The results of the experiments are summarized in Table 1. It follows from the table that the studied materials are decomposed by the acid treatment independently from the rate of its crushing (excluding the monolithic pyrochlore). The phosphate and borosilicate glasses turned out to be the most vulnerable.

The results of the treatment are given in Table 2.

\section{Treatment of ceramic and glass-type materials, containing plutonium}

On the basis of data obtained during the study of the Ce-containing compositions, treatment of the ceramic and glass-type materials containing plutonium was made practically under the same regimes and using monolithic specimens. To achieve the maximal level of decomposing the materials, with regard to the borosilicate glass and the ceramics more strict method, i.e., melting with various items, has been applied. The results of the given experiments are presented in Table 3.

The closeness of the results obtained with the data about different methods of dissolving the Pucontaining hard-to-dissolve residues, natural ores, minerals previously published in technical literature, indicate that it is possible to apply the proposed ways of recovery with regard to the ceramic and glasstype immobilization forms (Fig. 1).

That is why one can infer that regardless of the component contained in the matrix of the material to be recovered (e.g., cerium, plutonium), there is a respective correlation of its quantitative transfer into the solutions, especially the acid ones.

It means that except for a chemical barrier (an immobilization form), one needs to use other types of barriers (e.g., geological, engineered) that could be used for the safe storage and disposal of Pucontaining materials. 


\section{Research and Development Plutonium Immobilization Contract Activities}

\section{Conclusions}

1. Work has been done to define the possibility of dissolving ceramic (on the base of $\mathrm{ZrO}_{2}, \mathrm{ZrSiO}_{4}$, pyrochlore) and glass-type (phosphate and borosilicate glasses) materials containing cerium and plutonium. Two methods have been used-dissolution in mineral acids and melting.

2. Stability of the ceramics was identified as considerably higher than that of the glass-type materials. The pyrochlore with the density of $5.2 \mathrm{~g} / \mathrm{cm}^{3}$ is stable with regard to a boiling mixture acid. The phosphate and borosilicate glasses are dissolved in mineral acids. To completely decompose the borosilicate glass, it is necessary to apply the method of melting.

3. It was established that the most stable ceramic is a composition based on $\mathrm{ZrO}_{2}$. Versus the other ceramic compositions (zircon, pyrochlore at $4.6 \mathrm{~g} / \mathrm{cm}^{3}$ ), it is not broken off while melting. The pyrochlore at $5.2 \mathrm{~g} / \mathrm{cm}^{3}$ is decomposed partially. The use of more aggressive fusing agents permits us to dissolve all ceramic materials either completely (ceramics based on $\mathrm{ZrO}_{2}$ ) or partially (pyrochlore at $5.2 \mathrm{~g} / \mathrm{cm}^{3}$ ). However, its high corrosive aggressiveness hardly allows it to be utilized at a practical scale. The extraction of the constituents (including $\mathrm{Pu}$ ) is achieved on the account of dissolving the residues, forming after the treatment of the melt by water, by mineral acids.

4. It is necessary to fabricate ceramic samples based on pyrochlore at $5.2 \mathrm{~g} / \mathrm{cm}^{3}$ and more, and to carry on large-scale tests with the purpose of obtaining its actual chemical stability.

5. At the same time, it is advisable to continue the development and investigation of new types of ceramic, glass-or mineral-type materials, which may have greater chemical stability in melts. 


\section{Nonproliferation Studies of Pu Recovery from Pu Glass and Pu Ceramic Immobilization Forms}

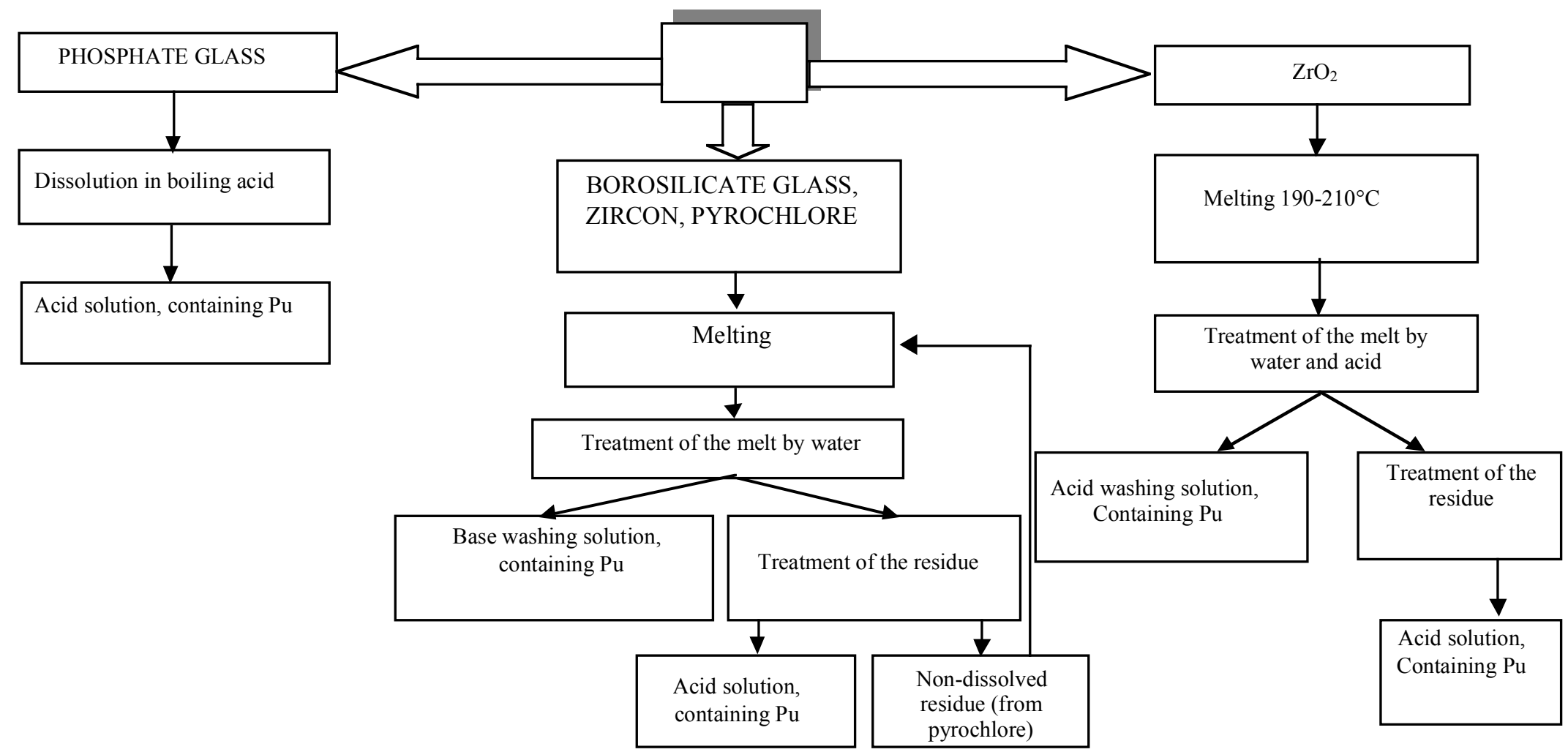

Fig. 1. A general scheme of processing ceramic and glass-type materials, containing plutonium. 
Table 1. Dissolution of Ce-containing ceramic and glass-type materials in mineral acids.

\begin{tabular}{|c|c|c|c|c|c|c|c|c|c|}
\hline \multirow[t]{2}{*}{ Material } & \multirow[t]{2}{*}{ Reagent } & \multicolumn{4}{|c|}{ Crushed specimen } & \multicolumn{4}{|c|}{ Monolithic specimen } \\
\hline & & $\begin{array}{c}\text { Weight } \\
\text { g }\end{array}$ & $\begin{array}{l}\text { Duration } \\
\text { min }\end{array}$ & $\begin{array}{l}\text { Yield of the } \\
\text { non-dissolved } \\
\text { residue, \% wt }\end{array}$ & $\begin{array}{c}\text { Ce recovery } \\
\% \text { wt }\end{array}$ & $\begin{array}{c}\text { Weight } \\
\text { g }\end{array}$ & $\begin{array}{c}\text { Duration } \\
\text { min }\end{array}$ & 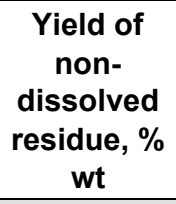 & $\begin{array}{c}\text { Ce } \\
\text { recovery, } \\
\% \text { wt }\end{array}$ \\
\hline 1. Phosphate $g$ & & & & & & & & & \\
\hline $\begin{array}{l}\text { 2. Borosilicate } \\
\text { glass }\end{array}$ & & & & & & & & & \\
\hline $\begin{array}{l}\text { 3. } \mathrm{ZrSiO}_{4}(80) \\
\mathrm{IZrO}_{2}(15)\end{array}$ & & & & \multicolumn{4}{|c|}{ Details removed by editor } & & \\
\hline $\begin{array}{l}\text { 3. } \mathrm{ZrSiO}_{4}(60) \\
\mathrm{IZrO}_{2}(30)\end{array}$ & & & & & & & & & \\
\hline 5. Pyrochlore & & & & & & & & & \\
\hline
\end{tabular}

Table 2. Meting of Ce-containing ceramic and glass-type materials with $\mathrm{NaOH}$.

\begin{tabular}{|c|c|c|c|c|c|c|c|c|}
\hline \multirow[t]{3}{*}{ Material } & \multirow{2}{*}{\multicolumn{2}{|c|}{$\begin{array}{l}\text { Reagent of the } \\
\text { treatment of }\end{array}$}} & \multicolumn{4}{|c|}{ Crushed specimen } & \multirow{2}{*}{\multicolumn{2}{|c|}{ Monolithic specimen }} \\
\hline & & & \multirow{2}{*}{$\begin{array}{l}\text { Weight, } \\
\text { g }\end{array}$} & \multirow{2}{*}{$\begin{array}{c}\text { Yield of the } \\
\text { non-dissolved } \\
\text { residue, } \\
\% \text { wt }\end{array}$} & \multicolumn{2}{|c|}{ Content of $\mathrm{Ce}, \%$ wt in } & & \\
\hline & melt & residue & & & $\begin{array}{c}\text { Non- } \\
\text { dissolved } \\
\text { residue }\end{array}$ & $\begin{array}{c}\text { Acid } \\
\text { solution }\end{array}$ & $\begin{array}{l}\text { Weight, } \\
\text { g }\end{array}$ & $\begin{array}{c}\text { Yield of the non- } \\
\text { dissolved residue, \% wt }\end{array}$ \\
\hline \multicolumn{9}{|c|}{ 6. Phosphate glass } \\
\hline \multicolumn{9}{|l|}{$\begin{array}{l}\text { 7. Borosilicate } \\
\text { glass }\end{array}$} \\
\hline \multicolumn{9}{|l|}{$\begin{array}{l}\text { 8. } \mathrm{ZrSiO}_{4}(80) \\
\mathrm{IZrO}_{2}(15)\end{array}$} \\
\hline $\begin{array}{l}\text { 9. } \mathrm{ZrSiO}_{4}(60) \\
\mathrm{IZrO}_{2}(30)\end{array}$ & & & & \multicolumn{4}{|c|}{ Details removed by editor } & \\
\hline 10. Pyrochlore & & & & & & & & \\
\hline 11. Pyrochlore & & & & & & & & \\
\hline 12. Pyrochlore & & & & & & & & \\
\hline
\end{tabular}

*After dissolution of the melt in water the residue has been treated. 
Nonproliferation Studies of Pu Recovery from Pu Glass and Pu Ceramic Immobilization Forms

Table 3. The results of treating Pu-containing ceramic and glass-type materials by versatile reagents.

\begin{tabular}{|c|c|c|c|c|c|c|c|c|c|}
\hline \multirow[t]{2}{*}{ Material } & \multirow[t]{2}{*}{ Weight, $\mathbf{g}$} & \multirow[t]{2}{*}{$\begin{array}{l}\text { Fusing } \\
\text { agent }\end{array}$} & \multicolumn{2}{|c|}{$\begin{array}{l}\text { Reagent of the } \\
\text { treatment of }\end{array}$} & \multirow{2}{*}{$\begin{array}{l}\text { The yield of the } \\
\text { non-dissolved } \\
\text { residue } \\
\% \text { wt }\end{array}$} & \multirow{2}{*}{$\begin{array}{l}\text { Pu content in the } \\
\text { non-dissolved } \\
\text { residue, } \\
\% \mathrm{wt}\end{array}$} & \multicolumn{3}{|c|}{$\begin{array}{l}\text { Pu recovery, } \\
\% \text { of initial }\end{array}$} \\
\hline & & & Melt & Residue & & & Aqueous & Base & Acid \\
\hline \multicolumn{10}{|l|}{$\begin{array}{l}\text { 1. Phosphate } \\
\text { glass }\end{array}$} \\
\hline \multicolumn{10}{|l|}{$\begin{array}{l}\text { 2. Borosilicate } \\
\text { glass }\end{array}$} \\
\hline \multicolumn{10}{|l|}{ 3. $\mathrm{ZrSiO}_{4}$} \\
\hline \multicolumn{10}{|l|}{ 4. $\mathrm{ZrSiO}_{4}$} \\
\hline 5. $\mathrm{ZrO}_{2}$ & & & & \multicolumn{3}{|c|}{ Details removed by editor } & & & \\
\hline 6. $\mathrm{ZrO}_{2}$ & & & & & & & & & \\
\hline 7. $\mathrm{ZrO}_{2}$ & & & & & & & & & \\
\hline 8. Pyrochlore * & & & & & & & & & \\
\hline 9. Pyrochlore ** & & & & & & & & & \\
\hline 10. Pyrochlore ${ }^{\star *}$ & & & & & & & & & \\
\hline 11. Pyrochlore ${ }^{\star *}$ & & & & & & & & & \\
\hline 12. Pyrochlore ${ }^{\star \star}$ & & & & & & & & & \\
\hline
\end{tabular}

*Sample with density of $4.6 \mathrm{~g} / \mathrm{cm}^{3}$; **Samples with density of $5.2 \mathrm{~g} / \mathrm{cm}^{3}$ 


\title{
Manufacture and Delivery of Salt Washing Apparatus for $\mathrm{PuO}_{2}$ [B506207]
}

\section{A. V. Bychkov, RIAR}

\begin{abstract}
The agreement B506207 between LLNL and the SSC Russian Federation RIAR deals with the manufacture, test, and delivery to LLNL of apparatus for washing ceramic powder (particles) from the soluble salts. RIAR has developed an apparatus to remove the soluble chloride salts from the ceramic particles of different origin, involving nuclear fuel, by salt dissolution in distilled water and separation of the insoluble ceramic particles from the water solution by centrifuging. A salt washing apparatus will be used to prepare radioactive ceramic wastes before their immobilization because some kinds of waste contain soluble salts.

The salt washing apparatus shown in Fig. 1 is a low-speed settling-filtration centrifuge. The ground ceramic material containing soluble salts is loaded in the centrifuge glass (1). The glass is filled with distilled water and soluble salts, which are mixed with the glass in an inclined position. When mixing is completed, the glass is returned to the vertical position, and solution is circulated through the layer of ground material distributed over the glass walls. The clarified solution is removed to the collector (4) to control fullness of ingress. After several repeated washing cycles, the apparatus is dried. The product is unloaded by centrifuging to an exhausting device.
\end{abstract}

Table 1. Performance attributes.

\begin{tabular}{|l|l|}
\hline \hline Material loading, $\mathrm{kg}$ & up to 8 \\
\hline Volume of washing solution, I & 2 \\
\hline washing cycle duration & $40-55 \mathrm{~min}$. \\
\hline Cycle number & $5-10$ \\
\hline Drying temperature, ${ }^{\circ} \mathrm{C}$ & 80 \\
\hline Drying duration, $\mathrm{h}$ & $2-3$ \\
\hline Frequency of glass rotation, $\mathrm{I} / \mathrm{min}$. & \\
-during mixing & 50 \\
-in solution removal & 650 \\
-in drying & 50 \\
\hline
\end{tabular}




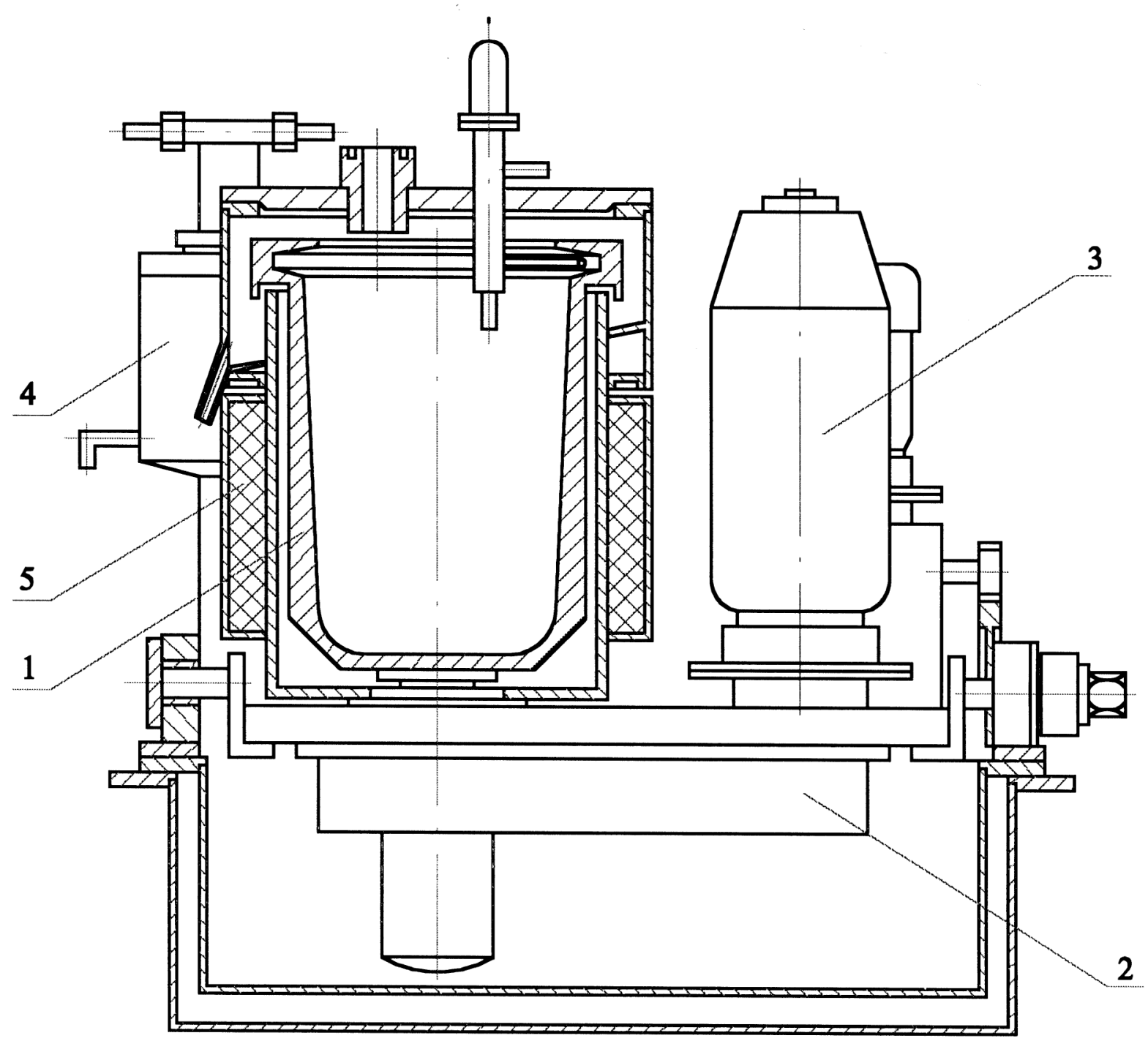

Fig. 1. Salt washing apparatus: (1) centrifuge glass, (2) reducer of main driving, (3) engine with variable critical speed, (4) collector for salt solution, and (5) furnace. 


\section{Russian-US Experts Workshop Support}

\section{Moshkov, KRI}

\section{Task 2: Project Review Meeting Documentation and Records [B338290]}

The following work has been performed for the period:

1. The viewgraph presentations, written papers, in hard copy and electronic files, of the meeting participants have been collected during the project review meeting and bound together with the project review meeting agenda, list of the U.S. and Russian attendees, and list of papers to form a written record of the project review meeting.

2. The KRI has made the necessary arrangements and payments (attachment 4) for the project review meeting November 1 through 4, 1999, in St. Petersburg at the SEC.

3. KRI paid all costs for meeting area for accommodation of the 46 U.S. and Russian participants of the project review meeting. This included meeting room, viewgraph equipment, interpreter booth, all associated equipment and head sets for the simultaneous translation on November 1, 2, 3 and 4 .

4. KRI paid costs of the 24 Russian participants from MINATOM sites for lodging at the SEC.

5. KRI provided local transportation for the U.S. meeting participants to and from their hotel to the project review meeting place at SEC.

6. KRI provided the necessary administrative support required to arrange the project review meeting location, communicated with the Russian co-chair and the Russian participants. This included distributing the project review meeting agendas and announcements.

7. KRI provided refreshments for breaks, working lunches for four days and one working dinner with a speaker on November 2, at the SEC.

8. KRI provided for auxiliary meeting facilities such as photocopying equipment, paper and overhead projectors. 
Other LLNL-Russian Contracts and Topics 


\section{Matrices for Radioactive Waste Immobilization: Status and Prospects}

\section{S.V. Yudintsev, IGEM RAS}

\section{Introduction}

Up to now, 72 forms for HLW immobilization have been suggested throughout the world, including 45 unique HLW forms (Gray, 1996). Besides, more than 20 potential $\mathrm{Pu}$ and the other actinides crystalline hosts exist. Goal of research performed in IGEM RAS (in cooperation with VNIINM and SIA "Radon") is to select the appropriate form (or forms) for Russian actinide-containing HLW solidification. These forms should be adapted to the Russian realities, in the first turn: types of HLW accumulated in the country, available industrial-scale methods of HLW forms fabrication, and consistency with host environment at potential sites of HLW disposal. Below these main Russian conditions are briefly outlined.

\section{Types (compositions) of High Level Wastes}

CURRENTLY EXISTING:

- $\quad$ Liquid HLW from Spent Fuel Reprocessing (potential forms are glasses, Synrocs);

- Excess weapons-grade Pu not available for usage as fuel at MOX-reactor power plants (potential forms are vitreous materials (LaBS- and ATS-glass), ceramics);

- Plutonium residues and scrap of complex chemical composition (glass-ceramics, ceramics);

ARISING IN THE NEAREST FUTURE:

- An-REE-Zr fraction after TRUEX / ACTINEX process (ceramics);

- Pu-bearing waste formed during weapons conversion and MOX fuel fabrication;

\section{Available Industrial-Scale Routes for HLW Forms Fabrication.}

CURRENTLY EMPLOYED AND MORE SUITABLE FOR INDUSTRIAL USAGE:

- Joule heated ceramic melter (EP-500-type furnace at PA "Mayak" is under testing);

- Inductive melting in a cold crucible (designed in Russia for HLW forms fabrication);

- Cold pressing and sintering (simplified MOX technology);

- High frequency heating.

LESS SUITABLE FOR INDUSTRIAL APPLICATION:

- Hot isostatic or uniaxial pressing (very high cost of waste forms fabrication);

- Plasma-chemical methods (low productivity of synthesis);

- $\quad$ Self propagating synthesis (uncontrolled parameters of the process); 


\section{Other LLNL-Russian Contracts and Topics}

\section{Consistency with Geological Conditions at Probable HLW Repository Sites.}

Chemical durability vitreous HLW forms disposed in silicate rocks will increase in the row:

alumophosphate < borosilicate < alumosilicate glass. Stability of crystalline matrices will also depend on the chemical composition of rocks (or more exactly underground waters) around the repository. For instance:

- at the "Mayak"-site, composed of basalts with low silica content (quartz is absent) more stable phases are: zirconia, sphene, zirconolite, perovskite, britholite, and pyrochlore.

- $\quad$ at the "Krasnoyarsk"-site, composed of granites with high silica content (quartz is present) more stable compounds are: zircon, sphene, monazite, murataite, and pyrochlore.

\section{Search for Crystalline Phases for Actinide Waste Immobilization}

During the operation of nuclear power plants and in the course of weapons-related programs a huge amount of actinide-containing HLW has been accumulated in Russia. Major kinds of actinide waste from simple to complex composition are listed in order below:

- Surplus weapons Pu, composed predominantly of plutonium isotopes and 0.5-3 wt\% Ga (this element is rather similar in its geochemical properties to $\mathrm{Al}^{3+}$ and especially $\mathrm{Fe}^{3+}$ );

- An-Zr-REEs fractions of HLW from spent fuel reprocessing, which composition is varied in the range: $10 \% \mathrm{AnO}_{2}: 60 \% \mathrm{REE}_{2} \mathrm{O}_{3}: 30 \% \mathrm{ZrO}_{2}-55 \% \mathrm{AnI}_{2}: 40 \% \mathrm{REE}_{2} \hat{\mathrm{I}}_{3}: 5 \% \mathrm{Zr}_{2}$, where An: U > Np > Am > $\mathrm{Pu}$; and REE: $\mathrm{Nd}>\mathrm{Ce}>\mathrm{La}>\mathrm{Pr}>\mathrm{Sm}$ (Sombret, 1986; Romanovski et al., 1996);

- Pu-containing residue waste from weapons production with complex composition: $30-88 \% \mathrm{Pu}$, up to $20 \% \mathrm{U}, 5 \% \mathrm{Am}, 5 \% \mathrm{Th}, 5 \% \mathrm{Ca}, 5 \% \mathrm{Mg}, 5 \% \mathrm{Na}, 5 \% \mathrm{~K}, 2 \% \mathrm{Fe}, 2 \% \mathrm{Ni}, 2 \% \mathrm{Ga}, 2 \% \mathrm{Al}, 2 \% \mathrm{Sr}, 2 \% \mathrm{Si}$, $2 \% \mathrm{Cr}, 2 \% \mathrm{Cu}, 2 \% \mathrm{Zn}, 1 \% \mathrm{Ta}, 1 \% \mathrm{~W}$ (after Burakov et al., 1998).

To provide plutonium nonproliferation, the materials should be immobilized in durable matrices excluding their further reuse. Vitreous forms have rather limited loading for actinides, low durability and provide potential possibility for reextraction of $\mathrm{Pu}$. These are the most essential reasons to study crystalline phases as alternative forms for actinides. The US have already selected for this purpose titanate pyrochlore-composed ceramics produced by cold pressing and sintering (Ebbinghaus et al., 1998). The goal of our study is searching for appropriate forms for the Russian actinide waste immobilization.

Search for the crystalline hosts is carried on in IGEM RAS for the last four years in close cooperation with specialists from SIA "Radon" and Bochvar Institute of Inorganic Materials (Laverov et al., 1996, 1997, 1999; Smelova et al., 1999; Stefanovsky et al., 1999; Yudintsev et al., 1998, 1999 1, 19992). Up to now 21 of various phases with different chemical and structural properties have been examined throughout the world as potential actinide host (Fielding and White, 1987; Lutze and Ewing, 1988; Ewing, 1999). These compounds include:

1. Zirconates: cubic zirconia-based An-REEs solid solution.

2. Titanates: zirconolite, pyrochlore, murataite, perovskite, crichtonite, aeshynite, et al.

3. Silicates: zircon, britholite, garnet.

4. Titano-silicates: sphene, perrierite-chevkinite.

5. Phosphates: monazite, NZP, et al. 


\section{Research and Development Plutonium Immobilization Contract Activities}

6. Aluminates: garnet- and perovskite-structured phases, hibonite.

The phases have been evaluated taking into account the following characteristics:

- Maximum content of actinides and REEs in the solid solutions;

- Chemical durability of the phases and their stability under radioactive damage;

- Possibility for synthesis of the phases by cold pressing and sintering and through inductive melting in a cold crucible.

In order to select the most optimal compound, an image of ideal actinide host has to be determined. In our opinion such phase should correspond to the following requirements:

- Clear chemical composition and well-defined crystalline structure;

- High flexibility of the lattice, provided possibility for incorporation of ions differed in their charge and dimension, including actinide, neutron absorbers and processing contaminants;

- Great isomorphic capability (solid solution limit) in respect of actinides and other elements;

- High chemical durability to water affection and stability under radioactive decay influence;

- Synthesis by existing industrial-scale routes of HLW immobilization, in the first turn by cold pressingsintering and inductive melting in a cold crucible followed by crystallization;

- Low cost from production expense point of view.

Based on our experimental study, we suggest that (titanate, zirconate)-based ceramics composed of fluorite-related oxides (zirconia, pyrochlore, zirconolite, murataite) are the promising forms for incorporation of surplus weapons-usable Pu and An-Zr-REE fraction of separated liquid HLW. Silicatebased garnet-britholite ceramics designed in VNIINM may be employed for immobilization of An-Zr-REE group of the HLW also. For immobilization of actinide-bearing complex wastes from Pu production, glassceramics are prospective hosts.

\section{Relevant Publications}

1. Burakov B.E. and Anderson E.B. Development of crystalline ceramic for immobilization of TRU wastes in V.G. Khlopin Radium Institute. Proc. of the NUCEF '98 International Conference. JAERIConf. 99-004 (Part 1). P.307-326.

2. Drozhko E.G., Suslov A.P., Fetisov V.I., et al. Basic directions and problems of radioactive waste management program in the "Mayak" production association, Chelyabinsk, Russia. High Level Radioactive Waste and Spent Fuel Managem. Edited by P.H. Ahlstroem, C.C. Chapman, R. Kohout, and J. Marek. Amer. Soc. Mechan. Eng. NY. 1993. Vol.2. P.17-20.

3. Ebbinghaus B.B., VanKonynenburg R.A., Ryerson F.J, et al. Ceramic formulation for the immobilization of plutonium. Proc. of the "Waste Management '98". 1998. CD-version.

4. Ewing R.C. Nuclear waste forms for actinides. Proc. Nat. Acad. Sci. USA. 1999. Vol.96. P.3432-3439.

5. Fielding P.F. and White T.J. Crystal chemical incorporation of high level waste species in aluminotitanate-based ceramics: Valence, location, radiation damage and hydrothermal durability. J. Mater. Res. 1987. Vol.2. P.387-414. 


\section{Other LLNL-Russian Contracts and Topics}

6. Gray L.W. and Kan T. Safety aspects with regard to plutonium vitrification techniques. In: Disposal of Weapon Plutonium. Edited by E.R. Merz and C.E. Walter. Kluwer Acad. Publ. The Netherlands. 1996. P.209-220.

7. Laverov N.P., Omelianenko B.I., Yudintsev S.V., Nikonov B.S. Zirconolite as a matrix for immobilization of High-Level Wastes. Geology of Ore Deposits. 1996. Vol.38. P.345-362.

8. Laverov N.P., Omelianenko B.I., Yudintsev S.V., Nikonov B.S., Sobolev I.A., Stefanovsky S.V. Mineralogy and geochemistry of matrices for the immobilization of High-Level Radioactive Wastes. Geology of Ore Deposits. 1997. Vol.39. P.211-228.

9. Laverov N.P., Yudintsev S.V., Omelianenko B.I., et al. Murataite ceramics for the immobilization of actinides. Geology of Ore Deposits. 1999. Vol.41. P.85-93.

10. Lutze W. and Ewing R.C. (Editors). Radioactive Waste Forms for the Future. Elsev. Science Publ., North-Holland. 1988. 778p.

11. Romanovski V.N., Smirnov I.V., Shadrin A.Yu., et al. Use of modified TRUEX-process for reprocessing of HLW at "Mayak" PA. Proc. of the Int. Conf. "Spectrum '98". Amer. Nucl. Soc. La Grange Park. IL. 1998. Vol.1. P.576-580.

12. Smelova T.V., Krylova N.V., Yudintsev S.V., Nikonov B.S. Silicate matrix for actinide wastes. Proc. of the Russian Academy of Sciences. 1999. To be published. (in Russ.).

13. Sombret C.G. Waste forms for conditioning high level radioactive solutions. The Geological Disposal of High Level Radioactive Wastes, Ath.: Theop. Publ. 1987, P.69-159.

14. Stefanovsky S.V., Yudintsev S.V., Nikonov B.S., Gorshkov A.I., Sivtsov A.V, Lapina M.I., Ewing R.C. Pyrochlore-type phases for actinides and rare earth elements immobilization. MRS '98 Symp. Proc. Vol.556. 1999.

15. Yudintsev S.V., Ewing R.C. Disequilibrium and metastability in high-level waste forms. Proc. of XVI Mendeleev Congr. on General and Appl. Chem. Moscow. 1998. Vol.1. P.300.

16. Yudintsev S.V., Stefanovsky S.V., Ewing R.C. Structural and compositional relationships in titanatecomposed ceramics for actinide-bearing waste immobilization. Proc. ICEM '99.

17. Yudintsev S.V. Immobilizing matrices for actinides: status and prospects. Proc. of the Joint Russian Academy of Sciences - U.S. Department of Energy Workshop on "Science behind safe geological disposition of radioactive waste". Moscow. 1999. P.30. 


\section{Tables}

Table 1. Crystalline hosts proposed for actinide immobilization (compilation of published data with our revisions and corrections).

\begin{tabular}{|c|c|c|c|}
\hline $\begin{array}{l}\text { CRYSTAL - CHEMICAL FORMULA OF (An, REE) - } \\
\text { CONTAINING COMPOUND }\end{array}$ & $\begin{array}{l}\text { Space } \\
\text { Group }\end{array}$ & $\begin{array}{l}\text { Maxim. An\&REE } \\
\text { contents, weight } \%\end{array}$ & $\begin{array}{l}\text { Natural } \\
\text { analogues }\end{array}$ \\
\hline \multicolumn{4}{|c|}{ I. ZIRCONATES } \\
\hline $\begin{array}{l}\text { 1. }\left[\mathrm{Zr}, \mathrm{An}^{4+},(\mathrm{An}, \mathrm{REE})^{3+}\right]^{\mathrm{V} / I I} \mathrm{O}_{2-\mathrm{x}} \\
\mathrm{An}=\mathrm{Th}, \mathrm{U}, \mathrm{Np}, \mathrm{Pu}, \mathrm{Am}, \mathrm{Cm}\end{array}$ & $\mathrm{Fm} 3 \mathrm{~m}$ & $\begin{array}{l}52 \mathrm{AnO}_{2} \\
40 \mathrm{REE}_{2} \mathrm{O}_{3}\end{array}$ & $\begin{array}{l}\text { tazheranite } \\
\text { uraninite }\end{array}$ \\
\hline 2. $(\mathrm{REE}, \mathrm{An})^{3+/ 4+}{ }_{2} \mathrm{Zr}_{2} \mathrm{O}_{7}$ & $\mathrm{Fd} 3 \mathrm{~m}$ & $60\left(\mathrm{AnO}_{2}+\mathrm{REE}_{2} \mathrm{O}_{3}\right)$ & absent \\
\hline \multicolumn{4}{|c|}{ II. TITANATES } \\
\hline 3. $\mathrm{An}^{\mathrm{VIII}} \mathrm{Ti}^{\mathrm{VI}}{ }_{2} \mathrm{O}_{6}$ & $\mathrm{C} 2 / \mathrm{m}$ & $\sim 50 \mathrm{AnO}_{2}$ & brannerite \\
\hline $\begin{array}{l}\text { 4. } \mathrm{A}^{\mathrm{VVIII}}{ }_{2} \mathrm{~B}^{\mathrm{VI}}{ }_{2} \mathrm{O}_{7-\mathrm{x}}(\mathrm{A}=\mathrm{Na}, \mathrm{Ca}, \mathrm{Ba}, \mathrm{Mn}, \mathrm{REE}, \mathrm{An} ; \mathrm{B}=\mathrm{Ti}, \mathrm{Nb} \text {, } \\
\mathrm{Zr}) \text {. }\end{array}$ & $\mathrm{Fd} 3 \mathrm{~m}$ & $\begin{array}{l}\sim 50 \mathrm{AnO}_{2} \\
26 \mathrm{REE}_{2} \mathrm{O}_{3}\end{array}$ & $\begin{array}{l}\text { pyrochlore, } \\
\text { betafite }\end{array}$ \\
\hline $\begin{array}{l}\text { 5. } \mathrm{A}^{\mathrm{VIII}} \mathrm{B}^{\mathrm{VIII}} \mathrm{C}^{\mathrm{Vl}-\mathrm{IV}}{ }_{2} \mathrm{O}_{7}(\mathrm{~A}=\mathrm{Ca}, \mathrm{REE}, \mathrm{An} ; \mathrm{B}=\mathrm{Zr}, \mathrm{An}, \mathrm{REE} ; \mathrm{C} \\
=\mathrm{Ti}, \mathrm{Nb}, \mathrm{Al}, \mathrm{Fe}) .\end{array}$ & $\begin{array}{l}\mathrm{C} 2 / \mathrm{c} \\
\mathrm{R} \overline{3} 2 / \mathrm{m}\end{array}$ & $\begin{array}{l}27 \mathrm{UO}_{2}, \mathrm{ThO}_{2}, \\
36 \mathrm{PuO}_{2}, \\
29 \mathrm{REE}_{2} \mathrm{O}_{3} \\
\end{array}$ & $\begin{array}{l}\text { zirconolite, } \\
\text { zirkelite, } \\
\text { polymignite }\end{array}$ \\
\hline 6. $A^{\mathrm{Xll}} \mathrm{B}^{\mathrm{Vl}} \mathrm{O}_{3}(\mathrm{~A}=\mathrm{Na}, \mathrm{Ca}, \mathrm{Sr}, \mathrm{REE}, \mathrm{An} ; \mathrm{B}=\mathrm{Ti}, \mathrm{Nb}, \mathrm{Al})$. & $\begin{array}{l}\text { Pm3m, } \\
\text { Pnma }\end{array}$ & $\begin{array}{l}40 \mathrm{REE}_{2} \mathrm{O}_{3} \\
10 \mathrm{AnO}_{2}\end{array}$ & $\begin{array}{l}\text { perovskite, } \\
\text { loparite }\end{array}$ \\
\hline $\begin{array}{l}\text { 7. } \mathrm{A}_{4} \mathrm{~B}_{2} \mathrm{C}_{7} \mathrm{O}_{22}(\mathrm{~A}=\mathrm{Ca}, \mathrm{Mn}, \mathrm{REE}, \mathrm{An} ; \\
\mathrm{B}=\mathrm{Ti}, \mathrm{Zr}, \mathrm{An} ; \mathrm{C}=\mathrm{Ti}, \mathrm{Al}, \mathrm{Mn}, \mathrm{Fe})\end{array}$ & $\mathrm{F} \overline{43 m}$ & $30\left(\mathrm{AnO}_{2}+\mathrm{REE}_{2} \mathrm{O}_{3}\right)$ & murataite \\
\hline $\begin{array}{l}\text { 8. } \mathrm{A}_{2-1}{ }^{\mathrm{XII}} \mathrm{B}^{\mathrm{VI-IV}}{ }_{19-21} \mathrm{O}_{36-38}\left(\mathrm{~A}=\mathrm{Na}, \mathrm{Ca}, \mathrm{REE}, \mathrm{An} ; \mathrm{B}^{\mathrm{Vl-lV}}=\mathrm{Zr} \text {, }\right. \\
\mathrm{Ti}, \mathrm{Fe}, \mathrm{Al}) \text {. }\end{array}$ & R3 & $\begin{array}{l}8 \mathrm{AnO}_{2} \\
10 \mathrm{REE}_{2} \mathrm{O}_{3}\end{array}$ & $\begin{array}{l}\text { crichtonite, } \\
\text { loverengite }\end{array}$ \\
\hline $\begin{array}{l}\text { 9. } A^{V V I I I} T i^{V / l} B^{V / I} O_{6}(A=R E E, A n ; \\
B=N b, T i, A l, F e)\end{array}$ & Pcan/bnm & $\begin{array}{l}20 \mathrm{AnO}_{2} \\
30 \mathrm{REE}_{2} \mathrm{O}_{3}\end{array}$ & $\begin{array}{l}\text { aeshynite, } \\
\text { euxenite }\end{array}$ \\
\hline \multicolumn{4}{|c|}{ III. PHOSPHATES } \\
\hline 10. $\left(\mathrm{REE}_{\mathrm{Ce}}, \mathrm{An}, \mathrm{Ca}\right)^{\mathrm{IX}} \mathrm{PO}_{4}$ & $\mathrm{P} 2{ }_{1} / \mathrm{n}$ & $\begin{array}{l}20 \mathrm{AnO}_{2} \\
60 \mathrm{REE}_{2} \mathrm{O}_{3}\end{array}$ & monazite \\
\hline 11. $\mathrm{Na}, \mathrm{Ca}, \mathrm{REE}^{\mathrm{VI}}(\mathrm{Zr}, \mathrm{An})^{\mathrm{VI}}{ }_{2}\left(\mathrm{PO}_{4}\right)_{3}$ & $R \overline{3} c$ & $20\left(\mathrm{AnO}_{2}+\mathrm{REE}_{2} \mathrm{O}_{3}\right)$ & kosnarite \\
\hline 12. $\mathrm{Th}_{3}\left(\mathrm{PO}_{4}\right)_{4}$ & $?$ & $70 \mathrm{AnO}_{2}$ & absent \\
\hline 13. $\mathrm{Th}_{4-\mathrm{x}}(\mathrm{U}, \mathrm{Np}, \mathrm{Pu})_{x}\left(\mathrm{PO}_{4}\right)_{4} \mathrm{P}_{2} \mathrm{O}_{7}$ & $?$ & $65 \mathrm{AnO}_{2}$ & absent \\
\hline \multicolumn{4}{|c|}{ IV. SILICATES } \\
\hline 14. $(\mathrm{Zr}, \mathrm{Hf}, \mathrm{Pu})^{\mathrm{VIII}} \mathrm{SiO}_{4}$ & $44_{1} / \mathrm{amd}$ & 8-10 $\mathrm{AnO}_{2}$ & zircon \\
\hline 15. $(\mathrm{Ca}, \mathrm{REE}, \mathrm{An})^{\mathrm{VII-IX}}{ }_{10}\left[\mathrm{SiO}_{4}\right]_{6} \mathrm{O}_{2}$ & $\mathrm{P} 6_{3} / \mathrm{m}$ & $\begin{array}{l}10 \mathrm{AnO}_{2} \\
60 \mathrm{REE}_{2} \mathrm{O}_{3}\end{array}$ & britholite \\
\hline $\begin{array}{l}\text { 16. }(\mathrm{Ca}, \mathrm{Y}, \mathrm{REE})^{\mathrm{VIII}}{ }_{3} \mathrm{~B}^{\mathrm{VI}}{ }_{2}\left[\mathrm{SiO}_{4}\right]_{3} \\
(\mathrm{~B}=\mathrm{Fe}, \mathrm{Al}, \mathrm{Ga}) .\end{array}$ & la3d & $\begin{array}{l}5 \mathrm{AnO}_{2} \\
10 \mathrm{REE}_{2} \mathrm{O}_{3}\end{array}$ & $\begin{array}{l}\text { garnet- } \\
\text { andradite }\end{array}$ \\
\hline \multicolumn{4}{|c|}{ V. TITANO-SILICATES } \\
\hline 17. $(\mathrm{Ca}, \mathrm{REE}, \mathrm{An})^{\mathrm{V} / \mathrm{I}}(\mathrm{Ti}, \mathrm{Al})^{\mathrm{VI}} \mathrm{Si}^{\mathrm{jV}} \mathrm{O}_{5}$ & $\mathrm{C} 2 / \mathrm{c}$ & $\begin{array}{l}10 \mathrm{AnO}_{2} \\
10 \mathrm{REE}_{2} \mathrm{O}_{3}\end{array}$ & sphene \\
\hline $\begin{array}{l}\text { 18. } \mathrm{A}^{\mathrm{X}}{ }_{4} \mathrm{~B}^{\mathrm{VI}}{ }_{3} \mathrm{Ti}^{\mathrm{V} \mathrm{V}}{ }_{2} \mathrm{Si}^{\mathrm{V}}{ }_{4} \mathrm{O}_{22}(\mathrm{~A}=\tilde{\mathrm{Na}}, \mathrm{Sr}, \mathrm{REE}, \mathrm{An} ; \mathrm{B}=\mathrm{Mg}, \mathrm{Fe} \text {, } \\
\mathrm{Al}, \mathrm{Zr}) .\end{array}$ & $\mathrm{P} 2{ }_{1} / \mathrm{a}$ & $\begin{array}{l}23 \mathrm{AnO}_{2}, \\
40 \mathrm{REE}_{2} \mathrm{O}_{3}\end{array}$ & $\begin{array}{l}\text { chevkinite, } \\
\text { perrierite }\end{array}$ \\
\hline \multicolumn{4}{|c|}{ VI. ALUMINATES } \\
\hline 19. $\left(\mathrm{REE}, \mathrm{An}^{3+}\right)^{\mathrm{Xll}} \mathrm{Al}^{\mathrm{Vl}} \mathrm{O}_{3}$ & Pnma/R3 & perovskite type & of structure \\
\hline 20. $(\mathrm{Y}, \mathrm{REE})^{\mathrm{VIIII}}{ }_{3}(\mathrm{Al}, \mathrm{Ga})^{\mathrm{VI}}{ }_{2}\left(\mathrm{Al}^{\mathrm{IV}} \mathrm{O}_{4}\right)_{3}$ & la3d & garnet type & of structure \\
\hline 21. (Ñà,REE) $)^{\mathrm{XII}}(\mathrm{Al}, \mathrm{Ti})^{\mathrm{V}-\mathrm{IIV}}{ }_{12} \mathrm{O}_{19}$ & $\mathrm{P} 6_{3} / \mathrm{mmc}$ & $14 \mathrm{REE}_{2} \mathrm{O}_{3}$ & hibonite \\
\hline
\end{tabular}




\section{Other LLNL-Russian Contracts and Topics}

Table 2. Most typical structures of (An,REE)-bearing compounds.

\begin{tabular}{|c|c|c|c|c|}
\hline \multicolumn{5}{|c|}{$\begin{array}{c}\text { Types of the lattice, examples of compounds, } \\
\text { space groups of symmetry }\end{array}$} \\
\hline Fluorite-structured & $\begin{array}{l}\text { Perovskite- } \\
\text { structured }\end{array}$ & Garnet-structured & Apatite-structured & Zircon-structured \\
\hline $\begin{array}{l}(\mathrm{Pu}, \mathrm{U}) \mathrm{O}_{2}^{\mathrm{ss}} \\
\mathrm{ZrO}_{2}{ }^{\mathrm{s}}, \text { pyrochlore, } \\
\text { murataite, } \\
\text { zirconolite }\end{array}$ & $\begin{array}{l}\text { titanates \& } \\
\text { aluminates of } \mathrm{Ca} \text {, } \\
\mathrm{REE} \text {, and } \mathrm{An}\end{array}$ & $\begin{array}{l}\text { silicates \& } \\
\text { aluminates of } \mathrm{Ca} \text {, } \\
\mathrm{Fe}, \mathrm{Al}, \mathrm{Y}, \mathrm{REE} \text { and } \\
\text { An }\end{array}$ & $\begin{array}{l}\text { silicates \& } \\
\text { phosphates of An, } \\
\text { REE }\end{array}$ & $\begin{array}{l}\text { silicates of } \mathrm{Zr}, \mathrm{An} \\
(\mathrm{Th}, \mathrm{U}, \mathrm{Pu}) \text {, } \\
\text { phosphate of } \mathrm{Y}\end{array}$ \\
\hline $\begin{array}{l}\mathrm{Fm} 3 \mathrm{~m}, \mathrm{Fd} 3 \mathrm{~m}, \\
\mathrm{~F} \overline{4} 3 \mathrm{~m}, \mathrm{R} \overline{3} 2, \\
\mathrm{C} 2 / \mathrm{c}\end{array}$ & $\begin{array}{l}\text { Pcmn, R } \overline{3} \mathrm{~m}, \\
\text { Pm3m }\end{array}$ & la3d & $\mathrm{P} 6_{3} / \mathrm{m}$ & $14_{1} /$ amd \\
\hline
\end{tabular}

Table 3. Most important exchanges in the crystalline hosts influenced on their actinide and lanthanide content.

\begin{tabular}{|c|c|}
\hline Scheme of exchange & Example of phases \\
\hline \multicolumn{2}{|c|}{ Aliovalent substitutions: } \\
\hline $\mathrm{Zr}^{4+}=\mathrm{An}^{4+}(\mathrm{U}, \mathrm{Np}, \mathrm{Pu})$ & zirconia, zirconolite, pyrochlore, murataite, zircon \\
\hline $\mathrm{REE}^{3+}=\mathrm{An}^{3+}(\mathrm{Am}, \mathrm{Cm})$ & pyrochlore, monazite, britholite \\
\hline \multicolumn{2}{|c|}{ Altervalent substitutions: } \\
\hline \multicolumn{2}{|c|}{ a) In the same structural site: } \\
\hline $2 \mathrm{Ca}^{2+}=\mathrm{Na}^{+}+(\mathrm{An}, \mathrm{REE})^{3+}$ & pyrochlore, perovskite, sphene \\
\hline $3 \mathrm{Ca}^{2+}=2(\mathrm{An}, \mathrm{REE})^{3+}+$ vacancy & perovskite, zirconolite \\
\hline $2 \mathrm{REE}^{3+}=\mathrm{Ca}^{2+}+\mathrm{An}^{4+}$ & pyrochlore, monazite \\
\hline \multicolumn{2}{|c|}{ b) In different structural site: } \\
\hline $\mathrm{Ca}^{2+}+\mathrm{Ti}^{4+}=(\mathrm{An}, \mathrm{REE})^{3+}+(\mathrm{Al}, \mathrm{Fe})^{3+}$ & perovskite, zirconolite, sphene \\
\hline $\mathrm{Ca}^{2+}+2 \mathrm{Ti}^{4+}=(\mathrm{An}, \mathrm{Ce})^{4+}+2(\mathrm{Al}, \mathrm{Fe})^{3+}$ & perovskite, zirconolite, sphene \\
\hline $\mathrm{Ca}^{2+}+\mathrm{Ti}^{4+}=(\mathrm{An}, \mathrm{Ce})^{4+}+(\mathrm{Mg}, \mathrm{Fe})^{2+}$ & zirconolite, pyrochlore, sphene \\
\hline $2 \mathrm{REE}^{3+}+\mathrm{Ti}^{4+}=2 \mathrm{An}^{4+}+(\mathrm{Mg}, \mathrm{Fe})^{2+}$ & zirconolite, pyrochlore \\
\hline $\mathrm{REE}^{3+}+\mathrm{P}^{5+}=\mathrm{Ca}^{4+}+\mathrm{Si}^{4+}$ & monazite, britholite \\
\hline
\end{tabular}


Table 4. Summary of published data on elements normalized leaching rates $-R_{\mathrm{i}}\left(g \times \mathrm{m}^{-2} \times\right.$ day $\left.^{-1}\right)$ at

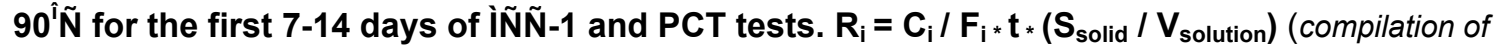
published data with our revisions and corrections).

\begin{tabular}{|c|c|c|c|c|c|c|c|c|}
\hline Phase & $\mathrm{Ca}$ & $\mathrm{Ce}$ & Gd & $\mathbf{U}$ & $\mathrm{Np}$ & $\mathrm{Pu}$ & $\mathrm{Cm}$ & $\alpha / \mathrm{g}, 20^{\circ} \mathrm{C}$ \\
\hline Zirconia & & & & & & $10^{-5}$ & & \\
\hline $\begin{array}{l}\text { Zirco- } \\
\text { nolite }\end{array}$ & $\begin{array}{l}5 * 10^{-2} \\
4 * 10^{-1}\end{array}$ & $7 * 10^{-4}$ & $10^{-4}$ & & & $\begin{array}{l}10^{-4} \\
10^{-2}\end{array}$ & $\begin{array}{l}10^{-4} \\
10^{-4}\end{array}$ & $\begin{array}{l}10^{19} \\
\Delta=5 \%\end{array}$ \\
\hline $\begin{array}{l}\text { Perov- } \\
\text { skite }\end{array}$ & & $<10^{-4}$ & & & & & & $\begin{array}{l}5 * 10^{19} \\
\Delta=12 \%\end{array}$ \\
\hline $\begin{array}{l}\text { Pyro- } \\
\text { chlore }\end{array}$ & & & & $10^{-4}$ & & $\begin{array}{l}10^{-2} \\
4 * 10^{-1}\end{array}$ & $\begin{array}{l}7 * 10^{-4} \\
10^{-2}\end{array}$ & $\begin{array}{l}3 * 10^{18} \\
\Delta=5 \%\end{array}$ \\
\hline Synroc-C & $5 * 10^{-3}$ & $5 * 10^{-5}$ & $3 * 10^{-5}$ & $10^{-4}$ & $10^{-4}$ & $2 * 10^{-5}$ & $\begin{array}{l}3 * 10^{-4} \\
2 * 10^{-3}\end{array}$ & $\begin{array}{l}10^{19} \\
\Delta=6 \%\end{array}$ \\
\hline Synroc-F & $10^{-2}$ & & $10^{-4}$ & $10^{-5}$ & & $10^{-4}$ & & $\begin{array}{l}10^{19} \\
\Delta=6 \%\end{array}$ \\
\hline Monazite & & & & $10^{-3}$ & & & & \\
\hline NZP & $7 * 10^{-1}$ & $8 * 10^{-4}$ & $4 \times 10^{-4}$ & & & & & $10^{19}$ \\
\hline Zircon & & \multicolumn{5}{|c|}{$\begin{array}{ll}3 * 10^{-4} \text { (loss of total weight } \\
2 * 10^{-2} \text { of zircon grains) }\end{array}$} & & $\begin{array}{l}8 * 10^{18} \\
\Delta=16 \%\end{array}$ \\
\hline Britholite & \multicolumn{4}{|c|}{$\begin{array}{l}2 * 10^{-2} \text { - crystalline } \\
3 * 10^{-1} \text { - amorphous }\end{array}$} & & $\begin{array}{l}3 * 10^{-2} \\
3 * 10^{-1}\end{array}$ & $\begin{array}{l}4 * 10^{-3} \\
4 * 10^{-2}\end{array}$ & $\begin{array}{l}4 * 10^{18} \\
\Delta=5 \%\end{array}$ \\
\hline Murataite & & & & $<10^{-5}$ & & & & $?$ \\
\hline
\end{tabular}

Figures in the last column indicate a dose of $\alpha$-decay events needed for complete metamictization of lattice and its volume increase $\left(\Delta=\mathrm{V}-\mathrm{V}_{\mathrm{o}}\right)$. 
Other LLNL-Russian Contracts and Topics

Table 5. Industrial routes for waste forms fabrication.

\begin{tabular}{|c|c|c|c|c|}
\hline \multirow{3}{*}{$\begin{array}{l}\text { Compound } \\
\mathrm{ZrO}_{2}^{\text {sol.solution }}\end{array}$} & \multicolumn{2}{|c|}{ Melting - crystallization } & \multicolumn{2}{|c|}{ Solid phase synthesis } \\
\hline & \multicolumn{2}{|c|}{ JHM IMCC } & \multicolumn{2}{|c|}{$\mathrm{HP} \quad \mathrm{CP}+\mathrm{S}$} \\
\hline & \pm & + & + & + \\
\hline Zirconolite & \pm & + & + & + \\
\hline Perovskite & \pm & + & + & + \\
\hline Pyrochlore & \pm & + & + & + \\
\hline Murataite & \pm & + & + & + \\
\hline Britholite & \pm & + (vitreous & + & + \\
\hline Garnet & \pm & + phase may & + & + \\
\hline Sphene & \pm & +be present) & + & + \\
\hline $\mathrm{NaZr}_{2}\left(\mathrm{PO}_{4}\right)_{3}$ & $?$ & - & + & + \\
\hline Monazite & - & - & + & + \\
\hline Zircon & - & - & + & + \\
\hline $\begin{array}{l}\text { Range of the } \\
\text { process parameters }\end{array}$ & $\begin{array}{l}1000- \\
1300^{\circ} \tilde{N} \\
0.1 \mathrm{ÌPa}, \\
\text { air medium }\end{array}$ & $\begin{array}{l}1200-1900 \text { î̃, } \\
0.1 \text { ìPà, air }\end{array}$ & $\begin{array}{l}1200^{\hat{i}} \tilde{\mathrm{N}}+ \\
20-140 \text { ÌPà, } \\
\text { argon, N2, } \\
\mathrm{H}_{2} / \mathrm{N}_{2}\end{array}$ & $\begin{array}{l}14 \text { ÌPà; } 1350^{\hat{i}} \tilde{N} \text {, } \\
\text { air, argon, } \\
\mathrm{H}_{2} / \mathrm{N}_{2}\end{array}$ \\
\hline
\end{tabular}

JHM - Joule heated melting, IMCC- inductive melting in a cold crucible, HP - hot pressing,

$\mathrm{CP}+\mathrm{S}$ - cold pressing followed by sintering.

${ }^{(+)}$- synthesis is possible; $\left({ }^{ \pm}\right)$- very difficult due to high melting temperature of the phase;

$(-)$ - synthesis is impossible; (?) - no data.

Table 6. Major differences in solid state (cold pressing-sintering) and melting routes of ceramic forms fabrication.

\begin{tabular}{|c|c|c|}
\hline FEATURES & SOLID STATE ROUTE & THROUGH MELTING ROUTE \\
\hline CONDITIONS & CONSTANT T (P) & DECREASING T \\
\hline $\begin{array}{l}\text { RATE LIMITING } \\
\text { FACTOR }\end{array}$ & DIFFUSION IN SOLID STATE & DIFFUSION IN LIQUID (MELT) \\
\hline$D_{i}^{s S s}=f(T)$ & $\log _{10}\left(D^{\operatorname{tmm}} / D^{s s s}\right)>5$ & $\mathrm{D}_{\mathrm{i}}^{\mathrm{tm} \mathrm{r}_{\mathrm{i}}=\mathrm{f}(\mathrm{T}, \text { melt composition })}$ \\
\hline PHASES FORMATION & SIMULTANEOUS & IN DEFINITE ROW \\
\hline SIZE OF GRAINS & $\begin{array}{l}\text { VERY SMALL } \\
\text { (a few } \mu \mathrm{m})\end{array}$ & $\begin{array}{l}\text { DEPENDENT ON RATE OF COOLING } \\
\text { REGIME }\end{array}$ \\
\hline UNREACTED OXIDES OF BATCH & RATHER TYPICAL & NOT TYPICAL \\
\hline $\begin{array}{l}\text { FABRICATION OF SINGLEPHASE } \\
\text { FORM }\end{array}$ & POSSIBLE & IMPOSSIBLE \\
\hline PHASES GRAIN COMPOSITION & $\begin{array}{l}\text { UNIFORM IN ALL PARTS OF } \\
\text { GRAINS }\end{array}$ & $\begin{array}{l}\text { OFTEN NONUNIFORM } \\
\text { (ZONED CRYSTALS) }\end{array}$ \\
\hline GLASS APPEARANCE & UNCOMMON & $\begin{array}{l}\text { COMMON IN (Si, AI-P)-BASED } \\
\text { SYSTEMS }\end{array}$ \\
\hline
\end{tabular}

$D$ - coefficient of diffusion. ${ }^{\text {sss }}$ - solid state synthesis, ${ }^{\text {tmr }}$ - through melting route. 


\section{Study of Sorption-selective Properties of Special Asbestos}

\section{A. G. Tsvetokhin, VNIITF, C-70 \\ M. V. Logunov, A. I. Bardov, and A. N. Rychkov, PA Mayak}

One of the basic trends of evolving sorption methods of purifying liquid intermediate and low-level radioactive waste is based on using cheap and available collectors.

The usage of inorganic sorbents on a ground of natural and modified minerals, chemical production waste, sludge, etc., is proposed to recover long-term radionuclides, in particular actinide elements.

A task of this research was to study sorption-selective properties of some grades of special asbestos being fabricated by the combine "Asbest" such as: moisturized short-fiber rhodusite, blue rhodusite asbestos, dried long-fiber blue asbestos (DA), and moisturized fragile chrisotile asbestos (MA).

Sorption parameters of the asbestos have been defined with regard to cesium, strontium, uranium, and cobalt under static and dynamic conditions within $\mathrm{pH}$ of $1-11$ by its contact with multicomponent solutions as well as complicated solutions and natural waters.

It was established that the given materials sorb cesium and strontium slightly. But at the same time, they are apt to incorporate cobalt and especially uranium. Upon the results of static experiments, a rate of sorption has been calculated:

$$
S=\left(I_{0}-I_{p}\right)^{*} I_{0}^{-1}
$$

And a distribution coefficient:

$$
\begin{aligned}
& \mathrm{K}_{\mathrm{d}}=\mathrm{S}^{*}(1-\mathrm{S})^{-1 *} V^{*} \mathrm{~m}^{-1} \text {, where } \\
& \mathrm{I}_{0} \text { - initial concentration (activity) of the component; } \\
& \mathrm{I}_{\mathrm{p}} \text { - equal (final) concentration of the components; } \\
& \mathrm{V} \text { - volume of the solution, } \mathrm{ml} ; \\
& \mathrm{m} \text { - weight of a specimen of the sorbent; }
\end{aligned}
$$

For almost all samples of the asbestos, the value of $K_{d}$ of uranium was about $(n \pm \Delta n)^{*} 10^{3} \mathrm{mg} / \mathrm{l}$. The presence of weighty amounts of sodium and calcium in the solution, which are basic components of highactive liquid waste and natural waters, do not effect the sorption of uranium. At the same time, oxalate and acetate ions practically suppress this process $\left(K_{d}<50\right)$.

One should note that the values of $K_{d}$ in a range of $1 * 10^{2}-4 * 10^{4}$ were determined with the accuracy of 2$5 \%$, and the values $K_{d}$ less then 100 and more $4 * 10^{4}$ with an accuracy of $10-25 \%$.

On the basis of the results obtained for purifying the water from cobalt and uranium, the most effective sorbents (DA, MA) have been chosen. Testing of the sorbents under dynamic conditions has demonstrated that the increase of specific loading of the sorption for more than $1-3 \mathrm{~h}^{-1}$ is not permissible. While using the asbestos MA, a 30-50 fold reduction of the uranium concentration in a simulated solution is provided at least in 70 volumes of filtrate.

The feeding of actual underground waters of a complicated composition onto the sorbent results in a considerable decrease in a filtration cycle. 


\section{Other LLNL-Russian Contracts and Topics}

A preliminary scrutiny of a prospective water purification flowchart has been made. The use of chemical treatment of the water (e.g., precipitation, coagulation) with eventual mechanical filtration is assumed. By the way, purified water is assumed to feed onto the filters with the collectors of radionuclides. 


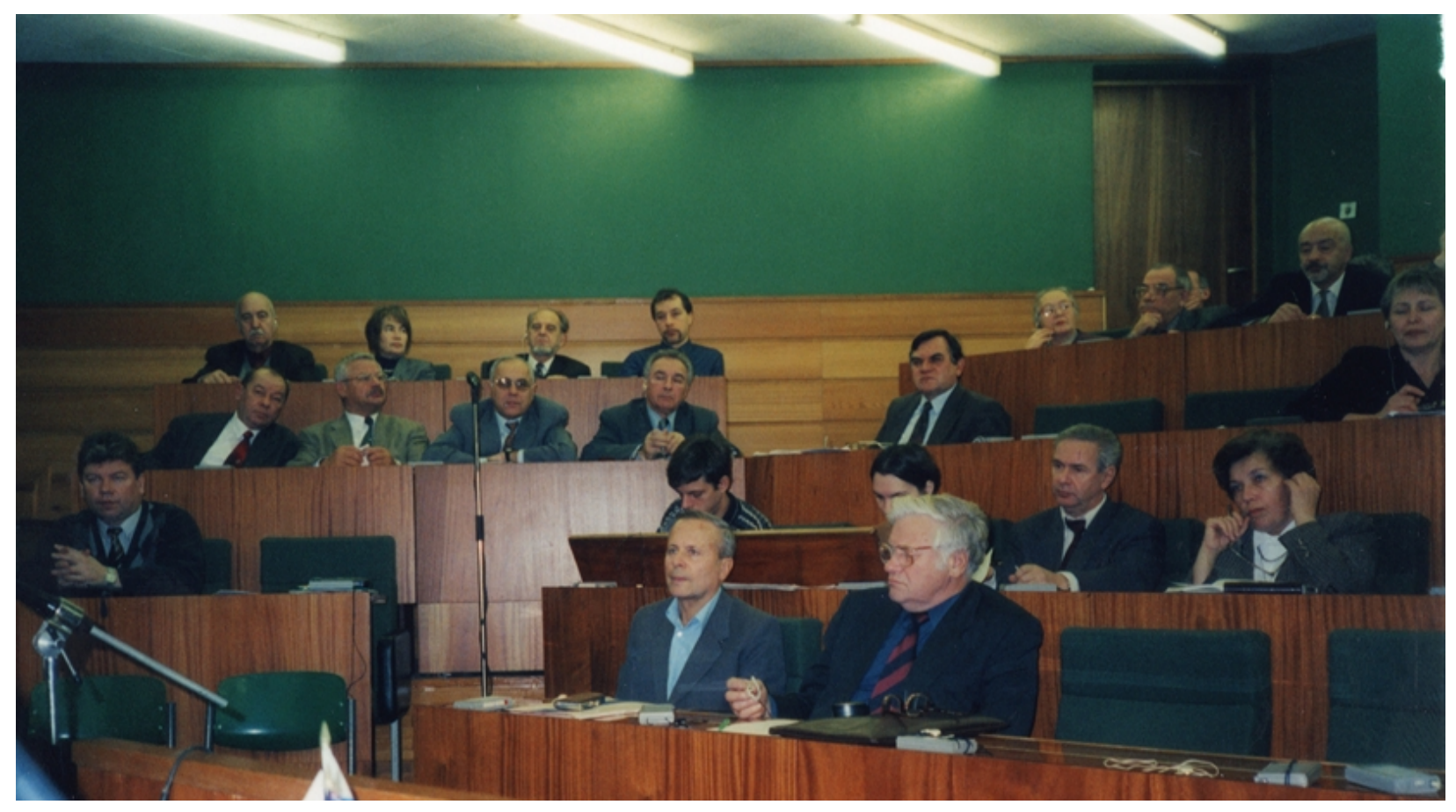

[Front, left to right] Vitaly Il'yashenko, VNIINM; Leonard Lazarev, KRI; [2nd row] Alexander Nazakov, Vladimir Gupalo, VNIINM;Tatyana Borisova, VNIPIPT; Valery Beygul, VNIPIPT; Elena Zakharova, RASIPC; [3rd row] Yuri Glagolenko, Sergey Rovny, Mayak; Albert Aloy, KRI; (unidentified); Vladimir Legin, KRI; Ludmila Petrova, Minatom; [Back row] (unidentified); Ludmila Zarizyna, KRI; Oleg Alexeyev, VNIINM; Boris Burakov, Elena llyenko, Sergey Bartenev, KRI; V. I. Golentson, GSPI.

\section{Closing Session}





\section{Future Direction for Russian Plutonium Immobilization}

\section{Jardine, LLNL; G. Borisov, VNINM}

\section{Topics for Development}

Based on the meetings and discussions, the following were identified as major topics requiring further development. They are recorded as presented in the summgary and discussion session of November 4 , 1999, without additional editing comments in this report.

\section{RIAR}

- The planned radiation damage experiments of the US ceramic composition are well along. It is recommended that RIAR's capabilities to fabricate other ceramics and glasses with $\mathrm{Pu}^{238}$ and $\mathrm{Cm}^{244}$ be noted for future work.

- The metal-to-oxide conversion process and the waste streams will be defined in the new engineering feasibility study, B506204. When completed, this will allow the RIAR needs for immobilization to be better defined and pursued.

- In their studies of immobilizing wastes from the metal-to-oxide conversion process, RIAR recognized the gap and need for defining the storage and disposal site conditions, but perhaps more important, they noted the transportation issues that are not currently being assessed. These gaps should be addressed.

- It is proposed to construct a database containing the specific amounts of plutonium and HEU in research and test reactor fuel elements and targets existing in Russia. These fissile materials are scattered in Russia at a large number of sites that may not be properly protected. The small inventories with specific complications towards using existing reprocessing head-end equipment makes reprocessing unattractive and immobilization for disposal attractive. An engineering feasibility study of how to immobilize the tens of kilograms of $\mathrm{Pu}^{239}$ and hundreds of kilograms of HEU is needed, including an inventory of such sources.

\section{VNIINM}

- VNIINM proposed to expand the types of measurements of radiation damage on plutonium-containing ceramics and glasses using accelerators and other nonradioactive methods.

- VNIINM commented that the study of boron basalt glasses for the CMP at Mayak is a breakthrough due to the first-of-a-kind study and the type of glass composition being pursued.

- VNIINM commented on the importance of the integrated immobilization of solid forms plus geologic disposal condition tests proposed in Moscow on October 25 by VNIPIPT, VNIINM, KRI and the RASICP.

- The proposed study of C-70's survey and inventory of plutonium sources on their site and then assessing immobilization options is another breakthrough. An earlier study by VNIPIET was done for 


\section{Future Direction for Russian Plutonium Immobilization}

$\mathrm{C}-70$ to cement wastes but this in not acceptable. The wastes containing $\mathrm{Pu}^{239}$ in materials, such as $\mathrm{Pu}^{239}$-Be sources and $\mathrm{Pu}^{239}$ smoke detectors, are examples where attention is needed at C-70.

- VNIINM is eager to use its MOX facility and equipment in Moscow to make plutonium ceramics of all kinds. They propose to study ways to improve the US ceramic towards recoverability and to scale-up the small size $\mathrm{KRI}$ ceramic work with $\mathrm{ZrO}_{2}$ and $\mathrm{ZrSiO}_{4}$ using plutonium.

\section{KRI}

- KRI proposed their Pu glass samples that were made and characterized under previous contracts be used for storage and geologic disposal tests. It was further suggested the RAS-ISP be made a center so that RAS people could have access to samples with actual plutonium.

- $\quad \mathrm{KRI}$ suggested the notion of setting up a pilot industrial scale test facility at K-26. The idea would be to test and set up Russian technologies for the West to observe, and perhaps, adopt if interested.

- $\mathrm{KRI}$ is developing a calcium aluminium silicate glass that they believe might be used for MOX plutonium-containing waste and residues.

- $\mathrm{KRI}$ is developing a granite perovskite ceramic obtained with melting that they think may be useful for Russia plutonium-containing wastes. They are also pursuing ISTC projects to fund this work.

- $\quad \mathrm{KRI}$ made a comment that a $\mathrm{PuZrO}_{2}$ fuel would be a good thing to pursue and proposed sending such pellets to RIAR for testing and then to send the irradiated pellets back to KRI for characterization.

\section{VNIPIPT}

- VNIPIPT summarized the proposed integrated geologic disposal-storage and plutonium waste form testing discussed at VNIPIPT on October 25, 1999.

\section{VNIITF}

- The site wants to proceed with inventorying and studying the immobilization of some plutonium wastes rather than recovering them. The comment was made that if wastes were cemented, this would require 20 rail cars of cement [Note: too much volume]. The Pu materials could be stored in a more secure way, from a sense of safety, also.

\section{Other St. Petersburg Comments}

In addition to the remarks summarized above, the following comments were gathered from several side meetings held during the St. Petersburg meeting.

- Mayak: Agreements were reached on the SOW specific assignments for GSPI and VNIPIET, proposed after the October 26 meeting. This gives VNIPIET the proposed overall lead for comparing the three Mayak options for the technical and economic feasibility study.

- A possible visit to Tomsk was discussed in order to clarify sources of weapons plutonium-containing materials at their site that could be immobilized.

- The University representative from Nyzhny Novgorod prepared a summary of the meeting by collecting inputs from participants. The summary will be put in the Journal Radiochemistry, of which she is an editor. A draft of the summary is in Appendix D of this document. 


\section{Closing Session}

- The Minatom representative stated that any new plutonium process in Russia will have to have a sound immobilization process of wastes for the safety arguments with the public and local authorities or nothing would proceed. Minatom also commented that they did not know how relatively advanced the Russian immobilization studies were compared to the current joint MOX and conversion studies until this meeting. Minatom was particularly surprised by the extensive progress made by K-26.

- The K-26 representatives proposed a meeting December 20-21 in St. Petersburg to discuss the Declaration of Intent (DOI) and the Investment Justification (IJ). The DOI is proceeding and should be finished by then. A meeting at K-26 in late January is proposed to discuss the next phase of the IJ. 
Future Direction for Russian Plutonium Immobilization 


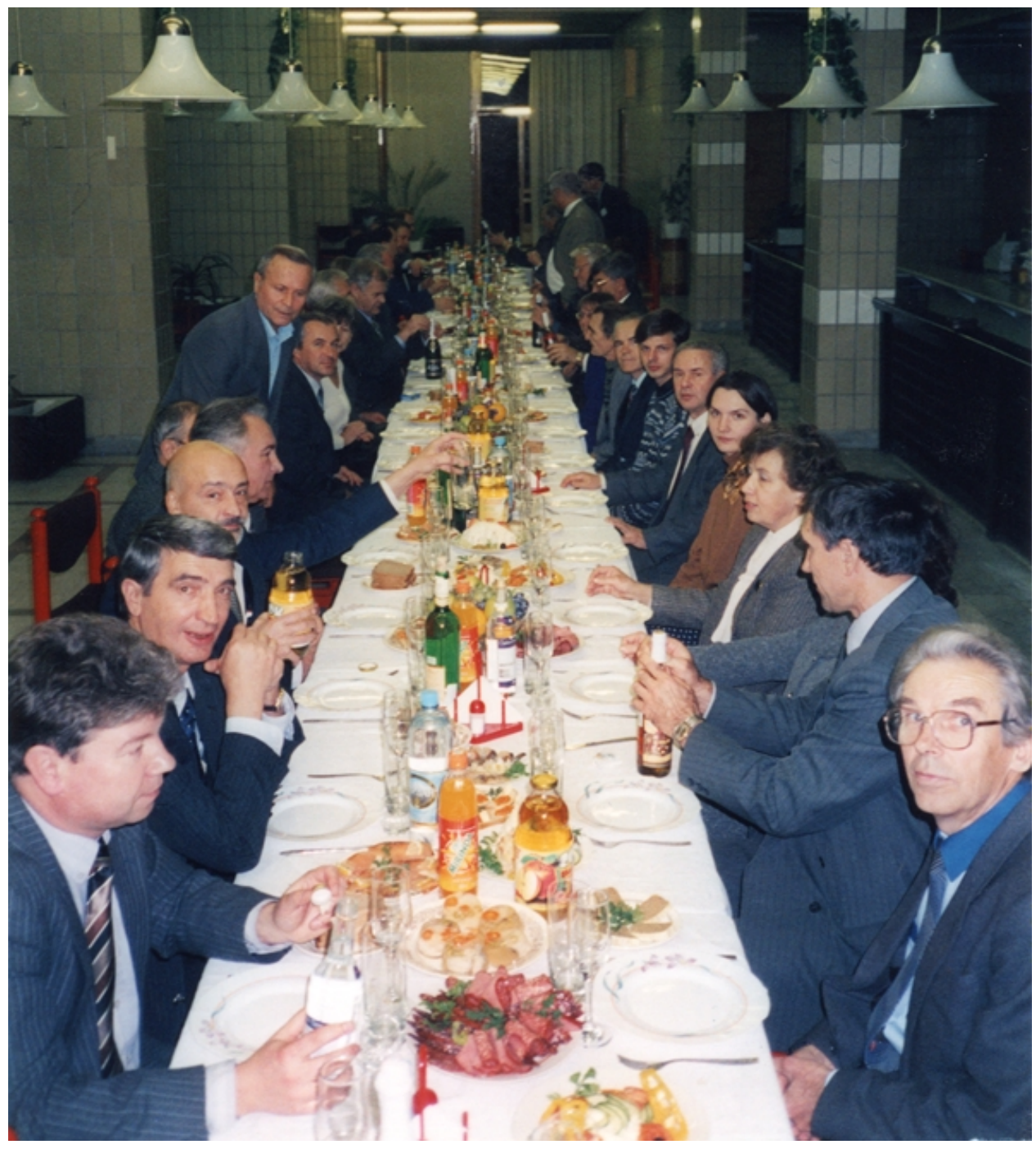

Meeting participants at evening banquet.

\section{Meeting Summary}





\section{Meeting Overview Report-Accomplishments and Conclusions}

\section{Jardine, LLNL}

\section{Introduction}

Forty-four experts from 15 Russian organizations took part in the meeting. They represented the following Russian scientific research institute centers, planning and design institutes, universities and various industrial enterprises: A. A. Bochvar All-Russia Scientific Research Institute of Inorganic Materials (VNIINM), a state science center (SSC); the V. G. Khlopin Radium Institute (KRI), a scientific production association (SPA); the Scientific Research Institute of Atomic Reactors (RIAR), a SSC; VNIPIPT AllRussian Research and Design Institute of Production Engineering (VNIPIPT); the All-Russia Scientific Research Institute of Theoretical Physics (VNIITF, Sneshinsk); the Institute of Physical Chemistry of the Russian Academy of Sciences (RAS); the Institute of Ore-Deposit Geology, Petrography, Mineralogy, and Geochemistry of the RAS (IGEM); the Nizhnii Novogorod N. I. Lobachevskii State University; All-Russian Design and Research Institute of Complex Power Technology (VNIPIET); the Scientific Research and Design Institute of Installation Technology (NIKIMT); the State Union Design Institute (GSPI); and the industrial sites of Mayak Production Association; the Mining and Chemical Combine at Krasonayarsk-26 (K-26); and the Tomsk Siberian Chemical Combine. Most of those participating in the meeting were contractors under these contracts. Representatives of the US Department of Energy and the Russian Federation Ministry of Atomic Energy (Minatom) also took part in the meeting.

The meeting agenda is presented in Appendix A. Attendees are listed in Appendix B. The papers, with titles and authors as originally planned, are listed in Appendix $C$. A summary of participant contributions to the meeting collected by Professor Orlova is presented as Appendix D.

\section{Selected Remarks}

"The objective is to develop in these Russian projects the engineering and technical bases as well as the Russian approvals needed to conduct industrial scale immobilization of plutonium-containing materials at a Russian industrial site by 2005 . Supporting R\&D projects are carried out at the Russian Institutes that directly support the specific technical needs of the Russian industrial sites to immobilize plutoniumcontaining materials."

"Special R\&D on plutonium-containing materials is also carried out to support excess weapons disposition in both Russia and the US. This currently includes nonproliferation studies of plutonium recovery from immobilization forms and accelerated radiation damage studies of the US specified plutonium ceramic for immobilizing plutonium."

L. Jardine 


\section{Questions}

John F. Baker, US Department of Energy, provided a response to the following questions:

What is the main thing for your country [is seeking] from the activity of LLNL and Russian Organizations and from American financial support of Russia on the Pu-problem?

These activities contribute to the US-Russian process of irreversible nuclear arms reductions as well as to both countries' nonproliferation objectives. Plutonium immobilization provides technical options other than burning MOX fuel in nuclear reactors as a means to disposition excess weapons plutonium.

What was the direct Program goal that was solved during the Meeting?

The St. Petersburg Meeting brought Russian plutonium experts together, in many cases for the first time, from 15 different organizations from within Russia to discuss, exchange, and integrate their plutonium technical work results and future plans. These interactions will provide a sound foundation for defining the future technical activities for both the Russian participants and the US.

What new successes would the American side await from Russian -American collaboration in the future?

The joint goal of the Russian work is to establish a full-scale plutonium immobilization facility at a Russian industrial site by 2005. This work of the meeting and future work will provide the bases for joint decisions and determine if such a goal can be achieved.

\section{Summary of Scientific Accomplishments}

The reports of LLNL contract work presented at the meeting fall into two groups as documented in the published strategy and approach: Group 1, R\&D on plutonium immobilization and Group 2, the engineering technology and industrial scale immobilization of plutonium (an overview of contracts). Both groups are also united by the common goal of nonproliferation of fissile materials, nuclear materials security, and the solution of the radioecological problems of Russia, and the world as a whole.

The scientific principles of the incorporation of Pu-containing materials and waste in glass and ceramic matrices were discussed in the meeting.

In its reports, the Radium Institute presented the results of R\&D on the development and synthesis of plutonium-containing phosphate and borosilicate glasses. They also reported work on the gathering and generation of raw data for conducting engineering feasibility studies of the immobilization of plutoniumcontaining sludges of the Mining and Chemical Combine (K-26) and the Mayak Production Association. A strategic approach to the immobilization of plutonium-containing sludges of the Mayak Production Association was presented. The results of research on the solubility of plutonium in different kinds of glass, their resistance to leaching, and the sedimentation of plutonium from glass melts during prolonged holding production runs were summarized. The approach to the engineering aspects of vitrification is based on the production of borosilicate glass compounds incorporating up to $50 \%$ of the mass of the plutonium sludge waste components while microwave heating is performed. A glass melter pilot plant is housed in the hot cell of the Central Plant Laboratory of the Mining and Chemical Combine (K-26).

At the A. A. Bochvar All-Russia Scientific Research Institute of Inorganic Materials, a range of work related to the immobilization of plutonium-containing materials is now under way. It involves the development of glass-like and mineral-like matrices incorporating up to $10 \mathrm{wt} \%$ plutonium (phosphate and 


\section{Meeting Summary}

borosilicate glasses; compounds based on pyroxenes, borobasalts, and garnets), and the study of their basic physical and chemical properties, including determination of the homogeneity, chemical resistance, and leachability of the materials produced. Various process flow diagrams for handling plutoniumcontaining materials by using modern science-intensive methods of solidification, such as induction melting in a cold crucible and vitrification by microwave heating, were presented. These are being developed and studied both independently and jointly with other scientific organizations such as NIKIMT, the Radium Institute, and others. Within the framework of this research, engineering feasibility studies are being carried out to determine approaches and to select the most nearly optimal processing methods to build pilot and industrial scale plants for handling plutonium-containing wastes, residues, and sludge from past military activities at the Ministry of Atomic Energy industrial sites (i.e., the Mining and Chemical Combine, the Siberian Chemical Complex, the Mayak Production Association, the All-Russia Scientific Research Institute of Theoretical and Experimental Physics, and the Scientific Research Institute of Atomic Reactors). Alternatives are being determined and a number of studies are currently under way to solve the problem of handling and immobilizing plutonium-containing wastes from future activities related to the conversion of metallic plutonium and the production of mixed-oxide fuel (MOX) in Russia. Furthermore, preliminary research aimed at studying the behavior of immobilized forms under simulated conditions of temporary storage and geological disposal is under way.

At the Radium Institute research has been conducted on adapting existing experience in ceramic synthesis by using plutonium and, in some cases, simulant elements (e.g., Ce, Eu) for experiments to immobilize plutonium and americium. The optimal compositions and conditions of synthesis of Pucontaining ceramics based on zirconium dioxide, zirconium/zirconium dioxide, and pyrochlore have been determined. It was shown that all the ceramics synthesized had high resistance to plutonium leaching. Data have been obtained on the isomorphic capacity of the ceramic matrices.

There were discussions by IGEM of various kinds of crystalline materials based on zirconates, titanates, aluminates, phosphates, and silicates, including analogs of natural minerals. They were discussed as possible matrices for incorporation of actinide-containing waste as were various methods of synthesizing them-fusion methods, crystallization, solid-phase reactions, heating and pressing (molding) conditions, and the composition of the gas atmosphere. Comparisons were made of the leaching characteristics of plutonium, americium, and other radioactive and non-radioactive elements under hydrothermal conditions (the Institute of Ore-Deposit Geology, Petrography, Mineralogy, and Geochemistry of the RAS).

The properties of a ceramic developed at LLNL were investigated by three Russian organizations: KRI, VNIINM, and RIAR. This oxide ceramic based on the structure of the mineral pyrochlore has been made the baseline composition for the US concept of immobilization of excess-plutonium. The basic results of the synthesis and crystal-chemical analysis of various ceramic samples containing cerium, uranium, and plutonium-239 were presented. New data have been obtained on the specifics of phase formation as a function of the composition and conditions of synthesis of ceramics. Research is now being conducted on accelerated radiation damage using $\mathrm{Pu}^{238}$ due to alpha decay and on the effect of such damage on the properties of ceramics when immobilized plutonium containing waste is buried (the Scientific Research Institute of Atomic Reactors, a Russian Federation SSC, KRI and VNIINM.

The conditions for producing a ceramic containing $\mathrm{Pu}^{238}$ and the conditions for joint accelerated tests of the radiation resistance of the ceramic from LLNL (the Russian Federation Scientific Research Institute of the radiation resistance of the LLNL ceramic by Atomic Reactors, a SSC; the All-Russia Scientific Research Institute of Inorganic Materials, a SSC; and the Radium Institute, have been drawn up and approved by LLNL experts. 


\section{Meeting Overview Report-Accomplishments and Conclusions}

The plutonium-containing waste formed at the Scientific Research Institute of Atomic Reactors during the development and experimental adoption of the pyrochemical process of MOX fuel production has been characterized and classified. Schemes and processes have been proposed for processing these plutonium residues into either reactor fuel and into immobilized forms. This includes work at RIAR related to similar forthcoming tasks in the development of corresponding schemes to process of the first arriving shipments of "weapons-grade" plutonium metal that is converted to oxide using molten salt processes (the Scientific Research Institute of Atomic Reactors, a Russian Federation SSC).

The results of laboratory research on physical and chemical processes of the interaction of plutonium solutions with gneiss-type rocks and materials from the breakdown of engineering barriers of geologic repositories at high temperatures and various pressures (up to $30 \mathrm{MPa}$ ) were scrutinized in relation to the problem of the geological burial of immobilized plutonium forms. This research simulates, in an accelerated environment, the actual process of the slow breakdown, by ground water, of the elements of the multibarrier system of the geologic repository for immobilized plutonium-containing wastes and the confinement of most of the plutonium leached from the matrices to the neighboring rock zones of the underground repository. Experiments showed that the increase in pressure associated with depth reduces the strength with which the plutonium is bound to the rocks. In addition, the first results were presented from laboratory research on the physical and chemical characteristics of actual plutoniumcontaining samples of phosphate and borosilicate glasses, produced by plutonium sludge wastes from weapons-grade plutonium production (the All-Russia Scientific Research Institute of Industrial Technology, the Institute of Physical Chemistry of the Russian Academy of Sciences, and the Mining and Chemical Combine).

Technical and economic feasibility studies have been made of several scenarios at K-26 for the immobilization of plutonium-containing sludges: waste solidification with and without plutonium extraction, with incorporation in matrices of borosilicate or phosphate glass. An underground pilot plant for plutonium-containing wastes and fission product solidification using microwave energy has been installed in the hot cell of the Central Plant Laboratory of the Mining and Chemical Combine. The plant has undergone radioactive materials testing. Prototypes of the glasses have been produced, with incorporation of simulated and real production waste recovered from storage tanks. The engineering parameters of the solidification process have been determined. Studies have been made of the chemical stability and industrial strength of the glass product and the leachability of certain radionuclides from it (the Mining and Chemical Combine). The microwave melting system was developed and shipped for waste solidification at the industrial site of the Mining and Chemical Combine by NIKIMT.

Thin-film inorganic sorbents based on zeolites and hard-to-dissolve inorganic compounds that are selective for cesium, strontium, and uranium and that have high capacity as well as thermal, chemical, and radiation resistance have undergone testing at the Central Plant Laboratory of the Mayak Production Association. These heat-treated sorption products are said to be suitable for safe long-term storage (the All-Russia Scientific Research Institute of Theoretical Physics, the Ural'sk State Technical University-Ural'sk Polytechnic Institute). A method of removing cobalt and uranium from liquid radioactive wastes and natural waters using special brands of asbestos has also been developed. The method has been tested at the Central Plant Laboratory of the Mayak Production Association. A simple and economical method has been developed for removal of uranium from radioactive contaminated lubricants and cooling fluids, using demulsifiers and decontaminants (the All-Russia Scientific Research Institute of Theoretical Physics). 


\section{Meeting Summary}

Research has been conducted on the separation and recovery of plutonium from the glass and ceramic immobilization forms of Pu-containing glass and ceramics from the standpoint of nuclear-weapons nonproliferation (the Radium Institute; the All-Russia Scientific Research Institute of Inorganic materials, a RF SSC).

The results were presented from the cooperation between Russian Federation state science centers and LLNL on the purchase by the US party of a device developed at the Scientific Research Institute of Atomic Reactors, a RF SSC, for washing residual chloride salts from $\mathrm{PuO}_{2}$ precipitates so that plutonium oxide can be used directly in the US excess fissile-materials immobilization program processes.

There were discussions of proposals on future contracts between LLNL and Russian organizations in the area of plutonium immobilization in Russia. These included contracts related to work on the technology and industrial scale immobilization of plutonium at K-26 and Mayak, as well as R\&D on plutonium immobilization in glass and ceramics and on burial in geological formations of immobilized solid forms.

There also were discussions of questions and proposals for the creation of a unified Russian center for the investigation of the chemical and radiation stabilities of a glass that contains radioactive waste; questions of americium immobilization from future plutonium conversion activities; changes in the properties of immobilized materials during long-term storage and geologic disposal; and expansion of work at industrial sites (the behavior of waste under burial conditions - the Mayak Production Association and the Mining and Chemical Combine) as being key issues en route to success in solving the environmental plutonium problems and the disposition of excess weapons plutonium.

\section{Conclusions}

In summary, this was an excellent meeting. The first objective-to bring the Russian organizations, experts, and managers together to review and discuss their work with each other-was achieved. It was remarkable to have 15 different Russian organizations attend a single meeting on Russian plutonium immobilization at a single place.

The papers have now been collected, and once a proceedings is prepared by LLNL, the second objective -to publish a meeting summary and proceedings—will also have been met. These proceedings will document the wide extent of the Russian plutonium immobilization activities, provide a reference for the work, and make it available to others. The reports of technical work with actual plutonium materials collected here make this the most comprehensive document ever assembled of technical engineering and R\&D details of weapons plutonium immobilization in Russia, and perhaps in the world. It is both a pleasure and a privilege to have the opportunity to work with such world-class experts in plutonium technologies. 
Meeting Overview Report-Accomplishments and Conclusions 
VI. Appendices 



\title{
Appendix A. Agenda
}

\author{
Review of LLNL Contract Work for Immobilization \\ of Excess Weapons Plutonium in Russia \\ State Regional Education Center (SEC) \\ Aerodromnaya 4 \\ 197348 St. Petersburg, Russia
}

November 1-4, 1999

\section{Opening Session}

1. Introductions and Objectives. L. Jardine - LLNL

2. Russian Plutonium Immobilization Strategy and Framework G. Borisov - VNIINM

3. Overview of the Russian Plutonium Immobilization Contracts L. Jardine - LLNL

II. Engineering and Industrial Site Plutonium Immobilization Contract ActivitiesTechnical and Economic Engineering Feasibility Study of Weapons Plutonium Sludge Immobilization at the K-26 Site

1.1 Overview of the K-26 Study (B347376). K. Kudinov - MCC-K-26

1.2 Engineering Results and Summary of K-26 Study (B347376) A. Shvedov - VNIPIET

1.3 Economic Comparisons of Pu Immobilization and Pu Recovery (B347376) N. Shafrova - VNIPIET

1.4 The Next Engineering Phase: Declaration of Intent (B506210).... A. Shvedov - VNIPIET

\section{Engineering Tests and Demonstrations at the K-26 Site}

2.1 The K-26 Underground Hot Cell Microwave Melting Facility Tests for Immobilization of Pu (B347376).

A. Tretyakov - MCC-K-26

2.2 Development of Borosilicate Glass for Pu Microwave Melting

Technology (B347376) A. Aloy - KRI

2.3 Development of Phosphate Glass for Pu Microwave Melting Technology (B347376) G. Borisov - VNIINM

2.4 Microwave Melting System Development (B500995) M. Molokhov - NIKIMT

\section{Sludge Immobilization at the Mayak Site}

3.1 Overview and Approach for the Mayak study (B506201). S. Rovny - Mayak

3.2 The Technical and Economic Feasibility Study (B506208).... A. Shvedov - VNIPIET 


\section{Appendix A. Agenda}

3.3 The VNIINM Approach for Developing Immobilization Technology for

Plutonium Sludges (B506206)

T. Smelova - VNIINM

3.4 The KRI Approach for Developing Immobilization Technology for

Plutonium Sludges (B506209).

A. Aloy - KRI

3.5 The Planned Mayak Engineering Feasibility Study for Immobilizing Future MOX Plutonium Residues and Wastes

S. Rovny - Mayak

\section{Technical and Economic Engineering Feasibility Study for Immobilizing Plutonium Containing Pyrochemical Salts at the RIAR Site (B506204) A. Bychkov - RIAR}

III. Research and Development (R\&D) Plutonium Immobilization Activities

1. Plutonium Glasses for Immobilization

1.1 Summary of the UTA Contract Glass Work (UTA-330 Mod1) ................................ Matyunin - VNIINM

1.2 Summary Pu Glasses Developed for the Mayak Site (B501119) ........................ Y. Matyunin - VNIINM

1.3 Summary of Pu Glasses Developed for Pu Immobilization (B338247)................................ A. Aloy - KRI

1.4 Summary of Pu Glasses Developed for the K-26 Site (B501118) ...................................... Aloy - KRI

\section{Plutonium Ceramics for Immobilization}

2.1 Summary of Pu Ceramics Developed for Pu immobilization (B338247) .......................... Burakov - KRI

2.2 Summary of Pu Ceramics Developed for Pu immobilization (B501118)

B. Burakov - KRI

2.3 Summary of Supporting VNIINM Pu Immoblization Activities (B338243).....

G. Borisov - VNIINM

2.4. Summary of Pu Ceramic Fabrication with MOX Fabrication

Equipment and Methods (B503009)

G. Borisov - VNIINM

\section{Geologic Disposal for Plutonium Immoblization}

3.1 Summary of Pu Sorption-desorption Processes in Rock \& Materials of Destruction of Engineered Barriers, under Normal \& Higher Pressures \& Higher Temperature

(UTA-331, B338273) T. Gupalo - VNIPIPT

3.2 Summary of Mechanical \& Chemical Stability of Phosphate \&

Boron-silicate Glass at K-26 (B501120)

V. Beygul - VNIPIPT

3.3 Results of Laboratory-scale Tests on Pu Sorption-desorption

in Rock, for Contracts with VNIPIPT (UTA-331,B338272, B501120)

E. Zakharova - RAS

3.4 Ecological Safety Evaluation in Terms of Temporary

Underground Storage \& Disposal of Vitrified Pulp from Production

of Weapon $\mathrm{Pu}$ in K-26

T. Gupalo - VNIPIPT

\section{Accelerated Radiation Damage Studies of the US Pu Ceramic Formulation}

4.1 RIAR Studies of the US Pu Ceramics (B501111) Y. Volkov - RIAR 


\section{Non Proliferation Studies of Pu Recovery from Pu Glass and Pu Ceramic Immobilization Forms}

5.1 The KRI Pu Recovery Studies (B344864). L. Lazarev - KRI

5.2 The VNIINM Pu Recovery Studies (B344863) V. Ilyashenko - VNIINM

\section{Other LLNL Russian Contracts}

6.1 Purchase of RIAR $\mathrm{PuO}_{2}$ Salt Washer for US Domestic Immobilization Program Testing (B506207) A. Bychkov - RIAR

6.2 Russian -US Pu Experts Workshop Support (B338290) M. Moshkov - KRI

6.3 Immobilizing Matrices for Radionuclides: Status and Perspectives.

S. Yudintsev - IGEM

\section{Discussion of Future Direction for Russian Pu Immobilzation Engineering and Industrial Site Plutonium Immobilization Activities G. Borisov - VNIINM, L.Jardine - LLNL}

1.1 The K-26 Site Investment Justification for Pu Sludge Immobilization Feasibility study and ecological research of long-term storage of immobilized pulps in MCC underground facilities and their final disposal in deep geological formations. ..T. Gupalo - VNIINM

1.2 The Mayak Site: (a) Pu Immobilization Options and (b) The planned technical basis on disposal of a Pu pulp and future MOX-Pu remnants immobilized into glass and ceramics, for geological conditions of PO-Mayak site T. Gupalo - VNIINM

1.3 The RIAR Site.

1.4 Other Sites: Tomsk, C-70

Research and Development (R\&D) Plutonium Immobilization Activities

Plutonium Glasses for Immobilization

Plutonium Ceramics for Immobilization

Geologic Disposal for Plutonium Immobilization

V. Summary, Future Direction and Wrap-up .L. Jardine - LLNL, G. Borisov - VNIINM 
Appendix A. Agenda 


\section{Appendix B. Attendees}

U.S. and Russian Attendees, Russian Project Review Meeting, State Regional Education Center (SEC), St. Petersburg, Russia, November 1-4, 1999.

\begin{tabular}{|c|c|c|}
\hline Name & $\begin{array}{c}\text { Dates of Stay in } \\
\text { St.Petersburg (1999) }\end{array}$ & Institution \\
\hline John F. Baker & & DOE, USA \\
\hline Sheldon J. Cullison & & DOE, USA \\
\hline Leslie J. Jardine & & LLNL, USA \\
\hline L'udmila I. Petrova & $11 / 1-4$ & Minatom, Moscow \\
\hline Valery P. Beygul & $10 / 31-11 / 4$ & VNIPIPT, Moscow \\
\hline Vladimir S. Gupalo & $11 / 1-4$ & VNIPIPT, Moscow \\
\hline Tatyana A. Borisova & $11 / 1-4$ & VNIPIPT, Moscow \\
\hline Elena V. Zakharova & $11 / 1-4$ & RAS, Moscow \\
\hline Alexander A. Tretyakov & $10 / 31-11 / 4$ & K-26, Krasnoyarsk \\
\hline Lyudmila F. Manakova & $10 / 31-11 / 4$ & K-26, Krasnoyarsk \\
\hline Alexandre V. Bychkov & $10 / 31-11 / 3$ & RIAR, Samara \\
\hline A. N. Lukinykh & $10 / 31-11 / 5$ & RIAR, Samara \\
\hline Yury F. Volkov & $10 / 31-11 / 5$ & RIAR, Samara \\
\hline Leonid G. Babikov & $10 / 31-11 / 5$ & RIAR, Samara \\
\hline Albina I. Orlova & $10 / 31-11 / 4$ & State University, Nyzhny Novgorod \\
\hline Georg B. Borisov & $11 / 1-4$ & VNIINM, Moscow \\
\hline Alexander V. Nazarov & $11 / 1-4$ & VNIINM, Moscow \\
\hline Oleg A. Alexeyev & $11 / 1-4$ & VNIINM, Moscow \\
\hline Vitaly S. Ilyashenko & $11 / 1-4$ & VNIINM, Moscow \\
\hline Yuri I. Matyunin & $11 / 1-4$ & VNIINM, Moscow \\
\hline Mikhail N. Molokhov & $11 / 1-4$ & NIKIMT, Moscow \\
\hline Sergey V. Yudintsev & $11 / 1-4$ & IGEM, Moscow \\
\hline V. I. Golentson & $11 / 1-4$ & GSPI, Moscow \\
\hline Yuri V. Glagolenko & $11 / 1-5$ & "Mayak", Chelyabinsk \\
\hline Sergey I. Rovny & $11 / 1-5$ & "Mayak", Chelyabinsk \\
\hline Alexander G. Tsvetokhin & $10 / 31-11 / 5$ & VNIITF, Snezhinsk \\
\hline Vladislav M. Tavrin & $11 / 1-4$ & SChC, Tomsk \\
\hline Alexander A. Shvedov & & VNIPIET, St. Petersburg \\
\hline Valeriy T. Sorokin & & VNIPIET, St. Petersburg \\
\hline Valery N. Romanovskiy & & KRI, St. Petersburg \\
\hline Leonard N. Lazarev & & KRI, St. Petersburg \\
\hline Albert S. Aloy & & KRI, St. Petersburg \\
\hline Rem. I. Lubtsev & & KRI, St. Petersburg \\
\hline Mikhail M. Moshkov & & KRI, St. Petersburg \\
\hline Boris E. Burakov & & KRI, St. Petersburg \\
\hline Sergey A. Bartenev & & KRI, St. Petersburg \\
\hline Igor V. Smirnov & & KRI, St. Petersburg \\
\hline Vadim A. Startchenko & & KRI, St. Petersburg \\
\hline Vladimir F. Saprykin & & KRI, St. Petersburg \\
\hline Vladimir P. Popik & & KRI, St. Petersburg \\
\hline
\end{tabular}




\section{Appendix B. Attendees}

\begin{tabular}{|l|l|l|}
\hline Vladimir K. Legin & & KRI, St. Petersburg \\
\hline Elena I. Il'enko & & KRI, St. Petersburg \\
\hline Vladimir B. Kolokol'tsov & & KRI, St. Petersburg \\
\hline Lyudmila G. Tsarizyna & & KRI, St. Petersburg \\
\hline Ol'ga A. Iskhakova & & KRI, St. Petersburg \\
\hline Alexander V. Trofimenko & & KRI, St. Petersburg \\
\hline Stanislas Kuld & & Interpreter, St. Petersburg \\
\hline Elena Malofeeva & & Interpreter, Moscow \\
\hline
\end{tabular}




\section{Appendix C. Planned Papers}

1. Overview of the Russian Plutonium Immobilization Contracts ....................................... Jardine, LLNL

1. Russian Plutonium Immobilization Strategy and Framework G. Borisov, VNIINM

1. Development of Phosphate Glass for Pu Microwave Melting Technology (B347376)

G. Borisov, VNIINM

1. Summary of Supporting VNIINM Pu Immoblization Activities (B338243)

G. Borisov, VNIINM

1. Summary of Pu Ceramic Fabrication with MOX Fabrication Equipment and Methods (B503009) G. Borisov, VNIINM

1. The VNIINM Approach for Developing Immobilization Technology for Plutonium Sludges (B506206). T. Smelova, VNIINM

1. Summary of the UTA Contract Glass Work (UTA-330 Mod1) Y. Matyunin, VNIINM

1. Summary Pu Glasses Developed for the Mayak Site (B501119). Y. Matyunin, VNIINM

1. VNIINM Studies of the US Pu Ceramics (B506205) O. Alekseyev, VNIINM

1. The VNIINM Pu Recovery Studies (B344863) V. Ilyashenko, VNIINM

1. Summary of Pu Sorption-desorption Processes in Rock \& Materials of Destruction of Engineered Barriers, under Normal and Higher Pressures \& Higher Temperature (UTA-331, B338273) T. Gupalo, VNIPIPT

1. Ecological Safety Evaluation in Terms of Temporary Underground Storage and Disposal of Vitrified Pulp from Production of Weapon Pu in K-26. T. Gupalo, VNIPIPT

1. Summary of Mechanical \& Chemical Stability of Phosphate \& Boron-silicate Glass at K-26 (B501120) ..V. Beygul, VNIPIPT

1. Results of Laboratory-scale Tests on Pu Sorption-desorption in Rock, for Contracts with VNIPIPT (UTA-331, B338272, B501120). E. Zakharova, RAS

1. Microwave Melting System Development (B500995) M. Molokhov, NIKIMT

1. Immobilizing Matrices for Radionuclides: Status and Perspectives S. Yudintsev, IGEM

1. Overview of the K-26 Study (B347376) .K. Kudinov, MCC-K-26

1. The K-26 Underground Hot Cell Microwave Melting Facility Tests for Immobilization of Pu (B347376). A. Tretyakov, MCC-K-26

1. Overview and Approach for the Mayak study (B506201) S. Rovny, Mayak

1. The Planned Mayak Engineering Feasibility Study for Immobilizing Future MOX Plutonium Residues and Wastes

S. Rovny, Mayak

1. RIAR Studies of the US Pu Ceramics (B501111) Y. Volkov, RIAR

1. Purchase of RIAR $\mathrm{PuO}_{2}$ Salt Washer for US Domestic Immobilization Program Testing (B506207) A. Bychkov, RIAR 


\section{Appendix C. Planned Papers}

1. Technical and Economic Engineering Feasibility Study for Immobilizing Plutonium-Containing Pyrochemical Salts at the RIAR Site (B506204) A. Bychkov, RIAR

1. Engineering Results and Summary of K-26 Study (B347376) A. Shvedov, VNIPIET

1. The Next Engineering Phase: Declaration of Intent (B506210) A. Shvedov, VNIPIET

1. The Technical and Economic Feasibility Study (B506208) A. Shvedov, VNIPIET

1. Economic Comparisons of Pu Immobilization and Pu Recovery (B347376) N. Shafrova, VNIPIET

1. The KRI Approach for Developing Immobilization Technology for Plutonium Sludges (B506209). A. Aloy, KRI

1. Development of Borosilicate Glass for Pu Microwave Melting Technology (B347376) A. Aloy, KRI

1. Summary of Pu Glasses Developed for Pu Immobilization (B338247) A. Aloy, KRI

1. Summary of Pu Glasses Developed for the K-26 Site (B501118) A. Aloy, KRI

1. Summary of Pu Ceramics Developed for Pu immobilization (B338247) B. Burakov, KRI

1. Summary of Pu Ceramics Developed for Pu immobilization (B501118) B. Burakov, KRI

1. KRI Studies of the US Pu Ceramics (B506203) B. Burakov, KRI

1. The KRI Pu Recovery Studies (B344864) L. Lazarev, KRI 


\section{Appendix D. Participant Contributions to the Meeting}

\section{A. Orlova, State University, Nyzhny Novgorod}

Editor's note: The university representative, Professor Albina Orlova, suggested and then carried out her recommendation to collect inputs from participants and to produce a summary of the meeting. A draft of her Russian text was received, translated, and is presented below. We thank her for her suggestion and for following this task through to completion.

\section{Summary}

From November 1 to November 4, 1999, a Russian-American scientific seminar was held in St. Petersburg to review work under contracts with the US DOE and Lawrence Livermore National Laboratory (LLNL) performed in Russia on the problems of immobilization of excess quantities of weapons-grade plutonium in Russia. The seminar was organized by the American party in conjunction with the V. G. Khlopin Radium Institute, a scientific production association (SPA).

Leslie J. Jardine, Russian Projects Manager, LLNL, commented in the seminar opening on the history of these Russian-American colloraborations. Russian-American activities on the disposition of plutonium from excess weapons were initiated after a September 1993 speech by President Clinton at the United Nations and a following January 1994 Clinton-Yeltsen Summit in Moscow. This Summit led to the creation of joint expert working groups on the topic of disposition of excess weapons plutonium that then performed specific technical activities. The first Russian-American experts' meeting on this topic occurred in January 1995 at Los Alamos National Laboratory. Specific technical activities for six working groups were subsequently defined, carried out and reported at the October 1996 P8 Nuclear Experts meeting in Paris. The original six working groups of plutonium experts were: 1. water reactors. 2. fast reactors, 3. immobilization, 4. geologic disposal, 5. storage, and 6. stabilization.

The working groups continued after the P8 meeting with USDOE funding. In April 1997, the immoblization, stabilization, and geologic disposal working groups were integrated into a single group. The technical efforts in Russia were refocused into the specific needs of the Russian plutonium production industrial sites of Mayak, Krasnoyarsk-26 and Tomsk. A strategy and approach for the working immobilization group was developed, published (UCRL-JC-129790 4/98; UCRL-JC-132920 2/99) and are now being implemented. This meeting summarizes the progress and status of the implementation,

Over the years and to date, over $\$ 2$ million has been committed by the US in funding to various Russian Minatom organizations for related weapons plutonium immobilization and geologic disposal R\&D topics. An additional $\$ 2$ million has been committed todate for engineering technical and economic feasibility studies at Krasnoyarsk-26 and Mayak. An Agreement between the Russian Federation Government and the US Government for Scientific and Technical Cooperation in the Management of Plutonium that has been withdrawn from Nuclear Military Nuclear Programs was signed on July 14, 1998. This agreement authorizes the work. Numerous reports involving plutonium topics have been generated by LLNL contracts with Russian organizations of Minatom.. 


\section{Appendix D. Participant Contributions}

At the present time, 23 contracts devoted to plutonium immobilization have been issued to various Russian organizations. This intriguing and extraordinary cooperation on certain aspects of the weapons plutonium problem is now progressing well and much work with plutonium has been completed. St. Petersburg was selected as the time and the place to discuss and summarize the technical results in order to determine future areas of cooperation on the plutonium-immobilization problem.

Forty-four experts from 15 Russian organizations took part in the seminar. They represented Russian scientific research institute centers, planning and design institutes, universities and various industrial enterprises: the A. A. Bochvar All-Russia Scientific Research Institute of Inorganic Materials (VNIINM), a state science center (SSC); the V. G. Khlopin Radium Institute (KRI), a SPA; the Scientific Research Institute of Atomic Reactors (RIAR), a SSC; VNIPIPT All-Russian Research and Design Institute of Production Engineering (VNIPIPT); the All-Russia Scientific Research Institute of Theoretical Physics; the Institute of Physical Chemistry of the Russian Academy of Sciences (RAS); the Institute of Ore-Deposit Geology, Petrography, Mineralogy, and Geochemistry of the RAS (IGEM); the Nizhnii Novogorod N. I. Lobachevskii State University; All-Russian Design and Research Institute of Complex Power Technology (VNIPIET)1; the Scientific Research and Design Institute of Installation Technology (NIKIMT); the State Union Design Institute (GSPI); the Mayak Production Association and Mining and Chemical Combine (K26); and the Tomsk Siberian Chemical Combine. Most of those participating in the seminar were contractors under these contracts. Representatives of the US Department of Energy and the Russian Federation Ministry of Atomic Energy also took part in the seminar.

The reports of LLNL contract work presented at the seminar fall into two groups as documented in the published strategy and approach: group I - R\&D on plutonium immobilization, and group 2 - the engineering technology and industrial scale immobilization of plutonium (an overview of contracts). Both groups are also united by the common goal of nonproliferation of fissile materials, nuclear materials security, and the solution of the radioecological problems of Russia, and the world as a whole.

The scientific principles of the incorporation of Pu-containing materials and waste in glass and ceramic matrices were discussed in the seminar.

In its reports, the Radium Institute presented the results of R\&D on the development and synthesis of plutonium-containing phosphate and borosilicate glasses and of work on the gathering and generation of raw data for conducting an engineering feasibility studies of the immobilization of plutonium-containing sludges of the Mining and Chemical Combine (K-26) and the Mayak Production Association. A strategic approach to the immobilization of plutonium-containing sludges of the Mayak Production Association was presented. The results of research on the solubility of plutonium in different kinds of glass, their resistance to leaching, and the sedimentation of plutonium from glass melts during prolonged holding production runs were summarized. The approach to the engineering aspects of vitrification is based on the production of borosilicate glass compounds incorporating up to $50 \%$ of the mass of the plutonium sludge waste components while microwave heating is performed. A glass melter pilot plant is housed in the hot cell of the Central Plant Laboratory of the Mining and Chemical Combine (K-26).

At the A. A. Bochvar All-Russia Scientific Research Institute of Inorganic Materials, a range of work related to the immobilization of plutonium-containing materials is now under way. It involves the development of glass-like and mineral-like matrices incorporating up to $10 \mathrm{wt}$ \% plutonium (phosphate and borosilicate glasses; compounds based on pyroxenes, borobasalts, and garnets), and the study of 
their basic physical and chemical properties, including determination of the homogeneity, chemical resistance, and leachability of the materials produced. Various process flow diagrams for the handling of plutonium-containing materials by using modern science-intensive methods of solidification, such as induction melting in a cold crucible and vitrification by microwave heating, are being developed and studied (both independently and jointly with other scientific organizations such as: NIKIMT, the Radium Institute, and others). Within the framework of this research, engineering feasibility studies are being carried out to determine approaches and to select the most nearly optimal processing method in order to build pilot and industrial scale plants for handling plutonium-containing wastes, residues, and sludge from past military activities at the Ministry of Atomic Energy industrial sites (the Mining and Chemical Combine, the Siberian Chemical Complex, the Mayak Production Association, the All-Russia Scientific Research Institute of Theoretical and Experimental Physics, the Scientific Research Institute of Atomic Reactors). Alternatives are being determined and a number of studies are currently under way to solve the problem of handling and immobilizing plutonium-containing wastes from future activities related to the conversion of metallic plutonium and the production of mixed-oxide fuel (MOX) in Russia. Furthermore, preliminary research aimed at studying the behavior of immobilized forms under simulated conditions of temporary storage and geological disposal is under way.

At the Radium Institute, research has been conducted on adapting existing experience in ceramic synthesis by using plutonium , and in some cases simulant elements ( $\mathrm{Ce}$, Eu, etc.), for experiments to immobilize plutonium and americium. The optimal compositions and conditions of synthesis of Pucontaining ceramics based on zirconium dioxide, zirconium/zirconium dioxide, and pyrochlore have been determined. It was shown that all the ceramics synthesized had high resistance to plutonium leaching. Data have been obtained on the isomorphic capacity of the ceramic matrices.

There were discussions by IGEM of various kinds of crystalline materials (based on zirconates, titanates, aluminates, phosphates, and silicates, including analogs of natural minerals) as possible matrices for incorporation of actinide-containing waste, various methods of synthesizing them (including fusion methods - crystallization, solid-phase reactions), heating and pressing (molding) conditions, and the composition of the gas atmosphere. Comparisons were made of the leaching characteristics of plutonium, americium, and other radioactive and nonradioactive elements under hydrothermal conditions (the Institute of Ore-Deposit Geology, Petrography, Mineralogy, and Geochemistry of the RAS).

The properties of a ceramic developed at LLNL were investigated by three Russian organizations, KRI, VNIINM and RIAR. This oxide ceramic based on the structure of the mineral pyrochlore has been made the baseline composition for the US concept of immobilization of excess plutonium. The basic results of the synthesis and crystal-chemical analysis of various ceramic samples containing cerium, uranium, and plutonium-239 were presented. New data have been obtained on the specifics of phase formation as a function of the composition and conditions of synthesis of ceramics. Research is now being conducted on accelerated radiation damage using Pu238 due to alpha decay and on the effect of such damage on the properties of ceramics when immobilized plutonium containing waste is buried (the Scientific Research Institute of Atomic Reactors, a Russian Federation SSC, KRI and VNIINM.

The conditions for producing a ceramic containing plutonium-238 and the conditions for joint accelerated tests of the radiation resistance of the ceramic from LLNL (the Russian Federation Scientific Research Institute of Atomic Reactors, a SSC; the All-Russia Scientific Research Institute of Inorganic Materials, a SSC; and the Radium Institute) have been drawn up and approved by LLNL experts.

The plutonium-containing waste formed at the Scientific Research Institute of Atomic Reactors during the development and experimental adoption of the pyrochemical process of MOX fuel production has been 


\section{Appendix D. Participant Contributions}

characterized and classified. Schemes and processes have been proposed for processing these plutonium residues into either reactor fuel and into immobilized forms. This includes work at RIAR related to similar forthcoming tasks in the development of corresponding schemes to process of the first arriving shipments of "weapons-grade" plutonium metal that is converted to oxide using molten salt processes (the Scientific Research Institute of Atomic Reactors, a Russian Federation SSC).

The results of laboratory research on physical and chemical processes of the interaction of plutonium solutions with gneiss-type rocks and materials from the breakdown of engineering barriers of geologic repositories at high temperatures and various pressures (up to $30 \mathrm{MPa}$ ) were scrutinized in relation to the problem of the geological burial of immobilized plutonium forms. This research simulates, in an accelerated environment, the actual process of the slow breakdown, by ground water, of the elements of the multibarrier system of the geologic repository for immobilized plutonium-containing wastes and the confinement of most of the plutonium leached from the matrices to the neighboring rock zones of the underground repository. Experiments showed that the increase in pressure associated with depth reduces the strength with which the plutonium is bound to the rocks. In addition, the first results were presented from laboratory research on the physical and chemical characteristics of actual plutoniumcontaining samples of phosphate and borosilicate glasses, produced by plutonium sludge wastes from weapons-grade plutonium production (the All-Russia Scientific Research Institute of Industrial Technology, the Institute of Physical Chemistry of the Russian Academy of Sciences, and the Mining and Chemical Combine).

Technical and economic feasibility studies have been made of several scenarios at K-26 for the immobilization of plutonium-containing sludges: waste solidification with and without plutonium extraction, with incorporation in matrices of borosilicate or phosphate glass. An underground pilot plant for plutonium-containing wastes and fission product solidification using microwave energy has been installed in the hot cell of the Central Plant Laboratory of the Mining and Chemical Combine. The plant has undergone radioactive materials testing. Prototypes of the glasses have been produced, with incorporation of simulated and real production waste recovered from storage tanks. The engineering parameters of the solidification process have been determined. Studies have been made of the chemical stability and industrial strength of the glass product and the leachability of certain radionuclides from it (the Mining and Chemical Combine). The microwave melting system was developed and shipped for waste solidification at the industrial site of the Mining and Chemical Combine by NIKIMT.

Thin-film inorganic sorbents based on zeolites and hard-to-dissolve inorganic compounds that are selective for cesium, strontium, and uranium and that have high capacity as well as thermal, chemical, and radiation resistance have undergone testing at the Central Plant Laboratory of the Mayak Production Association. These heat-treated sorption products are said to be suitable for safe long-term storage (the All-Russia Scientific Research Institute of Theoretical Physics, the Ural'sk State Technical University-Ural'sk Polytechnic Institute). A method of removing cobalt and uranium from liquid radioactive wastes and natural waters using special brands of asbestos has also been developed. The method has been tested at the Central Plant Laboratory of the Mayak Production Association. A simple and economical method has been developed for removal of uranium from radioactive contaminated lubricants and cooling fluids, using demulsifiers and decontaminants (the All-Russia Scientific Research Institute of Theoretical Physics).

Research has been conducted on the separation and recovery of plutonium from the glass and ceramic immobilization forms of Pu-containing glass and ceramics from the standpoint of nuclear-weapons 
nonproliferation (the Radium Institute; the All-Russia Scientific Research Institute of Inorganic materials, a RF SSC).

The results were presented from the cooperation between Russian Federation state science centers and LLNL on the purchase by the US party of a device developed at the Scientific Research Institute of Atomic Reactors, a RF SSC, for washing residual chloride salts from $\mathrm{PuO}_{2}$ precipitates so that plutonium oxide can be used directly in the US excess fissile-materials immobilization program processes.

There were discussions of proposals on future contracts between LLNL and Russian organizations in the area of plutonium immobilization in Russia. These included contracts related to work on the technology and industrial scale immobilization of plutonium at K-26 and Mayak, as well as R\&D on plutonium immobilization in glass and ceramics and on burial in geological formations of immobilized solid forms.

There also were discussions of questions and proposals for the creation of a unified Russian center for the investigation of the chemical and radiation stabilities of a glass that contains radioactive waste; questions of americium immobilization from future plutonium conversion activities; changes in the properties of immobilized materials during long-term storage and geologic disposal; and expansion of work at industrial sites (the behavior of waste under burial conditions-the Mayak Production Association and the Mining and Chemical Combine) as being key issues en route to success in solving the environmental plutonium problems and the disposition of excess weapons plutonium.

Leslie Jardine stated :

"The objective is develop in these Russian projects the engineering and technical bases as well as the Russian approvals needed to conduct industrial scale immobilization of plutonium-containing materials at a Russian industrial site by 2005. Supporting R\&D projects are carried out at the Russian Institutes that directly support the specific technical needs of the Russian industrial sites to immobilize plutoniumcontaining materials.

Special R\&D on plutonium-containing materials is also carried out to support excess weapons disposition in both Russia and the US. This currently includes nonproliferation studies of plutonium recovery from immobilization forms and accelerated radiation damage studies of the US specified plutonium ceramic for immobilizing plutonium."

John F. Baker, US Department of Energy, provided a response to questions:

"What is the main thing for your country from the activity of LLNL and Russian Organizations and from American financial support of Russia on the Pu-problem?"

"These activities contribute to the US Russian process of irreversible nuclear arms reductions as well as to both country's non-proliferation objectives. Plutonium immobilization provides technical options other that burning MOX fuel in nuclear reactors as a means to disposition excess weapons plutonium."

What was the direct Program goal that was solved during the Meeting? 


\section{Appendix D. Participant Contributions}

The Petersburg Meeting brought Russian plutonium experts together, in many cases, for the first time from 15 different organizations from within Russia to discuss, exchange, and integrate their plutonium technical work results and future plans. These interactions will provide a sound foundation for defining the future technical activities for both the Russian participants and the US.

3. What new successes would the American side await from Russian -American collaboration in the future?

"The joint goal of the Russian work is to establish a full-scale plutonium immobilization facility at a Russian industrial site by 2005 . This work of the meeting and future work will provide the bases for joint decisions if such a goal can be achieved." 


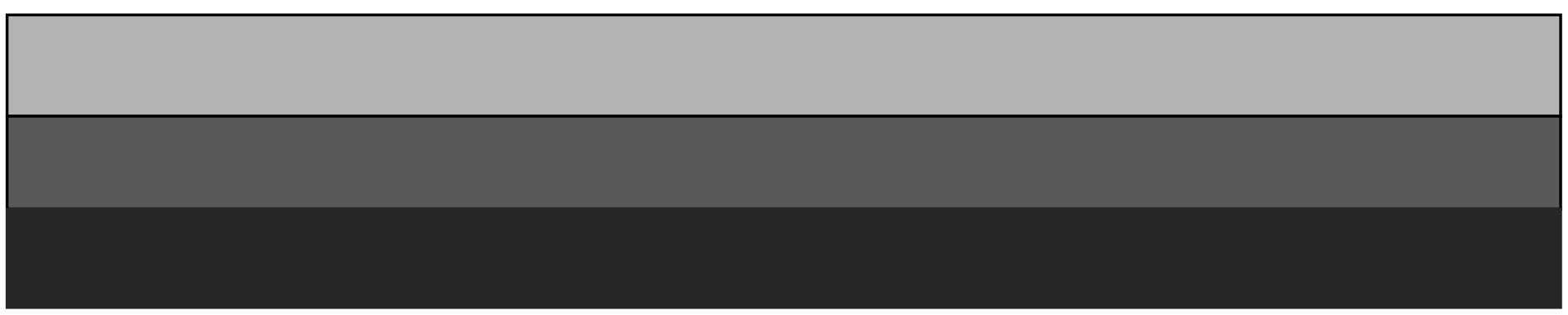

